An International Journal

Volume 17 Number 1

March 2021

CONTENTS

Technical Papers

Therite Kashan Khan and Jia-Bao Yan

作

Shi-Yi Wang, An-Ying Chen and Hai-Ying Wan

Fatigue Properties of Inclined Cruciform Welded Joints with Artificial Pits

Zhi-Yu Jie, Wu-Jun Wang, Ping Zhuge, Ya-Dong Li and Xing Wei

Sehaviour of Novel Stiffened Angle Shear Connectors at Ambient

Experimental Study on Seismic Behavior of Innovative Multi-Cellular CFT-Walls with Tie-Bolts

Gen-Shu Tong, Chen-Hao Lin, Zhong-Zheng Hu and Shuang-Long Yang

Parametric and Comparison Study of A New and Traditional A

Performance and Capacity Calculation Methods of Self-Stressing Steel Slag Concrete Filled Steel Tubular Short Columns Subjected to Axial Load Yuan Fang, Feng Yu, Rui Bai, Lin Xu, Yuan-Di Qian and Guo-Sheng Xiang

Behaviour of Reinforced Joints Between Steel Beam and L-Shaped Wide Limb Composite Column Rong-Quan Ma, Ping-Yu Zhao, Hui-Yong Ban, Yuan-Qing Wang, Yu-Zheng Zhao and Cheng-Bo Peng

Stability Study on Scaffolds with Inclined Surfaces and Extended Jack Bases in Construction

fui-Lin Peng, Shu-Hong Wang, Chung-Sheng Wang and Judy P. Yang

Enhancing Collapse-Resistance of Steel Frame Joints Based on Folded Axillary Plates

Bao Meng, Liang-De Li, Wei-Hui Zhong, Ji-Ping Hao and Zheng Tan
Copyright $\odot 2021$ by :

The Hong Kong Institete

Website: http://2www.hkisc.org

ISSN 1816-112X

Siended, Materials Science Citation Index and ISI Alerting

Cover: Project: Skyboat; Structural Engineers: XinY \& Yuanlizhu; Architect: Zhong Huaying Studio, Nanjing University,

Client: Guangxi Leye Dashi Wei Tourism Development Co., Ltd; Co-design: Lili \& Sh Mhai Zhonglian. PhotoOLi

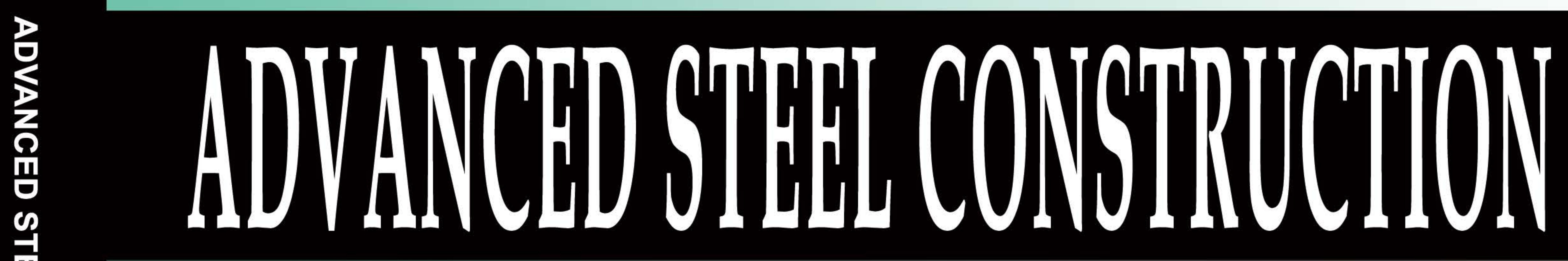

an International ]ounal ISSN 1816-112X

Volume 17 Number 1

March 2021

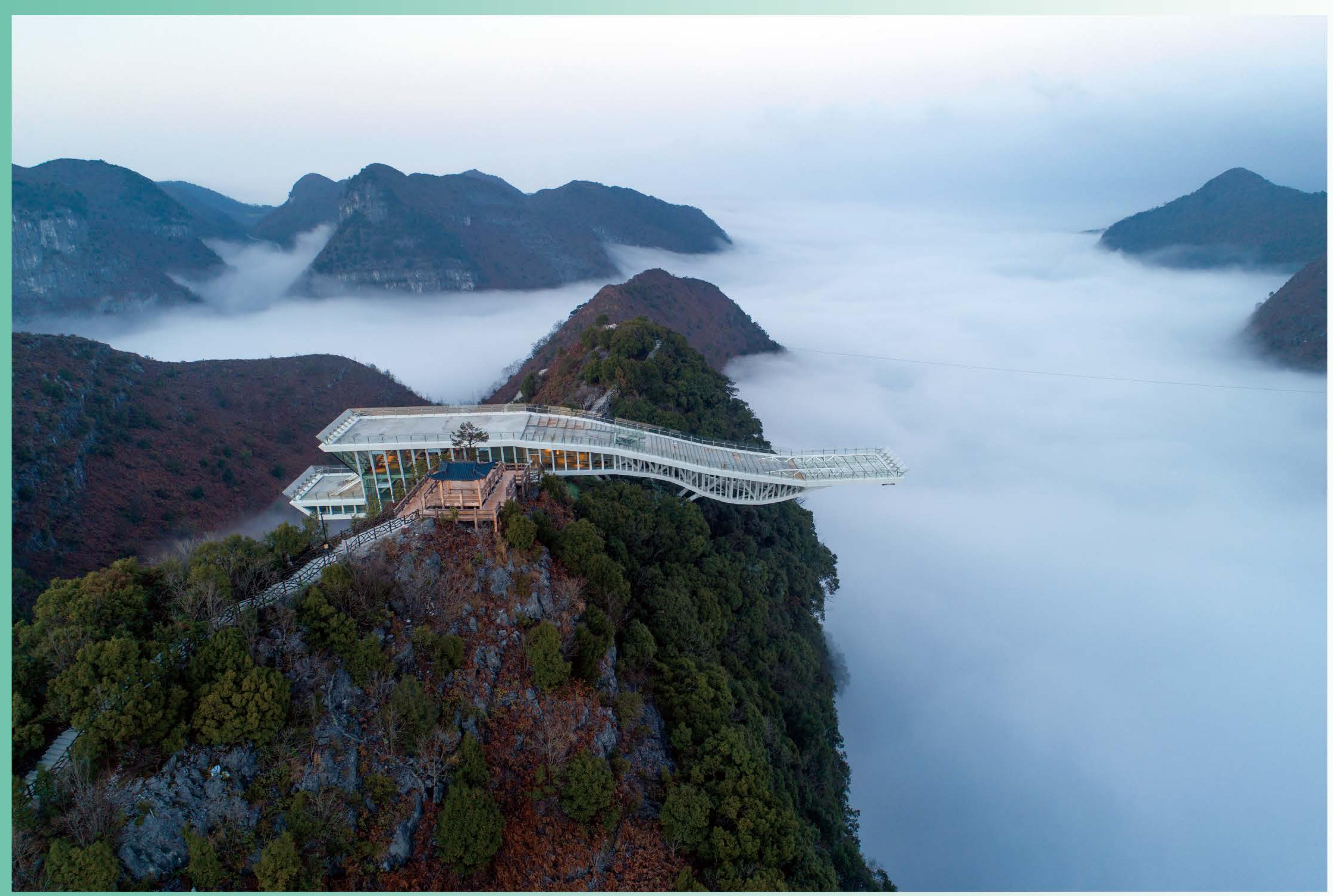

Editors-in-Chief

S.L. Chan, The Hong Kong Polytechnic University, Hong Kong, China

W.F. Chen, University of Hawaii at Manoa, USA

R. Zandonini, Trento University, Italy 


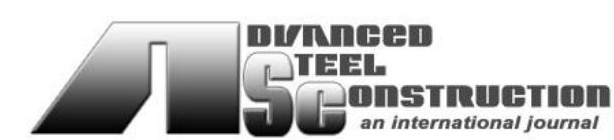

ISSN 1816-112X

Science Citation Index Expanded, Materials Science Citation Index and ISI Alerting

EDITORS-IN-CHIEF
Asian Pacific, African
and organizing Editor
S.L. Chan
The Hong Kong Polyt. Univ.,
Hong Kong, China
American Editor
W.F. Chen
Univ. of Hawaii at Manoa, USA
European Editor
R. Zandonini
Trento Univ., Italy

Trento Univ., Italy

\section{ASSOCIATE EDITORS}

Y.P. Liu

The Hong Kong Polyt. Univ., Hong Kong, China

S.W. Liu

Sun Yat-Sen Univ., China

INTERNATIONAL

EDITORIAL BOARD

F.G. Albermani

Central Queensland Univ., Australia

I. Burgess

Univ. of Sheffield, UK

F.S.K. Bijlaard

Delft Univ. of Technology, The Netherlands

R. Bjorhovde

The Bjorhovde Group, USA

M.A. Bradford

The Univ. of New South Wales, Australia

D. Camotim

Technical Univ. of Lisbon, Portugal

C.M. Chan

Hong Kong Univ. of Science \& Technology, Hong Kong, China

T.H.T. Chan

Queensland Univ. of Technology, Australia

T.M. Chan

The Hong Kong Polyt. Univ., Hong Kong, China

Z.H. Chen

Tianjin Univ., China

S.P. Chiew

Nanyang Technological Univ., Singapore

W.K. Chow

The Hong Kong Polyt. Univ., Hong Kong, China

\section{G.G. Deierlein}

Stanford Univ., California, USA

L. Dezi

Univ. of Ancona, Italy

D. Dubina

The Politehnica Univ. of Timosoara, Romania

R. Greiner

Technical Univ. of Graz, Austria

L. Gardner

Imperial College of Science, Technology and Medicine, UK

Y. Goto

Nagoya Institute of Technology, Japan

\section{Advanced Steel \\ Construction an international journal} H. Han

Tsinghua Univ. China

S. Herion

University of Karlsruhe, Germany

G.W.M. Ho

Ove Arup \& Partners Hong Kong Ltd., Hong Kong, China

B.A. Izzuddin

Imperial College of Science, Technology and

Medicine, UK

J.P. Jaspart

Univ. of Liege, Belgium

S. A. Jayachandran

IIT Madras, Chennai, India

S.E. Kim

Sejong Univ., South Korea

S. Kitipornchai

The Univ., of Queensland, Australia

D. Lam

Univ. of Bradford, UK

H.F. Lam

City Univ. of Hong Kong, Hong Kong, China

G.Q. L

Tongji Univ., China

J.Y.R. Liew

National Univ. of Singapore, Singapore

E.M. Lui

Syracuse Univ., USA

Y.L. Mo

Univ. of Houston, USA

J.P. Muzeau

CUST, Clermont Ferrand, France

D.A. Nethercot

Imperial College of Science, Technology and

Medicine, UK

Y.Q. N

The Hong Kong Polyt. Univ., Hong Kong, China

D.J. Oehlers

The Univ. of Adelaide, Australia

J.L. Peng

Yunlin Uni. of Science \& Technology, Taiwan, China

K. Rasmussen

The Univ. of Sydney, Australia

J.M. Rotter

The Univ. of Edinburgh, UK

C. Scawthorn

Scawthorn Porter Associates, USA

P. Schaumann

Univ. of Hannover, Germany

Y.J. Shi

Tsinghua Univ., China

G.P. Shu

Southeast Univ. China

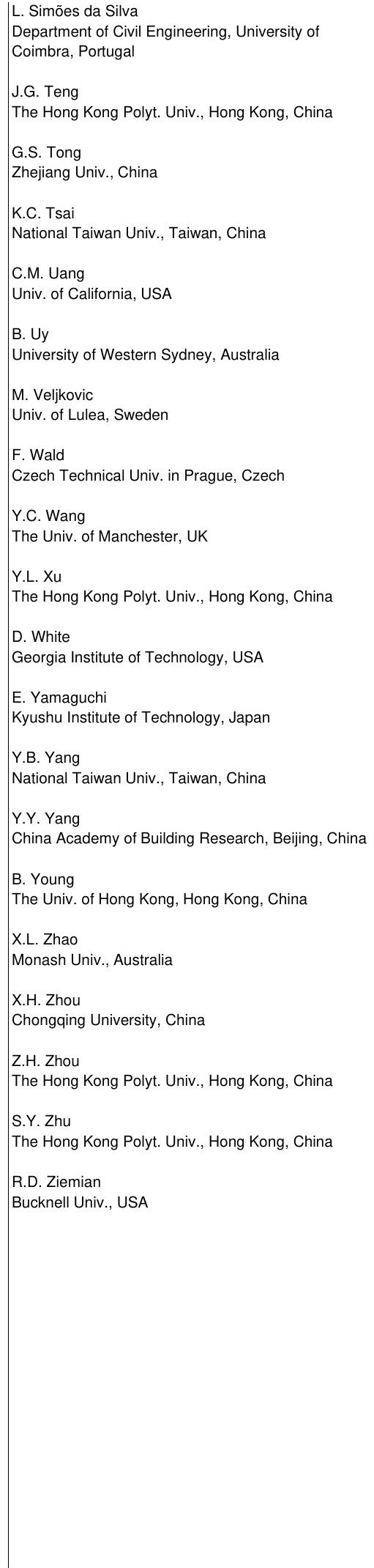

Cover: Project: Skyboat; Structural Engineers: Xin Y \& Yuanlizhu; Architect: Zhong Huaying Studio, Nanjing University; Client: Guangxi Leye Dashi Wei Tourism Development Co., Ltd; Co-design: Lili \& Shanghai ZhongJian. Photo (c) Lijin e-copy of IJASC is free to download at "www.ascjournal.com" in internet and mobile apps. 


\section{General Information Advanced Steel Construction, an international journal}

\section{Aims and scope}

The International Journal of Advanced Steel Construction provides a platform for the publication and rapid dissemination of original and up-to-date research and technological developments in steel construction, design and analysis. Scope of research papers published in this journal includes but is not limited to theoretical and experimental research on elements, assemblages, systems, material, design philosophy and codification, standards, fabrication, projects of innovative nature and computer techniques. The journal is specifically tailored to channel the exchange of technological know-how between researchers and practitioners. Contributions from all aspects related to the recent developments of advanced steel construction are welcome. 


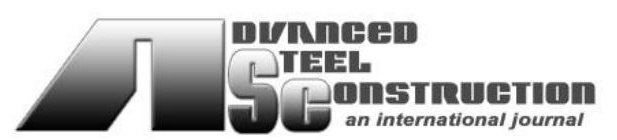

ISSN 1816-112X

Science Citation Index Expanded, Materials Science Citation Index and ISI Alerting

\section{EDITORS-IN-CHIEF}

\section{Asian Pacific, African and organizing Editor}

S.L. Chan

The Hong Kong Polyt. Univ., Hong Kong, China

Email: ceslchan@polyu.edu.hk

\section{American Editor}

W.F. Chen

Univ. of Hawaii at Manoa, USA

Email:waifah@hawaii.edu

\section{European Editor}

R. Zandonini

Trento Univ., Italy

Email: riccardo.zandonini@ing.unitn.it

\section{Advanced Steel Construction an international journal}

VOLUME 17 NUMBER 1

March 2021

Technical Papers

Numerical Studies on The Seismic Behaviour of A Prefabricated Multi-Storey 1 Modular Steel Building with New-Type Bolted Joints

Kashan Khan and Jia-Bao Yan

Seismic Behaviour of Concrete-Filled Steel Tube Frames with External Composite 10 Wall Panels

Shi-Yi Wang, An-Ying Chen and Hai-Ying Wan

Fatigue Properties of Inclined Cruciform Welded Joints with Artificial Pits

Zhi-Yu Jie, Wu-Jun Wang, Ping Zhuge, Ya-Dong Li and Xing Wei

Behaviour of Novel Stiffened Angle Shear Connectors at Ambient and Elevated 28 Temperatures

Karim Nouri, N H Ramli Sulong, Zainah Ibrahim and Mahdi Shariati

Experimental Study on Seismic Behavior of Innovative Multi-Cellular CFT-Walls 39 with Tie-Bolts

Gen-Shu Tong, Chen-Hao Lin, Zhong-Zheng Hu and Shuang-Long Yang

Parametric and Comparison Study of A New and Traditional Aluminum Alloy 50 Joint Systems

Yu-Qi Jiang, Hui-Huan Ma, Guang-Tong Zhou and Feng Fan

Performance and Capacity Calculation Methods of Self-Stressing Steel Slag 59 Concrete Filled Steel Tubular Short Columns Subjected to Axial Load Yuan Fang, Feng Yu, Rui Bai, Lin Xu, Yuan-Di Qian and Guo-Sheng Xiang

Behaviour of Reinforced Joints Between Steel Beam and L-Shaped Wide Limb 66 Composite Column

Rong-Quan Ma, Ping-Yu Zhao, Hui-Yong Ban, Yuan-Qing Wang, Yu-Zheng Zhao and Cheng-Bo Peng

Stability Study on Scaffolds with Inclined Surfaces and Extended Jack Bases in 73 Construction

Jui-Lin Peng, Shu-Hong Wang, Chung-Sheng Wang and Judy P. Yang

Enhancing Collapse-Resistance of Steel Frame Joints Based on Folded Axillary 84 Plates

Bao Meng, Liang-De Li, Wei-Hui Zhong, Ji-Ping Hao and Zheng Tan 



\title{
NUMERICAL STUDIES ON THE SEISMIC BEHAVIOUR OF A PREFABRICATED MULTI-STOREY MODULAR STEEL BUILDING WITH NEW-TYPE BOLTED JOINTS
}

\author{
Kashan Khan and Jia-Bao Yan *
}

School of Civil Engineering/Key Laboratory of Coast Civil Structure Safety of Ministry of Education, Tianjin University, Tianjin 300350, China

*(Corresponding author: E-mail: ceeyanj@163.com)

\section{A B S T R A C T}

Prefabricated modular steel (PFMS) construction is an industrial technique of construction that enhances productivity, site safety, and construction quality. The assembling of prefabricated buildings needs an accurate connecting system to ensure structural integrity and effective transfer of loads and moments. Therefore, in the current study, a new-type bolted joints having a long tenon-gusset plate for horizontally, and long beam bolts for vertically connecting modular units have been developed. Nonlinear static analysis was carried out by the finite element (FE) analysis software ABAQUS. The bending performance of the joints with varying parameters and modular units with different forces scenario, was studied. To analyse the seismic performance of modular steel building (MSB), a simplification of the detailed joint with the connector was performed. Then the seismic response of full-scale four-storey simplified MSB was studied by dynamic analysis. The results revealed that joints possessed stable load-carrying capacity with adequate ductility and seismic performance. The simultaneous application of axial, lateral tension, and compression forces affected ultimate capacity, initial stiffness, and ductility of single modules more than the double modules. Moreover, the simplified model accurately mimicked the bending behaviour of joints with a fluctuation of $<4 \%$ in capacities. Inter-storey drift ratios (IDR) of both the shorter and longer directions of MSB were found lower than the code limits of $2.5 \%$. Hence, the static analysis on joints and modular units, and dynamic analysis on MSB authenticated the effectiveness of developed joints to resist and distribute the lateral loads. Finally, the accuracy of FE analysis was verified by analysing twelve bending tests on joints listed in the references.

\section{A R T I C L E H I S T O R Y}

$\begin{array}{ll}\text { Received: } & \text { 7 April } 2020 \\ \text { Revised: } & \text { 23 September } 2020 \\ \text { Accepted: } & \text { 24 September } 2020\end{array}$

\section{K E Y W O R D S}

New-type bolted joint; Modular units;

Modular steel building;

Nonlinear static analysis;

Dynamic analysis;

Inter-storey drift ratio

\section{Introduction}

Prefabricated modular steel (PFMS) construction is an offsite construction in which structural members, panels, and facilities are preassembled in the factory to form modular units, then transported to the site and finally assembled to form the MSB [1,2]. Such construction technique, besides, the potential of dismantling and reusing, reduces assembling time, constructional wastage, maintenance cost, and also improves accuracy, material quality, and productivity in repetitive structures [3-5]. Nowadays, due to the economic sector and modern urbanization, prefabrication is gaining more attention in midto-high rise buildings compared to conventional onsite construction $[3,6]$. The construction technique, detailing requirements, and a various number of connections to assemble modular units to form MSB, make these buildings different from the traditional on-site steel buildings $[7,8]$. Based on the load transferring mechanism, modular units are mainly categorized into load-bearing, and corner-supported modules. Load-bearing modules use C-sectioned compression resisting walls to transfer gravity loads. In contrast, cornersupported modules use edge beams and columns to transfer both gravity and lateral loads [4,9]. The proper connection arrangement among modular units and appropriate lateral force resisting systems are essential for the transfer of lateral forces in MSB [10,11]. The primary purpose of connections in MSB is to provide alternate load-transfer paths and maintain structural integrity if severe damage to the adjacent structural components occurs [12,13]. The lateral bearing capacity of the joint consisted of supporting plate, and blind bolts was analysed by the cyclic loading, and finally, a simplified theoretical model based on the verified FE analysis was developed [14]. The seismic performances of exterior edge connection having a box with a threaded post-tensioned rod inserted in hollow structural section (HSS) columns were studied with a series of experiments [15]. Tensile and seismic behaviours of the proposed automatic plug-in connection in MSB were experimentally studied by Dai et al. (2019) [16]. The structural performance of the Vector Bloc joint was experimentally studied against axial and bending loads $[1,17]$. The rotational stiffness of the rotary joint in a modular structural system was investigated by experimental and theoretical ways by Chen et al. (2019) [18]. Lacey et al. (2019) experimentally studied the shear-slip and workability performance of the bolted joint, and FE analysis was carried out to explore the effect of various parameters [19]. The structural behaviour of the developed embedded column-foundation joint in MSB was analysed by experiments and FE analysis [10]. The influence of corrugated sidewalls (with and without openings) on the rigidity and seismic performance of MSB was analysed by experiments and detailed FE analysis $[20,21]$. The role of a new type of precast concrete core for being a new system to resist lateral forces was analysed under the wind and seismic loads by the use of FE analysis, and the response of the building was checked with the provided code provision $[22,23]$. The seismic performance of MSB frames, vertically connected by partial welding of columns and horizontally by angle clips and bolts, was evaluated using theoretical and experimental approaches $[24,25]$ Based on the experimental findings under monotonic lateral loading on the twostorey corner modular frame with and without the contribution of the corrugated shear wall, a theoretical derivation for the lateral stiffness of the modular system was proposed by Liu et al. (2020) [26]. The seismic response of a simplified MSB was analysed against pushover and dynamic analyses with the help of FE simulation [27]. The effect of a newly developed automatic interlocking system on the robustness performance of MSB was studied [3]. Zhang et al. (2020) investigated the bearing capacity of a full-scale modular unit under vertical and lateral loadings by using means of tests and FE analysis [28]. The studies previously recorded were found to be confined to the performance of corner joints, simplified frames or modular units without any proper detailed behaviour of connections, use of weaker sections and access holes, while, very least attention was paid to the behaviour of complex form of joints, i.e., middle joint, simplification of the joint to overcome computational efforts, combined effect of forces on the behaviour of modular units with the developed joint and the overall dynamic response of MSB against real earthquake accelerograms $[8,24,25,27,29,30]$. The main aim of the current study was to develop a newtype of bolted joint, analyse its bending performance, simplify and apply it in the full-scale modular units, and evaluate the overall seismic performance of the developed simplified multi-storey MSB.

Hence, in this study, a joint for HSS members was proposed. Using FE software ABAQUS, nonlinear structural behaviour of corner and middle joints was studied. In order to reduce the computational effort and evaluate the dynamic response of the MSB, a simplified model having a connector element as a replacement of joint, and the beam elements for solid structural members was developed. Then the structural performance of modular units against axial and lateral loads, while, MSB against earthquake loads were studied. This was followed by the validation of FE results with the results of twelve bending tests on joints in MSB. All the studies conducted led to a deeper understanding of the overall working process of the multi-storey MSB with such bolted joints.

\section{Connecting and working mechanism of MSB with the developed joint}

The details of connections in MSB are shown in Fig. 1(a), and the components of the developed joint are shown in Fig. 1(b). The joint mainly consists of the upper component, lower component, gusset plate (GP), beam, and column bolts for connecting modular units together. Beam bolts vertically, while, tenons, and GP horizontally connects the modular units together.

The force transfer mechanism showed by the joint against bending is shown in Fig. 2(b). The gap generation between the upper module and the lower module was notable when the bending moment was applied as a lateral displacement on the top of an upper modular frame. Due to gap generation, 
beams, because of bending, started facing bearing stresses and beam bolts, due to stretching, faced tensile forces. Simultaneously, the relative movement among column, tenon, and column bolt resulted in the exertion of shear force on column bolts. It was observed that the overall structural behaviour of MSB depended on the working and load-transfer mechanism of the joint.

\section{Experimental studies on the modular joints}

The bending behaviour of corner and middle joints was studied against static and quasi-static loadings. The behaviour of joints was compared with and without stiffeners. The joint comprised hollow plug-in welded to plate, and long tension bolts passed through beams to horizontally and vertically support the welded HSS columns and beams $[31,32]$.

\subsection{Details of tests}

The design of the connection was in accordance with the actual four-storey MSB built in China. Floor slabs of MSB were made of prefabricated concrete, while, lightweight composite boards were used to prepare partitions and ceilings. Both the ceiling boards and prefabricated floor slabs were connected to the inner face of beams using welded angles.

The main objective of the experiment was to analyse the structural behaviour, seismic performance, and load-carrying capacity of the proposed joint. Static loading, quasi-static loading, effect of diagonal stiffeners, crosssection of beams, and axial force ratio (AFR) were the main factors considered in the study. Twelve experiments were performed on six specimens of each corner and middle joints in the structural engineering laboratory of Tianjin University. Initially, four specimens for the joints, i.e., exterior and interior joints, were tested against monotonic loading to observe the lateral deformation and load-carrying capacity. Furthermore, eight specimens were tested against quasi-static loading to visualize the seismic performance of joints. The material properties and details of specimens are listed in Table 1 and 2. The specimens without stiffeners were used for the basic testing, whereas specimens reinforced with stiffeners used for parametric study. The lateral displacement of $100 \mathrm{~mm}$ using column-end technique was applied on the upper column with free end constrained condition, whereas floor beams (FB), ceiling beam (CB), and lower columns were pin-constrained. Chinese standard, "Regulation of seismic test method (JGJ101-96)," was used for quasi-static loading protocol. Two values of AFRs, i.e., 0.2 and 0.1, were considered for a comparative study.

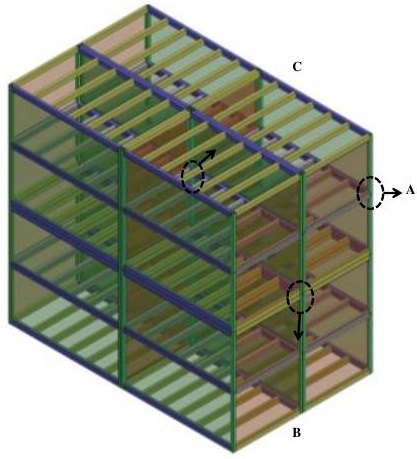

(a) PFMS building connections details
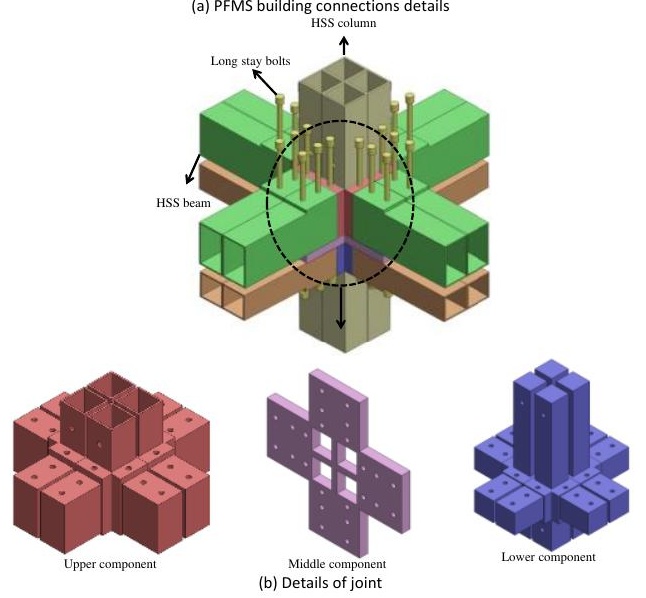

Fig. 1 Features of the developed connection in MSB

\subsection{Material properties}

The HSS columns, FBs, CBs, cover plates (CPs), supporting plates, GP, stiffeners, and beam bolts were made of Q345B steel, whereas cast steel Z35 was used for the production of connection components. Groove welding was adapted for the welding of columns and beams (FB, CB), while, fillet welding for stiffeners. The material properties listed in Table 1 were the same as the actual project.

\section{Finite element model}

\subsection{General}

Both ABAQUS/standard and dynamic-implicit types of solvers were considered for the development of FE models and analyses performed on the modular frame system with the developed joint. Lateral bending performance of new-type joints, simplified connector models, and modular units was studied using the tool of ABAQUS/standard. In contrast, the seismic performance of a simplified MSB with the developed connector model was analysed with a dynamic-implicit solver [33].

\subsection{Material model of a steel}

As steel was used in the study; therefore, the nonlinear isotropic/kinematic hardening model and von Mises yield criterion in ABAQUS/CAE were chosen. Bilinear stress-strain behaviour with strain hardening was used for defining the material model, as shown in Fig. 2(c) [34]. Poison's ratio " $v$ " and modulus of elasticity " $E_{s}$ " were defined as elastic material properties, whereas steel's yield strength " $f_{y}$ ", strain values " $\varepsilon$ " and ultimate strength " $f_{u}$ " were inputted as plastic material properties. The elastic and plastic material properties used in the study were the same as experimental values, as shown in Table 1 . The input criteria in FE simulation for the stress and strain are true stress and equivalent true plastic strain rather than engineering stress and strain. Therefore, values of true stress and strain can be obtained from the following equations using the values of engineering stress and strain.

$$
\begin{aligned}
& \sigma_{T}=\sigma_{E}\left(1+\varepsilon_{E}\right) \\
& \varepsilon_{T}=\ln \left(1+\varepsilon_{E}\right)-\frac{\sigma_{T}}{E_{S}}
\end{aligned}
$$

where, $\sigma_{T}$ and $\sigma_{E}$ denote true and engineering stress, whereas $\varepsilon_{T}$ and $\varepsilon_{E}$ represent true and engineering strain.

Table 1

Properties of materials used in the experimental study

\begin{tabular}{ccccc}
\hline Components & $\begin{array}{c}\text { Thickness } \\
(\mathrm{mm})\end{array}$ & $\begin{array}{c}\text { Yield } \\
\text { strength } \\
f_{\mathrm{y}}(\mathrm{MPa})\end{array}$ & $\begin{array}{c}\text { Ultimate } \\
\text { strength } \\
f_{\mathrm{u}}(\mathrm{MPa})\end{array}$ & $\begin{array}{c}\text { Elongati } \\
\text { on } \\
(\% \mathrm{age})\end{array}$ \\
\hline $\begin{array}{c}\text { Column \& beam } \\
\text { plate }\end{array}$ & 8 & 425 & 575 & 30 \\
$\begin{array}{c}\text { Stiffeners } \\
\text { Cast plug-in device }\end{array}$ & 16 & 350 & 510 & 26 \\
\hline
\end{tabular}

\subsection{Development of the FE model}

In order to avoid modelling complications and reduce computational effort, some simplifications were considered in the FE models, such as a hexagonal head of bolts and nuts were modelled together as circular, while, threads on nuts and bolts shank were not modelled. The space between the bolt and the hole was not considered. In order to reduce contact surfaces and increase mesh accuracy, the welded CP and beams were modelled together as a single unit. The details of the FE model and simplifications adopted during simulations are shown in Fig. 2(a).

\subsubsection{Meshing technique}

The 3-D deformable solid parts, such as HSS columns, FBs, CBs, and connection components, were meshed with hexagonal- structured mesh controls having an element type of 8-node linear brick, controlled hourglass, and reduced integration (C3D8R). High-stress regions and components like corners, joining regions, bolt holes, and slave surfaces in contact definition were finely meshed. Four FE models with mesh densities, such as very fine, fine, coarse, and very 
coarse with mesh sizes of $25,30,40$, and $50 \mathrm{~mm}$, were analysed against test conditions. The bearing capacity of the FE model was increased as the mesh size increased, i.e., from very fine mesh to coarse one, but the model with very coarse mesh showed a slight decrement in capacity compared to coarse one. The difference between capacities of coarse and very coarse mesh density models was not apparent. In contrast, the very fine mesh model stopped taking load farther than $73 \mathrm{~mm}$ and resulted in non-convergence, as shown in Fig. 5(a). Based on the detailed comparison between mesh convergence criteria and the test results, the accuracy of models with a fine mesh (mesh size of $30 \mathrm{~mm}$ ) in both load-carrying capacity and stress allocation, authenticated the accuracy of FE models with the least error tolerance. Therefore, structural members were meshed with 30 , a joint region with 10 and hole regions with the $8 \mathrm{~mm}$. While, structural members such as columns and beams were substituted with 3-D deformable wire elements, which were finely meshed with the 2-node linear beam space element type (B31).

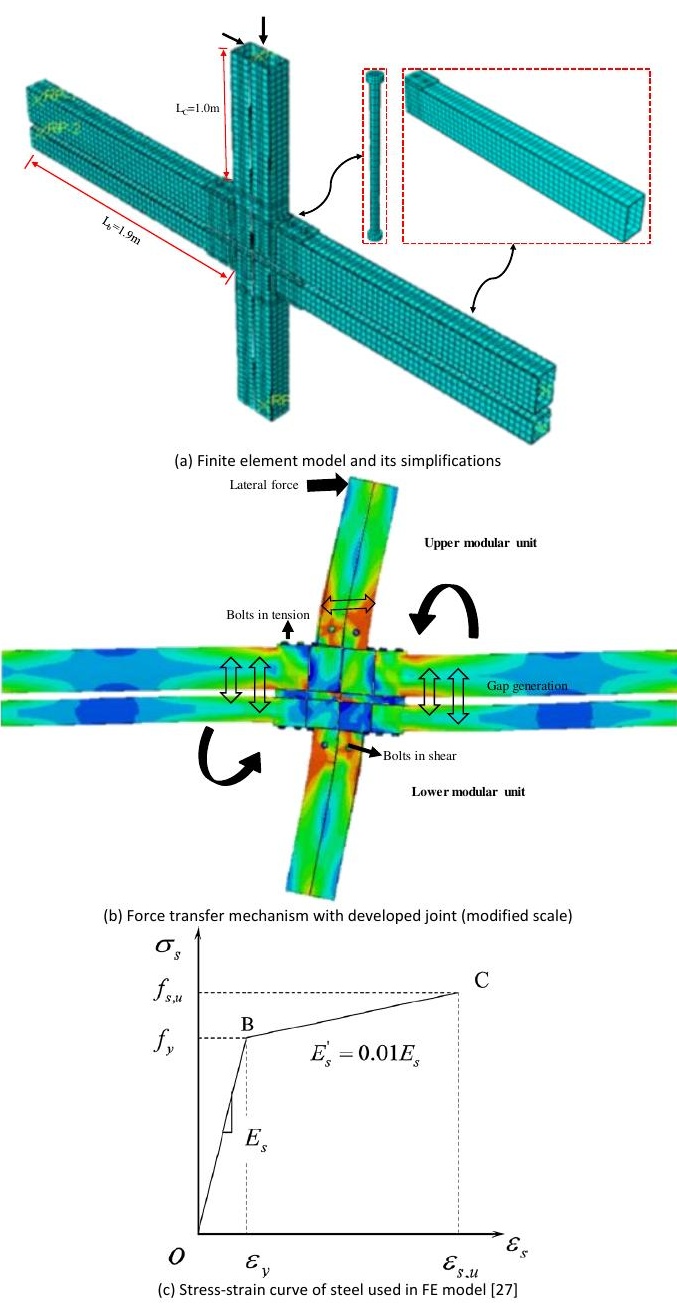

\subsubsection{Interactions}

The interaction between column and connection, beam and connection, column and bolt, and beam and bolt were modelled as surface-to-surface (standard) with "hard contact" as normal behaviour and "finite sliding" by "penalty friction formulation" as a tangential behaviour. The hard-contact formulation causes the two interacting surfaces to exchange pressure when contact each other, while, no pressure transfer with surface separation. Whereas, penalty friction formulation considers the frictional coefficient that allows relative motion and determines the frictional force between contacting surfaces. The accurate friction coefficient was chosen after validating the results of FE analysis with experimental findings. For the purpose, two FE models (with and without bolts friction) were analysed, and there was a very slight increase of $0.006 \%$ in load carrying capacity was found in the FE model that considered bolts friction, as shown in Fig. 5(b). Similarly, FE models with four different friction coefficient values, such as 0.3, 0.4, 0.5, and 0.6, were analysed. An increase in the capacity of models was found as the friction coefficient increased, but the increase in capacity between models with a friction coefficient of 0.3 and 0.6 was about $1.5 \%$, as shown in Fig. 5(c).

After the detailed comparison between FE and test results, bolts were modelled frictionless, whereas the friction coefficient was fixed as 0.3 for the remaining surface-to-surface interactions. For an accurate interaction between the adjacent modular units, the contact between columns and connections of adjacent modular units was considered as a hard contact.

\subsubsection{Boundary conditions and load application situations}

Following the bending experiments, movement at the bottom column in all directions, at the top column in $\mathrm{X}$ and $\mathrm{Z}$ direction, movement at $\mathrm{FB}$ and $\mathrm{CB}$ in $\mathrm{Y}$, and the rotation in Z-direction was restricted. The displacement-controlled loading was applied in a downward direction to the top column, as shown in Fig. 2(a) and 2(b), respectively. The movement at the base of the modular units was restrained, while, the rotation was released in all three directions. Lateral tension, compression, and axial loads with two values of AFR, i.e., 0.1 and 0.2 calculated by Eq. (3), were used, as shown in Fig. 9. Factored dead load as a self-weight of the whole structure and the live load from ASCE 7-10 were applied on FBs of modular units and multi-storey MSB [13,35]. For dynamic analysis, the translation in all directions except the direction chose for studying the structural performance, was restrained, while, the rotation in all directions was released at the base of MSB. Ground motion accelerations of various earthquakes were applied at the base, as shown in Fig. 12(a). Following Eq. (4) was considered to calculate the pretension force for bolts.

$$
\begin{aligned}
& N=(A F R) f_{y c} A_{s} \\
& P=\frac{0.9 \times 0.9 \times 0.9}{1.2} A_{e} f_{t v}
\end{aligned}
$$

where, $N$ is Axial force; $A F R$ is Axial force ratio in percentage; $A_{\mathrm{s}}$ is area of the steel section; $P$ represents the pretension force; $A_{e}$ denotes an effective area of the bolt, and $f_{t v}$ shows the tensile strength of a bolt, which is taken as $180 \mathrm{MPa}$.

Fig. 2 Material properties and FE modelling details

Table 2

\begin{tabular}{|c|c|c|c|c|c|c|c|c|}
\hline Sp. No & Type of joint & $\mathrm{CB}\left(\mathrm{mm}^{3}\right)$ & $\mathrm{FB}\left(\mathrm{mm}^{3}\right)$ & Column $\left(\mathrm{mm}^{3}\right)$ & Stiffener thickness (mm) & Bolts (mm) & $\operatorname{AFR}(\%)$ & Loading method \\
\hline S1 & Exterior & $150 \times 150 \times 8$ & $150 \times 250 \times 8$ & $150 \times 150 \times 8$ & None & 24 & 0.2 & Static \\
\hline $\mathrm{SC} 1$ & Interior & $150 \times 150 \times 8$ & $150 \times 250 \times 8$ & $150 \times 150 \times 8$ & None & 24 & 0.2 & Static \\
\hline S2 & Exterior & $150 \times 150 \times 8$ & $150 \times 250 \times 8$ & $150 \times 150 \times 8$ & 10 & 24 & 0.2 & Static \\
\hline $\mathrm{SC} 2$ & Interior & $150 \times 150 \times 8$ & $150 \times 250 \times 8$ & $150 \times 150 \times 8$ & 10 & 24 & 0.2 & Static \\
\hline QS1 & Exterior & $150 \times 150 \times 8$ & $150 \times 250 \times 8$ & $150 \times 150 \times 8$ & None & 24 & 0.2 & QS \\
\hline QSC1 & Interior & $150 \times 150 \times 8$ & $150 \times 250 \times 8$ & $150 \times 150 \times 8$ & None & 24 & 0.2 & QS \\
\hline QS2 & Exterior & $150 \times 150 \times 8$ & $150 \times 150 \times 8$ & $150 \times 150 \times 8$ & 10 & 24 & 0.2 & QS \\
\hline QSC2 & Interior & $150 \times 150 \times 8$ & $150 \times 150 \times 8$ & $150 \times 150 \times 8$ & 10 & 24 & 0.2 & QS \\
\hline QS3 & Exterior & $150 \times 150 \times 8$ & $150 \times 250 \times 8$ & $150 \times 150 \times 8$ & 10 & 24 & 0.2 & QS \\
\hline QSC3 & Interior & $150 \times 150 \times 8$ & $150 \times 250 \times 8$ & $150 \times 150 \times 8$ & 10 & 24 & 0.2 & QS \\
\hline QS4 & Exterior & $150 \times 150 \times 8$ & $150 \times 250 \times 8$ & $150 \times 150 \times 8$ & 10 & 24 & 0.1 & QS \\
\hline QSC4 & Interior & $150 \times 150 \times 8$ & $150 \times 250 \times 8$ & $150 \times 150 \times 8$ & 10 & 24 & 0.1 & QS \\
\hline
\end{tabular}

Information of the test specimens considered for the experimen 


\subsection{Verification of the FE modelling}

The load-displacement curves and failure patterns of twelve test specimens (i.e., S/SC/QS/QSC) of the corner and middle joints (with plug-in and long beam bolts) against monotonic (four specimens) and cyclic loadings (eight specimens) were compared with the results obtained from FE static analysis.

\subsubsection{Verifications of experimental results with the FE analysis}

The envelope load-displacement graphs for twelve test specimens of joints were compared with the results obtained from FE static analysis, as shown in Fig. 3. It was observed that the ultimate capacity, stiffness, and ductility of test specimens were well predicted by FE models. However, some minor fluctuations and inconstancies in stiffnesses or ultimate capacities between test and FE predicted curves were observed, which might be due to variation in material properties and behaviours, slight sectional imperfections during tests, dislocation during handling, flexible boundary conditions or simplifications performed during FE analysis.

The criteria of von Mises stress distribution were used to observe the failure modes of tests, as shown in Fig. 4. The main failure patterns observed in test specimens of joints, were gap generation and widening, tearing of welds of column or beam, stiffener breakage, local inward or outward buckling of the column, and tearing of column or beam. The stress concentrations showed by FE models in all specimens of joints (exterior and interior), local outward and inward buckling, welded regions under high stresses, and gap generation were following test results.

A comparison between the ultimate load-carrying capacities of tests and FE analysis, are shown in Table 3 . The mean of capacity ratios of test and FE was found 1.02, while, SD and coefficient of variation (Cov) were 0.12, which assured the accuracy of FE analysis. Specimens with test-to-FE ratios higher than 1.0 demonstrated that FE analysis showed an average slight underestimation, whereas below 1.0 indicated that FE analysis showed an average slight overestimation of the bearing capacity. With these validations, the precision of the developed FE model can be authenticated to simulate the overall structural response of the joint, connected modular units, and MSB with a developed joint.

\section{Numerical simulation of the modular frame systems}

\subsection{Geometry and detailing}

In the Fig. (1b), the main components of the new-type of joint, such as an upper, lower, and middle component (GP), assembled with columns and beams to connect eight modular units with their respective components and bolts. The dimensions of the joint used to study the behaviour of MSB are shown in Fig. 6(a).

The structural performance of full-scale modular units, i.e., $6 \times 3.6 \times 2.9 \mathrm{~m}^{3}$, was evaluated. After carrying out parametric studies considering the length of the respective column tenon, a length of $400 \mathrm{~mm}$ was initially chosen to investigate modular units, as shown in Fig. 9 [36]. Similarly, dimensions of fullscale four-storey simplified MSB with the detailed arrangement of connectors and details of boundary conditions are shown in Fig. 12(a).

\subsection{Structural performance of joint}

Nonlinear static analysis was conducted on FE models of the exterior corner and middle joints to evaluate the load-bearing capacity and the failure criteria of joints. Structural performance of joints (corner and middle), such as lateral bending capacities and stress accumulation, are shown in Fig. 7(a) and (b). It was observed that with a gradual increase of lateral displacement, load-carrying capacity linearly kept on increasing until the gap started generating between upper and lower modular beams, which resulted in beams yielding. Bearing stresses were developed in FBs with an increase in load. Finally, as the load reached the ultimate state, the system started dropping the capacity to take farther loading and remained stable for a while, which was then followed by bearing failure of FB. It was noted that both corner and interior joints showed stable ductile behaviour and prevented the failure of columns. In order to study the effect of two parameters, i.e., length of column tenon (such as 100, 200, 300, and $400 \mathrm{~mm}$ ) and the constructional gap between adjacently connected modular units (such as from-0-to-30 mm) on the structural performance of joint, nonlinear static analysis was performed. It was noted that the length of tenon largely influenced the structural performance and load-carrying capacity, while, gap showed marginal influence, as shown in Fig. 7(c). Although, an increase in stiffnesses and load-carrying capacities of joints was evident with an increase in the length of tenon, the difference in increment decreased from 50 to $14 \%$ as the length of tenon increased between 100 to 200 and 300 to $400 \mathrm{~mm}$. Moreover,

the failure mode showed by the model with a length of tenon as $100 \mathrm{~mm}$ was controlled by column, while, in other models, FB faced bearing failure.
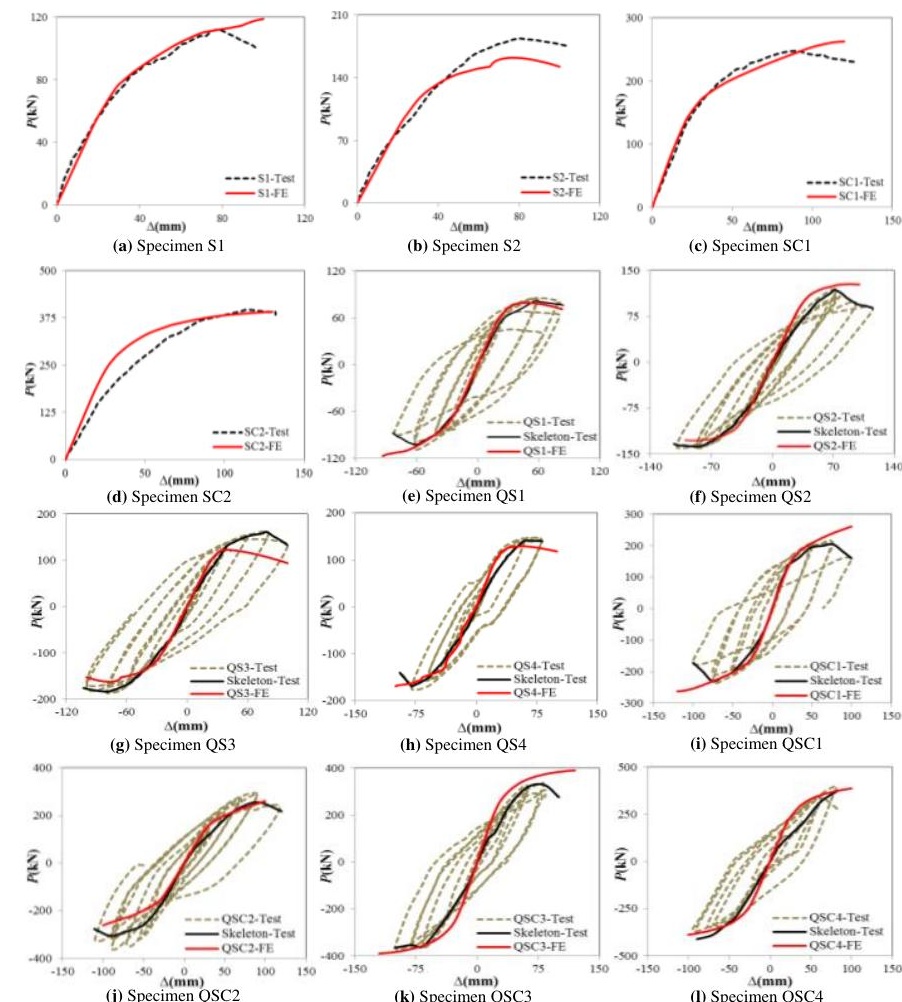

Fig. 3 Verification of load-displacement curves of test specimens with FE models
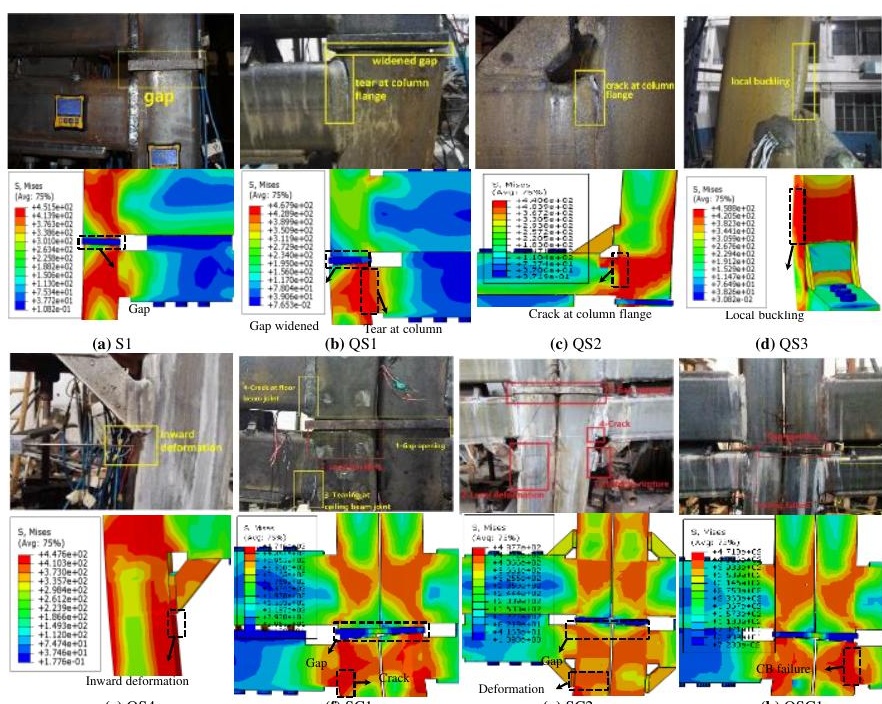

(c) QS2 (d) QS3
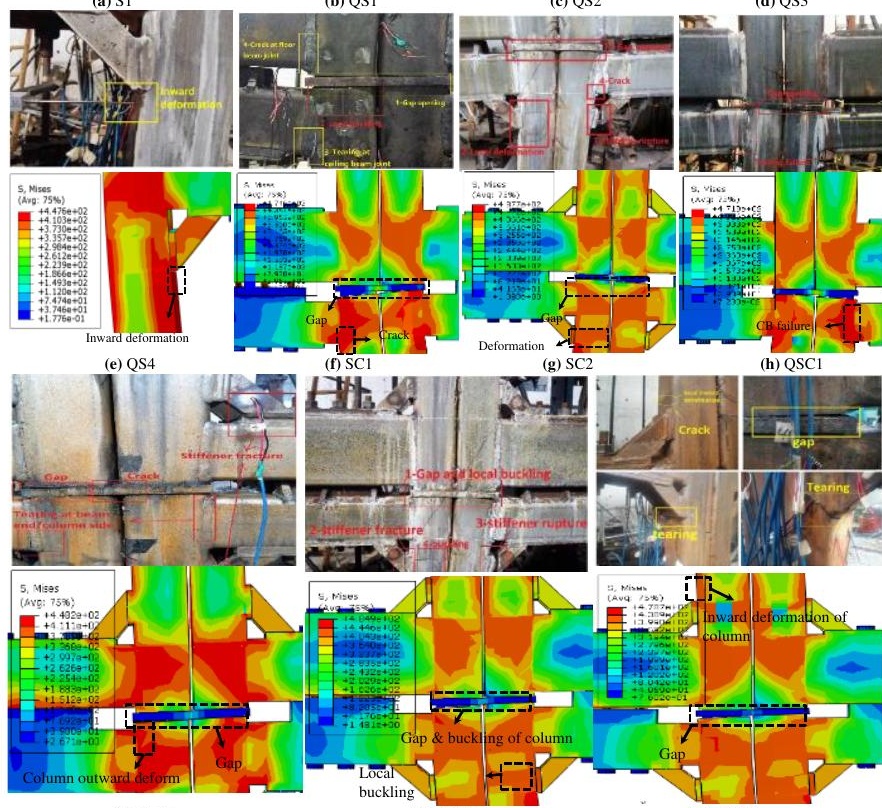

(i) QSC2

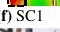

(g) $\mathrm{SC} 2$
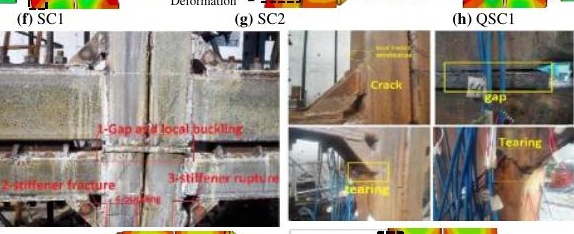
. 
Table 3

Test-to-FE comparison of ultimate loadings

\begin{tabular}{|c|c|c|c|c|c|}
\hline Sp. No & $\begin{array}{c}\text { Type of } \\
\text { joint }\end{array}$ & $\begin{array}{l}\text { Loading } \\
\text { technique }\end{array}$ & $\begin{array}{c}\text { Ultimate load } \\
(\text { Test }) / P_{\text {Test }}(\mathrm{kN})\end{array}$ & $\begin{array}{l}\text { Ultimate load } \\
(\mathrm{FE}) / P_{F E}(\mathrm{kN})\end{array}$ & $P_{\text {Test }} / P_{F E}$ \\
\hline S1 & Exterior & Static & 112 & 118 & 0.95 \\
\hline $\mathrm{SC} 1$ & Interior & Static & 248 & 262 & 0.95 \\
\hline S2 & Exterior & Static & 183 & 162 & 1.13 \\
\hline $\mathrm{SC} 2$ & Interior & Static & 396 & 392 & 1.01 \\
\hline \multirow[t]{2}{*}{ QS1 } & Exterior & $\mathrm{QS}+\mathrm{ve}$ & 81 & 79 & 1.02 \\
\hline & & QS -ve & -102 & -118 & 0.86 \\
\hline \multirow[t]{2}{*}{ QSC1 } & Interior & QS +ve & 205 & 261 & 0.79 \\
\hline & & QS -ve & 231 & 263 & 1.13 \\
\hline \multirow[t]{2}{*}{ QS2 } & Exterior & $\mathrm{QS}+\mathrm{ve}$ & 118 & 121 & 0.97 \\
\hline & & QS -ve & -137 & -127 & 1.07 \\
\hline \multirow[t]{2}{*}{ QSC2 } & Interior & $\mathrm{QS}+\mathrm{ve}$ & 255 & 261 & 0.98 \\
\hline & & QS -ve & -305 & -260 & 1.17 \\
\hline \multirow[t]{2}{*}{ QS3 } & Exterior & $\mathrm{QS}+\mathrm{ve}$ & 161 & 122 & 1.32 \\
\hline & & QS -ve & -183 & -162 & 1.13 \\
\hline \multirow[t]{2}{*}{ QSC3 } & Interior & QS +ve & 329 & 391 & 0.84 \\
\hline & & QS -ve & -364 & -389 & 0.94 \\
\hline \multirow[t]{2}{*}{ QS4 } & Exterior & $\mathrm{QS}+\mathrm{ve}$ & 141 & 129 & 1.09 \\
\hline & & QS -ve & -168 & -169 & 0.99 \\
\hline \multirow[t]{2}{*}{ QSC4 } & Interior & $\mathrm{QS}+\mathrm{ve}$ & 377 & 387 & 0.97 \\
\hline & & QS -ve & -411 & -388 & 1.05 \\
\hline Mean & & & & & 1.02 \\
\hline Cov & & & & & 0.12 \\
\hline
\end{tabular}
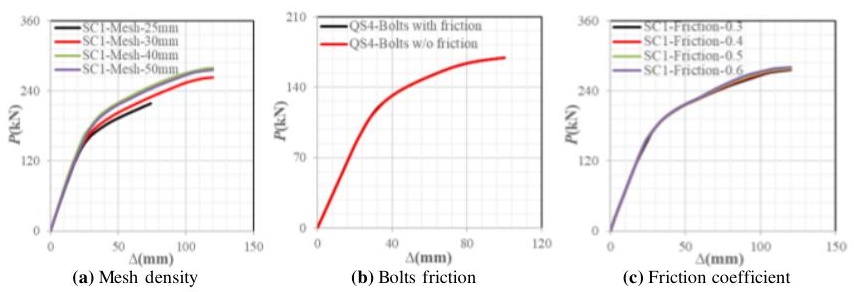

Fig. 5 Convergence study
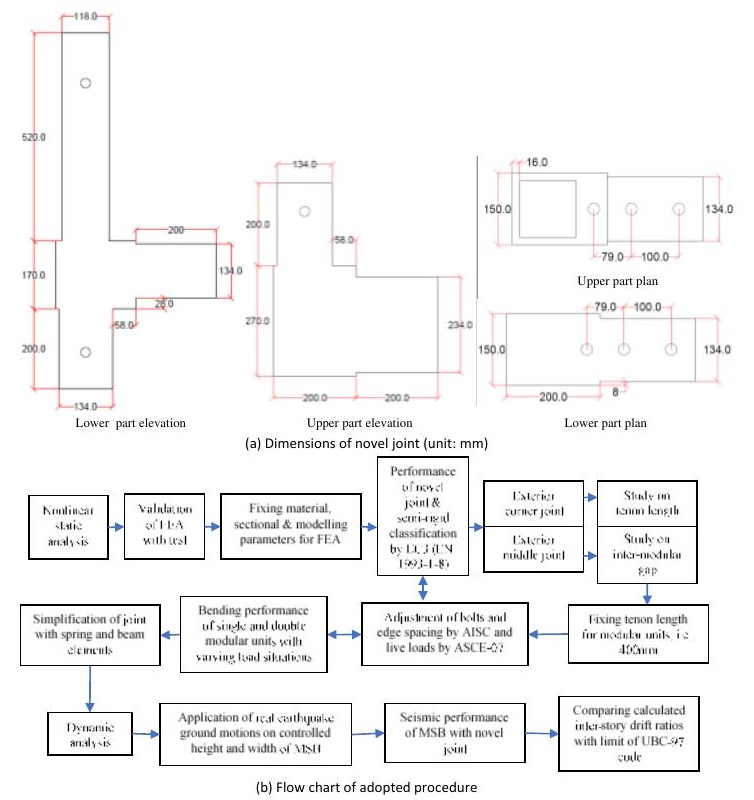

Fig. 6 Approaches adapted during FE analysis and design

\subsection{Simplification of joint with the connector}

For easy handling, reducing substantial computational effort, and analysing the structural performance of MSB, the complex and detailed FE model of the joint was simplified with the connector. In the simplified model, solid structural members, i.e., FBs, CBs, and columns, were replaced by 3-D beam elements, whereas components of joint with connector. The rotational stiffness for the connector was obtained from the moment-rotation relation of the detailed joint. Boundary conditions, material properties, sectional properties, and loading conditions were the same as for the analysis of the detailed FE model. The comparison of load-bearing capacities and stresses contours to analyse failure pattern of detailed solid and simplified beam element FE models of exterior corner joints are shown in Fig. 8(a), while, comparison for the exterior middle joint in Fig. 8(b). It was evident that the simplified models accurately predicted structural behaviour, stiffness, failure pattern, and load-carrying capacity of the detailed FE models of joints. The ratio of loading capacities of detailed and simplified FE models of joints with the error tolerance of less than $4 \%$ assured the accuracy of the developed simplified joint.
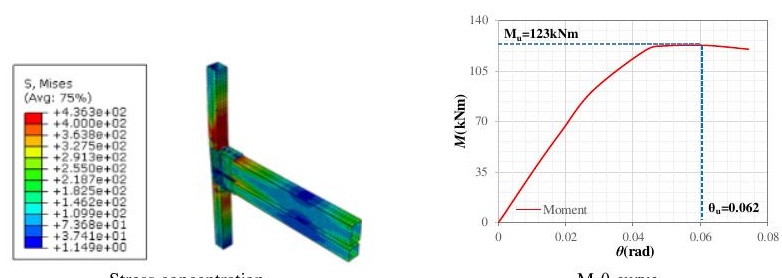

Stress concentratio

M- $\theta$ curve
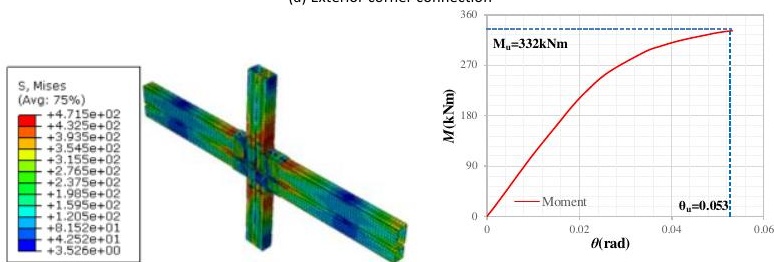

Stress concentration
(b) Exterior middle connection
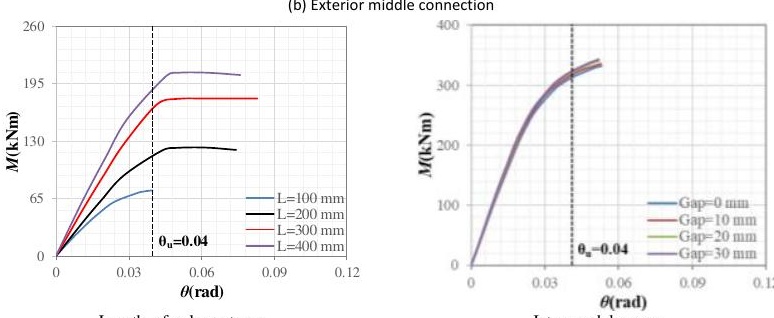

Length of column tenon

(c) Parametric study

$\theta($ rad $)$
Inter-modular gap

Fig. 7 Structural performance of developed joint
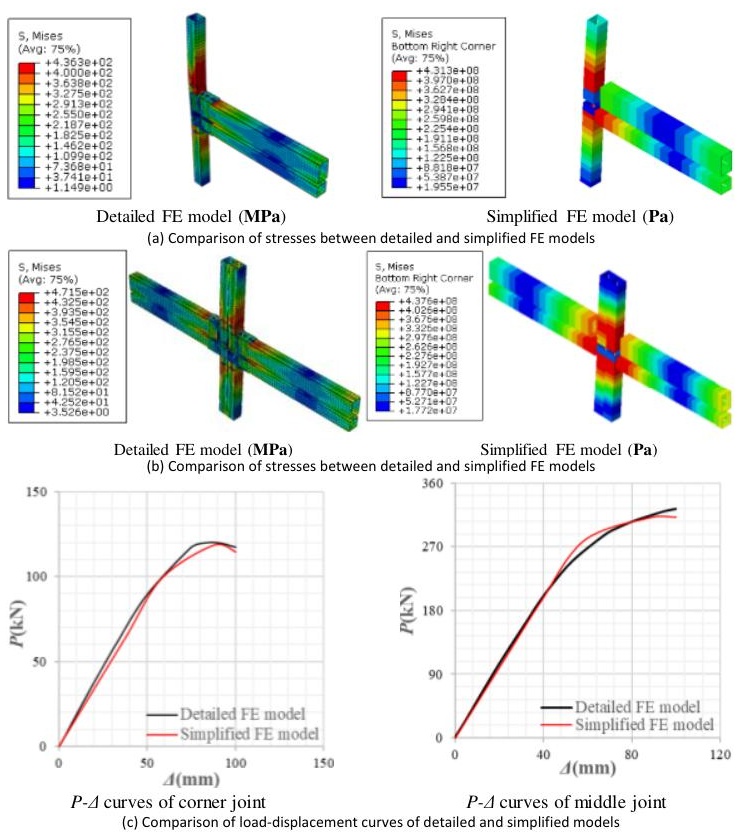

Fig. 8 Simplification of detailed joint 


\subsection{Structural performance of modular units with joint}

The overall performance of full-scale single and double modular units was studied with varying force scenarios, as shown in Fig. 9. For a single modular unit, CBs were connected to the lower component, while, FBs with an upper component of joint without GP and intermediate tenons. Whereas, GP was used for horizontally connecting double modular units. Boundary conditions were applied to the centre of joints by adding reference points. Axial, lateral tension and compression or combination of axial, tension, compression forces were applied on single and double modular units. Axial force ratio of 0.1 was used for models SM-2 (single modular unit) and DM-2 (double modular unit), whereas 0.2 for models SM-3 and DM-3. The trial and error approach was adapted for obtaining the lateral elastic-plastic behaviour of modular units. The structural behaviours and load-carrying capacity of modular units are shown in Figs. 9 and 10. It was observed that models SM-3 and DM-3 (with $\mathrm{AFR}=0.2$, lateral tension and compression forces) showed the least load carrying capacity, whereas SM6 and DM-6 (with only lateral compression force) showed the maximum bearing capacity. The ductility and load-carrying capacity possessed by double modular units were found better than the single modular units. Whether it was the single modular unit or double modular unit, the decrease in the number of loadings on modular units increased stiffness, bearing capacity, and ductility. The models observed bending of the column against tenons and beams against bolts, as shown in Fig. 2. The initial stiffnesses showed by models SM-1, SM-2, SM3, SM-4, SM-5 and SM-6 were found increasing with order of 0.76, 0.76, 0.76, 1.05, 1.05 and $2.2 \mathrm{kN} / \mathrm{mm}$, while, DM-1, DM-2, DM-3, DM-4, DM-5, DM-6 with $1.5,1.5,1.5,2.0,2.0$ and $4.2 \mathrm{kN} / \mathrm{mm}$. Bolts due to bending of beams faced shear stresses near heads, and beams faced bearing stresses against lateral displacement. Simultaneously, loss of stiffness was much obvious in single modular units, but double modular units showed force distribution among other structural members that highly increased the ductility performance. Similar structural behaviour was shown by SM-4 and SM-5, and DM-4 and DM-5. Nonlinearity in load-carrying behaviour was mainly due to a stress accumulation in $\mathrm{CB}$ and beam bolts.
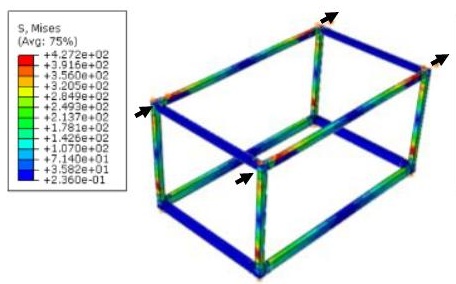

(a) SM-1
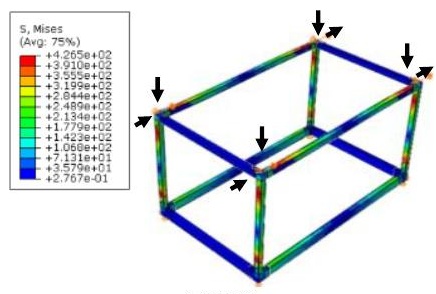

(c) SM-3
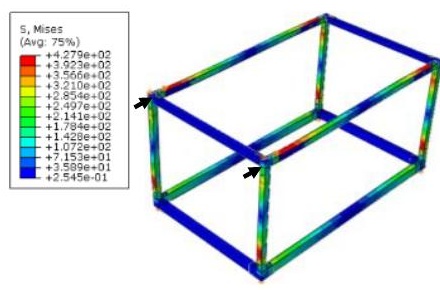

(e) SM-5
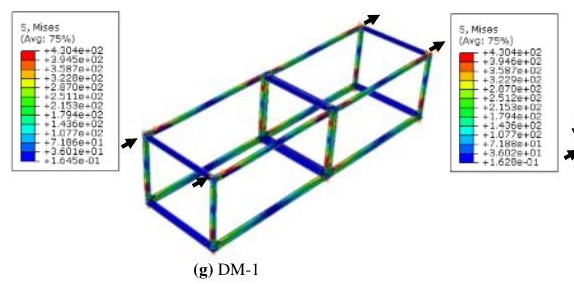
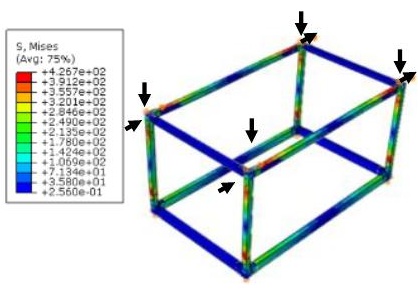

(b) SM-2
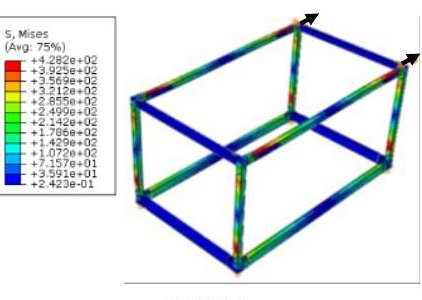

(d) SM-4
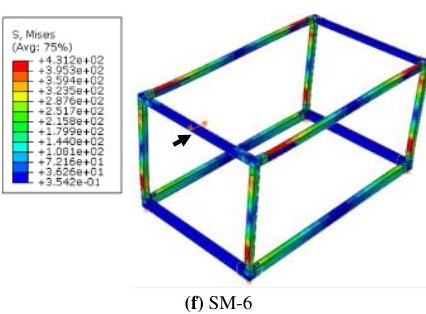

(f) SM-6

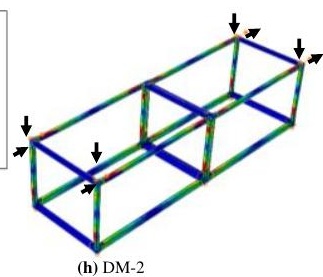

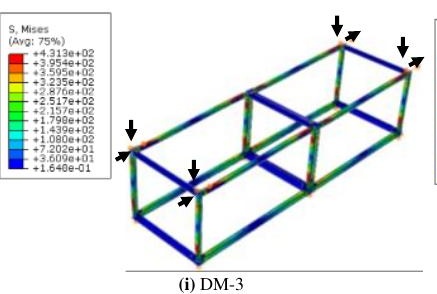
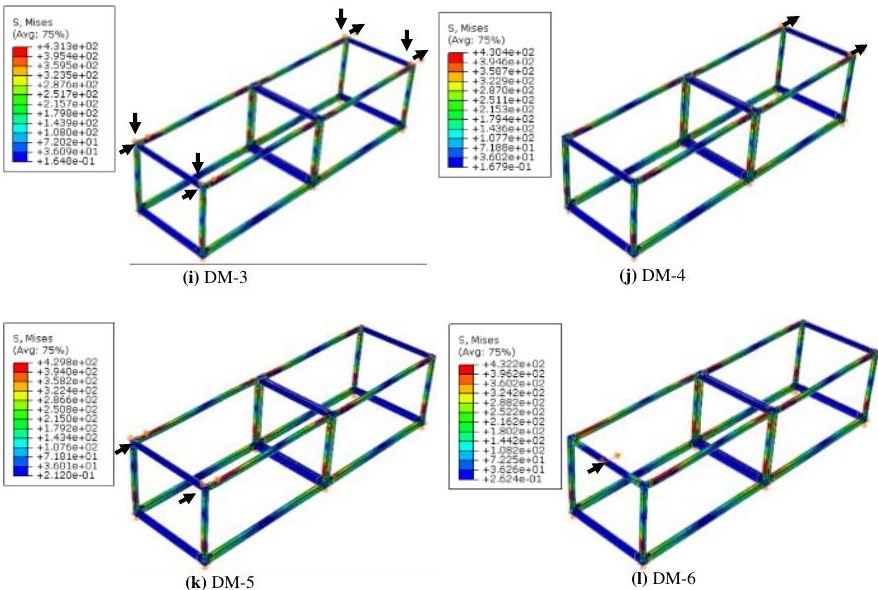

Fig. 9 von Mises stress distribution in single and double modular units
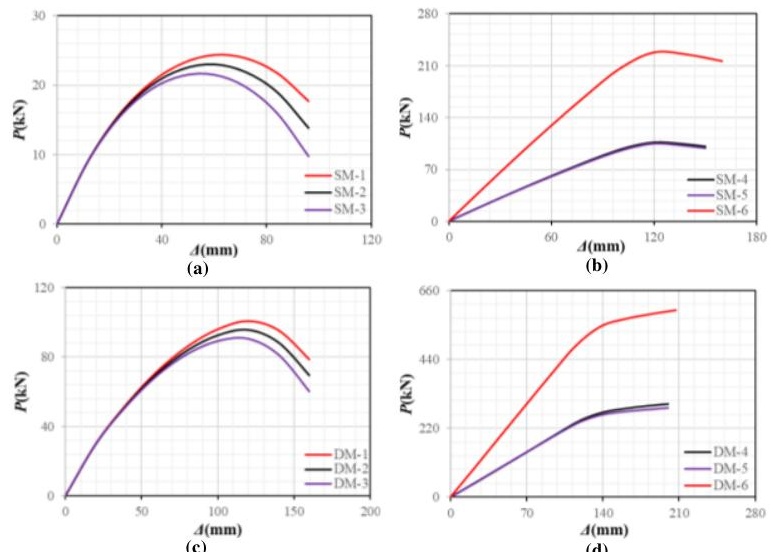

Fig. 10 Load-displacement curves of single and double modular units

\subsection{Structural performance of a multi-storey $M S B$}

In order to analyse the seismic performance of a developed MSB, a fourstorey simplified building with twelve modular units was considered. As shown in Fig. 10, to study the seismic behaviour of MSB, ground motion accelerations of real earthquakes (scaled at $1 / 10^{\text {th }}$ of real time) obtained from "PEER Strong Ground Motion Databases" were used for both along longer and shorter directions, as shown in Fig. 11 and 12(a). The details of applied ground motions in the current study are listed in Table 4. Edges of the columns (top and bottom) and adjacent modules were connected by coupling constraint. The rotation was released in all directions, whereas movement was fixed in all other directions except in the direction of the application of ground motions, as shown in Fig. 12(a).

For studying the seismic performance of MSB, two analyses were performed. Initially, eigenanalysis was carried out to find the natural frequency of various modes of the structure. Then dynamic implicit solver was used for studying the seismic behaviour of structure against accelerations of listed earthquakes. For damage in a structure, $5 \%$ damping $(\xi=0.05)$ was considered to find the damping coefficients, i.e., $\alpha=$ Mass proportion damping and $\beta=$ Stiffness proportion damping. Using Eq.5, natural frequencies obtained from the linear perturbation analysis at lower modes, i.e., $1^{\text {st }}$ and $3^{\text {rd }}$ modes, were used to find $\alpha$ and $\beta$. The calculated damping parameters $(\alpha, \beta)$ were inputted in the material properties, and dynamic analysis was carried out using a dynamic-implicit solver. The same procedure was adapted for both longer and shorter directions. The inter-storey drift ratio, which is the normalization of the difference of lateral displacement of consecutive floors by the storey height, is the best response parameter for studying the damage of buildings [37]. The IDRs obtained with the response to various ground motions were compared with the allowable code limit (UBC-97) of 2.5\% to examine the stability of MSB [38,39]. The IDRs obtained at each level and along both directions were represented in the Fig. 12(b). The pattern of IDRs along a shorter frame system was uniform with the longer frame system. In contrast, the average IDRs along a longer system were found averagely slightly larger than along a shorter system. The comparison of IDRs along both directions of frame systems was found lesser $(0.3 \%)$ than the specified code limit of $2.5 \%$, which ensured the safety of MSB with the 
developed joint. The distribution of IDRs along the height and horizontal directions of the frames varied with each record in terms of amplitude and peak ground acceleration but they followed a very similar pattern.

$$
\xi_{x}=\frac{\alpha}{2 \omega_{n i}}+\frac{\omega_{n i}}{2} \beta
$$

where, $\xi_{x}=$ Damping (5\%); $\alpha=$ Mass proportion damping; $\beta=$ Stiffness proportion damping, and $\omega_{n i}=$ Natural frequency at $i^{\text {th }}$ mode.

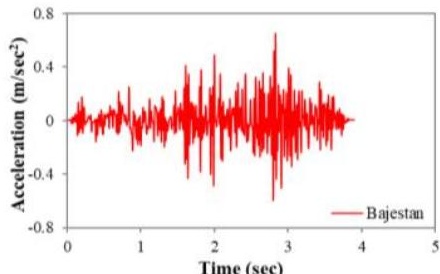

(a) Bajestan_Tabas, Iran

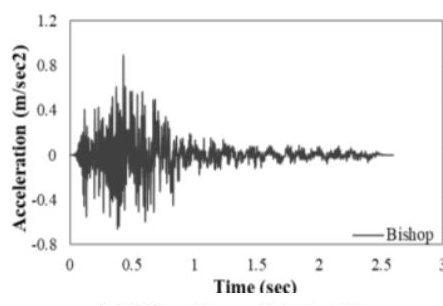

(c) Bishop_Mammoth Lakes-06

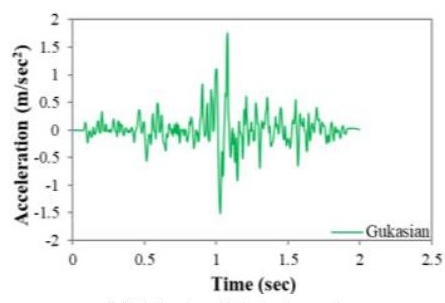

(e) Gukasian_Spitak, Armenia

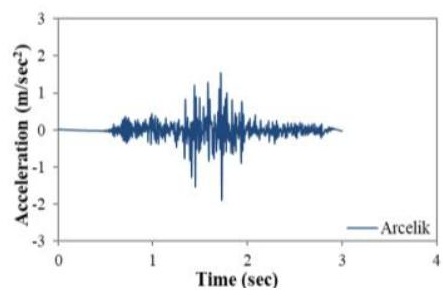

(g) Arcelik_Kocaeli, Turkey

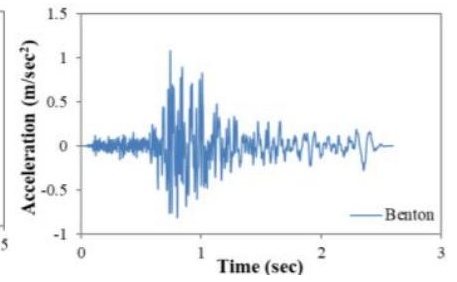

(b) Benton_Mammoth Lakes-06

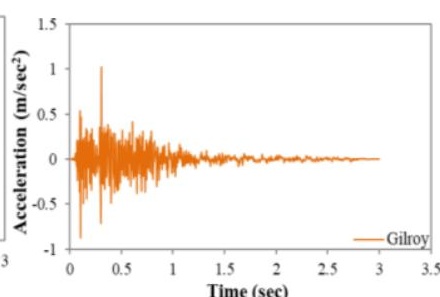

(d) Gilroy_Morgan Hill

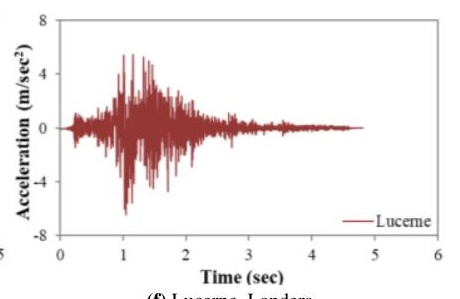

(f) Lucerne_Landers

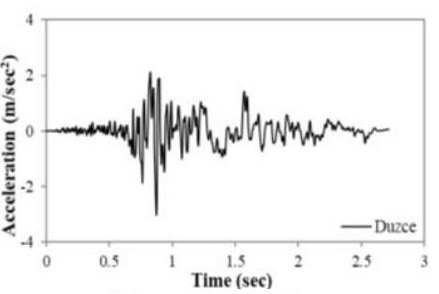

(h) Duzce_Kocaeli, Turkey

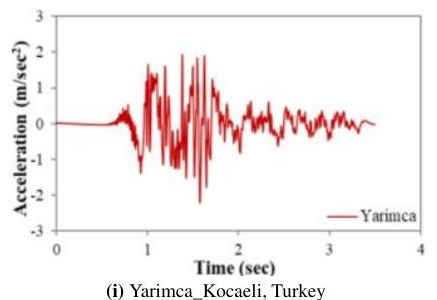

Fig. 11 Scaled earthquake records considered in the study $\left(1 / 10^{\text {th }}\right)$
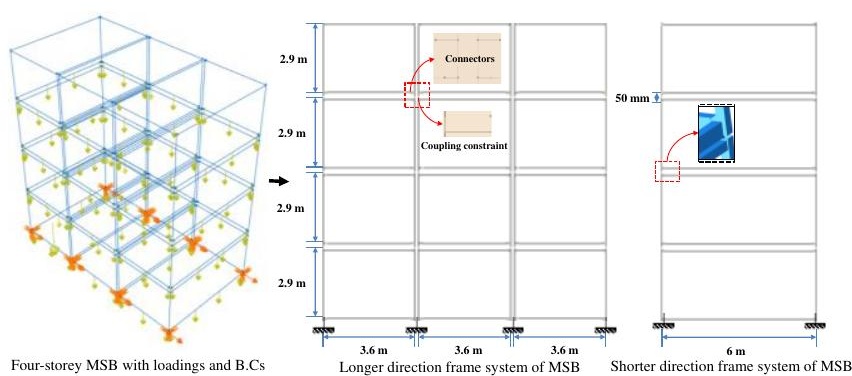

(a) Arrangement of spring connectors in PFMS frame system
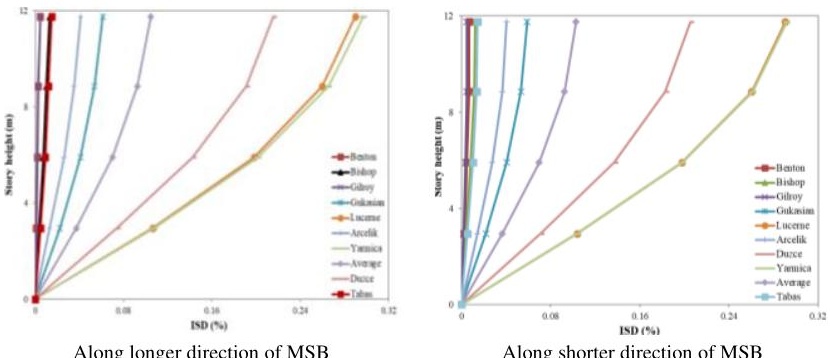

(b) Inter-storey drift ratios against various ground motions

Fig. 12 Structural performance of MSB with novel joint

Table 4

Record of considered ground motions

\begin{tabular}{|c|c|c|c|c|c|c|c|}
\hline S.No & $\begin{array}{c}\text { Station } \\
\text { No } \\
\end{array}$ & $\begin{array}{c}\text { Earthquake } \\
\text { name }\end{array}$ & $\begin{array}{l}\text { Station } \\
\text { name }\end{array}$ & $\begin{array}{l}\text { Time } \\
\text { (Year) }\end{array}$ & $\mathrm{M}_{\mathrm{w}}$ & $\begin{array}{l}\text { PGA } \\
(\mathrm{g}) \\
\end{array}$ & $\begin{array}{r}\text { Duration } \\
(\mathrm{sec})\end{array}$ \\
\hline 1 & 56 & Tabas, Iran & Bajestan & 1978 & 7.35 & 0.029 & 39 \\
\hline 2 & 430 & Mammoth & Benton & 1980 & 5.94 & 0.064 & 26 \\
\hline 3 & 437 & Mammoth & Bishop & 1980 & 5.94 & 0.083 & 26 \\
\hline 4 & 416 & Morgan & Gilroy & 1984 & 6.19 & 0.11 & 30 \\
\hline 5 & 13 & Spitak, & Gukasian & 1988 & 6.77 & 0.12 & 20 \\
\hline 6 & 25 & Landers & Lucerne & 1992 & 7.28 & 0.82 & 48 \\
\hline 7 & 600 & Kocaeli, & Arcelik & 1999 & 7.51 & 0.08 & 30 \\
\hline 8 & 709 & Kocaeli, & Duzce & 1999 & 7.51 & 0.21 & 27 \\
\hline 9 & 1144 & Kocaeli, & Yarimca & 1999 & 7.51 & 0.24 & 35 \\
\hline
\end{tabular}

\section{Standard design and analysis approaches}

For the detailed study on the structural performance of the modular frame system with developed joint, various standard analysis and design approaches were adopted. Material and sectional properties used in the FE analysis were chosen from experimental data [31,32]. The tenons in the joint were the main component for supporting columns and horizontally connecting modular units. The effect of tenon's length on overall structural performance and loading capacity was found evident. To evaluate the suitable length of tenon, the structural performance of the exterior corner connection with $1 / 10^{\text {th }}, 1 / 5^{\text {th }}, 1 / 3^{\text {rd }}$, and $1 / 2^{\text {nd }}$ of column's length was studied. The study revealed that tenon showed an apparent increase in load-carrying capacity, but an increase in strength decreased from 50 to $14 \%$ as length increased from 100 to $400 \mathrm{~mm}$. In accordance with the detailed analysis, the length of tenon was initially fixed for studying the performance of full-scale modular units. The purpose of nonlinear static analysis on joint and modular units was to obtain the forecasted lateral load-carrying capacity and failure pattern, and to provide relevant design recommendations. To obtain more realistic structural performance of modular units with the joint, performance of single and double modular units against various types of loadings was studied. The comprehensive study on structural performance suitably explained the behaviour, a structure may show with a developed joint. It was observed that beams and bolts controlled the failure behaviour; therefore, an appropriate design of edge distances and size or the number of bolts was needed.

To study the dynamic response and realistic seismic performance of MSB, ground motions of various catastrophic earthquakes were used in dynamic analysis. The simplified form of a joint (as discussed in section 5.3) with great accuracy made it easy to fully forecast the performance that a structure shows with such bolted joints in real earthquake situations. To study the stability effect, dynamic analysis was carried out on both horizontal directions of the frame system of MSB to find out important damage response parameters, i.e., IDR. The IDRs validated the safe behaviour showed by a low-storey MSB. The approaches adopted in analysis and design are shown in Fig. 6(b).

\section{Discussions}

Previously noted studies emphasized the importance of joints to resist lateral forces to ensure the integral and stable nature of MSB during catastrophic situations $[12,13,20]$. Therefore, in the current study, a new-type of the bolted joint was established, as shown in Fig. 1. The lateral bending performance of joints in terms of moment bearing capacity is presented in Fig. 7. The lateral load-carrying capacity showed by the joints was found comparatively better 
than the joints proposed earlier [40,41]. According to the previous work done on the beam-column joints, joints with a plastic rotation angle greater than 0.032 rad were considered suitable and recommended in strong seismic zones [42]. Whereas, as per the seismic provisions provided by the American institute of steel construction (AISC), the minimum plastic rotation angle accumulation showed by the joints in special moment frames (SMF) must be greater than 0.04 rad [43]. It was observed that the developed joints (corner with 0.062 and middle with $0.053 \mathrm{rad}$ ) fulfilled the requirements of high seismic performance and can be applied as a lateral force-resisting system in MSB. The length of column tenons played a significant role in regulating the seismic performance joints (i.e. strong columns-weak beams and plastic rotation $\geq 0.04 \mathrm{rad}$ ), while, increasing the inter-modular gap possessed a nonapparent role, as shown in Fig. 7. The strength, i.e., $0.25 M_{P} \leq M_{j} \leq M_{P}$ and stiffness classification criteria, i.e., $0.5 E I_{b} / L_{b} \leq S_{j i} \leq 25 E I_{b} / L_{b}$ for semi-rigid joints were listed in several studies [44-46]. The corner joint having single FB behaved as semi-rigid joint with strength $>0.5 M_{P}$ (i.e. $88.8 \mathrm{kNm}$ ) and rotational stiffness $>0.5 E I_{b} / L_{b}$ (i.e. 2749 $\mathrm{kNm} / \mathrm{rad}$ ), while, middle joint having two FBs showed strength $>0.5 M_{P}$ (i.e. $177 \mathrm{kNm}$ ) and rotational stiffness $>0.5 E I_{b} / L_{b}$ (i.e. $5498 \mathrm{kNm} / \mathrm{rad}$ ). Therefore, the developed joint validated the previously reported research regarding semirigid conditions.

Previously, other researches showed the performance of individual and combined modular units with shear walls. They studied the effect of different loading scenarios and opening in walls on the stiffness of MSB. Still, less importance was paid to the contribution of joints in the overall performance of modular units, i.e., single and double with axial, lateral tension, and compression loads $[47,48]$. The information obtained from detailed bending performance showed that the joint in a single modular unit possessed the tendency to bear lateral loads with proper utilization of the strengths of members. The increase in capacities and stiffnesses of double modular units authenticated the fact that the load was bored and after the accumulation of plastic deformation, load and stresses were effectively transferred to the members of adjacent modular. Few kinds of research were reported on the seismic response of simplified low-storey MSB $[6,8,27]$. It was stated that MSB possessed better seismic response in terms of base shear and IDR $(<0.5 \%$ for $0.3 \mathrm{~g}$ and $<1 \%$ for $2.0 \mathrm{~g}$ in four-storey MSB) due to more number of structural members compared to the traditional steel buildings $[15,27]$. In the current study, the IDRs along both directions showed by four-storey low-rise MSB exhibited variation with each record based upon their amplitude and peak ground acceleration, but followed a very similar pattern, found in previous researches. The peak IDRs of $<0.3 \%$ showed by MSB in both directions against ground motions of highest $(0.82 \mathrm{~g})$, median $(0.24 \mathrm{~g})$, and lowest $(0.029 \mathrm{~g})$ peak ground acceleration $(\mathrm{PGA})$ were in good compliance with the reported work and code limits $(<2.5 \%)$.

\section{Conclusions}

This study aimed to analyse the structural behaviour of MSB with a newtype of the bolted joint. The frame system included the HSS column, FB, CB, GP, CP, and bolts made of Q345B steel, while, joint with ZG35. The function of GP in the corner modular system was to vertically separate the modular units, whereas, besides, vertical separation to keep modular units intact in the middle and interior frames horizontally. The nonlinear static analysis on the joint and modular units, while, dynamic analysis on full-scale MSB were performed. Discussions were made on the structural performance of joint, modular units, and full-scale four-storey MSB. The focus of the study was to observe the seismic behaviour of joint, modular units, and MSB using FE software, ABAQUS. The following conclusions were drawn from the FE analyses;

1) The validity of the FE models was accurately proved by comparing the bending results of twelve test specimens of joints with the results obtained from FE analysis.

2) Both corner and middle joints showed high bearing capacity, ductility, and satisfactory seismic performance, i.e., strong columns-weak beams and accumulation of plastic rotation angle greater than 0.04 rad. Although, length of column tenon showed fundamental effects on the capacities and failure behavior of models, effects showed by the inter-modular gap were nonapparent.

3) Simplified models of the connector and beam-elements accurately predicted the structural behaviour and moment-bearing capacities of detailed joints with the least error tolerance of $<4 \%$. Simultaneously, the computational time and efforts were reduced to $90 \%$.

4) Nonlinear static analysis on full-scale single and double modular units with different loading scenarios showed that double modular units possessed better ductile behaviour, bearing capacity, and initial stiffness compared to single modular units. The joint evidently showed a good tendency of the distribution of loads among connected structural components and prevented premature failure. In contrast, an increase in the number of loadings decreased the capacity of modular units.
5) Seismic response of four-storey MSB in both horizontal directions revealed that the values of average IDRs along the longer direction of the building were slightly more significant than the shorter direction. Still, both were under the code limit of $2.5 \%$, which satisfied the safety requirements of low-rise MSB with the developed joint.

\section{Acknowledgment}

The authors are grateful for the scholarship provided by China scholarship council for the first author's study at Tianjin University.

\section{List of notations}

$\sigma_{T}=$ True stress

$\sigma_{E}=$ Engineering stress

$\varepsilon_{E}=$ True strain

$\varepsilon_{T}=$ Engineering strain

$E_{s}=$ Modulus of elasticity of steel

$N=$ Axial force

$A_{s}=$ Area of section

$f_{t v}=$ Tensile strength of the bolt

$\omega_{i}=$ Scale factor

$\varphi_{i}=i^{\text {th }}$ mode

$M_{P}=$ Plastic moment of the beam

$P=$ Force of pretension in the bolt

$A_{e}=$ Effective area of a bolt

$P=$ Lateral load

$\Delta=$ Lateral displacement

$\theta=$ Angle of rotation

$E_{s}=$ Elastic modulus of steel

$\mu=$ Frictional coefficient

$P_{\text {Test }}=$ Ultimate load resisted by a test specimen

$P_{F E}=$ Ultimate load resisted by the FE model

$\xi_{x}=$ Damping $(5 \%)$

$\alpha=$ Mass proportion damping

$\beta=$ Stiffness proportion damping

$\omega_{n i}=$ Natural frequency at $i^{\text {th }}$ mode

$S_{j i}=$ Rotational stiffness $(\mathrm{kNm} / \mathrm{rad})$

$M_{j}=$ Bending strength at the top of a column

\section{Abbreviations}

PFMS, Prefabricated modular steel; FE, Finite element; FB, Floor beam; Cov, Coefficient of variation; $\mathrm{CB}$, Ceiling beam; HSS, Hollow structural section; $\mathrm{CP}$, Cover plate; FS, Floor stringer; CS, Ceiling stringer; GP, Gusset plate; AFR, Axial force ratio; MSB, Modular steel building; IDR, Inter-storey drift ratio.

\section{References}

[1] J. Dhanapal, H. Ghaednia, S. Das, J. Velocci, Structural performance of state-of-the-art VectorBloc modular connector under axial loads, Eng. Struct. 183 (2019) 496-509. https://doi.org/10.1016/j.engstruct.2019.01.023.

[2] R. Jiang, C. Mao, L. Hou, C. Wu, J. Tan, A SWOT analysis for promoting off-site construction under the backdrop of China's new urbanisation, J. Clean. Prod. 173 (2018) 225-234. https://doi.org/10.1016/j.jclepro.2017.06.147.

[3] P. Sharafi, M. Mortazavi, B. Samali, H. Ronagh, Interlocking system for enhancing the integrity of multi-storey modular buildings, Autom. Constr. 85 (2018) 263-272. https://doi.org/10.1016/j.autcon.2017.10.023.

[4] R.M. Lawson, R.G. Ogden, R. Bergin, Application of modular construction in high-rise buildings, J. Archit. Eng. 18 (2012) 148-154. https://doi.org/10.1061/(ASCE)AE.19435568.0000057

[5] M. Kamali, K. Hewage, Development of performance criteria for sustainability evaluation of modular versus conventional construction methods, J. Clean. Prod. 142 (2017) 3592-3606 https://doi.org/10.1016/j.jclepro.2016.10.108.

[6] R. Feng, L. Shen, Q. Yun, Seismic performance of multi-story modular box buildings, J. Constr. Steel Res. 168 (2020) 106002. https://doi.org/10.1016/j.jcsr.2020.106002.

[7] A.W. Lacey, W. Chen, H. Hao, K. Bi, Review of bolted inter-module connections in modular steel buildings, J. Build. Eng. 23 (2019) 207-219. https://doi.org/10.1016/j.jobe.2019.01.035

[8] C.D. Annan, M.A. Youssef, M.H. El Naggar, Seismic vulnerability assessment of modular $\begin{array}{llllll}\text { steel buildings, J. } & \text { Earthq. } & \text { Eng. } & 13 & \text { (2009) 1065-1088. }\end{array}$ https://doi.org/10.1080/13632460902933881.

[9] J.Y.R. Liew, Y.S. Chua, Z. Dai, Steel concrete composite systems for modular construction of high-rise buildings, Structures. (2019) 0-1. https://doi.org/10.1016/j.istruc.2019.02.010.

[10] K.S. Park, J. Moon, S.S. Lee, K.W. Bae, C.W. Roeder, Embedded steel column-to-foundation connection for a modular structural system, Eng. Struct. 110 (2016) 244-257. https://doi.org/10.1016/j.engstruct.2015.11.034.

[11] E.F. Deng, L. Zong, Y. Ding, Y.B. Luo, Seismic behavior and design of cruciform bolted module-to-module connection with various reinforcing details, Thin-Walled Struct. 133 (2018) 106-119. https://doi.org/10.1016/j.tws.2018.09.033.

[12] Y.S. Chua, J.Y.R. Liew, S.D. Pang, Robustness of Prefabricated Prefinished Volumetric $\begin{array}{llll}\text { Construction } & \text { (PPVC) } & \text { High-rise } & \text { Building, }\end{array}$ https://doi.org/10.4995/asces2018.2018.6955. 
[13] P.M. Lawson, M.P. Byfield, S.O. Popo-Ola, P.J. Grubb, Robustness of light steel frames and modular construction, Proc. Inst. Civ. Eng. - Struct. Build. 161 (2008) 3-16. https://doi.org/10.1680/stbu.2008.161.1.3.

[14] B.H. Cho, J.S. Lee, H. Kim, D.J. Kim, Structural performance of a new blind-bolted frame modular beam-column connection under lateral loading, Appl. Sci. 9 (2019). https://doi.org/10.3390/app9091929.

[15] R. Sanches, O. Mercan, B. Roberts, Experimental investigations of vertical post-tensioned connection for modular steel structures, Eng. Struct. 175 (2018) 776-789. https://doi.org/10.1016/j.engstruct.2018.08.049.

[16] X.M. Dai, L. Zong, Y. Ding, Z.X. Li, Experimental study on seismic behavior of a novel plug-in self-lock joint for modular steel construction, Eng. Struct. 181 (2019) 143-164. https://doi.org/10.1016/j.engstruct.2018.11.075.

[17] J. Dhanapal, H. Ghaednia, S. Das, J. Velocci, Behavior of thin-walled beam-column modular connection subject to bending load, Thin-Walled Struct. (2019) 106536. https://doi.org/10.1016/j.tws.2019.106536.

[18] Z. Chen, Y. Liu, X. Zhong, J. Liu, Rotational stiffness of inter-module connection in mid-rise $\begin{array}{llllll}\text { modular steel buildings, } & \text { Eng. } & \text { Struct. } 196 & \text { (2019) } & 109273 .\end{array}$ https://doi.org/10.1016/j.engstruct.2019.06.009.

[19] A.W. Lacey, W. Chen, H. Hao, K. Bi, New interlocking inter-module connection for modular steel buildings: Experimental and numerical studies, Eng. Struct. 198 (2019) 109465. https://doi.org/10.1016/j.engstruct.2019.109465.

[20] Y. Ding, E.F. Deng, L. Zong, X.M. Dai, N. Lou, Y. Chen, Cyclic tests on corrugated steel plate shear walls with openings in modularized-constructions, J. Constr. Steel Res. 138 (2017) 675-691. https://doi.org/10.1016/j.jcsr.2017.08.019.

[21] Y. Yu, Z. Chen, Rigidity of corrugated plate sidewalls and its effect on the modular structural design, Eng. Struct. 175 (2018) 191-200. https://doi.org/10.1016/j.engstruct.2018.08.039.

[22] J. Bi, L. Zong, Q. Si, Y. Ding, N. Lou, Y. Huang, Field measurement and numerical analysis on wind-induced performance of modular structure with concrete cores, Eng. Struct. 220 (2020). https://doi.org/10.1016/j.engstruct.2020.110969.

[23] Z. Wang, W. Pan, Z. Zhang, High-rise modular buildings with innovative precast concrete shear walls as a lateral force resisting system, Structures. 26 (2020) 39-53. https://doi.org/10.1016/j.istruc.2020.04.006.

[24] C.D. Annan, M. Youssef, M.H. Naggar, Seismic performance of modular steel braced frames, 9h Can. Conf. Earthq. Eng. (2007). https://doi.org/10.13140/2.1.2132.2241.

[25] C.D. Annan, M.A. Youssef, M.H. El Naggar, Experimental evaluation of the seismic performance of modular steel-braced frames, Eng. Struct. 31 (2009) 1435-1446. https://doi.org/10.1016/j.engstruct.2009.02.024.

[26] Y. Liu, Z. Chen, J. Liu, Y. Bai, X. Zhong, X. Wang, Lateral stiffness evaluation on cornersupported thin walled modular steel structures, Thin-Walled Struct. 157 (2020) 106967. https://doi.org/10.1016/j.tws.2020.106967.

[27] A. Fathieh, O. Mercan, Seismic evaluation of modular steel buildings, Eng. Struct. 122 (2016) 83-92. https://doi.org/10.1016/j.engstruct.2016.04.054.

[28] J.F. Zhang, J.J. Zhao, D.Y. Yang, E.F. Deng, H. Wang, S.Y. Pang, L.M. Cai, S.C. Gao, Mechanical-property tests on assembled-type light steel modular house, J. Constr. Steel Res. 168 (2020) 105981. https://doi.org/10.1016/j.jcsr.2020.105981.

[29] S. Lee, J. Park, S. Shon, C. Kang, Seismic performance evaluation of the ceiling-bracket-type modular joint with various bracket parameters, J. Constr. Steel Res. 150 (2018) 298-325. https://doi.org/10.1016/j.jcsr.2018.08.008.

[30] S. Lee, J. Park, E. Kwak, S. Shon, C. Kang, H. Choi, Verification of the seismic performance of a rigidly connected modular system depending on the shape and size of the ceiling bracket, Materials (Basel). 10 (2017). https://doi.org/10.3390/ma10030263.

[31] Z. Chen, J. Liu, Y. Yu, C. Zhou, R. Yan, Experimental study of an innovative modular steel building connection, J. Constr. Steel Res. 139 (2017) 69-82. https://doi.org/10.1016/j.jcsr.2017.09.008.

[32] Z. Chen, J. Liu, Y. Yu, Experimental study on interior connections in modular steel buildings, Eng. Struct. 147 (2017) 625-638. https://doi.org/10.1016/j.engstruct.2017.06.002.

[33] ABAQUS (2013), User manual Version 6.13., DS SIMULIA Corp, Provid. RI, USA. (2013) $1-847$.

[34] J.-B. Yan, Finite element analysis on steel-concrete-steel sandwich beams, Mater. Struct. 48 (2015) 1645-1667. https://doi.org/10.1617/s11527-014-0261-3.

[35] ASCE, ASCE STANDARD Loads for Buildings, 2010.

[36] R.M. Lawson, J. Richards, Modular design for high-rise buildings, Proc. Inst. Civ. Eng. Struct. Build. 163 (2010) 151-164. https://doi.org/10.1680/stbu.2010.163.3.151.

[37] E. Miranda, S.D. Akkar, Generalized interstory drift spectrum, J. Struct. Eng. 132 (2006) 840-852. https://doi.org/10.1061/(ASCE)0733-9445(2006)132:6(840).

[38] S.R. Uma, A.B. King, T.J. Holden, D.K. Bell, Inter-storey Drift Limits for Buildings at Ultimate limit States, GNS Sci. Consult. Rep. 16 (2009) 1-33.

[39] Code, Uniform Building. "Uniform building code.," 1997.

[40] S. Sup, K. Woong, K. Sung, S. Yub, An Experimental Evaluation of Structural Performance for the Beam to Column Joints in Unit Modular System, J. Korean Soc. Steel Constr. 25 (2013) 255-265. https://doi.org/10.7781/kjoss.2013.25.3.255.

[41] Lee, Behavior of C-Shaped Beam to Square Hollow Section Column Connection in Modular Frame, J. Korean Soc. Steel Constr. 27 (2015) 471. https://doi.org/10.7781/kjoss.2015.27.5.471.

[42] X.C. Liu, A.X. Xu, A.L. Zhang, Z. Ni, H.X. Wang, L. Wu, Static and seismic experiment for welded joints in modularized prefabricated steel structure, J. Constr. Steel Res. 112 (2015) 183-195. https://doi.org/10.1016/j.jcsr.2015.05.003.

[43] B. Taranath, Seismic Provisions for Structural Steel Buildings, ANSI/AISC 341-10, Struct. Anal. Des. Tall Build. (2011) 355-410. https://doi.org/10.1201/b11248-8.

[44] EN 1993-1-1, Eurocode 3: Design of steel structures - Part 1-1: General rules and rules for buildings, 2005. https://doi.org/[Authority: The European Union Per Regulation 305/2011, Directive 98/34/EC, Directive 2004/18/EC].

[45] Y. Wang, J. Xia, R. Ma, B. Xu, T. Wang, Experimental Study on the Flexural Behavior of an Innovative Modular Steel Building Connection with Installed Bolts in the Columns, Appl. Sci. 9 (2019) 3468. https://doi.org/10.3390/app9173468.

[46] K.-S. Choi, H.-J. Kim, Analytical Models of Beam-Column joints in a Unit Modular Frame, J. Comput. Struct. Eng. Inst. Korea. 27 (2014) 663-672. https://doi.org/10.7734/coseik.2014.27.6.663.

[47] Y. Zuo, X. Zha, FEM and experimental study on mechanical property of container building with holes, Int. J. Steel Struct. 17 (2017) 175-194. https://doi.org/10.1007/s13296-015-0132y.

[48] K. Giriunas, H. Sezen, R.B. Dupaix, Evaluation, modeling, and analysis of shipping container building structures, Eng. Struct. $43 \quad$ (2012) $48-57$. https://doi.org/10.1016/j.engstruct.2012.05.001. 


\title{
SEISMIC BEHAVIOUR OF CONCRETE-FILLED STEEL TUBE FRAMES WITH EXTERNAL COMPOSITE WALL PANELS
}

\author{
Shi-Yi Wang ${ }^{1}$, An-Ying Chen ${ }^{1,}{ }^{*}$ and Hai-Ying Wan ${ }^{2}$ \\ ${ }^{1}$ School of Civil Engineering, Hefei University of Technology, Hefei, China \\ ${ }^{2}$ Anhui Collaborative Innovation Center for Advanced Steel Structure Technology and Industrialization, Hefei 230009, China \\ *(Corresponding author: E-mail: anyingchen@hfut.edu.cn)
}

\section{A B S T R A C T}

This study investigated the seismic performance of concrete-filled steel tube frames with external wall panels via experimental research, numerical and theoretical analysis. Pseudo-static tests were first performed on five concrete-filled steel tube frame specimens. The failure mode, hysteretic performance, stiffness degradation, strength degradation, ductility coefficient, and energy dissipation capacity in the essential components of the structural system were analysed. Besides, finite element analysis was then used to simulate the seismic performance of the specimen, and the predicted results were compared with the test results. A parametric analysis was then conducted to study the influence of the strength of the materials and the relative size of the wall openings on the structural system of the specimens. Finally, the numerical and experimental results were compared. The following results were obtained based on the observed failure modes of the specimens: (1) each specimen exhibited good seismic performance and safety reliability, (2) external wall panels improved the elastic stiffness and ultimate bearing capacity of concrete-filled steel tube frames, (3) the four-point support method effectively controlled the wall-plate displacement mode, and (4) the degree of horizontal constraint at the upper support joint connectors significantly affected the wall-plate displacement mode.

Copyright ( $) 2021$ by The Hong Kong Institute of Steel Construction. All rights reserved.

\section{Introduction}

Due to rapid social and economic growth and the implementation of industrialised construction in China, pre-fabricated buildings have been widely constructed. However, pre-fabricated buildings possess certain inherent defects that can have fatal consequences, e.g., weak integrity and poor seismic performance. Investigations following an earthquake revealed that the crumbling and destruction of the building envelope was one of the main causes of deaths and injuries. Therefore, while introducing steel structures, steel-concrete composite structures and other new structures systems into the pre-fabricated buildings, it is also important to conduct research on the seismic behaviour of pre-fabricated structural components such as concrete-filled steel tubes (CFSTs) and sandwich composite wall panels (SCWPs), as well as the envelope structure SCWPs constitute.

The SCWP is composed of two outer reinforced concrete (RC) layers a core insulation layer, and the connectors which linked the two RC layers. These panels do not require a secondary insulation layer structure and have excellent economic, social, and environmental benefits. Hence, SCWPs are expected to become the future building blocks of wall structures. However, further research is needed to study the reliability of the connection between SCWPs and the main structure. To this end, Markulak et al. performed tests on various types of masonry embedded in $\mathrm{H}$-shaped steel frames [1]. Benayoune et al. conducted both experimental and theoretical studies on the structural behaviour of precast concrete sandwich panels under flexural and axial loads [2-4]. Darzi et al. investigated the flexural stiffness and ultimate load capacity of novel ultralight composite sandwich panels made of plywood faces and bamboo or peeling cores [5]. Li and Dong studied the shear-resistance behaviour of a light composite shear wall [6]. Huang and Dai conducted a four-point bending test to investigate the flexural performance of the fiber reinforced polymer (FRP) connector enabled precast geopolymer concrete sandwich panel [7]. Xu and Li described quasi-static tests and simulations of both cast-in-situ and precast concrete sandwich walls [8].

The behaviour of CFST frame components has also been the subject of investigation. Han et al. described the behaviour of CFSTs under axial tension [9]. Moon et al. proposed a simplified model for the bending behaviour of CFSTs [10]. Pagoulatou et al. conducted a finite element analysis and investigated the compression behaviour of circular concretefilled double-skin steel tubes [11]. Lastly, Agheshlui et al. studied the tensile behaviour of groups of Ajax-anchored blind bolts used within square CFST sections [12].

Extensive research has been conducted on the hysteretic behaviour of CFSTs with SCWPs. Wang et al. conducted experiments on CFST frames with external SCWPs and studied the seismic behaviour of blind-bolted CFST frames infilled with precast SCWPs under various parameters [13].
Fang performed shaking-table tests and studied the destruction properties of autoclaved lightweight aerated concrete (ALC) external walls [14]. Ma and Jiang investigated the seismic performance of a new environmentally friendly gypsum-concrete composite interior wallboard and demonstrated its excellent seismic behaviour; they also found that the ductility of the proposed green wallboard was better than that of a conventional steel reinforced concrete wallboard [15]. Tasnimi and Mohebkhah studied the in-plane seismic behaviour of steel frames infilled with clay brick masonry and openings [16]. Hou et al. investigated the seismic behaviour of H-shaped steel frames with embedded lightweight infill wall panels $[17,18]$. Hashemi et al. also conducted cyclic loading tests on steel frame infill walls and explored the influence of the walls on the behaviour of the main structure [19]. Finally, Wang et al. explored the failure modes of and interaction between ALC walls and CFST frames under seismic loading tests [20,21].

The present study considered a wall panel joint utilising a four-point support flexible connection form to connect a precast concrete SCWP to a CFST frame. A pseudo-static test was then performed on the overall CFST frame. Simultaneously, the inter-laminar displacement mode of the external SCWP was analysed during the test, and the influence of the connecting bolt type on the overall seismic performance was studied.

\section{Experimental program}

\subsection{Design of specimens}

The main control parameters of the test included the presence or absence of an external SCWP in the frame, the steel beam span, the SCWP size, the size of the wall opening area, and the bolt type in the upper support joints. Five full-scale, single-floor, single-span frame specimens were designed, of which two were empty frames (KJ1 and KJ3) and three of which were CFST frames with external SCWPs (KJ2, KJ4, and KJ5). The steel used in the test was Q345B. The frame columns were square CFSTs with cross-sectional dimensions of $200 \mathrm{~mm} \times 200 \mathrm{~mm} \times 10 \mathrm{~mm}$, $3100 \mathrm{~mm}$ long, and filled with C30 concrete. The H-section beams were designed with cross-sectional dimensions of $300 \mathrm{~mm} \times 180 \mathrm{~mm} \times 6 \mathrm{~mm}$ $\times 10 \mathrm{~mm}$. The beam-column joints adopted a bolted-welded hybrid connection; in other words, the beam flange was welded to the outer diaphragm of the CFST column, and 10.9-grade M20 high-strength bolts were used to connect the beam web to the column. The thickness of the SCWPs was $150 \mathrm{~mm}$. The core thermal insulation layer was a $50 \mathrm{~mm}$ thick extruded polystyrene board, which was sandwiched between the $50 \mathrm{~mm}$ thick C30 reinforced concrete slabs. The surface layer of the SCWP was embedded with a steel reinforcing mesh of $\Phi 6$ @ 150, and a vertically arranged steel truss was connected to the steel mesh to form a steel mesh reinforcing skeleton. The main connections between the external wall 
panel and the main frame consisted of two upper and two lower connection joints; the lower joints were mainly used for bearing the load and the upper joints were mainly used for reducing the displacement of the wall. The external SCWP was placed vertically on the supporting plate of the lower joints and was connected to all four joints using bolts. Except for the upper joints of $\mathrm{KJ} 4$, which were connected to the bottom flange of the steel beam using ordinary 4.8 -grade bolts, all joints were connected using 10.9-grade M20 high-strength bolts. Details of the test specimens are shown in Fig. 1, and the investigating parameters can be seen in Table 1 .

Table 1

Parameters of test specimens

\begin{tabular}{cccccc}
\hline Specimen & $\begin{array}{c}\text { Beam } \\
\text { length } \\
L\end{array}$ & $\begin{array}{c}\text { Wall size } \\
(\mathrm{mm})\end{array}$ & $\begin{array}{c}\text { Opening } \\
\text { size }(\mathrm{mm})\end{array}$ & $\begin{array}{c}\text { Relative } \\
\text { opening } \\
\text { area }(\%)\end{array}$ & $\begin{array}{c}\text { Upper } \\
\text { joint bolt } \\
\text { type }\end{array}$ \\
\hline KJ1 & 2000 & - & - & - & - \\
KJ2 & 2000 & $1880 \times 2920$ & $600 \times 1500$ & 16.4 & $\begin{array}{c}\text { High- } \\
\text { strength } \\
\text { bolts }\end{array}$ \\
KJ3 & 2800 & - & - & - & $\begin{array}{c}- \\
\text { Ordinary } \\
\text { bJ4 }\end{array}$ \\
& 2800 & $2760 \times 2920$ & $600 \times 1500$ & 11.2 & $\begin{array}{c}\text { High- } \\
\text { strength } \\
\text { bolts }\end{array}$ \\
\hline KJ5 & 2800 & $2760 \times 2920$ & $600 \times 1500$ & 11.2 & \\
\hline
\end{tabular}

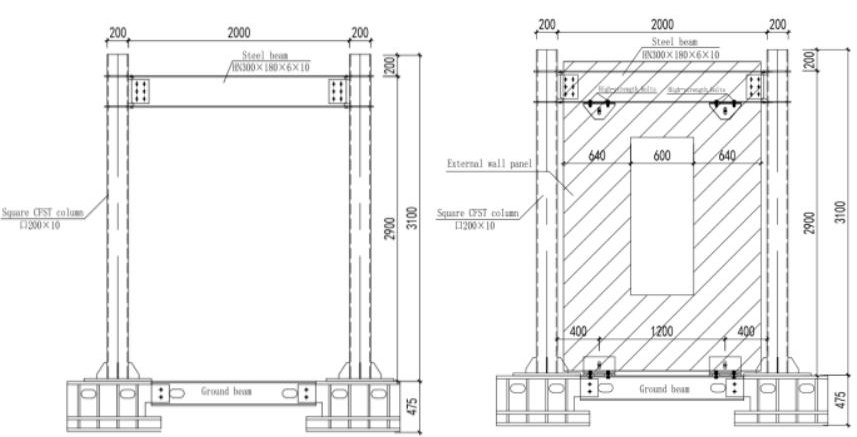

(a) KJ1

(b) $\mathrm{KJ} 2$

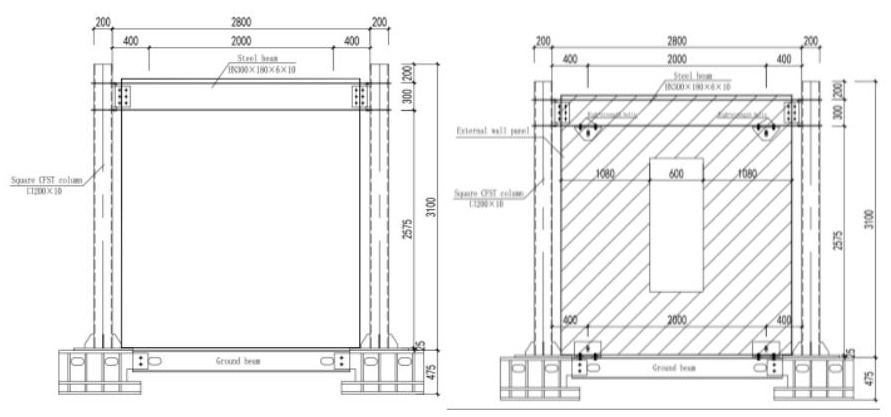

(c) $\mathrm{KJ} 3$

(d) KJ4
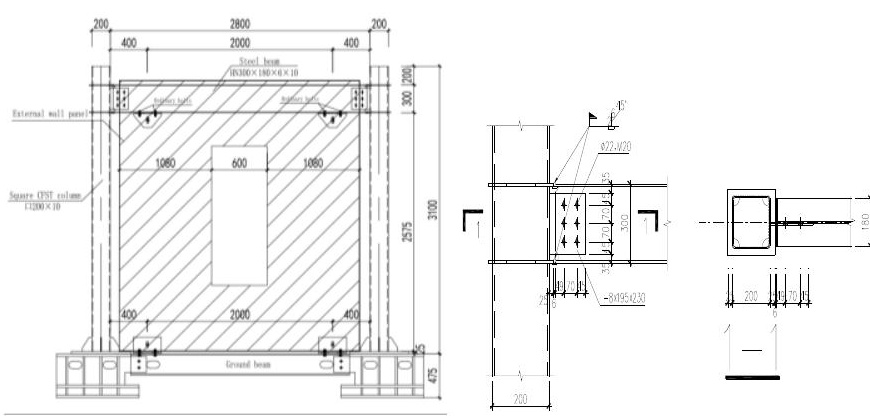

$\Downarrow \ldots$

(e) KJ5

(f) Details of beam-column joints
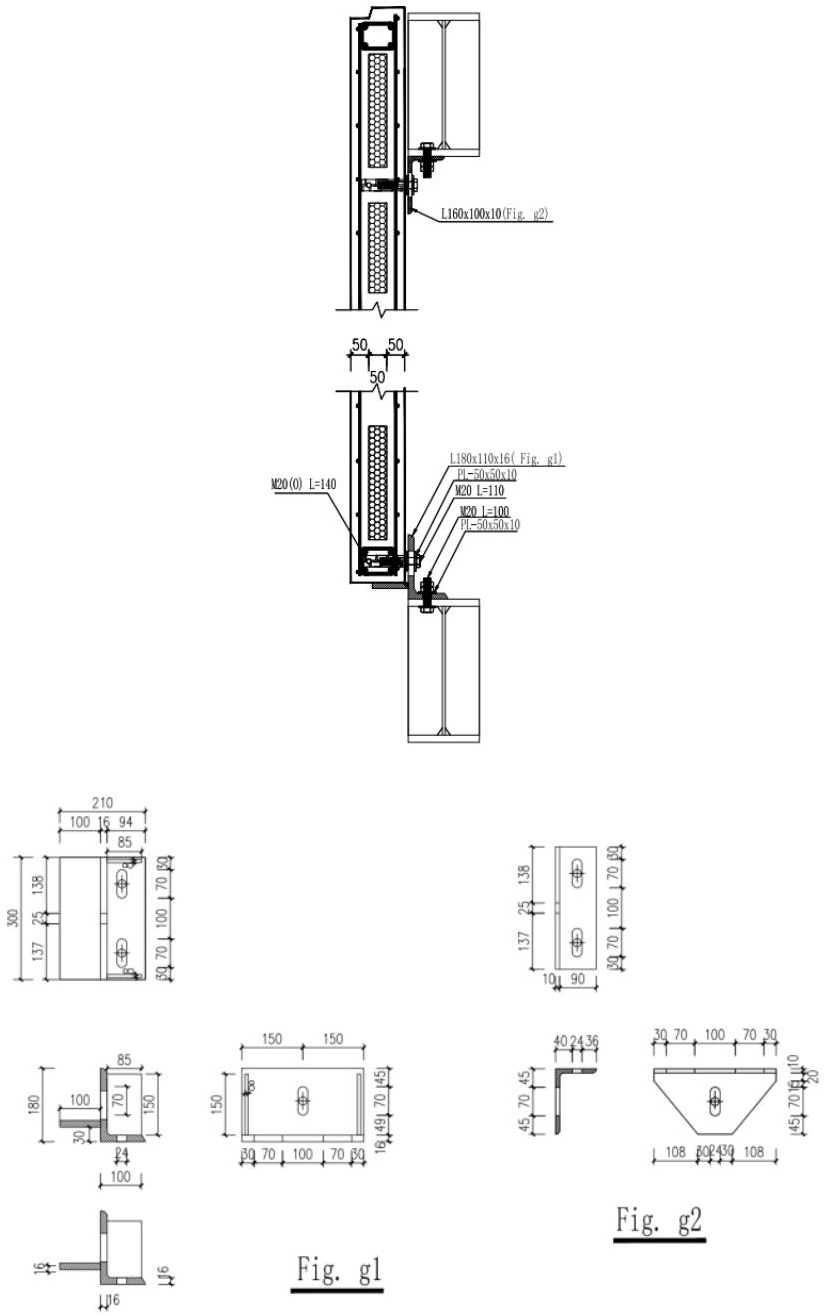

Fig. g2

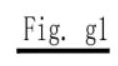

(g) Details of support joint connectors

Fig. 1 Specimen details (units: mm)

\subsection{Cyclic loading apparatus}

A hydraulic servo actuator (MTS, Inc.) was used to perform pseudostatic load to the specimens. One end of the actuator was fixed to a reaction wall, and the other end was connected to the test specimen through a loading head. The column base was connected to a steel pier, and this steel pier was anchored to the ground using anchor rebar. The column was fixed by the ground beam and the hydraulic jack to ensure that the rigid foundation would constrain the bottom of the column. Simultaneously, four constraining pull rods were located on each side of the specimen to ensure the stability of the entire frame during horizontal reciprocating loading. The arrangement of the experimental apparatus is shown in Fig. 2, and images of the test setup are shown in Fig. 3.

Before each specimen was formally loaded, a 5-mm lateral displacement was applied to the specimen by the actuator, then this displacement was reversed to $-5 \mathrm{~mm}$. This cycle was conducted twice to confirm that the loading system and measuring devices were well worked. All specimens were tested under low-cycle horizontal loads in accordance with ATC-24 guidelines [22], as illustrated in Fig. 4. The actuator applied a low-cycle reciprocating lateral displacement to each test specimen at a speed of $0.5 \mathrm{~mm} / \mathrm{s}$. The displacement $\Delta y$ at the yield point was considered as the control displacement ( $\Delta y$ for all the test specimens was $12 \mathrm{~mm}$ ). Before each test specimen yielded, the loading amplitude was controlled at levels of $0.25 \Delta y, 0.5 \Delta y$, and $0.7 \Delta y$, each of which was cycled twice. After the test specimens reached the yield point, loading levels of $1 \Delta y$, $1.5 \Delta y, 2 \Delta y, 3 \Delta y, 5 \Delta y, 7 \Delta y$, and $8 \Delta y$ were applied. The first three levels $(1 \Delta y, 1.5 \Delta y$, and $2 \Delta y)$ were cycled three times, and the remaining levels were cycled twice. 


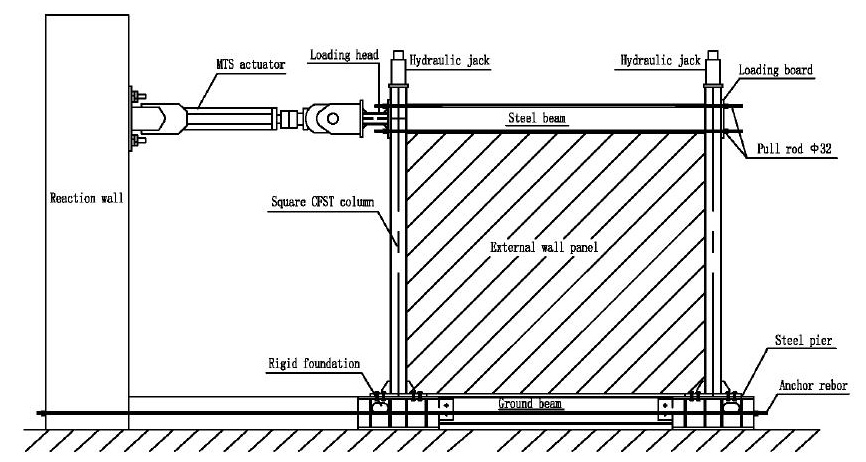

Fig. 2 Experimental setup

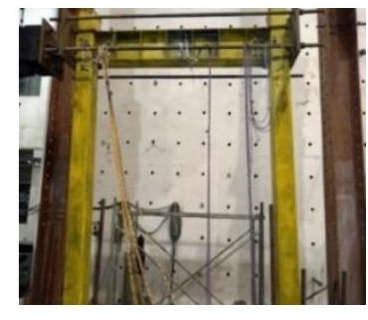

(a) KJ1

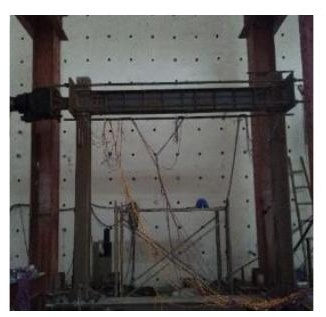

(c) $\mathrm{KJ} 3$

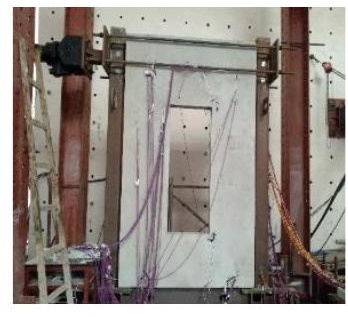

(b) KJ2

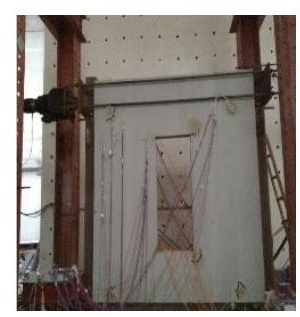

(d) $\mathrm{KJ} 2$

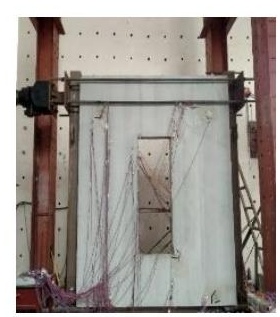

(e) KJ5

Fig. 3 Test setup photographs

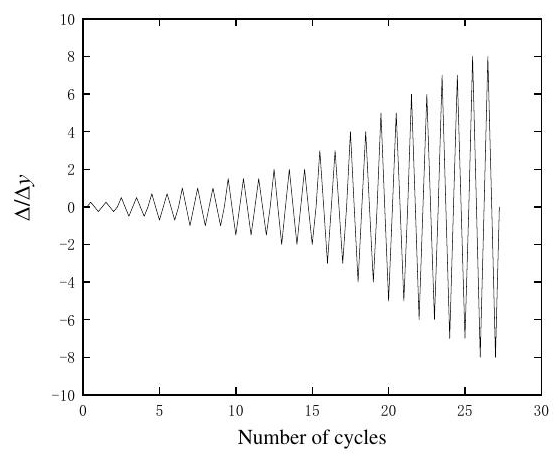

Fig. 4 Loading history

\subsection{Layout of strain gauges}

The following measurement parameters were determined based on the objective of this experimental research:

(1) Load and displacement at the test specimen loading position: During the test, the servo-hydraulic machine automatically collected the horizontal load $(\mathrm{P})$-horizontal displacement $(\Delta)$ data.

(2) Strain in key parts: A multifunctional static strain test system (JM3813) was used to record the strain in the test specimen during the test. Strain gauges were installed on three parts of the specimen: the steel frame, wall panel, and the support joint connectors. The numbers and locations of the strain gauges are shown in Fig. 5.

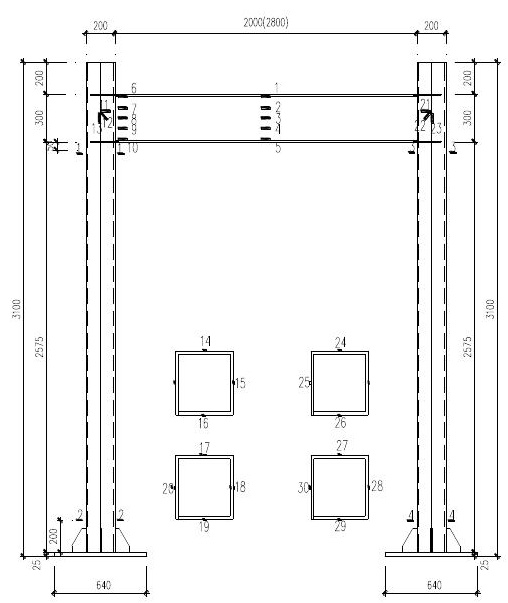

(a) Layout of strain gauges on CFST frame

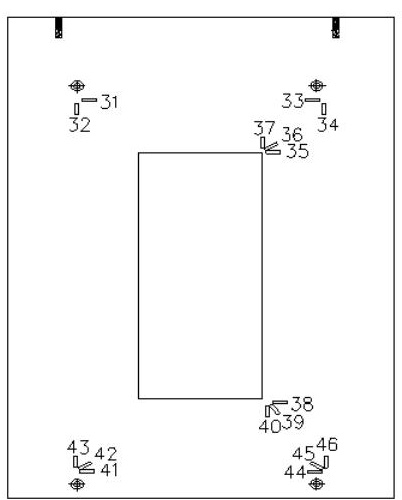

(b) Layout of strain gauges on panels
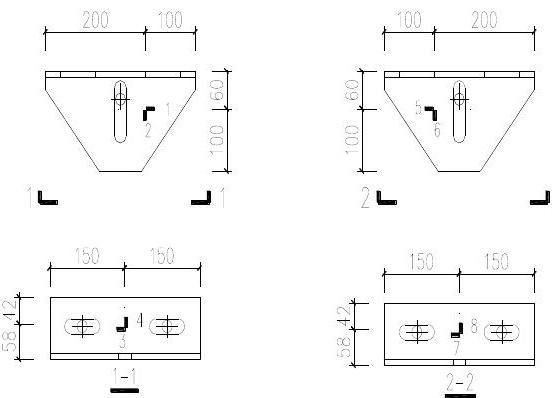

(c) Layout of strain gauges on upper connectors
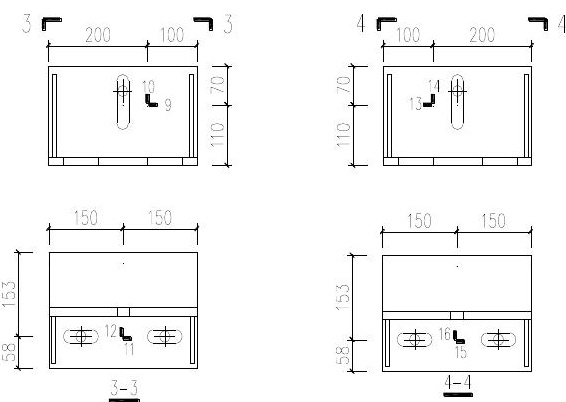

(d) Layout of strain gauges on lower connectors 


\section{Experimental observations}

\subsection{Specimen $K J 1$}

KJ1 was a pure square CFST frame with no SCWP. The specimen exhibited a high level of integrity and ductility as the applied displacement increased. When the column-end displacement reached $60 \mathrm{~mm}$ in the first $5 \Delta y$ cycle, the weld in the bottom flange of the steel beam began to crack. The flanges at both ends of the steel beam were considerably buckled at $96 \mathrm{~mm}$. Furthermore, the weld in the bottom flange at the right end of the steel beam was severely torn. The test was stopped when the bottom flange of the steel beam exhibited weld fracture. The failure mode of specimen $\mathrm{KJ} 1$ is shown in Fig. 6.

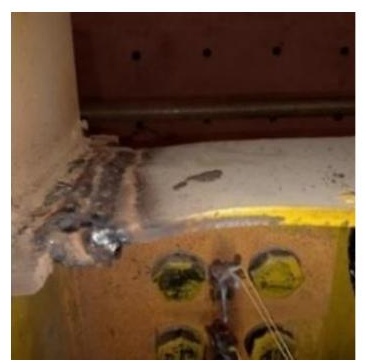

(a) Buckling in top flange

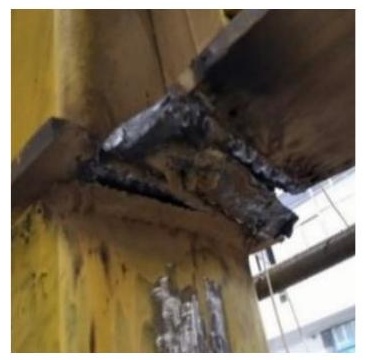

(c) Weld fracture in bottom flange

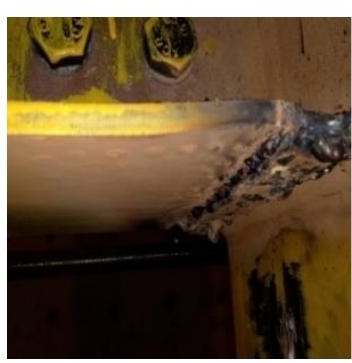

(b) Buckling in bottom flange

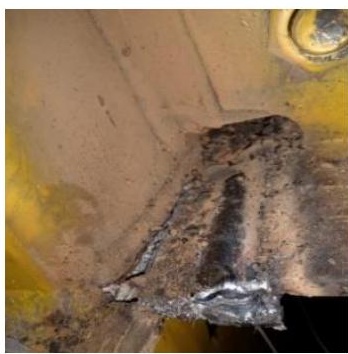

(d) Weld fracture in bottom flange
Fig. 6 Failure modes of beam in specimen KJ

\subsection{Specimen $K J 2$}

KJ2 was a CFST frame with an external SCWP. The specimen was well-stressed in the first and middle stages of the test load, and no apparent yielding or failure occurred. During this period, a faint sound of friction and squeezing of the steel was heard, indicating that a slight slippage of the specimen had occurred. When the displacement reached $60 \mathrm{~mm}$ in the first $5 \Delta y$ cycle, cracks appeared in the panel opening, the top flanges of the steel beam buckled slightly, the lower left corner of the wall panel separated from the lower support joint connector bracket, and the lower left joint bolt slid upwards in its vertically oblong hole. When the columnend displacement reached the first $7 \Delta y$ cycle, the top flanges at both ends of the steel beam buckled considerably; moreover, cracks appeared at the four corners of the wall panel opening and gradually extended towards the joint. The connecting bolt of the lower right joint was cut off at $-62 \mathrm{~mm}$ in the first $7 \Delta y$ cycle, and an instantaneous displacement occurred between the wall panel and the frame. Thereafter, the test was terminated. The failure modes of specimen KJ2 are shown in Fig. 7.

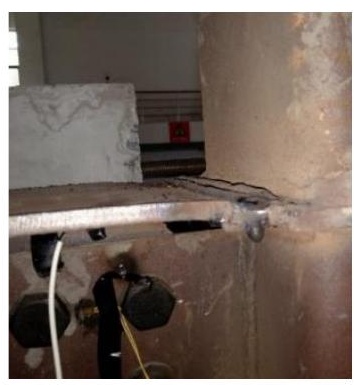

(a) Buckling in top flange

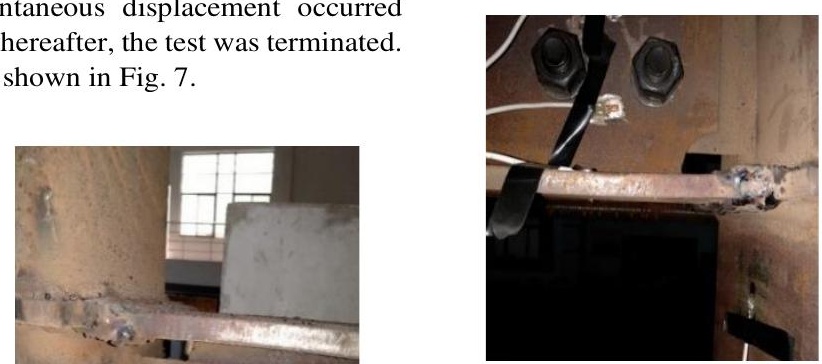

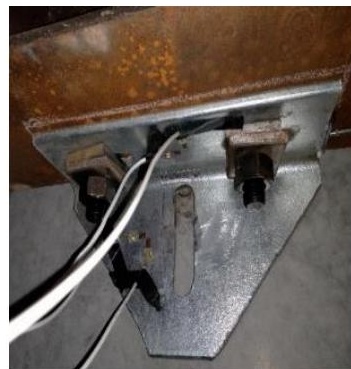

(d) Shearing of bolts

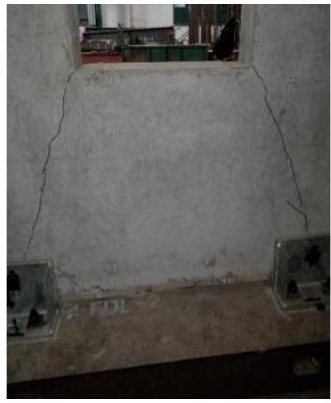

(f) Cracks around panel opening (e) Cracks around panel opening

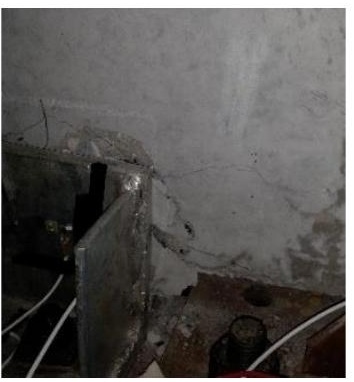

(g) Cracking of concrete around lower connectors

\subsection{Specimen $K J 3$}

KJ3 was a pure square CFST frame. The specimen exhibited good integrity and ductility with the increase of the applied displacement. When the displacement reached $60 \mathrm{~mm}$, the bottom flange at the left end of the steel beam began to buckle, and a slight tearing sound was heard from the weld. Similarly, when the applied displacement reached $-60 \mathrm{~mm}$ in the first $5 \Delta y$ cycle, the top flange at the left end of the steel beam buckled. When the loading reached $84 \mathrm{~mm}$ in the first $7 \Delta y$ cycle, the weld at the bottom flange at the right end of the steel beam was torn. Similarly, when the loading reached $-84 \mathrm{~mm}$ in the first $7 \Delta y$ cycle, the weld in the bottom flange at the left end of the steel beam was torn. After two cycles of $9 \Delta y$ loading, the welds at both ends of the beam were damaged considerably, and severe flange buckling occurred. The loading was then stopped. The failure modes of specimen $\mathrm{KJ} 3$ are shown in Fig. 8. (a) Buckling in bottom flange

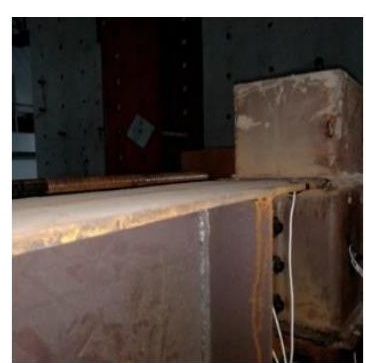

(b) Buckling in top flange 


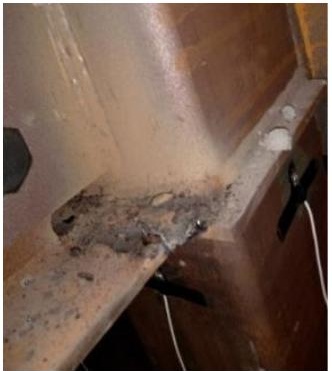

(c) Weld fracture in bottom flange

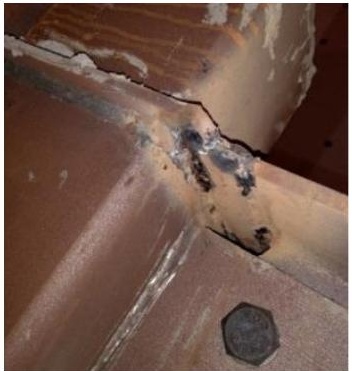

(d) Weld fracture in top flange
Fig. 8 Failure modes of beam in specimen KJ3

\subsection{Specimen KJ4}

KJ4 was a CFST frame with an external SCWP. The test specimen was well-stressed in the first and middle stages of the test load, and no apparent yielding or failure occurred. During this period, a slight sound of friction and squeezing of the steel was heard, indicating that slight slippage of the specimen had occurred. When the loading reached $36 \mathrm{~mm}$ in the first $3 \Delta y$ cycle, the upper support joint bolts slid in their holes, and small cracks developed on the inner face of the wall panel at the corners of the opening. The cracks gradually extended towards the joints and the right end of the wall panel was slightly lifted away from the lower joint plate at $-60 \mathrm{~mm}$. When the applied displacement reached $84 \mathrm{~mm}$ in the first $7 \Delta y$ cycle, oblique cracks appeared on the exterior surface of the wall panel at the four corners of the opening. Cracks appeared in the concrete at the embedded parts of the lower support joints of the wall panel, and the sliding of the bolts in the vertically oblong hole of the lower support joints was restricted. The connecting bolt of the joint was cut off at -78 $\mathrm{mm}$ in the first $7 \Delta y$ cycle, and an instantaneous displacement occurred between the wall panel and the frame. The failure modes of specimen KJ4 are shown in Fig. 9.
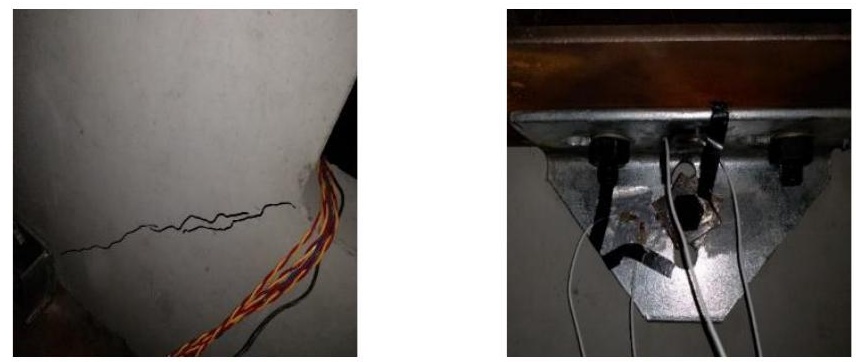

(a) Cracking around panel openings (b) Sliding of upper connector relative to steel beam

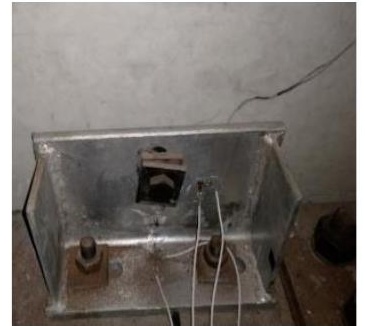

(c) Cracking of concrete around connectors

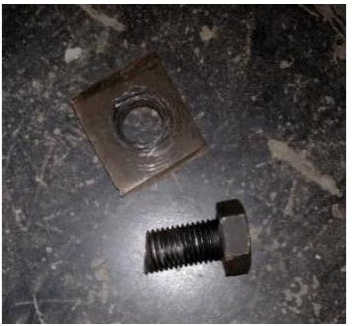

(d) Sheared connector bolt
Fig. 9 Failure modes of specimen KJ4

\subsection{Specimen $K J 5$}

KJ5 was a CFST frame with an external SCWP. The test specimen was well-stressed in the first and middle stages of the test load, and no apparent yielding or failure occurred. During this period, a slight sound of friction and squeezing of the steel was heard, indicating that the specimen had slightly slipped. When the applied displacement reached $60 \mathrm{~mm}$ in the first $5 \Delta y$ cycle, slight cracking occurred on inner surface of the concrete at the upper left and lower right corners of the wall panel opening that gradually extended towards their respective joints, the left end of the wall panel was slightly lifted away from the lower support joint connector, and the lower support joint was vertically elongated. The lower support joint connector bolts accordingly slid upwards, and the wall panel and lower right joint connector plate were squeezed together, cracking the former. Similarly, when the displacement reached $-60 \mathrm{~mm}$, small-scale concrete cracking occurred in the wall that progressively extended towards the joints; moreover, the right end of the wall panel was slightly lifted away from its lower support joint plate. The lower right connector bolt slid upwards in its hole, and the wall panel and the support plate of the lower left joint were squeezed together, cracking the former. When the loading reached $76 \mathrm{~mm}$, the lower right support joint connector bolt was sheared, and an instantaneous displacement occurred between the wall panel and frame. Similarly, when the applied displacement reached -60 $\mathrm{mm}$, the upper support joint connector bolts were sheared, and the panel exhibited an out-of-plane inclination. The failure modes of specimen KJ5 are shown in Fig. 10.

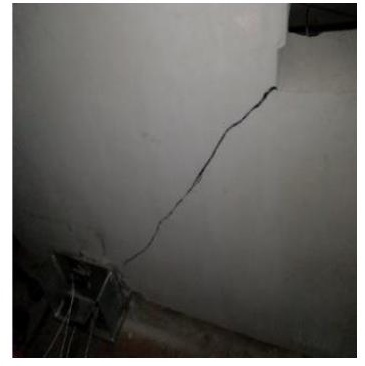

(a) Cracking in panel openings

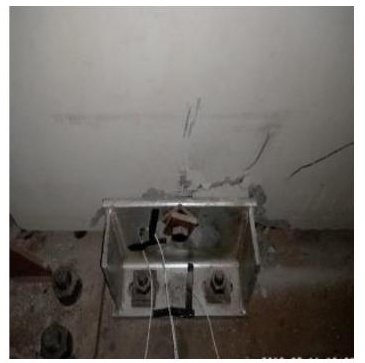

(c) Cracking of concrete at connectors

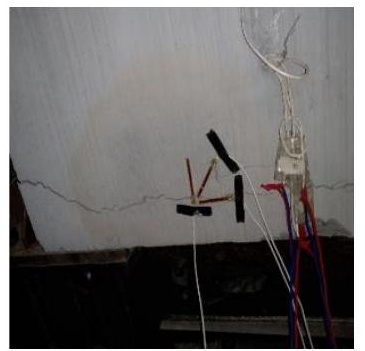

(e) Cracking in wall panel embedded parts

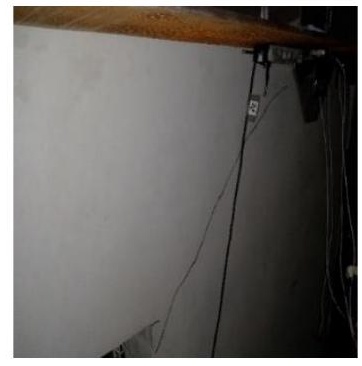

(b) Cracking in panel openings

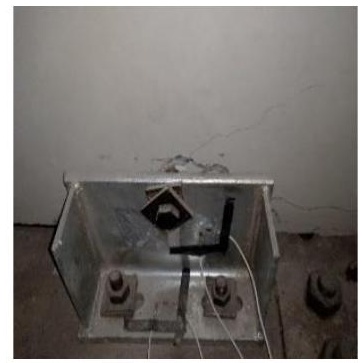

(d) Cracking of concrete at connectors

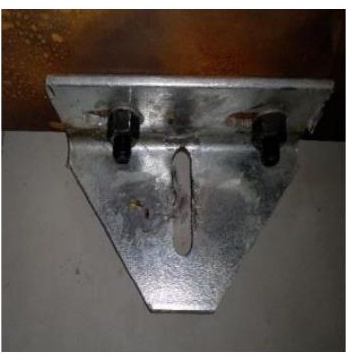

(f) Sheared connector bolt
Fig. 10 Failure modes of specimen KJ5

\section{Analysis of experimental results}

\subsection{Analysis of hysteresis curve}

The measured $\mathrm{P}-\Delta$ hysteresis curve for each specimen is shown in Fig. 11, from which the following conclusions were drawn:

(1) When the displacement magnitude was small in the early part of the test, the loading and unloading curves coincided and passed through the zero point without any reduction in stiffness. The residual deformations of the test specimens were small, and the specimens were in the elastic stage. As the displacement increased, an apparent rheostriction manifested in the curves, reflecting the aforementioned slide in the test. The slopes of the loading curves changed only slightly at this time; however, the slopes of the unloading curves decreased considerably, and the specimens exhibited some residual deformation. The main frames entered the elastoplastic stage; the overall stiffness gradually deteriorated; and the energy dissipation of the specimens gradually increased.

(2) $\mathrm{KJ} 2, \mathrm{KJ} 4$, and $\mathrm{KJ} 5$, which had external SCWPs, exhibited a 
considerably higher initial elastic stiffness than $\mathrm{KJ} 1$ and $\mathrm{KJ} 3$ (without external wall panels), and reached the limit state earlier. The wall panels were damaged before the frames, indicating that the overall structural stiffness of the frames was improved by the SCWPs.

(3) The hysteresis curves of $\mathrm{KJ} 2, \mathrm{KJ} 4$, and $\mathrm{KJ} 5$ all fluctuated considerably in the final loading cycle. Because the connecting bolts between the upper support joint and wall panel were sheared, the wall panel suddenly shifted relative to the frame, causing the sustained load to decrease. This indicates that the upper support joint connector is an essential force-bearing component that affects the ultimate bearing capacity of the entire specimen.

(4) The shear failure of the upper support joint bolts of KJ4 and KJ5 occurred at approximately $7 \Delta y$ and $5 \Delta y$, respectively. The presence of the wall panel was conducive to energy consumption and shock absorption, and delayed the onset of damage to the test specimen. Hence, the seismic performance of the overall structure was improved to a certain extent.

The horizontal $P-\Delta$ envelope curve was plotted for each specimen from the peak load points in each cycle of its hysteresis curve (Fig. 12). Because the obtained envelope curves exhibited no obvious yield point, the universal yield moment method was applied to identify the characteristic values [23], including the yield, limit, and failure points. The method can be explained in detail using Fig. 13. In the figure, the tangent $\mathrm{OH}$ of the skeleton curve passing through the origin $\mathrm{O}$ and the horizontal line of the extreme load point $\mathrm{G}$ intersect at point $\mathrm{H}$. The vertical line passing through $\mathrm{H}$ intersects point $\mathrm{I}$ on the $\mathrm{P}-\Delta$ curve; the line obtained by extending $\mathrm{OI}$ intersects $\mathrm{HG}$ and passes through $\mathrm{H}_{0}$; and the vertical line passing through $\mathrm{H}_{0}$ intersects point $\mathrm{B}$, which is the assumed yield point. Therefore, it was assumed that the descending and ascending sections of the skeleton curve were bilaterally symmetrical about the peak point. When calculating the eigenvalues, the measured points had to be curve-fitted to obtain the skeleton curve model. The characteristic values are shown in Table 2. The specimens with external SCWPs yielded and failed earlier than the empty-frame specimens, and their yield points were closer to the limit point. However, the specimens with external SCWPs exhibited a higher load carrying capacity, indicating that the external SCWPs reduced the overall ductility of the frame while improved the load carrying capacity. At the same column displacement, the load on $\mathrm{KJ} 2$ was higher than that on $\mathrm{KJ} 1$, and the loads on $\mathrm{KJ} 4$ and $\mathrm{KJ} 5$ were higher than that on KJ3. These results demonstrate that the external SCWP improved the overall rigidity of the CFST frame but had negligible effect on its bearing capacity.

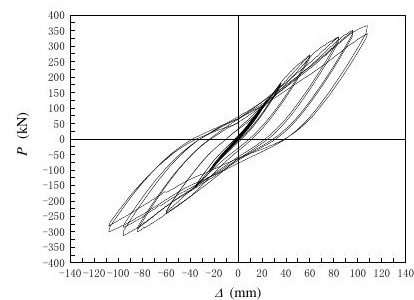

(a) KJ1

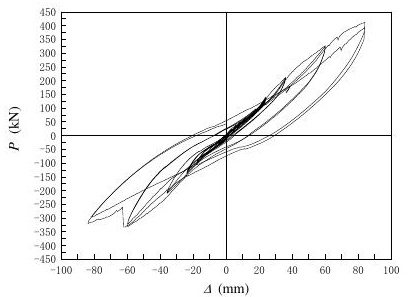

(b) $\mathrm{KJ} 2$

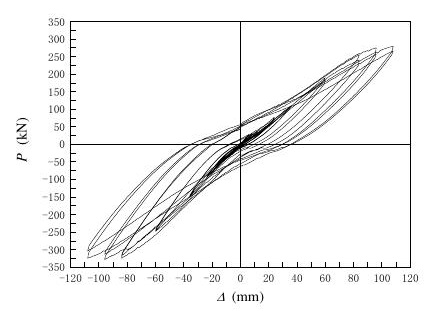

(c) $\mathrm{KJ} 3$

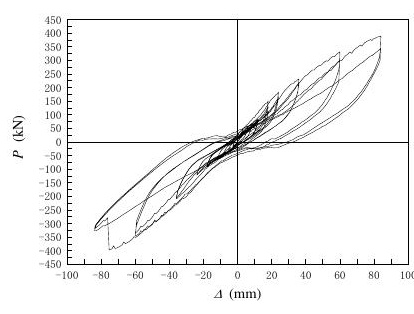

(e) KJ4

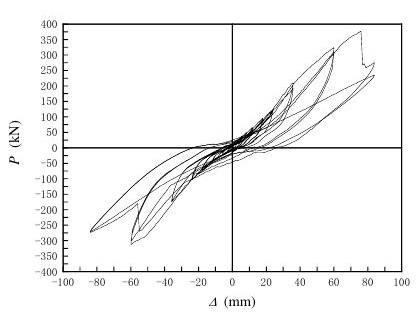

(f) KJ5

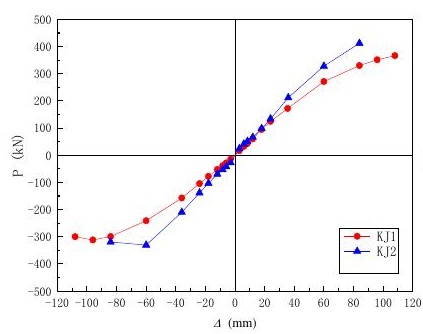

(a) KJ1 and KJ2

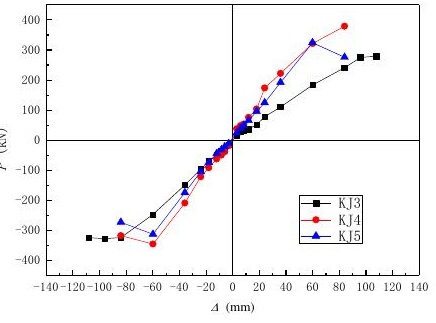

(b) $\mathrm{KJ} 3, \mathrm{KJ} 4$, and $\mathrm{KJ} 5$
Fig. 12 Load $(P)$-displacement $(\Delta)$ envelope curves of specimens

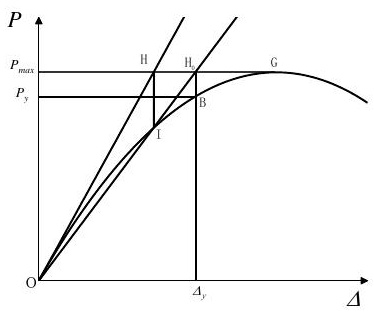

Fig. 13 General yield bending moment method

Table 2

Characteristic values of specimen load-displacement skeleton curves

\begin{tabular}{ccccccc}
\hline & \multicolumn{2}{c}{ Yield point } & \multicolumn{2}{c}{ Limit point } & \multicolumn{2}{c}{ Failure point } \\
Specimen & $\Delta y$ & $P_{y}$ & $\Delta_{\max }$ & $P_{\max }$ & $\Delta u$ & $P_{u}$ \\
& $(\mathrm{~mm})$ & $(\mathrm{kN})$ & $(\mathrm{mm})$ & $(\mathrm{kN})$ & $(\mathrm{mm})$ & $(\mathrm{kN})$ \\
\hline KJ1 (-) & 77.9 & 290.0 & 96.0 & 312.0 & 124.4 & 265.2 \\
$\mathrm{KJ} 2(-)$ & 57.4 & 321.2 & 62.4 & 332.3 & 75.4 & 282.4 \\
$\mathrm{KJ} 3(-)$ & 79.9 & 311.1 & 96.0 & 327.6 & 123.4 & 278.5 \\
$\mathrm{KJ} 4(-)$ & 66.9 & 385.9 & 75.4 & 396.7 & 94.5 & 337.2 \\
$\mathrm{KJ} 5(+)$ & 68.1 & 370.1 & 75.9 & 377.1 & 95.3 & 320.5 \\
\hline
\end{tabular}

\subsection{Strength degradation}

The strength degradation coefficient $\lambda_{i}=F_{j}^{i} / F_{j}^{i-1}$ was used to evaluate the strength degradation of cyclically loaded specimens [24]. Here, $F_{j}^{i}$ is defined as the peak load under the $i$-th loading cycle at the $j$ th loading displacement $(\Delta / \Delta y=j)$, and $F_{j}^{i-1}$ is defined as the peak load under the $i$-1 th loading cycle at the $j$-th loading displacement $(\Delta / \Delta y=j)$. The strength degradation coefficients of each specimen were calculated from the $P-\Delta$ hysteresis curves; the results are shown in Fig. 14. P and $\mathrm{N}$ in the figure represent the loads in positive and negative directions, respectively. Here, no apparent trend of strength degradation could be seen in the elastic stage; however, when the specimens were in the elastoplastic stage, the strength degradation coefficient gradually decreased. The strength degradation coefficients of all specimens were less than 1 in most cases, and the variation range was small; this indicates that the strength degradation of the specimen was small, and the specimen could be stable under the same load at different displacement loading cycles. As long as the wall and frame were not separated, the structure was still able to effectively resist lateral loads. Moreover, in $\mathrm{KJ} 2, \mathrm{KJ} 4$, and $\mathrm{KJ} 5$, the upper joint connector bolts were sheared between $5 \Delta y$ and $7 \Delta y$, and the load carrying capacity was reduced accordingly. However, the coefficient did not decrease significantly at this stage, indicating that the cracks in the wall and even the shear failure of the connecting bolts caused limited strength degradation, and that the specimen structure remained in a relatively stable state. 


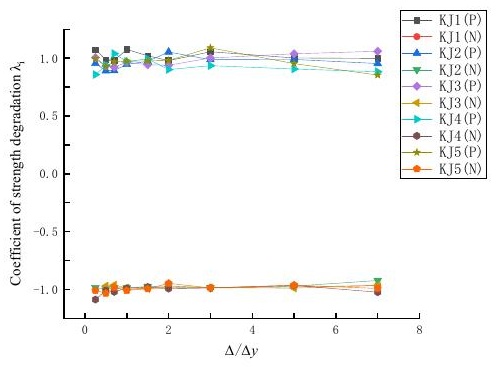

Fig. 14 Coefficient of strength degradation at the same loads

\subsection{Stiffness degradation}

In this study, the Stiffness degradation was discussed based on the secant stiffness. The stiffness degradation coefficient is defined by the following equation:

$K_{i}=\frac{\left|+F_{i}\right|+\left|-F_{i}\right|}{\left|+X_{\mathrm{i}}\right|+\left|-X_{i}\right|}$,

where $+F_{j}$ and $-F_{j}$ are the forward and reverse peak loading values, respectively, and under the $i$-th loading cycle when the horizontal displacement $\left(\Delta / \Delta_{y}\right)$ is equal to $I$, and $+X_{j}$ and $-X_{j}$ are the $i$-th positive and negative peak displacements, respectively.

The stiffness degradation coefficient $K_{i}$ corresponding to loading stage is shown in Fig. 15. The values at the elastic and failure stages were respectively $4.70-5.22$ and $3.09-4.80 \mathrm{kN} / \mathrm{mm}$ for specimen $\mathrm{KJ} 1,5.68$ 8.83 and $4.36-5.86 \mathrm{kN} / \mathrm{mm}$ for specimen $\mathrm{KJ} 2,3.38-5.13$ and $2.80-3.62$ $\mathrm{kN} / \mathrm{mm}$ for specimen $\mathrm{KJ} 3,5.16-7.82$ and $4.09-5.86 \mathrm{kN} / \mathrm{mm}$ for specimen $\mathrm{KJ} 4$, and $5.00-7.70$ and $3.33-5.40 \mathrm{kN} / \mathrm{mm}$ for specimen KJ5. It can be observed in Fig. 15 that the stiffness degradation curve of each specimen roughly follows the same trend: the failure stiffness of the specimen first decreases rapidly, then gradually stabilises, and finally decreases again. A comparison of the stiffness degradation curves of the specimens indicates that the stiffness of the CFST frame was enhanced by the installation of the SCWP.

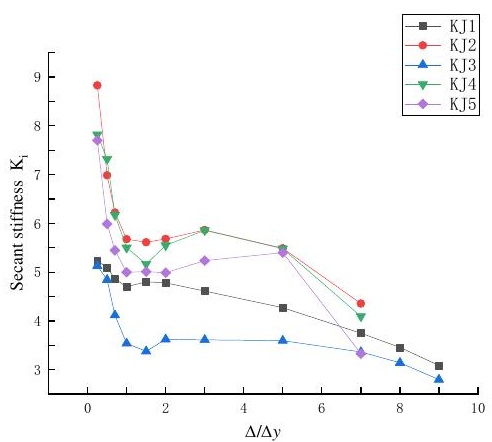

Fig. 15 Relationship between secant stiffness $K_{i}$ and its corresponding loading stage

\subsection{Analysis of load carrying capacity and ductility}

Ductility is an essential characteristic in the seismic design of a structure. It is usually evaluated by the ductility coefficients of the linear and angular displacements. The linear-displacement ductility coefficient $\mu$ is expressed as $\mu=\Delta_{u} / \Delta_{y}$, where $\Delta_{y}$ is the yield displacement and $\Delta_{u}$ is the failure displacement. The angular-displacement ductility coefficient $\mu_{\theta}$ is defined as $\mu_{\theta}=\theta_{u} / \theta_{v}$, where $\theta_{u}=\operatorname{arctg}\left(\Delta_{u} / H\right)$, $\theta_{y}=\operatorname{arct} g\left(\Delta_{y} / H\right)$, and $H$ is the storey height. Here, the failure displacement $\Delta u$ is defined as the displacement corresponding to the failure load $P_{u}=0.85 P_{\max }$. The correlation coefficients of the five specimens were thus calculated and are listed in Table 3.

According to the Code for Seismic Design of Buildings (GB500112010) [25], the limit of the elastic inter-storey horizontal drift angle of a high multi-storey steel structures $\left[\theta_{e}\right]$ is $1 / 250 \approx 4 \mathrm{mrad}$ and the limit of the elastoplastic inter-story horizontal drift angle $\left[\theta_{p}\right]$ is $1 / 50 \approx 20 \mathrm{mrad}$. As seen in Table 2, the determined displacement ductility coefficient is between 1.31 and 1.41, the elastic-limit displacement angle is between 6.08 and 6.19 times $\left[\theta_{e}\right]$, and the elastoplastic-limit displacement angle is between 1.37 and 1.73 times $\left[\theta_{p}\right]$. Thus, the ductility of each specimen was within the limits specified in the aforementioned code and therefore satisfied the seismic requirements.

Table 3

Ductility coefficients of specimens

\begin{tabular}{ccccccc}
\hline Specimen & $\begin{array}{c}\Delta_{y} \\
(\mathrm{~mm})\end{array}$ & $\begin{array}{c}\Delta_{u} \\
(\mathrm{~mm})\end{array}$ & $\begin{array}{c}\theta_{y} \\
(\mathrm{mrad})\end{array}$ & $\begin{array}{c}\theta_{u} \\
(\mathrm{mrad})\end{array}$ & $\mu$ & $\mu_{\theta}$ \\
\hline $\mathrm{KJ} 1$ & 77.9 & 124.4 & 28.32 & 45.21 & 1.60 & 1.60 \\
$\mathrm{KJ} 2$ & 57.4 & 75.4 & 20.87 & 27.41 & 1.31 & 1.31 \\
$\mathrm{KJ} 3$ & 79.9 & 123.4 & 29.05 & 44.84 & 1.54 & 1.54 \\
$\mathrm{KJ} 4$ & 66.9 & 94.5 & 24.32 & 34.35 & 1.41 & 1.41 \\
$\mathrm{KJ} 5$ & 68.1 & 95.3 & 24.76 & 34.64 & 1.40 & 1.40 \\
\hline
\end{tabular}

Note: $\Delta_{y}$ is the yield displacement, $\Delta_{u}$ is the failure displacement, $\theta_{y}$ is the yield displacement angle, $\theta_{u}$ is the failure displacement angle, $\mu$ is the linear-displacement ductility coefficient, and $\mu_{\theta}$ is the angular-displacement ductility coefficient.

\subsection{Dissipated energy}

The energy dissipation capacity is evaluated using the energy dissipation coefficient $E$ or equivalent viscous damping coefficient $\xi_{e}$, which can generally be measured using the area enclosed by the $P-\Delta$ hysteresis curve and calculated by the following formulas:

$\xi_{e}=\frac{1}{2 \pi} \frac{S_{A B C}+S_{C D A}}{S_{O B E}+S_{O D F}}$ and

$E=\frac{S_{A B C}+S_{C D A}}{S_{O B E}+S_{O D F}}=2 \pi \xi_{e}$,

where $S_{A B C}$ and $S_{C D A}$ represent the area of the $\mathrm{ABC}$ and $\mathrm{CDA}$ regions, respectively, and $S_{O B E}$ and $S_{O D F}$ represent the area of the OBE and ODF regions, respectively, of the $P-\Delta$ curve shown in Fig. 16. The equivalent viscous damping curves and cumulative energy consumption curves of the specimens are shown in Fig. 17 and Fig. 18, respectively. Accordingly, the following conclusions were drawn:

(1) The equivalent viscous damping coefficients were both large at the initial stage (before $2 \Delta y$ ) because of slippage and then decreased as the various slippages reached their limits. After $2 \Delta y$, the damping coefficient and energy consumption gradually increased because of the concrete cracking, the buckling of the flanges and web of the steel beam, and the sliding of the bolts in their holes.

(2) In the equivalent viscous damping coefficient graph, the curves for the specimens with external wall panels were higher than those for the empty-frame specimens, indicating that the damage and displacement of the wall panels partly affected the overall energy consumption capacity. The trends of the coefficient curves were similar, and the value of the coefficient of KJ4 was slightly larger than that of KJ5.

(3) The trends of the cumulative energy consumption curves of all specimens were similar. The energy consumption increased slowly before $3 \Delta y$ and then increased rapidly. The stage in which the energy consumption increased rapidly was correlated with the stage in which destruction was observed during the tests. The energy consumption of the CFST frame with external wall panels was considerably greater than that of the empty-frame specimens, and the energy consumption of KJ4 was marginally greater than that of KJ5.

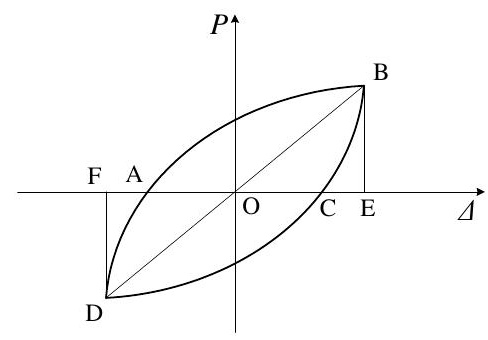

Fig. 16 Hysteresis curve 


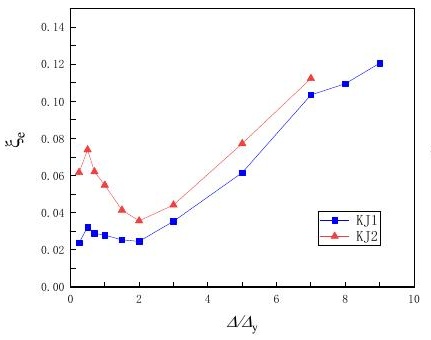

(a) $\mathrm{KJ} 1$ and $\mathrm{KJ} 2$

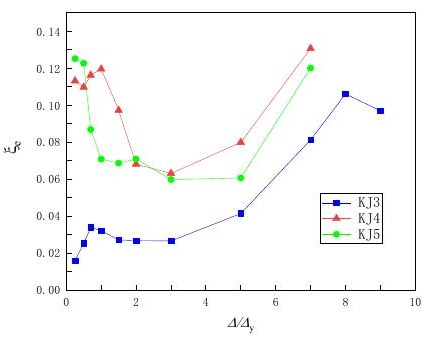

(b) $\mathrm{KJ} 3, \mathrm{KJ} 4$, and $\mathrm{KJ} 5$
Fig. 17 Equivalent viscous damping curves

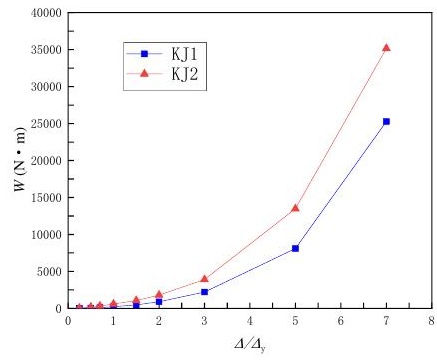

(a) $\mathrm{KJ} 1$ and $\mathrm{KJ} 2$

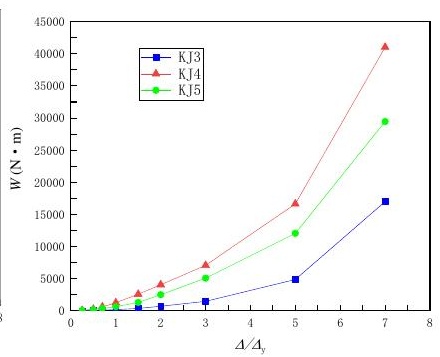

(b) $\mathrm{KJ} 3$, $\mathrm{KJ} 4$, and $\mathrm{KJ} 5$
Fig. 18 Cumulative energy consumption curves

\section{Finite element modelling}

After the quasi-static tests of the five specimens, the seismic performance of each specimen was analysed based on the observed phenomena and obtained data, and corresponding conclusions were drawn. To further investigate the mechanical properties and failure modes of the specimens under low-cycle reciprocating loads, the ABAQUS software was used to conduct non-linear numerical simulation analysis. Thus, ABAQUS finite element models were established based on the actual dimensions of test specimens $\mathrm{KJ} 1$ and $\mathrm{KJ} 2$. These models are shown in Fig. 19.

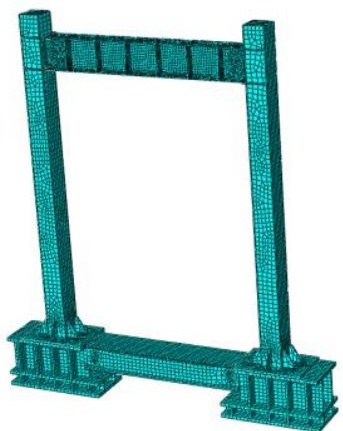

(a) $\mathrm{KJ} 1$

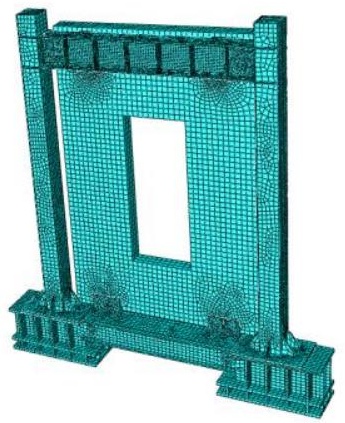

(b) $\mathrm{KJ} 2$
Fig. 19 ABAQUS finite element models

\subsection{Material modelling}

The finite element analyses included two main constitutive models of steel (Fig. 20). One was the secondary plastic flow model that considered five stages: the elastic, elastoplastic, plastic, strengthening, and secondary plasticising stages. The other model was a bi-linear model that considered only the elastic and strengthening stages. In the strengthening stages of bilinear model, the post yield stiffness was taken as $0.01 E s$ (where Es is the elastic modulus of the high-strength steel) [26-28]. The steel beam, steel column, steel pier, ground beam, and joint connection were simulated using the secondary plastic flow model, whereas the high-strength bolt and rebar embedded in the SCWP were simulated using the bi-linear model.

Concrete has different elastoplastic characteristics under tensile and compressive conditions, and a certain degree of loss and damage needs to be considered. Therefore, the concrete model applied in these analyses adopted the concrete constitutive relationship and damage plasticity stipulated in the Code for Design of Concrete Structures (GB50010-2010) [29].

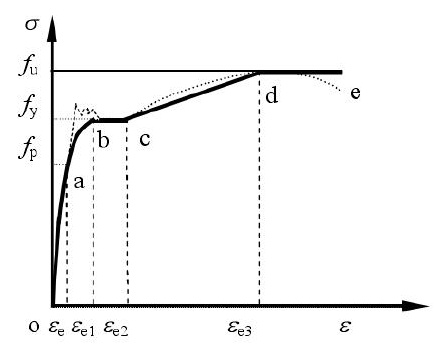

(a) Secondary plastic flow model

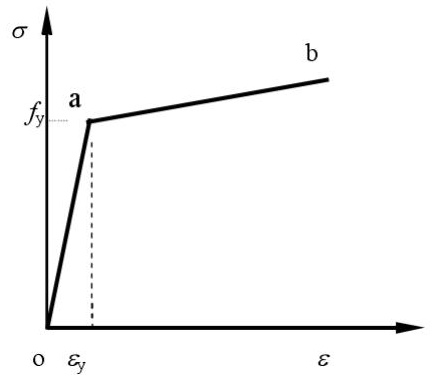

(b) Bi-linear model
Fig. 20 Stress-strain relationship curves of stee

\subsection{Description of finite element model}

The finite element models of $\mathrm{KJ} 1$ and $\mathrm{KJ} 2$ were established according to the actual dimensions of the specimens. The eight-node linear brick continuum element with incompatible modes (C3D8I) was considered to simulate the horizontal deformation of the specimens. The C3D8I elements were used for the concrete, steel beams, ground beams, steel pier, steel columns, bolts, connectors, and other components. Because the reinforcing skeleton was constrained within the wall panel by the embedded area, it was necessary to represent it using linear 3D solid elements and truss elements to replicate the actual stress state. Accordingly, the T3D2 element was used for the reinforcing skeleton in the wall. The mesh partitions are shown in Fig. 21.

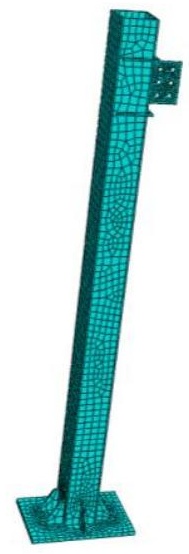

(a) Column

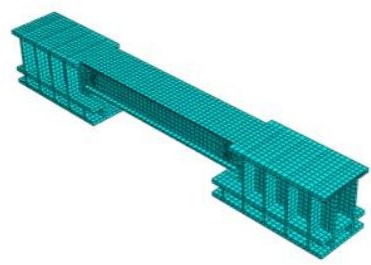

(c) Ground beam

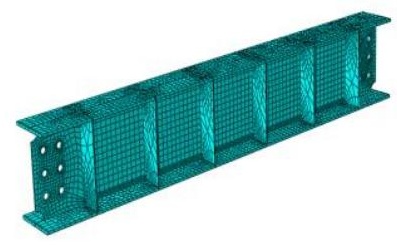

(b) beam

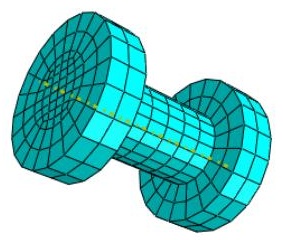

(d) Bolts 


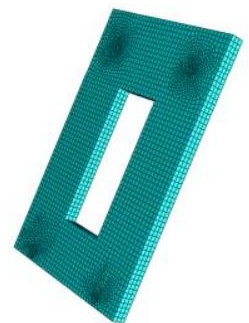

(e) Wall panels

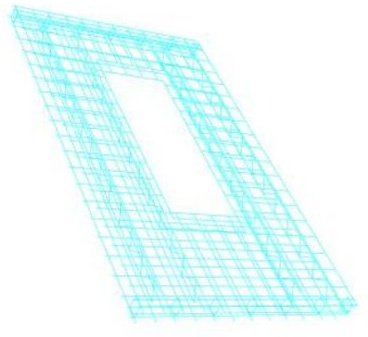

(f) Reinforcing skeleton
Fig. 21 Mesh partitions

The 'Tie' constraint was applied in ABAQUS to simulate the weld between the beam and the outer diaphragm; for example, the weld between the CFST column and the outer diaphragm. The binding constraint was also used between the bolt and its hole in the support joint connector plate because the bolts were firmly connected through this hole throughout the test and the wall panel was not pulled out. The surface-tosurface contact model was adopted to represent the contact between the bolt and specimen, and between the steel beam and support joint connector. The friction formula was set to the 'Penalty' formulation in the tangential direction of the contact pair, and the friction coefficient was set to 0.45 . The constraint between the reinforcing skeleton and wall panel, which both experience the same displacement and deformation, adopted the embedded form. The reinforcing skeleton was considered the embedded area, and the wall panel was considered the main area. To facilitate the loading of the specimen model, the loading surface was coupled to a reference point. This coupling was kinematic, and the constrained area was fully bound to the reference point in all six degrees of freedom. This made the constrained area rigid, and thus only the reference point had to be loaded when a load was applied.

To ensure the complete fixation of the column base, the displacement and rotation were constrained in all six degrees of freedom. The applied loads mainly consisted of:

(1) The pre-tension force applied to the high-strength bolts. According to the Technical Specification for High-Strength Bolt Connections of Steel Structures (JGJ 82-2011) [30], the pre-tension force of the 10.9grade M20 high-strength bolt should be $155 \mathrm{kN}$; therefore, a $155-\mathrm{kN}$ bolt load was applied to the middle surface of the bolt.

(2) The horizontal reciprocating displacement load. The same displacement load used in the actual loading system was applied to the reference point coupled to the loading surface. The cycle period was set according to the displacement amplitude.

\subsection{Validation of the finite element model}

To verify the accuracy of the finite element simulation, the Von-Mises stress contour and their associated experimental phenomena were selected for comparison at various key parts of the specimen, as shown in Fig. 22. The stress characteristics and failure modes obtained from the simulation, including the tearing of the welds, buckling of the steel beam flanges, cracking around the wall openings, and shearing of the support joint connector bolts, were essentially consistent with those obtained from the tests. Compared with the test results, the simulation results indicated greater stiffness, but the ultimate bearing capacities in the two sets of results were similar. This difference was due to the occurrence of various slip phenomena during the physical loading process of the test specimens, whereas it was assumed that no slipping occurred between the frame and SCWP in the finite-element models. A parametric analysis conducted using the finite element simulation indicated that the main factors influencing the seismic performance of the overall frame were the strength of the steel and the relative size of the wall openings in the SCWPs. The strength of the steel considerably improved the ultimate bearing capacity of the structure, but its influence on the elastic stiffness was minor. However, the relative size of the wall openings had a clear effect on both the ultimate bearing capacity and elastic stiffness of the overall structure.
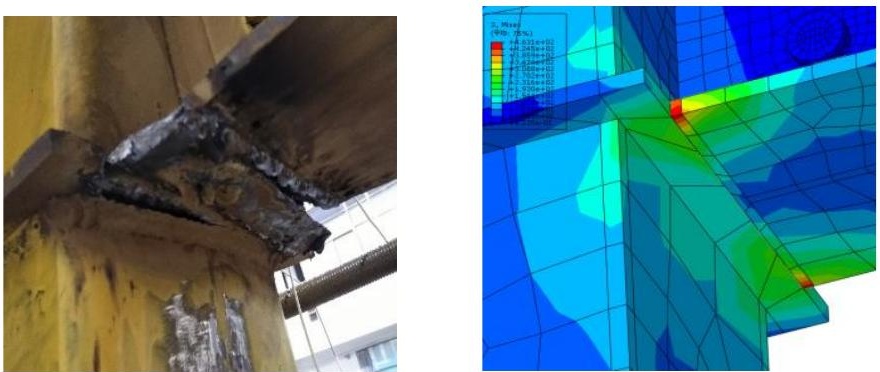

(a) Weld fracture in bottom flange
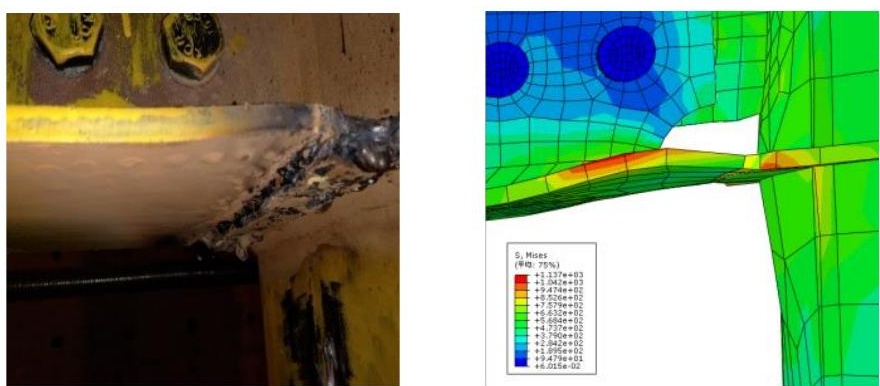

(b) Buckling in bottom flange of beam
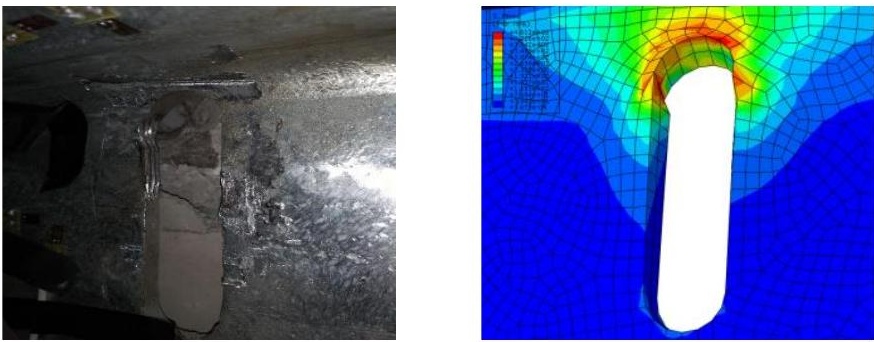

(c) Failure at upper joint connector

Fig. 22 Failure modes and stress contour

\section{Conclusions}

In this study, the seismic performance of CFST frames with external SCWPs was investigated by quasi-static tests, nonlinear finite element simulation, and theoretical analysis. Following conclusions can be drawn based on the conducted investigations:

(1) The failure modes of CFST frames with external SCWPs mainly consist of concrete cracking around the wall openings (which extended towards the joints), concrete cracking at the lower support joints, buckling of the flanges and webs of the steel beams, and weld tearing at the beamcolumn joints. The high-strength bolts of the upper joint connectors first underwent tearing and breaking, and were then sheared, causing the bearing capacity of the structure to decrease.

(2) The CFST frames with external SCWPs exhibited high ductility and good seismic behaviour. The displacement ductility coefficient is between 1.31 and 1.41 ; the elastic-limit displacement angle is between 6.08 and 6.19 times $\left[\theta_{e}\right]$, and the elastoplastic-limit displacement angle is between 1.37 and 1.73 times $\left[\theta_{p}\right]$. The external composite wall panels functioned together with the main frame to resist seismic loads through the joint connections, thereby reducing the damage to the main frame. Simultaneously, the external SCWPs also improved the elastic stiffness and ultimate bearing capacity of the CFST frame. For a single frame, the external SCWP increased the initial elastic stiffness by approximately 40 $50 \%$ and the ultimate bearing capacity by approximately $15-20 \%$. Furthermore, it was discovered that the degree of horizontal constraint at the upper joint connectors had a significant effect on the SCWP displacement mode.

(3) The non-linear finite element analysis effectively simulated the mechanical properties, failure mode, and seismic performance of the test specimens. Thus, the analysis was determined to be accurate and valid. The analysis method and results can serve as a reference for similar engineering applications. A parametric analysis subsequently conducted using the finite element simulation demonstrated that the main influences on the seismic performance of the overall frame were the strength of the steel and the relative size of the wall openings. 
(4) The experiments and theoretical analyses reported herein were conducted for a single storey frame. In actual conditions, the interaction between different storeys and spans will also affect the overall seismic performance and the displacement between the walls. It is therefore important to study wall structures considering multiple stories and multiple spans to obtain more realistic results.

\section{References}

[1] Markulak D., Radić I. and Sigmund V., "Cyclic testing of single bay steel frames with various types of masonry infill", Engineering Structures, 51, 267-277, 2013.

[2] Benayoune A., Samad A.A., Trikha D.N., Ali A.A. and Ellinna S.H.M., "Flexural behaviour of precast concrete sandwich composite panel-Experimental and theoretical investigations", Construction and Building Materials, 22(4), 580-592, 2008.

[3] Benayoune A., Samad A.A.A., Trikha D.N., Ali A.A.A. and Ashrabov A.A., "Structural behaviour of eccentrically loaded precast sandwich panels", Construction and Building Materials, 20(9), 713-724, 2006.

[4] Benayoune A., Samad A.A., Ali A.A. and Trikha D.N., "Response of precast reinforced composite sandwich panels to axial loading", Construction and Building Materials, 21(3), 677-685, 2007.

[5] Darzi S., Karampour H., Gilbert B.P. and Bailleres H., "Numerical study on the flexural capacity of ultra-light composite timber sandwich panels", Composites Part B: Engineering, $155,212-224,2018$

[6] Li S.C. and Dong Y.L., "Shear-resistant behavior of light composite shear wall", Journal of Central South University, 22(7), 2768-2775, 2015

[7] Huang J.Q. and Dai J.G., "Flexural performance of precast geopolymer concrete sandwich panel enabled by FRP connector", Composite Structures, 280, 112563, 2020.

[8] Xu G. and Li A., "Seismic performance of a new type precast concrete sandwich wall based on experimental and numerical investigation", Soil Dynamics and Earthquake Engineering, $122,116-131,2019$

[9] Han L.H., He S.H. and Liao F.Y., "Performance and calculations of concrete filled steel tubes (CFST) under axial tension", Journal of Constructional Steel Research, 67(11), 1699-1709, 2011.

[10] Moon J., Roeder C.W., Lehman D.E. and Lee H.E., "Analytical modeling of bending of circular concrete-filled steel tubes", Engineering Structures, 42, 349-361, 2012.

[11] Pagoulatou M., Sheehan T., Dai X.H. and Lam D., "Finite element analysis on the capacity of circular concrete-filled double-skin steel tubular (CFDST) stub columns", Engineering Structures, 72, pp.102-112, 2014.

[12] Agheshlui H., Goldsworthy H., Gad E. and Yao H., "Tensile behavior of groups of anchored blind bolts within concrete-filled steel square hollow sections", Journal of Structural Engineering, 142(2), 04015125, 2016
[13] Wang J., Li B. and Li J., "Experimental and analytical investigation of semi-rigid CFST frames with external SCWPs", Journal of Constructional Steel Research, 128, 289-304, 2017.

[14] Fang M.J., "Seismic behavior study of external wall panels in steel frames", Advanced Materials Research, 243, 1425-1428, 2011.

[15] Ma S. and Jiang N., "Experimental investigation on the seismic behavior of a new-type composite interior wallboard", Materials and Structures, 49(12), 5085-5095, 2016.

[16] Tasnimi A.A. and Mohebkhah A., "Investigation on the behavior of brick-infilled steel frames with openings, experimental and analytical approaches", Engineering Structures, 33(3), 968980, 2011.

[17] Hou H., Chou C.C., Zhou J., Wu M., Qu B., Ye H., Liu H. and Li J., "Cyclic tests of steel frames with composite lightweight infill walls", Earthquakes and Structures, 10(1), 163-178, 2016.

[18] Hou H., Qiu C., Wang J. and Li G., "An experimental study on sandwich composite panel infilled steel frames", International Journal of Advanced Steel Construction, 8(3), 226-241, 2012.

[19] Hashemi S.J., Razzaghi J., Moghadam A.S. and Lourenço P.B., "Cyclic testing of steel frames infilled with concrete sandwich panels", Archives of Civil and Mechanical Engineering, 18, 557-572, 2018.

[20] Wang B., Wang J., Gong X. and Liu B., "Experimental studies on circular CFST frames with ALC walls under cyclic loadings", International Journal of Steel Structures, 14(4), 755-768, 2014.

[21] Wang J. and Li B., "Cyclic testing of square CFST frames with ALC panel or block walls", Journal of Constructional Steel Research, 130, 264-279, 2017.

[22] ATC-24, Guidelines for Cyclic Seismic Testing of Components of Steel Structures, Applied Technology Council, Redwood City (CA), 1992.

[23] Yao Q., Civil Engineering Structure Testing, Architecture Industrial Press of China, Beijing, 2001 (in Chinese).

[24] JGJ/T 101-2015, Specification for Seismic Testing of Buildings, Architecture Industrial Press of China, Beijing, 2015 (in Chinese)

[25] GB50011-2010, Code for Seismic Design of Buildings, Architecture Industrial Press of China, Beijing, 2010 (in Chinese)

[26] Southeast University, Tianjin University and Tongji University, Principles of Concrete Structural Design, China Architecture \& Building Press, Beijing, 2016 (in Chinese).

[27] Bruneau M., Uang C.M. and Sabelli S.R., Ductile Design of Steel Structures. McGraw Hil Professional, 2011

[28] Wang J., Shen Q. and Li B., "Seismic behavior investigation on blind bolted CFST frames with precast SCWPs", International Journal of Steel Structures, 18(5), 1666-1683, 2018.

[29] GB50010-2010, Code for Design of Concrete Structures, Architecture Industrial Press of China, Beijing, 2010 (in Chinese)

[30] JGJ 82-2011, Technical Specification for High Strength Bolt Connections of Steel Structures, Architecture Industrial Press of China, Beijing, 2011 (in Chinese). 


\title{
FATIGUE PROPERTIES OF INCLINED CRUCIFORM WELDED JOINTS WITH ARTIFICIAL PITS
}

\author{
Zhi-Yu Jie ${ }^{1,}{ }^{*}$, Wu-Jun Wang ${ }^{1}$, Ping Zhuge ${ }^{1}$, Ya-Dong $\mathrm{Li}^{2}$ and Xing Wei ${ }^{2}$ \\ ${ }^{l}$ Department of Civil Engineering, Ningbo University, Ningbo 315211, China \\ ${ }^{2}$ School of Civil Engineering, Southwest Jiaotong University, Chengdu 610031, China \\ "(Corresponding author: E-mail:jiezhiyu_8@163.com)
}

\section{A B S T RA C T}

Experimental and numerical investigations on the fatigue properties of inclined corroded cruciform joints were conducted in this paper. Two artificial hemispherical notches were used to simulate pitting corrosion damage. Fatigue tests were carried out under uniaxial tensile cyclic loading. The fatigue S-N curves considering different types of corrosion damage were fitted by regression analysis. A relative hot spot stress concentration factor (HSSCF) concept was proposed. The influence of the pit size on the relative HSSCF of the cruciform joints was analyzed based on a numerical analysis. The fatigue notch factor (FNF), which considered the effect of corrosion pits, was used to describe the fatigue strength reduction. The FNF method and the Theory of Critical Distances (TCD) were employed to predict the fatigue life of corroded cruciform joints. It is concluded that pitting corrosion damage reduces the fatigue strength, but specimens without and with smaller corrosion pits exhibited similar fatigue strengths at 2 million cycles. The pit depth and radius are the main parameters affecting the relative HSSCFs, and an equation as a function of the pit depth and radius is obtained. The predicted S-N equations correlate well with the experimental results. The maximum error of the fatigue life calculation results based on these two methods is only $-27.8 \%$. They can be used to predict the fatigue life of corroded cruciform joints.

\section{A R T I C LE H IS T O R Y}

$\begin{array}{ll}\text { Received: } & 27 \text { March } 2020 \\ \text { Revised: } & \text { 2 October } 2020 \\ \text { Accepted: } & \text { 12 October } 2020\end{array}$

\section{K E Y W O R D S}

Inclined cruciform joints;

Corrosion pits:

Hot spot stress concentration

factor;

Fatigue notch factor;

Fatigue life

Copyright $@ 2021$ by The Hong Kong Institute of Steel Construction. All rights reserved.

\section{Introduction}

In recent years, many long-span steel bridges have been built in China. Fatigue and corrosion are two major factors affecting the durability and safety of steel bridges. Environmental corrosion causes a reduction in the thickness, surface roughness, and material strength. For steel bridges subjected to repeated loads and corrosive environments, more severe damage occurs compared to when only repeated loads. Repeated loads and corrosive environments accelerate the fatigue crack initiation and decrease the fatigue life during the service time. Consequently, the investigation of fatigue damage for steel bridges under corrosion conditions is currently a very urgent issue. Some researchers have tried to explore the effect of corrosion damage on the fatigue behavior of engineering materials $[1,2]$. However, there is almost no research on the fatigue properties of corroded welded structures.

A majority of studies on the fatigue assessment of inclined welded structures have been performed. Kim and Kainuma [3] discussed the fatigue behavior of load-carrying cruciform welded joints inclined to repeated loadings and predicted the fatigue life by using the effective stress method. Wang et al. [4] presented an analytical method for the fatigue estimation of inclined welds connecting corrugated plates to flange plates. Khurshid [5] studied the fatigue behavior of butt welds inclined to uniaxial loading from a multiaxial fatigue concept. Susmel et al. [6, 7] used four different stresses and the modified Wöhler curve method to assess the fatigue behavior of inclined welds under uniaxial loading. Generally, the nominal stress, the hot spot stress, the notch stress, and the Theory of Critical Distances (TCD) are applied to the fatigue analyses of welded structures. Compared to the nominal stress and the notch stress, additional computational work is not required for the hot spot stress, and it can be used to model complex welded details that are not included in design codes, such as IIW (the International Institute of Welding) [8], Eurocode3 [9], and DNV (Det Norske Veritas) [10]. Due to the stress fields directly determined by the finite element analysis, the TCD as a useful tool is conveniently used for fatigue estimation [11-16].

Pitting corrosion as serious localized damage causes stress concentrations in a corrosive environment. These corrosion pits are detrimental to the fatigue life, and the effect increase with increasing service time [17-19]. The shapes of corrosion pits are extremely irregular, and they can usually be simplified to a hemisphere or semi-ellipsoid for the convenience of research [20]. Numerous discussions on the relationship between the stress concentration factor (SCF) and the shapes and sizes of corrosion pits are presented. Albrecht [21] pointed out that the SCF had a linear relationship with the pit depth. Cerit [22] concluded that there was a nonlinear relationship between the SCF and pit aspect ratio (the ratio of the pit depth to the pit diameter). However, Kolios [23] found that the SCF showed a linear relation with the aspect ratio. Liu [24] believed that the SCFs depended on the geometrical properties of the corrosion pits. Many scholars reveal that the reduction in the fatigue strength of corrosion members correlates with the corrosive parameters, such as the pit shapes and sizes [25, 26]. Sharifi and Rahgozar [27] gave a function using the average corrosion depth and time as variables to describe the fatigue notch factor (FNF). Ma et al. [28] investigated the effect of the notch depths and aspect ratios on the fatigue life under different stress loadings. Li et al. [29] found that the relative maximum pit depth of corroded bars was related to the fatigue life. Adasooriya et al. [30-33] estimated the fatigue strength of corroded members based on the full-range S-N curve method and the continuum damage mechanics method. However, very few studies address the effect of corrosion pits on the fatigue behavior of welded joints. The fatigue strength curves of welded details that depend on time and a corrosive media have not been discussed in the design guidelines [10]. The same reduction degree of the fatigue strength for different corrosive time is considered in DNV. Further studies are needed to assess the effect of geometrical sizes of the corrosion pits on the fatigue properties of corroded welded joints.

This paper studied the fatigue performance of corroded inclined cruciform joints based on experimental and numerical methods. Two artificial pits in the vicinity of the weld ends were constructed to model the pitting corrosion of cruciform joints. Fatigue tests were carried out on corroded cruciform joints. Fatigue test data were discussed based on fatigue S-N curves by comparison to existing experimental results. A hot spot stress concentration factor (HSSCF) was obtained in the numerical analysis, and a relative HSSCF concept considering the influence of corrosion pits on the stress fields was proposed. The relationship between relative HSSCF and pit size was obtained by the least squares method. Due to the adverse effect of pits, a fatigue notch factor (FNF) was used to describe the reduction in the fatigue strength. The FNF method based on the S-N curve of uncorroded cruciform joints and the TCD were used to assess the fatigue life of corroded cruciform joints. The feasibility and accuracy of the two assessment methods were verified via fatigue test data.

\section{Experimental research}

To simulate the complex stress states of welded joints, load-carrying cruciform joints with $45^{\circ}$ inclined full penetration welds were processed using Q345qC steel plates with a thickness of $16 \mathrm{~mm}$ [34]. These joints were manually welded by $\mathrm{CO}_{2}$ gas shielded welding technology. The chemical composition and mechanical properties are presented in Tables 1 and 2, respectively. The geometrical configuration of a cruciform joint is shown in Fig. 1. 
Table 1

Chemical composition of Q345qC steel (in weight \%)

\begin{tabular}{cccccccccc}
\hline Material & $\mathrm{C}$ & $\mathrm{Si}$ & $\mathrm{Mn}$ & $\mathrm{P}$ & $\mathrm{S}$ & $\mathrm{V}$ & $\mathrm{Cr}$ & $\mathrm{Mo}$ & $\mathrm{Ni}$ \\
\hline Q345qC steel & 0.17 & 0.27 & 1.43 & 0.014 & 0.011 & 0.02 & 0.01 & 0.04 & 0.05 \\
\hline
\end{tabular}

Table 2

Mechanical properties of Q345qC steel

\begin{tabular}{ccccc}
\hline Material & Thickness & Yield strength & Tensile strength & Elongati \\
\hline Q345qC & 16 & 360 & 575 & $28 \%$ \\
\hline
\end{tabular}
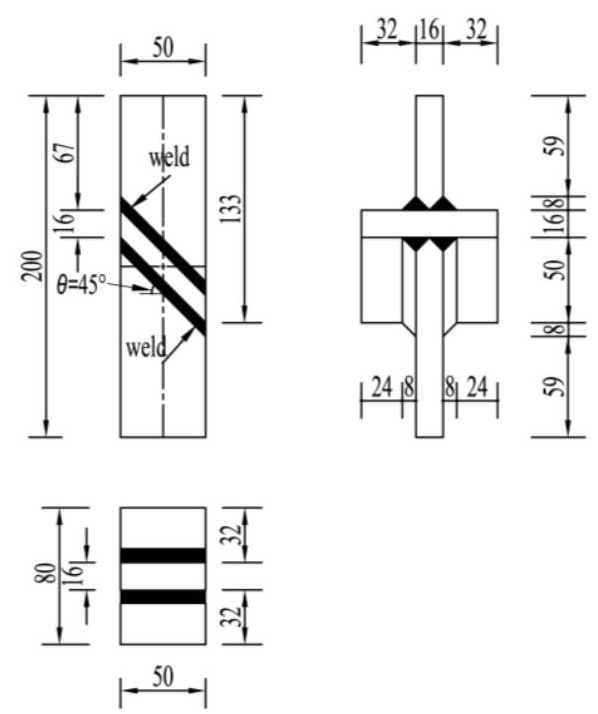

Fig. 1 Configures of the cruciform joints

\subsection{Artificial pits tests}

Studies on metal corrosion in corrosive environments have been carried out for many years. A great number of test data on the corrosion rate of metallic material in different environments can be collected. From these data, it is found that corrosion loss meets the following relationship in a corrosive environment:

$$
D=A t^{B}
$$

where $D$ is the average corrosion depth (mm), $t$ is the number of years, and $A$ and $B$ are the fitted parameters. According to the test data in [35], the parameters for pitting corrosion in a marine atmospheric environment are listed in Table 3. Finally, the mean values of $A$ and $B$ are used to assess the relationship between pit depth and exposure time.

Table 3

Parameters for pitting corrosion

\begin{tabular}{ccc}
\hline No. & $A$ & $B$ \\
\hline 1 & 0.071 & 0.79 \\
2 & 0.207 & 1.12 \\
3 & 0.058 & 0.57 \\
4 & 0.033 & 1.60 \\
5 & 0.047 & 0.63 \\
6 & 0.035 & 0.43 \\
7 & 0.051 & 0.60 \\
8 & 0.025 & 0.54 \\
9 & 0.113 & 0.96 \\
10 & 0.016 & 1.00 \\
11 & 0.090 & 0.92 \\
12 & 0.027 & 0.61 \\
13 & 0.032 & 1.44 \\
\hline
\end{tabular}

\begin{tabular}{ccc}
\hline Mean & 0.062 & 0.86 \\
\hline
\end{tabular}

To investigate the influence of pitting corrosion on the fatigue properties of cruciform joints, the regular pit shapes were taken into account for the convenience of research. Thus, two different hemispherical pits in the welded joints were artificially produced based on Ref. [36]. Two pit depths ( $d=1 \mathrm{~mm}$ and $2 \mathrm{~mm}$ ) and pit widths ( $w=3.5 \mathrm{~mm}$ and $4 \mathrm{~mm}$ ) were considered. The pit radius $R$ maintained a constant value of $2 \mathrm{~mm}$. These corrosion pits were located near the weld ends where fatigue cracks easily initiated. The specific geometrical dimensions of the corrosion pits were detailed in [37]. The distributions of corrosion pits of cruciform joints are shown in Fig. 2.

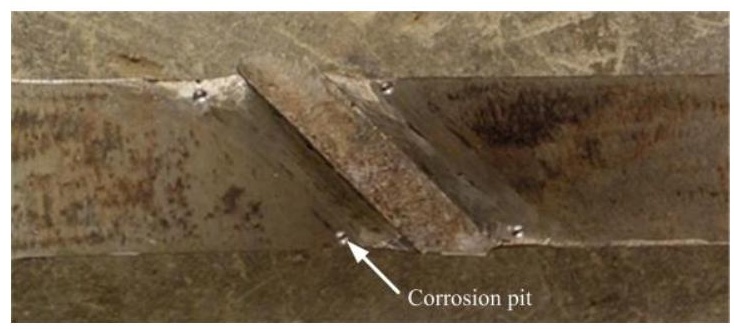

Fig. 2 Cruciform joint with artificial corrosion pits

\subsection{Fatigue tests}

Fatigue tests were carried out under uniaxial constant amplitude repeated loading. A stress ratio of 0.1 and a sinusoidal wave with a loading frequency of approximately $5 \mathrm{~Hz}$ were applied. A total of 27 specimens were designed for three different stress ranges ( $\Delta \sigma=140 \mathrm{MPa}, 160 \mathrm{MPa}$, and $180 \mathrm{MPa}$ ) and pit depths $(d=0 \mathrm{~mm}, 1 \mathrm{~mm}$, and $2 \mathrm{~mm})$. The maximum and minimum loads in one cycle were represented by the symbols $P_{\max }$ and $P_{\min }$, respectively. The corresponding loading conditions are listed in Table 4 , and a fatigue specimen is illustrated in Fig. 3.

Table 4

Loading conditions

\begin{tabular}{|c|c|c|c|c|}
\hline $\begin{array}{l}\text { Types of } \\
\text { corrosion }\end{array}$ & Specimen No. & $\begin{array}{c}\text { Stress range } \\
\text { (MPa) }\end{array}$ & $P_{\min }(\mathrm{kN})$ & $P_{\max }(\mathrm{kN}$ \\
\hline \multirow{3}{*}{$\mathrm{P} 0(d=0, R=0)$} & P0S1 & 140 & 12.4 & 124.4 \\
\hline & P0S2 & 160 & 14.2 & 142.0 \\
\hline & P0S3 & 180 & 16.0 & 160.0 \\
\hline \multirow[t]{3}{*}{$\mathrm{P} 1(d=1 \mathrm{~mm}, R=2$} & P1S1 & 140 & 12.4 & 124.4 \\
\hline & P1S2 & 160 & 14.2 & 142.0 \\
\hline & P1S3 & 180 & 16.0 & 160.0 \\
\hline \multirow[t]{3}{*}{$\mathrm{P} 2(d=2 \mathrm{~mm}, R=2$} & $\mathrm{P} 2 \mathrm{~S} 1$ & 140 & 12.4 & 124.4 \\
\hline & $\mathrm{P} 2 \mathrm{~S} 2$ & 160 & 14.2 & 142.0 \\
\hline & $\mathrm{P} 2 \mathrm{~S} 3$ & 180 & 16.0 & 160.0 \\
\hline
\end{tabular}

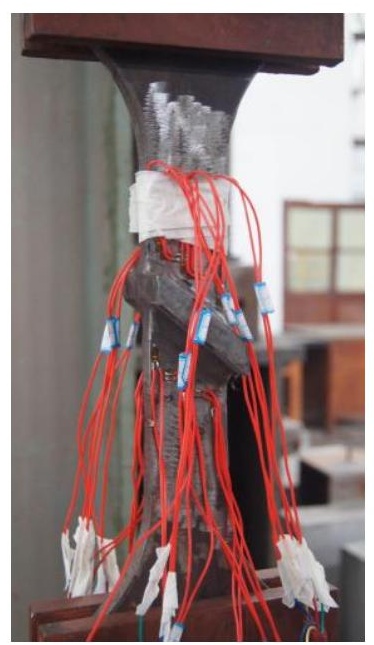

Fig. 3 Fatigue specimen 


\subsection{Results analysis}

The fatigue crack initiation and growth of uncorroded and corroded cruciform joints are shown in Fig 4. The fatigue cracks of all the specimens are generated at the weld toes due to the more obvious stress concentration. Fatigue cracks of uncorroded cruciform joints grow in a straight line, but the fatigue crack propagation path of corroded cruciform joints is a broken line. The fatigue crack first descends and then goes through the pit. The main reason for this behavior may be that the stress and strain fields vary due to the existence of corrosion pits

The fatigue fracture morphology of the cruciform joints is shown in Fig. 5 A semi-elliptical crack propagation trajectory can be observed in the cross section. There are two distinct parts: the smooth part and the rough part. The smooth part contains the fatigue crack initiation and growth stages, and the rough part is the rapid fracture stage.

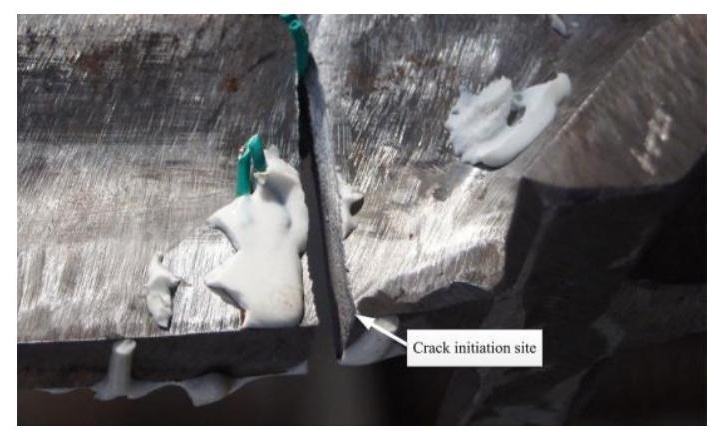

(a) no pit

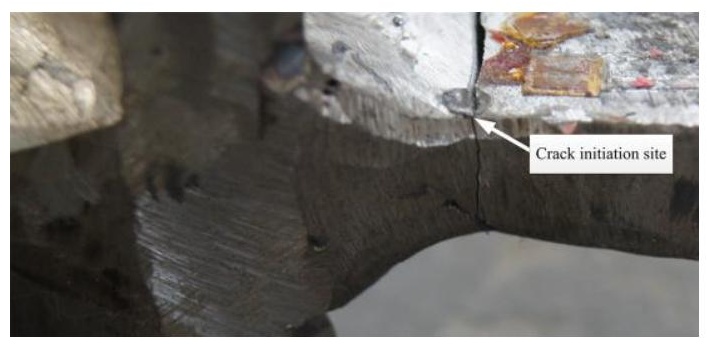

(b) pit 1

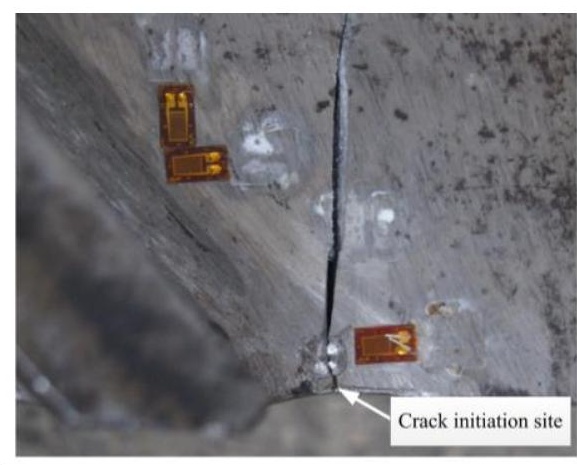

(c) pit 2

Fig. 4 Fatigue crack growth of corroded joints and uncorroded joints

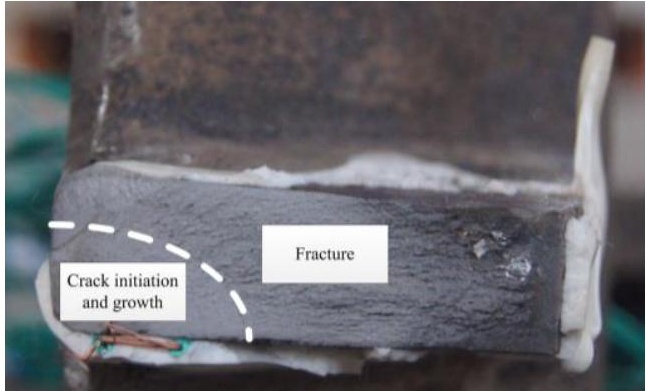

(a) no pit

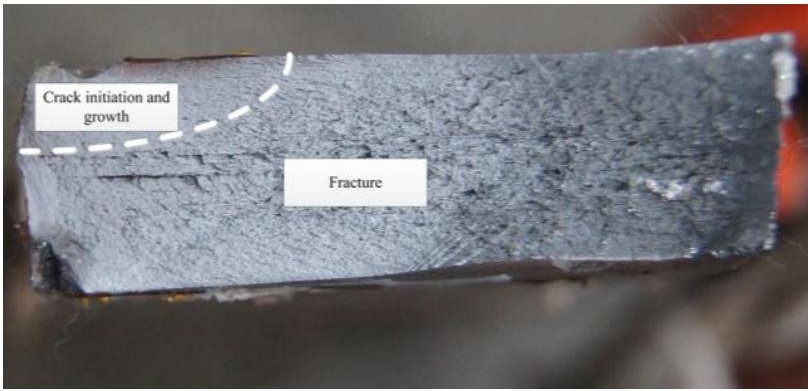

(b) pit 1

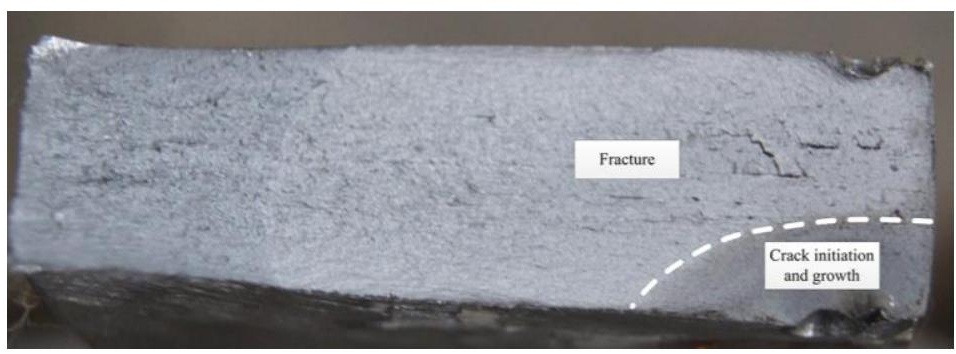

(c) pit 2

Fig. 5 Fatigue fracture morphology of corroded joints and uncorroded joints

The S-N curve is generally used to describe the relationship between stress range $\Delta \sigma$ and fatigue life $N$ based on many experimental results. The equation can be expressed as:
$\Delta \sigma^{m} N=C$ 
where $C$ and $m$ are constants for different metal materials. Eq. (2) is rewritten based on a logarithmic form:

$m \log \Delta \sigma+\log N=\log C$

According to the test results and literature [3], the relationship of stress range vs. mean fatigue life is reported in Fig. 6. The mean and design curves of FAT71 (a stress range of $71 \mathrm{MPa}$ at 2 million cycles with a survival probability of $P_{\mathrm{s}}=97.7 \%$ ) in DNV [10] are also illustrated in Fig. 6.

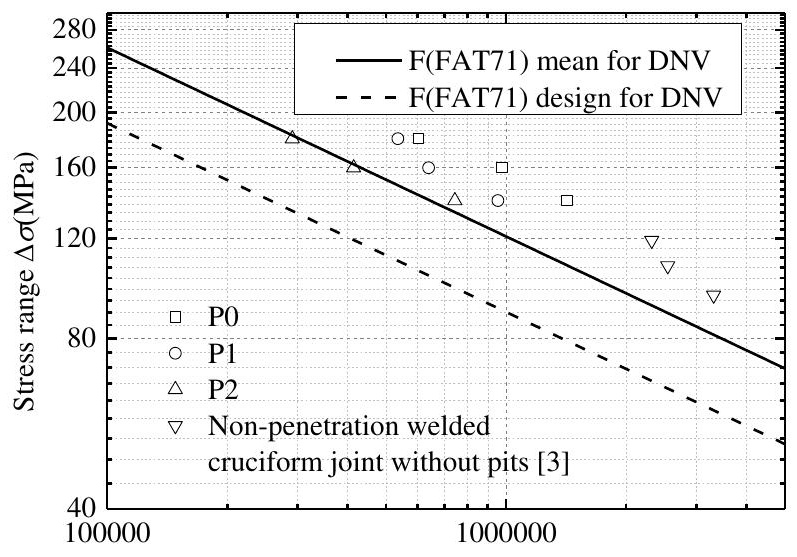

Fatigue life $N($ cycles $)$

Fig. 6 The relationship of stress range vs. mean fatigue life

Regression analysis was employed to obtain the $\log N$ vs. $\log \Delta \sigma$ relationship. An inverse slope of 3 was recommended by the fatigue design specification and chosen in this study [9]. The S-N equations of inclined full penetration fillet welded cruciform joints with $P_{\mathrm{s}}=50 \%$ can be expressed as:

$\log N=12.573-3 \log \Delta \sigma$ for $\mathrm{P} 0$

$\log N=12.438-3 \log \Delta \sigma$ for $\mathrm{P} 1$

$\log N=12.252-3 \log \Delta \sigma$ for $\mathrm{P} 2$

Similarly, the S-N equation for inclined non-penetration fillet welded cruciform joints with no pit can be obtained:

$\log N=12.510-3 \log \Delta \sigma$

The design curves (the mean values-two standard deviation) were determined. The design S-N equations of inclined full penetration fillet welded cruciform joints with $P_{\mathrm{s}}=97.7 \%$ were expressed as:

$\log N=12.198-3 \log \Delta \sigma$ for $\mathrm{P} 0$

$\log N=12.182-3 \log \Delta \sigma$ for P1

$\log N=11.840-3 \log \Delta \sigma$ for $\mathrm{P} 2$

The DNV categories of the welded joints and regression analysis results based on Eq. (8)-(10) are listed in Table 5.
Table 5

DNV categories and regression analysis results

\begin{tabular}{ccccc}
\hline & & & $\Delta \sigma \quad$ at & Corrosion \\
Categories & $\log (C)$ & $m$ & 2 million & condition \\
& & & cycles (MPa) & \\
\hline D & 12.164 & 3 & 90 & No \\
E & 12.010 & 3 & 80 & No \\
F & 11.855 & 3 & 71 & No \\
D & 11.687 & 3 & 62 & Yes \\
E & 11.533 & 3 & 55 & Yes \\
F & 11.378 & 3 & 49 & Yes \\
\hline P0 & 12.198 & 3 & 92 & No \\
P1 & 12.182 & 3 & 91 & Yes \\
P2 & 11.840 & 3 & 70 & Yes \\
\hline
\end{tabular}

It is evident that the fatigue strength of inclined full penetration welded cruciform joints is larger than that of the non-penetration weld. This conclusion is in agreement with the specifications [9]. The inclination weld increases the fatigue strength of uncorroded cruciform joints. It increases by $30 \%$ from $71 \mathrm{MPa}$ to $92 \mathrm{MPa}$ at 2 million cycles. The fatigue strengths of the $\mathrm{P} 0$ and P1 specimens are very close and almost the same as that of the uncorroded category D. The fatigue strengths of categories D, E, and F under corrosion conditions decrease by $31 \%$. However, the fatigue strength of the cruciform joints with pit 2 is reduced by $24 \%$. It is evident that environmental corrosion can reduce the fatigue strength of cruciform joints. The same reduction factor of the fatigue strength used in DNV is very inappropriate. The reduction of the fatigue strength of corroded cruciform joints needs to be quantitatively described. The relation between fatigue strength and geometrical sizes of corrosion pits is needed to conduct an in-depth analysis from a numerical aspect.

\section{Stress concentration analysis}

\subsection{Finite element model}

A 3D finite element model that used quadratic 10-node tetrahedral elements (SOLID92) was developed to simulate the linear elastic stress fields via the commercial software ANSYS. A Young's modulus of $210 \mathrm{GPa}$ and Poisson's ratio of 0.3 were applied to the elastic material properties. A constant stress range of $\Delta \sigma=160$ and a fixed constraint were imposed on both sides of the long steel plates. Fig. 7 plots the FE model of the corroded cruciform joints. The stress distributions of the uncorroded and corroded cruciform joints are plotted in Fig. 8.

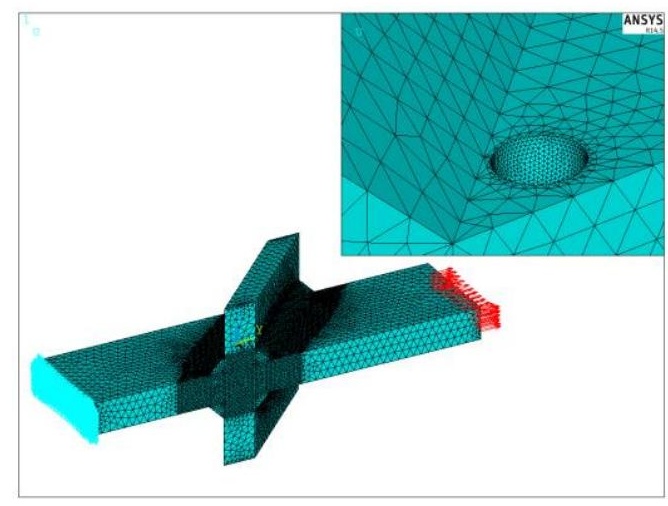

Fig. 7 FE model 


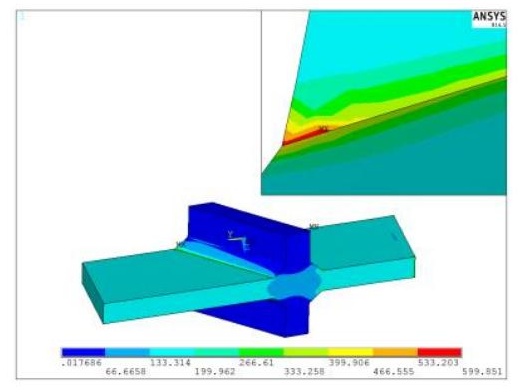

(a) P0

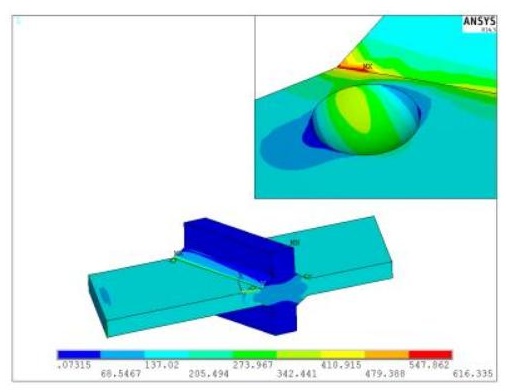

(b) P1

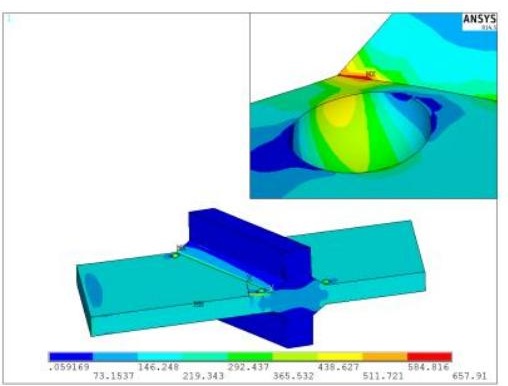

(c) P2

Fig. 8 Stress distributions of the welded joints

The maximum von Mises stress occurs at the weld toes, where fatigue crack are generated. The stress concentrations around the pits are less severe than those of the weld toes. This is consistent with the findings of the fatigue test results. The maximum von Mises stress increases with an increase in the pit depth. The effect of corrosion pits on the stress concentration of cruciform joints is very evident. The relationship between geometrical sizes of corrosion pits and stress concentrations needs to be further studied. However, the mesh size has a significant influence on the maximum stress of the weld toes due to a stress singularity. The hot spot stress can be used to assess the variation in the stress fields for corroded cruciform joints.

\subsection{Hot spot stress concentration factors}

The estimated hot spot stress using the linear extrapolation method can be obtained as follows [8]:

$\sigma_{\mathrm{hs}}=1.67 \sigma_{0.4 \mathrm{t}}-0.67 \sigma_{1.0 \mathrm{t}}$

where $\sigma_{\mathrm{hs}}$ is the hot spot stress of the weld toe, and $\sigma_{0.4 \mathrm{t}}$ and $\sigma_{1.0 \mathrm{t}}$ are the nodal stresses for the two extrapolation points at distances of $0.4 t$ and $1.0 t$ in front of the weld toe (Fig. 9).

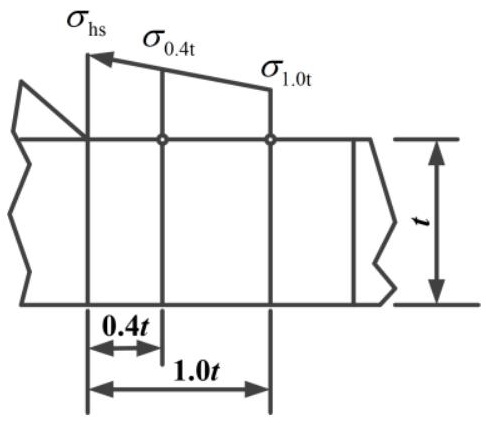

Fig. 9 The definition of hot spot stress

The hot spot stress concentration factor (HSSCF), $K_{\mathrm{hs}}$, is described by the following formula:

$K_{\mathrm{hs}}=\frac{\sigma_{\mathrm{hs}}}{\sigma_{\text {nom }}}$

where $\sigma_{\text {nom }}$ is the nominal stress. To investigate the effect of the pit geometrical size on $K_{\mathrm{hs}}$, different pit depths and radii are considered. A relative $\mathrm{HSSCF}, K_{\mathrm{rhs}}$, is defined as the following:

$K_{\mathrm{rhs}}=\frac{K_{\mathrm{hs}}(d, R)}{K_{\mathrm{hs}}(d=0, R=0)}$

The mesh size had an important influence on the HSSCF. Thus, the mesh gradually increased until convergence. The HSSCFs for different pit depths and radii are shown in Table 6 . Figs. 10-12 plot the relationships between $K_{\text {rhs }}$ and $d, d / w$, and $R$.
Table 6

Size parameters and HSSCFs for different pit depths and radii

\begin{tabular}{|c|c|c|c|c|c|}
\hline No. & $\begin{array}{l}\text { Pit depth } \\
d(\mathrm{~mm})\end{array}$ & $\begin{array}{l}\text { Pit width } \\
w(\mathrm{~mm})\end{array}$ & $d / w$ & $\begin{array}{c}\text { Pit radius } \\
R(\mathrm{~mm})\end{array}$ & $\begin{array}{c}\text { Hot spot stress } \\
\text { concentration } \\
\text { factor } K_{\mathrm{hs}} \\
\end{array}$ \\
\hline 1 & 0 & 0 & - & 0 & 1.083 \\
\hline 2 & 0.25 & 1.323 & 0.189 & 1 & 1.084 \\
\hline 3 & 0.5 & 1.732 & 0.289 & 1 & 1.084 \\
\hline 4 & 0.75 & 1.936 & 0.387 & 1 & 1.090 \\
\hline 5 & 1 & 2 & 0.5 & 1 & 1.102 \\
\hline 6 & 0.375 & 1.984 & 0.189 & 1.5 & 1.083 \\
\hline 7 & 0.5 & 2.236 & 0.224 & 1.5 & 1.084 \\
\hline 8 & 0.75 & 2.598 & 0.289 & 1.5 & 1.117 \\
\hline 9 & 1 & 2.828 & 0.354 & 1.5 & 1.171 \\
\hline 10 & 1.125 & 2.905 & 0.387 & 1.5 & 1.202 \\
\hline 11 & 1.5 & 3 & 0.5 & 1.5 & 1.297 \\
\hline 12 & 0.5 & 2.646 & 0.189 & 2 & 1.089 \\
\hline 13 & 0.75 & 3.122 & 0.240 & 2 & 1.136 \\
\hline 14 & 1 & 3.464 & 0.289 & 2 & 1.209 \\
\hline 15 & 1.5 & 3.873 & 0.387 & 2 & 1.418 \\
\hline 16 & 2 & 4 & 0.5 & 2 & 1.730 \\
\hline
\end{tabular}

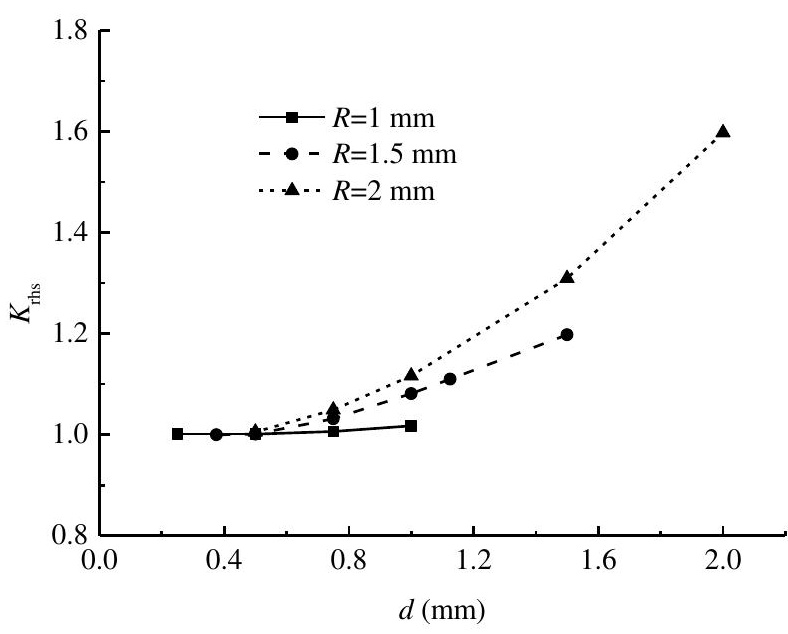

Fig. $10 K_{\text {rhs }}$ versus $d$ for different pit radii 


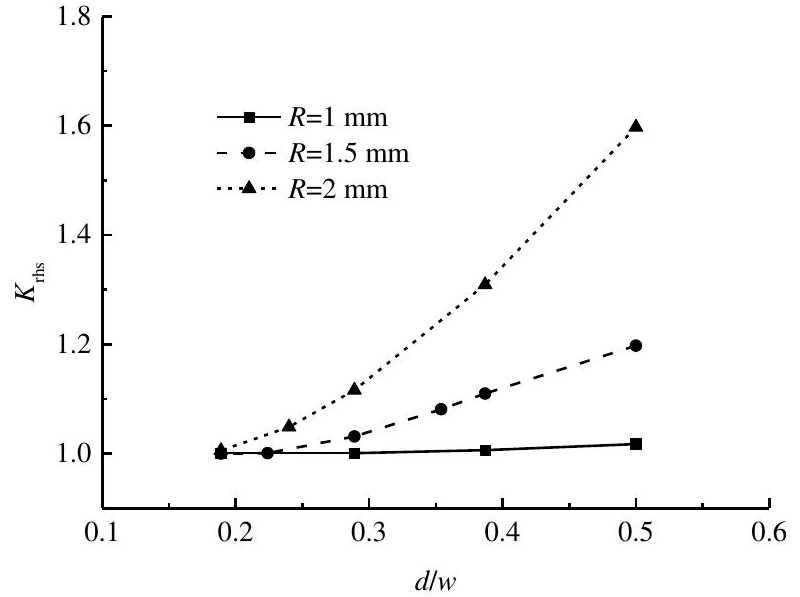

Fig. $11 K_{\text {rhs }}$ versus $d / w$ for different pit radii

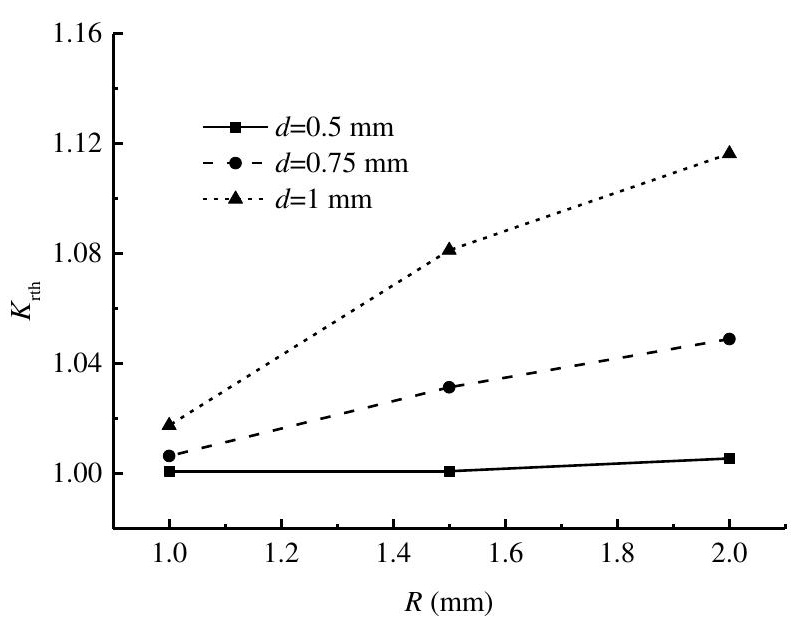

Fig. $12 K_{\text {rhs }}$ versus $R$ for different pit depths

It shows that $K_{\mathrm{rhs}}$ increases with the increase in $d, d / w$, and $R$. The rates of change of $K_{\text {rhs }}$ increase with the increase in $R$ and $d$. When $R=1 \mathrm{~mm}, K_{\text {rhs }}$ is nearly unchanged. However, the relationships between $K_{\text {rhs }}$ and $d$ and $d / w$ vary substantially when $R \geq 1.5 \mathrm{~mm}$. The relative HSSCF should consider the effects of the pit depth and pit radius. The polynomial regression analysis is carried out based on the least squares method. The relative HSSCF equation can be expressed as:

$$
K_{\mathrm{rhs}}=1.085-0.235 d+0.240 d^{2}-0.095 R+0.051 R^{2} \text { for } 0<d / R \leq 1 \text { and } 1 \leq R \leq 2
$$

where the pit depth $d$ and pit radius $R$ have units of millimeters, the correlation coefficient is 0.992 , and the standard deviation is 0.020 . Thus, it is convenient to obtain the relative HSSCF based on the pit depth and pit radius.

\subsection{Fatigue notch factor}

The fatigue notch factor (FNF), $K_{\mathrm{f}}$, is defined by the ratio of the fatigue strength of a plain component $\Delta \sigma_{\mathrm{S}}$ to that of a notched component $\Delta \sigma_{\mathrm{N}}$ under the same conditions, as shown in Fig. 13 . Therefore, $K_{\mathrm{f}}$ can be generally written as:

$K_{\mathrm{f}}=\frac{\Delta \sigma_{\mathrm{S}}}{\Delta \sigma_{\mathrm{N}}}$

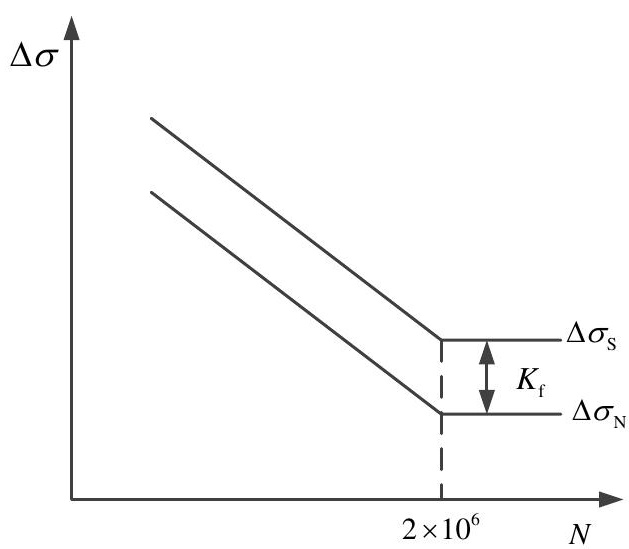

Fig. 13 Definition of the FNF

Based on Eqs. (4)-(6), the FNFs for P1 and P2 are 1.110 and 1.280 at $N=2 \times 10^{6}$ cycles, respectively. According to the computational results of the relative HSSCF, the relationship between $K_{\mathrm{f}}$ and $K_{\text {rhs }}$ is shown in Fig. 14. $K_{\mathrm{f}}$ increases with the increase of $K_{\mathrm{rhs}}$, and there is a linear relationship between them. Therefore, the equation can easily predict the fatigue life of corroded welded joints. The FNF is fitted by the least squares method. The expression of the FNF is written as:

$$
K_{\mathrm{f}}=1+0.486\left(K_{\text {rhs }}-1\right)
$$

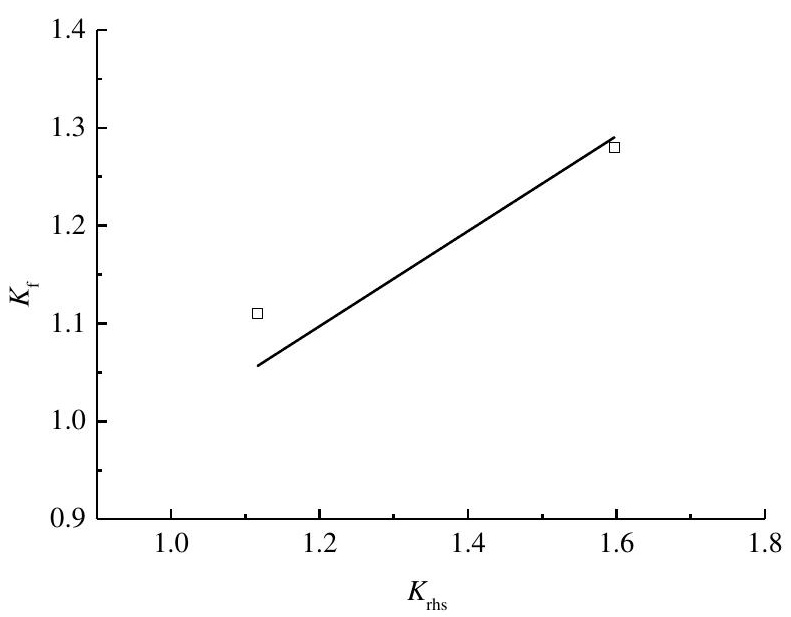

Fig. 14 The relationship between $K_{\mathrm{f}}$ and $K_{\mathrm{rhs}}$

\section{Fatigue life prediction}

\subsection{The FNF method}

The S-N equation considering the FNF can be expressed as:

$\left(K_{\mathrm{f}} \Delta \sigma\right)^{m} N=C$

Eq. (17) can be rewritten as:

$\log N=\log C-m \log \left(K_{\mathrm{f}} \Delta \sigma\right)=\left(\log C-m \log K_{\mathrm{f}}\right)-m \log \Delta \sigma$

The predicted S-N equations of corroded cruciform joints can be expressed as follows based on Eq. (4):

$\log N=12.502-3 \log \Delta \sigma$ for $\mathrm{P} 1$

$\log N=12.242-3 \log \Delta \sigma$ for $\mathrm{P} 2$ 
equations of the corroded cruciform joints are very close to the experimental equations.

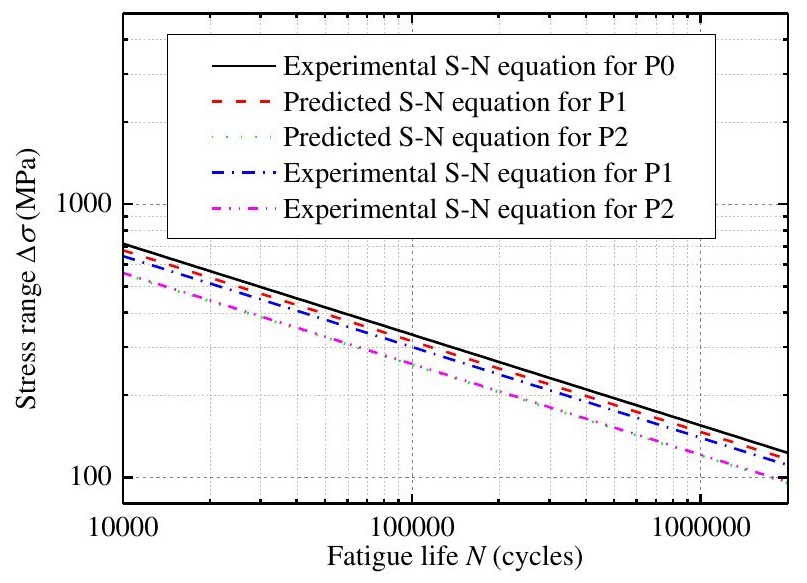

Fig. 15 Experimental and predicted $S-N$ equations

\subsection{Theory of Critical Distances (TCD)}

The TCD has been recently developed for the fatigue assessment of notched members [38]. The TCD can be summarized as four different ways: the point method (PM), the line method (LM), the area method (AM), and the volume method (VM) [39] (Fig. 16). The PM was employed to predict the fatigue life owing to the simple calculation without considering complex post-processing. The distance along the bisector of the weld toes from the potential crack initiation site is equal to $0.5 \mathrm{~mm}$ [7]. In addition, the stress range of the plain specimens at $N=2 \times 10^{6}$ cycles is $256.23 \mathrm{MPa}$ [40]. The accuracy and reliability of the PM in evaluating the fatigue life of inclined cruciform joints with artificial corrosion pits are checked using fatigue test data. A comparison of the fatigue life estimated by the FNF method and the TCD and experimental results is plotted in Fig. 17.
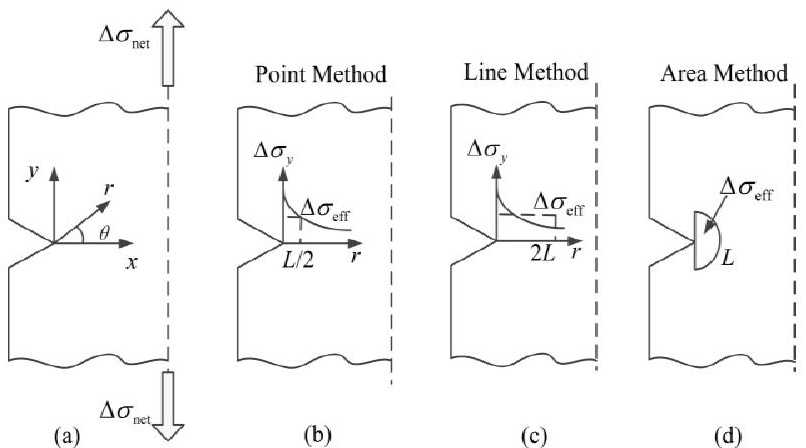

(b)

(c)

(d)

Fig. 16 Local coordinate system (a); the PM (b); the LM (c); and the AM (d)

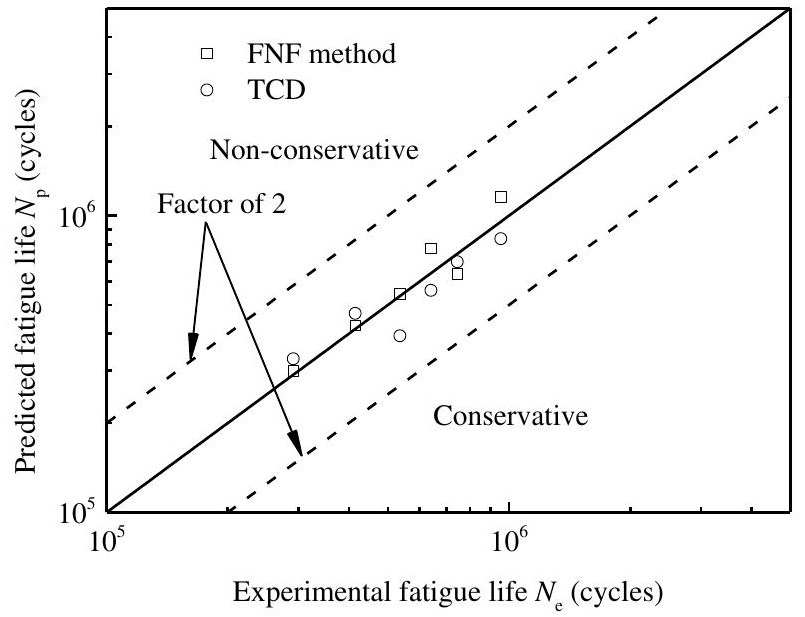

Fig. 17 Fatigue life experimental results versus predicted results
The maximum error of the predicted fatigue life results is only $-27.8 \%$. Fatigue life predicted results agree well with experimental results. Thus, the accuracy of the two methods used to assess the fatigue life is validated. The $\mathrm{S}-\mathrm{N}$ equations of the cruciform joints considering different corrosive time can be estimated by the FNF expression and the S-N equations of uncorroded cruciform joints.

\section{Conclusions}

This paper studied the effect of pitting corrosion damage on the fatigue properties of corroded inclined cruciform welded joints. Based on the above analyses, the following conclusions can be obtained.

(1) The fatigue cracks of all the specimens are generated at weld toes due to the more obvious stress concentration. The fatigue crack propagation paths of uncorroded and corroded cruciform joints are different due to the existence of pits.

(2) The fatigue strength of the inclined full penetration fillet welded cruciform joints is larger than that of the non-penetration weld. The inclination weld increases the fatigue strength of the uncorroded welded joints Fatigue strengths of the P0 and P1 specimens are very close and almost the same as that of the uncorroded category $\mathrm{D}$. The same reduction factor of the fatigue strength for different types of corrosion damage used in DNV is very inappropriate.

(3) The relative HSSCF should consider the effects of the pit depth and pit radius. There is a linear relationship between FNF and relative HSSCF. The predicted S-N equations of the corroded welded joints are very similar to the experimental equations.

(4) The maximum error of the predicted fatigue life results is only $-27.8 \%$. There is good agreement between fatigue life predicted results and experimental results. The accuracy and reliability of these two methods applied to the fatigue life estimation are validated by fatigue test data.

\section{Acknowledgements}

This research is supported by National Natural Science Foundation of China (51708305), Zhejiang Provincial Natural Science Foundation of China (LQ17E080005), Open Foundation of State Key Laboratory Cultivation Base of Mountain Bridge and Tunnel Engineering (CQSLBF-Y17-1), and K. C. Wong Magna Fund in Ningbo University.

\section{References}

[1] Li F. M., Luo X. Y. and Wang K. J. et al., "Pitting Damage Characteristics on Prestressing Steel Strands by Combined Action of Fatigue Load and Chloride Corrosion", Journal of Bridge Engineering, 2017, Vol.22, No.7, pp.4017023.

[2] Larrosa N. O., Akid R. and Ainsworth R. A., "Corrosion-Fatigue: A Review of Damage Tolerance Models", International Materials Reviews, 2018, Vol.63, No.5, pp.283-308.

[3] Kim I. and Kainuma S., "Fatigue Life Assessment of Load-Carrying Fillet-Welded Cruciform Joints Inclined to Uniaxial Cyclic Loading", International Journal of Pressure Vessels and Piping, 2005, Vol.82, No.11, pp.807-813.

[4] Wang Z. Y. and Wang Q. Y., "Fatigue Assessment of Welds Joining Corrugated Steel Webs to Flange Plates", Engineering Structures, 2014, Vol.73, pp.1-12.

[5] Khurshid M., Barsoum Z. and Barsoum I. et al., "The Multiaxial Weld Root Fatigue of But Welded Joints Subjected to Uniaxial Loading", Fatigue \& Fracture of Engineering Materials \& Structures, 2016, Vol.39, No.10, pp.1281-1298.

[6] Susmel L., "Nominal Stresses and Modified Wöhler Curve Method To Perform The Fatigue Assessment of Uniaxially Loaded Inclined Welds", Proceedings of the Institution of Mechanical Engineers, Part C: Journal of Mechanical Engineering Science, 2014, Vol.228, No.16, pp.2871-2880.

[7] Zamzami I. A. and Susmel L., "On the Use of Hot-Spot Stresses, Effective Notch Stresses and the Point Method to Estimate Lifetime of Inclined Welds Subjected to Uniaxial Fatigue Loading", International Journal of Fatigue, 2018, Vol.117, pp.432-449

[8] Hobbacher A., "Recommendations for Fatigue Design of Welded Joints and Components", Welding Research Council, 2009.

[9] Eurocode 3: "Design of Steel Structures Part 1-9: Fatigue", 2005.

[10] Det Norske Veritas, "Fatigue Design of Offshore Steel Structures", 2010.

[11] Righiniotis T. D. and Imam B. M., Chryssanthopoulos M. K., "Fatigue Analysis of Riveted Railway Bridge Connections Using the Theory of Critical Distances", Engineering Structures, 2008, Vol.30, No.10, pp.2707-2715.

[12] Shahri M. M. Sandström R , and Osikowicz W., "Critical Distance Method to Estimate the Fatigue Life Time of Friction Stir Welded Profiles", International Journal of Fatigue, 2012, Vol.37, pp.60-68.

[13] Zhou H., Wen J. and Wang Z. et al., "Fatigue Crack Initiation Prediction of Cope Hole Details in Orthotropic Steel Deck Using the Theory of Critical Distances", Fatigue \& Fracture of Engineering Materials \& Structures, 2016, Vol.39, No.9, pp.1051-1066.

[14] Al Zamzami I. and Susmel L., "On The Accuracy of Nominal, Structural, and Local Stres Based Approaches in Designing Aluminium Welded Joints Against Fatigue", International Journal of Fatigue, 2017, Vol.101, pp.137-158.

[15] Karakas Ö., Zhang G. and Sonsino C. M., "Critical Distance Approach for The Fatigue Strength Assessment of Magnesium Welded Joints in Contrast to Neuber's Effective Stress Method", International Journal of Fatigue, 2018, Vol.112, pp.21-35.

[16] Al Zamzami I., Davison B. and Susmel L., "Nominal and Local Stress Quantities to Design Aluminium-to-Steel Thin Welded Joints against Fatigue", International Journal of Fatigue, 2019, Vol.123, pp.279-295. 
[17] Soape J., "Investigating the Effects of Corrosion on the Fatigue Life of Welded Steel Attachments", Texas A\&M University, College Station, US, 2012.

[18] Yang S., Yang H. and Liu G. et al., "Approach for Fatigue Damage Assessment of Welded Structure Considering Coupling Effect Between Stress and Corrosion", International Journal of Fatigue, 2016, Vol.88, pp.88-95.

[19] Fu Y., Xiong J. J. and Shenoi R. A., "New Models for Depicting Corrosion Fatigue Behaviour and Calendar Life of Metallic Structural Component", Proceedings of the Institution of Mechanical Engineers, Part C: Journal of Mechanical Engineering Science, 2017, Vol.231, No.2, pp.207-222.

[20] Xu S. H., Ren S. B. and Wang Y. D., "Effects of Pitting Corrosion on the Fatigue Behavior of Q235 Steel", Journal of Harbin Institute of Technology (New Series), 2017, Vol.24, No.1, pp.81-90. (in Chinese)

[21] Albrecht P., Shabshab C. F., and Li W. et al., "Remaining Fatigue Strength of Corroded Steel Beams", 1990

[22] Cerit M., Genel K. and Eksi S., "Numerical Investigation on Stress Concentration of Corrosion Pit", Engineering Failure Analysis, 2009, Vol.16, No.7, pp.2467-2472.

[23] Kolios A., Srikanth S. and Salonitis K., "Numerical Simulation of Material Strength Deterioration due to Pitting Corrosion", Procedia CIRP, 2014, Vol.13, pp.230-236.

[24] Liu G., Huang Y. and Zhang Q. et al., "Fatigue Damage Estimation of Welded Joints Considering Mechanochemical Interaction", 36th International Conference on Ocean, Offshore and Arctic Engineering, Trondheim, Norway, 2017.

[25] Bray G. H., Bucci R. J. and Colvin E. L. et al., "Effect Of Prior Corrosion on the S/N Fatigue Performance of Aluminum Sheet Alloys 2024-T3 and 2524-T3", ASTM International, 1997, pp.89-103.

[26] Dicecco S., Altenhof W. and Hu H. et al., "High-Cycle Fatigue of High-Strength Low Alloy Steel Q345 Subjected to Immersion Corrosion for Mining Wheel Applications", Journal of Materials Engineering and Performance, 2017, Vol.26, No.4, pp.1758-1768.

[27] Sharifi Y., Rahgozar R., "Fatigue Notch Factor in Steel Bridges Due to Corrosion", Archives of Civil and Mechanical Engineering, 2009, Vol.9, No.4, pp.75-83.

[28] Ma Y. F., Wang Q. and Guo Z. Z. et al., "Static and Fatigue Behavior Investigation of Artificial Notched Steel Reinforcement", Materials, 2017, Vol.10, No.5, pp.532-545.
[29] Li S. B., Tang H. W. and Gui Q. et al., "Fatigue Behavior of Naturally Corroded Plain Reinforcing Bars", Construction and Building Materials, 2017, Vol.152, pp.933-942.

[30] Adasooriya N. D. and Siriwardane S. C., "Remaining Fatigue Life Estimation of Corroded Bridge Members", Fatigue \& Fracture of Engineering Materials \& Structures, 2014, Vol.37, No.6, pp.603-622.

[31] Adasooriya N. D., Hemmingsen T. and Pavlou D., "Fatigue Strength Degradation of Metals in Corrosive Environments", IOP Conference Series: Materials Science and Engineering, Norway, 2017.

[32] Sun B., "A Continuum Model for Damage Evolution Simulation of The High Strength Bridge Wires due to Corrosion Fatigue", Journal of Constructional Steel Research, 2018, Vol.146, pp.76-83.

[33] Adasooriya N. D., Pavlou D. and Hemmingsen T., "Fatigue Strength Degradation of Corroded Structural Details: a Formula for S-N Curve", Fatigue \& Fracture of Engineering Materials \& Structures, 2020, Vol.43, No.4, pp.721-733.

[34] GB/T 714-2015. "Structural Steel for Bridge", 2015. (in Chinese)

[35] Cao C. N., "Corrosion in Natural Environment of Materials in China", Chemical Industry Press, Beijing, China, 2005. (in Chinese)

[36] Jakubowski M., "Influence of Pitting Corrosion on Fatigue and Corrosion Fatigue of Ship Structures Part I Pitting Corrosion of Ship Structures", Polish Maritime Research, 2013, Vol.21, No.1, pp.62-69.

[37] Jie Z. Y., Li Y. D. and Wei X. et al., "Fatigue Life Prediction of Welded Joints with Artificial Corrosion Pits Based on Continuum Damage Mechanics", Journal of Constructional Steel Research, 2018, Vol.148, pp.542-550.

[38] Susmel L., "Multiaxial Notch Fatigue: from Nominal to Local Stress-Strain Quantities", Woodhead \& CRC, Cambridge, UK, 2009.

[39] Louks R. and Susmel L., "The Linear-Elastic Theory of Critical Distances to Estimate High-Cycle Fatigue Strength of Notched Metallic Materials at Elevated Temperatures", Fatigue \& Fracture of Engineering Materials \& Structures, 2015, Vol.38, No.6, pp.629-640.

[40] Li H., Zhao B. and Zhu H., "Numerical Simulation of Fatigue Performance of Diaphragm of Large-Span Bridge Orthotropic Deck", Complexity, 2018. 


\title{
BEHAVIOUR OF NOVEL STIFFENED ANGLE SHEAR CONNECTORS AT AMBIENT AND ELEVATED TEMPERATURES
}

\author{
Karim Nouri ${ }^{1, *}, \mathrm{~N}$ H Ramli Sulong ${ }^{1,2}$, Zainah Ibrahim ${ }^{1, *}$ and Mahdi Shariati ${ }^{1}$ \\ ${ }^{1}$ Department of Civil Engineering, Faculty of Engineering, University of Malaya, 50603 Kuala Lumpur, W.Persekutuan Kuala Lumpur, Malaysia \\ ${ }^{2}$ School of Civil \& Environmental Enginnering, Science \& Engineering Faculty, Queensland University of Techenology, 2 George St, Brisbane QLD 4000, Australia \\ *(Corresponding authors: E-mail: k.nouri@siswa.um.edu.my; zainah@um.edu.my)
}

\section{A B S T RA C T}

This paper presents experimental studies to investigate the behaviour of stiffened angle shear connectors subjected to isothermal fire loading. Push-out tests were conducted on 48 specimens covering various geometries of stiffened angle shear. The specimens were initially heated at room temperature, which gradually increased to target temperatures, and loaded up to failure for the assessment of their shear resistance at high temperatures. The behaviour of these connectors at ambient and high temperatures was compared. Results showed that the full-length stiffened angle shear connectors exhibited higher shear resistance compared with the half-length ones, whereas the ductility of the half-length stiffened shear connectors was greater than that of the full-length ones; the connector fracture governed the failure mode. Although heating exerted a substantially destructive effect on the resistance of the shear connectors, it led to increased ductile behaviour.

Copyright $(\odot 2021$ by The Hong Kong Institute of Steel Construction. All rights reserved.

\section{Introduction}

Composite structures employing normal-weight concrete have been used in bridge construction for more than half a century, with the related literature dating back to the 1920 s [1-3]. In recent decades, the main progress in composite structures has been due to the outcome of the basic design provisions nominated by the American Institute of Steel Construction in 1961 [4]. Shear connectors between concrete slabs and steel beams in composite construction play a significant role in the seismic response of a structure [5]. They provide the essential shear connection for composite action in flexure, which is used to distribute the large horizontal inertial forces in a slab to the main lateral loadresisting elements of the structure. During an earthquake, such shear connectors are adjusted to reverse cyclic loading [6].

Headed studs, perfobond ribs, channels and wires are known as the most common shear connectors. Recently, the demand for innovative shear connectors has led to other forms of connection by using steel angles, coldformed shapes and powder-actuated attachments. In developing countries, stud connectors are minimally utilised in the industry due to not only the lack of skill labour but also the cost of manufacturing. Although the most common shear connector is headed stud, perfobond ribs, channels and angle shear connectors are also widely adopted due to ease of installation, availability and higher loadcarrying capacity. In addition, angle and channel shear connectors do not require inspection rules that are used for stud connectors, such as the bending test. During the installation of transverse slab reinforcement, shear connectors are less problematic than perfobond connectors. Hence, angle and channel shear connectors are amongst the most preferred choices to overcome the drawbacks of headed studs and perfobond shear connectors in composite beams. Angle profile can be used in L- and C-shaped angle connectors. Between these two, $\mathrm{C}$-shaped angle shear connectors have better performance and high shear resistance [7-14].

A composite structure requires the consideration of the design process under risk conditions, given that the behaviour of a composite structural system under fire is outstandingly different from its behaviour at ambient temperatures. The investigations on the Broadgate fire and the Cardington structure [15] have improved the conception of structural interactions and load distribution occurring in a real building under fire. The structures are typical examples of the current UK steel construction with concrete-profiled deck floor slabs performing compositely with hot-rolled steel beams mostly left unprotected. Although tests have indicated that high temperatures might be sustained, the results are inadequate and do not explain the mechanics governing the structures' response to fire. The interactions amongst thermal expansion, large deformation effects, material degradation and 3D effects on a building have complicated the understanding of the behaviour of composite members through the development and investigation of high-quality numerical and analytical models. Few studies have focused on the behaviour of isolated members in composite structures.
A R T I C LE H I S T ORY

$\begin{array}{ll}\text { Received: } & 16 \text { February } 2020 \\ \text { Revised: } & 15 \text { October } 2020 \\ \text { Accepted: } & 26 \text { October } 2020\end{array}$

\section{K E Y W O R D S}

Stiffened Shear Connector; Composite;

Angle;

Monotonic Loading,

Elevated Temperature;

Ambient Temperature
Sanad et al. [16] studied the structural action in a two-way slab and composite beam structure subjected to compartment fire, showing that 1) the performance of indeterminate structures under fire was governed by thermal expansion and 2) local yielding and large deflections reduced the damage to the overall structure. Mäkeläinen and Ma [17] studied the thermal and structural performance of a slim floor beam under fire through a numerical analysis by applying ISO standard fire and natural fire. The results showed that an increment in temperature significantly influenced the flexural capacity of the beam, which depended on the shear connection to maintain performance. In the last study performed by Mirza and Uy [18], FEM and experimental tests were conducted to analyse the effects of raised temperatures on the behaviour of composite steel-concrete beams for solid and profiled steel sheeting slabs. In the current study, material properties varied with temperature; hence, the behaviour of reinforced concrete slabs under fire conditions highly depended on the interaction of the surrounding elements. In the following, steel sheet slabs exhibited great fire resistance compared with ambient temperature strength [18].

Rodrigues and Laím [19, 20] conducted a comprehensive experimental study on T, T-block, T-perfobond and perfobond shear connectors at different temperatures to assess the structural behaviour of the shear connectors under fire. From the current study, elevated temperatures adversely influenced the connector load-carrying capacity, in which T-perfobond connectors exhibited the worst behaviour, whereas $\mathrm{T}$ connectors showed the best one. The perfobond connections obtained from the two connectors indicated the worst behaviour in the fire, whereas the connector with one hole and without any steel reinforcement passing through it showed the best behaviour. A study conducted with partial composite beams with flat lightweight concrete slabs showed an overall reduction in the composite beam load-carrying capacity due to being heated at elevated temperatures and post-fire ambient conditions. The composite beams and connections sustained the loading and heating up to $700{ }^{\circ} \mathrm{C}$ on the service level. However, the shear tab connection fractured during cooling, which highlighted the significance of the heating and cooling phases of a fire [21]. To improve the performance of L-shaped angle shear connectors, stiffened angle shear connectors were proposed. The stiffener was prefabricated, and its welding procedure was as simple as the welding of angle shear connectors (which requires nonspecific equipment); accordingly, the advantages of $\mathrm{C}$-shaped angle shear connectors could remain for stiffened angle shear connectors. This research focused on the behaviour assessment of the stiffened angle shear connectors at ambient and elevated temperatures with isothermal condition. The three elevated temperature levels of isothermal heating were $550{ }^{\circ} \mathrm{C}, 700{ }^{\circ} \mathrm{C}$ and $850{ }^{\circ} \mathrm{C}$. The shear connector behaviour in terms of failure mode, ductility, load-carrying capacity, strength at ambient temperatures, the effect of temperature on the mentioned parameters and the heat distribution at different temperature elevations was examined. 


\section{Test programme}

\subsection{Test plan}

Forty-eight push-out tests were conducted and divided into two series. Each series used two types of angle section with heights of 100 and $75 \mathrm{~mm}$ and three different lengths of 30,50 and $80 \mathrm{~mm}$ as shear connectors. Then, each type was divided into two groups on the basis of its stiffener height, i.e. full- and halflength stiffener. As reflected in the name, full-length stiffened means that the stiffener has a height equal to the shear connector's height. On the contrary, half-length stiffened means that the height of the stiffener is half of the height of the shear connector. Four specimens were considered for each group under monotonic loading at ambient temperatures, $550{ }^{\circ} \mathrm{C}, 700{ }^{\circ} \mathrm{C}$ and $850{ }^{\circ} \mathrm{C}$. The specimens were labelled for the identification of their individual behaviour. The specimens' ID and the geometric properties of the angle shear connectors are presented in Table 1. In the symbolisation of the specimens in the table, the first letter indicates the type of shear connector, which is angle shear connector; the next two or three digits represent the height; the next two digits represent the length; the second letter is the height of the stiffener, and the last digits define the temperature.

\subsection{Specimens}

Push-out specimens comprised a steel I-section (IPE270) beam with two reinforced concrete slabs attached to each flange of the beam. The stiffened shear connector was attached to each beam flange by welding, and $10 \mathrm{~mm}$ diameter steel bar hoops were used at the top and bottom of the slab to reinforce the concrete. Details of the push-out specimens are in accordance with the recent studies on the behaviour of $\mathrm{C}$-shaped angle and channel shear connectors under different conditions [8, 12, 14, 22-27]. To design a stiffener, a triangle-shaped truss was considered and was expected to have a vital role in increasing the ultimate load capacity of the shear connector. Hence, this concept can reduce the number of shear connectors in a structure, which not only assists in saving steel and installation time but also leads to cost savings. The implication of this design is that the triangle-shaped stiffener increases the strength and stiffness of the connector in transferring the load to the beam. The strength enhancement has significant role and effect at elevated temperature when the mechanical strength of steel drops dramatically. The schematic of the test specimens is shown in Fig. 1. The properties of steel components in this study were tested in accordance with coupon tensile test ASTM 370 (ASTM 2005) [28]; the material properties of the steel components are provided in Table 2.

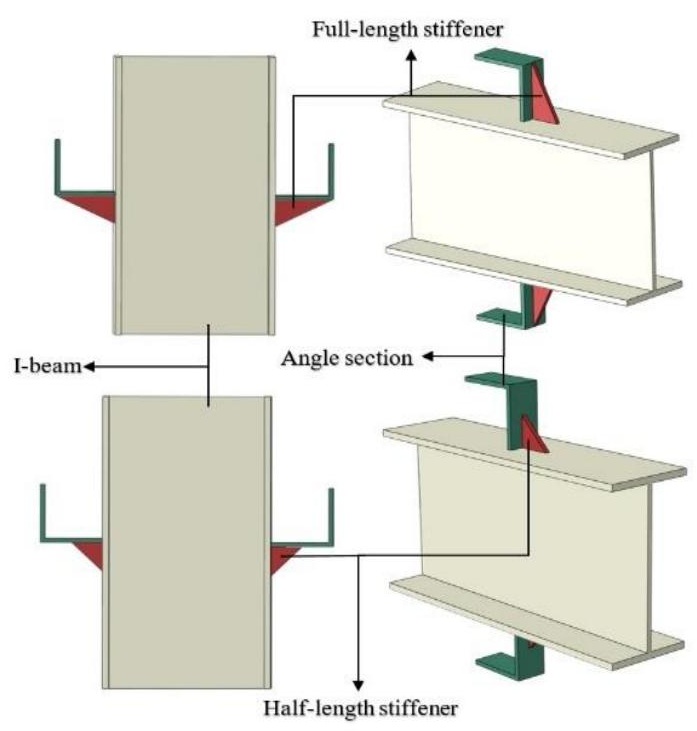

Fig. 1 Details of test specimens

Table 1

Specimen IDs and geometrical properties of angle shear connectors

\begin{tabular}{cccccc}
\hline NO & ID & $\begin{array}{c}\text { Height } \\
(\mathrm{mm})\end{array}$ & $\begin{array}{c}\text { Length } \\
(\mathrm{mm})\end{array}$ & Stiffener & Temperature $\left({ }^{\circ} \mathrm{C}\right)$ \\
\hline 1 & A-100-80-F-A & 100 & 80 & F - 100 & 25 \\
2 & A-100-80-F-550 & 100 & 80 & F - 100 & 550 \\
3 & A-100-80-F-700 & 100 & 80 & F - 100 & 700
\end{tabular}

8

A-100-80-H-A

A-100-80-H-550

A-100-80-H-700

A-100-80-H-850

A-100-50-F-A

A-100-50-F-550

A-100-50-F-700

A-100-50-F-850

A-100-50-H-A

A-100-50-H-550

A-100-50-H-700

A-100-50-H-850

A-100-30-F-A

A-100-30-F-550

A-100-30-F-700

A-100-30-F-850

A-100-30-H-A

A-100-30-H-550

A-100-30-H-700

A-100-30-H-850

A-75-80-F-A

A-75-80-F-550

A-75-80-F-700

A-75-80-F-850

A-75-80-H-A

A-75-80-H-550

A-75-80-H-700

A-75-80-H-850

A-75-50-F-A

A-75-50-F-550

100

80

F - 100

850

100

100

100

80

H - 50

H - 50

H - 50

H - 50

F - 100

F - 100

F - 100

F - 100

H - 50

H - 50

H - 50

H - 50

F - 100

F - 100

F - 100

F - 100

H - 50

H - 50

H - 50

H - 50

F - 100

F - 100

F - 100

F - 100

H - 50

H - 50

H - 50

H - 50

F - 100

F - 100

F - 100

F - 100

A-75-50-F-850

A-75-50-H-A

A-75-50-H-550

H - 50

H - 50

$\mathrm{H}-50$

H - 50

F - 100

F - 100

F - 100

F - 100

H - 50

H -50

H - 50

H - 50

Table 2

Coupon tensile test result

\begin{tabular}{cccc}
\hline Specimens & 1 & 2 & 3 \\
\hline Fy (MPa) & 338.8 & 341.85 & 340 \\
Fu (MPa) & 493.86 & 495.03 & 495.77 \\
Elongation (\%) & 24.23 & 23.74 & 24.16 \\
Fy Average (MPa) & & 340.22 & \\
\hline
\end{tabular}




\begin{tabular}{cc}
\hline Fu Average (MPa) & 494.89 \\
Elongation Average (\%) & 24.04 \\
$F_{u} / F_{y}$ & 1.45 \\
\hline
\end{tabular}

\subsection{Concrete materials and mix proportions}

Air-dry condition aggregates were used in the concrete mixes, in which the fine aggregate was graded silica sand with a maximum nominal size of $4.75 \mathrm{~mm}$, and the coarse aggregate was crushed granite with a maximum nominal size of $10 \mathrm{~mm}[29,30]$. The cement used in all mixes was ordinary Portland cement corresponding to ASTM C150 (cement) type II [31-33]. To attain acceptable workability, a superplasticiser (SP; Rheobuild 1100) was used in the concrete mixes (Table 3). Superplasticizer (SP) (dark brown and $\mathrm{pH}$ of 6.0-9.0) has a specific gravity of approximately 1.195 [34]. Short, angle lengths were used due to the concrete slab size limitation. All push-out specimens were cast in a horizontal position similar to site situations, whilst a qualified reliable concrete for both sides of the specimen slabs was assumed (Fig. 2). To measure the compressive strengths, standard cylinders with $150 \mathrm{~mm}$ diameter and $300 \mathrm{~mm}$ length and standard cubes with $100 \mathrm{~mm}$ length were cast with the push-out specimens simultaneously. All the specimens, cylinders and cubes were cured in water for 28 days before testing (Fig. 3a). The concrete strength was measured during the cylinder and cube compression tests. The requirements of ASTM C39 (ASTM 2005) [35] were adopted for the compressive strength test procedure, and the mean of the concrete compression strength was calculated. The average strength of concrete compression was $50 \mathrm{MPa}$ (Fig. 3b).

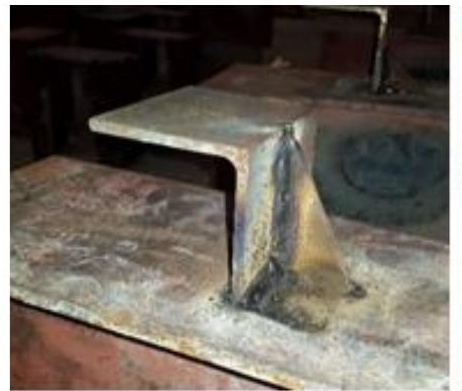

(a) beams with welded connectors

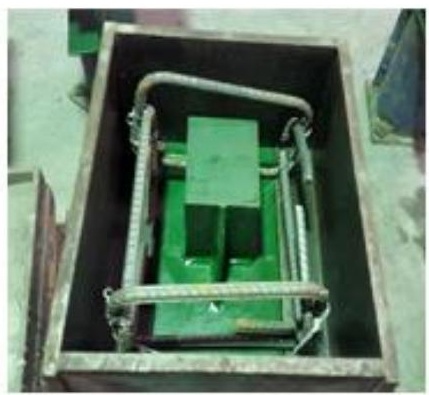

(b) molding and rebar placement

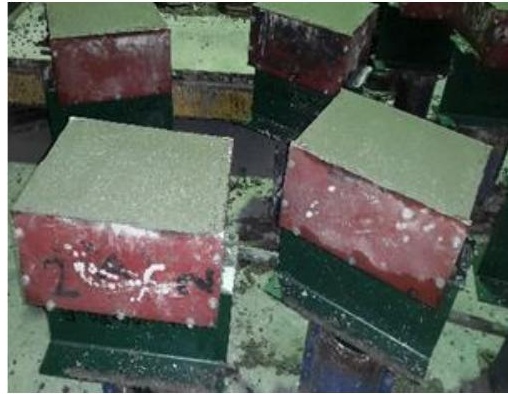

(c) poured concrete

Fig. 2 Fabrication and preparation of push-out specimens

Table 3

Mix proportions of concrete materials by weight

\begin{tabular}{|c|c|c|c|c|c|c|c|c|c|}
\hline 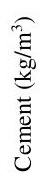 & 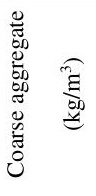 & 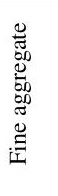 & 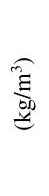 & 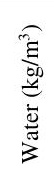 & 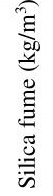 & $\begin{array}{l}\frac{\partial}{2} \\
\stackrel{2}{\infty}\end{array}$ & $\frac{U}{3}$ & 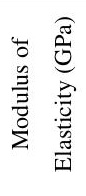 & 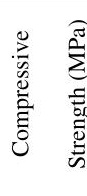 \\
\hline 460 & 910 & 825 & & 168 & 40 & 0.5 & 0.37 & 39 & 35 \\
\hline
\end{tabular}

\subsection{Loading and test procedure}

The specimens were initially heated at room temperature and increased to a target temperature, then they were loaded up to failure. The loading condition was based on isothermal heating conditions. Each series of specimens was tested under monotonic loading at temperatures of $25^{\circ} \mathrm{C}, 550{ }^{\circ} \mathrm{C}, 700{ }^{\circ} \mathrm{C}$ and $850{ }^{\circ} \mathrm{C}$. The desired temperatures were obtained using flexible ceramic pad (FCP) heating elements (Fig. 4a) that used a high-voltage electrical transformer
(Fig. 4b) for FCP heating through a high-resistance wire. This method was used in previous research by Haremza et al. [36]. The sample in the heated zone was thermally insulated with Rockwool (Fig. 5), which had a density of $128 \mathrm{~kg} / \mathrm{m} 3$ to avoid losing heat during the test. The temperature was recorded using a calibrated temperature recorder (Fig. 4c) for the flange temperature. Two type$\mathrm{K}$ thermocouple cables (Fig. 6) were installed in the middle and top of the shear connector and connected to the data logger to observe heat expansion through the shear connector embedded in the reinforced concrete.

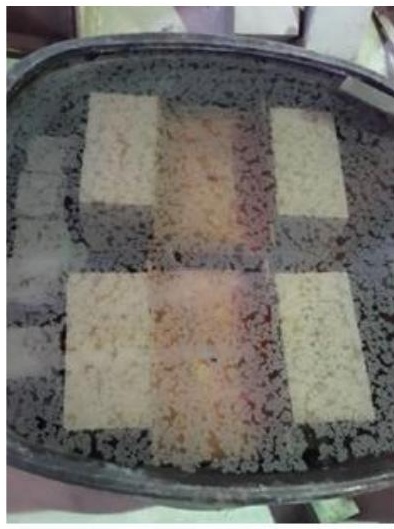

Fig. 3a Curing all specimens

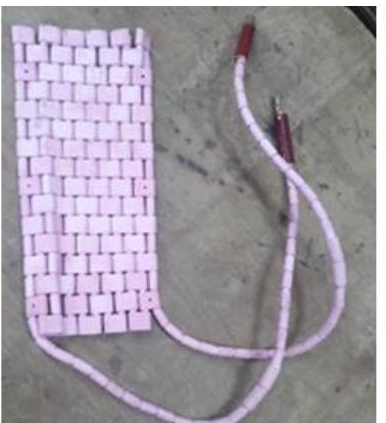

(a) Flexible Ceramic Pad (FCP)

elements

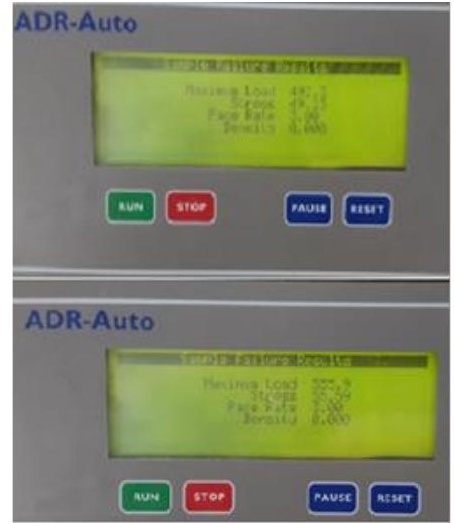

Fig. 3b Compression test results

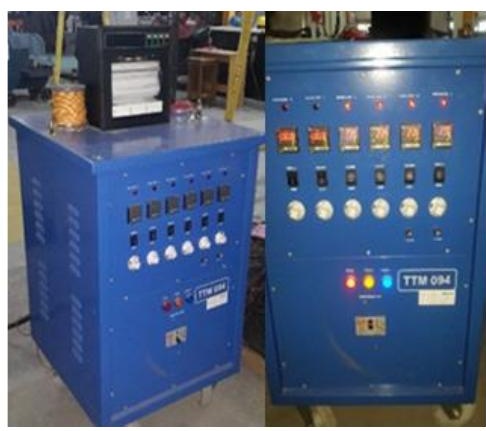

(b) Electrical transformer for heating heating the CFPs

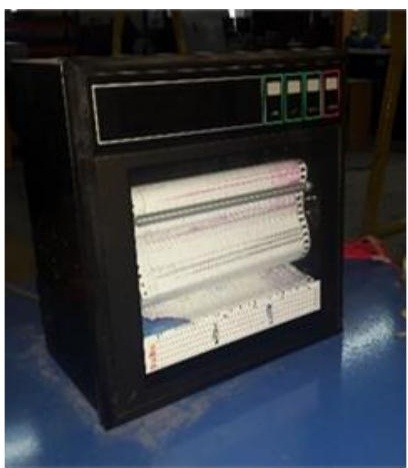

(c) Calibrated temperature recorder

Fig. 4 Equipment for the fire test

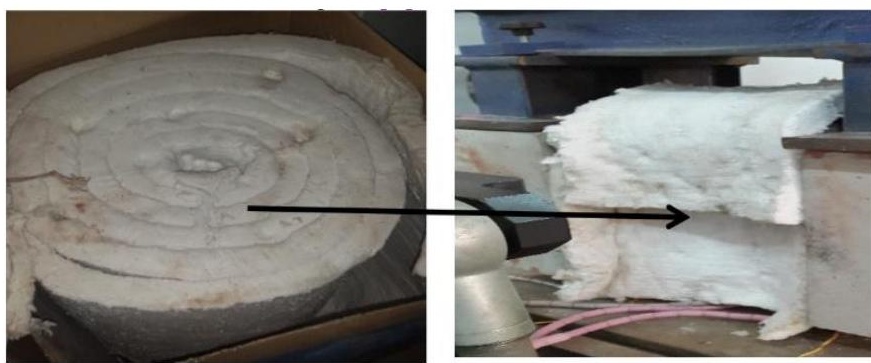

Fig. 5 Rock-wool for specimen isolation 


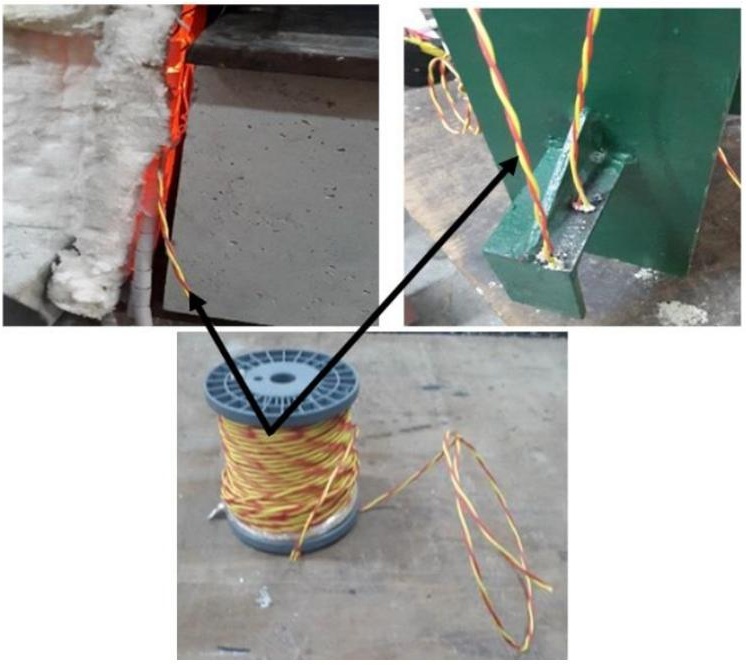

Fig. 6 Type-K thermocouple cables used for measuring the temperature in specimens

A universal testing machine with $600 \mathrm{kN}$ capacity was used to apply a monotonic load. Fig. 7 shows the push-out test setup. Displacement control was used at a rate of $0.04 \mathrm{~mm} / \mathrm{s}$ for the monotonic loading [13,37]. The practical load and relative slip between the I-beam and the concrete slab were automatically recorded at each time step by using the universal machine. The universal testing machine was able to plot a loading versus displacement graph. The behaviour of the stiffened shear connectors could be assessed on the basis of raw data and graph.
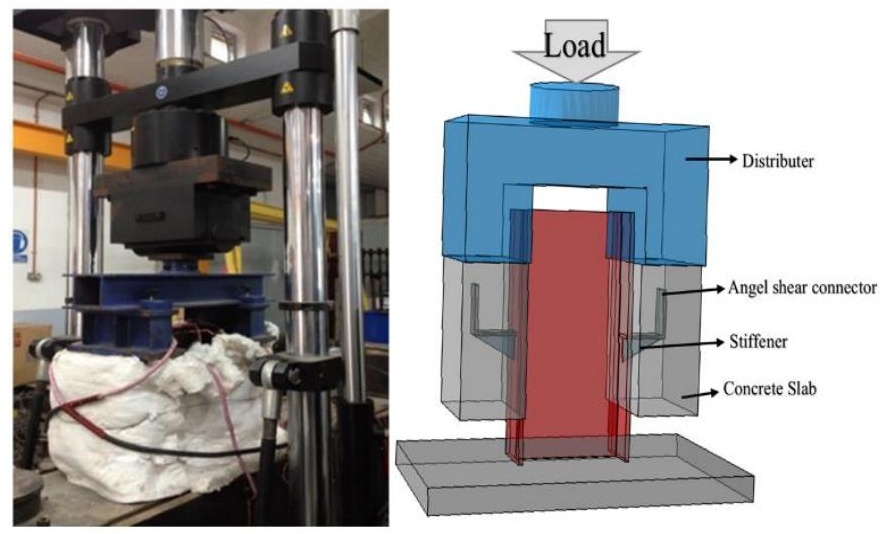

Fig. 7 Typical test setup for specimens at elevated temperatures

Regarding the steel I-beams, on the basis of the universal test machine deck, a change in the angle connector orientation resulted in a variation in the ultimate strength of the connectors and relative stiffness $[12,38]$ accepted in all pushout tests (Fig. 7). When the push-out sample temperature was constant, the ultimate load capacity gained from the tests at room temperature was followed by heating up of the specimens to target temperature at the same heating rate based on the ISO 834 fire curve [39].

\section{Results and discussion}

\subsection{Heat distribution}

The stiffened angle shear connectors were tested at different temperatures. The temperature of a stiffened angle shear connector was monitored using a type-K thermocouple, which was connected to the I-beam and the top and middle of the shear connector, as shown in Fig. 8. The propagation of heating through the I-beam and shear connector was measured. As indicated in Fig. 9a$\mathrm{c}$, the heat distribution through the specimens followed the same pattern due to the heat transfer coefficient of concrete and steel. The temperature distribution at three different locations is summarised in Table 4 . For the tests at $550{ }^{\circ} \mathrm{C}$ and $700{ }^{\circ} \mathrm{C}$, the percentage of temperature reduction in the middle and top of a shear connector compared with the flange temperature was within the similar ranges of $53 \%-54 \%$ and $73 \%-75 \%$, respectively. The temperature reduction for the same locations in the $850{ }^{\circ} \mathrm{C}$ test was much lower, i.e. $42 \%$ and $58 \%$, respectively. All temperature reductions from the I-beam to the shear connector strongly depended on the thermal conductivity of the steel and concrete and the time of heat application to reach the target temperature.

This result showed that the temperature at the flange was higher at the top of the shear connector, which was caused by the transfer of heat to the concrete. The concrete attracted heat from the flange and shear connector; therefore, the area that surrounded the shear connector received substantial heat which had a destructive effect on the concrete's properties. The strength of concrete drops in the area where the concrete stresses are high, which leads to concrete crushing and propagation of cracks. The strength properties of steel and concrete at elevated temperature decrease with time. Accordingly, if the structure is on fire, the strength and stability of the structure diminish tremendously over time. The average temperature of the shear connector increased by $50 \%$ from $700{ }^{\circ} \mathrm{C}$ to $850{ }^{\circ} \mathrm{C}$, which indicated an extensive damaging effect on its behaviour and proved that, at elevated temperature, a stiffer design is required to address the drawback that the designed stiffener can assist and sustain the shear connector significantly. Thus, the flange of the I-beam at the bottom of the stiffened shear connector had the highest temperature-induced destructive effect on the mechanical properties of steel, leading to the fracture of the shear connector in this area.

Table 4

Heat distribution in the I-beam and shear connector

\begin{tabular}{|c|c|c|c|c|c|c|c|}
\hline Location & 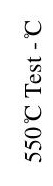 & 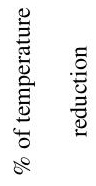 & 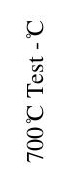 & 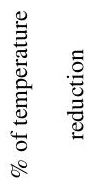 & $\begin{array}{l}u \\
1 \\
1 \\
0 \\
0 \\
0 \\
0 \\
\infty \\
\infty\end{array}$ & 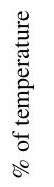 & 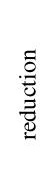 \\
\hline Flange of I beam & 551 & - & 701 & - & 855 & - & \\
\hline Middle of shear connector & 260 & $53 \%$ & 325 & $54 \%$ & 493 & $42 \%$ & \\
\hline Top of shear connector & 157 & $72 \%$ & 175 & $75 \%$ & 355 & $58 \%$ & \\
\hline
\end{tabular}

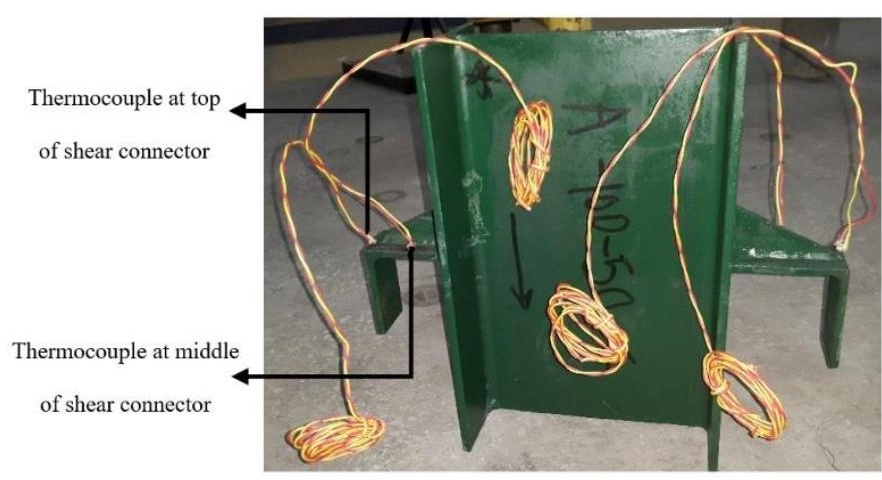

Fig. 8 Type-K thermocouple connected to the middle and top of the connector

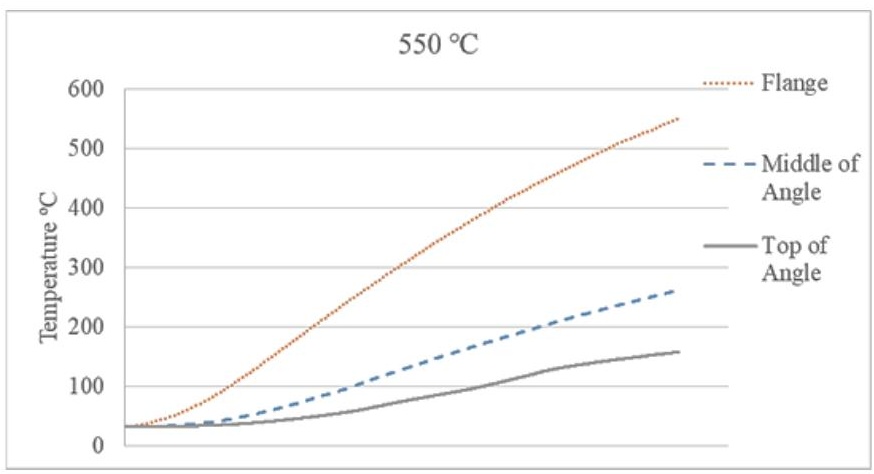

(a) Propagation of heat through at $550^{\circ} \mathrm{C}$ 


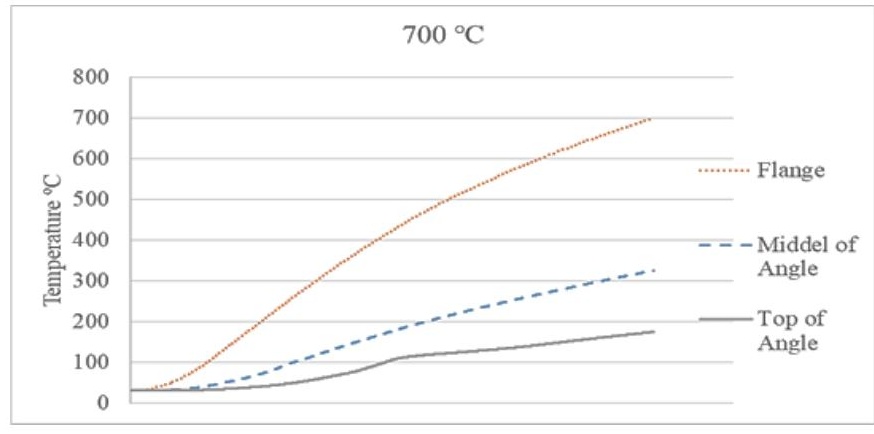

(b) Propagation of heat through at $700^{\circ} \mathrm{C}$

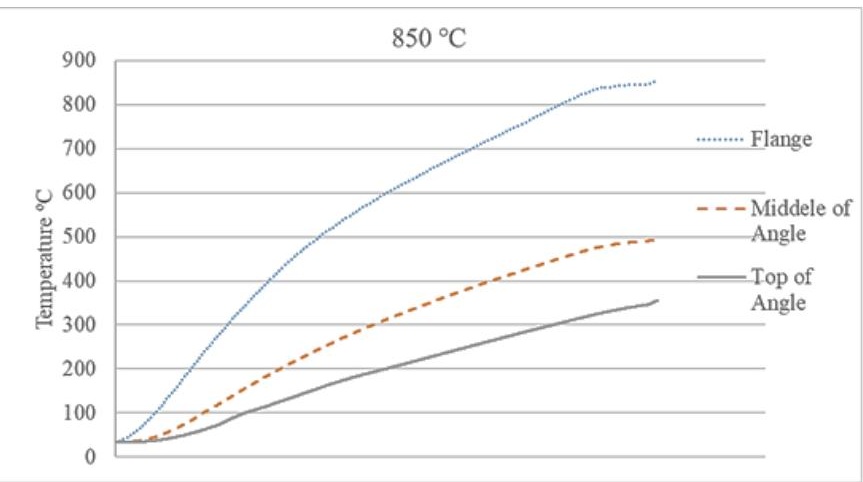

(c) Propagation of heat through at $850^{\circ} \mathrm{C}$

Fig. 9 Propagation of heat through the I-beam and shear connector

\subsection{Failure type}

The push-out specimens indicated two types of failure: connector fracture and concrete crushing splitting. The former was found in most of the specimens at room and elevated temperatures (Fig. 10), in which it occurred from the upper welding line. Although most specimens failed with the same type of failure at ambient and elevated temperatures, the failure at ambient temperatures was less ductile than that at elevated temperatures, which was caused by the stiffener that made the shear connectors stiff at ambient temperatures. At elevated temperatures, the shear connectors behaved more ductile due to the reduction in steel strength. Concrete crushing occurred around the connectors for the stiffened shear connectors with $80 \mathrm{~mm}$ width at room temperature. In fact, the width of the $\mathrm{C}$-shaped shear connector plays a vital role in terms of its strength. Therefore, the connector area facing the force is enhanced by increasing the width of the angle profile, which leads to concrete crushing at ambient and elevated temperatures.

The potential damage to strength caused by heating must be considered. The heating included the vaporisation of free water at approximately $100{ }^{\circ} \mathrm{C}$, which meant that humidity had no effect on the concrete strength during the test; the dissociation of $\mathrm{Ca}(\mathrm{OH})_{2}$ into $\mathrm{CaO}$ and $\mathrm{H}_{2} \mathrm{O}$ between $400{ }^{\circ} \mathrm{C}$ and $500{ }^{\circ} \mathrm{C}$; and the quartz transformation of some aggregates above $600^{\circ} \mathrm{C}$; the concrete started sweating and cracking at approximately $450^{\circ} \mathrm{C}$ [40]. The failure mode observed under monotonic loading at elevated temperatures for the stiffened angle shear connectors was accompanied by a longitudinal crack throughout the slab.

The observed cracks were due to concrete and steel isotropic essence. The thermal increase of the concrete depended on temperature alteration. Some cracks formed around the surface of the connectors and in a direction parallel to the steel I-beam. As Bazant and Kaplan [41] observed, cracking occurs due to structural stresses in concrete caused by inhomogeneous thermal increases, which are expressed as a temperature function on the basis of Eurocode 2 [42]. Figs. 11 and 12 show the mentioned phenomenon during and after the hightemperature experiments, respectively.
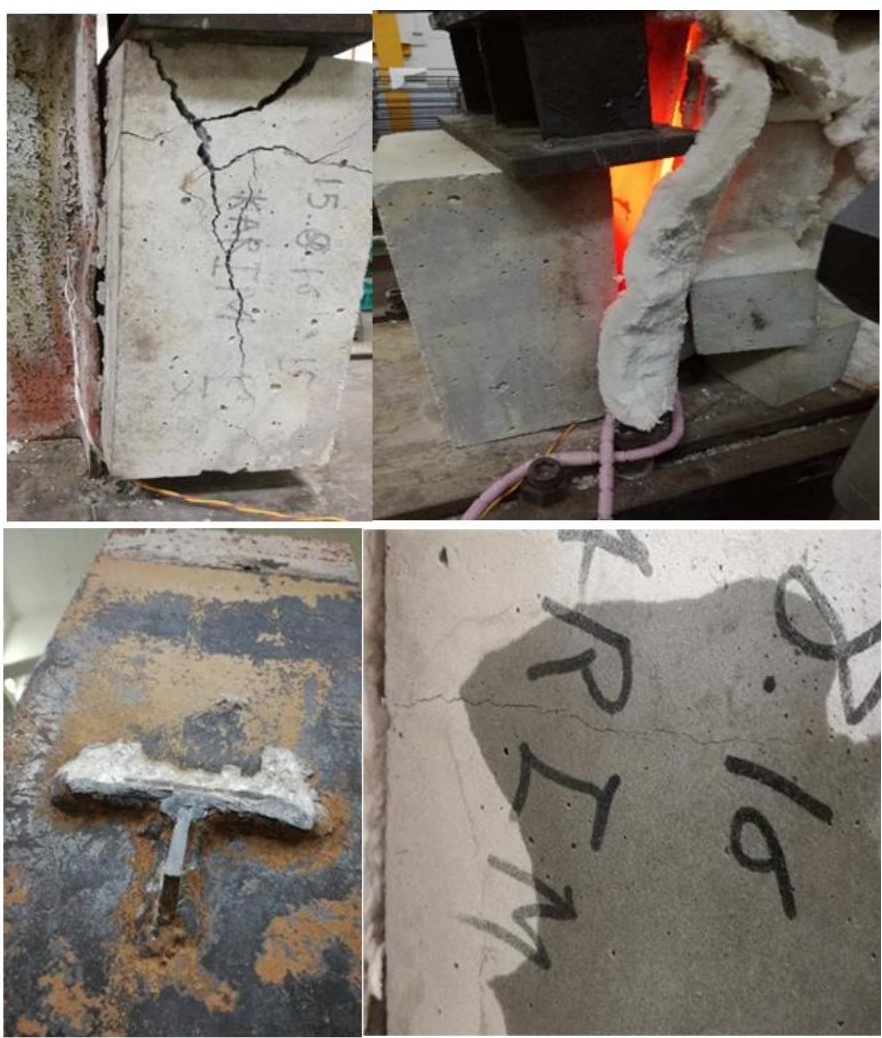

Fig. 10 Typical failure of a stiffened angle shear connector specimen

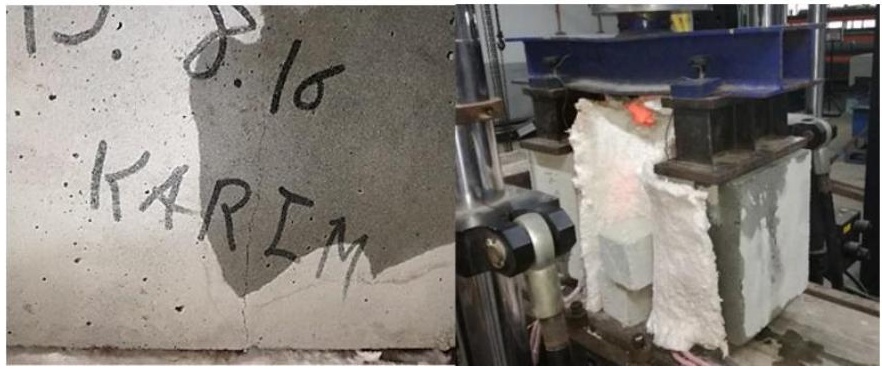

Fig. 11 Cracks on concrete slab during connector specimen failure at ambient and elevated temperatures

\subsection{Load-slip analysis}

Tables 5 and 6 show the highest capacity of shear and slip load gained from the test specimens by referring to the load-slip curve for the monotonic load of all the push-out experiment specimens at all temperatures, as shown in Fig. 13a1. The load-slip curves were plotted using a universal testing machine with 600 $\mathrm{kN}$ capacity. The universal testing machine recorded load versus displacement every second. In addition, a distributer was used to apply load on both concrete slabs. The distributer was made using 2 UC $100 \times 100 \times 17.20 \mathrm{~kg}$; hence, the deflection of the distributer during the test under $600 \mathrm{kN}$ was $0.018 \mathrm{~mm}$, which was neglected in the analysis. Shear resistance data and the highest slip related to the push-out experiments for all samples are also shown in Tables 5 and 6 .

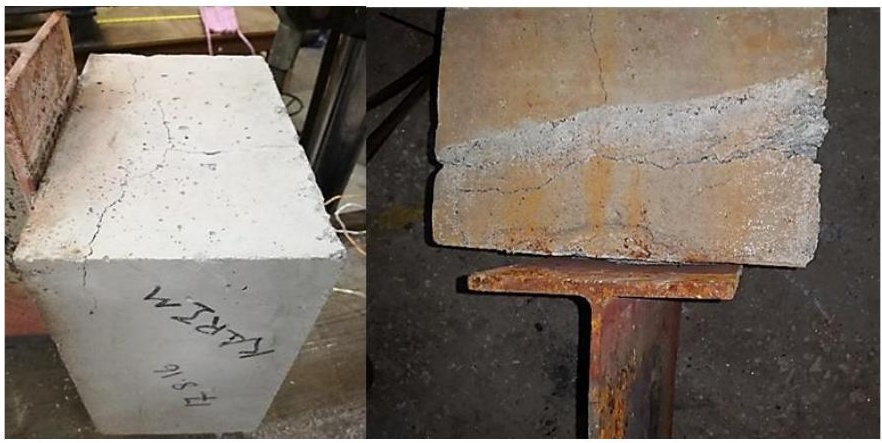

Fig. 12 Cracks on concrete slab after connector specimen failure at elevated temperature 
Karim Nouri et al.

33

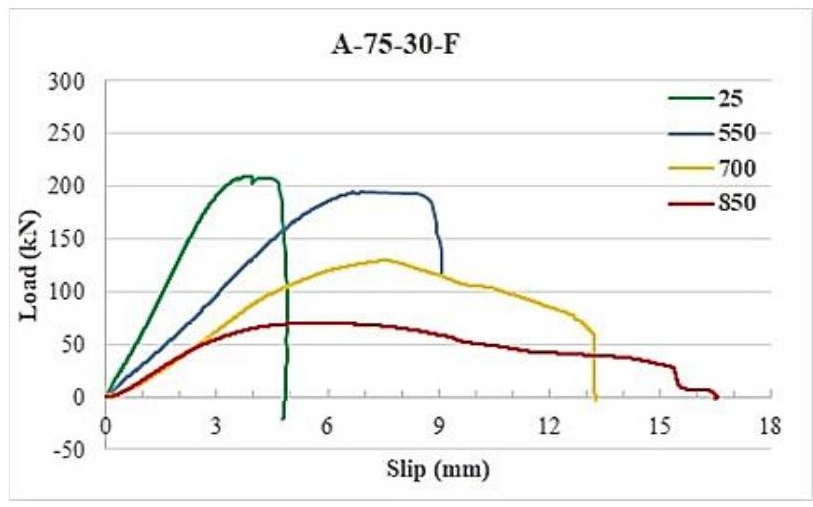

(a) A-75-30-F

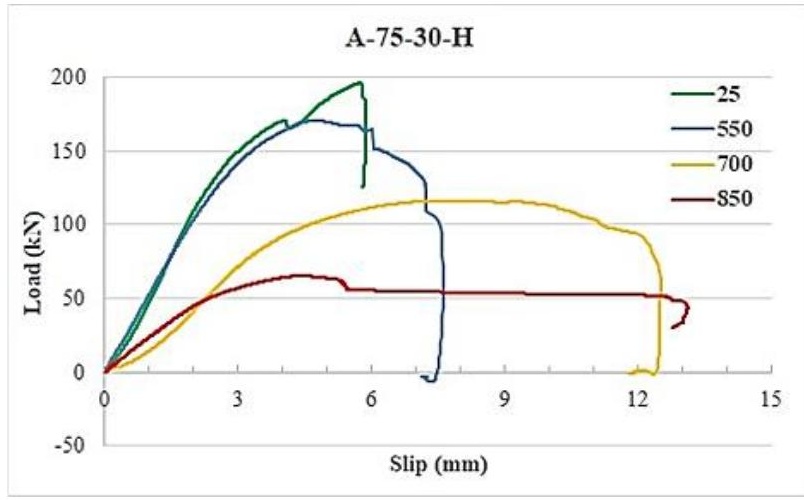

(b) A-75-30-H

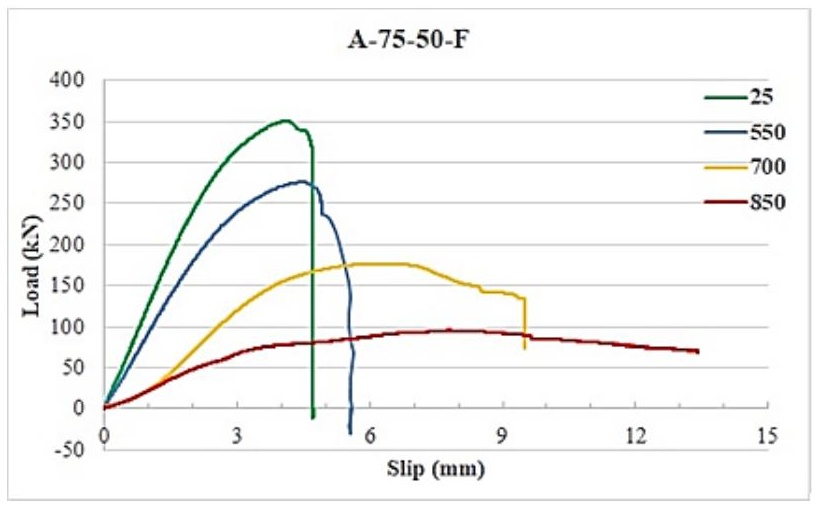

(c) A-75-50-F

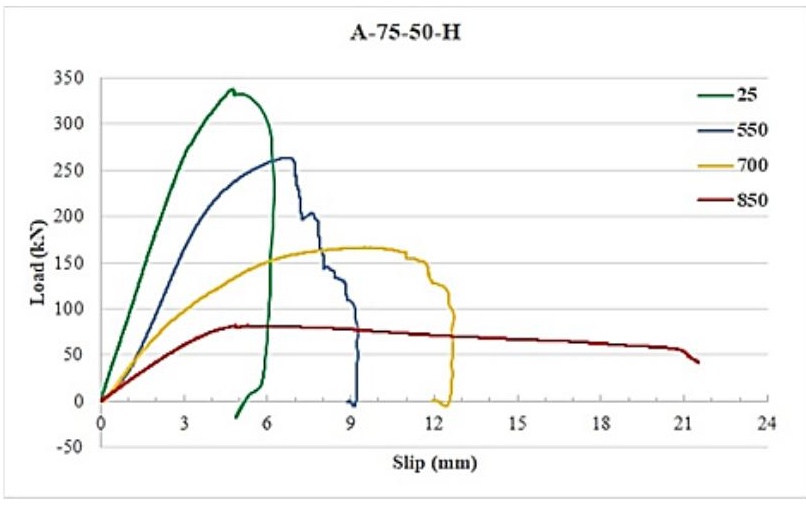

(d) A-75-50-H

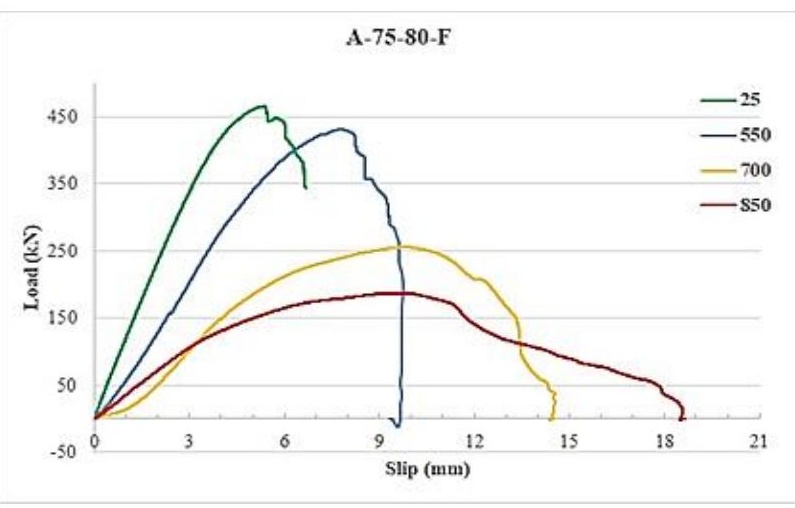

(e) A-75-80-F

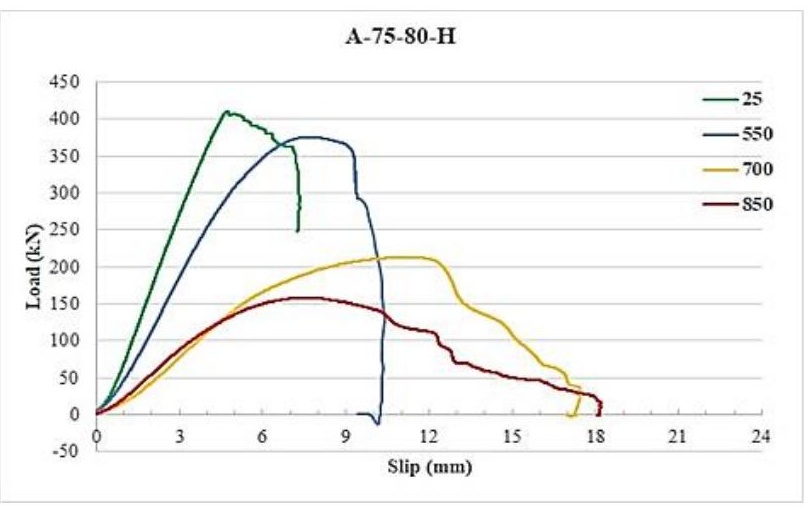

(f) A-75-80-H

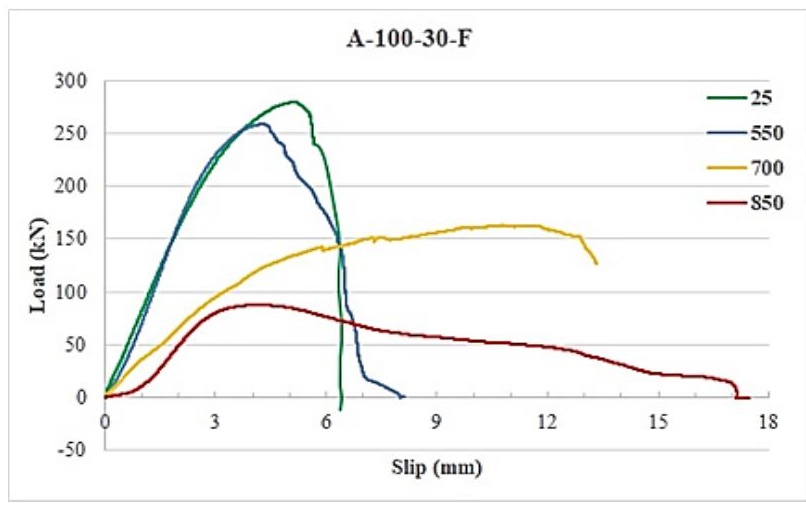

(g) A-100-30-F

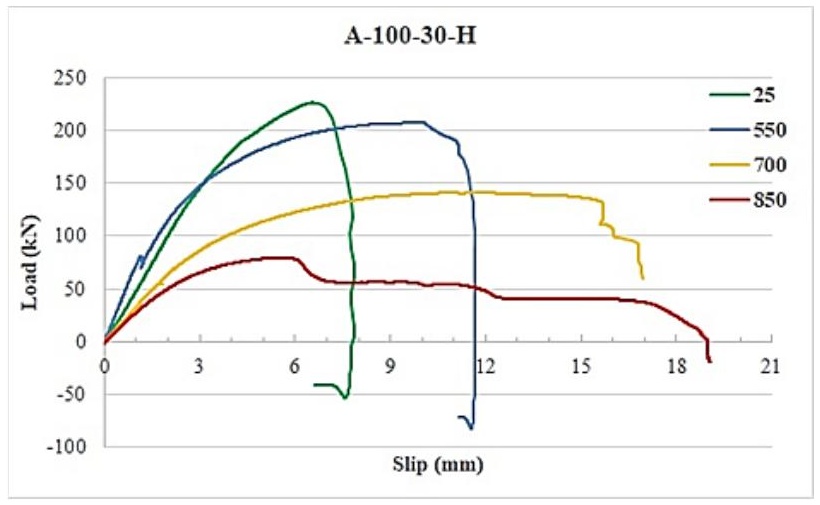

(h) A-100-30-H 


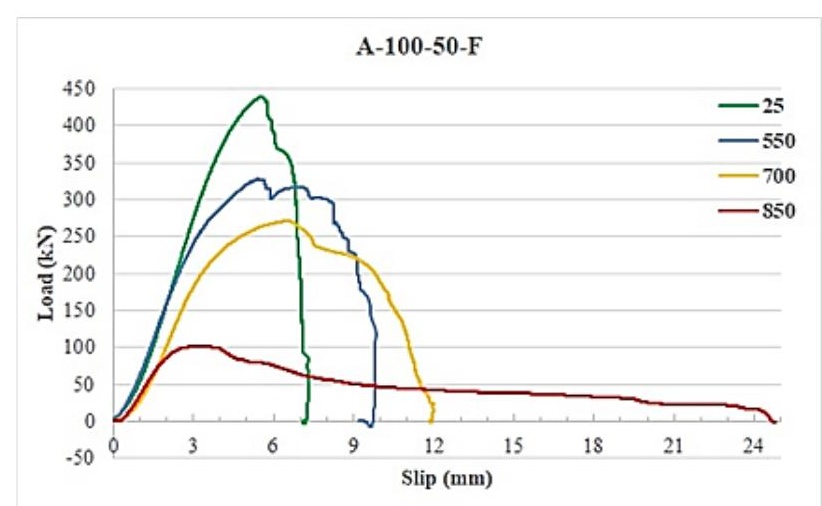

(i) A-100-50-F

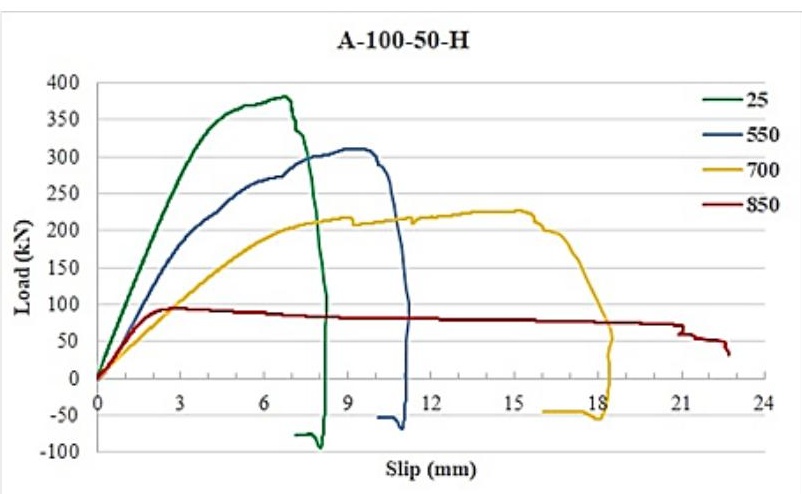

(j) A-100-50-H

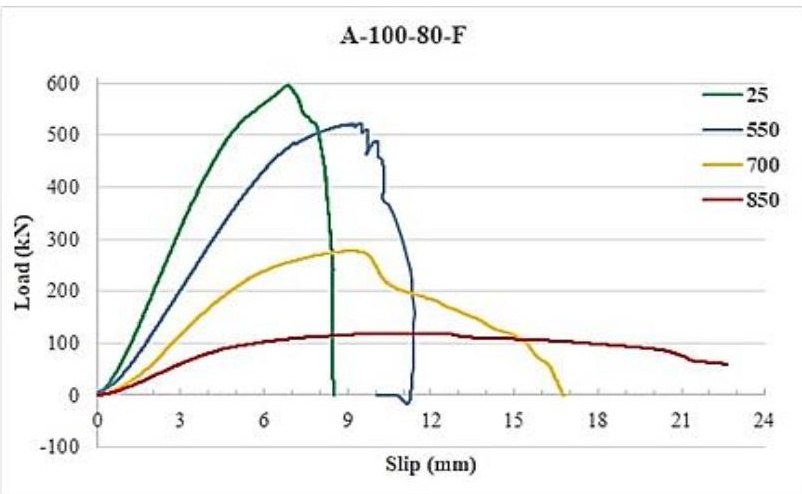

(k) A-100-80-F

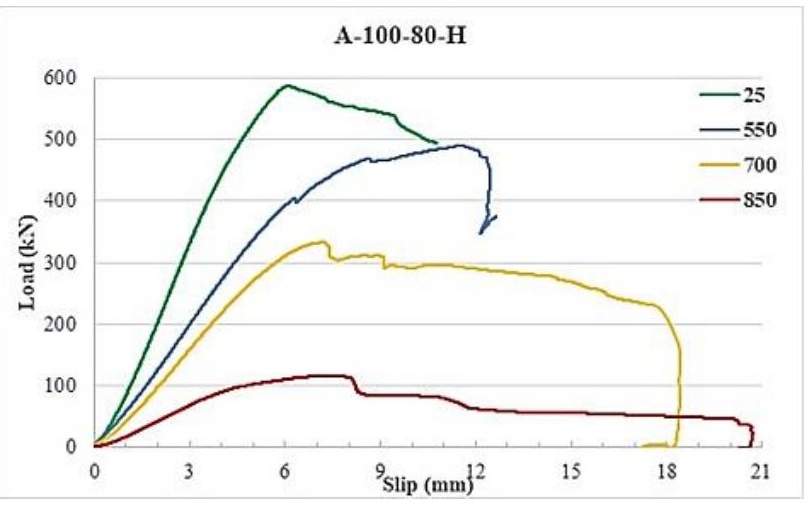

(1) A-100-80-H

Fig. 13 Load-slip curve for monotonic load at different temperatures
Table 5

Summary of failure loads and slips for all tested angle shear connector specimens in Group 1

\begin{tabular}{|c|c|c|c|c|c|c|}
\hline Specimen ID & 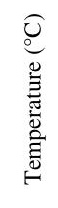 & 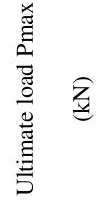 & 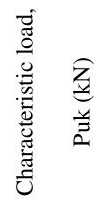 & 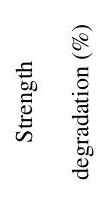 & 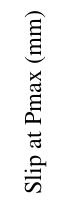 & 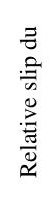 \\
\hline A-75-30-F & 25 & 209.75 & 188.77 & - & 4.91 & 2.93 \\
\hline A-75-30-F & 550 & 195.44 & 175.90 & 6.82 & 9.10 & 5.48 \\
\hline A-75-30-F & 700 & 129.55 & 116.60 & 38.23 & 13.28 & 5.74 \\
\hline A-75-30-F & 850 & 70.12 & 63.11 & 66.57 & 16.57 & 3.73 \\
\hline A-75-30-H & 25 & 195.90 & 176.31 & - & 5.88 & 4.65 \\
\hline A-75-30-H & 550 & 170.93 & 153.84 & 12.75 & 7.62 & 3.46 \\
\hline A-75-30-H & 700 & 116.22 & 104.60 & 40.67 & 12.51 & 5.05 \\
\hline A-75-30-H & 850 & 65.63 & 59.06 & 66.50 & 13.11 & 3.22 \\
\hline A-75-50-F & 25 & 350.22 & 315.20 & - & 4.72 & 2.99 \\
\hline A-75-50-F & 550 & 275.54 & 247.99 & 21.32 & 5.61 & 3.20 \\
\hline A-75-50-F & 700 & 176.62 & 158.95 & 49.57 & 9.51 & 4.23 \\
\hline A-75-50-F & 850 & 95.42 & 85.87 & 72.76 & 13.41 & 5.72 \\
\hline A-75-50-H & 25 & 338.37 & 304.53 & - & 6.25 & 3.78 \\
\hline A-75-50-H & 550 & 263.67 & 237.30 & 22.08 & 9.26 & 4.79 \\
\hline A-75-50-H & 700 & 166.45 & 149.80 & 50.81 & 12.72 & 5.92 \\
\hline A-75-50-H & 850 & 81.81 & 73.63 & 75.82 & 21.51 & 3.86 \\
\hline A-75-80-F & 25 & 465.13 & 418.61 & - & 6.67 & 4.00 \\
\hline A-75-80-F & 550 & 431.48 & 388.33 & 7.23 & 9.75 & 5.99 \\
\hline A-75-80-F & 700 & 255.80 & 230.22 & 45.00 & 14.54 & 7.04 \\
\hline A-75-80-F & 850 & 187.41 & 168.67 & 59.71 & 18.65 & 6.30 \\
\hline A-75-80-H & 25 & 410.38 & 369.34 & - & 7.32 & 4.09 \\
\hline A-75-80-H & 550 & 375.36 & 337.83 & 8.53 & 10.38 & 5.72 \\
\hline A-75-80-H & 700 & 213.29 & 191.96 & 48.03 & 17.45 & 7.68 \\
\hline A-75-80-H & 850 & 158.55 & 142.69 & 61.37 & 18.20 & 5.42 \\
\hline
\end{tabular}

Table 6

Summary of failure loads and slips for all tested channel shear connector specimens in Group 2

\begin{tabular}{|c|c|c|c|c|c|c|}
\hline Specimen ID & 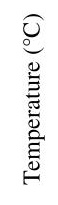 & 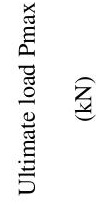 & 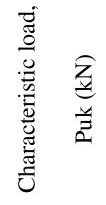 & 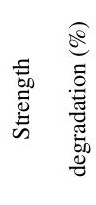 & 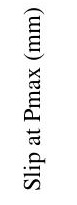 & 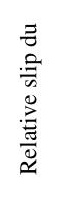 \\
\hline A-100-30-F & 25 & 279.58 & 251.62 & - & 6.44 & 3.67 \\
\hline A-100-30-F & 550 & 258.89 & 233.00 & 7.40 & 8.11 & 3.07 \\
\hline A-100-30-F & 700 & 163.21 & 146.89 & 41.62 & 13.33 & 6.80 \\
\hline A-100-30-F & 850 & 87.63 & 78.87 & 68.66 & 17.47 & 5.76 \\
\hline A-100-30-H & 25 & 226.54 & 203.88 & - & 7.85 & 5.01 \\
\hline A-100-30-H & 550 & 208.38 & 187.54 & 8.01 & 11.66 & 5.43 \\
\hline A-100-30-H & 700 & 141.51 & 127.36 & 37.53 & 16.92 & 6.65 \\
\hline A-100-30-H & 850 & 79.77 & 71.79 & 64.79 & 19.05 & 3.68 \\
\hline A-100-50-F & 25 & 439.48 & 395.53 & - & 7.33 & 4.42 \\
\hline A-100-50-F & 550 & 328.24 & 295.41 & 25.31 & 9.84 & 4.21 \\
\hline A-100-50-F & 700 & 270.84 & 243.75 & 38.37 & 12.00 & 4.50 \\
\hline A-100-50-F & 850 & 101.59 & 91.43 & 76.88 & 24.79 & 2.16 \\
\hline A-100-50-H & 25 & 380.76 & 342.68 & - & 8.25 & 4.16 \\
\hline A-100-50-H & 550 & 310.87 & 279.79 & 18.35 & 11.19 & 6.80 \\
\hline
\end{tabular}




\begin{tabular}{lcccccc} 
A-100-50-H & 700 & 226.28 & 203.65 & 40.57 & 18.54 & 7.00 \\
A-100-50-H & 850 & 95.36 & 85.82 & 74.96 & 22.71 & 1.86 \\
A-100-80-F & 25 & 596.39 & 536.75 & - & 8.48 & 5.41 \\
A-100-80-F & 550 & 521.35 & 469.22 & 12.58 & 11.40 & 9.73 \\
A-100-80-F & 700 & 277.10 & 249.39 & 53.54 & 16.82 & 6.51 \\
A-100-80-F & 850 & 119.16 & 107.24 & 80.02 & 22.62 & 6.72 \\
A-100-80-H & 25 & 587.25 & 528.53 & - & 10.77 & 5.02 \\
A-100-80-H & 550 & 490.19 & 441.17 & 16.53 & 12.64 & 7.45 \\
A-100-80-H & 700 & 332.77 & 299.49 & 43.34 & 18.44 & 5.69 \\
A-100-80-H & 850 & 115.75 & 104.17 & 80.29 & 20.72 & 5.20 \\
\hline
\end{tabular}

The load-slip curve for a single angle with stiffener was analysed to identify the stiffened angle shear connector's mechanical characteristics. Slip occurred under monotonic loading between the concrete block and the I-beam for all specimens at all temperatures. Consequently, sufficient ductility could be observed at all temperatures for the stiffened angle shear connectors, thereby satisfying the required ductility factor for shear connectors set by Eurocode 4) [43], which recommends that a connector can be regarded ductile under $6 \mathrm{~mm}$ slip capacity. This requirement was met for the samples at ambient temperatures. Samples at elevated temperatures satisfied this demand more easily than those at ambient temperatures because the elevated temperatures resulted in a large slip on the sample due to the mechanical properties exhibited by steel under high temperatures. Therefore, the samples at elevated temperatures were more ductile than those at ambient temperatures. An increase in temperature resulted in enhanced ductility and reduced strength because the strength of steel reduced at elevated temperature, making it substantially malleable and causing considerable ductile behaviour. In short, the stiffened angle shear connector with $75 \mathrm{~mm}$ height at ambient temperatures possessed a relative slip within the range of $4.72-7.32 \mathrm{~mm}$. At $550{ }^{\circ} \mathrm{C}, 700{ }^{\circ} \mathrm{C}$ and $850{ }^{\circ} \mathrm{C}$, the slips were $5.61-$ $10.38,9.51-7.45$ and $13.11-21.51 \mathrm{~mm}$, respectively. For the abovementioned shear connector with $100 \mathrm{~mm}$ height, at peak load, all specimens at ambient temperatures obtained a relative slip within the range of $6.49-10.77 \mathrm{~mm}$. Comparatively, the ranges of slip at temperatures of $550{ }^{\circ} \mathrm{C}, 700{ }^{\circ} \mathrm{C}$ and $850{ }^{\circ} \mathrm{C}$ were $8.11-12.64,12.00-18.54$ and $17.47-24.79 \mathrm{~mm}$, respectively. The majority of the samples showed a yield plateau from the load-slip curve, and the load capacity decreased rapidly and resulted in an abrupt completion of the load-slip curve because of the connectors' fracture. The yield plateau in the load-slip curve was observed at elevated temperature. This yield plateau was due to the effect of heating on steel, which showed that the shear connector reached the ultimate condition and the stiffener sustained the connector and illustrated the strength reduction in steel and great softening of steel at elevated temperatures. Consequently, with the increase in temperature, a decrease in connector strength was observed, which was between $6.82 \%$ and $75.82 \%$ in the stiffened angle shear connectors with $75 \mathrm{~mm}$ height and between $7.40 \%$ and $80.29 \%$ in those with $100 \mathrm{~mm}$ height at all temperatures. On the basis of the experimental data at high temperatures, the mentioned temperatures negatively affected the loadcarrying capacity of the connectors. In fact, elevated temperature in terms of time has an extraordinary destructive effect on the material properties, stability and failure of structure.

\subsection{Comparison of shear strength at ambient temperature}

The strength of shear connectors is one of their vital characteristics. This study has determined that, at ambient temperature, when the width was increased from $30 \mathrm{~mm}$ to 50 and $80 \mathrm{~mm}$, the strength was enhanced by an average of $66 \%$ and $126 \%$, respectively; when the shear connector's height was increased from $75 \mathrm{~mm}$ to $100 \mathrm{~mm}$, its strength was enhanced by approximately $26 \%$. Therefore, the width of a shear connector is more effective than its height similar to a nonstiffened shear connector. This research indicated that the stiffened angle shear connector at ambient temperature performed considerably better than the nonstiffened angle shear connector in the previous studies. Fig. 14a-h show a comparison of previous studies [8-11] of nonstiffened shear connectors embedded in normal and high-strength concrete with stiffened shear connectors; the minimum of strength enhancement was $93 \%$ and the maximum was $259 \%$, which confirmed the role of stiffeners with respect to the strength of shear connectors. Hence, the novelty of this work is that the designed stiffener enhances the strength significantly; the shape of the stiffener works as a truss to support the shear connector at ambient and elevated temperatures. This strength enhancement contributes significantly in terms of saving steel, cost and time, and stiffened shear connectors are considerably safer compared with nonstiffened shear connectors.

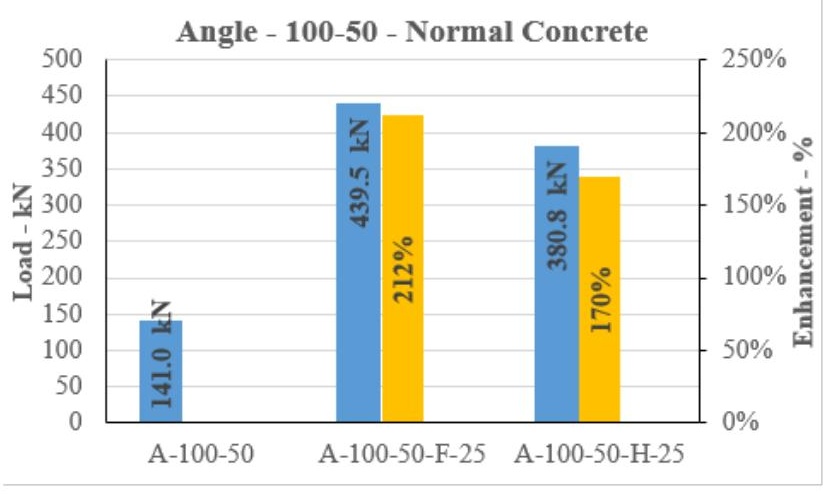

(a) 100-50 - Normal concrete

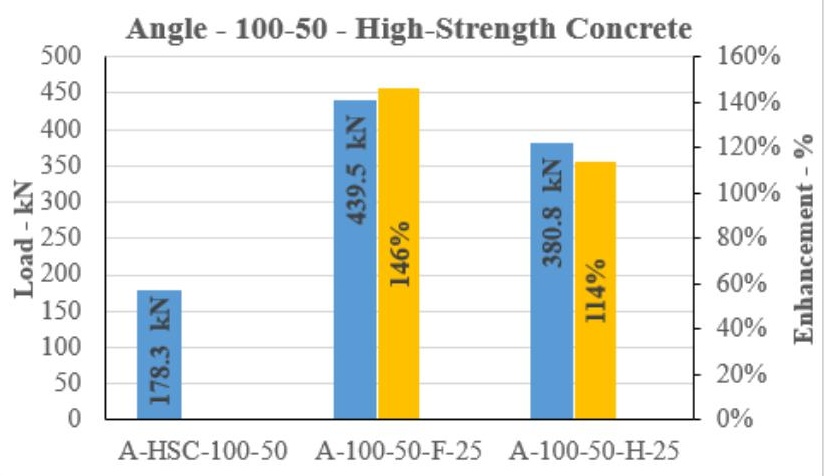

(b) 100-50 - High-Strength Concrete

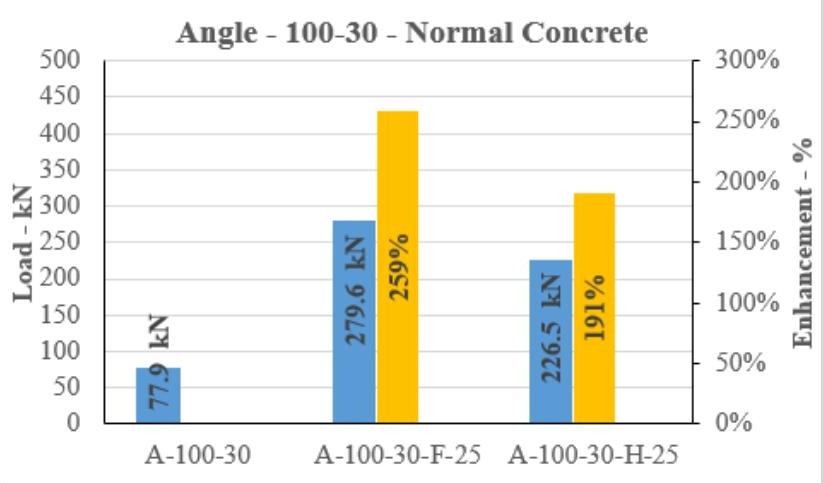

(c) 100-30 - Normal concrete

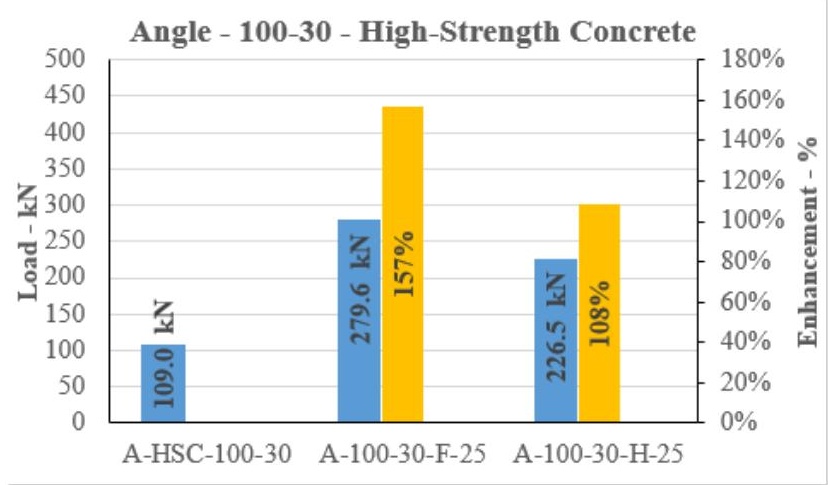

(d) 100-30 - High-Strength Concrete 


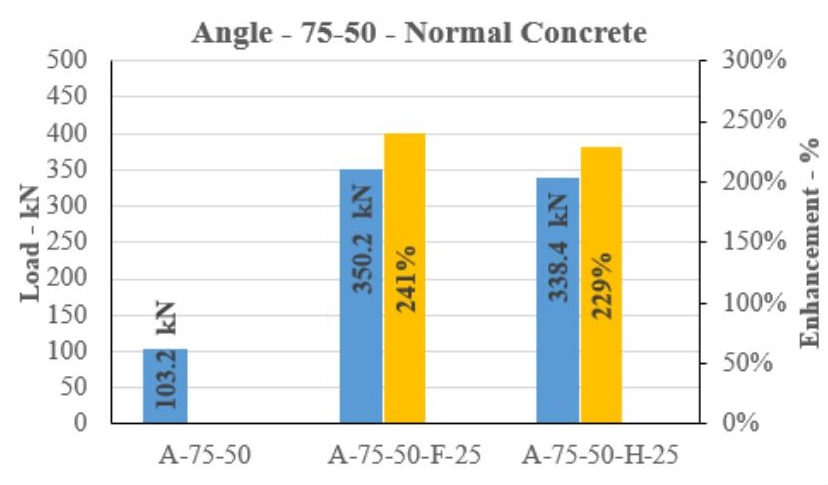

(e) 75-50 - Normal concrete

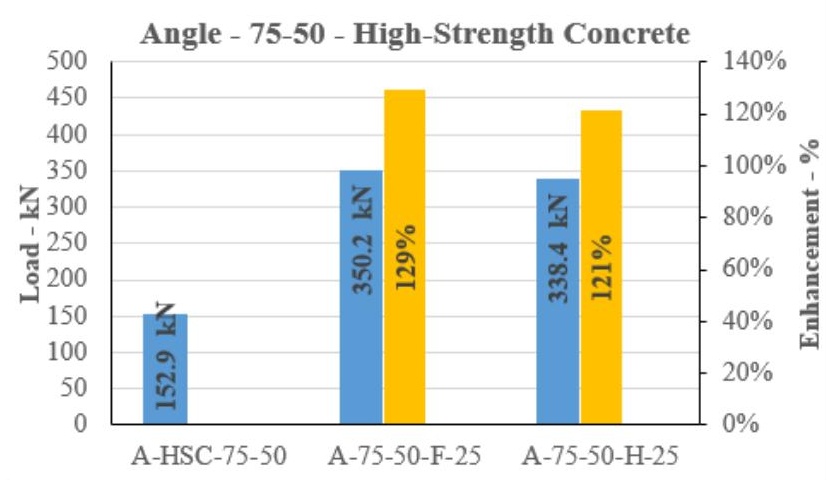

(f) 75-50 - High-Strength Concrete

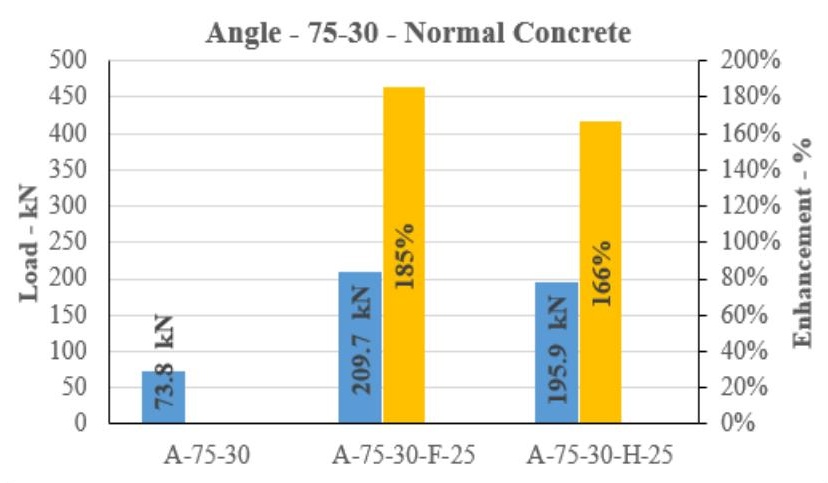

(g) 75-30 - Normal concrete

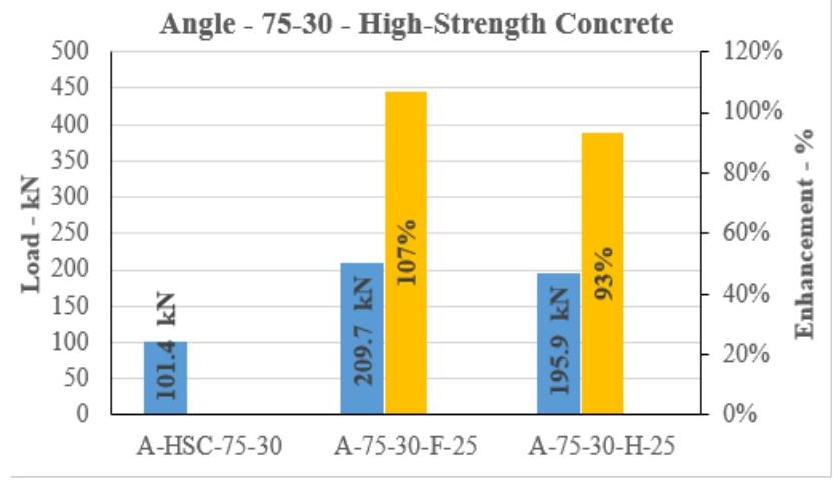

(h) 75-30 - High-Strength Concrete

Fig. 14 Strength enhancement of stiffened shear connectors compared with angle shear connectors embedded in normal- and high-strength concrete

\subsection{Shear strength reduction}

In accordance with Fig. 13, the load-slip curves are related to the monotonic load for all push-out samples at ambient and elevated temperatures. The final load and flexibility data in Tables 5 and 6 enable the shear durability decline for various shear connectors to be compared. High temperature adversely affected the resistance and stiffness of the angle shear connectors. Fig. 15 illustrates the influence of high temperature on the load-carrying capacity of the shear connectors in relation with the ones obtained at ambient temperatures. The ultimate load-carrying capacity of the angle shear connector decreased by approximately $6.82 \%-80.02 \%$ for the full-length stiffener and approximately $8.01 \%-80.20 \%$ for the half-length stiffener at different temperatures. Specifically, the strength reduction for the connector with $100 \mathrm{~mm}$ height was $68.60 \%-64.79 \%$ for $30 \mathrm{~mm}$ width, $76.68 \%-74.96 \%$ for $50 \mathrm{~mm}$ width and $80.02 \%-80.29 \%$ for $80 \mathrm{~mm}$ width. Likewise, the strength reduction for the 75 $\mathrm{mm}$ stiffened angle shear connector was $66.57 \%-66.50 \%$ for $30 \mathrm{~mm}$ width, $72.86 \%-75.82 \%$ for $50 \mathrm{~mm}$ width and $59.71 \%-61.37 \%$ for $80 \mathrm{~mm}$ width. Strength reduction at any temperature for the different shear connectors was nearly the same, which showed that the geometry and shape of the stiffened shear connectors had no effect on their strength. In addition, strength reduction depended strongly on temperature in terms of time due to specific heat. The specific heat of steel was enhanced by increasing the temperature. Accordingly, heating accelerated by increasing the temperature, which caused an acceleration in the strength reduction of steel. The trend of accelerating strength reduction could be determined by considering heating in terms of time, which was caused by the heat transfer coefficient. The reduction factors of the characteristic resistance (Pelevated/Pambient) for the stiffened angle shear connector decreased and converged with rising temperature (Figs. 15a and 15b). In consideration of the specimens, the standard deviations of the results were always less than 0.1 (Figs. 15a and 15b), illustrating the relation of full- and half-length stiffened angle shear connectors at elevated temperature; then the ambient temperatures approached each other for testing at different temperatures.

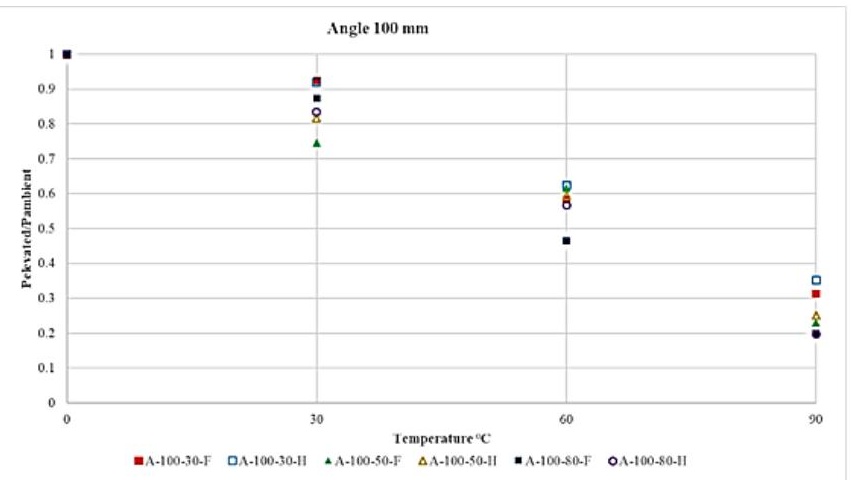

Fig. 15a Relative values of ultimate load-carrying capacity of $100 \mathrm{~mm}$ specimens

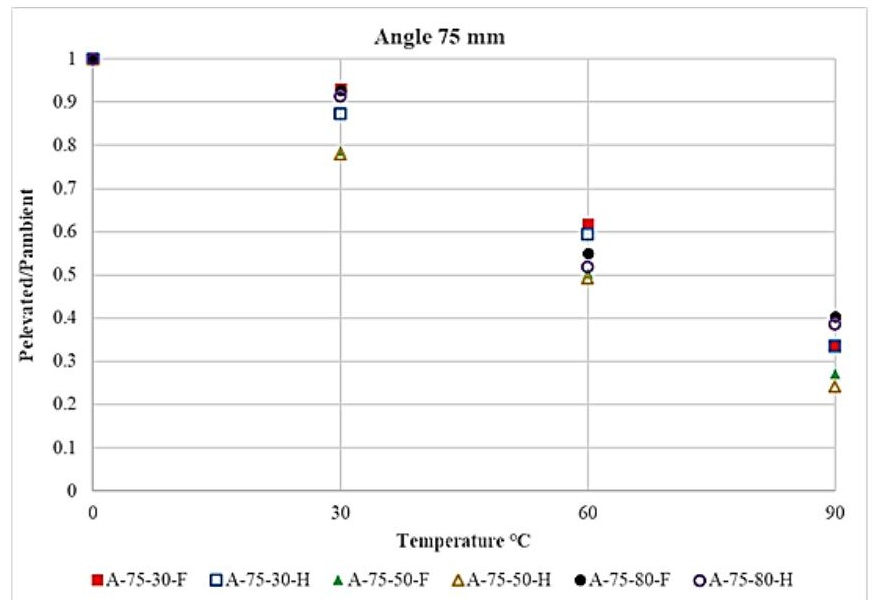

Fig. 15b Relative values of ultimate load-carrying capacity of $75 \mathrm{~mm}$ specimens

\subsection{Ductility factor}

A material's capacity to endure plastic deformation without breaking is called ductility. The load-slip curves allowed the evaluation of the shear connectors' flexibility factor $(\mu)$, thereby enabling an efficient comparison of the samples' flexibility. The ductility factor is a dimensionless quantity expressed as a ratio of ultimate deformation to yield deformation. With reference to the mentioned curve, flexibility may be assessed by applying a flexibility factor that is explained through an equivalent elastoplastic load deflection curve, as observed in Fig. 16. 


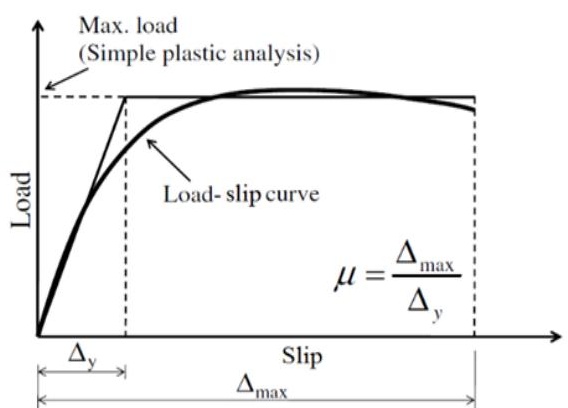

Fig. 16 Definition of ductility factor

The mentioned curve was idealised through two straight lines showing the original hardness and ultimate durability. These lines cross each other as the same yield dislocation $\Delta_{\mathrm{y}}$. The ultimate deflection, which is shown as $\Delta_{\max }$, is the deflection subjected to failure in the shear connector. The equivalent flexibility factor was measured as $\Delta_{\max } / \Delta_{\mathrm{y}}$. A high flexibility factor indicates a flexible composite system. In general, the direct relationship could be defined as follows: when the flexibility factor increases for a certain system, a decrease in the inelastic redistribution of the applied load is observed [27]. The results presented in Table 7 showed that the ductility of the shear connectors with 75 and $100 \mathrm{~mm}$ height improved by averages of $155 \%$ and $179 \%$, respectively, by elevating the temperature; however, the ductility of the stiffened angle shear connector with $100 \mathrm{~mm}$ height and $50 \mathrm{~mm}$ width (full- and half-length stiffeners) had the highest ductility amongst all the shear connectors and increased by $530 \%$. The geometry of the stiffened shear connector and temperature played a vital role with respect to the ductility of the shear connectors. The ductility of the shear connectors increased by decreasing the length of the connectors at ambient and elevated temperatures in most specimens. The shear connector with $80 \mathrm{~mm}$ width had lower ductility compared with the shear connector with 30 $\mathrm{mm}$ width. Despite the width of the shear connector, the length of the stiffener and the height of the shear connector played a vital role in the ductility factor. The ductility was enhanced by increasing the height of the shear connector, and the stiffened shear connectors with a half-length stiffener were more ductile than those with a full-length stiffener. With an increase in the width of the shear connectors, the stiffness increased, thereby reducing ductility. Ductility was considerably affected by temperature. Although increasing temperature reduced the strength of steel and concrete due to their properties, it enhanced ductility. The load-slip curves in Fig. 10 indicate that, at ambient temperatures, the shear connector with $80 \mathrm{~mm}$ width bore the highest load compared with those with 30 and $50 \mathrm{~mm}$ width; nevertheless, the ductility at this temperature was nearly in a stable range. When the temperature was increased to $550{ }^{\circ} \mathrm{C}$, the shear connector with $80 \mathrm{~mm}$ width had the highest carrying load, and the shear connector with $30 \mathrm{~mm}$ width became increasingly ductile. At $700{ }^{\circ} \mathrm{C}$, the shear connectors exhibited the same behaviour as that at $550{ }^{\circ} \mathrm{C}$. At $850{ }^{\circ} \mathrm{C}$, the shear connector with $80 \mathrm{~mm}$ width still obtained the highest load, whereas the shear connector with $50 \mathrm{~mm}$ width demonstrated more ductility. In summary, the shear connector with $80 \mathrm{~mm}$ width could carry more load. The shear connector with $100 \mathrm{~mm}$ height was more ductile than that with $75 \mathrm{~mm}$ height due to the use of a stiffener. In addition, using a half-length stiffener facilitated the enhancement of ductility more than adopting a full-length stiffener. The results generally showed that the ductility of a stiffened angle shear connector increased by raising the temperature, as illustrated in Fig. 17a-b.

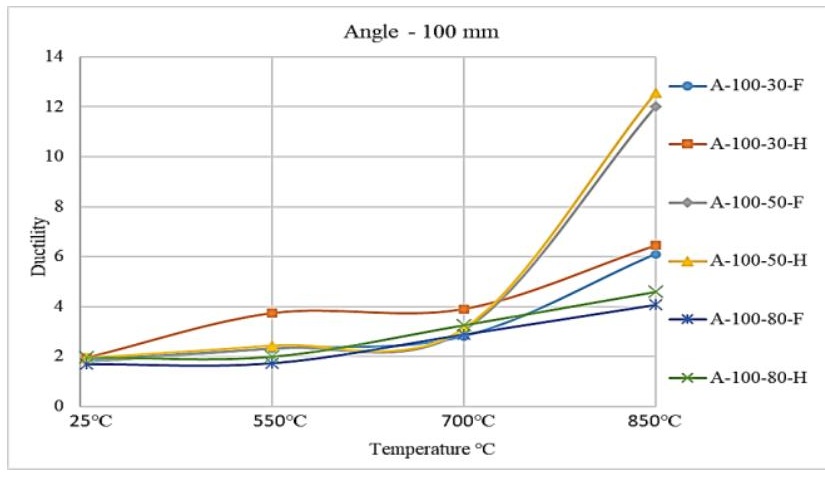

(a) Stiffened angle $-100 \mathrm{~mm}$ heigth

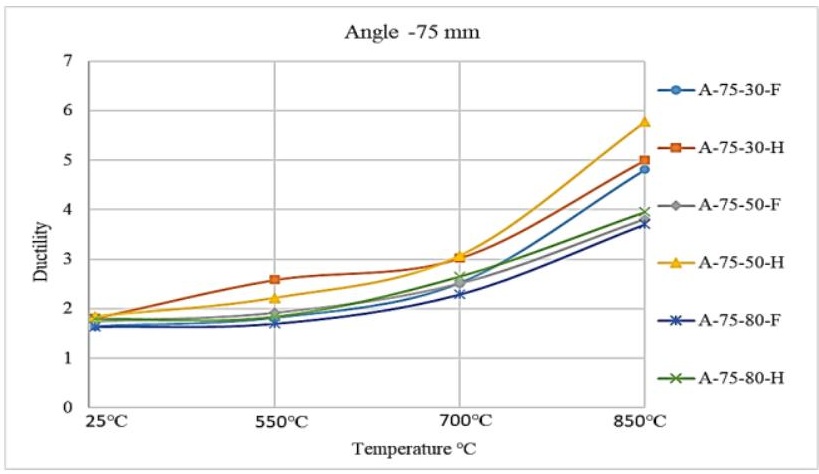

(b) Stiffened angle $-75 \mathrm{~mm}$ heigth

Fig. 17 Ductility-temperature graphs of stiffened angle shear connectors

Table 7

Ductility factor for each specimen of angle shear connector

\begin{tabular}{|c|c|c|c|c|c|}
\hline & Specimen ID & Temperature & max slip & $\Delta \mathrm{y}$ & $\mu$ \\
\hline 1 & A-100-30-F & 25 & 6.4 & 3.16 & 2.04 \\
\hline 2 & A-100-30-F & 550 & 8.1 & 2.9 & 2.80 \\
\hline 3 & A-100-30-F & 700 & 13.3 & 4.59 & 2.90 \\
\hline 4 & A-100-30-F & 850 & 17.5 & 2.79 & 6.26 \\
\hline 5 & A-100-30-H & 25 & 7.9 & 4 & 1.96 \\
\hline 6 & A-100-30-H & 550 & 11.7 & 3 & 3.89 \\
\hline 7 & A-100-30-H & 700 & 16.9 & 4 & 4.23 \\
\hline 8 & A-100-30-H & 850 & 19.1 & 2.7 & 7.06 \\
\hline 9 & A-100-50-F & 25 & 7.3 & 4.1 & 1.79 \\
\hline 10 & A-100-50-F & 550 & 9.8 & 3.5 & 2.81 \\
\hline 11 & A-100-50-F & 700 & 12.0 & 3.6 & 3.33 \\
\hline 12 & A-100-50-F & 850 & 24.8 & 2 & 12.40 \\
\hline 13 & A-100-50-H & 25 & 8.3 & 3.7 & 2.23 \\
\hline 14 & A-100-50-H & 550 & 11.2 & 4.3 & 2.60 \\
\hline 15 & A-100-50-H & 700 & 18.5 & 5.8 & 3.20 \\
\hline 16 & A-100-50-H & 850 & 22.7 & 1.8 & 12.62 \\
\hline 17 & A-100-80-F & 25 & 8.5 & 4.7 & 1.80 \\
\hline 18 & A-100-80-F & 550 & 11.4 & 6.2 & 1.84 \\
\hline 19 & A-100-80-F & 700 & 16.8 & 5.6 & 3.00 \\
\hline 20 & A-100-80-F & 850 & 22.6 & 5.2 & 4.35 \\
\hline 21 & A-100-80-H & 25 & 10.8 & 4.8 & 2.24 \\
\hline 22 & A-100-80-H & 550 & 12.6 & 6.2 & 2.04 \\
\hline 23 & A-100-80-H & 700 & 18.4 & 5.4 & 3.42 \\
\hline 24 & A-100-80-H & 850 & 20.7 & 4.4 & 4.71 \\
\hline 25 & A-75-30-F & 25 & 4.9 & 2.8 & 1.75 \\
\hline 26 & A-75-30-F & 550 & 9.1 & 4.63 & 1.96 \\
\hline 27 & A-75-30-F & 700 & 13.3 & 5 & 2.66 \\
\hline 28 & A-75-30-F & 850 & 16.6 & 3.2 & 5.18 \\
\hline 29 & A-75-30-H & 25 & 5.9 & 3.2 & 1.84 \\
\hline 30 & A-75-30-H & 550 & 7.6 & 2.9 & 2.63 \\
\hline 31 & A-75-30-H & 700 & 12.5 & 4 & 3.13 \\
\hline 32 & A-75-30-H & 850 & 13.1 & 2.6 & 5.04 \\
\hline 33 & A-75-50-F & 25 & 4.7 & 2.6 & 1.82 \\
\hline 34 & A-75-50-F & 550 & 5.6 & 2.65 & 2.12 \\
\hline 35 & A-75-50-F & 700 & 9.5 & 3.7 & 2.57 \\
\hline 36 & A-75-50-F & 850 & 13.4 & 3.5 & 3.83 \\
\hline 37 & A-75-50-H & 25 & 6.2 & 3.3 & 1.89 \\
\hline
\end{tabular}




\begin{tabular}{llllll}
38 & A-75-50-H & 550 & 9.3 & 4.1 & 2.26 \\
39 & A-75-50-H & 700 & 12.7 & 4.1 & 3.10 \\
40 & A-75-50-H & 850 & 21.5 & 3.6 & 5.98 \\
41 & A-75-80-F & 25 & 6.7 & 3.7 & 1.80 \\
42 & A-75-80-F & 550 & 9.7 & 5.6 & 1.74 \\
43 & A-75-80-F & 700 & 14.5 & 6.2 & 2.35 \\
44 & A-75-80-F & 850 & 18.7 & 4.8 & 3.89 \\
45 & A-75-80-H & 25 & 7.3 & 4 & 1.83 \\
46 & A-75-80-H & 550 & 10.4 & 5.2 & 2.00 \\
47 & A-75-80-H & 700 & 17.5 & 6.4 & 2.73 \\
48 & A-75-80-H & 850 & 18.2 & 4.6 & 3.96 \\
\hline
\end{tabular}

\section{Conclusions}

In this study, stiffened angle shear connectors were proposed and tested in a push-out test. The samples' temperatures were initially increased from room temperature to $550{ }^{\circ} \mathrm{C}, 700{ }^{\circ} \mathrm{C}$ and $850{ }^{\circ} \mathrm{C}$, and they were successively loaded to failure to evaluate their resistance and relative flexibility at high temperatures. In most push-out samples at room or target temperature, a connector fracture was observed. In consideration of the load-slip curves for all samples, at the ultimate load, the relative slip of the stiffened angle shear connectors was within the range of $4.72-10.77 \mathrm{~mm}$ at room temperature. The mentioned ranges for all samples at $550^{\circ} \mathrm{C}, 700{ }^{\circ} \mathrm{C}$ and $850^{\circ} \mathrm{C}$ were $5.61-12.64,9.51-18.54$ and $13.11-$ $24.79 \mathrm{~mm}$, respectively. In conclusion, shear durability decreases of $155 \%$ and $179 \%$ for various stiffened angle shear connectors with 75 and $100 \mathrm{~mm}$ height, respectively, were observed. On the basis of the obtained data, a relationship was found between flexibility and temperature. As the test temperatures increased, the connectors' flexibility increased due to the properties of steel at elevated temperatures. In general, at elevated temperatures, more flexibility was observed for long connectors compared with that for short connectors. The results of this research showed that temperature had a destructive effect on the properties of concrete and steel and affected the load capacity of the shear connectors. The load capacity of the mentioned connectors at elevated temperatures was considerably lower than at ambient temperatures. Moreover, the shear strength was reduced by decreasing the load capacity. Strength reductions of $6.82 \%-80.02 \%$ and $8.01 \% 80.20 \%$ were observed for full- and half-length stiffeners, respectively. These results illustrated that the ductility of connectors increased by increasing the temperature. Given that the strength and mechanical properties of steel and concrete decrease significantly at elevated temperature, a specific design is required to address the mentioned drawback. Hence, the novelty of this work in designing a stiffener for angle shear connectors clearly has a vital role in enhancing the resistance of shear connectors at elevated temperature.

\section{Acknowledgements}

The authors would like to acknowledge the support of University of Malaya UMRG (University of Malaya Research Grant), Project Number: RP004C13AET and IPPP Grant, Project Number: PG084-2016A.

\section{References}

[1] Viest, I.M., et al., Composite construction design for buildings. 1997: McGraw-Hill New York.

[2] Viest, I. Investigation of stud shear connectors for composite concrete and steel T-beams. in Journal Proceedings. 1956.

[3] Hegger, J., S. Rauscher, and C. Goralski, Push-out tests on headed studs in high-strength concrete. Special Publication, 2005. 228: p. 769-786.

[4] Manual, S.C., American institute of steel construction. Inc., Thirteenth Edition, First Print, 2005.

[5] Slutter, R.G. and G.C. Driscoll Jr, Flexural strength of steel and concrete composite beams. 1963.

[6] Hawkins, N.M. and D. Mitchell, Seismic response of composite shear connections. Journal of Structural Engineering, 1984. 110(9): p. 2120-2136

[7] Tahmasbi, F., et al., Shear capacity of C-shaped and L-shaped angle shear connectors. PloS one, 2016. 11(8): p. e0156989.

[8] Shariati, M., N.R. Sulong, and M.A. Khanouki, Experimental assessment of channel shear connectors under monotonic and fully reversed cyclic loading in high strength concrete. Materials \& Design, 2012. 34: p. 325-331.

[9] Shariati, M., et al., Comparison of behaviour between channel and angle shear connectors under monotonic and fully reversed cyclic loading. Construction and Building Materials, 2013. 38: p. 582-593.

[10] Shariati, M., et al., Behaviour of C-shaped angle shear connectors under monotonic and fully reversed cyclic loading: An experimental study. Materials \& Design, 2012. 41: p. 67-73.

[11] Shariati, M., et al., Fatigue energy dissipation and failure analysis of angle shear connectors embedded in high strength concrete. Engineering Failure Analysis, 2014. 41: p. 124-134.
[12] Maleki, S. and S. Bagheri, Behavior of channel shear connectors, Part I: Experimental study. Journal of Constructional Steel Research, 2008. 64(12): p. 1333-1340.

[13] Maleki, S. and S. Bagheri, Behavior of channel shear connectors, Part II: Analytical study. Journal of Constructional Steel Research, 2008. 64(12): p. 1341-1348.

[14] Maleki, S. and M. Mahoutian, Experimental and analytical study on channel shear connectors in fiber-reinforced concrete. Journal of Constructional Steel Research, 2009. 65(8-9): p. 1787-1793.

[15] O'Connor, M. and D. Martin, Behaviour of a multi-storey steel framed building subjected to fire attack. Journal of Constructional Steel Research, 1998. 1(46): p. 295.

[16] Sanad, A., et al., Composite beams in large buildings under fire-numerical modelling and structural behaviour. Fire Safety Journal, 2000. 35(3): p. 165-188.

[17] Mäkeläinen, P. and Z. Ma, Fire resistance of composite slim floor beams. Journal of constructional steel research, 2000. 54(3): p. 345-363.

[18] Mirza, O. and B. Uy, Behaviour of headed stud shear connectors for composite steel-concrete beams at elevated temperatures. Journal of Constructional Steel Research, 2009. 65(3): p. 662-674.

[19] Rodrigues, J.P.C. and L. Laím, Experimental investigation on the structural response of T, Tblock and T-Perfobond shear connectors at elevated temperatures. Engineering structures, 2014. 75: p. 299-314

[20] Rodrigues, J.P.C. and L. Laím, Behaviour of perfobond shear connectors at high temperatures. Engineering Structures, 2011. 33(10): p. 2744-2753.

[21] Fuh-Gwo, Y. and R.E. Miller, A new finite element for laminated composite beams. Computers \& structures, 1989. 31(5): p. 737-745.

[22] Shariati, M., et al. Experimental and analytical study on channel shear connectors in light weight aggregate concrete. in Proceedings of the 4th international conference on steel \& composite structures. 2010.

[23] Shariati, M., et al. Behavior of channel shear connectors in normal and light weight aggregate concrete (experimental and analytical study). in Advanced Materials Research. 2011. Trans Tech Publ.

[24] Shariati, A., et al., Investigation of channel shear connectors for composite concrete and steel T-beam. International journal of physical sciences, 2012. 7(11): p. 1828-1831.

[25] Shariati, A., N. RamliSulong, and M. Shariati, Various types of shear connectors in composite structures: A review. International journal of physical sciences, 2012. 7(22): p. 2876-2890.

[26] Shariati, M., et al. Fatigue energy dissipation and failure analysis of channel shear connector embedded in the lightweight aggregate concrete in composite bridge girders. in Fifth international conference on engineering failure analysis. 2012.

[27] Baran, E. and C. Topkaya, An experimental study on channel type shear connectors. Journal of Constructional Steel Research, 2012. 74: p. 108-117.

[28] ASTM, A., 370, "Standard Test Methods and Definitions for Mechanical Testing of Steel Products". Anual Book of Standard, 2005.

[29] Sajedi, F. and H.A. Razak, The effect of chemical activators on early strength of ordinary Portland cement-slag mortars. Construction and Building Materials, 2010. 24(10): p. 19441951.

[30] Neville, A., Properties of concrete. Malaysia: Prentice Hall. 2008.

[31] Razak, H.A. and F. Sajedi, The effect of heat treatment on the compressive strength of cement-slag mortars. Materials \& Design, 2011. 32(8-9): p. 4618-4628.

[32] ASTM, C., Standard test method for compressive strength of cylindrical concrete specimens. 2012.

[33] Neville, A. and J. Brooks, Concrete technology. Malaysia: Prentice Hall. 2008.

[34] Sajedi, F., Mechanical activation of cement-slag mortars. Construction and Building Materials, 2011. doi:10.1016/j.conbuildmat.2011.05.001.

[35] ASTM, C., 39 (2004)"Standard test method for compressive strength of cylindrical concrete specimens.". Annual Book of ASTM Standards, 2005.

[36] Haremza, C., A. Santiago, and L.S. da Silva, Experimental behaviour of heated composite steel-concrete joints subject to variable bending moments and axial forces. Engineering Structures, 2013. 51: p. 150-165.

[37] Maleki, S. and S. Bagheri, Behavior of channel shear connectors, Part II: Analytical study. Journal of Constructional Steel Research, 2008. 64 p. 1341-1348.

[38] Maleki, S. and S. Bagheri, Behavior of channel shear connectors, Part I: Experimental study. Journal of Constructional Steel Research, 2008. 64 p. 1333-1340.

[39] Tests, I., Elements of Building Construction, ISO-834. International Organization for Standardization. Geneva, 1975.

[40] Harmathy, T., Thermal properties of concrete at elevated temperatures. Journal of Materials, 1970.

[41] Bazant, Z.P. and M.F. Kaplan, Concrete at high temperature. Material Properties and Mathematical ModelsLongman Group Limited, Essex, England, 1996.

[42] CSN, E., 1-2: Eurocode 2: Design of Concrete Structures-Part 1-2: General Rules-Structural Fire Design. 2006, CNI, Praha.

[43] Eurocode, E., 4: Design of composite steel and concrete structures-Part 1-2: General rulesStructural fire design. British Standards Institution, BS EN, 1994: p. 1-2. 


\title{
EXPERIMENTAL STUDY ON SEISMIC BEHAVIOR OF INNOVATIVE MULTI-CELLULAR CFT-WALLS WITH TIE-BOLTS
}

\author{
Gen-Shu Tong *, Chen-Hao Lin, Zhong-Zheng Hu and Shuang-Long Yang
}

Department of Civil Engineering, Zhejiang University, Hangzhou 310058, China

*(Corresponding author: E-mail: tonggs@zju.edu.cn)

\section{A B S T RA C T}

The hysteretic behavior of an innovative multi-cellular concrete-filled steel tube walls (CFT-walls) with tie-bolts was studied. Seven full-scale tests were conducted under constant axial loads and cyclic lateral loads. The tie-bolts were arranged to fix connectors, attach the wall studs as well as enhance the confinement between steel sheets and infill concrete. The axial compression ratio was taken be the limit which may encounter in real projects. Before the treatment of the test results, the $P-\Delta$ effect was excluded from the lateral force-drift curves as it is considered independently in the current design codes.

All the specimens presented similar spindle-shaped lateral force versus displacement hysteretic curves and failed in the severe plastic local buckling-tension cycles of the steel sheets and the crushing of concrete. No discernible pinching effect and out-of-plane buckling were observed and the specimens showed favorable hysteresis behavior, deformation capacity, and energy dissipation during the tests. The tie-bolts arranged at middle tubes and the width-to-thickness ratios of the faceplates had no discernible effect on the behavior in the investigated range. The point when the force reached two-thirds of the maximum lateral force was defined as the yield point of the member. Based on test results, two idealized backbone curves were proposed. Moreover, the hysteretic curves of all the specimens were calculated using the fiber element method and showed good agreement with the experimental results.

\section{A R T I C LE H I S T O R Y}

$\begin{array}{ll}\text { Received: } & 17 \text { April } 2020 \\ \text { Revised: } & 22 \text { October } 2020 \\ \text { Accepted: } & 26 \text { October } 2020\end{array}$

\section{K E Y W O R D S}

Composite wall;

Seismic behavior;

Experimental study;

Hysteresis characteristic

Fiber element method

\section{Introduction}

Shear walls are the most common structural components that resist earthquakes or wind loads in high-rise buildings. To meet the lateral stiffness and strength demand of high-rise buildings, various composite shear walls formed of steel and concrete were proposed. The bi-steel steel-concrete-steel sandwich composite construction is one such walls ${ }^{[1]}$ and is used in cores and staircase $^{[2]}$.

A similar type of wall, the double skin composite wall(DSC-walls) with interior studs and tie bolts(Fig.1(a)), was studied in [3,4,5]. DSC-walls are disadvantageous in that column-type local buckling occurs in the faceplates between the rows of the headed studs/tie bolts. It is well known that column-type buckling causes the loss of post-buckling strength and stiffness and decreases the vertical load capacity rapidly. Thus, Zhang et. al ${ }^{[6]}$ based on a review of the experimental results from the open literature and on finite element (FE) analysis, proposed $t \sqrt{E / f_{\mathrm{y}}}$ as the upper limit of the distance between the headed studs or tie bolts, where $E$ is Young's modulus, $f_{\mathrm{y}}$ is the yield strength of steel, and $t$ is the thickness of the faceplates. For Q355 steel, $t \sqrt{E / f_{\mathrm{y}}}$ is $24 t$, which is an extremely short distance for application in residential buildings. Yang et. $\mathrm{al}^{[7]}$ proposed a more stringent limit on this distance.
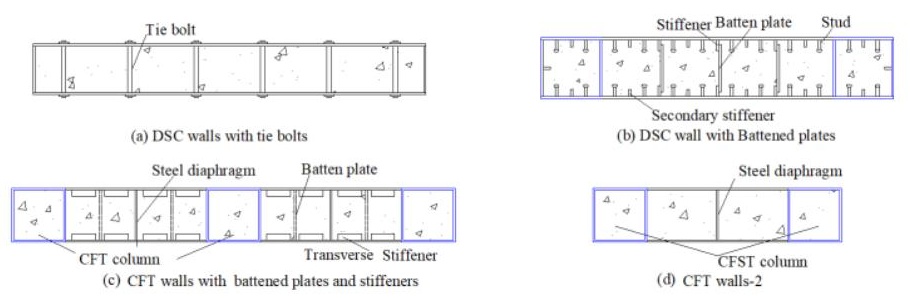

Fig. 1 Different configurations of DSC walls

Nie et. al ${ }^{[8]}$ studied the cyclic behavior of DSC walls using battened plates; the cross-section of their wall is shown in Fig.1(b). Huang et. al. ${ }^{[9]}$ studied the cyclic behavior of concrete-filled DSC walls using battened plates and transverse stiffeners, as shown in Fig.1(c). Guo et. al ${ }^{[10]}$ conducted a static test on short concrete-filled steel tube walls (CFT-walls) to determine their vertical load capacity as well as a horizontal cyclic test on two specimens under given vertical loads. The cross-section is shown in Fig.1(d).

A new type of patented wall composed of a series of concrete-filled rectangular tubes was proposed by Hangxiao Steel Structures Corporation Limited(Patent No. CN103993682b, 2014) (hereafter, abbreviated as HX-CFT-walls). Moreover, it was applied rapidly in China in residential buildings (more than 1 million sqm have been built since 2014). The manufacture of HX-CFT-walls begins with a cold-formed square or rectangular box section; subsequently, a series of cold-formed lipped U-sections are added and welded by automatic arc welding (Fig.2(a)). After pieces of walls are manufactured, they are assembled into L- or T-shaped walls by welding either onsite or in the shop, depending on the strength demand and transportability. The wall thicknesses are $150 \mathrm{~mm}$ (lower stories) and $130 \mathrm{~mm}$ (upper stories), and the steel plate thicknesses are $5 \mathrm{~mm}$ and $4 \mathrm{~mm}$ when the heights of residential buildings are less than $80 \mathrm{~m}$, the seismic ground acceleration is less than $0.2 \mathrm{~g}$, and the basic wind pressure is less than $0.5 \mathrm{kN} / \mathrm{m}^{2}$ (based on the maximum average wind speed of $10 \mathrm{~min}$ in 50 years). Thicker walls $(180-400 \mathrm{~mm}$ ) and thicker plate $(6-16 \mathrm{~mm})$ are required when the buildings are higher and/or the loadings are larger or the earthquakes are more severe.

Different from the bi-steel ${ }^{\mathrm{TM}}$ steel-concrete-steel sandwich panels ${ }^{[3]}$ and DSC-walls with studs and tie bolts ${ }^{[5]}$, HX-CFT-walls have similar behavior to CFT columns. The local faceplate buckling of each cell is prohibited by restricting the width-to-thickness ratio of the faceplate to that allowed for the CFT columns. Thus, the concrete in each cell is continuously and equally confined along the height. Zhang et. $\mathrm{al}^{[11,12]}$ reported cyclic tests on concrete-filled cold-formed tube walls(Figs.2(a1) and (a2)) under given axial forces. These tests verified the similarity of HX-CFT-walls and CFT columns in terms of the seismic resistance behavior.

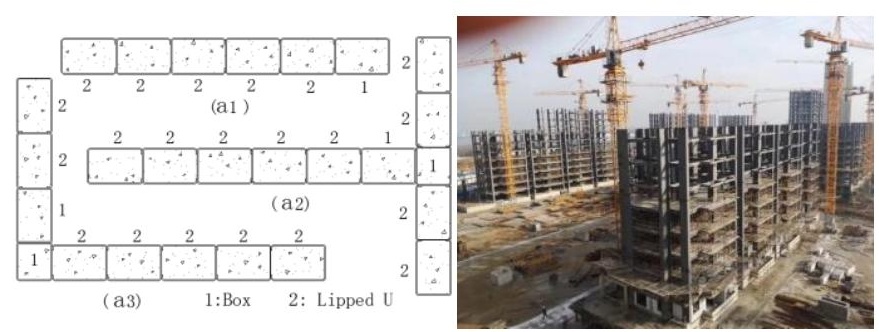

(a)Linear, L-/T-shaped CFT column T-walls (b) High-rise building using CFT-walls, Yantai, China

Fig. 2 Concrete-filled multi-cell steel tube walls and their application 


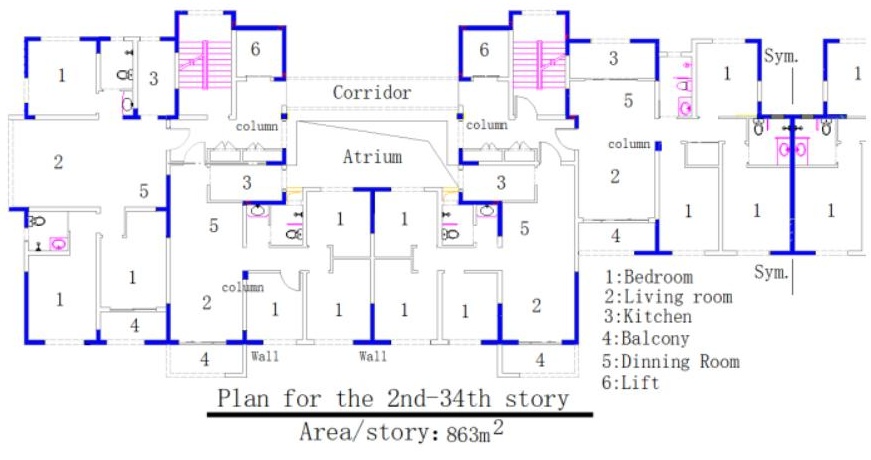

Fig. 3 Plan layout of HX-CFT walls in a residential house in Baotou, Inner Mongolia

Since cold-formed thin-walled steel sections are adopted in HX-CFT-walls, high-rise residential buildings can be built with affordable steel content, and automatic production lines have been developed so that the manufacturing costs are also reduced. Unlike DSC-walls whose applications are mainly in cores and staircases, HX-CFT-walls are arranged in plans, similar to concrete shear walls. Fig.3 illustrates a plan layout of HX-CFT-walls in a residential house of 34 stories and with a height of $97 \mathrm{~m}$. The street block is composed of 12 high-rise residential buildings using HX-CFT-walls and located in Baotou, Inner Mongolia, China.

However, such CFT-walls have some difficulties in attaching exterior cladding walls because welding connectors onto the cold-formed rectangular tubes with a thickness of $4-5 \mathrm{~mm}$ leads to permanent welding distortion. To avoid such difficulties, a modified CFT-wall, as shown in Fig.4, was proposed, in which tie-bolts are introduced to fix connectors and attach the wall studs. Tie-bolts can also increase the interfacial slip-resistant rigidity and strength between concrete and faceplates. The entire cross-section of this CFT wall is formed in such a way that a rectangular box and a cell with tie bolts are arranged alternately. Only one line of tie-bolts is used in the cells to ensure a good confining effect of the closed tubes on concrete.

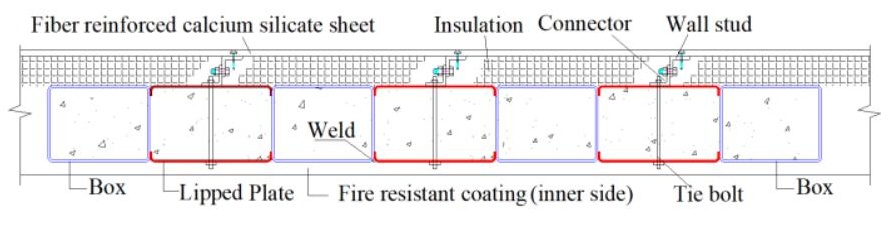

Fig. 4 CFT-walls with tie-bolts

This paper reports an experimental study on the behavior of the above mentioned modified CFT-walls with tie bolts. The bolt-to-bolt distance in the vertical direction is $0.5-0.55$ times the width of the tied cell so that the local elastic buckling stress of a faceplate is 1.844-1.603 times the buckling stress of the untied plate. Thus, the width-to-thickness ratio of the cells with tie-bolts can be $20-30 \%$ greater than that of a cell without tie-bolts. The tie bolts are required to be able to withstand a lateral pressure of $2 \mathrm{MPa}$ within their attribute area. A confining pressure of $2 \mathrm{MPa}$ is regarded as being able to provide ductility to the infill concrete. Wider bolted cells may slightly reduce the number of welds, which is the reason for introducing this modification.

Cyclic loading tests were conducted on seven full-scale specimens. The failure mode, hysteresis loops, lateral stiffness, ductility, and energy dissipation capacity of the specimens are presented and discussed. The width-to-thickness ratios of lengthwise steel sheets are beyond the limitations recommended by Chinese $\operatorname{codes}^{[15]}$ and Eurocode $4^{[16]}$, which will be discussed in Section 2.1. Therefore, the effect of the tie-bolts on the buckling capacity of the steel sheets was also evaluated. Furthermore, fiber element models of the seven specimens were proposed and verified by the experimental results.

\section{Experimental program}

\subsection{Test specimens}

Seven full-scale CFT-walls with tie-bolts labeled from GHQ-1 to GHQ-7 were tested under cyclic lateral loading. The cross-sections of the specimens consist of two square boundary tubes and three or four rectangular cells. The cells next to the boundary tubes are formed by two cold-formed lipped steel sheets and tie-bolted. The middle cells are normal rectangular tubes. Flare V-groove welds with the minimum effective throat equal to the plate thickness are used to connect the tubes.

The limiting width-to-thickness ratio for square CFT columns recommended in Chinese codes ${ }^{[13]}$ and Eurocode $4^{[14]}$ are

$$
\begin{gathered}
{[b / t]_{\mathrm{CECS}}=60 \varepsilon_{\mathrm{k}}} \\
{[b / t]_{\mathrm{EC} 4} \leq 52 \varepsilon_{\mathrm{k}}}
\end{gathered}
$$

where $b$ and $t$ are the width and thickness of the steel tubes and steel sheets, respectively, and $\varepsilon_{\mathrm{k}}=\sqrt{235 / f_{\mathrm{y}}}$. For $f_{\mathrm{y}}=345 \mathrm{~N} / \mathrm{mm}^{2}$, the $[b / t]$ limits imposed by Eqs.(1) and (2) are 49.5 and 42.9. The boundary boxes of the specimens have $b / t$ ratios of 40 and 37.5. The width-to-thickness ratio of the second cell next to the boundary tube is determined as follows.

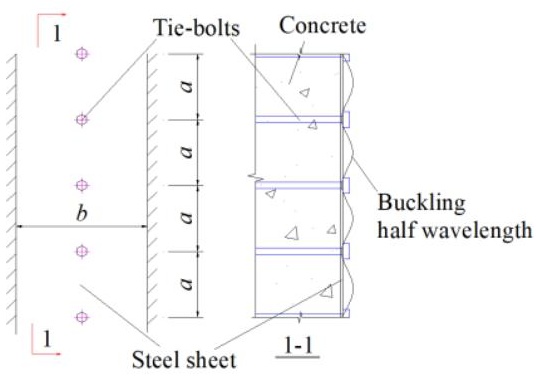

Fig. 5 Buckling of tie-bolted faceplates

Fig.5 shows a faceplate with tie-bolts; its width is $b$, and the distance between the tie-bolts is $a$. Behind the faceplate is the infill concrete, preventing the faceplate buckling toward concrete; therefore, the only possible buckling mode is shown on the right side in Fig.5. The longitudinal edges are modeled as fixed; therefore, the buckling stress of the faceplate ${ }^{[15]}$ is

$$
\sigma_{\mathrm{cr}}=\left(\beta^{2}+\frac{2}{3}+\frac{1}{\beta^{2}}\right) \frac{4 \pi^{2} E t^{2}}{12\left(1-\mu^{2}\right) b^{2}}
$$

Where $\beta=a / b$. The minimum buckling stress occurs when $\beta=1$.

$$
\sigma_{\mathrm{cr}, \min }=\frac{10.667 \pi^{2} E t^{2}}{12\left(1-\mu^{2}\right) b^{2}}
$$

If the distance $a$ was equal to the width $b$, the node lines of the faceplate buckles would be automatically located at the tie-bolts, and no tie-bolts works. Therefore, the distance $a$ is taken to be less than the width $b$. Table 1 lists the buckling factors for $\beta$ of $0.5-1.0$. The width-to-thickness ratios $(b / t)_{\mathrm{E} . \mathrm{y}}$ for which the buckling stress is equal to $f_{\mathrm{y}}=235 \mathrm{MPa}$ are also listed. Based on the well-known winter's formula, when the normalized width-to-thickness ratio $\lambda=\sqrt{f_{\mathrm{y}} / \sigma_{c r}}$ is equal to 0.673 , the inelastic buckling strength is equal to the yield strength. The corresponding width-to-thickness ratios are also listed in Table 1. Referring to Table 1 , the $b / t$ ratio for the tie-bolted cell is set to 1.2 times that in Eq.(1), i.e., $1.2 \times 49.5=59.4$. The middle cells have a smaller bending stress; therefore, their $b / t$ ratios are also set to 1.2 times that in Eq.(1)

\begin{tabular}{|c|c|c|c|c|}
\hline$\beta$ & Buckling factor & $(b / t)_{\mathrm{E}, \mathrm{y}}$ & $0.673(b / t)_{\mathrm{E}, \mathrm{y}}$ & Comments \\
\hline 1 & 10.67 & 90.58 & 60.96 & Based on Eq.(1) \\
\hline 0.8 & 11.48 & 93.96 & 63.23 & not attractive \\
\hline 0.7 & 12.79 & 99.19 & 66.75 & $\begin{array}{l}1.1 \text { times in Eq.(1), not } \\
\text { attractive for practice }\end{array}$ \\
\hline 0.6 & 15.22 & 108.19 & 72.81 & 1.2 times in Eq.(1), acceptable \\
\hline 0.55 & 17.10 & 114.69 & 77.18 & 1.29 times in Eq.(1), acceptable \\
\hline 0.5 & 19.67 & 122.99 & 82.78 & 1.36 times Eq.(1), acceptable \\
\hline
\end{tabular}
in GHQ-1/3/6/7 to check their effect.

Table1

Determination of distance between tie-bolts $\left(f_{y}=235 \mathrm{~N} / \mathrm{mm}^{2}, E=200000 \mathrm{~N} / \mathrm{mm}^{2}\right)$

The minimum thickness of the HX-CFT-walls is taken as $130 \mathrm{~mm}$, which was found to ensure the quality of concrete when the wall height was $9 \mathrm{~m}$ (three stories) after the concrete pouring trials. GHQ-1-6 have wall thicknesses of 130 $\mathrm{mm}$, and boundary box $160 \times 4$ is introduced to improve the out-of-plane stability of the walls; concurrently, it has a limited effect on the in-plane behavior. Specimen GHQ-7 has a uniform wall thickness of $150 \mathrm{~mm}$. It was demonstrated by past experience that when the wall thickness is equal to and greater than $150 \mathrm{~mm}$, the out-of-plane buckling of the CFT-walls will not 
occur in the test.

Details of the specimens are shown in Fig.6 and listed in Table 2. Specimens GHQ-1 and GHQ-2 have identical geometries, whereas their axial force ratios, arrangement patterns of the tie-bolts, and loading histories are different. Specimens GHQ-3 and GHQ-4 have smaller width-thickness ratios than GHQ-1/GHQ-2 to examine the effect of these parameters. The middle cells of Specimens GHQ-5 and GHQ-6 have smaller widths than GHQ-4/GHQ-3, respectively.
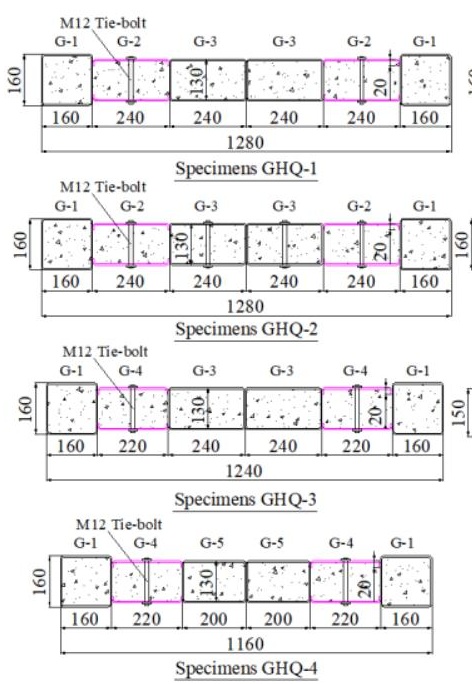

(a) Sectional configuration of specimens

\section{$-1$}
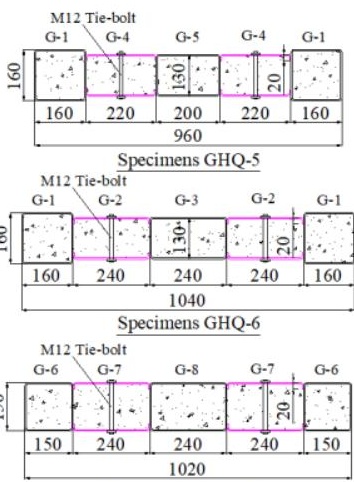

Specimens GHQ-7

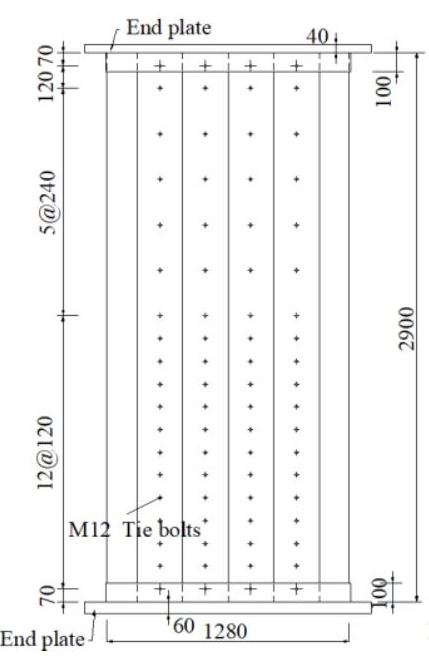

(b) Front view of Specimen 2

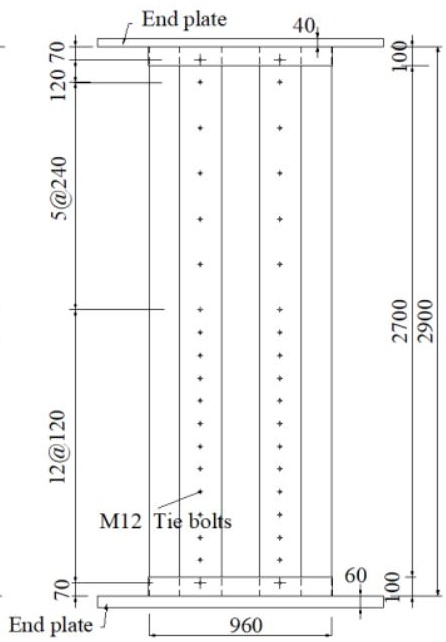

(c) Front view of Specimen 5

Fig. 6 Test specimens

Table 2

Summary of test specimens (height $=2900 \mathrm{~mm}$ )

\begin{tabular}{|c|c|c|c|c|c|c|c|c|}
\hline \multirow{2}{*}{$\begin{array}{l}\text { No. } \\
\text { GHQ }\end{array}$} & \multirow{2}{*}{ Configuration } & \multicolumn{3}{|c|}{ Width-to-thickness ratio of faceplates } & \multirow{2}{*}{$\begin{array}{c}\text { Wall } \\
\text { width } B(\mathrm{~mm})\end{array}$} & \multirow{2}{*}{$\begin{array}{l}\text { Loading } \\
\text { history }\end{array}$} & \multirow{2}{*}{$\begin{array}{l}\text { Axial force } \\
\text { ratio } n_{\mathrm{d}} / n_{r}\end{array}$} & \multirow{2}{*}{ Axial force $(\mathrm{kN})$} \\
\hline & & $1^{\text {stbox }}$ & $2^{\text {nd }}$ cell(bolted) & Mid-cell & & & & \\
\hline 1 & $\mathrm{G} 1+\mathrm{G} 2 \mathrm{~b}+\mathrm{G} 3+\mathrm{G} 3+\mathrm{G} 2 \mathrm{~b}+\mathrm{G} 1$ & 40 & 60 & 60 & 1280 & Type 1 & $0.56 / 0.30$ & 3450 \\
\hline 2 & $\mathrm{G} 1+\mathrm{G} 2 \mathrm{~b}+\mathrm{G} 3 \mathrm{~b}+\mathrm{G} 3 \mathrm{~b}+\mathrm{G} 2 \mathrm{~b}+\mathrm{G} 1$ & 40 & 60 & 60 & 1280 & Type 2 & $0.50 / 0.27$ & 3100 \\
\hline 3 & $\mathrm{G} 1+\mathrm{G} 4 \mathrm{~b}+\mathrm{G} 3+\mathrm{G} 3+\mathrm{G} 4 \mathrm{~b}+\mathrm{G} 1$ & 40 & 55 & 60 & 1240 & Type 2 & $0.56 / 0.30$ & 3350 \\
\hline 4 & $\mathrm{G} 1+\mathrm{G} 4 \mathrm{~b}+\mathrm{G} 5+\mathrm{G} 5+\mathrm{G} 4 \mathrm{~b}+\mathrm{G} 1$ & 40 & 55 & 50 & 1160 & Type 2 & $0.56 / 0.30$ & 3170 \\
\hline 5 & $\mathrm{G} 1+\mathrm{G} 4 \mathrm{~b}+\mathrm{G} 5+\mathrm{G} 4 \mathrm{~b}+\mathrm{G} 1$ & 40 & 55 & 50 & 960 & Type 2 & $0.56 / 0.30$ & 2690 \\
\hline 6 & $\mathrm{G} 1+\mathrm{G} 2 \mathrm{~b}+\mathrm{G} 3+\mathrm{G} 2 \mathrm{~b}+\mathrm{G} 1$ & 40 & 60 & 60 & 1040 & Type 2 & $0.56 / 0.30$ & 2880 \\
\hline 7 & $\mathrm{G} 6+\mathrm{G} 7 \mathrm{~b}+\mathrm{G} 8+\mathrm{G} 7 \mathrm{~b}+\mathrm{G} 6$ & 37.5 & 60 & 60 & 1020 & Type 2 & $0.56 / 0.30$ & 2880 \\
\hline
\end{tabular}

Tie bolts are arranged at the center of the hollow section sections next to the boundary tubes, and the middle cells of GHQ-2 are also tie-bolted because their faceplates have a larger $b / t$ ratio than that in Eq.(1). The distances between the tie bolts are doubled in the upper half of all the specimens because the upper parts have smaller bending moments in the tests(Figs 6(b) and (c), $240 \mathrm{~mm}$ and $120 \mathrm{~mm}$, respectively).

The specimens have top and bottom endplates of $40 \mathrm{~mm}$ and $60 \mathrm{~mm}$, respectively. To avoid fracture of the welds between the wall and the endplates, vertical strengthening plates $100 \times 6$ were attached to the wall and welded to the top and bottom of the specimens.

The limits on the normalized design axial force(defined as the ratio of the design value of the axial force and the design value of the yield strength) in the primary seismic concrete wall are taken as 0.35 and 0.4 for ductility classes DCH(high) and DCM(medium), respectively. Considering that the CFT-walls have higher ductility than concrete shear walls, for a residential building of $80 \mathrm{~m}$, past experiences have revealed that the normalized design axial forces are approximately 0.5 for most CFT-walls. Therefore, it is chosen as 0.5 for all the specimens in this study.

\subsection{Material properties}

Table 3

Material properties of steel

\begin{tabular}{ccccccc}
\hline $\begin{array}{c}\text { Thickness } \\
(\mathrm{mm})\end{array}$ & $\begin{array}{c}E_{\mathrm{s}} \\
(\mathrm{GPa})\end{array}$ & $\begin{array}{c}\text { Yield } \\
\text { strength } \\
(\mathrm{MPa})\end{array}$ & $\begin{array}{c}\text { Yield } \\
\text { strain } \\
(\%)\end{array}$ & $\begin{array}{c}\text { Ultimate } \\
\text { strength } \\
(\mathrm{MPa})\end{array}$ & $\begin{array}{c}\text { Ultimate } \\
\text { strain } \\
(\%)\end{array}$ & $\begin{array}{c}\text { Elongation } \\
(\%)\end{array}$ \\
\hline 4 & 208 & 350 & 0.185 & 495 & 23.4 & 30 \\
\hline
\end{tabular}

Design strength grade $\mathrm{C} 40$ was used in all the specimens; the average cubic strength of six $150 \times 150 \times 150$ cubic specimens of the used concrete is $f_{\mathrm{cu}}=54.9 \mathrm{MPa}$ and $3: 1$ prism strength is $f_{\mathrm{pr}}=0.76 f_{\mathrm{cu}}=41.7 \mathrm{MPa}$. The test was conducted according to the Chinese "Standard for Test Method of Mechanical Properties on Ordinary Concrete" (GB/T 50081-2002) ${ }^{[16]}$. All the steel tubes were manufactured from Q345 steel sheets with a measured average thickness of $4.0 \mathrm{~mm}$. The properties of the steel tubes, as listed in Table 3, were obtained from tensile tests conducted on coupons taken from the same batch of steel sheets.

\subsection{The setup and loading procedure}

All the tests were conducted using the multi-functional loading device shown in Fig.7. The specimens are bolted to the bottom block with M24(10.9s) high-strength bolts, which are clamped to the reaction floor by eight anchors. The specimens are also bolted to the top beam, which connects to the horizontal hydraulic jack. The top beam is of $400 \mathrm{~mm}$ in height and can distribute vertical loads to the top of the specimens. The horizontal and vertical hydraulic jacks have a capacity of $1500 \mathrm{kN}$ and $25000 \mathrm{kN}$, respectively. 


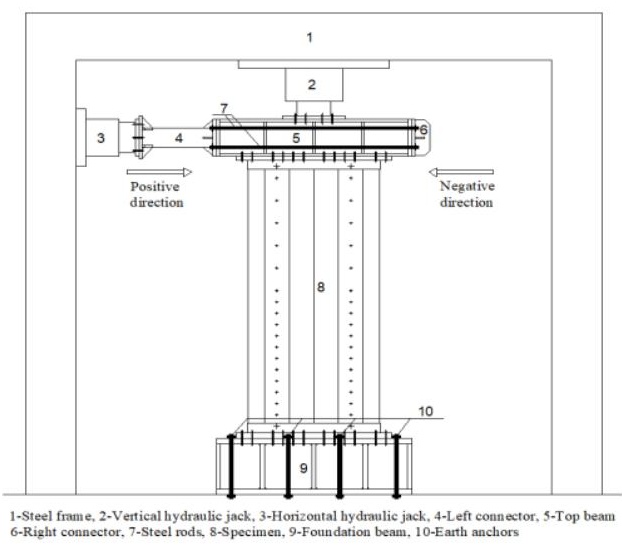

Fig. 7 Test setup

The design/real axial load ratio $n_{\mathrm{d}} / n_{\mathrm{r}}$, and the corresponding axial force are listed in Table 2. The design/real axial load ratio $n_{\mathrm{d}} / n_{\mathrm{r}}$, is defined based on Eqs.(5) and (6).

$$
\begin{aligned}
& n_{\mathrm{d}}=\frac{1.25 N}{A_{\mathrm{c}} f_{\mathrm{c}}+A_{\mathrm{s}} f} \\
& n_{\mathrm{r}}=\frac{N}{A_{\mathrm{c}} f_{\mathrm{pr}}+A_{\mathrm{s}} f_{\mathrm{y}}}
\end{aligned}
$$

where $f_{\mathrm{pr}}$ is the $\operatorname{prism}(150 \times 150 \times 450)$ compressive strength of concrete, $f_{\mathrm{pr}}=0.76 f_{\mathrm{cu}}=41.7 \mathrm{Mpa}, f_{\mathrm{y}}$ is the yielding strength of the steel sheets, $f=f_{\mathrm{y}} / 1.165$, and $A_{\mathrm{c}}, A_{\mathrm{s}}$ are the areas of concrete and the steel tubes, respectively.

The axial force was first applied in five steps until the predetermined axial force was reached. The horizontal cyclic loading history was determined by the Chinese Specification of Testing Methods for Earthquake Resistant Building (JGJ 101-96) ${ }^{[17]}$. Load/displacement compound control was conducted in this test. Before the specimen yielded, the horizontal force was controlled by the load and applied in five levels, which corresponded to $1 / 5,2 / 5,3 / 5,4 / 5$, and 1 of the predicted yield strength of the specimen. When the specimen yielded, the lateral displacement was recorded and defined as yield displacement $\Delta y$, and then the horizontal force was controlled by displacement. Two types of loading procedures were conducted during the displacement-controlled. For specimen GHQ-1, the displacement level increment corresponded to $\Delta \mathrm{y}$, whereas it was changed to $0.5 \Delta \mathrm{y}$ in other specimen tests, as shown in Fig.8. Two circles were imposed at each displacement level, and the test was terminated when the axial force on the wall could not be maintained or the lateral load decreased below $85 \%$ of the maximum measured load capacity.

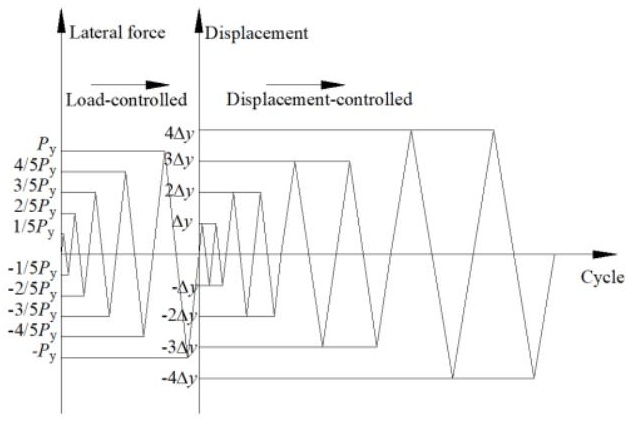

(a) Specimen GHQ-1(type 1)

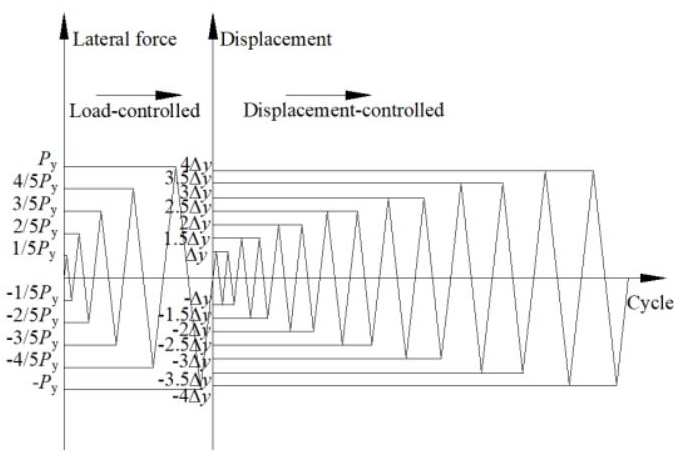

(b) Other specimens(type 2)

Fig. 8 Design loading history of specimens

\subsection{Instrumentation}

The instrumentation for the specimens is illustrated in Fig.9. Nine linear variable displacement transducers (LVDTs) were used. The in-plane horizontal displacements were measured by four LVDTs $(\mathrm{H}-1, \mathrm{H}-2, \mathrm{H}-3$, and H-5) along the heights of the walls. Two LVDTs(H-6 and H-7) monitored the possible out-of-plane deformation of the specimens, and three LVDTs(H-4, V-1, and V-2) monitored the displacement of the foundation beam. The lateral and vertical loads applied by the hydraulic jack were automatically recorded by the loading system.

For recording the observations and discussing the test results, the faces of the specimens coated with a whitewash are called as front sides, and the opposite faces are defined as the back sides of the specimens. In addition, the push (horizontal hydraulic jack from left to right) is defined as positive loading, and the pull (horizontal hydraulic jack from right to left) is defined as negative loading.

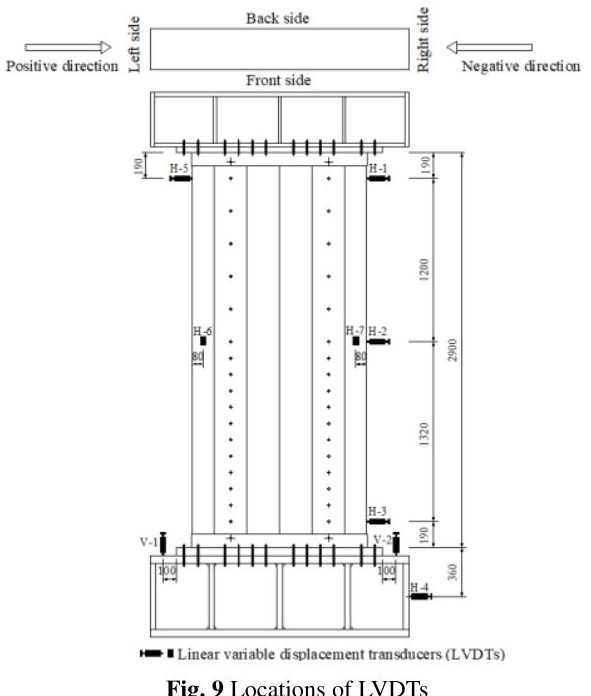

\section{Experimental results and discussion}

\subsection{General observations and failure modes}

In general, all the specimens demonstrated similar behaviors. Taking GHQ-2 as an example, it experienced the following three stages:

Quasi-elastic stage: The $\mathrm{P}-\Delta$ curve was approximately linear in the initial ascending part. No local buckling or physical deformation was observed. Subsequently, the specimen began to yield with some slight local buckling at the boundary tubes in the compression zone, as shown in Fig.10(a). The first plastic local buckling occurred at approximately $200 \mathrm{~mm}$ from the bottom of the boundary tubes in cycle $\Delta \mathrm{y}$.

Yielding development stage: After the plastic local buckling of the boundary tube, some local buckling occurred and developed in more locations during cycles $1.5 \Delta y$ to $2 \Delta y$, as illustrated in Figs.10(a) and(b). For cycle $2.5 \Delta y$, the specimen attained its ultimate strength, $P_{\max }$. Noticeable local buckling was observed at a height of $350 \mathrm{~mm}$ in the middle tubes.

Failure stage: As the buckling of the steel faceplates became severe and the concrete crushed gradually, the lateral load decreased to $0.85 P_{\max }$. The final collapse occurred with the fracture propagation of the steel profile at the buckling location (Fig.10(c)) and the crushing of concrete. The final failure mode of GHQ-2 is shown in Fig.10(d).

The failures of the other specimens are illustrated in Fig.11. During the test process, the out-of-plane deformation of the specimens was monitored by LVDTs H-6 and H-7. Except for the last circle of GHQ-1, no visible transverse displacement was observed. As Figs. 10 and 11 show, the half wavelength of the steel sheets is equal to the spacing of the tie-bolts $(120 \mathrm{~mm})$ for the tubes with tie-bolts, indicating that the local buckling of the steel tubes was restrained and the local buckling modes were changed. 


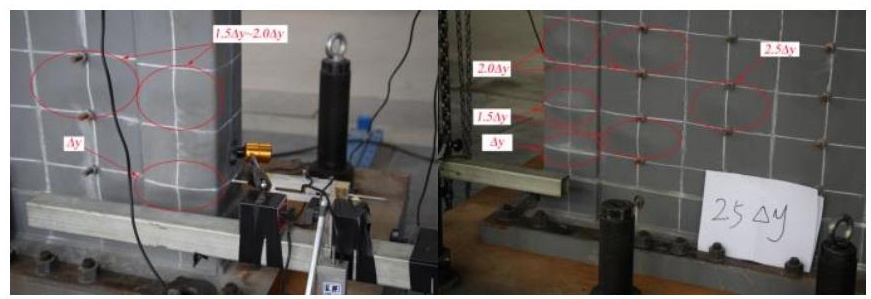

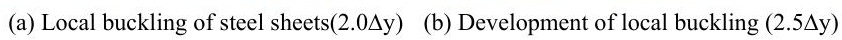

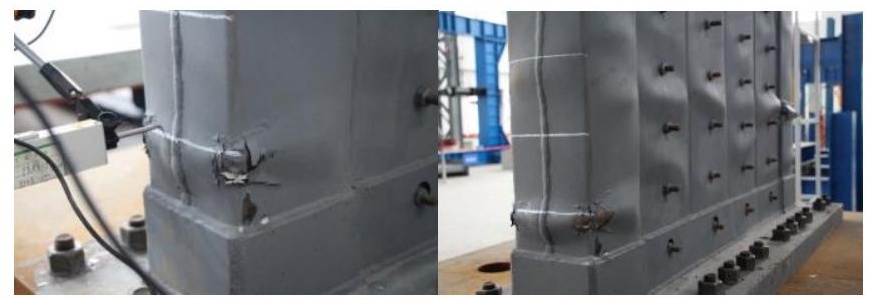

(c) Fracture propagation on the edge tube (d) Failure condition

Fig. 10 The Failure mode of Specimen GHQ-2

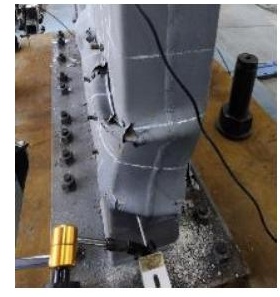

$\begin{array}{lll}\text { (a) Fracture propagation of steel and crushing of concrete in GHQ-1 } & \text { (b) Failure condition of GHQ-3 }\end{array}$

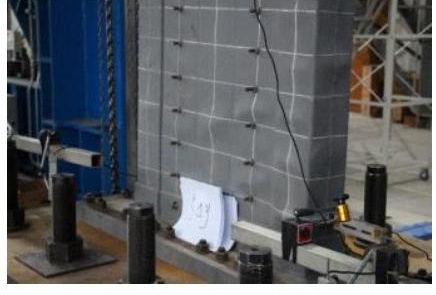

(d) Failure condition of GHQ-5
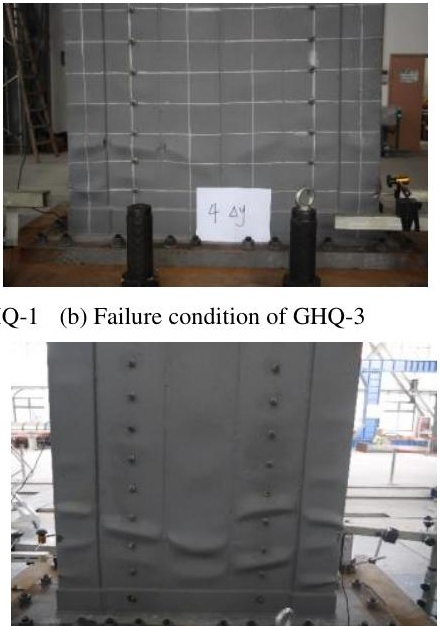

(e) Failure condition of GHQ-6 from the back view

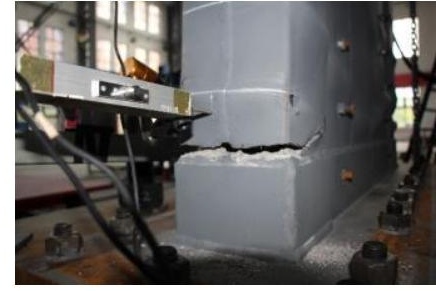

(c) Fracture propagation in GHQ-4

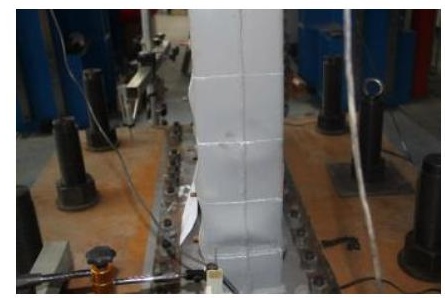

(f) Local buckling waves in GHQ-7

Fig. 11 Observation of specimens

\subsection{Lateral load-displacement hysteretic response}

For all the tested specimens, the lateral loads versus the corresponding displacements at the top of the wall eliminating the base rotation and movement are shown in Fig.12. All the hysteretic curves are spindle-shaped, without a noticeable pinching effect. The lateral load capacities decrease because the lateral drifts are beyond the maximum load point. Degeneration of the lateral load-carrying capacity is caused by a second-order effect, concrete crushing/tensile cracking, and the local buckling of the faceplates.

The load-displacement (story drift ratio) envelope curves connect the peak points of each loading cycle on the hysteretic curves, and the results are shown in Fig.13.

The following conclusions can be obtained from Figs.12 and Fig.13:

(1) The peak loads of GHQ-1,-2 are $984 \mathrm{kN}(\mathrm{GHQ}-1)$ and 1016 kN(GHQ-2), respectively. Although GHQ-1 has larger steps, they exhibited similar behaviors, which suggested that adding tie-bolts in the middle cells has a negligible effect. GHQ-3 has a smaller $b / t$ ratio at the tie-bolted cells than GHQ-1. The hysteretic curve is shown in Fig.12(c), and no capacity or ductility improvement over GHQ-1/2 is observed.

(2) GHQ-4 has cells with smaller width-to-thickness ratios, and improved ductility is expected. Comparing Fig.12(d) with Figs.12(a)-(c), a slightly slower degeneration of the lateral capacity is observed. The width of GHQ-4 is $9.4 \%$ smaller than that of GHQ-1/2; therefore, its maximum lateral capacity is lower.

(3) GHQ-5 has the same width-to-thickness ratio as GHQ-4; however, it has only one middle rectangular cell. Therefore, it is slender than GHQ-4. The average shear stress at the maximum lateral load is $74 \mathrm{~N} / \mathrm{mm}^{2}$, which is smaller than those of GHQ-1-GHQ-4. The role played by the bending moment is more dominant than that by the shear. GHQ-6 has a larger $b / t$ ratio than GHQ-5, and its hysteretic curve is similar to that of GHQ-4.

(4) GHQ-7 with a constant wall thickness $(150 \mathrm{~mm})$ presents a similar behavior to GHQ-6.

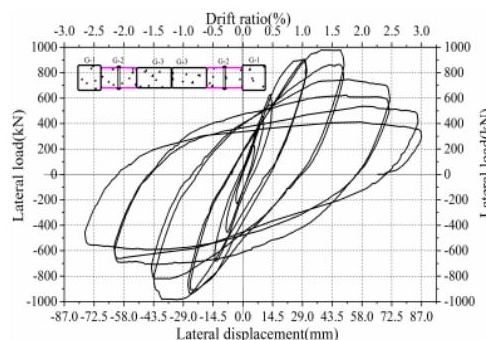

(a) Specimen GHQ-1

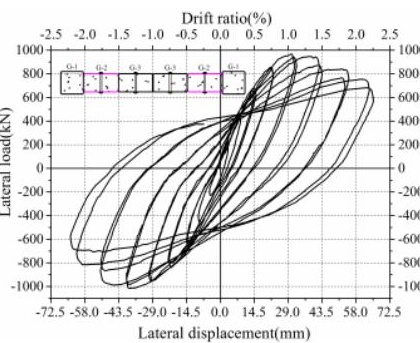

(b) Specimen GHQ-2

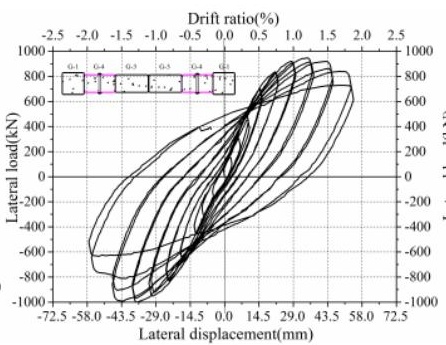

(c) Specimen GHQ-3

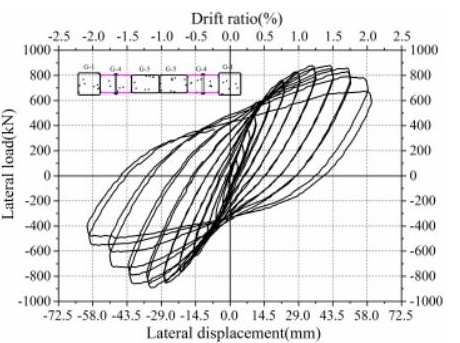

(d) Specimen GHQ-4

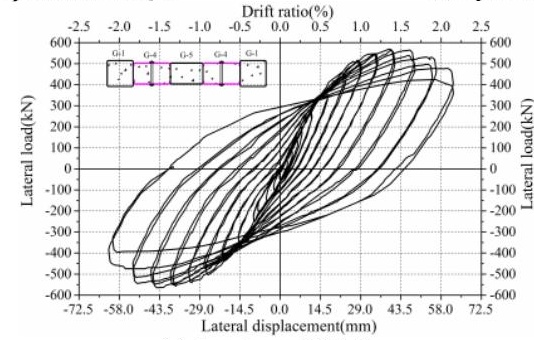

(e) Specimen GHQ-5

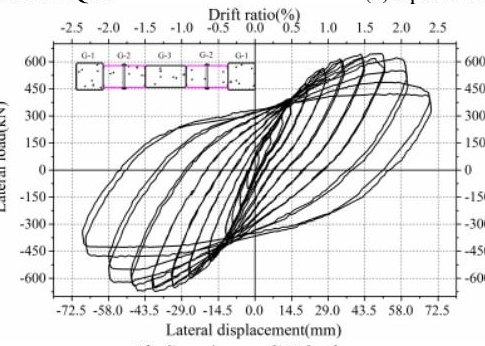

(f) Specimen GHQ-6

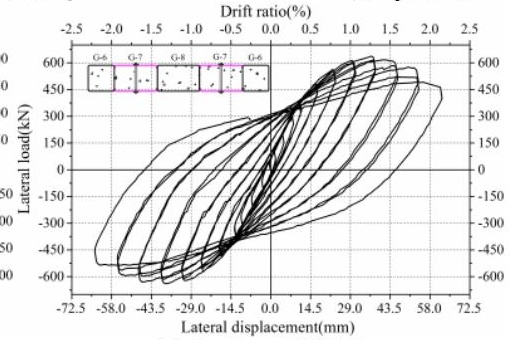

(g) Specimen GHQ-7

Fig. 12 Load--displacement (story drift ratio) hysteresis curves of specimens 


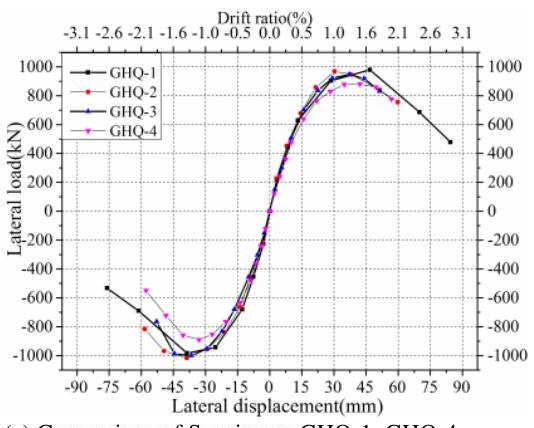

(a) Comparison of Specimens GHQ-1-GHQ-4

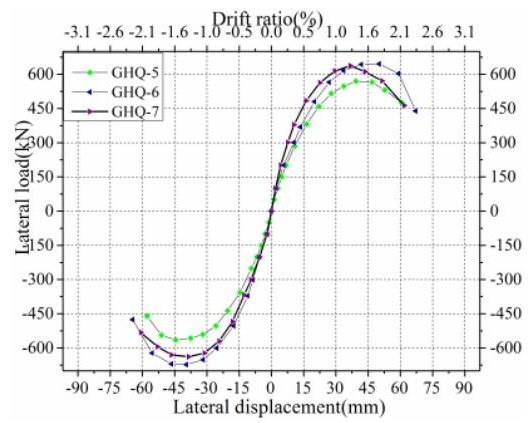

(b) Comparison of Specimens GHQ-5-GHQ-7

Fig. 13 Envelop curves of load--displacement
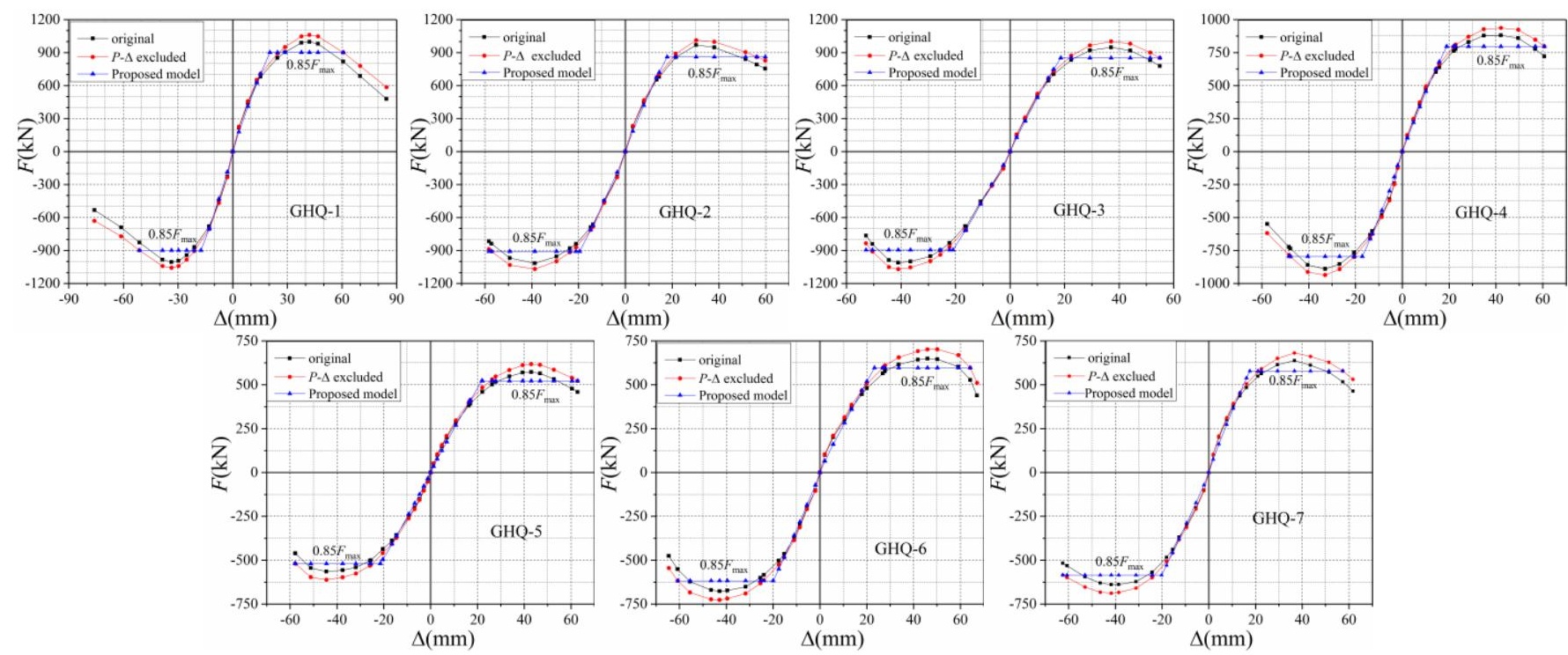

Fig. 14 Skeleton curves excluding $P-\Delta$ effect

\subsection{Response curves and ductility factor excluding $P-\Delta$ effect}

The hysteretic curves in Fig.12 and the skeleton curves in Fig.13 include the influences of the $P-\Delta$ effect. However, in the current design and study on the seismic behavior, this effect is isolated from the physical stiffness, as expressed in the following equilibrium equation for single-degree of freedom systems:

$m \ddot{\Delta}+c \dot{\Delta}+F_{\text {ep }}-P \Delta / h_{\text {st }}=-m a_{\mathrm{g}}$

Elastic-plastic hysteretic behavior is included in the term $F_{\text {ep }}$ and the $P-\Delta$ effect is considered as an independent term; therefore, the experimental curves must be corrected to isolate the $P-\Delta$ effect.

All the seven specimens failed at their bottom; their bending moments are

$$
M_{\text {base }}=P h_{\mathrm{st}}+N \Delta
$$

where $P$ is the horizontal force, $h_{\mathrm{st}}$ is the height of the specimen, $N$ is the axial load, $\Delta$ is the lateral displacement at the top, and $M_{\text {base }}$ is the moment including the $P-\Delta$ moment. If the same bending moment is produced by the lateral force only, then

$$
M_{\text {base }}=F h_{\text {st }}
$$

and one obtains

$$
F=P+\frac{N}{h_{\mathrm{st}}} \Delta
$$

The corrected lateral force $F$ - drift $\Delta$ curves for all the specimens are presented in Fig. 14.
The yield displacement $\Delta_{\mathrm{y}}$ is defined as follows: the yield strain of steel is $\varepsilon_{\mathrm{y}}=f_{\mathrm{y}} / E=350 / 200000=1750 \mu \varepsilon$, and the strain of concrete at $f_{\text {cu }}$ is approximately $1790 \mu \varepsilon$ for $\mathrm{C} 40$ concrete. Both the strains are similar; therefore, the yielding point on the lateral force-displacement curves can be defined as the edge steel fiber begins to yield and the infill concrete reaches its prismatic strength. The stress diagram of this state is shown in Fig.15, and the theoretical yield moment was calculated. Table 4 lists the yield moments $M_{\mathrm{y}}$ of the specimens. It is found that the yield moments are approximately 0.67 times the maximum bending moment $M_{\max }=F_{\max } h_{\mathrm{st}}$; therefore, point $0.67 F_{\max }$ is used as the yielding point, which is denoted by Point A in Fig. 16(c).

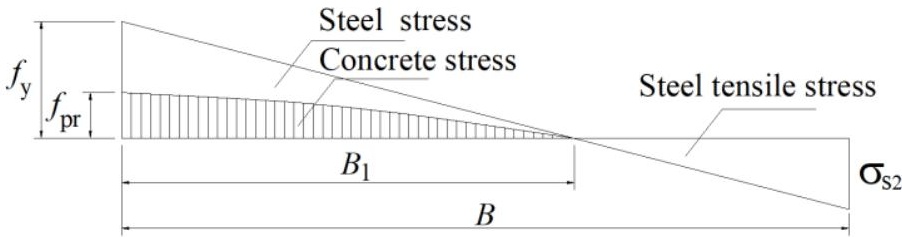

Fig. 15 Yield point definition

Connecting the origin to Point $\mathrm{A}$ and extending this line to $0.85 F_{\max }$, the displacement of this point is denoted as $\Delta_{\mathrm{y} \mu}=(0.85 / 0.667) \Delta_{\mathrm{y}}=1.27 \Delta_{\mathrm{y}}$. The useful limit of deformation $\Delta_{u}$ is Point $\mathrm{C}$ at which the lateral force drops to $85 \%$ of the maximum capacity. According to Newmark and Hall ${ }^{[18]}$ (Fig. 16(a)), the ductility factor is defined as

$\mu=\frac{\Delta_{\mathrm{u}}}{\Delta_{\mathrm{y \mu}}}$ 
Table 4

Yielding moments and components characteristics

\begin{tabular}{|c|c|c|c|c|c|c|c|}
\hline Specimen & $\alpha_{\mathrm{ck}}$ & $\begin{array}{c}\text { Shear deformation } \\
\text { percentage } \xi\end{array}$ & $\begin{array}{c}K_{\mathrm{s}} \\
\left(\mathrm{kN} / \mathrm{m} \times 10^{6}\right) \\
\end{array}$ & $\begin{array}{c}M_{\mathrm{y}} \\
\left(\mathrm{kN} \cdot \mathrm{m} \times 10^{6}\right) \\
\end{array}$ & $\begin{array}{c}M_{\mathrm{A}}\left(0.67 F_{\max } h_{\mathrm{st}}\right) \\
\left(\mathrm{kN} / \mathrm{m} \times 10^{6}\right)\end{array}$ & $M_{\mathrm{y}} / M_{\mathrm{A}}$ & $\phi_{c}$ \\
\hline GHQ-1 & 0.596 & $15.5 \%$ & 45.64 & 2327.4 & 2222.2 & 1.010 & 0.31 \\
\hline GHQ-2 & 0.596 & $15.5 \%$ & 45.64 & 2477.3 & 2067.3 & 1.075 & 0.33 \\
\hline GHQ-3 & 0.595 & $14.8 \%$ & 42.31 & 2202.3 & 2099.5 & 1.013 & 0.30 \\
\hline GHQ-4 & 0.592 & $12.3 \%$ & 35.75 & 2032.5 & 1972.8 & 1.057 & 0.41 \\
\hline GHQ-5 & 0.586 & $8.7 \%$ & 21.96 & 1247.7 & 1318.9 & 0.919 & 0.56 \\
\hline GHQ-6 & 0.590 & $10.7 \%$ & 26.91 & 1597.2 & 1490.4 & 1.017 & 0.56 \\
\hline GHQ-7 & 0.612 & $9.4 \%$ & 25.27 & 1466.6 & 1426.8 & 0.977 & 0.61 \\
\hline
\end{tabular}

Note: $\alpha_{\mathrm{ck}}=\frac{A_{\mathrm{c}} f_{\mathrm{pr}}}{A_{\mathrm{s}} f_{\mathrm{y}}+A_{\mathrm{c}} f_{\mathrm{pr}}}$

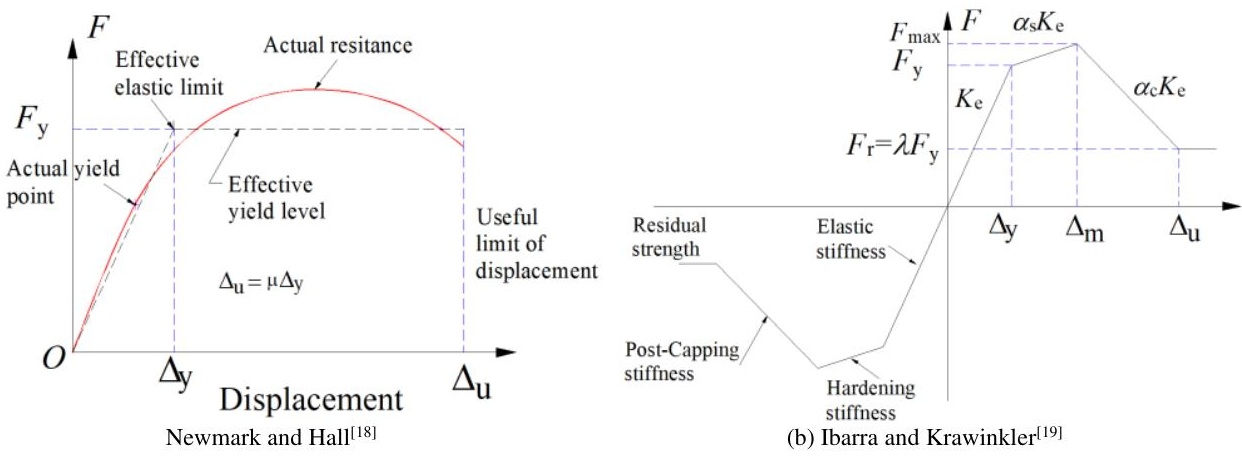

Fig. 16 Definition of ductility Factor

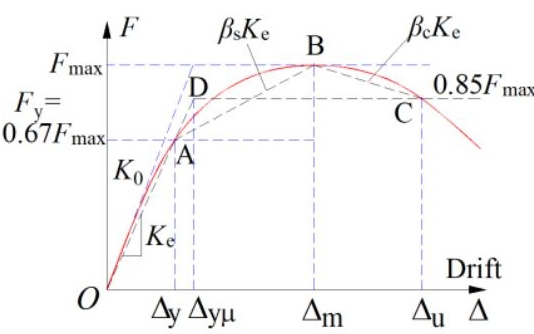

O-D-C: Newmark \& Hall

O-A-B-C: Ibarra \& Krawinkler (c) Present study

Table 5

Test results and parameters for Newmark and Hall's model

\begin{tabular}{|c|c|c|c|c|c|c|c|c|c|c|c|}
\hline Specimen & $\begin{array}{c}\text { Load } \\
\text { direction }\end{array}$ & $\begin{array}{l}F_{\max } \\
(\mathrm{kN})\end{array}$ & $\begin{array}{c}\Delta_{\mathrm{y \mu}} \\
(\mathrm{mm})\end{array}$ & $\begin{array}{c}K_{0} \\
\left(\mathrm{kN} / \mathrm{m} \times 10^{6}\right)\end{array}$ & $\begin{array}{c}K_{\mathrm{e}} \\
\left(\mathrm{kN} / \mathrm{m} \times 10^{6}\right)\end{array}$ & $\Delta_{\mathrm{u}}$ & $\mu$ & $\Delta_{\mathrm{m}}$ & $\tau_{\max }$ & $\Delta_{\mathrm{y}} / h$ & $\Delta_{\mathrm{u}} / h$ \\
\hline \multirow{2}{*}{ GHQ-1 } & + & 1060 & 19.4 & 65.97 & 46.31 & 60.7 & 3.12 & 42.1 & 95.6 & $1 / 190$ & $1 / 48$ \\
\hline & - & -1058 & -16.7 & 76.72 & 53.97 & -51.2 & 3.07 & -33.6 & -96.1 & $1 / 222$ & $1 / 57$ \\
\hline \multirow{2}{*}{ GHQ-2 } & + & 1012 & 17.0 & 73.12 & 50.43 & 56.2 & 3.30 & 30.3 & 94.6 & $1 / 217$ & $1 / 52$ \\
\hline & - & -1068 & -18.9 & 67.15 & 48.15 & -57.2 & 3.03 & -38.7 & -99.2 & $1 / 196$ & $1 / 51$ \\
\hline \multirow{2}{*}{ GHQ-3 } & + & 1001 & 18.0 & 64.13 & 47.35 & 55.0 & 3.06 & 37.1 & 95.5 & $1 / 206$ & $1 / 53$ \\
\hline & - & -1054 & -20.6 & 63.29 & 44.05 & -50.5 & 2.45 & -41.0 & -100.8 & $1 / 179$ & $1 / 57$ \\
\hline \multirow{2}{*}{ GHQ-4 } & + & 937 & 18.3 & 57.99 & 43.46 & 60.7 & 3.32 & 42.1 & 94.9 & $1 / 202$ & $1 / 48$ \\
\hline & - & -936 & -16.4 & 62.77 & 48.49 & -47.9 & 2.92 & -33 & -95.9 & $1 / 225$ & $1 / 61$ \\
\hline \multirow{2}{*}{ GHQ-5 } & + & 614 & 21.6 & 41.45 & 24.30 & 62.8 & 2.91 & 43.0 & 74.2 & $1 / 171$ & $1 / 46$ \\
\hline & - & -612 & -21.0 & 44.08 & 24.72 & -57.7 & 2.75 & -44.5 & -73.5 & $1 / 176$ & $1 / 50$ \\
\hline \multirow{2}{*}{ GHQ-6 } & + & 702 & 22.8 & 49.85 & 26.13 & 64.2 & 2.81 & 45.9 & 77.5 & $1 / 217$ & $1 / 45$ \\
\hline & - & -723 & -19.4 & 54.02 & 31.78 & -60.8 & 3.13 & -42.9 & -80.9 & $1 / 190$ & $1 / 48$ \\
\hline \multirow{2}{*}{ GHQ-7 } & + & 681 & 17.0 & 53.99 & 34.02 & 57.3 & 3.37 & 36.7 & 78.2 & $1 / 217$ & $1 / 51$ \\
\hline & - & -684 & -19.7 & 50.27 & 29.60 & -62.5 & 3.16 & -41.8 & -78.3 & $1 / 187$ & $1 / 46$ \\
\hline
\end{tabular}

Table 5 summarizes the lateral capacities excluding the $P-\Delta$ effect, displacements $\Delta_{\mathrm{y} \mu}, \Delta_{\mathrm{u}}$, and $\Delta_{\mathrm{m}}$, initial secant stiffness $K_{0}$ (computed by the first step lateral load and displacement), and secant stiffness at yield point A $K_{\mathrm{e}}$. The peak load and ductility of Specimens GHQ-1 and GHQ-2 are similar, which indicates that the arrangement of the binding bars in the middle tubes(G-1) has an insignificant effect. The length of the specimens has a significant effect on the peak load and the initial lateral stiffness, whereas it has a limited effect on the ductility of the specimens.

As can be seen from Table 5, the useful drift ratios are in the range of $1 / 45-1 / 61$ with the ductility factors varying from 2.45 to 3.37 , which indicates that all the specimens have good ductility and exhibit ductile post-peak-load behavior as expected. Two parameters $-B / h_{\mathrm{st}}, \tau_{\max } / f_{\mathrm{y}}-$ are correlated to the ductility factor $\mu$, as shown in Fig.17; however, no explicit relations are found. Here, $B / h_{s t}$ is the inverse of the shear span-depth ratio, which is an important factor affecting the ductility of reinforced concrete beams and columns, $\tau_{\max }$ is the average shear stress at $F_{\max }$ neglecting the contribution of the infill concrete.

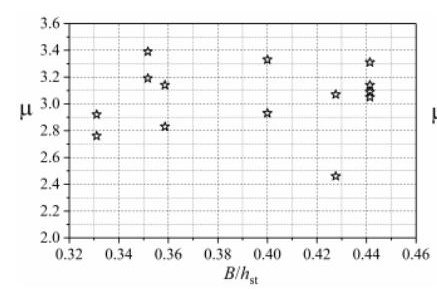

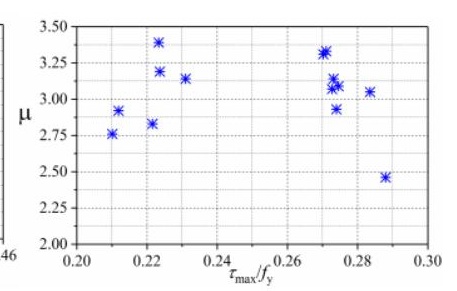

Fig. 17 Correlation of ductility factors with parameters $B / h_{s t}$ and $\tau_{\max } / f_{\mathrm{y}}$

The varied factors of the seven specimens, i.e., with/without tie-bolts in the middle cells(GHQ-1 and GHQ-2) and the width-to-thickness ratios of the faceplates $(50,55,60)$, have no discernible effect on the ductility.

Figs.16(b) and (c) also show a trilinear model, O-A-B-C, which was adopted by Ibarra and Krawinkler ${ }^{[19]}$. Ratios $\Delta_{\mathrm{m}} / \Delta_{\mathrm{y}}$ and $\Delta_{\mathrm{u}} / \Delta_{\mathrm{y}}$ and the parameters are listed in Table 6. 
Table 6

Parameters for Ibarra and Krawinkler's model

\begin{tabular}{|c|c|c|c|c|c|}
\hline Specimen & Load direction & $\mu_{\mathrm{m}}=\Delta_{\mathrm{m}} / \Delta_{\mathrm{y}}$ & $\mu_{\mathrm{u}}=\Delta_{\mathrm{u}} / \Delta_{\mathrm{y}}$ & $\beta_{s}$ & $\beta_{c}$ \\
\hline \multirow{2}{*}{ GHQ-1 } & + & 2.76 & 3.98 & 0.284 & 0.185 \\
\hline & - & 2.57 & 3.92 & 0.318 & 0.167 \\
\hline \multirow{2}{*}{ GHQ-2 } & + & 2.26 & 4.20 & 0.396 & 0.116 \\
\hline & - & 2.61 & 3.87 & 0.309 & 0.180 \\
\hline \multirow{2}{*}{ GHQ-3 } & + & 2.63 & 3.90 & 0.307 & 0.177 \\
\hline & - & 2.53 & 3.12 & 0.321 & 0.378 \\
\hline \multirow{2}{*}{ GHQ-4 } & + & 2.93 & 4.23 & 0.259 & 0.174 \\
\hline & - & 2.56 & 3.72 & 0.320 & 0.195 \\
\hline \multirow{2}{*}{ GHQ-5 } & + & 2.54 & 3.70 & 0.323 & 0.192 \\
\hline & - & 2.70 & 3.50 & 0.295 & 0.281 \\
\hline \multirow{2}{*}{ GHQ-6 } & + & 3.44 & 3.58 & 0.320 & 0.221 \\
\hline & - & 2.81 & 3.99 & 0.274 & 0.191 \\
\hline \multirow{2}{*}{ GHQ-7 } & + & 2.75 & 4.30 & 0.286 & 0.145 \\
\hline & - & 2.69 & 4.03 & 0.293 & 0.167 \\
\hline Mean & & 2.70 & 3.95 & 0.308 & 0.198 \\
\hline
\end{tabular}

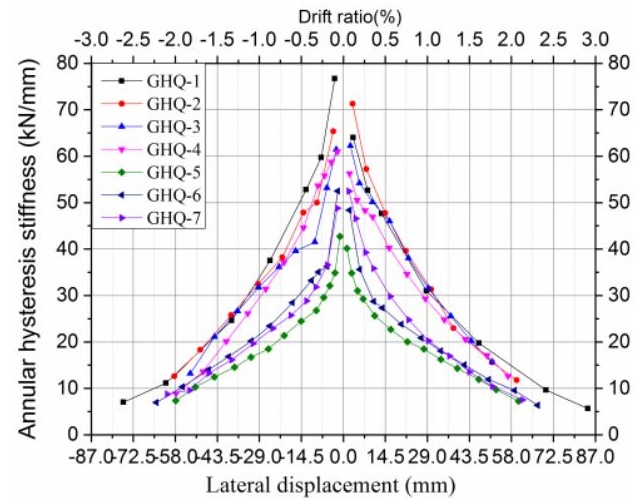

(a) Dimensional

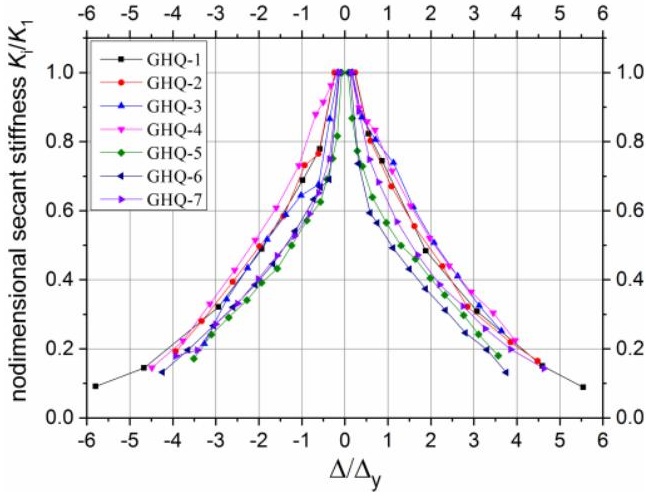

(b) Non-dimensional

Fig. 18 Stiffness degradation curves

\subsection{Lateral stiffness}

3.4.1. Initial stiffness and concrete reduction factor

The cross-sectional properties of the initial secant rigidity are expressed as $(E I)_{\mathrm{sec}, 0}=E_{\mathrm{s}} I_{\mathrm{s}}+\phi_{\mathrm{c}} E_{\mathrm{c}} I_{\mathrm{c}}$ and $(G A)_{\mathrm{sec}, 0}=\left(G_{\mathrm{s}} A_{\mathrm{sw}}+\phi_{\mathrm{c}} G_{\mathrm{c}} A_{\mathrm{c}}\right) / 1.2$,

where $E_{\mathrm{s}}, E_{\mathrm{c}}$ are the elastic moduli of steel and concrete, respectively; $G_{\mathrm{s}}, G_{\mathrm{c}}$ are the shear moduli of steel and concrete, taken as $E_{\mathrm{s}} / 2.6$ and $E_{\mathrm{c}} / 2.4$, respectively; $I_{\mathrm{s}}, I_{\mathrm{c}}$ are the inertia moments of steel and concrete; $\phi_{\mathrm{c}}$ is the reduction factor accounting for the nonlinear behavior of concrete and tensile and shear cracks of concrete; $A_{\mathrm{sw}}=2 B t$ is the steel web area of a CFT-wall, where $B$ is the wall width and $t$ is the thickness of the faceplates; and $A_{\mathrm{c}}$ is the concrete area.

The initial secant rigidities of the specimens are expressed as

$K_{0}=\frac{\frac{3(E I)_{\mathrm{se}, 0}}{h_{\mathrm{st}}^{3}} \cdot \frac{(G A)_{\mathrm{sec}, 0}}{h_{\mathrm{st}}}}{\frac{3(E I)_{\mathrm{sec}, 0}}{h_{\mathrm{st}}^{3}}+\frac{(G A)_{\mathrm{sec}, 0}}{h_{\mathrm{st}}}}$

The yield point secant rigidity is

$K_{\mathrm{e}}=\frac{\frac{3(E I)_{\mathrm{sec}, y}}{h_{\mathrm{st}}^{3}} \cdot \frac{(G A)_{\mathrm{sec}, \mathrm{y}}}{h_{\mathrm{st}}}}{\frac{3(E I)_{\mathrm{sec}, \mathrm{y}}}{h_{\mathrm{st}}^{3}}+\frac{(G A)_{\mathrm{sec}, y}}{h_{\mathrm{st}}}}$

$K_{0}$ and $K_{\mathrm{e}}$ are calculated based on the test results and are summarized in Table 5. Ratio $K_{\mathrm{e}} / K_{0}$ is within $0.6-0.7$. The theoretical rigidity considering only steel is

$$
K_{\mathrm{s}}=\frac{\frac{3 E I_{\mathrm{s}}}{h_{\mathrm{st}}^{3}} \cdot \frac{G A_{\mathrm{sw}}}{h_{\mathrm{st}}}}{\frac{3 E_{s} I_{\mathrm{s}}}{h_{\mathrm{st}}^{3}}+\frac{G A_{\mathrm{sw}}}{h_{\mathrm{st}}}}
$$

$K_{\mathrm{s}}$ is also provided in Table 4 . It was found that $K_{\mathrm{e}}$ is only slightly greater than $K_{\mathrm{s}}$, which suggests that the contribution of concrete to the lateral stiffness is small.

Based on the initial secant stiffness of the tested specimens, the reduction factor $\phi_{\mathrm{c}}$ is computed and listed in Table 4, which is within 0.3-0.6. It is found that the specimens with smaller $B / h_{\mathrm{st}}$ (bending deformation dominant) having a larger $\phi_{c}$. In addition, the initial shear deformation values in percentage $\xi$ listed in Table 4 were computed as follows:

$$
\xi=\frac{\frac{3(E I)_{\mathrm{sec}, 0}}{h_{\mathrm{st}}^{3}}}{\frac{3(E I)_{\mathrm{sec}, 0}}{h_{\mathrm{st}}^{3}}+\frac{(G A)_{\mathrm{sec}, 0}}{h_{\mathrm{st}}}}
$$

\subsubsection{Stiffness degradation}

The stiffness of the specimens decrease gradually as the lateral displacement and test circles increase, which is mainly due to the cumulative plastic damage during the test. To investigate the stiffness degradation of the specimens, secant hysteresis stiffness $K_{i}$ is defined as

$$
K_{i}=\frac{\left| \pm P_{i}\right|}{\left| \pm y_{i}\right|}
$$

where $K_{i}$ is the annular hysteresis stiffness of the $i$ th cycle at the displacement 
level of $I$, and $P_{i}, y_{i}$ are the maximum lateral force and the corresponding displacement of the $i$ th cycle at the displacement level of $I$, respectively.

Figs.18(a) and (b) show the dimensional and non-dimensional stiffness degradation of the specimens at various displacements (drift ratios), respectively. The initial annular stiffness is mainly controlled by the bending stiffness around the cross-sectional strong axis of the specimens when the other parameters are the same. Fig.18(b) shows that the stiffness of the slenderer specimens(GHQ-5 to GHQ-7) decreases more steeply after the specimens yield.

\subsection{Energy dissipation capacity}

The energy dissipated at each loading level can be measured as the area enclosed by the hysteresis loop. An equivalent hysteretic damping coefficient, $h_{e}^{[20]}$, is used in this study to evaluate the energy dissipation capacity of the specimens, as expressed in Eq. (14).

$$
h_{e}=\frac{1}{2 \pi} \frac{S_{\mathrm{ABCDEF}}}{S_{\triangle \mathrm{OCH}}+S_{\triangle \mathrm{OFG}}}
$$

where $S_{\mathrm{ABCDEF}}$ is the area enclosed by the hysteresis loop indicated in Fig.19, $S_{\mathrm{OCH}}$ and $S_{\mathrm{OFG}}$ are the areas of triangles $\mathrm{OCH}$ and $\mathrm{OFG}$ (the shadowed areas), respectively, illustrated in the inset of Fig.19. These areas are computed, and the equivalent hysteretic damping coefficients $h_{e}$ of the specimens are depicted in Fig.19.

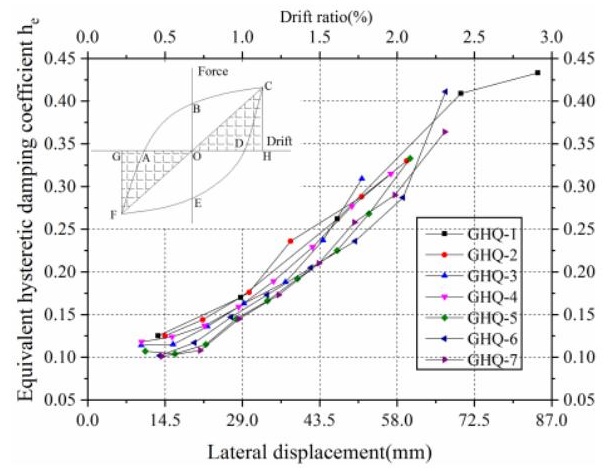

Fig. 19 Energy dissipation capacity of specimens

As expected, $h_{e}$ increases with increasing lateral displacement. Before the yielding of the specimens, the values of the coefficient are approximately 0.10 . During the yielding development stage, it ranges from 0.10 to 0.15 . The final equivalent damping coefficients of all the specimens are over 0.3 , which indicates that the specimens have good energy dissipation capacity. As all the specimens have similar values of equivalent damping coefficients, the configuration of the shear walls has a limited effect on the energy dissipation capacity of the specimens.

\section{Fiber element method}

The fiber element method is a highly efficient numerical scheme for simulating the monotonic and cyclic behaviors of composite cross-sections, including circular ${ }^{[21]}$ and square CFT columns ${ }^{[22,23,24]}$ and concrete-filled double-skin steel-plate composite walls ${ }^{[25]}$. In the fiber element model, the cross-section components are discretized into small fibers, as shown in Fig.20, and the uniaxial stress-strain curves are used for each fiber of the cross-section. Compared to the conventional finite element method, the fiber element method has a lower computational cost with fewer degrees of freedom because only sectional fibers are required in the analysis. Hence, the fiber element method

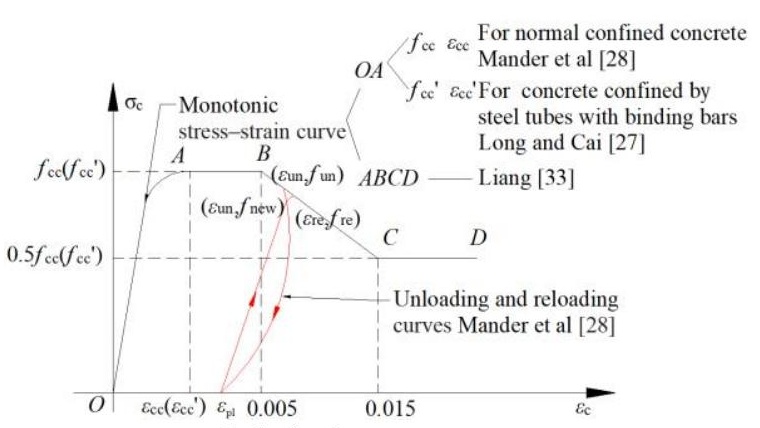

(a) Confined concrete was employed to simulate the cyclic performance of the seven specimens in this study.

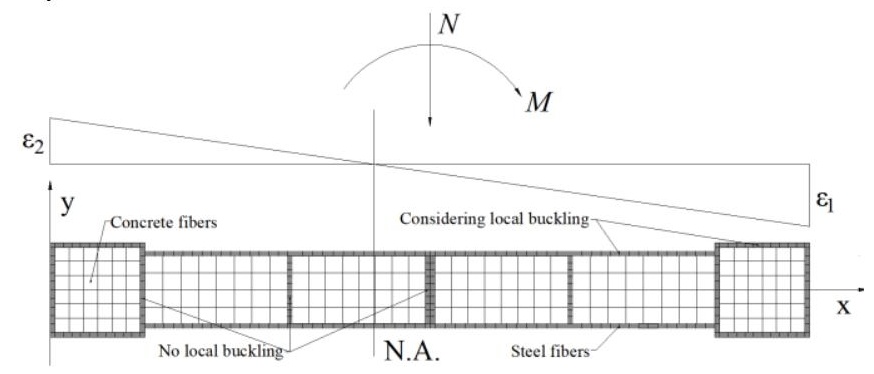

Fig. 20 Discretization of composite shear walls

In addition, the following assumptions are made in the analysis:

(1) Plane sections of the concrete core and steel sheets remain plane, and the material fibers in the cross-section are subjected only to the uniaxial stress states during the analysis.

(2)The slip between the concrete and a steel tube is not considered which was demonstrated to have little effect on the strength ${ }^{[26]}$.

(3)The tensile strength of concrete and the effects of creep and shrinkage are neglected.

(4) The effects of concrete confinement and tie-bolts on the strength and ductility are considered in the stress-strain model for confined concrete ${ }^{[27,28]}$.

(5) The shear deformation of a double-skin-profiled composite shear wall was studied by $\mathrm{Nie}^{[29]}$ and Zhang ${ }^{[30]}$, who found that the shear deformations accounted for approximately $20 \%$ of the total deformation when the shear span ratio of the wall was 2.0. As discussed in Section 3.4.1, the shear deformation accounts for $10 \%-15 \%$ of the total lateral deformation(Table 4 ) in the very initial state. In the late stage, it was found that the shear modulus of concrete rapidly drops to zero ${ }^{[31]}$, and the shear deformation contributes a greater part to the total lateral deformation. In this study, it is assumed that the shear deformation percentage in the total deformation is doubled in the late stage, i.e., $30 \%$ for GHQ-1-3, 25\% for GHQ-4, and 20\% for GHQ-5-7.

The stress-strain relationships of the confined concrete and steel sheets are shown in Fig.21; they consist of two parts: (1) a monotonic behavior during compression and tension, and (2) hysteresis rules governing the behavior under cyclic loading. For the confined concrete, the effect of the tie-bolts on the concrete core, such as the concrete in G-2 of Specimen GHQ-1, was considered using the material model proposed by Long and $\mathrm{Cai}^{[27]}$. Considering the local buckling of the steel sheets, as shown in Fig.20, the stress-strain relationship incorporating a descending stage proposed by Thai ${ }^{[32]}$ was used to determine the post-local buckling behavior of the steel sheets. The main parameters and formula are presented in Fig.21, and more details on the stress-strain relationships of the confined concrete and steel sheets can be found in the papers by Marder ${ }^{[28]}$, Liang ${ }^{[33]}$, and $\mathrm{Shi}^{[34]}$.

The hysteretic and envelop curves calculated by the fiber element method are compared to the experimental results, as shown in Fig.22, and a good agreement is found. In addition, the yield and inelastic local buckling points of the edge steel fiber were obtained. The fiber element models have slightly higher lateral stiffness than the experimental values, which may be owing to the assumption of shear deformations of the shear walls, local bending of the faceplates, and slippage of the foundation beam and bolts, as discussed by $\mathrm{Han}^{[35]}$. The fiber element method used in this study is effective with reasonable accuracy; however, the weld cracks and thereby the loss of strength in both the nearby steel and concrete cannot be incorporated into the model. This is the cause of the difference between the method and experimental results in the late post-peak stage.

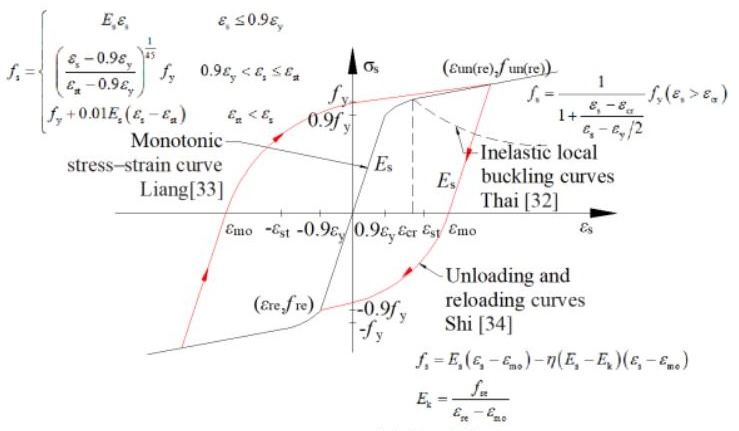

(b) Steel sheets 

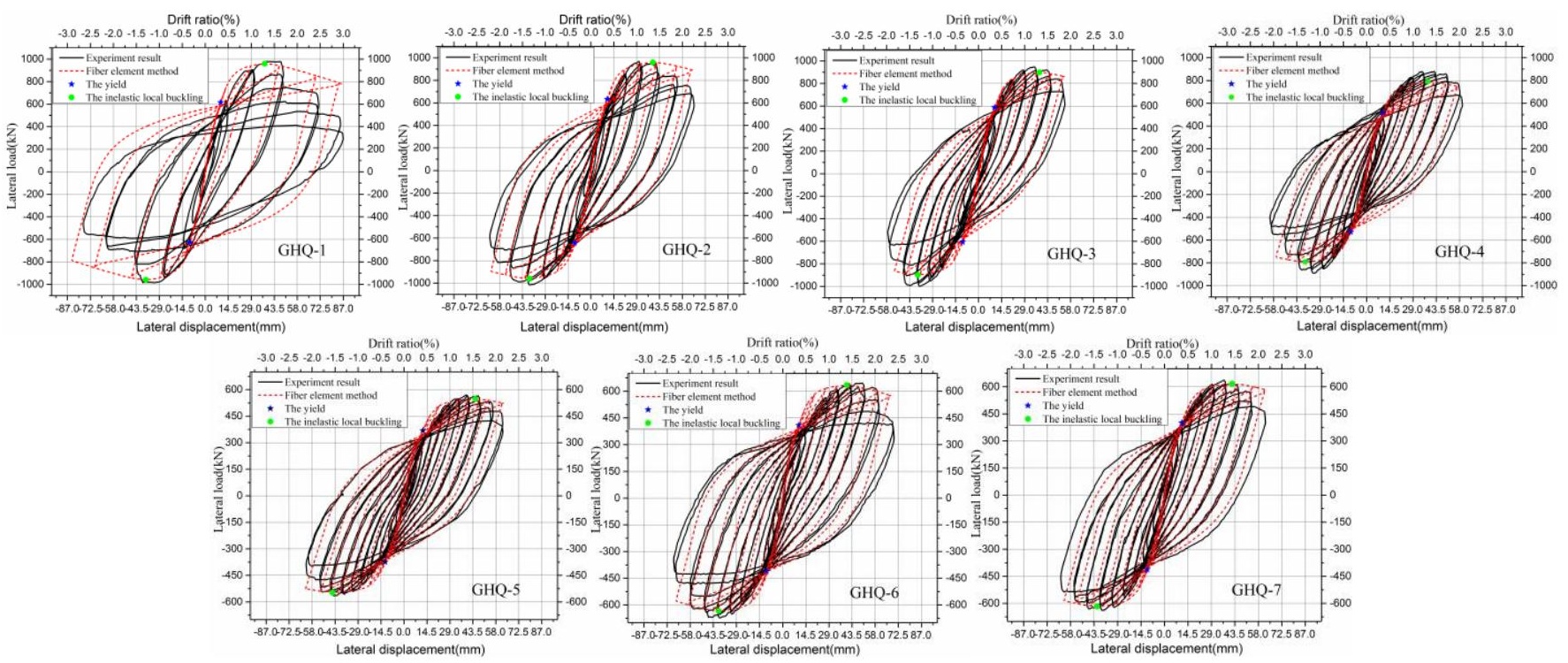

Fig. 22 Comparison between experimental hysteretic curves and calculated curves

\section{Summary and conclusions}

In present study, the hysteretic behavior of an innovative multi-cellular CFT-walls with tie-bolts was studied. Seven full-scale tests were conducted under constant axial and cyclic lateral loads. The axial force was taken to be the limit used in practice. The width-to-thickness ratios of the faceplates and the total width of the walls were varied among the specimens.

Before the treatment of the test results, the $P-\Delta$ effect was excluded from the lateral force-drift curves because the $P-\Delta$ effect is considered independently in the current design codes.

The following conclusions can be drawn:

(1) All the specimens show similar hysteretic behaviors and failure patterns during the tests. The lateral force versus displacement hysteretic curves are spindle-shaped without a discernible pinching effect, which indicates that the specimens have favorable hysteresis behavior, deformation capacity, and energy dissipation.

(2) Failure was triggered by the plastic local buckling of the faceplates and the tensile cracks of the cold-formed corner after repeated tension and local buckling. As the buckling deformation of the steel faceplates became severe and the concrete crushed gradually, the specimens failed during the fracture

\section{References}

[1] Pryer J.W. and Bowerman H.G., "The development and use of British steel bi-steel", Journal of Constructional Steel Research, 46(1-3), 15-0, 1998.

[2] Gough V. and Grubb K., "Fast Steel cores", Modern Steel Constrction, AISC, June, 2007.

[3] Bowerman H.G. and Chapman J.C., "Bi-steel ${ }^{\mathrm{TM}}$ steel-concrete-steel sandwich construction", Composite Construction in Steel and Concrete IV, 656-667, 2002.

[4] McKinley B. and Boswell L.F., "Behaviour of double skin composite construction", Journal of Constructional Steel Research, 58 (10), 1347-1359, 2002.

[5] Eom T.S., Park H.G., Lee C.H., Kim J.H. and Chang I.H., "Behavior of double skin composite wall subjected to in-plane cyclic loading", Journal of Structural Engineering, 135 (10), 1239-1249, 2009.

[6] Zhang K., Varma A. H., Malushte S. R. and Gallocher S., "Effect of shear connectors on local buckling and composite action in steel concrete composite walls", Nuclear Engineering and Design, 269, 231- 239, 2014

[7] Yang Y., Liu J.B. and Fan J.S., "Buckling behavior of double-skin composite walls: An experimental and modeling study", Journal of Constructional Steel Research, 121, 126-135, 2016.

[8] Nie J.G., Hu H.S., Fan J.S., Tao M.X., Li S.Y. and Liu F.J., "Experimental study on seismic behavior of high-strength concrete filled double-steel-plate composite walls", Journal of Constructional Steel Research, 88, 206-219, 2013.

[9] Huang S.T., Huang Y.S., He A., Tang X.L., Chen Q.J., Liu X.P. and Cai J., "Experimental study on seismic behaviour of an innovative composite shear wall", Journal of Constructional Steel Research, 148, 165-179, 2018

[10] Guo L.H., Wang Y.H. and Zhang S.M., "Experimental study of rectangular multi-partition steel-concrete composite shear walls", Thin Walled Structures, 130, 577-592, 2018

[11] Zhang X.M., Qin Y. and Chen Z.H., "Experimental seismic behavior of innovative composite shear walls", Journal of Constructional Steel Research, 116, 218-232, 2016.

[12] Zhang X.M., Qin Y., Chen Z.H. and Jie L., "Experimental behavior of innovative T-shaped composite shear walls under in-plane cyclic loading", Journal of Constructional Steel Research, 120, 143-159, 2016.

[13] T/CECS 546-2018, Technical standard for structures with concrete-filled multi-cellular steel tube walls, China Association for Engineering Construction Standardization, China JiHua Press, 2018

[14] Eurocode 4, Design of composite steel and concrete structures, Part 1.1: General rules and rules for buildings, British Standards Institution, London, 1994

[15] P.S. Bulson, The Stability of flat plates, Chatto\&Windus, London, 1970.

[16] GB/T50081-2002, Test Method of Mechanical Properties on Ordinary Concrete, China propagation of the steel profile and the crushing of the concrete.

(3) Based on the experimental observations, the tie-bolts can suppress the local buckling half-wavelength of the steel sheets, validating the design method of the specimens.

(4) The presence of tie-bolts in the middle tubes (G-1) of Specimen GHQ-2 has an insignificant effect on the peak load and ductility of the specimens owing to a low stress distribution. This suggests that the tie-bolts may not be present in the middle cells, even if the middle cells have a larger width-to-thickness ratio than that in the edge CFT columns.

(5) The width-to-thickness ratios of the faceplates have no discernible effect on the behavior in the investigated range $(50,55,60)$ when the boundary tubes are the same.

(6) Two idealized models for the hysteretic curves were proposed. One was Newmark and Hall's model, in which the average ductility factor of the specimens is 3.10. The second was Ibarra and Krawinkler's trilinear model, in which the average "peak drift/yield drift" ductility is 2.70 and the average "useful drift/yield drift" ratio is 3.95

(7) The hysteretic and envelop curves calculated by the fiber element method are compared to the experimental results, and a good agreement is found.

Ministry of Construction, Beijing, 2003.

[17] JGJ 101-96, Specification of Testing Methods for Earthquake Resistant Building. China Planning Press, Beijing, 1997

[18] Newmark N. M. and Hall W.J., "Earthquake spectra and design", Earthquake Engineering Research Institute, 1982.

[19] Ibarra L. F., MedinaR. A. and Krawinkler H, "Hysteretic models that incorporate strength and stiffness deterioration", Earthquake Engineering and Structural Dynamics. 34, 1489-1511, 2005

[20] Nie J.G., Fan J.S., Liu X.G. and Huang Y., "Comparative study on steel plate shear walls used in a high-rise building", Journal of Structural Engineering, 139(1), 85-97, 2012.

[21] Liang Q.Q., "Nonlinear analysis of circular double-skin concrete-filled steel tubular columns under axial compression", Engineering Structures, 131, 639-650, 2017.

[22] Patel V.I., Liang Q.Q. and Hadi M.N.S, "Numerical analysis of high-strength concrete-filled steel tubular slender beam-columns under cyclic loading", Journal of Constructional Stee Research, 92, 183-194, 2014.

[23] Zubydan A.H. and Elsabbagh A.I., "Monotonic and cyclic behavior of concrete-filled steel-tube beam-columns considering local buckling effect", Thin WalledStructures.49 (4), 465-481, 2011

[24] Wang Y.T., Cai J. and Long Y.L., "Hysteretic behavior of square CFT columns with binding bars", Journal of Constructional Steel Research, 131, 162-175, 2017.

[25] Hu H.S., Nie J.G. and Eatherton M.R., "Deformation capacity of concrete-filled steel plate composite shear walls", Journal of Constructional Steel Research, 103, 148-158, 2014.

[26] Hajjar J. F., Schiller P. H. and Molodan A., "A distributed plasticity model for concrete-filled steel tube beam-columns with interlayer slip", Engineering Structures, 20 (8), 663-676, 1998.

[27] Long Y.L. and Cai J., "Stress-strain relationship of concrete confined by rectangular steel tubes with binding bars", Journal of Constructional Steel Research, 88, 1-14, 2013.

[28] Mander J.B., Priestley M.J.N. and R. Park, "Theoretical stress-strain model for confined concrete", Journal of Structural Engineering, ASCE, 114(8), 1804-26, 1988.

[29] Nie J.G., Ma X.W., Tao M.X., Fan J.S. and Bu F.M., "Effective stiffness of composite shear wall with double plates and filled concrete", Journal of Constructional Steel Research, 99, $140-148,2014$

[30] Zhang X.M., Experimental study and theoretical analysis on seismic performance of composite shear wall with steel tubes and filled concrete, Tianjin University, Tianjin, 2016.

[31] Rahal K. N., "Post-cracking shear modulus of reinforced concrete membrane elements", Engineering Structures, 32(1), 218-225, 2010.

[32] Thai H.T., Uy B. and Khan M., "A modified stress-strain model accounting for the local buckling of thin-walled stub columns under axial compression", Journal of Constructional Steel Research, 111, 57-69, 2015. 
[33] Liang Q.Q., "Performance-based analysis of concrete-filled steel tubular beam columns, par I: theory and algorithms", Journal of Constructional Steel Research, 65(2), 363-72, 2009.

[34] Shi G., Wang M., Bai Y., Wang F., Shi Y.J. and Wang Y.Q., "Experimental and modeling study of high-strength structural steels under cyclic loading", Engineering Structures. 37, $1-13,2012$.

[35] Han W.L., "Discussion on "Experimental seismic behavior of innovative composite shear walls” by Xiaomeng Zhang, Ying Qin and Zhihua Chen [J Constr Steel Res 2016; 116(1): 218-232] and "Experimental behavior of innovative T-shaped composite shear walls under in-plane cyclic loading" by Xiaomeng Zhang, Ying Qin, Zhihua Chen and Li Jie [J Constr Steel Res 2016; 120(4): 143-159]", Journal of Constructional Steel Research, 147, 187-190, 2018. 


\title{
PARAMETRIC AND COMPARISON STUDY OF A NEW AND TRADITIONAL ALUMINUM ALLOY JOINT SYSTEMS
}

\author{
Yu-Qi Jiang ${ }^{5}$, Hui-Huan Ma ${ }^{1,2,3,4 *}$, Guang-Tong Zhou ${ }^{5}$ and Feng Fan ${ }^{5}$ \\ ${ }^{1}$ School of Civil Engineering, Sun Yat-Sen University, Guangzhou, PR China \\ ${ }^{2}$ Southern Marine Science and Engineering Guangdong Laboratory (Zhuhai), PR China \\ ${ }^{3}$ Guangdong Key Laboratory of Oceanic Civil Engineering, PR China \\ ${ }^{4}$ Key Laboratory of Building Fire Protection Engineering and Technology of MPS \\ ${ }^{5}$ Harbin Institute of Technology, Harbin, 150090, China \\ * (Corresponding author: E-mail: mahh5@mail.sysu.edu.cn)
}

\section{A B S T RA C T}

Aluminum alloy penetrating (AAP) joint system is a new type of semi-rigid aluminum alloy joint developed by adding a U-shaped connector and a penetrating member to the original Aluminum Alloy Temcor (AAT) joint. For the commonly used aluminum materials in structural engineering, 6061-T6 aluminum alloy, the static out-of-plane bending moment resistance tests of six specimens of the AAP joints are carried out. The failure modes and moment $(\mathrm{M})$-rotation $(\Phi)$ curves of different cover shapes are obtained. Considering the influence of factors such as the contact surface, installation gap and bolt pre-tightening force on the joint, finite element method is used to establish simulation models of AAP joints and AAT joints, and the failure modes and $M-\Phi$ curves are obtained. By comparing the static performance of the two joints, the stiffness and bearing capacity of the new AAP joint are significantly better than the traditional AAT joints. The parameter analysis of the rotational resistance performance of AAP joints and AAT joints under bending moment and different axial tension and pressure is carried out. Comparing the rotation performance of the two joints under different axial forces, the axial tension force is a more unfavorable load for the joints, and the AAP joints perform better than the AAT joints after being subjected to the axial tensile load.

\section{ART I CLE H I S T ORY}

$\begin{array}{ll}\text { Received: } & 25 \text { May } 2020 \\ \text { Revised: } & \text { 5 October } 2020 \\ \text { Accepted: } & 27 \text { October } 2020\end{array}$

\section{K E Y W O R D S}

Aluminum alloy penetrating (AAP) joint;

Aluminum alloy Temcor (AAT) joint;

Moment-rotation curve;

Failure mode;

Rotational resistance performance:

Numerical simulation

\section{Introduction}

The aluminum alloy was first applied to architectural structures in European and American countries in the 1940s. It was widely used because of the unique advantages of aluminum alloy materials [1].Its technology originated from the aerospace industry at the time. China began the application and research of aluminum alloy structures in the 1990s. The use of aluminum in building structures has come a new trend [2]. As a structural material, aluminum is light and corrosion-resistant which has the irreplaceable advantages of other building materials [3]. Meanwhile, aluminum structures have a strong modern feel and convenient construction [4], so it has broad application prospects in large-span landmark buildings such as sports and performance venues [5]. Currently, domestic large-span aluminum space structures are mainly divided into three types: single-layer spherical reticulated shells, bolt-ball jointed grids, and double-layer reticulated shells.

In recent years, with the increasing requirements for the beautiful appearance of buildings, single-layer free-form surface structures have received a growing number of attention, and the requirements for aluminum alloy joints have gradually increased. Based on the traditional requirements of rigidity and bearing capacity, higher requirements have been put forward on the direction angles of spatial connections, installation accuracy and construction speed of aluminum joints [6]. In this regard, research and development of new aluminum joints have been carried out at home and abroad, such as the self-piercing riveted joints [7, 8], T-stub joints [9, 10], aluminum welded connections [11], cast aluminum joints [12]. Research on the aluminum space structures in China started relatively late. Currently, the most widely used joint system is Temcor joint system. Temcor joint is equipped with $\mathrm{H}$-section members. For the mechanical performance of Temcor joint, domestic scholars have conducted a lot of analysis and research. Series of experimental and numerical investigations of Temcor joint in normal and high temperature environments were carried out. [13-23] Zhang [24] carried out a numerical simulation analysis of Temcor joints, and pointed out that the stress of the cover plate was mainly normal stress, which gradually decreased from the middle to the edge. The stress of the member was small and did not yield. The failure mode of the Temcor joints was the bolt yields under shear. Qian [25] proposed that the number of bolts and bolt holes, the size of the cover plate and the amount of arching were important parameters that affected the mechanical performance of the Temcor joints. The lower limit of the cover plate thicknesses of was determined by the thickness of flanges, and the lower limit of the plate diameter was determined by the size of the end of the member. Zou [26] carried out a finite element numerical simulation analysis of Temcor joint, and found that the stress at the contact surface between the cover plates and the numbers was relatively large, but the stress distribution was uniform and reasonable. There was a phenomenon of stress concentration near the bolt holes. The bending stiffness of the joint was calculated out of the joint. It was pointed out that the AAT joint was a semi-rigid joint.

In this paper, based on the traditional AAT joint, the method of adding a $U$ connector and a penetrating member was proposed to develop a new type of aluminum semi-rigid joint, AAP joint. The static rotational resistance performance tests of AAP joints with different gusset shapes and gusset thicknesses under out-of-plane moment were carried out, and the failure modes and M- $\Phi$ curves were obtained. The simulation analysis models of AAP joints and AAT joints corresponding to the experiment were established by using the ABAQUS. The static performance of the two joints, like $M-\Phi$ curves failure modes, was compared. Then, the parameter analysis of the anti-rotation performance of AAP joints and AAT joints considering the influence of axial forces was carried out, and the differences of two joints were analyzed.

\section{AAT joint system and AAP joint system}

Aluminum space structures have prevailed with the application of largespan aluminum roofs, grids, and shells. Because of its poor weldability, aluminum structures are mainly connected by mechanical connections in which the aluminum alloy Temcor (AAT) joint is the most common, as shown in Fig. 1. At present, AAT joint is used in many new single-layer reticulated shell structures in China, for example, the Shanghai Science and Technology Museum built in 2001 is a traditional single-layer aluminum reticulated shells jointed by AAT joints. However, the AAT joint only uses the top and bottom gusset bolts to connect the gusset and the flange, the web of the member is disconnected in the joint region. There are deficiencies such as unclear force transmission path and poor shear resistance performance. 


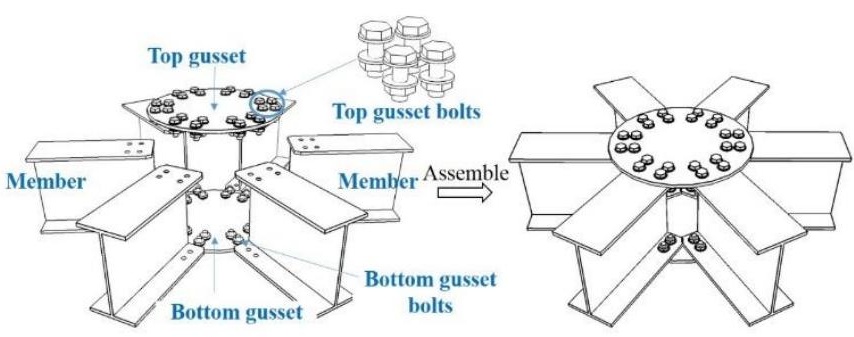

Fig. 1 AAT joint system

Aiming at modifying the disadvantages of the AAT joint in structural and mechanical performance, a new type of semi-rigid aluminum penetrating joint system is designed and developed in this paper, as shown in Fig. 2.The penetration of a joint member has solved the problem of discontinuity of the web in the joint region. At the same time, a U-shaped piece is added to tightly connect the webs of penetrating member and short member. This design improves the overall stiffness and shear resistance of the joint.
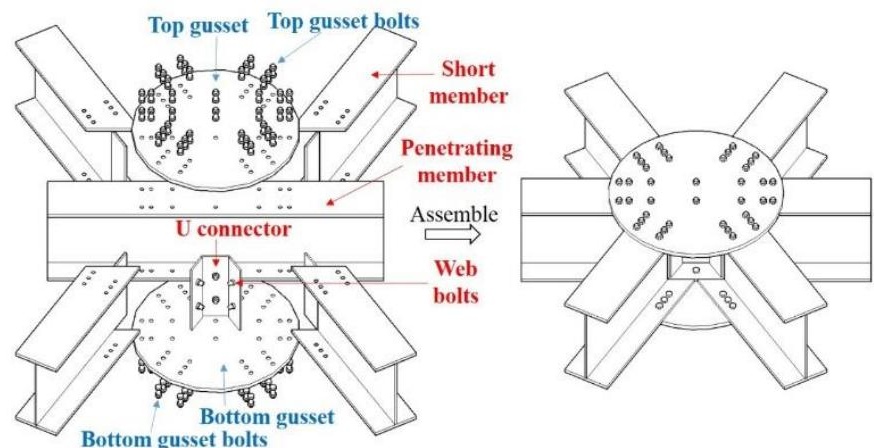

Fig. 2 AAP joint system

\section{Numerical simulation method of joint rotational resistance}

The joint rotational resistance performance is affected by many parameters such as the connection methods, component sizes and bolt forms. Using the large-scale finite element analysis software ABAQUS to analyze the force condition and performance of the joint is a very suitable and efficient method. In this chapter, ABAQUS finite element software was used to establish finite element models of AAP joints and AAP joints corresponding to the test sizes. The stiffness and ultimate bearing capacity of AAT joint and AAP joint were compared, and the difference between the two joints was analyzed.

\subsection{Establishment of numerical models}

The ABAQUS finite element software was used to analyze the mechanical performance of the AAP and AAT joints with $6 \mathrm{~mm}$ and $12 \mathrm{~mm}$ gussets. In order to achieve a comparative study between the finite element analysis (FEA) and test results, the dimensions of numerical models were exactly the same as those of the test specimens, and the dimensions of gussets, members and bolts of AAT models were the same as AAP models. The boundary conditions of the pinned constraints were applied at the ends of the six members, and six equal vertical loads were applied near the gussets to simulate the closest constraint and load conditions to the test. Numerical models of AAP joints used solid elements in ABAQUS, such as the 3D octahedral reduced integral element, C3D8R Element. Based on the three-dimensional octahedral reduction integration, during the meshing process of the joint numerical models, the locations with large stress and obvious deformation were finely meshed to obtain more accurate calculation results, such as bolts of gussets and webs, bolt holes, areas near bolt holes and U-shaped connectors, etc. However, the mesh size in other locations where the joint models had less deformation and stress became larger to increase efficiency. The numerical model was shown in Fig. 3.

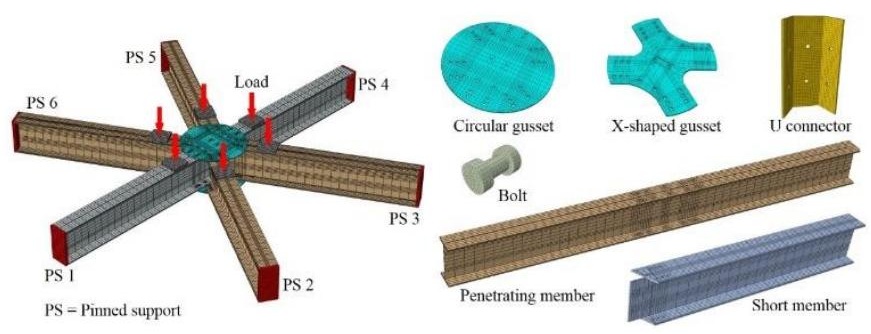

(a) AAP joint model
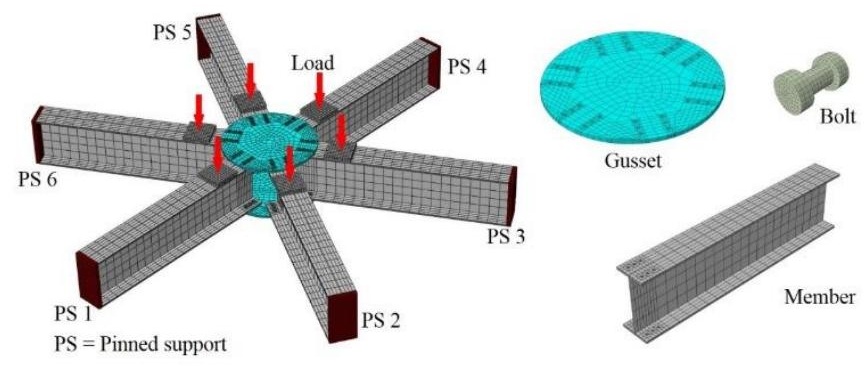

(b) AAT joint model

Fig. 3 Numerical simulation models

The material constitutive model of aluminum members and gusset adopted the classic Ramberg-Osgood aluminum material model. The expected properties of the constitutive model were very close to the actual material properties, so it was widely accepted and used, and its general form was shown in equation (1):

$\varepsilon=\frac{\sigma}{E}+0.2\left(\frac{\sigma}{f_{0.2}}\right)^{n}$

In the above equation, $\sigma$ was the stress of the aluminum alloy, and $\varepsilon$ was the strain corresponding to the stress $\sigma . f_{0.2}$ was the stress value of the residual strain $0.2 \%, E$ was the elastic modulus, and $\mathrm{n}$ is equal to 41.542 . In order to reduce the error between the test and the numerical simulation, the material property data of the aluminum 6061-T6 measured in the material property test was used. Poisson's ratio, $v$, was 0.3 , and density of aluminum, and $\rho_{\mathrm{Al}}$ was $2700 \mathrm{~kg} / \mathrm{m}^{3}$ The model of the bolt material used an ideal elastic-plastic model of stainless steel A4-70 with $f_{0.2}$ equal to $450 \mathrm{MPa}$, elastic modulus, $E$, equal to $200000 \mathrm{MPa}$. Poisson's ratio, $v$, was 0.3 , and density, $\rho_{\mathrm{B}}$ was $7800 \mathrm{~kg} / \mathrm{m}^{3}$.

In non-linear analysis, the surface-to-surface contact needed to be defined in the numerical models. In addition to the contact between gussets and the flanges of the members, the source of the contact pair was mainly from the bolts and the U-shaped connectors, as shown in Fig. 4. A total of 386 contact pairs were provided in one AAP joint, and 300 contact pairs in one AAT joint, as shown in Table 1 below. The tangential action adopted the 'penalty' friction model. Taking into account the relevant provisions of the 'GB50429-2007 Aluminum Alloy Structure Design Code' on the anti-slip coefficient of the friction surface of aluminum alloys, the friction factor of 'penalty' friction in this article was 0.3 .
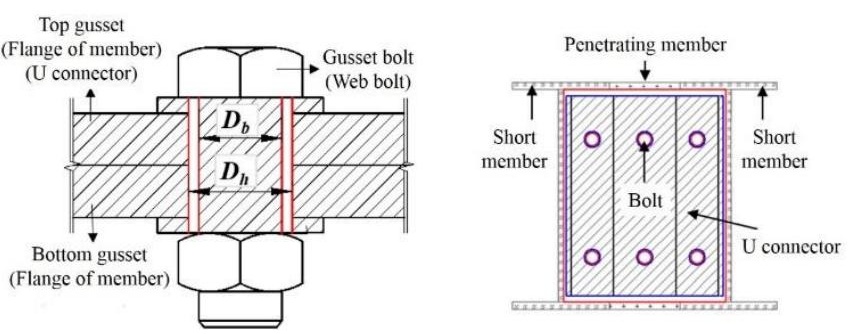

Fig. 4 Diagrams of contact pairs

There were 12 pairs of tie contacts of the AAP joint numerical model, half of which came from the end plates and the end of the member to achieve the pinned connection setting. The other half came from the loading plates and the flanges of members, which applied vertical force to the joint to avoid local buckling failure due to concentrated loads. 
Table 1

Statistics of contact pair

\begin{tabular}{|c|c|c|c|c|c|}
\hline Joint type & Number & Contact type & Master surface & Slave surface & Quantity \\
\hline \multirow{12}{*}{ AAP } & 1 & Surface-surface contact & Gusset & Flange & 10 \\
\hline & 2 & Surface-surface contact & Gusset & Screw & 76 \\
\hline & 3 & Surface-surface contact & Gusset & Nut & 76 \\
\hline & 4 & Surface-surface contact & Flange & Screw & 76 \\
\hline & 5 & Surface-surface contact & Flange & Nut & 76 \\
\hline & 6 & Surface-surface contact & U connector & Screw & 12 \\
\hline & 7 & Surface-surface contact & U connector & Nut & 12 \\
\hline & 8 & Surface-surface contact & Web & Screw & 10 \\
\hline & 9 & Surface-surface contact & Web & Nut & 8 \\
\hline & 10 & Surface-surface contact & U connector & Flange & 4 \\
\hline & 11 & Surface-surface contact & U connector & Web & 6 \\
\hline & 12 & Surface-surface contact & Penetrating & Short & 20 \\
\hline \multirow{7}{*}{ AAT } & Summation & Surface-surface contact & - & - & 386 \\
\hline & 1 & Surface-surface contact & Gusset & Flange & 12 \\
\hline & 2 & Surface-surface contact & Gusset & Screw & 72 \\
\hline & 3 & Surface-surface contact & Gusset & Nut & 72 \\
\hline & 4 & Surface-surface contact & Flange & Screw & 72 \\
\hline & 5 & Surface-surface contact & Flange & nut & 72 \\
\hline & Summation & Surface-surface contact & - & - & 300 \\
\hline
\end{tabular}

In the calculation of the numerical simulation, the pretension force of the bolt was taken into account. Deng Hua [27] used the pressure sensor to test the pretension force of the bolt in the shear test of the ring groove rivet connection of the aluminum alloy plate. The consistent air pressure and working stroke made the pretension force applied to each rivet basically the same. Therefore, the pretension force in this paper used the average value of the pre-tightening force obtained from the above study, $18.85 \mathrm{kN}$.

\subsection{Finite element model validation}

The numerical results were compared with the experimental results to validate their accuracy before the FEA method was applied to the investigation of AAP and AAT joints. The test focused on the rotational resistance performance of 6 specimens of AAP joints which could accurately find out the actual bearing capacity and failure status of the joints. The experimental data such as failure modes and moment-rotation curves of the AAP joint rotating under the out-of-plane moment were obtained to study the stress distribution and force transmission mechanism.

The test device, supports of specimens and connection device were shown in Fig. 5. This test loading device was a 200-ton hydraulic push-pull jack. The hydraulic jack is fixed on the bottom beam of the annular reaction frame. The force sensor was placed between the jack and the distribution beam. The distributive beam is welded by six $\mathrm{H}$-section steel beam, which divided the vertical concentrated force exerted by the jack into six and equally loaded on each member. The $\mathrm{H}$-section members and gussets of the test specimens were made from 6061-T6 aluminum alloy material. U-shaped connectors were made from stainless steel. Each component was connected by Huck bolts. The specific parameter settings of the test piece were shown in Table 2 . This test mainly studied the influence of the gusset thicknesses and shapes on the overall stiffness and ultimate bearing capacity.

Table 2

Specific parameters of specimens

\begin{tabular}{ccccc}
\hline Group number & $\begin{array}{c}\text { Specimen } \\
\text { number }\end{array}$ & Specimens & Gusset shape & Gusset thickness \\
\hline G1 & 2 & G1-1, G1-2 & Circular & $6 \mathrm{~mm}$ \\
G2 & 2 & G2-1, G2-2 & Circular & $12 \mathrm{~mm}$ \\
G3 & 2 & G3-1, G3-2 & X-shaped & $12 \mathrm{~mm}$ \\
\hline
\end{tabular}

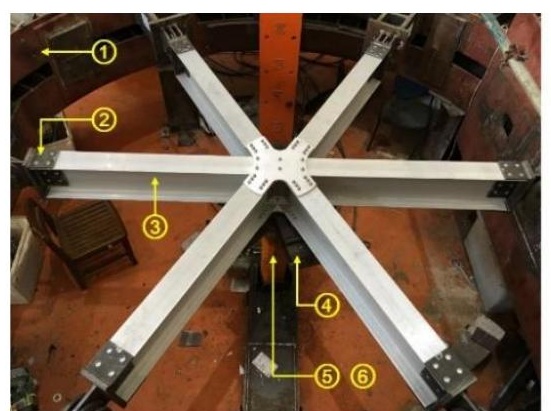

(1) Circular rigid reaction

(2) Pinned connection

(3) Specimen

(4) Distributive beam

(5) Force sensor

(6) Hydraulic jack

Fig. 5 Experimental device

After completing the establishment of the numerical model, the joint was numerically simulated in a bending moment state. The bending $M-\Phi$ curves and stress cloud diagrams at failure stage of the AAP joints obtained from experiments and numerical simulations were shown in Fig. 6 and 7. Further analysis of the $M$ - $\Phi$ curves gained the main characteristic parameters shown in Table 3. It was found that the joint simulation results were close to the test results, with an error of about $4 \%$. It could be considered that the results of and the numerical simulation were accurate and effective.

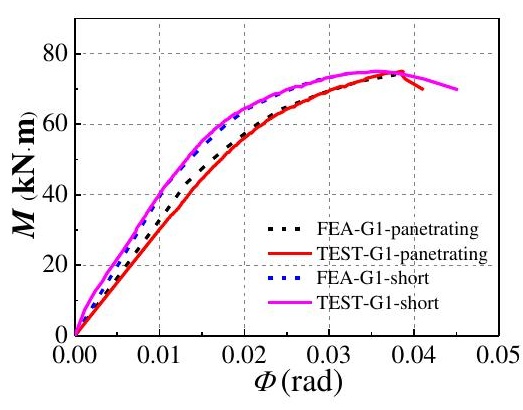

(a) G1 


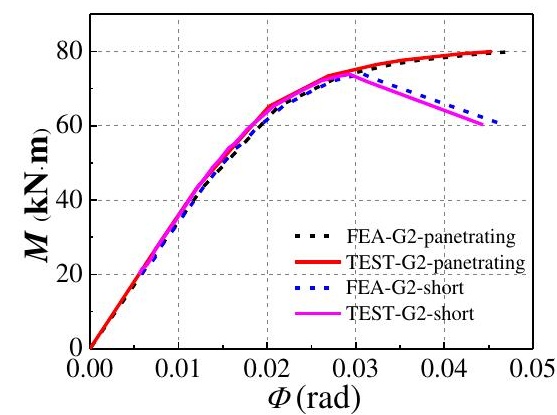

(b) G2

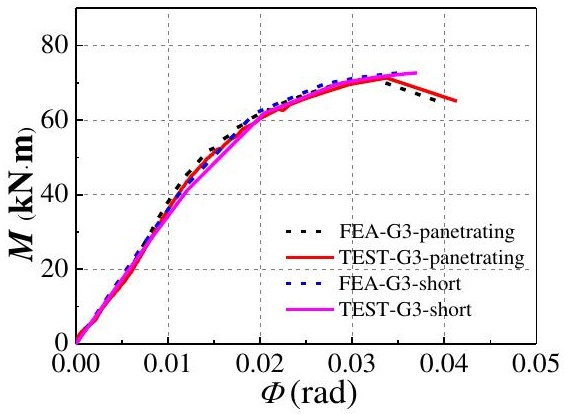

(c) G3

Fig. 6 Comparison of $M-\Phi$ curves of test and numerical simulation results
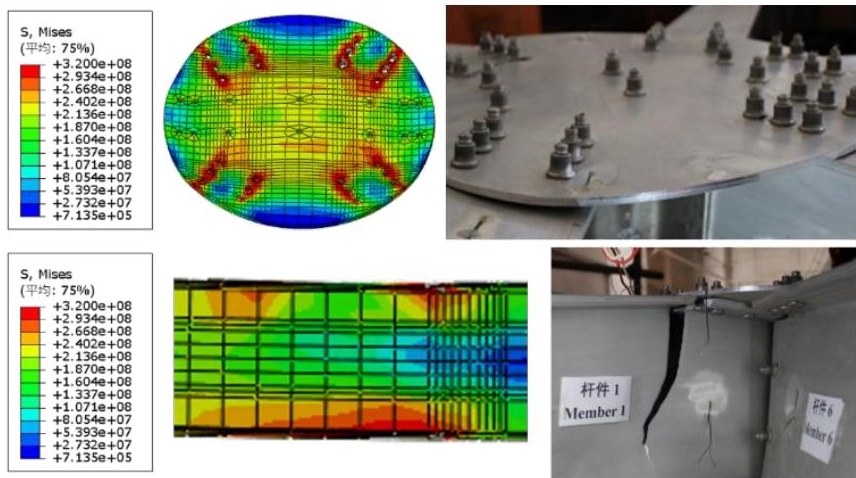

(a) G1
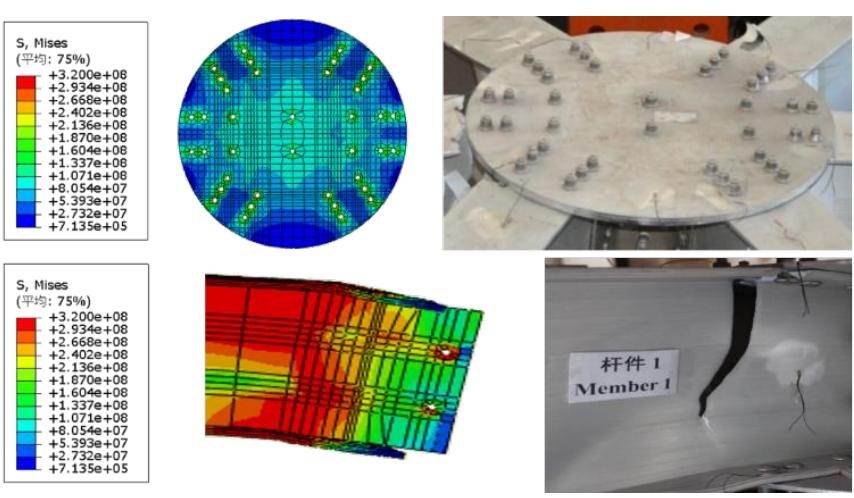

(b) G2
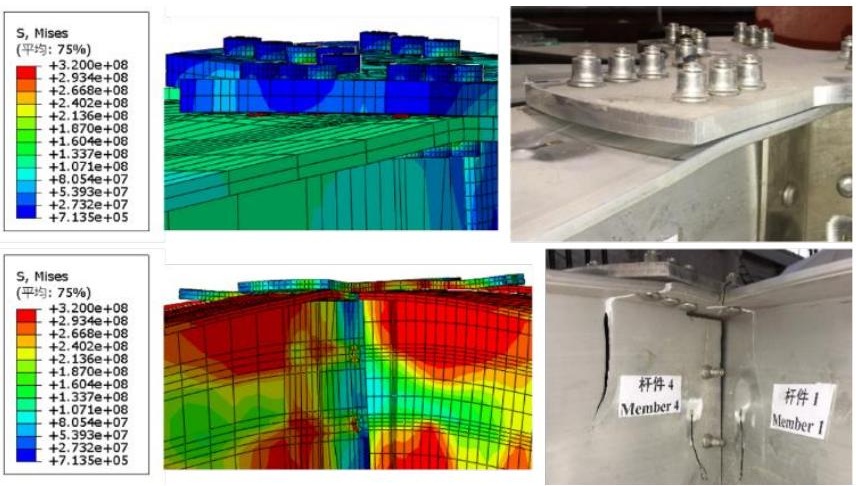

(c) G3

Fig. 7 Failure modes of test and numerical simulation

Table 3

Comparison of results from numerical simulation and test

\begin{tabular}{|c|c|c|c|c|c|c|c|c|c|}
\hline \multirow[t]{2}{*}{ Group number } & \multicolumn{3}{|c|}{$K_{\mathrm{i}}(\mathrm{kN} \cdot \mathrm{m} / \mathrm{rad})$} & \multicolumn{3}{|c|}{$M_{\mathrm{i}}(\mathrm{kN} \cdot \mathrm{m})$} & \multicolumn{3}{|c|}{$M_{\mathrm{u}}(\mathrm{kN} \cdot \mathrm{m})$} \\
\hline & $K_{\mathrm{i}, \text { test }}$ & $K_{\mathrm{i}, \mathrm{FEA}}$ & Error & $M_{\mathrm{i}, \text { test }}$ & $M_{\mathrm{i}, \text { FEA }}$ & Error & $M_{\mathrm{u} \text {, test }}$ & $M_{\mathrm{u}, \mathrm{FEA}}$ & Error \\
\hline G1 & 3163.6 & 3158.5 & $0.2 \%$ & 53.1 & 55.2 & $4.0 \%$ & 71.42 & 72.48 & $1.5 \%$ \\
\hline G2 & 3182.2 & 3175.5 & $0.2 \%$ & 55.2 & 54.7 & $0.9 \%$ & 73.76 & 75.21 & $2.0 \%$ \\
\hline G3 & 3183.5 & 3190.5 & $0.2 \%$ & 54.8 & 53.9 & $1.6 \%$ & 72.15 & 74.28 & $3.0 \%$ \\
\hline
\end{tabular}

\section{Numerical simulation comparison of AAP and AAT joints under beading moment}

As shown in Fig. 8, the comparison curves of the moment-rotation relationship of AAP and AAT joints under pure bending state was analyzed. It could be found that there was a large difference between the moment-rotation curves of the two kinds of joints. From the curve, the AAP joints were significantly better than the AAT joints in terms of initial rotational stiffness and ultimate bearing capacity. The overall change trends of the two types of joint curves were basically the same, and they both had obvious three-stage characteristics. After analyzing the bending moment curves, the main parameters shown in Table 4 were obtained. Analysis of the finite element simulation results of the two types of joints revealed that: (i) the initial rotational stiffness of the AAP joints increased by $38 \%$ compared with the AAT joints when the thickness of the gussets was $12 \mathrm{~mm}$, and the ultimate bearing capacity increased by $47 \%$. (ii) When the thickness of the gussets was $6 \mathrm{~mm}$, compared with the AAT joints, the initial rotational stiffness, $\mathrm{Ki}$, of the penetration members of AAP joints increased by $38 \%$, and $\mathrm{Ki}$ of the short members increased by $20 \%$. The elastic ultimate moment of the joint increased by $70 \%$, and the ultimate moment increased by $90 \%$.

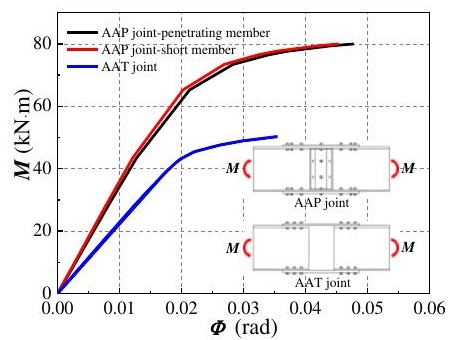


(a) $12 \mathrm{~mm}$ gusset joints

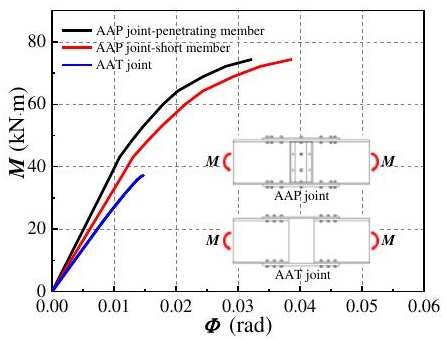

(b) $6 \mathrm{~mm}$ gusset joints

Fig. 8 Comparison of moment-rotation curves of AAP and AAT joints

Table 4

Characteristic parameters of moment-rotation curves of AAP and AAT joints

\begin{tabular}{|c|c|c|c|c|c|}
\hline $\begin{array}{c}\text { Gusset } \\
\text { thickness }\end{array}$ & Joint type & $\begin{array}{c}\text { Member } \\
\text { type }\end{array}$ & $\begin{array}{c}K_{\mathrm{i}} \\
(\mathrm{kN} \cdot \mathrm{m} / \mathrm{rad})\end{array}$ & $\begin{array}{c}M_{\mathrm{i}} \\
(\mathrm{kN} \cdot \mathrm{m})\end{array}$ & $\begin{array}{c}M_{\mathrm{u}} \\
(\mathrm{kN} \cdot \mathrm{m})\end{array}$ \\
\hline \multirow{3}{*}{$t=12 \mathrm{~mm}$} & \multirow{2}{*}{ AAP } & Penetrating & 3181.9 & 54.8 & 72.1 \\
\hline & & Short & 3192.1 & 55.0 & 72.1 \\
\hline & AAT & - & 2291.0 & 30.5 & 48.8 \\
\hline \multirow{3}{*}{$t=6 \mathrm{~mm}$} & \multirow{2}{*}{ AAP } & Penetrating & 3163.9 & 53.6 & 71.2 \\
\hline & & Short & 2766.3 & 53.6 & 71.2 \\
\hline & AAT & - & 2291.0 & 31.4 & 37.1 \\
\hline
\end{tabular}

To further compare the differences in the performance of the two types of joints, the case where the two joints were subjected to the same load was selected, as shown in Fig. 9. When the joints with $12 \mathrm{~mm}$ gussets were subjected to a bending moment of $45 \mathrm{kN} \cdot \mathrm{m}$ (the joints with $6 \mathrm{~mm}$ gussets were subjected to a bending moment of $35 \mathrm{kN} \cdot \mathrm{m}$ ), the AAT joint has basically entered the yield stage, and the stress in the area around the outermost bolt holes of the member has exceeded the yield stress. The overall stress value of the AAP joint was relatively low. Except for the high stress value around the bolt holes, there was basically no region in the plastic stage, and most parts of the H-shaped aluminum members were still in the elastic stage. Especially, the stress value of the web in the central area of the penetrating member was significantly lower. The bending moment on the member transferred to the web of penetrating member through the bolts. The penetrating web shared the load, thereby reduced the stress on the other components. Comparing the gussets of the two joints, under the same external load, most of the stress values of the AAT gusset were greater than the AAP gusset. The stress diagram of AAP joint gusset also proved that the X-shaped gusset had some significance, like reducing the use of materials in areas with less stress and avoiding excessive use of materials.
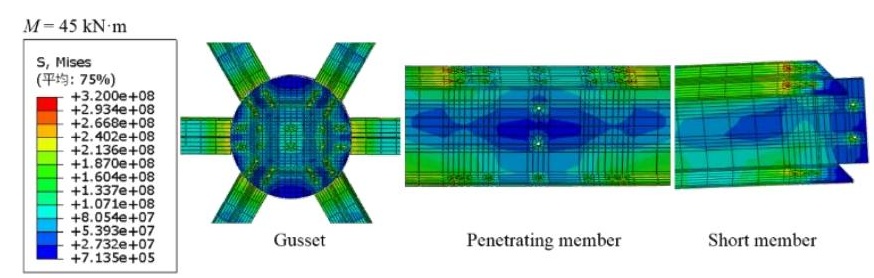

Penetrating member

Short member

(a) AAP joint with $12 \mathrm{~mm}$ gussets
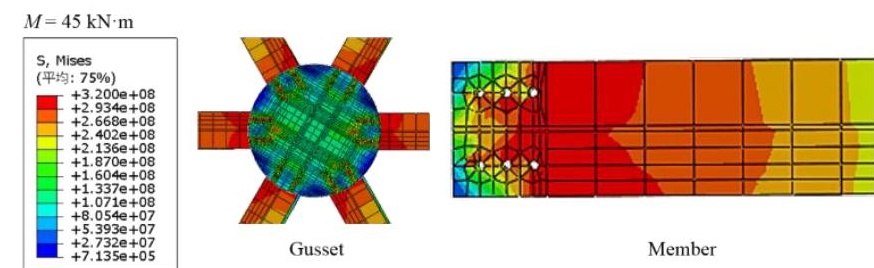

Gusset

Member
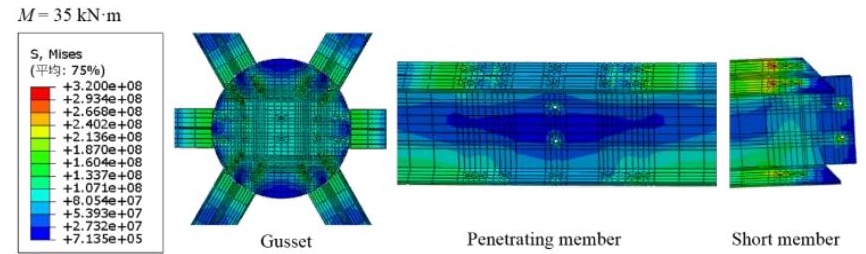

Penetrating member

Short member

(c) AAP joint with $6 \mathrm{~mm}$ gussets
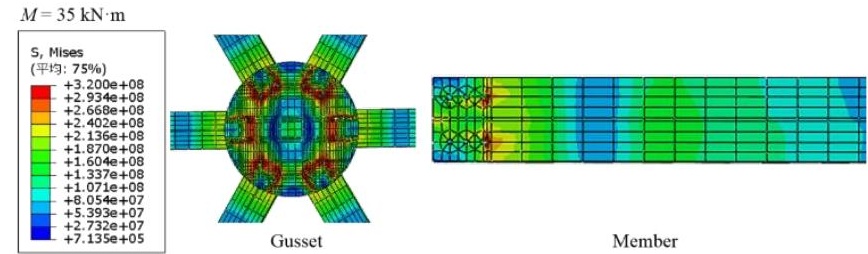

(d) AAT joint with $6 \mathrm{~mm}$ gussets

Fig. 9 Failure modes of AAP and AAT joints

Comparing the rotation resistance performance of the AAP and AAT joints under out-of-plan bending state, the AAT joint failure modes was the tear failure of the members. This was because the flanges and gussets of AAT joints were only connected by bolts and gusset, and the central web was missing. In addition, the thickness of the joint webs was only $5 \mathrm{~mm}$ of which the local stability was weak. Therefore, the finite element results indicated that the webs in the joint area have undergone significant buckling. This proved that the use of the penetrating members and $U$ connectors enhanced the stability of joint area, and solved the problem of the weak connection of the AAT joints in which the members and gussets were connected by bolts. $U$ connector connected the webs of members more closely to avoid buckling or yielding of the webs due to shear stress and local compressive stress. This modification was equivalent to setting web stiffeners in the joint area, thereby the bearing capacity of the joints was effectively improved.

\section{Parameter analysis of rotational resistance performance of AAP and AAT joints considering the influence of axial forces}

5.1. Numerical simulation models of joints considering the influence of axial force

In the actual stress process of the aluminum space structures, the joints are subjected to the combination of bending moments and axial forces, rather than just one of them. Therefore, it is necessary to attach great importance to the performance of joints under the action of forces and bending moments during the design. According to the analysis above, the differences of numerical simulation and test results of AAP and AAT joint are small, so the simulation results are accurate and effective. Numerical simulation methods was adopted in this chapter to continue the analysis and research on the performance of joints under the combination of moments and axial forces, as shown in Fig. 10. Because there is a certain distinction in the joint composition of AAT joints and AAP joints, their mechanical behaviors are different, it is very important to compare the bending performance of AAP and AAT joints with the same geometric parameters under eccentric bending moments. Based on the original joint models, the following adjustments are made in this section: (i) Settings of analysis step: one more step was added between the bolt pretension force and pure bending to apply the axial force load. This setting met the stress state of the joints first receiving the axial force and then the bending moment. (ii) Settings of boundary conditions: When the axial load was applied, only the displacement constraint along the axis of the member was allowed, and the displacement and rotation in other directions were restricted. The boundary conditions in Section 4.1 were maintained when the bending moment was applied. In addition, the basic characteristics of the numerical models including the mesh division, material properties, and bolt pretension are maintained.

(b) AAT joint with $12 \mathrm{~mm}$ gussets 


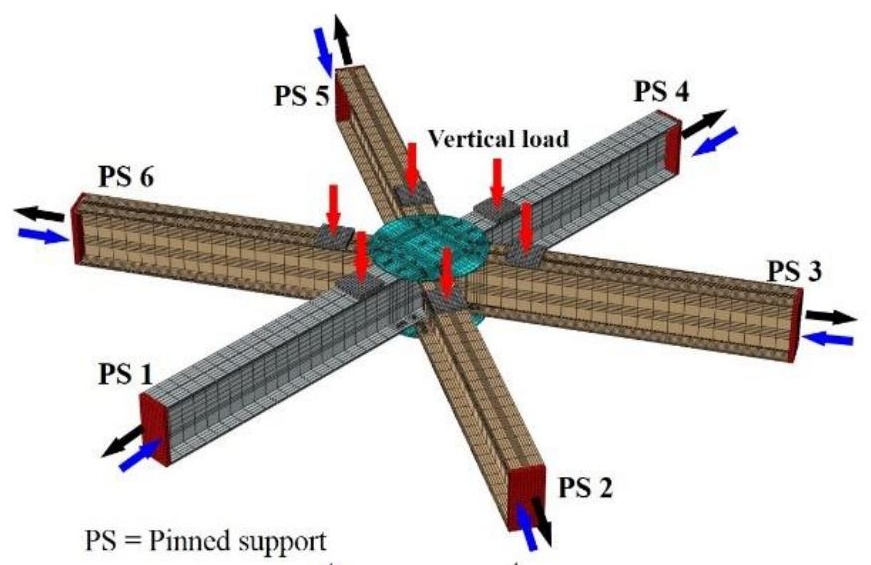

Axial compression (f) and tension (f) force is applied to the PSs.

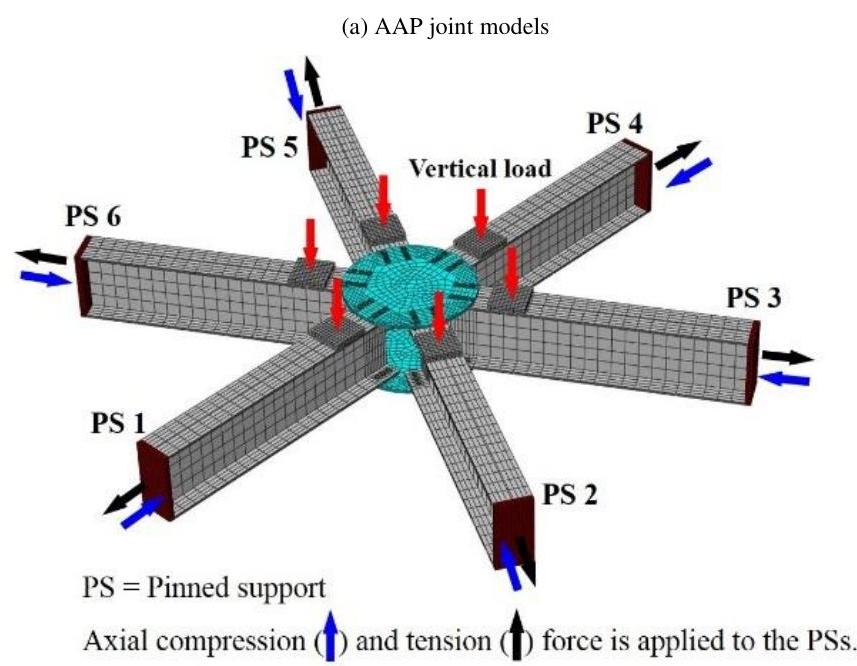

(b) AAT joint models

Fig. 10 Numerical simulation models considering axial forces

\subsection{Rotation resistance performance of $A A P$ and $A A T$ joints under tension and bending moment}

Numerical simulation research on rotation resistance of AAP joints and AAT joints under axial tensile load $\left(N_{\mathrm{t}}\right)$ and out-of-plane bending moment was carried out, because the maximum axial tensile force that the AAP join could withstand when subjected to axial tensile load was $600 \mathrm{kN}$, and the maximum axial tensile load of the AAT joints was $400 \mathrm{kN}$. Therefore, this section studied the rotation resistance performance of the AAP joints and AAT joints after bearing 0 to $600 \mathrm{kN}$ and 0 to $400 \mathrm{kN}$ axial forces, respectively. The momentrotation curves were shown in Fig. 11 below, and further analysis of the $M-\Phi$ curves could obtain the characteristic parameters about the joint performance, as shown in Table 5 below. The results indicated that: (i) as the axial tension increased, the $K_{\mathrm{i}}$ and $M_{\text {sup }}$ of the AAP and AAT joints gradually decreased. (ii) Compared with the short members of the AAP, with the increase of axial tension, the difference in initial rotational stiffness of penetrating members gradually increased. The initial rotational stiffness decreased slowly and then quickly, decreasing only $1 \%$ when the axial tension was $200 \mathrm{kN}$. Then, it decreased $16 \%$ when the axial tension was $400 \mathrm{kN}$. When the $N_{\mathrm{t}}$ reached a maximum of 600 $\mathrm{kN}, K_{\mathrm{i}}$ decreased $33 \%$. The yielding moments of the penetrating members and short members of the AAP were not much different. The descent rate of yielding bending moment was basically maintained at a linear speed. For each increase of $200 \mathrm{kN}$ in axial tension, the yielding moment of the joint reduced by about $20 \%$.

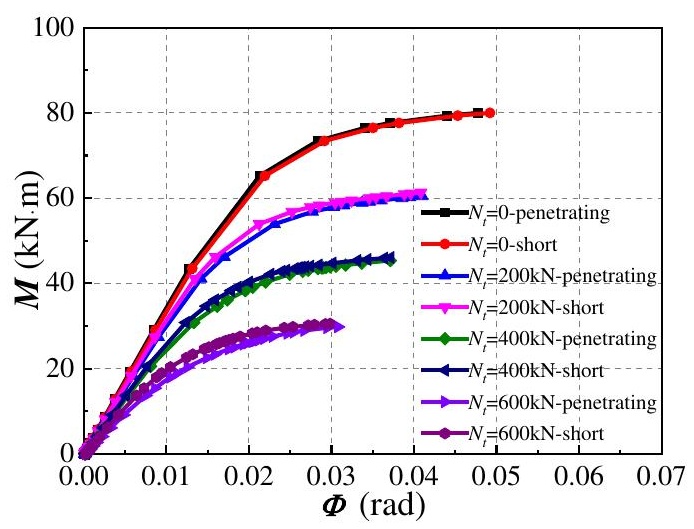

(a) AAP joints

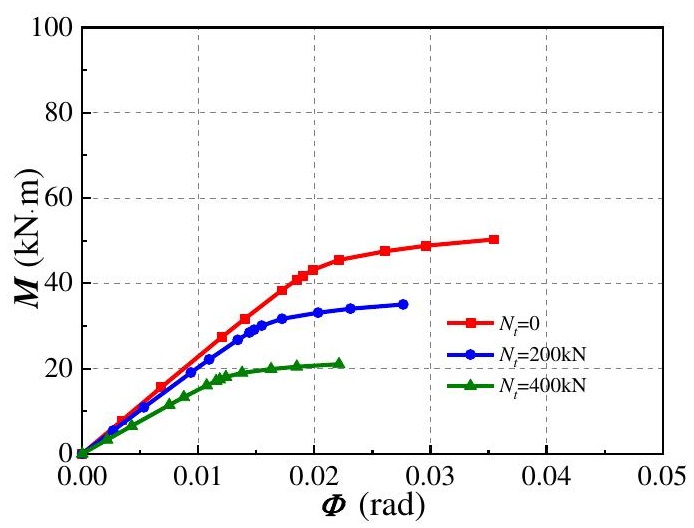

(b) AAT joints

Fig. $11 M-\Phi$ curves of joints under tension and bending

Table 5

The key parameters of AAP and AAT joints under bending moment and tension force

\begin{tabular}{|c|c|c|c|c|c|}
\hline \multirow[t]{2}{*}{ Joint type } & \multicolumn{2}{|c|}{$\begin{array}{c}\text { Axial tension } \\
(\mathrm{kN})\end{array}$} & \multirow{2}{*}{$\begin{array}{c}\text { Stiffness } \\
(\mathrm{kN} \cdot \mathrm{m} / \mathrm{rad}) \\
K_{\mathrm{i}}\end{array}$} & \multicolumn{2}{|c|}{$\begin{array}{c}\text { Moment } \\
(\mathrm{kN} \cdot \mathrm{m})\end{array}$} \\
\hline & & & & $M_{\mathrm{i}}$ & $M_{\mathrm{u}}$ \\
\hline \multirow{8}{*}{ AAP } & 0 & Penetrating & 3181 & 55.0 & 75.6 \\
\hline & & Short & 3179 & 55.0 & 75.6 \\
\hline & 200 & Penetrating & 3161 & 41.1 & 60.2 \\
\hline & & Short & 3042 & 41.1 & 60.2 \\
\hline & 400 & Penetrating & 2679 & 20.6 & 44.7 \\
\hline & & Short & 2554 & 20.6 & 44.7 \\
\hline & 600 & Penetrating & 2139 & 9.1 & 29.6 \\
\hline & & Short & 1822 & 9.1 & 29.6 \\
\hline \multirow{3}{*}{ AAT } & 0 & & 2249 & 31.7 & 50.3 \\
\hline & 200 & & 2003 & 19.0 & 35.0 \\
\hline & 400 & & 1405 & 11.4 & 21.0 \\
\hline
\end{tabular}

The related data parameters of AAP joint were compared laterally with the AAT joint, and the initial rotational stiffness and yield bending moment were plotted in Fig. 12. The figures revealed that: (i) when subjected to tensile and bending loads, the change trend of $\mathrm{Ki}$ and Msup of the AAT joints were the same as those of AAP joint. (ii) AAP joints can bear larger axial load than AAT joints under axial tension. Under the identical axial force, the initial rotational stiffness and yield moment of AAP joints were significantly higher than AAT joint, and the advantage of rotation resistance performance of AAP joints was obvious. 


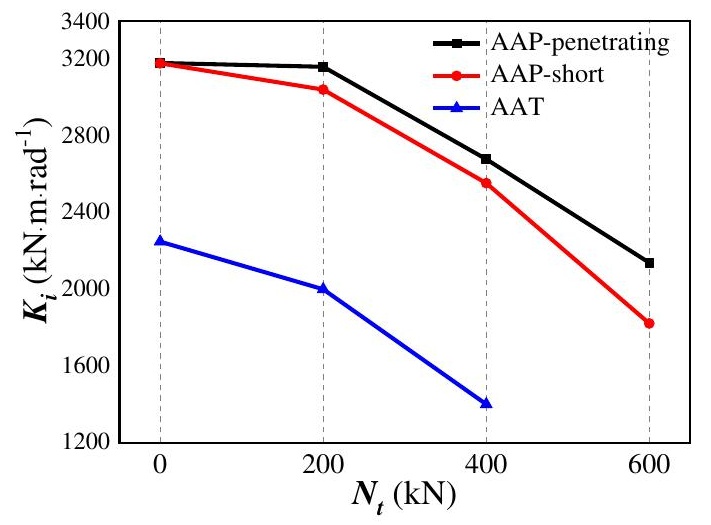

(a) Curves of initial stiffness

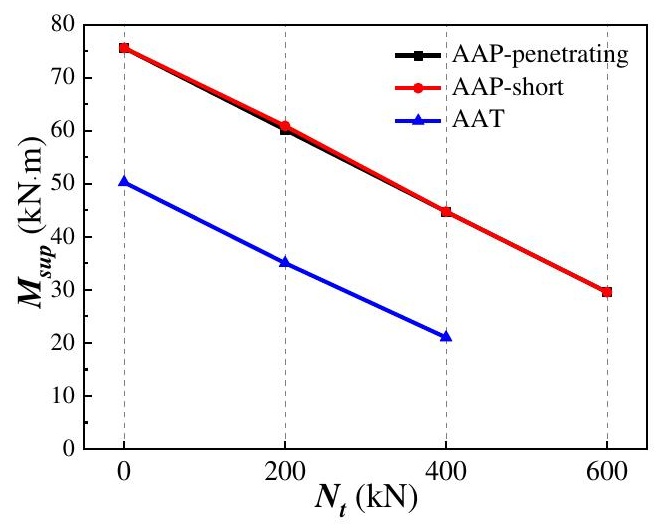

(b) Curves of yield moment

Fig. 12 Curves of Characteristic parameters and axial tension

The failure modes at a pull force of 400kN were shown in Fig. 13 below. In the figure, a small area of the gusset bolts of AAP joints entered yield under the action of axial tension, while a large area of gusset bolts of the AAT entered yield stage, because the only bolts AAT joint resisted shear force. Comparing the two forms of webs, it could be found that under the action of the axial tension load, $\mathrm{U}$ connector played the role of supporting ribs. Although the webs of the penetrating members enterd yielding, the webs deformed little. However, the webs of AAT joints underwent large deformation when the axial force and bending moment were applied.

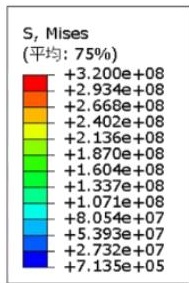

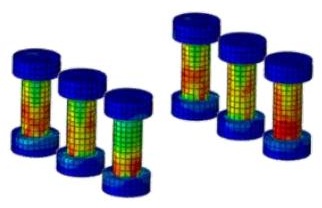

Gusset bolts

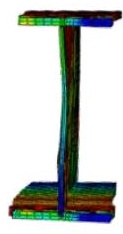

Member

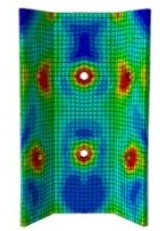

U connector (a) Failure modes of AAP joint

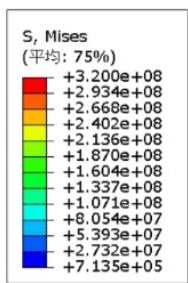

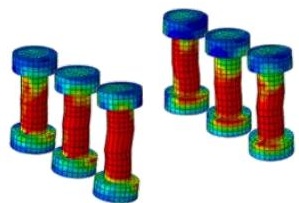

Gusset bolts

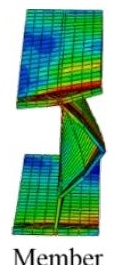

Member (b) Failure modes of AAT join

Fig. 13 Failure modes under tension and bending
5.3. Rotation resistance performance of AAP and AAT joints under compression and bending moment

Numerical simulation research on the rotational resistance of AAP joint and AAT joint under axial compression load $\left(N_{\mathrm{p}}\right)$ and out-of-plane bending load was conducted in this section. Because the maximum axial pressure that the AAP joints could withstand was $900 \mathrm{kN}$, and the maximum axial compressive load of AAT joints was $600 \mathrm{kN}$, so this section studied the rotation resistance performance of AAP joints and AAT joints after bearing 0 to $900 \mathrm{kN}$ and 0 to $600 \mathrm{kN}$ axial pressure, respectively. The moment-rotation curves were shown in Fig. 14 below, and further analysis of curves could obtain the characteristic parameters about the performance, as shown in Table 6 below.

The following conclusions could be drawn: (i) at the axial compression $\mathrm{Np}$ greater than $200 \mathrm{kN}$, the $K_{\mathrm{i}}$ and yielding moment of the AAP joints continued decreasing with the increase of axial pressure. Compared with the short members, the penetrating members of AAP had a slower decrease in initial stiffness and ultimate bending moment as the axial compression increased. (ii) When the axial compression of the AAP joints was less than $800 \mathrm{kN}$, the initial stiffness and yield moment of the joint reduced by about $10 \%$ compared with the pure bending state; but as the joint axial pressure continued to increase to $900 \mathrm{kN}$, the initial stiffness and yield moments had a greater decrease, the degree of decline was saverally $17 \%$ and $40 \%$. (iii) The initial rotational stiffness and yielding moment of the AAT joints decreased as the axial compression increased, and the average degree of decline was greater than that of the AAP joint.

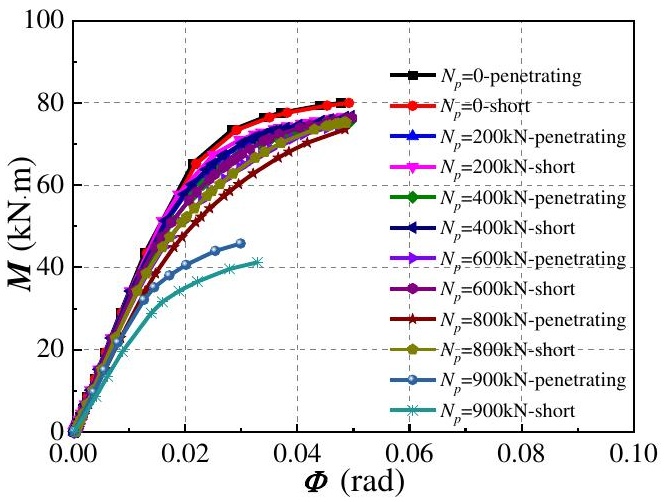

(a) AAP joints

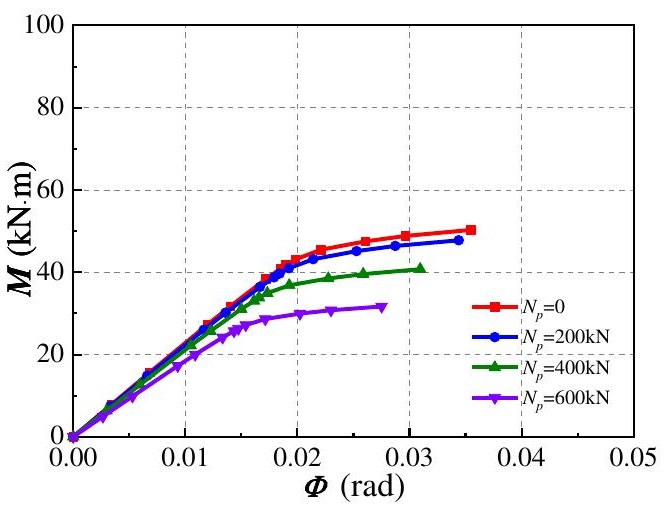

(b) AAT joints

Fig. $14 M-\Phi$ curves of joints under compression and bending

Table 6

The key parameters of AAP and AAT joints under bending and compression

\begin{tabular}{|c|c|c|c|c|c|}
\hline \multirow[t]{2}{*}{ Joint type } & \multicolumn{2}{|c|}{$\begin{array}{c}\text { Axial tension } \\
(\mathrm{kN})\end{array}$} & \multirow{2}{*}{$\begin{array}{c}\text { Stiffness } \\
(\mathrm{kN} \cdot \mathrm{m} / \mathrm{rad}) \\
K_{\mathrm{i}}\end{array}$} & \multicolumn{2}{|c|}{$\begin{array}{c}\text { Moment } \\
(\mathrm{kN} \cdot \mathrm{m})\end{array}$} \\
\hline & & & & $M_{\mathrm{i}}$ & $M_{\mathrm{u}}$ \\
\hline \multirow{5}{*}{ AAP } & 0 & Penetrating & 3181 & 55.0 & 75.6 \\
\hline & & Short & 3179 & 55.0 & 75.6 \\
\hline & 200 & Penetrating & 3280 & 34.2 & 74.8 \\
\hline & & Short & 3277 & 34.2 & 74.6 \\
\hline & 400 & Penetrating & 3169 & 34.2 & 71.9 \\
\hline
\end{tabular}




\begin{tabular}{|c|c|c|c|c|c|}
\hline & \multirow{3}{*}{600} & Short & 3152 & 34.2 & 70.5 \\
\hline & & Penetrating & 3049 & 22.8 & 69.8 \\
\hline & & Short & 2994 & 22.8 & 68.8 \\
\hline & \multirow[t]{2}{*}{800} & Penetrating & 2953 & 22.8 & 68.3 \\
\hline & & Short & 2850 & 22.8 & 65.6 \\
\hline & \multirow[t]{2}{*}{900} & Penetrating & 2666 & 21.0 & 44.0 \\
\hline & & Short & 2223 & 19.6 & 39.6 \\
\hline \multirow{4}{*}{ AAT } & 0 & & 2249 & 31.7 & 50.3 \\
\hline & 200 & & 2197 & 31.0 & 47.7 \\
\hline & 400 & & 2000 & 22.0 & 40.7 \\
\hline & 600 & & 1703 & 17.2 & 31.7 \\
\hline
\end{tabular}

Fig. 15 compared the characteristic parameters of the moment-rotation curves of AAP joints and AAT joints under axial compressive load and bending moment. The Figures revealed that: (i) AAP joints could withstand larger load than AAT joints when subjected to axial compressive load. (ii) When the pressure was less than $200 \mathrm{kN}$, the initial rotational stiffness of the AAP joints slightly increased, and these phenomena did not appeal in the AAT joints. (iii) Under the same axial pressure, the initial rotational stiffness and yield moment of AAP joints were significantly higher than those of AAT joints. (iv) with the increase of $\mathrm{Np}$, the decrease of $\mathrm{Ki}$ and Msup of the AAP joints were significantly slower than those of the AAT joints.

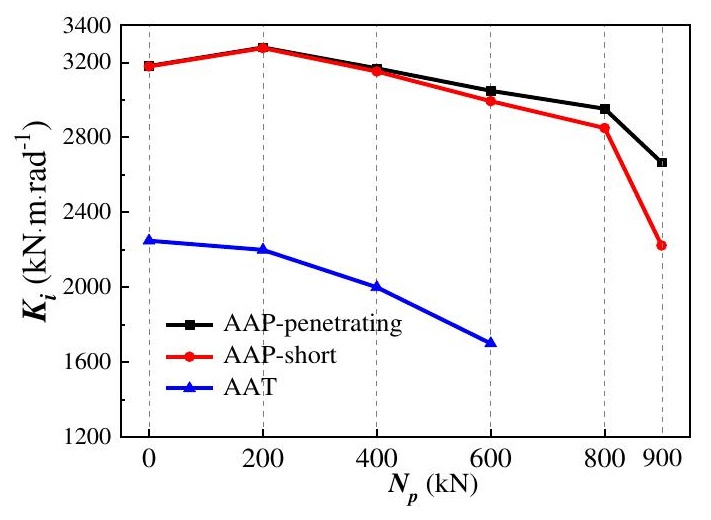

(a) Curves of initial stiffness

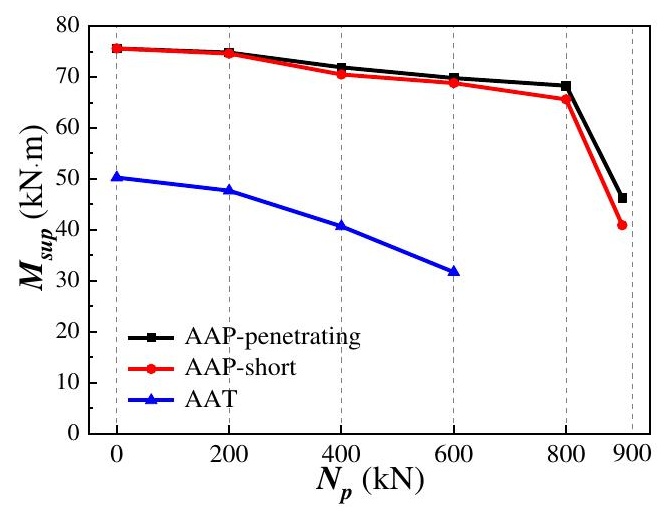

(b) Curves of yield moment

Fig. 15 Curves of Characteristic parameters and axial compression

The failure modes of the AAP joints and the AAT joints under compression were shown in Fig. 16. For the penetrating members of AAP joints, a large area of the web bolts yielded, and the stress value of $\mathrm{U}$ connectors was also very high, yielding around the bolt holes. However, the stress values of gusset bolts and gussets were relatively low. For AAT joints, gussets and gusset bolts entered large-area yielding, and the gussets and webs buckled due to the bending load.

\section{References}

[1] W. M. Doyle, “Aluminum alloys: structure and properties", Metal Science, 35.11, 408,1976. [2] J. Dwight, "Aluminium design and construction", Spon Press, 1999.

[3] R Kissell, "Aluminum Structures - A Guide to Their Specifications and Design", 2002.

[4] F. M. Mazzolani, “Aluminium Structural Design”, Springer Vienna, 2003.
Because the joint of AAT joint was composed of a simple connection between the members and the gussets through the gusset bolts, when the joint was under axial load, the force could only be transmitted by the gusset bolts. During this period, the stress of the webs was small, and not fully utilized. This also caused a significant reduction in the rotational resistance of the AAT joints when subjected to axial force loading. The web bolts of the AAP joints could share a large part of the shear force. Compared with the AAT joints, they were less sensitive to changes in axial pressure and showed higher initial rotational stiffness and yield bending moment.

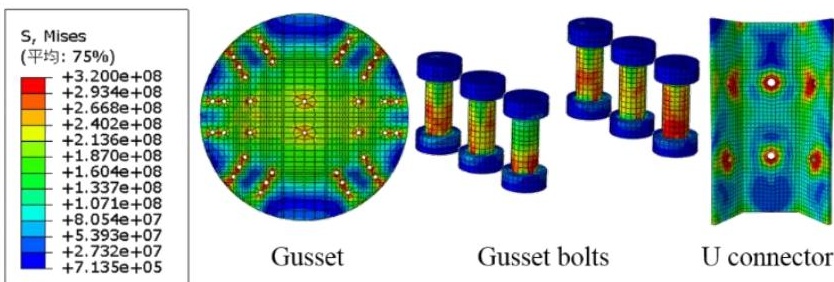

(a) AAP joints
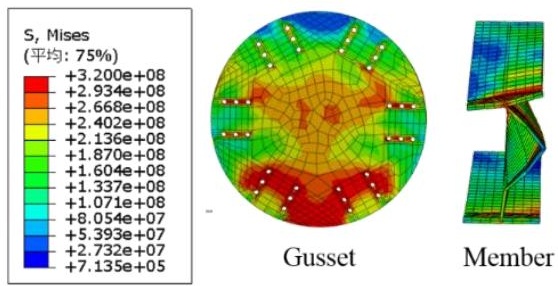

(b) AAT joints

Fig. 16 Failure modes under axial compression and bending

\section{Conclusions}

A new type of semi-rigid AAP joint was developed by adding U-shaped connectors and penetrating members to the original AAT joint. The rotation resistance performance of AAP joints was researched through experiments. The anti-rotation performance of the AAP and AAT joints under pure bending were compared by the numerical simulation method, tension bending and compression bending. The following conclusions were obtained:

(1) Static tests of AAP joints under the out-of-plane moment of different parameters was carried out. The bending rotational resistance performance of the joints were obtained. The moment-rotation curves of penetrating members and short members were defined. The main parameters reflecting the joints' mechanical performance were defined, including the initial bending stiffness $K_{\mathrm{i}}$, initial moment $M_{\mathrm{i}}$, yield stiffness $K_{\mathrm{u}}$ and yield bending moment $M_{\text {sup. }}$.

(2) Comparing the rotation resistance performance of AAP joints and traditional AAT joints in pure bending state, the initial rotational stiffness and yielding moment of AAP joints were significantly improved. The setting of $U$ connector and penetrating members enhanced the connection between the members and gussets.

(3) AAP joints were superior to AAT joints under the combination of axial forces and bending moment. Failure modes of AAP joints were the full-section yield of the members in the joint area, while the failure modes of AAT joints were shear yield of the gusset bolts. Under axial forces, the initial stiffness and yield moment were improved. Meanwhile, it was found that the axial tension was a more unfavorable load for the AAP and AAT joints, and the axial pressure had little effect on the rotational resistance.

\section{Acknowledgements}

This research is supported by The National Science Fund for Distinguished Young Scholars (Grant No. 51525802).

[5] F. M. Mazzolani, “ Structural Applications of Aluminium in Civil Engineering”, Structural Engineering International, 16(4), 280-285, 2006

[6] A. K. Mukhopadhyay, "Selection and Design Principles of Wrought Aluminium Alloys for Structural Applications', Materials Science Forum, 710,50-65, 2012.

[7] N. H. Hoang, A. G. Hanssen, M. Langseth, R. Porcaro, "Structural behaviour of aluminium self-piercing riveted joints: an experimental and numerical investigation", International 
Journal of Solids and Structures, 49 3211-3223, 2012.

[8] L.Han, M.Thornton, M. Shergold, "A comparison of the mechanical behaviour of selfpiercing riveted and resistance spot welded aluminium sheets for the automotive industry", Materials and Design, 31, 1457-1467, 2010.

[9] G.D. Matteis, A. Mandara, F.M. Mazzolani, "T-stub aluminium joints: influence of behavioural parameters", Computers \& Structures, 78, 311-327, 2000

[10] G.D. Matteis, M.T. Naqash, G. Brando, "Effective length of aluminium T-stub connections by parametric analysis", Engineering Structures, 41, 548-561, 2012.

[11] T.K. Chan, R.F.D.P. Goff, "Welded aluminium alloy connections: test results and BS8118", Thin-Walled Structures, 36, 265-287, 2000.

[12] Y.Q. Wang, C. Luo, Y.J. Shi, "Design and research of cast aluminum joint in aluminum alloy spatial structures", International Conference on Electric Technology \& Civil Engineering, IEEE, 2011.

[13] H.H. Ma, F. Fan, P. Wen, H. Zhang, S.Z. Shen, "Experimental and numerical studies on a single-layer cylindrical reticulated shell with semi-rigid joints". Thin-Walled Structures, 86, $1-9,2015$.

[14] H.H. Ma, L. W. Yu, F. Fan, Z. W. Yu, "Mechanical performance of an improved semi-rigid joint system under bending and axial forces for aluminum single-layer reticulated shells", Thin-Walled Structures, 142, 332-339, 2019.

[15] H.H. Ma, Y.Q. Jiang, C. R. Li, Z. W. Yu, F. Fan, "Performance analysis and comparison study of two aluminum alloy joint systems under out-of-plane and in-plane loading. An experimental and numerical investigation", Engineering Structures, 214, 110643, 2020.

[16] H. Liu, Z. Chen, S. Xu, Y. Bu, "Structural behavior of aluminum reticulated shell structures considering semi-rigid and skin effect", Structural Engineering \& Mechanics, 54, 121-133, 2015.

[17] H. Liu, Y. Ding, Z. Chen, "Static stability behavior of aluminum alloy single-layer spherical latticed shell structure with Temcor joints", Thin-Walled Structures, 120, 355-365, 2017.

[18] Z. Xiong, X.N. Guo, Y.F. Luo, S.J. Zhu, Y.P. Liu, "Experimental and numerical studies on single-layer reticulated shells with aluminium alloy gusset joints", Thin-Walled Structures, 118, 124-136, 2017.

[19] Z. Xiong, X.N. Guo, Y.F. Luo, S.J. Zhu, "Elasto-plastic stability of single-layer reticulated shells with aluminium alloy gusset joints", Thin-Walled Structures, 115, 163-175, 2017.

[20] X.N. Guo, Z. Xiong, Y.F. Luo, L.Q. Qiu, J. Liu, "Experimental investigation on the semirigid behaviour of aluminium alloy gusset joints", Thin-Walled Structures, 87, 30-40, 2015.

[21] Z. Xiong, X.N. Guo, Y.F. Luo, H. Xu, "Numerical analysis of aluminium alloy gusset joints subjected to bending moment and axial force", Engineering Structures, 152, 1-13, 2017.

[22] X.N. Guo, S.J. Zhu, X. Liu, L.L. Liu, "Experimental study on hysteretic behavior of aluminum alloy gusset joints", Thin-Walled Structures, 131, 883-901, 2018.

[23] X.N. Guo, S.J. Zhu, X. Liu, K. Wang, "Study on out-of-plane flexural behavior of aluminum alloy gusset joints at elevated temperatures", Thin-Walled Structures, 123, 452-466, 2018.

[24] J. Zhang, J. Zhao, "Analysis of stiffness of gusset-type joints for single-layer reticulated shells", Industrial Construction, 35(4), 88-90, 2005. (In Chinese)

[25] J.H. Qian, P.F. Zhao, C.X. Hao, T. Song, J.D. Zhao, "Development study on large span aluminum alloy dome structure", Building Science, 16(5), 7-12, 2007. (In Chinese)

[26] L. Zou , G. X. Dai, "Finite element analysis of aluminum alloy dome disc cover joints (TEMCOR joints)", National Symposium on Modern Structural Engineering, 638-646, 2009. (In Chinese)

[27] H. Deng, W. Chen, G. Bai, S. Dong, "Experimental study on shearing behavior of lockbolted lap connection for aluminum alloy plates", Journal of Building Structures 37(1), 143-149, 2016. (In Chinese) 


\title{
PERFORMANCE AND CAPACITY CALCULATION METHODS OF SELF-STRESSING STEEL SLAG CONCRETE FILLED STEEL TUBULAR SHORT COLUMNS SUBJECTED TO AXIAL LOAD
}

\author{
Yuan Fang ${ }^{1}$, Feng Yu ${ }^{1, *}$, Rui Bai ${ }^{2}$, Lin Xu ${ }^{1}$, Yuan-Di Qian ${ }^{1,3}$ and Guo-Sheng Xiang ${ }^{1}$ \\ ${ }^{\prime}$ Department of Civil Engineering and Architecture, Anhui University of Technology, Ma'anshan, China \\ ${ }^{2}$ Department of Civil and Environmental Engineering, The Hong Kong Polytechnic University, Hung Hom, Kowloon, Hong Kong, China \\ ${ }^{3}$ Technology center, China MCC17 Group Co., Ltd., Ma'anshan, 243000, Anhui, China \\ *(Corresponding author.Email: fyuan86@163.com)
}

\section{A B S T R A C T}

This paper experimentally investigates the mechanical performance of the self-stressing steel slag concrete filled steel tubular (SSSCFST) columns. Six short columns subjected to axial load are tested and the accuracy of different prescriptive methods is evaluated. The effect of the studied parameters, such as the expansion rate of steel slag concrete (SSC) $\left(E_{\mathrm{x}}\right)$ and diameter-thickness ratio of steel tube $(D / t)$, is considered. The failure modes are observed and the load-displacement curves of the specimens are obtained. The SSSCFST short columns with the low confinement effect coefficient under axial load are damaged by shear deformation, while the outward loca buckling dominates the failure of the axially loaded SSSCFST short columns with the high confinement effect coefficient. It is observed that the incremental range of the load capacity can be raised by enhancing the expansion rate of SSC. The ultimate load capacity and displacement of the columns decrease as the diameter-thickness ratio increases. Compared with the experimental results, the Hong Kong Code CoPHK (2011) and Australian Standard AS5100-2017 (2017) underestimate the ultimate load capacity of the axially loaded SSSCFST short columns. While, better predictions on the column strength can be achieved by the British Standard BS EN1994-2 (2005) and Chinese Specification DBJ/T13-51-2010 (2010). Additionally, a validated finite element (FE) model for the SSSCFST short columns is adopted to perform parametric studies to broaden the available experimental results about their behaviors.
ARTICLE H IST O RY

\begin{tabular}{ll}
\hline & \\
Received: & 13 July 2020 \\
Revised: & 5 November 2020 \\
Accepted: & 9 November 2020
\end{tabular}

\section{K E Y W O R D S}

Steel slag concrete;

Expansion rate;

Diameter-thickness ratio;

Failure modes;

Ultimate load capacity.

Copyright $(\odot) 2021$ by The Hong Kong Institute of Steel Construction. All rights reserved.

\section{Introduction}

Steel slag, the industrial by-product of steel-making, accounts for $15 \%$ to $20 \%$ of all steel production [1]. The annual output of steel slag was approximately 21 million tons in Europe, 14 million tons in Japan and over 100 million tons in China [2]. However, little steel slag was utilized. In China, over 400 million tons of the steel slag have been deposited leading to the problems in the resource waste, the lands occupation and the potential water and soil pollution. Therefore, dealing with these steel slags rationally and effectively has become an urgent issue. Recently, many scholars suggested to use the steel slags as the substitutes for concrete aggregates in civil engineering [3-4]. However, the volume instability of steel slags restricts its application. Theoretical and experimental studies on the volume stability of the steel slag concrete (SSC) have been extensively conducted and the some stabilizing measures have been developed, such as the SSC with the siliceous or fly ash [5-6], carbonization maintenance [7], and decreasing the content of $\mathrm{MgO}$ and $f-\mathrm{CaO}[8]$

Concrete filled steel tubular (CFST) columns, which have the high bearing capacity and good ductility, are convenient for the construction and have been extensively applied in civil engineering [9-10]. Nevertheless, the shrinkage crack of core concrete has a certain effect on the mechanical properties of CFST columns. To reduce the shrinkage, the SSSCFST column, which uses the SSC instead of the ordinary concrete as the filling material, is proposed for engineering structures. The slight expansion of the SSC can availably improve the mechanical properties of the composite columns and reduce the shrinking cracks. Yu et al. [11] conducted the tests on the compensated shrinking SSC and suggested the methods for calculating its ultimate stress, strain, Young's modulus and Poisson's ratio. Beggas et al. [12] investigated the thermal conductivity of the SSC and showed that the SSC could significantly enhance the thermal property of the SSC filled thin-wall steel tube structures. Zeghiche et al. [13] presented a non-linear FE model to study the performance of the cold formed steel tube filled with crystallized slag aggregate concrete. The effects of the section dimension, the infilled concrete and its age were investigated. Ferhoune et al. [14] examined the performance of the crushed crystallized slag concrete filled rectangular tube subjected to eccentric compression and confirmed that the load capacity was sensitive to the eccentric load and the length of stubs.

At present, numerous theoretical and experimental investigations on the SSC and CFST have been carried out and fruitful results have been achieved. However, few studies focus on the performance and design methods of the SSSCFST columns. In this study, the performance of the axially loaded SSSCFST short columns was experimentally investigated and six columns were designed and tested. The effects of the expansion rate of $\operatorname{SSC}\left(E_{\mathrm{x}}\right)$ and diameter-thickness ratio $(D / t)$ were analyzed. The results of load capacity of the columns calculated by the current CFST design provisions were compared with the experimental data, and the accuracy of the prescriptive methods for the design of the SSSCFST short columns was evaluated. In addition, a validated FE model for the axially loaded SSSCFST short columns was employed to conduct the parametric studies.

\section{Experimental program}

\subsection{Material properties}

In this study, all the seamless tubes were made of Q235 steel with the outer diameter of $140 \mathrm{~mm}$. Three types of steel tubes with thickness of 2.08 $\mathrm{mm}, 3.63 \mathrm{~mm}$ and $4.22 \mathrm{~mm}$ were used in the tests. By the method suggested in the Chinese code GB/T228.1-2010 [15], the corresponding average yield and ultimate strength of these three types of steel tubes were measured as 176.3MPa, 233.2MPa, 236.9MPa and 311.5MPa, 295.7MPa, 300.8MPa, respectively. The SSC was made of graded gravel (the particle size range was $5 \mathrm{~mm} \sim 31.5 \mathrm{~mm}$ ), steel slag, P. O 42.5 cement and water. The accumulation density of steel slag was $965 \mathrm{~kg} / \mathrm{m}^{3}$. The ratio between the components of the SSC, i.e., cement: water: graded gravel: steel slag, was 365:201:961:621.

Two different expansion rates of SSC, such as $E_{\mathrm{x}}=2.8 \times 10^{-4}, E_{\mathrm{x}}=-3.5 \times 10^{-4}$, were prepared. $E_{\mathrm{x}}$ is determined by the following formula.

$E_{\mathrm{xt}}=\left(L_{\mathrm{t}}-L_{0}\right) / L_{\mathrm{e}}$

In which, $E_{\mathrm{xt}}$ represents the $t$-th day expansion rate of SSC, $L_{\mathrm{e}}$ denotes the gauge length of SSC, $L_{0}$ stands for the length of SSC on the 3-th day, and $L_{\mathrm{t}}$ represents the length of SSC on the $t$-th day.

Different expansion rates of SSC were obtained by changing the particle sizes of steel slag. For the SSC with $E_{\mathrm{x}}=2.8 \times 10^{-4}$, the particle size range of steel slag was $1.18 \mathrm{~mm} \sim 2.36 \mathrm{~mm}$. For the SSC with $E_{\mathrm{x}}=-3.5 \times 10^{-4}$, the particle size range of steel slag was $0.15 \mathrm{~mm} \sim 0.6 \mathrm{~mm}$. Table 1 listed the components of the SSC and the corresponding strength measured according to Chinese Code GB50010-2010 [16]

\subsection{Specimens design and manufacture}

Two parameters, the expansion rate of SSC $E_{\mathrm{x}}$ and diameter-thickness ratio $D / t$ were studied in this analysis. Six specimens, including three SCA-1 
series short columns and three SCA-2 series short columns, subjected to axial load were carried out. The length of both series specimens was $500 \mathrm{~mm}$. The specific dimensions of the specimens were listed in Table 2.

The specimens were cut to the designed length from a long tube, and the end sections were polished and flatted. Two $300 \mathrm{~mm} \times 300 \mathrm{~mm} \times 10 \mathrm{~mm}$ steel plates were prepared for each column as the end plates. During the specimen fabrication, a steel plate was welded to the bottom of the steel tube. The SSC was poured into the steel tube, and a poker vibrator was employed for compaction. A plastic film and an aluminum sheet were used to seal the surface of the concrete to simulate the real curing environment. After the concrete was set, the aluminum sheet and the plastic film were removed, and the other steel plate was welded to the top of the specimen. During the process, the welding quality was checked, and the geometric centers of the plate and steel tube were aligned.

Table 1

Components of the SSC and the measured strength (Yu et al., [17])

\begin{tabular}{|c|c|c|c|c|c|c|c|c|}
\hline \multirow{2}{*}{$\begin{array}{l}\text { Particle size of steel } \\
\text { slag / mm }\end{array}$} & \multicolumn{4}{|c|}{ Material usage $/ \mathrm{kg} \cdot \mathrm{m}^{-3}$} & \multirow{2}{*}{$\begin{array}{l}\text { Cube compressive } \\
\text { strength / MPa }\end{array}$} & \multirow{2}{*}{$\begin{array}{c}\text { Expansion rate } E_{\mathrm{x}} \\
\qquad / 10^{-4}\end{array}$} & \multirow{2}{*}{$\begin{array}{l}\text { Elastic modulus } \\
\qquad / 10^{4} \mathrm{MPa}\end{array}$} & \multirow{2}{*}{ Poisson's ratio } \\
\hline & Water & Portland cement & Graded gravel & Steel slag & & & & \\
\hline $1.18 \sim 2.36(100 \%)$ & 201 & 365 & 961 & 621 & 34.29 & -3.5 & 3.61 & 0.242 \\
\hline $\begin{array}{l}0.15 \sim 0.3(75 \%) \\
0.3 \sim 0.6(25 \%)\end{array}$ & 201 & 365 & 961 & 621 & 21.85 & 2.8 & 2.74 & 0.222 \\
\hline
\end{tabular}

Table 2

Design parameters of the specimens

\begin{tabular}{cccccc}
\hline Specimen & $L / \mathrm{mm}$ & $D / \mathrm{mm}$ & $t / \mathrm{mm}$ & $D / t$ & $E_{\mathrm{x}} / 10^{-4}$ \\
\hline SCA1-1 & 500 & 140 & 2.08 & 67.3 & 2.8 \\
SCA2-2 & 500 & 140 & 2.08 & 67.3 & -3.5 \\
SCA3-1 & 500 & 140 & 3.63 & 38.6 & 2.8 \\
SCA4-2 & 500 & 140 & 3.63 & 38.6 & -3.5 \\
SCA5-1 & 500 & 140 & 4.22 & 33.2 & 2.8 \\
SCA6-2 & 500 & 140 & 4.22 & 33.2 & -3.5 \\
\hline
\end{tabular}

Note: $D, t, L$, and $E_{\mathrm{x}}$ are the measured steel tube outside diameter, thickness, length, and the expansion rate of SSC, respectively.
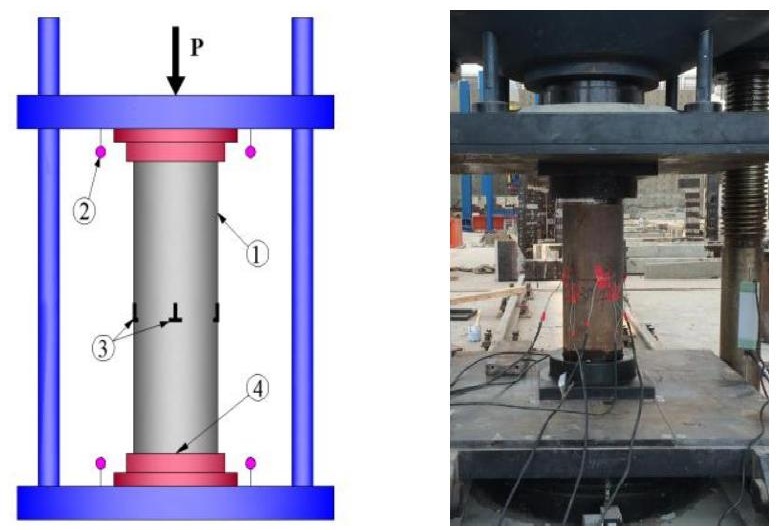

(1) Specimen (2) LVDT (3) Strain gauge (4) Steel column cap

Fig. 1 Test set-up and measuring points arrangement

As shown in Fig. 1, a $5000 \mathrm{kN}$ hydraulic compression testing machine was used for applying the monotonic static loads. The axial and circumferential strains at the mid-height of each steel tube were measured at four positions around the perimeter by eight strain gauges. Four LVDTs (Linear Variable Differential Transformers) were used to monitor the movements of the end steel plates, and two LVDTs were placed at a side. The steel column caps were set at both ends of the column, and the compression test was carried out directly on the hydraulic compression testing machine. The preloading process was conducted before the formal test to ensure that the test setup was correctly installed, and the measuring instruments run well.

Firstly, the load-controlled scheme (step loading approach) was carried out. Each loading level was estimated to be $1 / 15$ of the column theoretical load capacity and kept constant for 5 minutes. Then, the displacementcontrolled loading scheme (step loading controlled by displacement) was used when the load reached to approximately $85 \%$ of the theoretical load capacity. When the columns were closed to the damage or the load began to decline, the specimen was slowly and continuously loaded until the columns failed or the load reduced to $85 \%$ of the column ultimate load capacity.

\section{Experimental results and analysis}

\subsection{Failure progress and modes}

Several experimental phenomena, such as the gradual drop of the rust, the local yielding of steel tube, the slight sound of the inner SSC crushing, and the local buckling, were noticed in the tests. The failure process of the specimens experienced three stages as elasticity, elastoplasticity and plasticity. In the early and middle experimental stages, the specimen's appearance remained intact, which was similar to the conventional CFST short columns. As the load increased to $70 \% \sim 80 \%$ of the ultimate strength, the rust fell off gradually and tubes started to yield. The slight sound of the SSC crushing could be occasionally heard in this stage. As the load reached $90 \%$ $95 \%$ of the ultimate strength, local buckling appeared near the ends or center of the columns. Finally, the shear deformation dominated the failure of the SSSCFST short columns with the low confinement effect coefficient under axial compression, see Fig. 2 (a), (b) and (d), while the outward local buckling dominated the failure of the SSSCFST short columns with the high confinement effect coefficient under axial compression, as shown in Fig. 2 (c), (e) and (f) Generally, more local buckling occurred in the columns with higher expansion rate of SSC. For example, one local buckling appeared in the SCA4-2 column, while three local buckling appeared in the SCA3-1 column. Moreover, the buckling was more serious as the column with smaller diameter-thickness ratio, as shown in Fig. 2 (a) and (e)

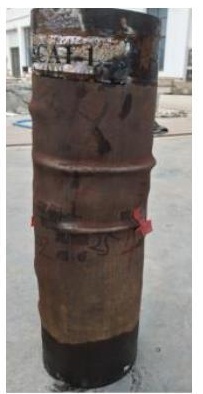

(a) SCA1-1

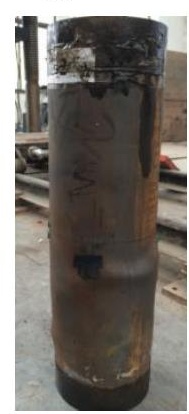

(d) SCA4-2

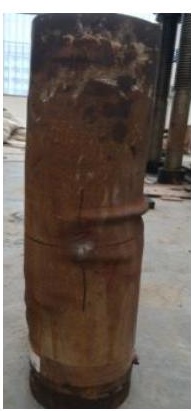

(b) SCA2-2

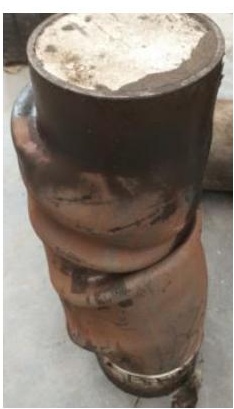

(e) SCA5-1

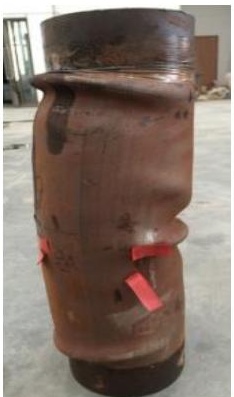

(c) SCA3-1

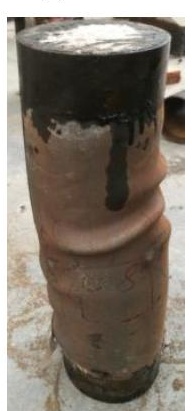

(f) SCA6-2
Fig. 2 The failure modes of the SSSCFST short columns 


\subsection{Ultimate load capacity analysis}

Fig. 3 shows the influences of two parameters, i.e., $E_{\mathrm{x}}$ and $D / t$, on the ultimate load capacity of the axially loaded SSSCFST short columns. The incremental range of load capacity $\left(N_{\mathrm{u}} / N_{0}\right)$ [17] of the axially loaded columns was plotted in Fig. 3(a). In which, $N_{\mathrm{u}}$ represents the ultimate load capacity, $N_{0}$ denotes the nominal compressive strength, $N_{0}=f_{\mathrm{y}} A_{\mathrm{s}}+f_{\mathrm{c}} A_{\mathrm{c}}, f_{\mathrm{y}}$ is the yield strength of the steel tube, $f_{\mathrm{c}}$ is the compressive strength of the core concrete, $A_{\mathrm{s}}$ and $A_{\mathrm{c}}$ represent the cross-sectional area of the steel tube and core concrete, respectively. As can be seen from the comparison, the average incremental range of load capacity increases by $11.8 \%$ with the expansion rate rising from $-3.5 \times 10^{-4}$ to $2.8 \times 10^{-4}$. The impact of the $E_{\mathrm{x}}$ on the incremental range of load capacity is more significant when the $D / t$ is larger. For instance, the improvement of the incremental range of load capacity of the column with the $D / t=33.2$ is $10.5 \%$. In contrast, the improvement of the incremental range of load capacity of the column with the $D / t=67.3$ is $14.4 \%$.

According to the results plotted in Fig. 3(b), the ultimate load capacity of the column decreases almost linearly as the $D / t$ increases. Taking the columns with the $E_{\mathrm{x}}=2.8 \times 10^{-4}$ as examples, when the $D / t$ increases from 38.6 to 67.3 , the ultimate load capacity decreases by $38.5 \%$. The reason is that the steel tube with a higher $D / t$ has a weaker constraint on the infill, which decreases the member load capacity.

In consequence, the increase in the $E_{\mathrm{x}}$ or the reduction in the $D / t$ in a reasonable range can effectively enhance the ultimate load capacity of the axially loaded SSSCFST short columns.

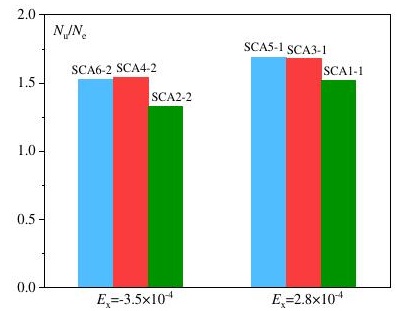

(a) Expansion rate of SSC

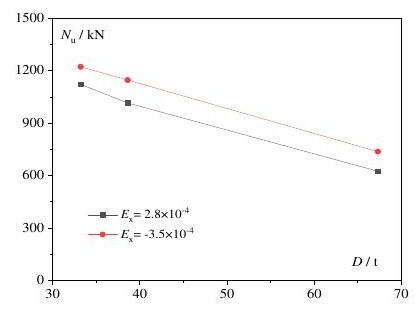

(b) Diameter-thickness ratio
Fig. 3 Influence of the variable parameters on the load capacity

\subsection{Load-displacement analysis}

Fig. 4 depicts the influence of the two studied parameters on the load-displacement $(N-\Delta)$ curves of the axially loaded SSSCFST short columns. In which, $N$ represents the axial load, $\Delta$ denotes the axial displacement of the short columns. As can be seen from the figure that the load-displacement curves of the two series columns have the similar trends. Initially, the load-displacement curves of the columns increase approximately linearly and the slope of the load-displacement curves decreases with the increase of the $D / t$, as shown in Fig. 4(a). This may come from that when the diameter of the outer steel tube remains unchanged, increasing the $D / t$ will correspondingly reduce the initial combined stiffness of the column section. At this stage, the slope of the load-displacement curves decreases with the increase of the $E_{\mathrm{x}}$, as shown in Fig. 4(b). This is mainly because in this study, the strength and elastic modulus of the SSC with the high $E_{\mathrm{x}}$ are smaller than those of the SSC with the low $E_{\mathrm{x}}$, resulting in the low initial stiffness of the columns with high $E_{\mathrm{x}}$. With the increase of load, the load-displacement curves deviate from linear growth, and the obvious inflection points appear on the curves. The increase in the $D / t$ decreases the yield strength of the columns. Subsequently, the load capacity grows slowly, while the axial displacement develops faster. The ultimate axial displacement of the columns decreases as the $D / t$ increases. The reason is that the decrease of the $D / t$ correspondingly weakens the confinement effect of the outer steel tube on the core SSC. Comparatively, the effect of the $E_{\mathrm{x}}$ on the ultimate axial displacement is not significant.
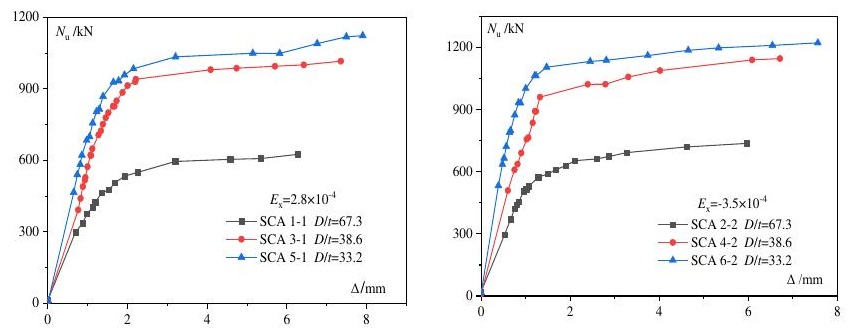

(a) Diameter-thickness ratio
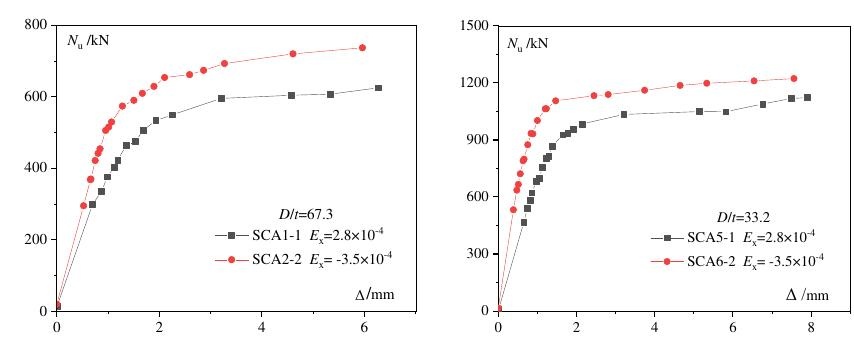

(b) Expansion rate of SSC

Fig. 4 Influence of the variable parameters on the load-displacement curves

\subsection{Ultimate strain analysis}

Fig. 5 describes the influences of the $E_{\mathrm{x}}$ and $D / t$ on the column ultimate strains. In which, $\varepsilon_{\text {alim }}$ and $\varepsilon_{\text {clim }}$ represent the ultimate axial and circumferential strains at the mid-height of the steel tube, respectively. In terms of the overall trend, the ultimate axial strain $\varepsilon_{\text {alim }}$ is larger than the circumferential strain $\varepsilon_{\text {clim }}$. As shown in Fig.5(a), with the increase of the $E_{\mathrm{x}}$, the column ultimate axial and circumferential strains increase. Taking the specimens SCA1-1 and SCA2-2 as examples, the ultimate axial strain and circumferential strain of the column increase by $5.0 \%$ and $18.8 \%$ when the $E_{\mathrm{x}}$ increases from $-3.5 \times 10^{-4}$ to $2.8 \times 10^{-4}$. This indicates that the increase of the $E_{\times}$ has a more obvious effect on the increase of the circumferential strain of the columns. Increasing the $D / t$ will decrease the ultimate axial strain and circumferential strain of the columns, as demonstrated in Fig. 5(b). Taking the specimens SCA3-1 and SCA5-1 as examples, the ultimate axial strain and circumferential strain of the column decrease by $15.0 \%$ and $9.9 \%$ when the $D / t$ of the specimen increases from 38.6 to 67.3 . This is mainly because the increase of the $D / t$ weakens the confinement effect of the steel tube on the core SSC, reduces the ultimate bearing capacity, and correspondingly decreases the ultimate strains of the columns.

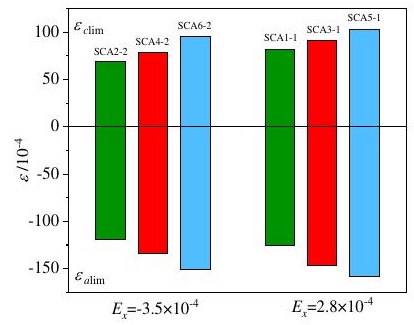

(a) Expansion rate of SSC

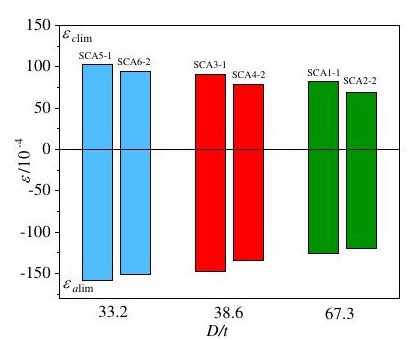

(b) Diameter-thickness ratio
Fig. 5 Influence of the variable parameters on the column ultimate strains

\section{Design recommendations}

Scholars have conducted numerous theoretical and experimental researches on the CFST and have compiled corresponding design specifications or codes for the CFST, such as the British Standard BS EN1994-2 [18], Hong Kong Code CoPHK [19], Australian Standard AS5100-2017 [20], and Chinese Specification DBJ/T 13-51-2010 [21]. In this section, the calculated results according to these specifications are compared to the SSSCFST short columns experimental data to verify the accuracy and applicability of the design approaches for the proposed structural form.

\subsection{BS EN1994-2}

BS EN1994-2 [18] was published under the authority of the Standards Policy and Strategy Committee. This code presents a design formula for the CFST members, which considers the composite action between the various elements forming the cross section. In this standard, the structural steel section should be universal section of grade S235 to S460 steel, a characteristic 28-day cube strength of concrete $f_{\text {cu }}$ should be not less than $20 \mathrm{MPa}$ for the CFST members. In addition, the maximum value $D / t$ of such cross-section parameters should be not exceed than $90\left(235 / f_{y}\right)$. The axial compressive bearing capacity of the CFST members can be calculated as follows.

$N_{\mathrm{u}}=\eta_{\mathrm{ao}} A_{\mathrm{s}} f_{\mathrm{y}}+A_{\mathrm{c}} f_{\mathrm{cu}}\left(1+\eta_{\mathrm{co}} \frac{t}{D} \frac{f_{\mathrm{y}}}{f_{\mathrm{cu}}}\right)$ 
$\eta_{\mathrm{ao}}=0.25(3+2 \bar{\lambda})$

$\bar{\lambda}=\sqrt{\frac{A_{\mathrm{s}} f_{\mathrm{y}}+A_{\mathrm{c}} f_{\mathrm{cu}}}{N_{\mathrm{cr}}}}$

$$
N_{\mathrm{cr}}=\pi^{2}(E I)_{\mathrm{e}} / L_{\mathrm{e}}^{2}
$$

where, $N_{\mathrm{u}}$ represents the nominal section capacity of the circular CFST columns, $A_{\mathrm{s}}$ and $A_{\mathrm{c}}$ are the cross-sectional area of the steel tube and concrete, respectively. $\eta_{\text {a }}$ and $\eta_{\text {co }}$ are the calculated coefficients when the axial compression CFST column section is circular. $\bar{\lambda}$ is the relative slenderness, and $N_{\text {cr }}$ is the elastic critical load, $(E I)_{\mathrm{e}}$ and $L_{\mathrm{e}}$ represent the effective flexural stiffness and length, respectively.

\subsection{CoPHK-2011}

CoPHK-2011 [19] was prepared by the Buildings Departments. The design formula of the compressive bearing capacity assuming the full section yielding is adopted for the composite structures. In another word, when the axial compression reaches the member ultimate design load, the steel yields and the infilled concrete reaches the ultimate compressive bearing capacity, simultaneously. The design formula in this code applied to CFST columns with steel yield strengths between $235 \mathrm{MPa}$ to $460 \mathrm{MPa}$ and normal weight concrete of strength classes $\mathrm{C} 25$ to $\mathrm{C} 60$. The relative slenderness ratio $\bar{\lambda}$ of the axially loaded CFST columns is not more than 0.5 . The plastic resistance may be calculated from the following expressions.

$N_{\mathrm{u}}=\eta_{\mathrm{ao}} A_{\mathrm{s}} f_{\mathrm{y}}+0.53 A_{\mathrm{c}} f_{\mathrm{cu}}\left(1+\eta_{\mathrm{co}} \frac{t}{D} \frac{f_{\mathrm{y}}}{0.8 f_{\mathrm{cu}}}\right)$

$\bar{\lambda}=\sqrt{\frac{\eta_{\mathrm{ao}} A_{\mathrm{s}} f_{\mathrm{y}}+0.8 A_{\mathrm{c}} f_{\mathrm{cu}}\left(1+\eta_{\mathrm{co}} \frac{t}{D} \frac{f_{\mathrm{y}}}{0.8 f_{\mathrm{cu}}}\right)}{N_{\mathrm{cr}}}}$

In this code, the values and calculations of the variables are the same as those in the British Standard BS EN1994-2 [18].

\subsection{AS5100 - 2017}

AS5100-2017 [20] was issued by Committee BD-090, Bridge Design. Considering the composite action between various components, this code provides the design formulas for predicting the circular and rectangular CFST columns, respectively. The design formula in this code applied to the circular CFST columns with a maximum yield stress of $690 \mathrm{MPa}$, and the relative slenderness $\bar{\lambda}$ is not greater than 0.5 . The ultimate nominal section capacity of the circular CFST columns under axial load can be calculated as follows.

$N_{\mathrm{u}}=\phi A_{\mathrm{s}} \eta_{\mathrm{ao}} f_{\mathrm{y}}+\phi_{\mathrm{c}} A_{\mathrm{c}} f_{\mathrm{cu}}\left(1+\frac{\eta_{\mathrm{co}} t f_{\mathrm{y}}}{D f_{\mathrm{cu}}}\right)$

$\bar{\lambda}=\sqrt{\frac{A_{\mathrm{s}} \eta_{\mathrm{ao}} f_{\mathrm{y}}+A_{\mathrm{c}} f_{\mathrm{cu}}\left(1+\frac{\eta_{\mathrm{co}} t f_{\mathrm{y}}}{D f_{\mathrm{cu}}}\right)}{N_{\mathrm{cr}}}}$

where, $\phi$ and $\phi_{c}$ denote the capacity factor for the steel and concrete, $\phi=0.9$ and $\phi_{\mathrm{c}}=0.65$.

\section{4. $D B J / T 13-51-2010$}

DBJ/T13-51-2010 [21] was issued by the Department of Housing and Urban-Rural of the Fujian Province. The design formula of the compressive bearing capacity using the unified theory was developed for the CFST members based on numerous experimental studies and numerical simulation analysis. In this specification, the strength grade of core concrete is not less than $\mathrm{C} 30$ and the water-cement ratio should not be greater than 0.45 . The concrete and steel are considered as a composite material. The material properties of the composite material are given in this specification. The axial compressive bearing capacity of the CFST members can be determined as follows.

$N \leq N_{\mathrm{u}}=f_{\mathrm{sc}} A_{\mathrm{sc}}$

$f_{\mathrm{sc}}=(1.14+1.02 \xi) f_{\mathrm{c}}$

where $f_{\mathrm{sc}}$ denotes the design value of compressive strength of the CFST members, $A_{\mathrm{sc}}$ stands for the section area of the CFST members, $\xi$ represents the confinement effect coefficient, $\xi=f_{\mathrm{y}} A_{\mathrm{s}} / f_{\mathrm{c}} A_{\mathrm{c}}$.

\subsection{Comparison of the theoretical and experimental results}

The comparisons between the theoretically calculated values $N_{\mathrm{ci}}$ from the above CFST design provisions and the experimental results $N_{\mathrm{u}}$ are summarized in Table 3. As shown in the table, the Australian Standard AS5100-2017 and Hong Kong Code CoPHK-2011 underestimate the load capacity of the SSSCFST short columns, from which the results are averagely $60.4 \%$ and $65.3 \%$, respectively, less than the experimental results. In contrast, the results from the British Specification BS EN1994-2 and the Chinese Specification DBJ/T13-51-2010 are relatively accurate with $15.1 \%$ and $29.9 \%$ differences, compared to the experimental results. Therefore, it is recommended to use BS EN1994-2 and DBJ/T13-51-2010 to calculate the ultimate load capacity of the axially loaded SSSCFST short columns.

Table 3

Contrast between the theoretical calculated and experimental results of columns

\begin{tabular}{|c|c|c|c|c|c|c|c|c|c|}
\hline \multirow[b]{2}{*}{ Specimen number } & \multirow{2}{*}{$\frac{\text { Experimental data }}{N_{\mathrm{u}} / \mathrm{kN}}$} & \multicolumn{2}{|c|}{ BS EN1994-2 [18] } & \multicolumn{2}{|c|}{ CoPHK-2011 [19] } & \multicolumn{2}{|c|}{ AS5100 - 2017 [20] } & \multicolumn{2}{|c|}{ DBJ/T13-51-2010 [21] } \\
\hline & & $N_{\mathrm{cl}} / \mathrm{kN}$ & $N_{\mathrm{u}} / N_{\mathrm{c} 1}$ & $N_{\mathrm{c} 2} / \mathrm{kN}$ & $N_{\mathrm{u}} / N_{\mathrm{c} 2}$ & $N_{\mathrm{c} 3} / \mathrm{kN}$ & $N_{\mathrm{u}} / N_{\mathrm{c} 3}$ & $N_{\mathrm{c} 4} / \mathrm{kN}$ & $N_{\mathrm{u}} / N_{\mathrm{c} 4}$ \\
\hline SCA1-1 & 625 & 551 & 1.13 & 366 & 1.71 & 388 & 1.61 & 479 & 1.30 \\
\hline SCA2-2 & 737 & 725 & 1.02 & 459 & 1.60 & 502 & 1.47 & 653 & 1.13 \\
\hline SCA3-1 & 1016 & 829 & 1.23 & 603 & 1.68 & 604 & 1.68 & 718 & 1.42 \\
\hline SCA4-2 & 1147 & 991 & 1.16 & 691 & 1.66 & 712 & 1.61 & 893 & 1.28 \\
\hline SCA5-1 & 1123 & 913 & 1.23 & 676 & 1.66 & 670 & 1.68 & 799 & 1.41 \\
\hline SCA6-2 & 1223 & 1071 & 1.14 & 762 & 1.60 & 776 & 1.58 & 974 & 1.26 \\
\hline Average value & - & - & 1.151 & - & 1.653 & - & 1.604 & - & 1.299 \\
\hline Mean square error & - & - & 0.071 & - & 0.038 & & 0.071 & - & 0.097 \\
\hline
\end{tabular}

\section{Finite element analysis}

\subsection{Material modeling}

The stress-strain relation of the steel tube is plotted in Fig. 6 [22]. The curve is linear initially, the plastic flow initiates after. Beyond the certain strain, the linearly hardening commences, and the stiffness is assumed to be zero after the ultimate strain is reached. The detailed relation can be 


$$
\sigma_{\mathrm{s}}=\left\{\begin{array}{l}
E_{\mathrm{s}} \varepsilon_{\mathrm{s}} \quad 0 \leq \varepsilon_{\mathrm{s}} \leq \varepsilon_{\mathrm{s} 1} \\
f_{\mathrm{sy}} \quad \varepsilon_{\mathrm{s} 1} \leq \varepsilon_{\mathrm{s}} \leq \varepsilon_{\mathrm{s} 2} \\
f_{\mathrm{sy}}+E_{s t}\left(\varepsilon_{\mathrm{s}}-\varepsilon_{\mathrm{s} 2}\right) \quad \varepsilon_{\mathrm{s} 2} \leq \varepsilon_{\mathrm{s}} \leq \varepsilon_{\mathrm{s} 3} \\
f_{\mathrm{su}} \quad \varepsilon_{\mathrm{s}} \geq \varepsilon_{\mathrm{s} 3}
\end{array}\right.
$$

where, $\sigma_{\mathrm{s}}, \varepsilon_{\mathrm{s}}$ are the equivalent stress and strain, $\varepsilon_{\mathrm{s} 1}$ represents the yield strain, $\varepsilon_{\mathrm{s} 2}=12 \varepsilon_{\mathrm{s} 1}$ is the hardening strain of steel tube, $\varepsilon_{\mathrm{s} 3}=120 \varepsilon_{\mathrm{s} 1}$ is the strain for the ultimate strength, $E_{\mathrm{s}}$ is the Young's modulus of steel tube, $E_{\mathrm{st}}=\xi E_{\mathrm{s}}$ is the strengthening Yong's modulus of steel tube, $\xi=1 / 216$ is the strengthening coefficient, $f_{\mathrm{sy}}$ is the yield strength of the steel tube, $f_{\mathrm{su}}=1.5 f_{\mathrm{sy}}$ is the ultimate strength of steel tube.

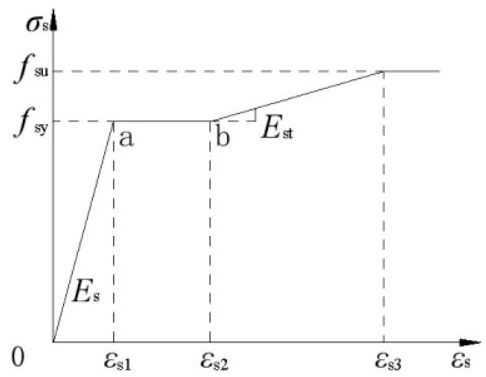

Fig. 6 The stress-strain relation of the steel tube

The existing studies show that [23] the characteristics of the stress-strain relationship curves of the core concrete of CFST are mainly related to the confinement effect coefficient $\xi$, which are mainly shown as the greater the value of $\xi$, the stronger the confinement action provided by the steel tube on the core concrete during the stress process. With the increase of deformation, the declining section of the stress-strain curve of the core concrete appears relatively late. Similar to the ordinary CFST, the strength of the SSSCFST can also be improved by the confinement action of steel tube on the core SSC. Therefore, the stress-strain relationship model of the core SSC of SSSCFST proposed in this study is modified on the basis of the stress-stress relationship model of the core concrete of CFST, as shown below.

$\sigma_{\mathrm{c}}=\sigma_{\mathrm{po}}\left[A \frac{\varepsilon_{\mathrm{c}}}{\varepsilon_{\mathrm{po}}}-B\left(\frac{\varepsilon_{\mathrm{c}}}{\varepsilon_{\mathrm{po}}}\right)^{2}\right]$

$$
\varepsilon_{\mathrm{c}} \leq \varepsilon_{\mathrm{po}}
$$

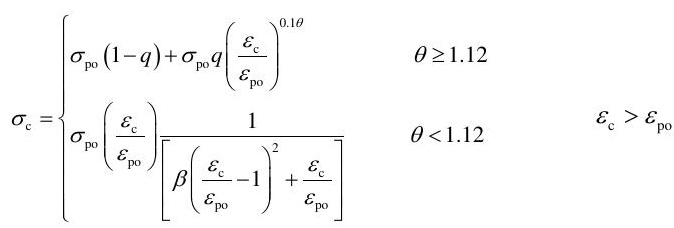

where, $\sigma_{\mathrm{c}}, \varepsilon_{\mathrm{c}}$ are the equivalent stress and strain of the axially loaded SSC, respectively. $\sigma_{\mathrm{po}}, \varepsilon_{\mathrm{po}}$ represent the uniaxial peak compressive stress and strain of the SSC. $\beta$ is the parameter, which was fitted by the regression analysis of the test data, $A=2-T, B=1-T, T=0.1 \theta^{0.745}, q=T /(0.2+0.1 \theta)$. $\theta\left(\theta=f_{\mathrm{y}} A_{\mathrm{s}} / f_{\mathrm{co}} A_{\mathrm{c}}\right)$ is the nominal confinement effect coefficient. $f_{\mathrm{co}}=0.67 f_{\mathrm{cu}}$ is the compressive strength of the SSC.

In view of the proposed model's adaptability and simplicity of calculation, the nominal confinement effect coefficient $\theta$ is not modified in this study and it is directly calculated by the formula of the confinement effect coefficient of CFST $\xi$. However, on the basis of experimental research, considering the influence of the self-stress between the steel tube and SSC, the strength enhancement coefficient of SSC $\mu$ is introduced, the key parameters of the stress-strain relationship model of the core concrete affected by the SSC, such as the uniaxial peak compressive stress $\sigma_{\mathrm{po}}$ and strain $\varepsilon_{\mathrm{po}}$ of the SSC, and the parameter $\beta$, are modified respectively, as shown below.

$\mu=1+K \frac{\sigma_{0}}{f_{\text {co }}}$

In which, $\sigma_{0}$ stands for the self-stress between the steel tube and SSC, as shown in Eq.(17), $K=3.0$ is the lateral confined coefficient determined by
$\sigma_{0}=E_{\mathrm{c}}\left(E_{\mathrm{x}}-E_{\mathrm{xr}}\right)$

where, $E_{\mathrm{c}}$ represents the Young's modulus of the SSC, $E_{\mathrm{xr}}$ denotes the confined expansion rate of the SSC [24].

$$
\begin{aligned}
& \sigma_{\mathrm{po}}=\mu f_{\mathrm{co}}\left[1.194+\left(\frac{13}{\mu f_{\mathrm{co}}}\right)^{0.45}\left(-0.07485 \theta^{2}+0.5789 \theta\right)\right] \\
& \varepsilon_{\mathrm{po}}=\varepsilon_{\mathrm{co}}+\left[1400+800 \frac{\mu f_{\mathrm{co}}-20}{20}\right] \theta^{0.2}
\end{aligned}
$$

$\beta=\left(2.36 \times 10^{-6}\right)^{\left[0.25+(\theta-0.5)^{7}\right]}\left(\mu f_{\text {co }}\right)^{2} \times 5 \times 10^{-4}$

In which, $\varepsilon_{\mathrm{co}}$ is the strain corresponding to the uniaxial compressive strength of the SSC, $\varepsilon_{\mathrm{co}}=1300+14.93 \mu f_{\mathrm{co}}$.

\subsection{Finite Element Model}

\subsubsection{Elements and contact interaction}

S4R and C3D8R are employed to mesh the steel tube and SSC. Simpson integral of 9 integral points is adopted to accurately simulate member element. The sensitivity investigation indicates that both the outer steel tube and core SSC are meshed with $20 \mathrm{~mm}$ element size. The typical FE model is depicted in Fig. 7.

Surface-to-surface contact interaction is adopted between the steel tube and SSC. Hard contact is designated as the interaction between two surfaces, the tangential behavior of contact surfaces is determined by the Coulomb friction model and the friction coefficient is set as 0.3 . Shell-to-solid-coupling contact interaction is employed between the steel tube and the loading plates.

\subsubsection{Load and boundary conditions}

Displacement controlled scheme is adopted in FE model analysis. Fixed constraints are applied to the bottom of the column and the constraints in the $\mathrm{X}$ and $\mathrm{Y}$ directions are applied to the top of the column, so as to ensure that the specimens only produce displacement in the $\mathrm{Z}$ direction. The incremental iteration approach is employed and the initial, minimum, and maximum increment are set as $0.01,1 \times 10^{-5}$ and 10 , respectively.

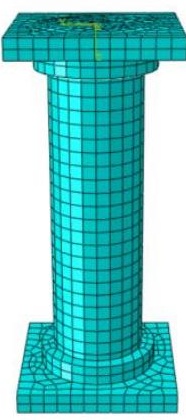

(a) Integral model

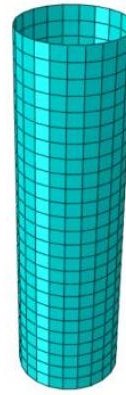

(b) Steel tube

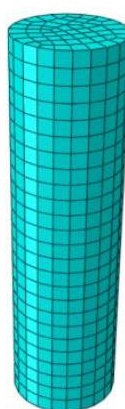

(c) SSC
Fig. 7 Typical FE model for the SSSCFST short column

\subsection{Verification of FE model}

The comparison of typical failure mode of the specimens is shown in Fig. 8. As can be seen from the figure, the most obvious failure characteristics of the specimens are the expansion of SSC in the middle and the bulge of the steel tube, which are basically consistent with the FE simulation results. For the test results, most of the specimens show uneven bulge and local buckling. After reaching the peak bearing capacity, the local buckling phenomenon is more obvious due to continuing loading. The reason for the small deviation between the FE simulation results and the experimental results is that the initial defects of the steel tube and SSC are not taken into account in the FE simulation. The calculation is stopped due to the convergence problem near the peak point, and the specimen's declining behavior after the peak point is 
not considered. Therefore, the failure modes simulated by the FE model don't exhibit obvious buckling phenomenon. In addition, test data of load capacity and ultimate compressive strain of the axially loaded SSSCFST short columns are compared with FE prediction results, as shown in Table 4. In which, $N_{\mathrm{c}}$ and $\varepsilon_{\text {cau }}$ represent the predicted values of the load capacity and ultimate compressive strain. $\varepsilon_{\text {au }}$ denotes the measured test data of the ultimate compressive strain. Obviously, the FE model established above can well predict the load capacity and ultimate compressive strain of the SSSCFST short columns under axial load. The average ratio of the $N_{\mathrm{c}} / N_{\mathrm{u}}$ and $\varepsilon_{\text {cau }} / \varepsilon_{\text {au }}$ are 1.051 and 0.948 , respectively, and the standard deviation of the $N_{\mathrm{c}} / N_{\mathrm{u}}$ and $\varepsilon_{\text {cau }} / \varepsilon_{\text {au }}$ are 0.0691 and 0.0156 , respectively.

Moreover, Fig. 9 depicts the comparisons between the measured stress-strain relation curves and the stress-strain curves predicted by FE analysis. In which, $\sigma_{\mathrm{a}}$ represents the compressive stress, $\varepsilon_{\mathrm{a}}$ denotes the axial compressive strain. The proposed FE model reasonably predicts the stress-strain response of the SSSCFST short columns under axial load. The change trends of the predicted curves and the measured curves are basically consistent. The estimated axial stiffness agrees well with the measured axial stiffness.
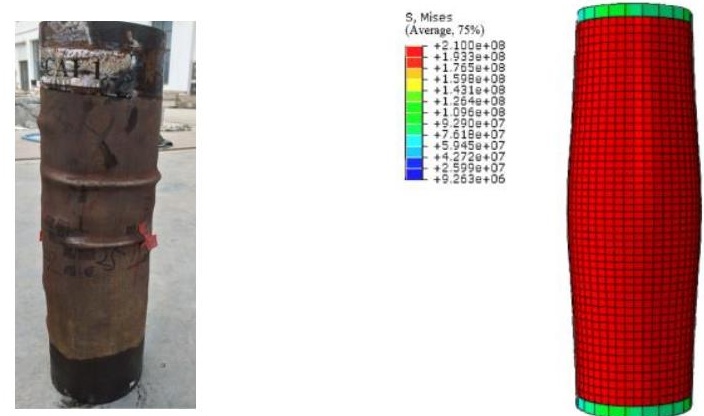

Fig. 8 Comparison between the column failure mode

Table 4

Comparisons between the measured test data and FE model predicted values

\begin{tabular}{|c|c|c|c|c|c|c|c|c|}
\hline Specimen & $D / \mathrm{t}$ & $E_{\mathrm{x}} / 10^{-4}$ & $N_{\mathrm{u}} / \mathrm{kN}$ & $N_{\mathrm{c}} / \mathrm{kN}$ & $\varepsilon_{\mathrm{au}}$ & $\varepsilon_{\mathrm{cau}}$ & $N_{\mathrm{c}} / N_{\mathrm{u}}$ & $\varepsilon_{\mathrm{cau}} / \varepsilon_{\mathrm{au}}$ \\
\hline SCA1-1 & \multirow{2}{*}{67.30} & 2.8 & 625 & 711 & -0.0125 & -0.0117 & 1.138 & 0.936 \\
\hline SCA2-2 & & -3.5 & 737 & 841 & -0.0119 & -0.0113 & 1.141 & 0.950 \\
\hline SCA3-1 & \multirow{2}{*}{38.56} & 2.8 & 1016 & 1035 & -0.0147 & -0.0139 & 1.019 & 0.946 \\
\hline SCA4-2 & & -3.5 & 1147 & 1141 & -0.0134 & -0.0131 & 0.995 & 0.978 \\
\hline SCA5-1 & \multirow{2}{*}{33.17} & 2.8 & 1123 & 1129 & -0.0158 & -0.0148 & 1.005 & 0.937 \\
\hline SCA6-2 & & -3.5 & 1223 & 1231 & -0.0151 & -0.0142 & 1.007 & 0.940 \\
\hline Average value & - & - & - & - & - & - & 1.051 & 0.948 \\
\hline Mean square error & - & - & - & - & - & - & 0.0691 & 0.0156 \\
\hline
\end{tabular}

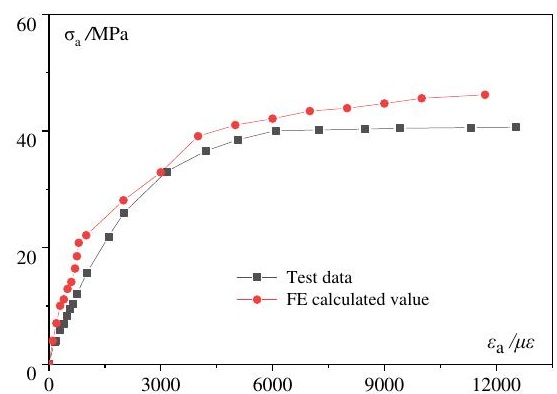

(a) SCA1-1

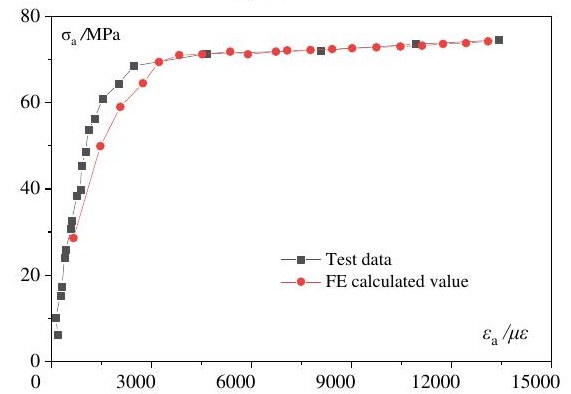

(d) SCA4-2

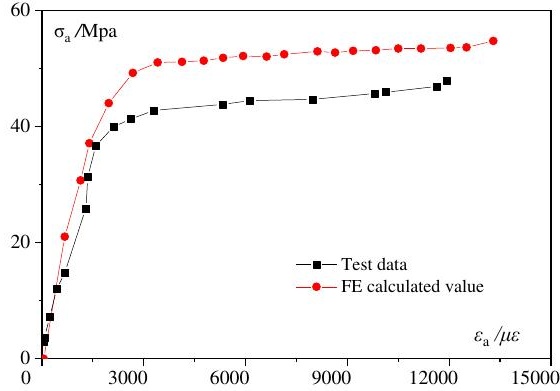

(b) SCA2-2

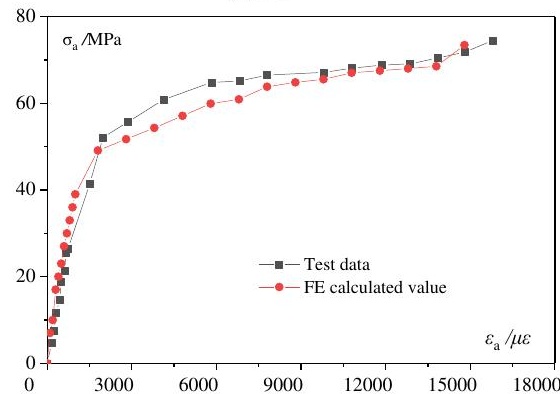

(e) SCA5-1

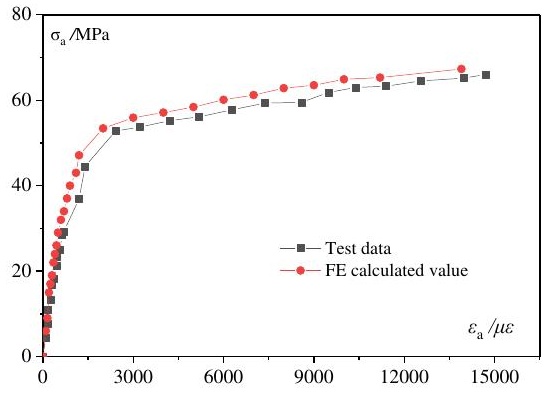

(c) SCA3-1

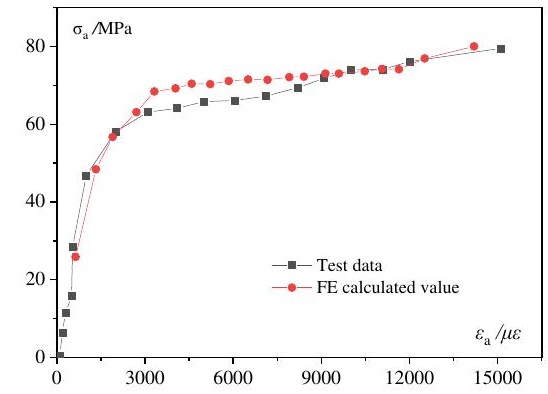

(f) SCA6-2

Fig. 9 Comparisons between the measured stress-strain curves and stress-strain curves predicted by FE analysis

\subsection{Parametric studies}

In this section, the parametric studies are conducted to examine the impacts of variation in the steel ratio $\alpha$ (when $t<<r, \alpha=A_{\mathrm{s}} / A_{\mathrm{c}} \approx 2 t / r$ ), the yield strength of steel tube $f_{\mathrm{y}}$, and the core concrete strength grade $f_{\mathrm{c}}$ on the member's mechanical behaviors. Specimen SCA 3-1 is employed as the comparative reference. Stress-strain $\left(\sigma_{\mathrm{a}}-\varepsilon_{\mathrm{a}}\right)$ relation curves of the axially loaded SSSCFST short columns with different steel ratios, yield strength of the steel tube, and core concrete strength grades are depicted in Fig. 10, Fig. 11 and Fig. 12.

As depicted in Fig. 10, the increase of steel ratio $\alpha$ will increase the initial stiffness, prolong the elastic stage of the specimen. This may come from that the confining effect of the steel tube on the SSC enhances with the increase of steel ratio. As the load increases, the columns come into the elastoplastic stage, and the stress of the SSSCFST short columns grows slowly, while the strain develops rapidly. The strain development rate decreases with the increase of the steel ratio.

As depicted in Fig. 11, initially the specimens are in the elastic stage and the stress-strain relation curves of the specimens with different steel yield strength $f_{\mathrm{y}}$ are basically identical. With the increase of load, the stress-strain relation curves deviate from linear growth, and the SSSCFST short columns enter elastoplastic stage. Subsequently, the specimens yield and the obvious inflection points appear on the stress-strain relation curves. After yielding, the stress increases slowly while the strain develops rapidly. 
The impact of the strength grade of core concrete $f_{\mathrm{c}}$ on the stress-strain relation curves of the SSSCFST short columns subjected to axial load is described in Fig. 12. Apparently, the stress-strain relation curves of the specimens with different strength grades of core concrete are basically consistent initially. As the load increases, the stress-strain relation curves increase non-linearly. As the load further increases, the obvious inflection points appear and the yield stress of the specimens increases as the strength grade of core concrete $f_{\mathrm{c}}$ enhances.

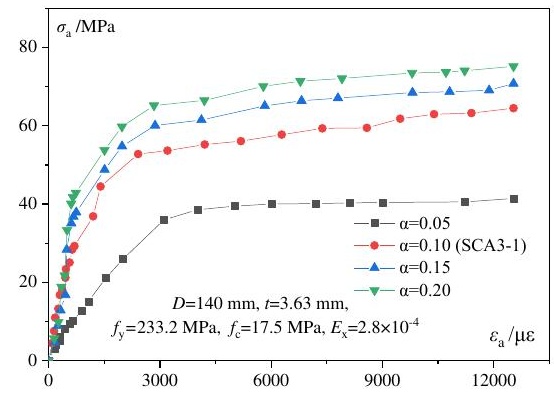

Fig. 10 Effect of $\alpha$ on the stress-strain relation curve

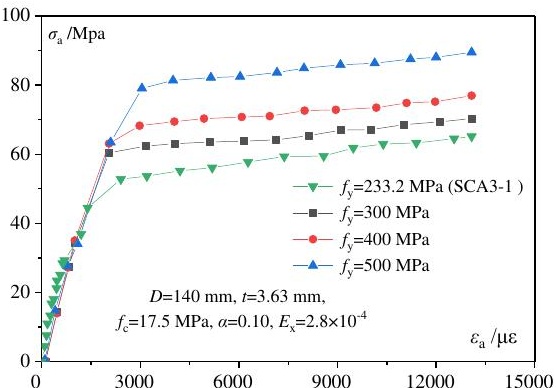

Fig. 11 Effect of $f_{y}$ on the stress-strain relation curve

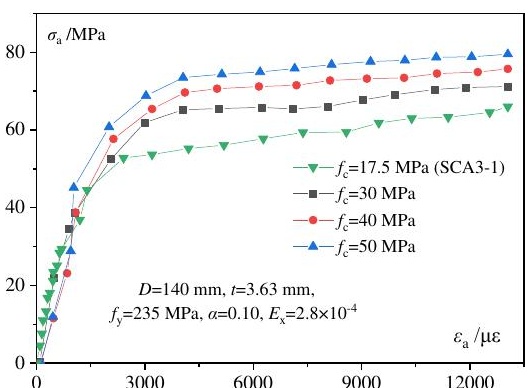

Fig. 12 Effect of $f_{\mathrm{c}}$ on the stress-strain relation curve

\section{Conclusions}

The mechanical performance of the six axially loaded SSSCFST short columns is investigated and the accuracy of the conventional design approaches for the innovative composite members is evaluated. The following conclusions can be drawn.

(1)The SSSCFST short columns with the low confinement effect coefficient under axial load are damaged by shear deformation, while the outward local buckling dominates the failure of the axially loaded SSSCFST short columns with the high confinement effect coefficient.

(2)The ultimate load capacity decreases as the diameter-thickness ratio increases. The incremental range of load capacity can be improved by enhancing the expansion rate. The member ultimate axial and circumferential strains increase with the increase of the expansion rate while they decrease with the increase of the diameter-thickness ratio.

(3) The load-displacement curves of the six SSSCFST short columns demonstrate similar trends, including three stages as elasticity, elastic-plasticity and plasticity. The ultimate axial displacement of the columns decreases with the increase of the diameter-thickness ratio while the

\section{References}

[1] Furlani E., Tonello G. and Maschio S., "Recycling of steel slag and glass cullet from energy saving lamps by fast firing production of ceramics", Waste Management, 30(8), $1714-1719,2010$

[2] Jiang Y., Ling T.C., Shi C. and Pan S.Y., "Characteristics of steel slags and their use in cement and concrete-a review", Resources Conservation and Recycling, 136, 187-197, 2018.

[3] Yu X., Tao Z., Song T.Y. and Pan Z., "Performance of concrete made with steel slag and waste glass", Construction and Building Materials, 114, 737-746, 2016.

[4] Yu F., Yao C., Hu Y., Fang Y., Niu K., and Xiang G. S. "Axial compressive behavior of self-stressing steel slag aggregate concrete filled steel tubular columns with bond-slip damage", Advanced Steel Construction, 16(1), 13-19, 2020.

[5] Liu J. and Wang D., "Influence of steel slag-silica fume composite mineral admixture on the properties of concrete", Powder Technology, 320, 230-238, 2017.

[6] Anastasiou E., Filikas K.G. and Stefanidou M., "Utilization of fine recycled aggregates in concrete with fly ash and steel slag", Construction and Building Materials, 50(50), 154-161, 2014

[7] Morone M., Costa G., Polettini A., Pomi R. and Baciocchi R., "Valorization of steel slag by a combined carbonation and granulation treatment", Minerals Engineering, 59, 82-90, 2014.

[8] Wang Q., Wang D. and Zhuang S., "The soundness of steel slag with different free $\mathrm{CaO}$ and MgO contents", Construction and Building Materials, 151, 138-146, 2017.

[9] Han L.H., Li W. and Bjorhovde R.., "Developments and advanced applications of concrete-filled steel tubular (CFST) structures: members", Journal of Constructional Steel Research, 100, 211-228, 2014.

[10] Yang C., Yu Z. X., Sun Y.P., Zhao L. and Zhao H., "Axial residual capacity of circular concrete-filled steel tube columns considering local buckling", Advanced Steel Construction, 14(3), 496-513, 2018.

[11] Yu F., Wang X.L., Yang Z. and Xu L., "Stress-strain relationship of shrinkage compensating steel-slag concrete", Journal of Building Materials, 20(4), 527-534, 2017. effect of expansion rate on the ultimate axial displacement is not significant.

(4) The paper evaluates the prescriptive methods in designing the SSSCFST columns under axial load. The comparisons between the test data and calculation results of the specification design formulas demonstrate that the British Specification BS EN1994-2 and Chinese Specification DBJ/T13-51-2010 can provide satisfactory results for the member load capacity.

(5) A validated FE model for the axially loaded SSSCFST short columns is adopted to perform parametric studies to broaden the available experimental results about their mechanical behaviors.

\section{Acknowledgements}

This work was sponsored by National Natural Science Foundation of China (No. 51578001, 51878002, 52078001), Outstanding Youth Fund of Anhui Province (No. 2008085J29), Natural Science Research Project of Anhui Universities (No. KJ2020A0234, KJ2020A0261), and the University Synergy Innovation Program of Anhui Province (No. GXXT-2019-005).

[12] Beggas D. and Zeghiche J., "The use of slag stone concrete to improve the therma performance of light steel buildings", Sustainable Cities and Society, 6(1), 22-26, 2013.

[13] Zeghiche N.F.J., "Numerical analysis of cold-formed steel welded tube filled with concrete made of crystallized slag aggregate", International Journal of Applied Electromagnetics and Mechanics, 16(1), 112, 2014.

[14] Ferhoune N., "Experimental behaviour of cold-formed steel welded tube filled with concrete made of crushed crystallized slag subjected to eccentric load", Thin-Walled Structures, 80(1), 159-166, 2014

[15] GB/T228.1-2010, Metallic Materials-Tensile Testing - Part 1: Method of Test at Room Temperature, China Architecture and Building Press, Beijing, China, 2010.

[16] GB50010-2010, Code for design of concrete structures, China Architecture and Building Press, Beijing, China, 2010

[17] Yu F., Fang Y., Zhang Y., Xu L. and Bai R.., "Mechanical behavior of self-stressing steel slag aggregate concrete filled steel tubular stub columns", Structural concrete, 21(1), 1597-1611, 2020.

[18] BS EN1994-2, Eurocode 4 - Design of composite steel and concrete structures - Part2: General rules and rules for bridges, British Standards Institution, London, British, 2005.

[19] CoPHK-2011, Code of practice for the structural use of steel, Buildings Department, Hong Kong SAR Government, Hong Kong, 2011.

[20] AS5100.6-2017, Australia Standard bridge design, Part 6: Steel and composite construction, Committee BD-090, Bridge Design, Sydney, Australia, 2017.

[21] DBJ/T13-51-2010, Technical specification for concrete-filled steel tubular structures, Fujian: Department of Housing and Urban-Rural of the Fujian Province, Fuzhou, China 2010.

[22] Ding F.X. and Yu Z.W., "Theoretical analysis of mechanical properties of concrete filled tubular steel stub columns", Engineering Mechanics, 22(1), 175-181, 2005.

[23] Han L.H., "Concrete Filled Steel Tubular Structure-theory and Application", Science Press, Beijing, China, 2016.

[24] Xu L., "Experimental study and theoretical analysis on static performance of the steel slag concrete-filled circular steel tube", Master Thesis, Anhui University of Technology, 2015. 


\title{
BEHAVIOUR OF REINFORCED JOINTS BETWEEN STEEL BEAM AND L-SHAPED WIDE LIMB COMPOSITE COLUMN
}

\author{
Rong-Quan Ma ${ }^{1}$, Ping-Yu Zhao ${ }^{2}$, Hui-Yong Ban ${ }^{2,}{ }^{*}$, Yuan-Qing Wang ${ }^{2}$, Yu-Zheng Zhao ${ }^{3}$ and Cheng-Bo Peng ${ }^{4}$ \\ ${ }^{1}$ College of Civil Engineering, Tongji University, Shanghai, China \\ ${ }^{2}$ Key Laboratory of Civil Engineering Safety and Durability of China Education Ministry, \\ Department of Civil Engineering, Tsinghua University, Beijing, China \\ ${ }^{3}$ Beijing Tianheng Construction Group Co. Ltd, Beijing, China \\ ${ }^{4}$ China Construction Eight Engineering Division Steel Structure Engineering Company, Shanghai, China \\ *(Corresponding author: E-mail: banhy@tsinghua.edu.cn)
}

\section{A B S T RA C T}

Specially-shaped composite columns have attracted more and more attention from either industry or academia, due to their benefits for improving efficiency of use and design of indoor space. This paper presents a research programme on the seismic behaviour of an innovative joint between steel beam and L-shaped wide limb composite column (LSWL-CC). Two full-scale cyclic loading tests are introduced, with failure modes, cyclic behaviour, ultimate capacities, rotation performance, ductility, and energy dissipation being clarified. By using SolidWorks, a parametric model of the joints between steel beams and LSWL-CCs is established, and effects of various parameters are analysed by finite element (FE) analyses through ABAQUS. The FE model is validated against the test results. Furthermore, effects of geometry of the RVPs and the column axial compression ratio on the stiffness, bearing capacity, plastic zone and ductility of the joints are analysed. It is found that, triangular RVPs can make the joints possess similar seismic performance compared with the specimens using trapezoid RVPs. It is suggested to locate the RVPs within the width of the flange in case of the beams and columns having identical width. In addition, optimised geometry of the RVPs with a curved edge may lead to better deformation performance for the joints. Specifically, length of the RVP is suggested to be 1.0 1.2 times height of the beam, its height shall be $1 / 4 \sim 1 / 3$ of the steel beam height, and its thickness shall be 1.2 times that of the beam flange. The research outcomes may provide valuable information for further research on structures with the L-shaped columns and the joints, and may promote their practical application.
A R T I C LE H I S T O RY

\begin{tabular}{|c|c|}
\hline Received: & 25 February 2020 \\
\hline Revised: & 10 November 2020 \\
\hline Accepted: & 10 November 2020 \\
\hline
\end{tabular}

\section{K E Y W O R D S}

Beam-to-column joints;

L-shaped wide limb composite

columns;

Reinforcing vertical plate;

Experimental study;

Finite element analysis;

Seismic performance

\section{Introduction}

Rectangular cross-section columns are widely applied in steel residential building structures, such as concrete-filled steel tube (CFST) ones (Lee et al. 2011, Jamaluddin et al. 2013, Patel et al. 2016, 2019) $)^{[1-4]}$, of which the width is normally larger than the thickness of walls, and therefore extended corners are resulted and may reduce indoor space. Use of specially-shaped reinforced concrete columns (Xue et al. 2017) ${ }^{[5]}$ and composite columns, such as L-shaped, $\mathrm{T}$-shaped and cross section ones, are adequate for solving this problem due to their benefits in efficient use and design of indoor space (Liu et al. 2019) ${ }^{[6]}$. However, because of their particular geometric properties, innovative beam-tocolumn joints with improved configurations are required for practical engineering.

Previously, extensive research has been focused on the behaviour of specially-shaped composite columns only, including the static behaviour under compression of L-shaped ones (Chen and Shen 2010, Liu et al. 2018, 2019, Rong et al. 2017, Xiong et al. 2017, Zhang et al. 2018, Zhou et al. 2015, 2016) ${ }^{[6-13]}$, of T-shaped ones (Liu et al. 2018, Rong et al. 2016, Tu et al. 2014, Wang and Chang 2013, Yang et al. 2010, $2015)^{[8,14-19]}$ and of other types (Wu et al. 2017) ${ }^{[20]}$, as well as their dynamic performance (Liu et al. 2018, Shen et al. 2013, Tu et al. 2014, Zhou et al. 2012 $)^{[14,21-23]}$. Extensive experimental investigations were conducted, with effects of various configurations of stiffeners, geometry and material strengths being elucidated, and design guidance or prediction formulae were proposed accordingly. In addition, Zhou et al. $(2015)^{[24]}$ and Zhang et al. $(2018)^{[25]}$ experimentally investigated seismic behaviour of frames with L-shaped composite columns, in which effects of axial compression ratio and beam-to-column stiffness ratios on seismic behaviour of the frames were clarified and the failure mechanism was discussed.

Regarding research on beam-to-column joints, previous work is mainly focusing on that with conventional circular or square CFST columns, including the joints with external diaphragms (Chen and Chung 2003, Li and Han 2011, Rezaifar and Younesi 2017) ${ }^{[26-28]}$, that with bolted connections (Lee et al. 2012, Tao et al. 2017, Thai et al. 2017) ${ }^{[29-31]}$ and with other configurations (Stephens et al. 2016) ${ }^{[32]}$. Investigations on beam-to-column joints fabricated with the specially-shaped composite columns are rather limited. Du et al. (2012) $)^{[33]}$ experimentally investigated frame joints with T-shaped CFST columns and steel beams as well as exterior diaphragms, and found that increase of width or overhanging length of the stiffening ring may improve the ductility of the joints. Xu et al. $(2012)^{[34]}$ tested three frame joints with crisscross CFST columns and steel beams under cyclic loadings, and clarified their failure mechanism as well as effects of axial compression ratios. Liu et al. $(2016)^{[35]}$ tested six steel reinforced concrete special-shaped column-beam joints on their seismic behaviour. Liu et al. (2017) ${ }^{[36]}$ tested four joints under cyclic loadings, and exterior diaphragm and vertical ribs were utilised in two groups, respectively. Both cross-shaped and T-shaped CFST columns were incorporated. Their effects on the seismic behaviour of the joints were elucidated and design equations for predicting the shear resistance were developed. Zhang et al. $(2018)^{[37,38]}$ introduced an innovative joint between L-shaped composite columns and steel beams by employing vertical stiffeners, and tested their cyclic performance. Based on the test results, a simplified trilinear model was proposed for predicting the shear strength versus shear deformation responses as well as a design method being introduced. Zeng et al. (2019) ${ }^{[39]}$ investigated experimentally a reduced-scale frame structure with concrete encased L-shaped steel section columns and steel beams on its seismic performance.

Diaphragms are commonly utilised for connecting tubular columns including CFST ones with steel beams. However, use of inner diaphragms may result in challenges for fabrication because it is difficult to be welded along the four edges inside the tubes; the exterior diaphragm is wider than the steel beams and needs more indoor space, and therefore it is inadequate for the specially-shaped columns. An innovative type of beamto-column joints with reinforcing vertical plates (RVPs) was presented herein for practical use of L-shaped wide-limb composite columns (LSWL-CCs), which are expected to shift the beam plastic hinges but not to increase width of the beam. An experimental programme on the joints was carried out to clarify their seismic performance, and numerical analyses were subsequently conducted with extensive range of parameters being involved. The research outcomes are helpful for understanding the mechanical responses of the reinforced joints, and may provide references for their engineering application.

\section{Experimental research}

\subsection{Test programme}

An experimental programme including two full-scale joint specimens were carried out previously by the authors (Ma et al. 2017) ${ }^{[40]}$, one with a lattice type 
of LSWL-CC (labelled as specimen I) and the other one with a solid type of LSWL-CC (labelled as specimen II). Their general configuration details are illustrated in Figs. 1 and 2, respectively. The composite column of the specimen I is composed of three square CFSTs as boundary elements and diagonal steeltube (ST) bracings, and that of the specimen II is composed of three square CFSTs as boundary elements as well and double steel plate composite walls. In the composite walls, thickness of the outside steel plate is $12 \mathrm{~mm}$ while thickness of the inner stiffener plate is $8 \mathrm{~mm}$. Hot-rolled H-shaped profile HN600 $\times 200 \times 11 \times 17$ was used to fabricate the steel beam, and two RVPs are attached on both sides of the beam end through welding, respectively, of which thickness is $25 \mathrm{~mm}$. It should be noted that the RVP of specimen I is a cut-corner plate, and that of specimen II is optimized to be a wedge for reducing potential stress concentration. The RVPs should be welded on the beam in factory to ensure the welding quality. Other geometric dimensions can be found in Figs. 1 and 2 .

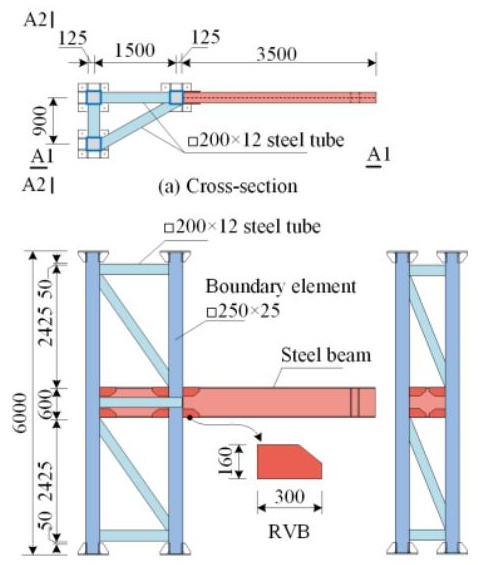

(b) $\mathrm{A} 2-\mathrm{A} 2$

(c) $\mathrm{A} 3-\mathrm{A} 3$

Fig. 1 Geometry of specimen I (Unit: mm)

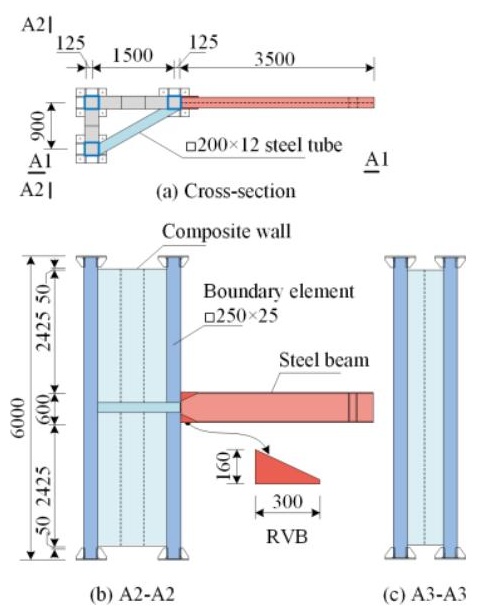

Fig. 2 Geometry of specimen II (Unit: $\mathrm{mm}$ )

The tubes in the boundary elements are fabricated from Q420C steel, and other steel components of the specimens are fabricated from Q345C steel. Material properties of the steel are given in Table 1, where the yield strength, the ultimate tensile stress and the elongation percentage after fracture of the steel plates are presented as $f_{\mathrm{y}}, f_{\mathrm{u}}$ and $A_{\mathrm{fr}}$, respectively. The boundary elements and the composite wall of specimen II are filled with concrete, of which equivalent compressive strength $f_{\mathrm{c}}$ is $39.6 \mathrm{MPa}$ on average.

Table 1

Material properties of steel

\begin{tabular}{ccccc}
\hline Grade & Thickness $(\mathrm{mm})$ & $f_{\mathrm{y}}(\mathrm{MPa})$ & $f_{\mathrm{u}}(\mathrm{MPa})$ & $A_{\mathrm{fr}}$ \\
\hline Q420C & 25 & 454.4 & 606.96 & 0.25 \\
\hline \multirow{2}{*}{ Q345C } & 25 & 358.1 & 517.8 & 0.30 \\
& 17 & 360.1 & 541.4 & 0.29 \\
& \multirow{2}{*}{ 12 (solid wall) } & 352.1 & 505.9 & 0.33
\end{tabular}

\begin{tabular}{cccc}
\hline 12 (ST bracing) & 390.5 & 519.3 & 0.29 \\
11 & 368.2 & 536.9 & 0.29 \\
8 & 352.8 & 520.7 & 0.33 \\
\hline
\end{tabular}

The test setup is shown in Fig. 3. Axial compressive force was applied at top of the boundary elements firstly and kept constant, and cyclic loads were applied vertically at the end of the beam, which was laterally braced to prevent lateral-torsional buckling. The axial compressive force applied was $11324.8 \mathrm{kN}$ with a compression ratio of being 0.6 . The cyclic loading downward is denoted as "+" and upward as "--"
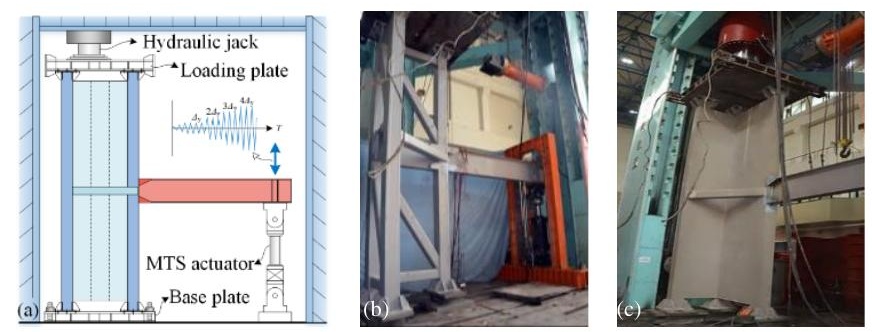

Fig. 3 Test setup: (a) illustration; (b) photo of specimen I (Ma et al. 2017 $7^{[40]}$ ); (c) photo of specimen II (Ma et al. 2017 $7^{[40]}$ )

Layout of measurement for the two specimens is shown in Fig. 4. The vertical linear variable displacement transformer (LVDT) D1 is used to measure the beam end deflection $\delta_{1}$. LVDTs D2 and D3 are placed diagonally to measure the panel zone's deformation $\left(\delta_{2}\right.$ and $\left.\delta_{3}\right)$. LVDTs D4 and D5 are used to measure the horizontal displacements $\delta_{4}$ and $\delta_{5}$ of the columns. LVDTs D6 and D7 are used to measure the shear deformation $\delta_{6}$ and $\delta_{7}$ of the zone of the RVPs. LVDTs D8 and D9 are used to measure the rigid body motion through readings $\delta_{8}$ and $\delta_{9}$. Strain gauges are arranged at the location where plastic hinge is expected to develop.

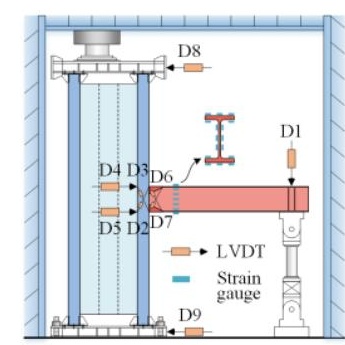

Fig. 4 Layout of measurement

\subsection{Test results and analyses}

Fig. 5 shows typical failure modes of the specimen I. With an increase of the cyclic loading levels, the beam flange adjacent to the RVPs buckled locally firstly, and then crack was observed within the flange. No visible deformation was identified in the LSWL-CC and the RVPs during the whole loading process. Similar failure modes were found for the specimen II, as shown in Fig. 6.
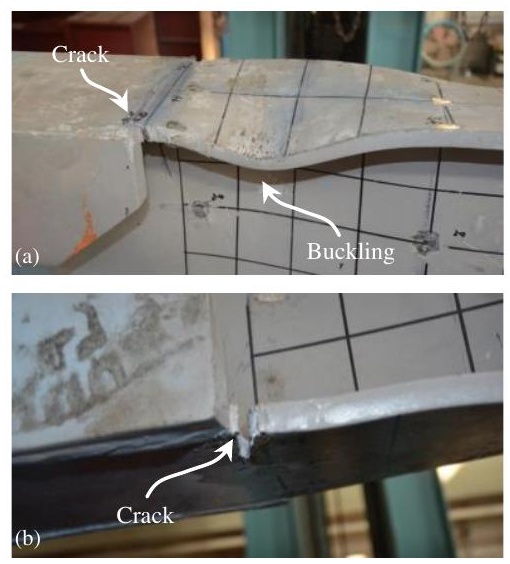

Fig. 5 Failure modes of specimen I: (a) local bucking and crack of top flange; (b) crack at bottom flange 


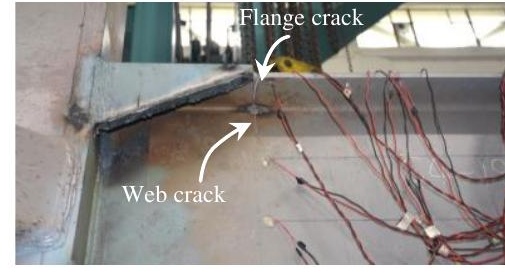

Fig. 6 Failure modes of specimen II

Cyclic loading versus deformation responses were obtained from test results, as shown in Fig. 7. It can be found that both specimens' exhibit a plump shape. Strength degradation was resulted from buckling or initiation of crack within the beam flanges. Plastic hinge within the beam can be developed out of region of the RVPs, and the maximum ratios $M / M_{\mathrm{p}}$ of specimens I and II are 1.13 and 1.10 , respectively, in which $M_{\mathrm{p}}$ is the full plastic moment capacity of the plastic hinge and is calculated as being $1031 \mathrm{kN} \cdot \mathrm{m}$ from the measured material properties in Table 1. However, development of the plastic deformation of the joints is still insufficient because of their brittle fracture. Based on the cyclic curves and corresponding envelop curves, characterised results including moments $M_{\mathrm{y}}, M_{\mathrm{u}}$ and rotations $\theta_{\mathrm{y}}, \theta_{\mathrm{u}}$ as well as initial elastic stiffness $K_{\mathrm{e}}$ are summarised in Table 2.
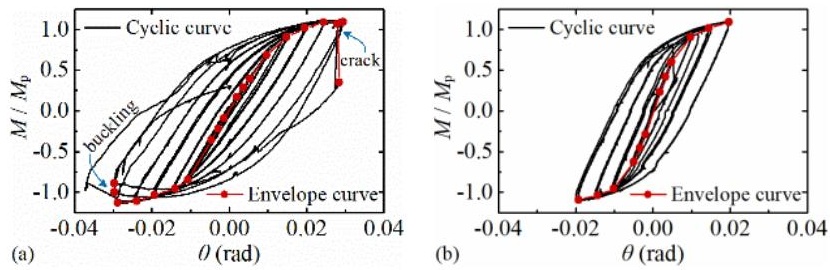

Fig. 7 Cyclic and envelope curves: (a) specimen I; (b) specimen II

Table 2

Characterised results from envelope curves (Ma et al. 2017) ${ }^{[40]}$

\begin{tabular}{lcccccc}
\hline \multirow{2}{*}{ Specimen } & \multirow{2}{*}{$\begin{array}{c}\text { Load } \\
\text { direction }\end{array}$} & \multicolumn{2}{c}{ Yield point } & \multicolumn{2}{c}{ Ultimate point } & \multirow{2}{*}{$K_{\mathrm{e}}$} \\
\cline { 3 - 6 } & $M_{\mathrm{y}}(\mathrm{kN} \cdot \mathrm{m})$ & $\theta_{\mathrm{y}}(\mathrm{rad})$ & $M_{\mathrm{u}}(\mathrm{kN} \cdot \mathrm{m})$ & $\theta_{\mathrm{u}}(\mathrm{rad})$ & $(\mathrm{kN} / \mathrm{mm})$ \\
\hline \multirow{2}{*}{ Specimen I } & - & -1026 & -0.01 & -1165 & -0.03 & 8.87 \\
& + & 992 & 0.01 & 1150 & 0.03 & \\
\hline \multirow{2}{*}{ Specimen II } & - & -881 & -0.009 & -1124 & -0.02 & \multirow{2}{*}{15.72} \\
& + & 834 & 0.008 & 1127 & 0.02 & \\
\hline
\end{tabular}

Based on the displacement measurements, the total beam end rotation $\theta(\mathrm{Hu}$ et al. 2014) $)^{[41]}$, rotation of the panel zone of beam-to-column joints $\theta_{\mathrm{pz}}$ (Shi et al. 2012) ${ }^{[42]}$, rotation of column $\theta_{\mathrm{c}}$ as well as beam rotation $\theta_{\mathrm{b}}$ can be derived. Contribution of each rotation component to the total beam end rotation in the last cycle at each loading level is shown in Fig. 8. It can be found that the beam rotation $\left(\theta_{\mathrm{b}}\right)$ is dominant for both specimens I and II. The maximum rotation of panel zone is about $1.8 \%$ and $1.0 \%$ of the total beam end rotation, respectively, for specimens I and II. Generally, the results indicate that the rotation capacity of specimen I was greater than that of specimen II. Table 3 gives results of displacement ductility ratio $\left(\mu_{\Delta}\right)$ and equivalent viscous damping coefficient $h_{\mathrm{e}}$.
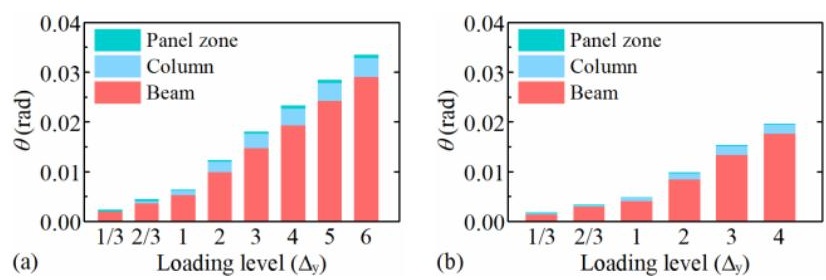

Fig. 8 Contribution of beam end rotation: (a) specimen I; (b) specimen II

Table 3

Ductility and energy dissipation results (Ma et al. 2017) $)^{[40]}$

\begin{tabular}{ccccc}
\hline \multirow{2}{*}{ Specimen I } & - & 2.45 & 2.38 & 0.267 \\
& + & 2.38 & & \\
\hline \multirow{2}{*}{ Specimen II } & - & 2.25 & 2.33 & 0.264 \\
& + & 2.40 & & \\
\hline
\end{tabular}

\section{Finite Element Modelling and Validation}

Based on the previous experimental research programme, a threedimensional finite element (FE) model of the joints was developed by using ABAQUS, as shown in Fig. 9. A bilinear stress-strain relation was employed to describe the uniaxial one of the steel, and the kinematic hardening model provided by ABAQUS was applied for the steel; the concrete damaged plasticity model was used for the concrete material. Material properties were determined based on the material test results. The Q420 steel tubes and concrete components were meshed by using C3D8R element, and the other steel components including the tubes in the joint zone were meshed through C3D10 element. The steel tube of the column and the steel beam as well as steel plates in the composite wall were tied together for simulating the welds. Hard contact relation between the steel tube and the in-filled concrete was defined, with a friction coefficient of 0.2 being adopted. Either the axial compression load at the top of the composite column or the cyclic loads at the beam end were applied on a reference point defined at the corresponding load surface. The column base was fixed and horizontal displacement of the column top was restrained. Lateral bracing supports were applied to the beam end. The loading process was identical to that in the experiment. Both material and geometric non-linearities were incorporated herein.
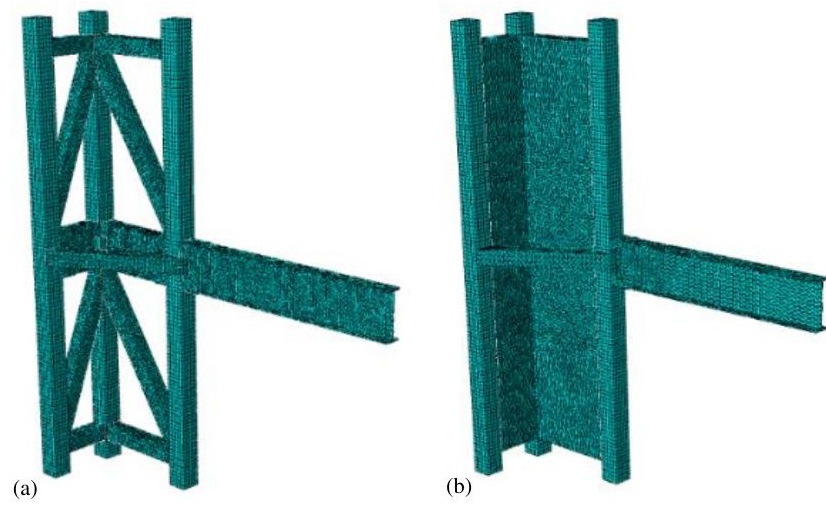

Fig. 9 Mesh of FE models: (a) specimen I; (b) specimen II

Based on the numerical analyses results, cyclic and envelop curves of the load versus displacement responses at the beam end for the two specimens were obtained, and were compared with the test results, as shown in Figs. 10 and 11, respectively. It can be found from the two figures that good agreement in general can be observed between the FE analyses and test results. The cyclic curves obtained from the FE analyses results are basically symmetric between the positive and negative directions, whilst the test curves are not; this is mainly resulted from cracks observed in the tension component during the test. The peak loads in the FE analyses results are close to that of the test results, but the unloading slope in the test curves is slightly lower due to existence of severe cracks. In summary, the FE model developed herein is demonstrated to be adequate for simulating the cyclic behaviour of the specific joints between steel beam and LSWW-CC, and therefore is adopted for further numerical analyses with extended parameters being considered.
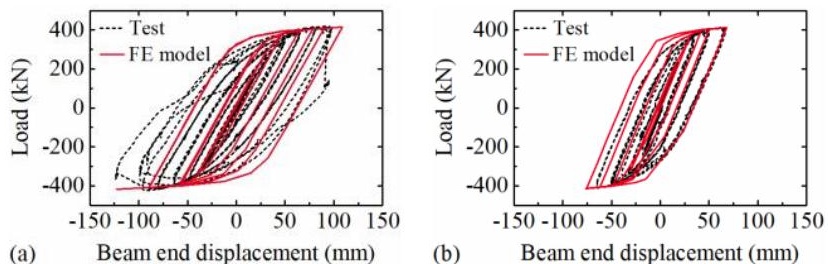

Fig. 20 Comparison of cyclic curves between FE modelling and test results: (a) specimen I; (b) specimen II
Specimen Load direction

$\mu_{\Delta}$

$\mu_{\Delta . \text { ave }}$ 


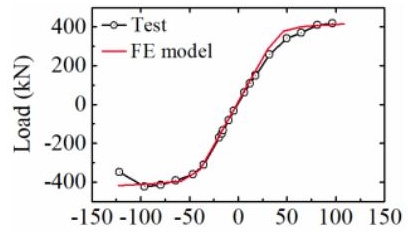

(a) Beam end displacement ( $\mathrm{mm})$

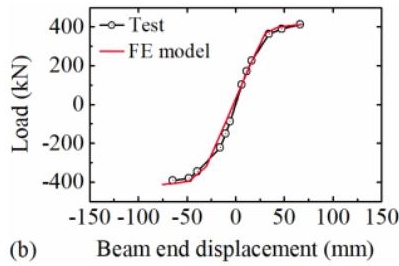

Fig. 11 Comparison of envelope curves between FE modelling and test results: (a) specimen I; (b) specimen II

\section{Parametric analyses}

\subsection{Effects of the RVPs}

To clarify effects of the RVPs on the seismic performance of the joints for LSWL-CCs, seismic behaviour of two joints were simulated by using the validated FE modelling approach, including the test specimen (labelled as CONT) as a control group, and another model with identical geometry but without RVPs. Based on the FE analysis results, their cyclic and envelop curves were obtained and are shown in Figs. 12 and 13, respectively, and Fig. 14 presents their stress distribution in the last loading cycle.

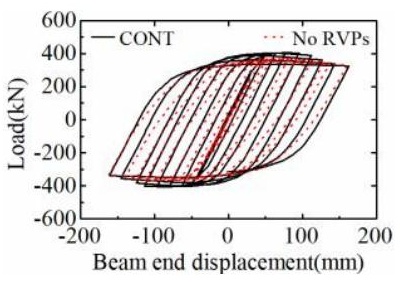

Fig. 32 Comparison of cyclic curves for models with and without RVPs

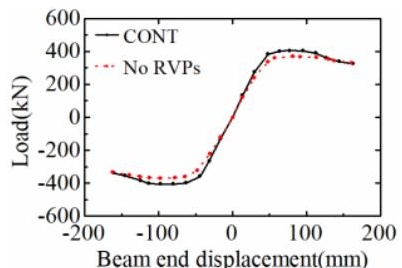

Fig. 13 Comparison of envelope curves for models with and without RVPs
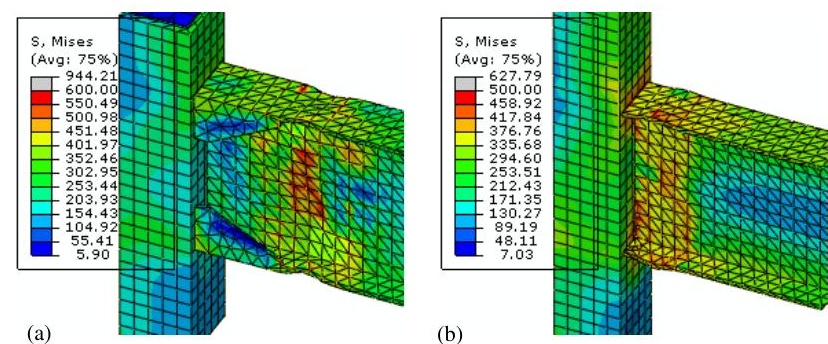

Fig. 14 Stress distribution in the last loading cycle: (a) with RVPs; (b) without RVPs

Based on comparisons in Figs. 12 and 13, it can be found that the joint with RVPs possesses a relatively higher ultimate loading capacity as well as a greater energy dissipation capacity. Meanwhile, from Fig.14, the maximum stress region of the joint without RVPs is closer to the welding zone between column and beam. By applying the RVPs, this maximum stress region has moved away from the welding zone, which is beneficial for preventing brittle failure of the welds.

Consequently, due to the benefits indicated previously in terms of improvement of the mechanical behaviour of the joints and less stress concentration within the welded zone, the RVPs are suggested in practice.

\subsection{Dimensions of the RVPs}

With the aim of clarifying effects of geometry of the RVPs (as illustrated in Fig. 15) on the seismic performance of the joints for LSWL-CCs developed herein, an extensive range of parametric analyses were conducted. Various values of length $a$, width $b$ and thickness $t$ of the flange-side RVPs were incorporated, and reasonable geometric dimensions are suggested for design guidance. Given that the deformation of the panel zone is very slight according to the test results, the FE models in the parametric analyses only consider that beam and boundary CFST element to focus on the beam-to-column joint Failure of the joint in the FE analyses is determined as the case when its loading capacity decreases by $15 \%$.

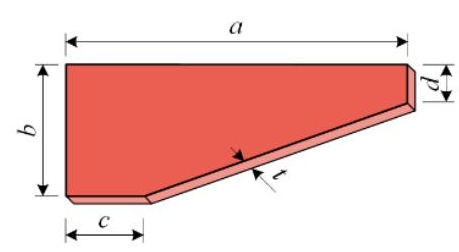

Fig. 45 Geometry of flange-side RVP

i) Effects of length of RVPs

To clarify effects of length of the RVPs on the seismic performance of the joint, five FE models including the test specimen (labelled as CONT) as a control group, were developed, and geometric parameters of the RVPs are given in Table 4 , in which $H$ is cross-sectional height of the steel beam, and $t_{\mathrm{f}}$ is thickness of the flange of the steel beam. Geometric dimensions of other components in the FE models are identical to that of the specimen. Based on the $\mathrm{FE}$ analyses results, their cyclic and envelop curves are obtained and are shown in Figs. 16 and 17, respectively, and other characteristic results are listed in Table 5.

Table 4

Geometric parameters of FE models with various lengths of RVPs

\begin{tabular}{cccccc}
\hline FE model & Length $a(\mathrm{~mm})$ & Width $b(\mathrm{~mm})$ & Thickness $t(\mathrm{~mm})$ & $c(\mathrm{~mm})$ & $d(\mathrm{~mm})$ \\
\hline CONT & $0.5 H$ & $1 / 4 H$ & $1.5 t_{\mathrm{f}}$ & 50 & 20 \\
L-1 & $0.75 H$ & $1 / 4 H$ & $1.5 t_{\mathrm{f}}$ & 50 & 20 \\
L-2 & $H$ & $1 / 4 H$ & $1.5 t_{\mathrm{f}}$ & 50 & 20 \\
L-3 & $1.2 H$ & $1 / 4 H$ & $1.5 t_{\mathrm{f}}$ & 50 & 20 \\
L-4 & $1.5 H$ & $1 / 4 H$ & $1.5 t_{\mathrm{f}}$ & 50 & 20 \\
\hline
\end{tabular}

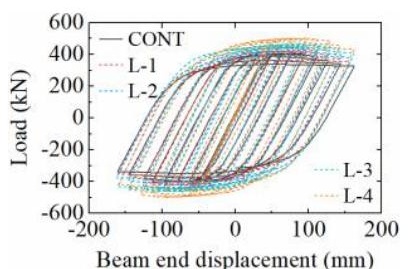

Fig. 56 Comparison of cyclic curves for models with different lengths of RVPs

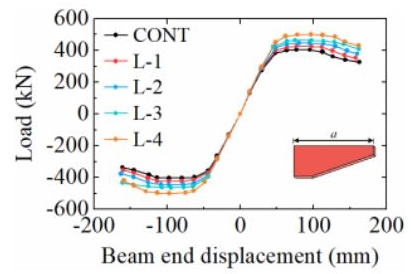

Fig. 17 Comparison of envelope curves for models with different lengths of RVPs

Table 5

Characteristic results of FE models with various lengths of RVPs

\begin{tabular}{cccccc}
\hline $\begin{array}{c}\text { FE } \\
\text { model }\end{array}$ & $\begin{array}{c}\text { Loading } \\
\text { direction }\end{array}$ & $\begin{array}{c}\text { Ultimate bearing } \\
\text { capacity }(\mathrm{kN})\end{array}$ & $\begin{array}{c}\text { Yield } \\
\text { displacement } \\
\Delta \mathrm{y}(\mathrm{mm})\end{array}$ & $\begin{array}{c}\text { Ultimate } \\
\text { displacement } \\
\Delta u(\mathrm{~mm})\end{array}$ & $\begin{array}{c}\text { Ductility } \\
\text { coefficient } \\
\mu\end{array}$ \\
\hline \multirow{2}{*}{ CONT } & Neg. & -404.92 & -44.01 & -145.31 & 3.30 \\
& Pos. & 404.95 & 48.15 & 144.00 & 2.99 \\
\multirow{2}{*}{ L-1 } & Neg. & -424.58 & -44.01 & -145.49 & 3.31 \\
& Pos. & 424.79 & 48.68 & 142.84 & 2.93 \\
\multirow{2}{*}{ L-2 } & Neg. & -446.20 & -44.01 & -162.93 & 3.70 \\
& Pos. & 445.90 & 48.68 & 160.14 & 3.29 \\
\hline
\end{tabular}




\begin{tabular}{llllll} 
L-3 & Neg. & -463.92 & -44.01 & -161.00 & 3.66 \\
& Pos. & 463.73 & 44.98 & 162.59 & 3.61 \\
& Neg. & -499.95 & -48.42 & -159.27 & 3.29 \\
L-4 & Pos. & 499.84 & 48.37 & 162.26 & 3.35 \\
\hline
\end{tabular}

The FE analyses results indicate that the cyclic curves of all the five models are plump, representing their good energy dissipation capacity. With an increase in the length of the RVPs, the loading capacity of the joints increase significantly from $405 \mathrm{kN}$ of the model CONT to $500 \mathrm{kN}$ of the model L- 4 . The five models all exhibite good deformation ability, and it can be seen from Table 5 that when the length of the RVPs is $1.0 \sim 1.2$ times of the cross-sectional height of the steel beam, the ductility coefficient is the largest, and this range for the length is recommended for practical usage.

\section{ii) Effects of width of RVPs}

To evaluate effects of width of the RVPs on the cyclic performance of the joint, four FE models including the test specimen (labelled as CONT) as a control group were developed, of which values of the geometric parameters are given in Table 6. Based on the FE analyses results, their cyclic and envelope curves are obtained and plotted in Figs. 18 and 19, respectively, and other characteristic properties are listed in Table 7.

\section{Table 6}

Geometric parameters of FE models with various widths of RVPs

\begin{tabular}{cccccc}
\hline FE model & Length $a(\mathrm{~mm})$ & Width $b(\mathrm{~mm})$ & Thickness $t(\mathrm{~mm})$ & $c(\mathrm{~mm})$ & $d(\mathrm{~mm})$ \\
\hline CONT & $0.5 H$ & $1 / 4 H$ & $1.5 t_{\mathrm{f}}$ & 50 & 20 \\
W-1 & $0.5 H$ & $1 / 3 H$ & $1.5 t_{\mathrm{f}}$ & 50 & 20 \\
W-2 & $0.5 H$ & $1 / 5 H$ & $1.5 t_{\mathrm{f}}$ & 50 & 20 \\
W-3 & $0.5 H$ & $1 / 8 H$ & $1.5 t_{\mathrm{f}}$ & 50 & 20 \\
\hline
\end{tabular}

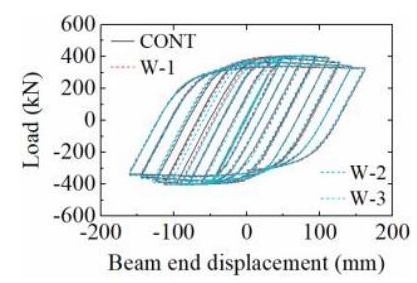

Fig. 68 Comparison of cyclic curves for models with different widths of RVPs

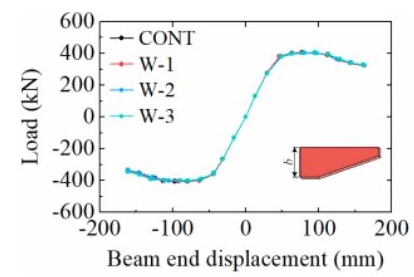

Fig. 19 Comparison of envelope curves for models with different widths of RVPs

Table 7

Characteristic results of FE models with various widths of RVPs

\begin{tabular}{cccccc}
\hline \multirow{2}{*}{ FE model } & $\begin{array}{c}\text { Loading } \\
\text { direction }\end{array}$ & $\begin{array}{c}\text { Ultimate } \\
\text { bearing } \\
\text { capacity }(\mathrm{kN})\end{array}$ & $\begin{array}{c}\text { Yield } \\
\text { displacement } \\
\Delta \mathrm{y}(\mathrm{mm})\end{array}$ & $\begin{array}{c}\text { Ultimate } \\
\text { displacement } \\
\Delta_{u}(\mathrm{~mm})\end{array}$ & $\begin{array}{c}\text { Ductility } \\
\text { coefficient } \\
\mu\end{array}$ \\
\hline \multirow{2}{*}{ CONT } & Neg. & -404.92 & -44.01 & -145.31 & 3.30 \\
& Pos. & 404.95 & 48.15 & 144.00 & 2.99 \\
& Neg. & -405.46 & -44.01 & -146.23 & 3.32 \\
W-1 & Pos. & 405.58 & 47.26 & 142.50 & 3.02 \\
& Neg. & -404.21 & -44.01 & -146.44 & 3.33 \\
& Pos. & 404.07 & 48.68 & 143.81 & 2.95 \\
& Neg. & -400.42 & -44.01 & -145.61 & 3.31 \\
& Pos. & 400.82 & 48.71 & 143.50 & 2.95 \\
\hline
\end{tabular}

Based on the FE analysis results, it can be found that the cyclic curves of all the four FE models are plump without any visible differences, indicating their good energy dissipation capacities as well as limited effects of variation in the width of the RVPs. Difference of the loading capacities of all the four models is lower than $1 \%$ generally. In case of the width being $1 / 8$ of the crosssectional height of the steel beam, the loading capacity is the lowest, and therefore a width no less than $1 / 5$ of the beam height is recommended for practice. All the four models possessed good deformation ability and similar ductility coefficients.

iii) Effects of thickness of RVPs

To understand effects of thickness of the RVPs on the seismic performance of the joints, five models including the test specimen (labelled as CONT) as the control group were developed, and their geometric parameters are listed in Table 8. Based on the FE analysis results, their cyclic and envelope curves with various thicknesses of the RVPs are shown in Figs. 20 and 21, respectively, and other characteristic properties are given in Table 9.

Table 8

Geometric parameters of FE models with various thickness of RVPs

\begin{tabular}{cccccc}
\hline FE model & Length $a(\mathrm{~mm})$ & Width $b(\mathrm{~mm})$ & Thickness $t(\mathrm{~mm})$ & $c(\mathrm{~mm})$ & $d(\mathrm{~mm})$ \\
\hline CONT & $0.5 H$ & $1 / 4 H$ & $1.5 t_{\mathrm{f}}$ & 50 & 20 \\
T-1 & $0.5 H$ & $1 / 4 H$ & $1.2 t_{\mathrm{f}}$ & 50 & 20 \\
T-2 & $0.5 H$ & $1 / 4 H$ & $1.0 t_{\mathrm{f}}$ & 50 & 20 \\
T-3 & $0.5 H$ & $1 / 4 H$ & $0.8 t_{\mathrm{f}}$ & 50 & 20 \\
T-4 & $0.5 H$ & $1 / 4 H$ & $0.5 t_{\mathrm{f}}$ & 50 & 20 \\
\hline
\end{tabular}

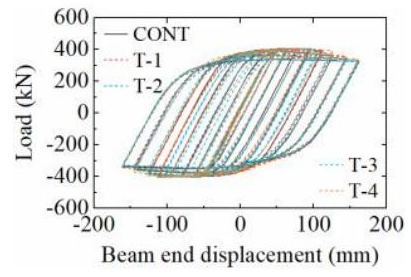

Fig. 20 Comparison of cyclic curves for models with different thickness of RVPs

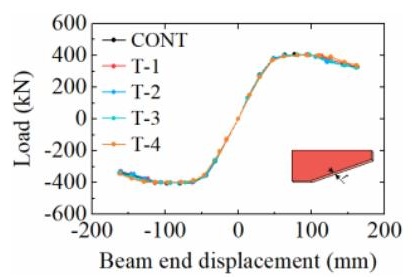

Fig. 21 Comparison of envelope curves for models with different thickness of RVPs

Table 9

Characteristic results of FE models with various widths of RVPs

\begin{tabular}{|c|c|c|c|c|c|}
\hline FE model & $\begin{array}{l}\text { Loading } \\
\text { direction }\end{array}$ & $\begin{array}{c}\text { Ultimate } \\
\text { bearing } \\
\text { capacity }(\mathrm{kN})\end{array}$ & $\begin{array}{c}\text { Yield } \\
\text { displacement } \\
\Delta_{\mathrm{y}}(\mathrm{mm})\end{array}$ & $\begin{array}{c}\text { Ultimate } \\
\text { displacement } \\
\Delta_{u}(\mathrm{~mm})\end{array}$ & $\begin{array}{c}\text { Ductility } \\
\text { coefficient } \\
\mu \\
\end{array}$ \\
\hline \multirow{2}{*}{ CONT } & Neg. & -404.92 & -44.01 & -145.31 & 3.30 \\
\hline & Pos. & 404.95 & 48.15 & 144.00 & 2.99 \\
\hline \multirow{2}{*}{$\mathrm{T}-1$} & Neg. & -403.82 & -44.01 & -146.29 & 3.32 \\
\hline & Pos. & 404.19 & 48.68 & 145.62 & 2.99 \\
\hline \multirow{2}{*}{$\mathrm{T}-2$} & Neg. & -402.78 & -44.01 & -142.68 & 3.24 \\
\hline & Pos. & 403.08 & 48.68 & 145.50 & 2.99 \\
\hline \multirow{2}{*}{$\mathrm{T}-3$} & Neg. & -402.28 & -46.32 & -146.50 & 3.16 \\
\hline & Pos. & 401.86 & 47.37 & 145.00 & 3.06 \\
\hline \multirow{2}{*}{$\mathrm{T}-4$} & Neg. & -399.57 & -46.57 & -148.50 & 3.19 \\
\hline & Pos. & 399.52 & 46.97 & 145.51 & 3.10 \\
\hline
\end{tabular}

Based on the FE analysis results it is indicated that, all the five models exhibit good energy dissipation capacities because of their plump cyclic curves. With a decrease of the RVP thickness, their loading capacities decrease generally from $405 \mathrm{kN}$ for the model CONT to $399.52 \mathrm{kN}$ for the model T-4. 
All the five models possess good deformation ability, and their ductility coefficients are generally constant. In practice, the thickness of the RVPs is recommended to be no less than half of the flange thickness of the steel beam.

\subsection{Optimisation of the RVPS}

In order to reduce the unfavourable effects of stress concentration on the mechanical behaviour of the joints and to prevent facture, both geometry and location of the RVPs are optimised. The cut corner one that is applied in specimen I as shown in Fig. 22(a), is firstly optimised to the wedge one as shown in Fig. 22(b), and then it is further moved towards the web, i.e. its vertical outside surface is flush with the toe of the beam flange as shown in Fig. 22(c).
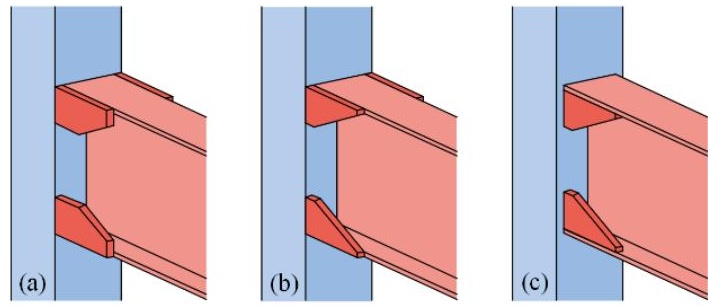

Fig. 22 Optimisation of RVPs: (a) cut corner one; (b) wedge one; (c) flush wedge one

FE models are established for the three types of joints, to which an identical loading spectrum is applied for comparison of their loading responses. Based on the FE analysis results, Figs. 23 and 24 present their stress distribution at the same loading level in elastic and inelastic ranges, respectively. Their load versus displacement curves are shown in Fig. 25.
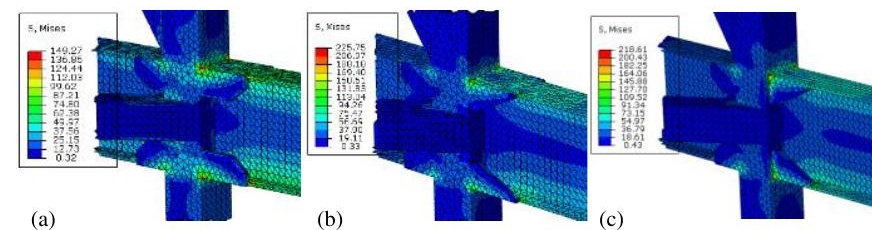

Fig. 23 Stress distribution in elastic state: (a) cut corner RVPs; (b) wedge RVPs; (c) flush wedge RVPs

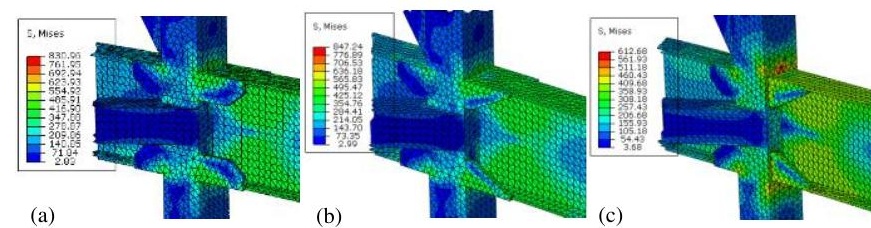

Fig. 24 Stress distribution in inelastic state: (a) cut corner RVPs; (b) wedge RVPs; (c) flush wedge RVPs

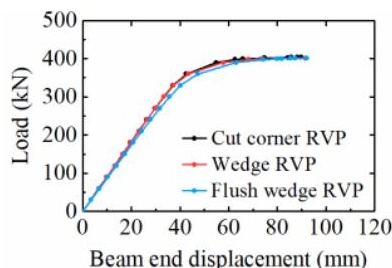

Fig. 25 Load-displacement curves of the joints with RVPs varying in geometry

Based on Figs. 23 25, it can be found that the joint with flush wedge RVPs possesses the lowest level of stress concentration, because its maximum stress magnitude is significantly less than the others', particularly in the inelastic range. With respect to the load versus displacement curves as shown in Fig. 25, no visible difference is observed between the two joints with cut corner and wedge RVPs; whilst for the joint with flush wedge RVPs, its initial stiffness is lower than the other two by $5 \%$ approximately. Ultimate bearing capacities of the three joints are basically the same.

Consequently, due to the benefits indicated previously for the use of the flush wedge RVPs in terms of reduction of the stress concentration but limited effects on the loading capacity and stiffness, the configuration details of the joints with the flush wedge RVPs are recommended in practice.

To further optimise the geometry of the RVP for reducing stress concentration, the cut corner RVP was modified into a plate with an arc edge, as shown in Fig. 26. Cyclic behaviour of another joint was simulated through the FE model, which applied the arc-edge RVPs; other parameters of the joint are kept the same as previous ones. Based on the FE analysis results, its cyclic and envelope curves are obtained and are compared with that of joints with cut corner RVPs in Figs. 27 and 28, respectively. Table 10 lists other characteristic mechanical properties.

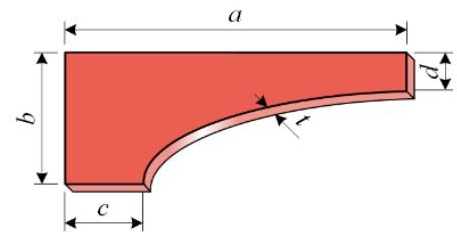

Fig. 26 Geometry of flange-side arc-edge RVP

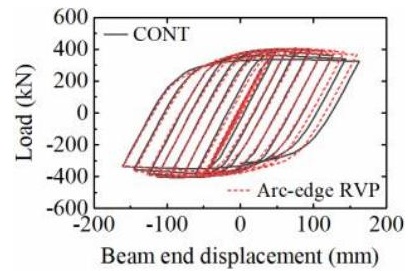

Fig. 27 Comparison of cyclic curves for models with cut corner and arc-edge RVPs

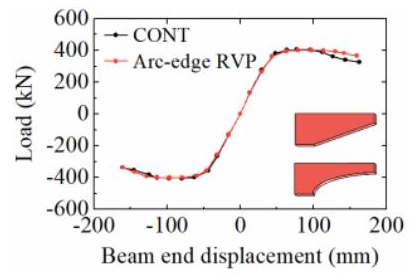

Fig. 28 Comparison of envelope curves for models with cut corner and arc-edge RVPs

Table 10

Characteristic results of FE models with cut corner and arc-edge RVPs

\begin{tabular}{cccccc}
\hline FE model & $\begin{array}{c}\text { Loading } \\
\text { direction }\end{array}$ & $\begin{array}{c}\text { Ultimate } \\
\text { bearing } \\
\text { capacity }(\mathrm{kN})\end{array}$ & $\begin{array}{c}\text { Yield } \\
\text { displacement } \\
\Delta_{\mathrm{y}}(\mathrm{mm})\end{array}$ & $\begin{array}{c}\text { Ultimate } \\
\text { displacement } \\
\Delta_{u}(\mathrm{~mm})\end{array}$ & $\begin{array}{c}\text { Ductility } \\
\text { coefficient } \\
\mu\end{array}$ \\
\hline \multirow{2}{*}{ BASE } & Neg. & -404.92 & -44.01 & -145.31 & 3.30 \\
& Pos. & 404.95 & 48.15 & 144.00 & 2.99 \\
ARC- & Neg. & -400.20 & -46.32 & -160.27 & 3.46 \\
PLATE & Pos. & 401.67 & 43.60 & 159.48 & 3.66 \\
\hline
\end{tabular}

It can be found that the cyclic curves of the two models are both plump, indicating their good energy dissipation capacity. The loading capacity of the joint with arc-edge RVPs is slightly lower than that of the other one. Both of them have good deformation ability; specifically, the ductility coefficient as well as the deformation ability of the joint with the arc-edge RVPs is slightly higher than that of the other, due to its reduced stress concentration.

\section{Conclusions}

Two full-scale steel beam-to-LSWW-CCs joints were tested to evaluate their seismic performance, and FE models were developed accordingly and further validated against the test results. Through an extensive range of parametric analyses, effects of geometry of the RVPs were clarified, and optimised shapes of the RVPs was proposed. Based on the research work presented herein, some conclusions are made as follows.

- The two specimens both fail due to cracks within the beam flange adjacent to the RVPs. Plastic hinge of this type of joint moves to the beam section adjacent to the RVPs as expected. The loading capacities of the two specimens are close to each other approximately and exceed the plastic moment capacity; rotations of the beam and column contribute the most to the total beam end rotation, and that of the panel zone can be neglected.

- Use of the RVPs may increase the loading and energy dissipation capacity, 
and reduced the stress concentration within the welded zone between the column and beam.

- The length of the RVPs possesses significant effects on the seismic performance of the joints, and with an increase of the length, the loading capacity increases and the ductility is generally constant. Effects of the width and the thickness of the RVP on seismic behaviour of the joints are insignificant.

- Based on the parametric analyses, it is recommended that the length of the RVP shall be 1.0 1.2 times the cross-sectional height of the steel beam, its width shall be no less than $1 / 5$ of the beam height, and its thickness shall be no less than half of the thickness of the beam flange.

- The cut corner RVP may be optimised into a wedge one without visible loose of either loading capacity or stiffness but with economic benefits in

\section{References}

[1] Lee, S.H., Uy, B., Kim, S.H., Choi, Y.H. and Choi, S.M., "Behavior of high-strength circular concrete-filled steel tubular (CFST) column under eccentric loading", Journal of Constructional Steel Research, 67(1): 1-13,2011.

[2] Jamaluddin, N., Lam, D., Dai, X.H. and Ye, J., "An experimental study on elliptical concrete filled columns under axial compression”, Journal of Constructional Steel Research, 87: 6$16,2013$.

[3] Patel, V.I., Uy, B., Prajwal, K.A. and Aslani, F., "Confined concrete model of circular, elliptical and octagonal CFST short columns", Steel and Composite Structures, 22(3): 497$520,2016$.

[4] Patel, V.I., Hassanein, M.F., Thai, H.T., Al Abadi, H., Elchalakani, M. and Bai, Y., "Ultrahigh strength circular short CFST columns: Axisymmetric analysis, behaviour and design", Engineering Structures, 179: 268-283,2019.

[5] Xue, J.Y., Zhou, C.F. and Liu, Z.Q., "Research on damage of solid-web steel reinforced concrete T-shaped columns subjected to various loadings", Steel and Composite Structures, 24(4): 409-423,2017.

[6] Liu, J.P., Song, H. and Yang, Y.L., "Research on mechanical behavior of L-shaped multi-cell concrete-filled steel tubular stub columns under axial compression", Advances in Structural Engineering, 22(2): 427-443,2019.

[7] Chen, Z.Y. and Shen, Z.Y., "Behavior of L-shaped concrete-filled steel stub columns under axial loading: Experiment", Advanced Steel Construction, 6(2): 688-697,2010.

[8] Liu, X.G., Xu, C.Z., Liu, J.P. and Yang, Y.L., "Research on special-shaped concrete-filled steel tubular columns under axial compression", Journal of Constructional Steel Research, 147: 203-223,2018

[9] Rong, B., Feng, C.X., Zhang, R.Y., You, G.C. and Liu, R., "Compression-bending performance of L-shaped column composed of concrete filled square steel tubes under eccentric compression", International Journal of Steel Structures, 17(1): 325-337,2017.

[10] Xiong, Q.Q., Chen, Z H., Zhang, W., Du, Y.S., Zhou, T and Kang, J.F., "Compressive behaviour and design of L-shaped columns fabricated using concrete-filled steel tubes", Engineering Structures, 152: 758-770,2017.

[11] Zhang, W., Chen, Z.H. and Xiong, Q.Q., "Performance of L-shaped columns comprising concrete-filled steel tubes under axial compression", Journal of Constructional Steel Research, 145: 573-590,2018.

[12] Zhou, T., Xu, M.Y., Wang, X.D., Chen, Z.H. and Qin, Y., "Experimental study and parameter analysis of L-shaped composite column under axial loading", International Journal of Steel Structures, 15(4):797-807,2015.

[13] Zhou, T., Xu, M.Y., Chen, Z.H., Wang, X.D. and Wang, Y.W., "Eccentric loading behavior of L-shaped columns composed of concrete-filled steel tubes", Advanced Steel Construction, 12(3): 227-244,2016.

[14] Liu, J.P., Yang, Y.L., Song, H. and Wang, Y.Y., "Numerical analysis on seismic behaviors of T-shaped concrete-filled steel tubular columns with reinforcement stiffeners", Advances in Structural Engineering, 21(9): 1273-1287,2018.

[15] Rong, B., You, G.C., Zhang, R.Y., Feng, C.X. and Liu, R., "Studies on T-shaped composite columns consist of multi separate concrete-filled square tubular steel sections under eccentric axial load", Steel and Composite Structures, 22(2): 217-234,2016.

[16] Tu, Y.Q., Shen, Y.F. and Li, P., "Behaviour of multi-cell composite T-shaped concrete-filled steel tubular columns under axial compression”, Thin-Walled Structures, 85: 57-70,2014.

[17] Wang, Q.T. and Chang, X., "Analysis of concrete-filled steel tubular columns with ' $T$ ' shaped cross section (CFTTS)", Steel and Composite Structures, 15(1): 41-55,2013.

[18] Yang, Y.L., Yang, H. and Zhang, S.M., "Compressive behavior of T-shaped concrete filled steel tubular columns", International Journal of Steel Structures, 10(4): 419-430,2010.

[19] Yang, Y.L., Wang, Y.Y., Fu, F. and Liu, J.C., "Static behaviour of T-shaped concrete-filled steel tubular columns subjected to concentric and eccentric compressive loads", Thin-Walled Structures, 95: 374-388,2015.

[20] Wu, H.P., Qiao, Q.Y., Cao, W.L., Dong, H.Y. and Zhang J.W., "Axial compressive behavior of special-shaped concrete filled tube mega column coupled with multiple cavities", Steel and Composite Structures, 23(6): 633-646,2017.

[21] Shen, Z.Y., Lei, M., Li, Y.Q., Lin, Z.Y. and Luo, J.H., "Experimental study on seismic behavior of concrete-filled L-shaped steel tube columns", Advances in Structural Engineering, 16(7): 1235-1247,2013.

[22] Tu, Y.Q., Shen, Y.F., Zeng, Y.G. and Ma, L.Y., "Hysteretic behaviour of multi-cell T-Shaped concrete-filled steel tubular columns", Thin-Walled Structures, 85: 106-116,2014.

[23] Zhou, T., Chen, Z.H. and Liu, H.B., "Seismic behavior of special shaped column composed of concrete filled steel tubes", Journal of Constructional Steel Research, 75: 131-141,2012.

[24] Zhou, T., Jia, Y.M., Xu, M.Y., Wang, X.D. and Chen, Z.H., "Experimental study on the seismic performance of L-shaped column composed of concrete-filled steel tubes frame structures", Journal of Constructional Steel Research, 114: 77-88,2015.

[25] Zhang, J.C., Li, Y., Zheng, Y. and Wang, Z.J., "Seismic damage investigation of spatial frames with steel beams connected to L-shaped concrete-filled steel tubular (CFST) columns", Applied Sciences, 8(10): 1713,2018.

[26] Cheng, C.T. and Chung L.L., "Seismic performance of steel beams to concrete-filled steel tubular column connections", Journal of Constructional Steel Research, 59(3): 405-426,2003.

[27] Li, W. and Han, L.H., "Seismic performance of CFST column to steel beam joints with RC slab: Analysis", Journal of Constructional Steel Research, 67: 127-139,2011. terms of less use of steel. Besides, by moving the RVP towards the web of the beam with its surface being flush with the flange toe, the stress concentration may be reduced and potential fracture would become less severe. Besides, use of the arc-edge RVP may also reduce the stress concentration. Both flush wedge and arc-edge RVPs are recommended to be applied in the joints.

The research outcomes may provide valuable reference for practical engineering of such joints and the LSWW-CCs. Despite this, there are still other factors, e.g., steel grade of the RVPs, welding methods of the RVPs, etc. influencing the mechanical performance of such new joint, and further research is needed to verify and improve the design guidance proposed herein.

[28] Rezaifar, O. and Younesi, A., "Experimental study discussion of the seismic behavior on new types of internal/external stiffeners in rigid beam-to-CFST/HSS column connections", Construction and Building Materials, 136: 574-589,2017.

[29] Lee, S.H., Kim, Y.H. and Choi, S.M., "Shear strength formula of CFST column-beam pinned connections", Steel and Composite Structures, 13(5): 409-421,2012.

[30] Tao, Z., Li, W., Shi, B.L. and Han, L.H., "Behaviour of bolted end-plate connections to concrete-filled steel columns", Journal of Constructional Steel Research, 134: 194-208,2017.

[31] Thai, H.T., Vo, T.P., Nguyen, T.K. and Pham, C.H., "Explicit simulation of bolted endplate composite beam-to-CFST column connections", Thin-Walled Structures, 119: 749-759,2017.

[32] Stephens, M.T., Berg, L.M., Lehman, D.E. and Roeder, C.W., "Seismic CFST column-toprecast cap beam connections for accelerated bridge construction", Journal of Structural Engineering, 142(9): 04016049,2016.

[33] Du, G.F., Ma, C. and Xu, C.X., "Experimental research on seismic behavior of exterior frame joints with T-Shaped CFST column and steel beam”, Advanced Materials Research, 368-373 $183-188,2012$.

[34] Xu, C.X., Liu, X.Q. and Zhang, J.C., "Experimental research on seismic behavior of spatial joints in a composite frame consisting of CFST crisscross section columns and steel beams", Proceedings of the Twelfth International Symposium on Structural Engineering, Wuhan, China, November, 2012 .

[35] Liu, Z.Q., Xue, J.Y. and Zhao, H.T., "Seismic behavior of steel reinforced concrete specialshaped column-beam joints", Earthquakes and Structures, 11(4): 665-680,2016.

[36] Liu, J.C., Yang, Y.L., Liu J.P. and Zhou, X.H. "Experimental investigation of special-shaped concrete-filled steel tubular column to steel beam connections under cyclic loading", Engineering Structures, 151: 68-84,2017.

[37] Zhang, W., Chen Z.H., Xiong, Q.Q. and Zhou, T., "Calculation method of shear strength of vertical stiffener connections to L-CFST columns", Advances in Structural Engineering, 21(6): 795-808,2018

[38] Zhang, W., Chen Z.H., Xiong, Q.Q., Zhou, T., Rong, X. and Du, Y.S., "Experimental seismic behaviour of L-CFST column to H-beam connections", Steel and Composite Structures, 26(6): 793-808,2018.

[39] Zeng, L., Ren, W.T., Zou Z.T., Chen, Y.G., Xie, W. and Li, X.J., "Experimental study on seismic behavior of frame structures composed of concrete encased columns with L-shaped steel section and steel beams", Earthquakes and Structures, 16(1): 97-107,2019.

[40] Ma, R.Q., Ban, H.Y., Zhao, Y.Z., Wang, Y.Q., Li, Q. and Liu, M. "Experimental study on seismic behavior of steel beam to wide-flange specially-shaped composite column connections", Journal of Building Structures, 38(6): 105-113,2017. (in Chinese)

[41] Hu F.X., Shi, G., Bai Y. and Shi, Y.J., "Seismic performance of prefabricated steel beam-tocolumn connections", Journal of Constructional Steel Research, 102: 204-216,2014.

[42] Shi, G., Fan, H., Bai, Y., Yuan, F, Shi, Y.J. and Wang, Y.Q., "Improved measure of beamto-column joint rotation in steel frames", Journal of Constructional Steel Research, 70: 298307,2012 . 


\title{
STABILITY STUDY ON SCAFFOLDS WITH INCLINED SURFACES AND EXTENDED JACK BASES IN CONSTRUCTION
}

\author{
Jui-Lin Peng ${ }^{1,}$, , Shu-Hong Wang ${ }^{2}$, Chung-Sheng Wang ${ }^{3}$ and Judy P. Yang ${ }^{4}$ \\ Department of Civil and Construction Engineering, National Yunlin University of Science and Technology, Yunlin, Taiwan, China. \\ ${ }^{2}$ School of Resource and Civil Engineering, Northeastern University, Shenyang, China. \\ ${ }^{3}$ Graduate School of Engineering Science and Technology, National Yunlin University of Science and Technology, Taiwan, China. \\ ${ }^{4}$ Department of Civil Engineering, National Chiao Tung University, Hsinchu, Taiwan, China. \\ *(Corresponding author: E-mail: pengjl@yuntech.edu.tw)
}

\section{A B S T R A C T}

A scaffolding system is a temporary structure that is commonly adopted on construction sites. As steel scaffolds are modular members manufactured with fixed dimensions, the total height of a scaffolding system seldom fits the headroom of a building when scaffolds are set up in multiple stories. This results in a difference in elevation, i.e. gap, between the top of the scaffolding system and the ceiling slab. In addition, scaffold configurations may need to be adjusted if the interior of a building has inclined planes on the ceiling slab or stairs on the ground. This study shows that the gap between the scaffold and the ceiling slab can be eliminated by altering the lengths of adjustable base jacks or adjustable U-head jacks. When the ceiling slab is inclined, it is suggested that a combined system of scaffolds with wooden shores of different lengths should be installed in the out-of-plane direction of the scaffold unit. This system can also be used when the ceiling slab is inclined and the ground has a difference in elevation (e.g., stairs) in a building. By using the second-order elastic analysis with semirigid joints, the load-bearing capacity and failure model are found to be very close to those obtained in the loading tests using various scaffold configurations. In the loading tests for reused scaffolds, the lower bound of the load-bearing capacity of the scaffolding systems can be obtained by applying a subsequent load on the scaffolding systems, which are commonly adopted on the construction sites. The strength reduction factor $(\phi)$ of these scaffolding systems installed by reused scaffolds can be obtained by calculating the mean value and standard deviation, which can serve as a reference for the strength design of scaffolding systems with different safety requirements.
ART I CLE H IS T O RY

$\begin{array}{ll}\text { Received: } & \text { 8 March } 2020 \\ \text { Revised: } & \text { 8 March 2020 } \\ \text { Accepted: } & \text { 10 September 2020 }\end{array}$

K E Y W O R D S

Buckling;

Critical load;

Loading test;

Scaffold;

Wooden shore

\section{Introduction}

In construction, scaffolding systems are commonly known as temporary structures, in which all steel scaffolds are modular members with fixed dimensions. When the scaffolds are installed in multiple stories, the total height of the scaffolding system often does not fit the headroom of the building. This leads to a gap between the top of the scaffolding system and the bottom of the ceiling slab. To eliminate such a gap, a combined structure of scaffolds is constructed by inserting other shores such as tubular steel adjustable shores or wooden shores, which is called the combined system of scaffolds with shores in this study. On the other hand, the gap between the top of the scaffolding system and the ceiling slab can also be closed by directly extending the length of adjustable U-head jacks on the top or adjustable base jacks at the bottom of the scaffolding system to make the overall height of the scaffolding system fit the headroom of the building. However, the stability behavior of this configuration has seldom been discussed so far. Furthermore, when the ceiling slab of the building is inclined, the stability behavior of the combined system of scaffolds with shores is different from that of the same system when the ceiling slab is not inclined. The situation is similar to the ground having an elevation difference such as stairs, thereby leading to an uneven bottom surface. The aforementioned situations might affect the load-bearing capacity of the combined system of scaffolds with shores, and the potential collapse risk of the combined system of scaffolds with shores might be increased. Fig. 1 shows the collapse of falseworks in construction of an iron and steel company in Central Taiwan; this accident caused one death and several injuries.

By treating scaffolds as temporary supports, Yu et al. investigated the loadbearing capacity of modular steel scaffolds in the laboratory; they also conducted numerical analyses to compare with the results obtained in the loading tests and to confirm the relationship between story numbers and load capacity in modular steel scaffolds used in Hong Kong [1,2]. Pieńko and Błazik-Borowa investigated the nodes of scaffolds based on numerical analysis, in which the load-bearing capacitiy of the nodes of scaffolds were analyzed by considering joint interaction of scaffolds with the use of nonlinear material [3]. Jia et al. investigated the slipping and rotational stiffnesses in the right-angle coupler connections of scaffolds based on experimental tests, and they focused on some specific issues, such as bolt-tightening torques, different coupler combinations, loading patterns, and conditions of new and old components [4]. Zhao et al. investigated the influence of member imperfection and joint stiffness on the load-bearing capacity of modular scaffolds by using the finite element method, where the influences of the splice joint stiffness and the screw jack stiffness on the load-bearing capacity of modular scaffolds were discussed [5]

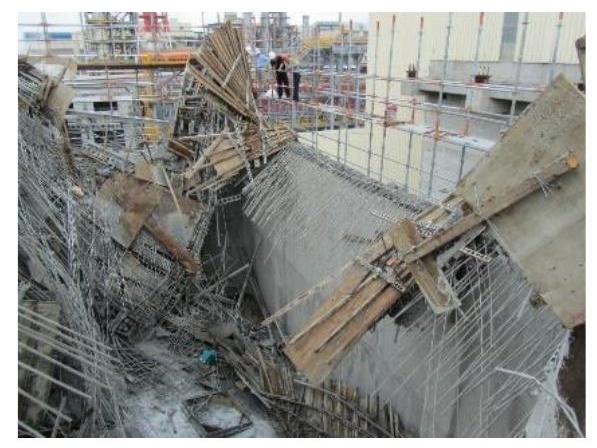

Fig. 1 Scene of the collapse of falsework in construction of an iron \& steel company in Central Taiwan

Upon treating a scaffolding structural system as a temporary support, Peng et al. investigated the ultimate loads of various single-row scaffolding structural systems [6]. When multi-bay setups of scaffolds were considered, the ultimate loads of the two-story scaffolds increased with the number of bays. Peng et al. further investigated the ultimate loads and failure models of an outdoor fullscale heavy-duty scaffolding structural system to verify the mechanical behavior of scaffolds [7]. In this study, it is revealed that the ultimate load and failure model of the isolated three-story heavy-duty scaffold system were similar to those of the two-story heavy-duty scaffold system. Liu et al. investigated the mechanical behavior of tube and coupler scaffolds with $\mathrm{X}$ bracings [8], in which two full-scale scaffolding structural systems with $\mathrm{X}$ bracings were tested in the laboratory, and a finite element analysis was conducted to compare the discrepancies between the analyzed and experimental results.

Among other configurations of scaffolding, Sevim et al. investigated the structural behavior of tie-bar numbers on the suspended scaffolding systems in the laboratory. In this study, they tested fifteen suspended scaffolding systems and obtained the load-displacement curves; particularly, the optimal suspended scaffolding system in terms of safety and cost was determined [9].

Concerning the reliability and probability of scaffold failure, Zhang et al. investigated the ultimate strength uncertainty of multi-story scaffolds through the use of an appropriate statistical framework with the second-order inelastic analysis $[10,11]$. The reliability-based analyses were performed on the basis of a data survey and a probabilistic model of the load-bearing capacity of scaffolds 


\section{during grouting.}

From the aforementioned studies, it is shown that most researchers have focused their attention on the load-bearing capacities and failure models of various scaffolds, such as frame-type scaffolds, and tube and coupler steel scaffolds. In addition the vertical load of fresh concrete is considered as the major external load applied on a scaffolding system. Nevertheless, these studies have seldom considered the load-bearing capacities and failure models of the combined system of scaffolds with shores. Furthermore, these studies have seldom explored the boundary conditions of an inclined ceiling slab or uneven ground, and the issue of adjustable U-head jacks and adjustable base jacks in scaffold systems. The present study focuses on these issues for practical application in construction sites.

\section{Research significance}

To understand the critical load and failure model of various scaffold configurations, this study explores the stability behavior of a scaffolding system by considering the following conditions: the inclined ceiling slab, an elevation difference on the ground (e.g. stairs), and the extension of adjustable U-head jacks on the top and adjustable base jacks at the bottom of the system. Furthermore, two subsequent loads are applied to the scaffolding system during the loading tests in order to understand the lower bound of the load-bearing capacity of scaffolding systems commonly used in construction.

In the test of two subsequent loads, the critical load of the scaffolding system is obtained when the first load is applied. After unloading the first load, the scaffolding system returns to its original condition. Then, the second load is applied to simulate the worst case of the load-bearing capacity of the scaffolding system. The ratio of the load-bearing capacity of the scaffolding system under the second load to that under the first load can be considered as the strength reduction factor of the scaffolding system, which may serve as a reference for strength design of the scaffolding system in the future. This study includes the following highlights:

- To determine the effect of extended adjustable U-head jacks on the top and adjustable base jacks at the bottom of the system on the loadbearing capacity of the scaffolding system;

- To determine the effect of the top inclined plane on the load-bearing capacity of the combined system of scaffolds with shores;

- To determine the effect of the top inclined plane and uneven ground on the load-bearing capacity of the combined system of scaffolds with shores; and

- To determine the lower bound of the load-bearing capacity of "scaffolding system" and "combined system of scaffolds with shores".

\section{Dimensions and material properties}

This study adopts door-type steel scaffolds to conduct tests and analysis. The overall configuration of the door-type scaffolding structure is shown in Fig. 2. Additionally, six specimens are randomly selected from door-type steel scaffolds in the laboratory to find the mechanical properties of scaffolds.

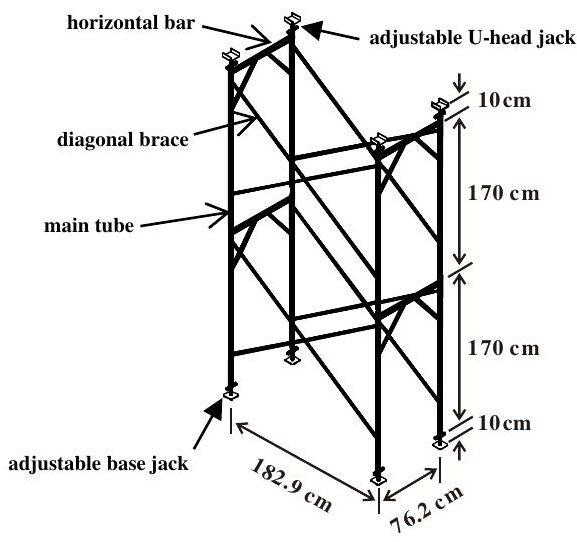

Fig. 2 Dimensions and schematic diagram of the two-story scaffolding system of basic configuration

The mean dimensions of the structural members are given as follows: For the door-type steel scaffolds, main tube: mean outer diameter $\Phi=42.4 \mathrm{~mm}$, mean thickness $t=2.10 \mathrm{~mm}$; horizontal bar: mean outer diameter $\Phi=42.2 \mathrm{~mm}$, mean thickness $t=2.08 \mathrm{~mm}$; diagonal brace: mean outer diameter $\Phi=26.6 \mathrm{~mm}$, mean thickness $t=1.66 \mathrm{~mm}$; cross brace: mean outer diameter $\Phi=21.2 \mathrm{~mm}$, mean thickness $t=1.46 \mathrm{~mm}$; adjustable base jack and adjustable U-head jack: mean outer diameter $\Phi=24.9 \mathrm{~mm}$. The mean square area of the wooden shores is obtained by measuring the cross sections of the wooden shores, and it is calculated as $30.25 \mathrm{~cm}^{2}$. The cross-sectional moment of inertia is $I_{y}=I_{z}=$ $76.2552 \mathrm{~cm}^{4}$

Additionally, three sets of door-type steel scaffolds are selected for the material test. The following data are obtained from the material tests: mean elastic modulus $E=196 \mathrm{kN} / \mathrm{mm}^{2}$, mean yielding stress $F_{y}$ $=0.36 \mathrm{kN} / \mathrm{mm}^{2}$, mean ultimate strength $F_{u}=4.47 \mathrm{kN} / \mathrm{mm}^{2}$. For the wooden shores, the mean elastic modulus $E=1245 \mathrm{kN} / \mathrm{mm}^{2}$, mean yielding stress $F_{y}=0.046 \mathrm{kN} / \mathrm{mm}^{2}$.

\section{Numerical analysis}

In this study, the "second-order elastic analysis with semi-rigid joints" is adopted for the numerical analysis of the scaffolding systems. To simulate the initial imperfection of the overall scaffolding systems in the analysis, the notional lateral forces are applied to vertical members on mutually perpendicular planes. NIDA, a software package developed by Professor S.L. Chan of the Hong Kong Polytechnic University, was adopted for analysis in this study $[12,13,14,15]$. In the second-order elastic analysis, both the P- $\Delta$ effect and $\mathrm{P}-\delta$ effect of the structural members are considered.

\section{Test planning}

\subsection{Scaffolding system with adjustable base jacks and adjustable U-head jacks of different lengths}

\subsubsection{Basic configuration of a scaffolding system}

A scaffolding system with a basic two-story configuration is adopted in the tests. The adjustable base jack and adjustable U-head jack used in the scaffolding system for the tests are both $10 \mathrm{~cm}$ in length. The dimensions of the two-story scaffolding system are shown in Fig. 2. The critical load and failure model of the two-story scaffolding system obtained in the tests are compared with the test results of other scaffold configurations adopted in this study.

\subsubsection{Scaffolding system with extended adjustable U-head jacks}

To fit the total height of the scaffolding system with the headroom of the building, workers may adjust the length of the adjustable U-head jacks on the top of the scaffolds. In the experiment, the adjustable U-head jacks of the scaffolding system are extended to a full length of $65 \mathrm{~cm}$, and the scaffold configuration is shown in Fig. 3(A)

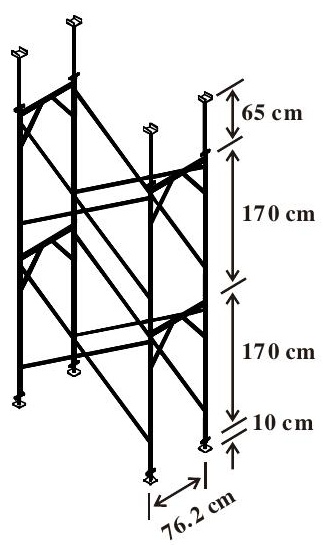

(A) Extended U-head jacks

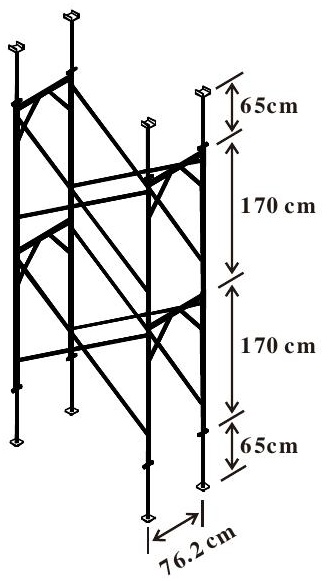

(B) Extended U-head jacks and base jacks
Fig. 3 Schematic diagram of the scaffolding system with extended adjustable U-head jacks and adjustable base jacks

\subsubsection{Scaffolding system with extended adjustable U-head jacks and adjustable} base jacks

For the case that the total height of the scaffolding system with extended U-head jacks does not fit the headroom of the building, workers may adjust the length of the adjustable base jacks as well. In the experiment, both the adjustable U-head jacks and adjustable base jacks are extended to a full length of $65 \mathrm{~cm}$. The corresponding configuration is shown in Fig. 3(B).

\subsection{Two-story combined system of scaffolds with wooden shores}

5.2.1. Wooden shores of the same length $(\alpha=1.0)$ 
To solve the problem of insufficient length of scaffolds when fitting the headroom of a building, it is advisable to consider setting up other shores on the top of scaffolds to close the gap between the scaffold and the ceiling slab. For the sake of convenience in the loading tests and numerical analyses, wooden shores are served as "other shores" in this study. Fig. 4 shows the setup of the combined system of scaffolds with wooden shores of the same length. To clearly explain the length of the wooden shores in this study, the ratio of the length of the wooden shores to that of the scaffolds $(1.7 \mathrm{~m}$ ) is defined as $\alpha$ (namely, $\alpha$ is the wooden shore length divided by1.7 $\mathrm{m}$ ).

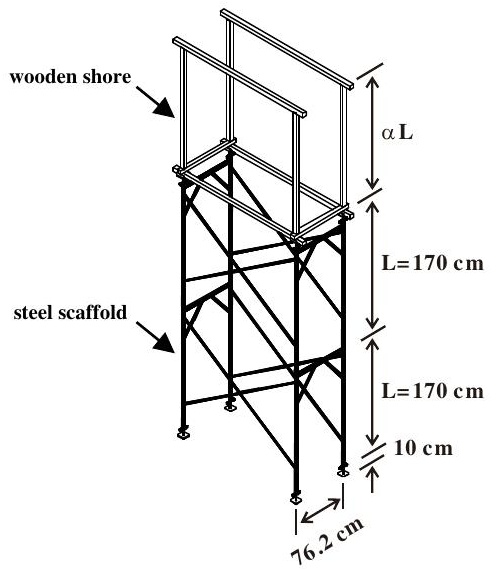

Fig. 4 Schematic diagram of the two-story combined system of scaffolds with wooden shores

The length of the wooden shores adopted in the experiment is $1.7 \mathrm{~m}$, which results in $\alpha=1(=1.7 \mathrm{~m} / 1.7 \mathrm{~m})$. The results of the experiment can be compared with those obtained in the experiment using a two-story scaffolding system and a combined system of scaffolds with wooden shores underneath an inclined ceiling slab.

\subsubsection{Wooden shores of the same length $(\alpha=0.382)$}

For the case that the gap between the scaffolds and the ceiling slab is not very large, shorter wooden shores may be used to adjust the total height of the scaffolding system. The corresponding configuration is shown in Fig. 4. To clearly compare the test results of the scaffolding system with the extended adjustable U-head jacks, the length of the wooden shores on the top of the scaffolds is set as $65 \mathrm{~cm}$, which is the same as the length of the extended adjustable U-head jacks. These results can be used to compare the performance of the scaffolding system with top wooden shores with that of the system extended by adjustable U-head jacks.

\subsubsection{Inclined ceiling slab}

To explore the stability behavior of the combined system of scaffolds with wooden shores underneath an inclined ceiling slab, the configurations shown in Fig. 5 are adopted in the experminet. Since there are strong axes and weak axes in a scaffolding structure, for the sake of convenience, this study defines the $x y$ plane in the in-plane direction of a scaffold unit and the $y z$-plane in the out-ofplane direction of a scaffold unit.
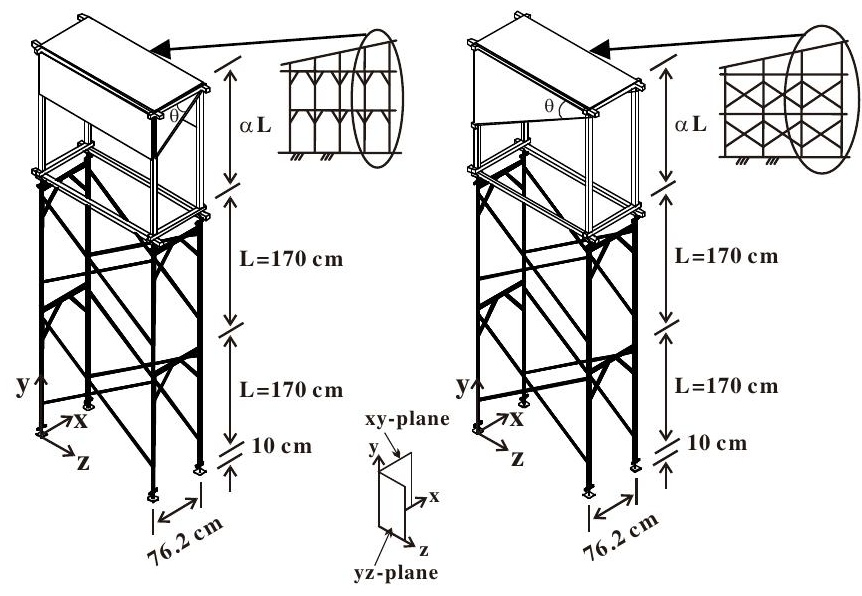

(A) Inclined plane in the in-plane direction (xy-plane)

(B) Inclined plane in the out-of-plane direction (yz-plane)

Fig. 5 Schematic diagram of the combined system of scaffolds with wooden shores with an inclined plane $\theta=30^{\circ}$ and wooden shore length $\alpha=1$
As shown in Fig. 5(A), the inclined plane of the ceiling slab is on the xyplane; that is, it inclines in the in-plane direction. As shown in Fig. 5(B), the inclined plane of the ceiling slab is on the yz-plane; that is, it inclines in the outof-plane direction.

As shown in Fig. 5(A) and Fig. 5(B), the longest wooden shore on the upper layer of the scaffolding structure is $1.7 \mathrm{~m}(\alpha=1)$. The inclination angle of the ceiling slab $(\theta)$ is $30^{\circ}$ downward. In the in-plane direction, the shorter wooden shores are $126 \mathrm{~cm}$ long $\left(=170-76.2 \times \tan 30^{\circ}\right)$; in the out-of-plane direction, the shorter wooden shores are $64.4 \mathrm{~cm}$ long $\left(=170-182.9 \times \tan 30^{\circ}\right)$. The test results can be compared with the cases without inclined ceiling slabs. They can also be used to review the stability behavior of scaffolding systems with ceiling slabs inclined in two different directions.

\subsubsection{Inclined ceiling slab and uneven ground surface}

Due to the interior configuration of buildings, it is common to see an inclined ceiling slab on the top and an uneven ground surface at the bottom. The stability behavior of the combined system of scaffolds with wooden shores under these conditions is explored. The configurations of the combined system of scaffolds with wooden shores under both out-of-plane and in-plane inclined directions are also adopted in this study (as shown in Fig. 6).

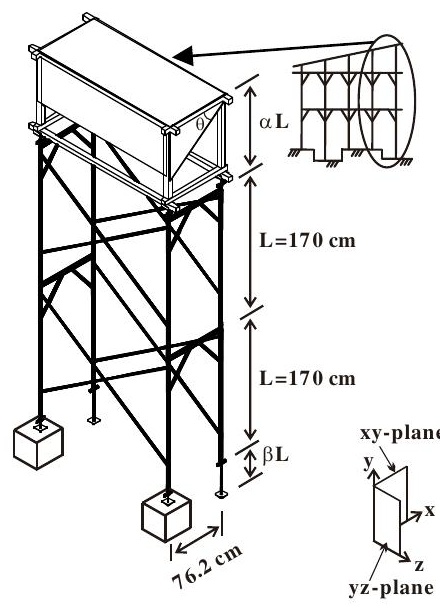

(A) Inclined plane in in-plane direction $\left(\theta=30^{\circ}, \alpha=0.5, \beta=0.15\right)$

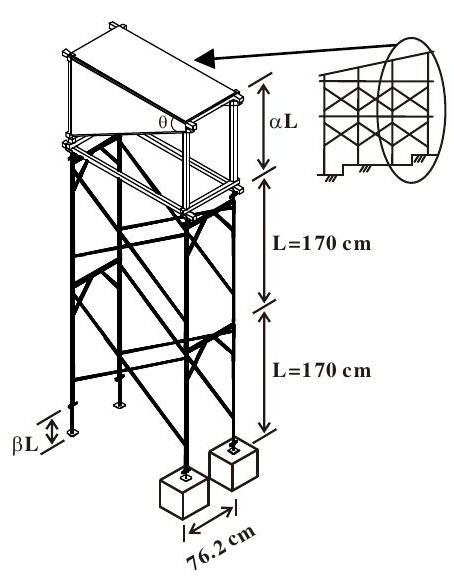

(B) Inclined plane in out-of-plane direction $\left(\theta=30^{\circ}, \alpha=0.7, \beta=0.15\right)$
Fig. 6 Schematic diagram of the combined system of scaffolds with wooden shores with an inclined plane $\theta=30^{\circ}$ and wooden shore length $\alpha=0.5 \& 0.7$

Fig. 6(A) shows the combined system of scaffolds with wooden shores under conditions of uneven top and bottom surfaces in the in-plane direction. As shown in Fig. 6(A), in the two-story combined system of scaffolds with wooden shores, the longer wooden shores are $85 \mathrm{~cm}(\alpha=0.5)$, the inclination angle of the ceiling slab is $30^{\circ}\left(\theta=30^{\circ}\right)$, the shorter wooden shores are $41 \mathrm{~cm}$ $\left(=85-76.2 \times \tan 30^{\circ}\right)$, and the length of the base jack at one side is $25.5 \mathrm{~cm}(=$ $0.15 \times 170, \beta=0.15)$.

Similarly, Fig. 6(B) shows the combined system of scaffolds with wooden shores under conditions of uneven top and bottom surfaces in the out-of-plane direction. As shown in Fig. 6(B), in the two-story combined system of scaffolds with wooden shores, the longer wooden shores are $119 \mathrm{~cm}(\alpha=0.7)$, the inclination angle of the ceiling slab is $30^{\circ}\left(\theta=30^{\circ}\right)$, the shorter wooden shores are $13.4 \mathrm{~cm}\left(=119-182.9 \times \tan 30^{\circ}\right)$, and the length of the base jack at one side is $25.5 \mathrm{~cm}(=0.15 \times 170, \beta=0.15)$.

\section{Discussions on results of tests and analyses}

\subsection{Scaffolding system with adjustable base jacks and U-head jacks of different lengths}

\subsubsection{Basic configuration of scaffolding system}

Two sets of two-story scaffolding systems with basic configurations were used in the experiment, and the test results are shown in Table 1. As shown in Table 1, the mean critical load of the two-story scaffolding system is 107.383 $\mathrm{kN}$ and the corresponding mean vertical deformation is $5.932 \mathrm{~mm}$. The results of the loading tests are shown in Fig. 7. As shown in Fig. 7, the structural deformation occurs in the front row of the scaffolding system, while the buckling mainly occurs in the in-plane direction. The load vs. vertical displacement curve of the two-story scaffolding system with a basic configuration under the loading test is shown in Fig. 8. Since the trend of the load vs. vertical displacement curves obtained from other tests in this study is similar to these obtained herein, the results from other tests are not included due to limited space. 
Table 1

Test results of the scaffolding system with adjustable base jacks and adjustable U-head jacks of different lengths

\begin{tabular}{|c|c|c|c|c|c|c|c|c|c|c|}
\hline \multirow{2}{*}{ Item } & \multirow{2}{*}{ Type } & \multirow{2}{*}{$\begin{array}{l}\text { Fig- } \\
\text { ure }\end{array}$} & \multirow{2}{*}{$\begin{array}{l}\text { Configu- } \\
\text { ration }\end{array}$} & \multirow{2}{*}{ Numbering } & \multirow{2}{*}{ Unit } & \multicolumn{3}{|c|}{ (a).Test value } & \multirow{2}{*}{$\begin{array}{l}\text { (b). Analy- } \\
\text { sis }(\mathrm{kN})\end{array}$} & \multirow{2}{*}{$\begin{array}{l}((a-b) / a) \\
\times 100 \%\end{array}$} \\
\hline & & & & & & Group A & Group B & Mean & & \\
\hline \multirow{2}{*}{1} & \multirow{2}{*}{$\begin{array}{l}\text { 2-story scaffod Sys- } \\
\text { tem }\end{array}$} & & \multirow{2}{*}{$\begin{array}{l}\text { Flat slab and } \\
\text { ground }\end{array}$} & $\begin{array}{c}\text { BN2D } \\
\text { (BN2DT) }\end{array}$ & $\mathrm{kN}$ & $\begin{array}{l}108.795 \\
(96.380) \\
\end{array}$ & $\begin{array}{l}105.971 \\
(90.898) \\
\end{array}$ & $\begin{array}{l}107.383 \\
(93.644) \\
\end{array}$ & \multirow{2}{*}{107.19} & \multirow{2}{*}{$0.2 \%$} \\
\hline & & & & Deformation & $\mathrm{mm}$ & $\begin{array}{c}5.189 \\
(4.275)\end{array}$ & $\begin{array}{c}6.675 \\
(4.791)\end{array}$ & $\begin{array}{c}5.932 \\
(4.533)\end{array}$ & & \\
\hline \multirow[b]{2}{*}{2} & \multirow{4}{*}{$\begin{array}{c}\text { U-head jacks/ base } \\
\text { jacks of different } \\
\text { lengths }\end{array}$} & & \multirow{2}{*}{$\begin{array}{l}\text { Ext. U-head } \\
\text { jacks }\end{array}$} & $\begin{array}{c}\mathrm{UJ}_{\mathrm{J}} 65 \mathrm{D} \\
\left(\mathrm{U}_{\mathrm{J}} 65 \mathrm{DT}\right)\end{array}$ & $\mathrm{kN}$ & $\begin{array}{l}111.786 \\
(79.336) \\
\end{array}$ & $\begin{array}{l}108.020 \\
(83.033) \\
\end{array}$ & $\begin{array}{l}109.903 \\
(81.185) \\
\end{array}$ & \multirow[b]{2}{*}{106.80} & \multirow[b]{2}{*}{$2.8 \%$} \\
\hline & & & & Deformation & $\mathrm{mm}$ & $\begin{array}{c}8.096 \\
(6.669)\end{array}$ & $\begin{array}{l}8.300 \\
(7.094)\end{array}$ & $\begin{array}{c}8.198 \\
(6.882)\end{array}$ & & \\
\hline \multirow[b]{2}{*}{3} & & & \multirow[b]{2}{*}{$\begin{array}{l}\text { Ext. U-head and } \\
\text { base jacks }\end{array}$} & $\begin{array}{c}\text { UJ65J65D } \\
(\mathrm{UJ} 65 \mathrm{~J} 65 \mathrm{DT}) \\
\end{array}$ & $\mathrm{kN}$ & $\begin{array}{c}81.346 \\
(65.381) \\
\end{array}$ & $\begin{array}{c}75.011 \\
(54.211) \\
\end{array}$ & $\begin{array}{c}78.179 \\
(59.791) \\
\end{array}$ & \multirow[b]{2}{*}{74.49} & \multirow[b]{2}{*}{$4.7 \%$} \\
\hline & & & & Deformation & $\mathrm{mm}$ & $\begin{array}{c}7.607 \\
(5.234)\end{array}$ & $\begin{array}{l}7.150 \\
(6.203)\end{array}$ & $\begin{array}{c}7.379 \\
(5.719)\end{array}$ & & \\
\hline
\end{tabular}

Notes:

1. Data in parentheses denote test values of the second load after the scaffolding system is unloaded and then reloaded.

2. All test configurations include the adjustable base jacks and U-head jacks if not otherwise specified.

3. In the numerical analysis of this study, the joint stiffness of the steel scaffolds is $2500 \mathrm{kN}-\mathrm{cm} / \mathrm{rad}$; that of the adjustable base and U-head jacks is $450 \mathrm{kN}$-cm/rad.

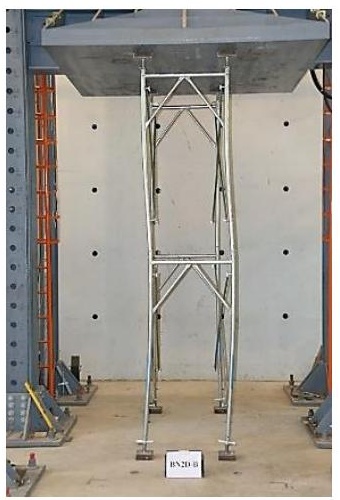

Fig. 7 Deformation of the two-story scaffolding system with basic configuration after loading

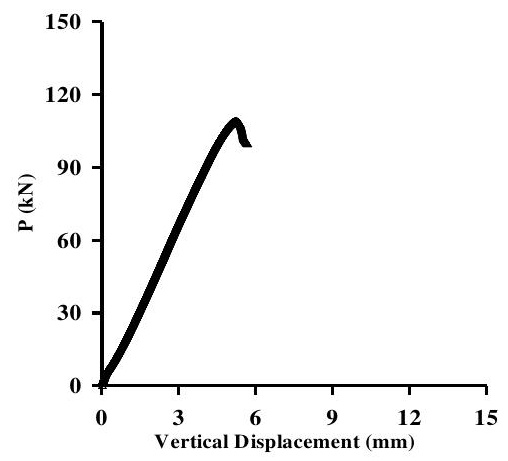

Fig. 8 Load vs. displacement curve of the two-story scaffolding system with basic configuration (BN2D-A) after loading

After finishing this test, the scaffolding system was unloaded and rearranged to its original condition to prepare for the second load. The second load simulates the worst case of the load-bearing capacity of the reused scaffolding system on construction sites. As shown in Table 1, the mean critical load of the two-story scaffolding system under a second load is $93.644 \mathrm{kN}$ and the corresponding mean vertical deformation is $4.533 \mathrm{~mm}$. Again, when the scaffolding system fails, the deformation mainly occurs in the front row and the buckling mainly occurs in the in-plane direction.

The second-order elastic analysis with semi-rigid joints was adopted in this study. With reference to previous studies of second-order elastic analyses on the joint stiffness of scaffolds, the stiffness values of each joint in the scaffolding system can be obtained and are shown in Fig. 9(A). As shown in Fig. 9(A), it is observed that the joint stiffness $\left(k_{S I}\right)$ between vertical tubes of the scaffolding system is $2500 \mathrm{kN}-\mathrm{cm} / \mathrm{rad}$, and the joint stiffness of base jacks and U-head jacks $\left(k_{s 2}\right)$ is $450 \mathrm{kN}-\mathrm{cm} / \mathrm{rad}$. After analysis, the critical load of the scaffolding system was obtained as $107.19 \mathrm{kN}$.

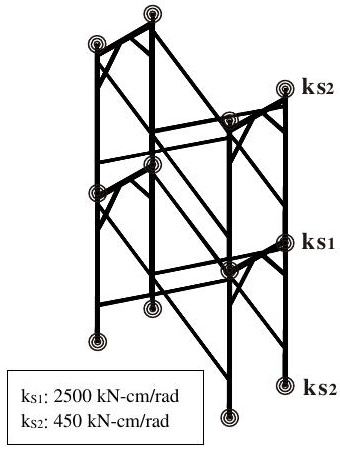

(A) scaffolding system

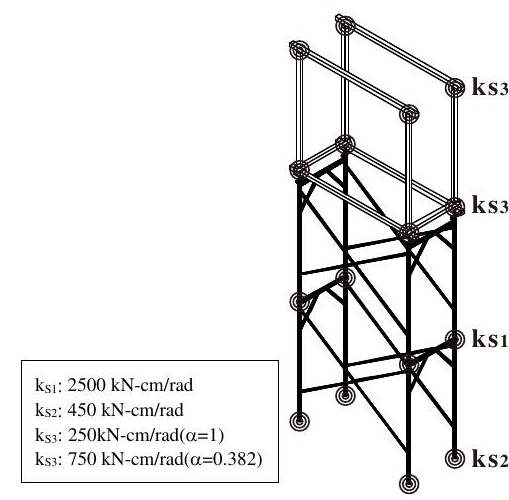

(B) combined system of scaffolds with wooden shores
Fig. 9 Schematic diagram of the spiral spring stiffness of various joints and their positions in the scaffolding system and combined system of scaffolds with wooden shores

Fig. 10(A) shows the deformation of the scaffolding system of basic configuration after loading, which is similar to that of the two-story scaffolding system as shwon in Fig. 7. Fig. 10(B) shows the relationship between the total vertical load and horizontal displacement on point A of the scaffolding system. Due to limited space, if similar setups of the scaffolding systems give similar analysis results to this case, they will be omitted from now on.

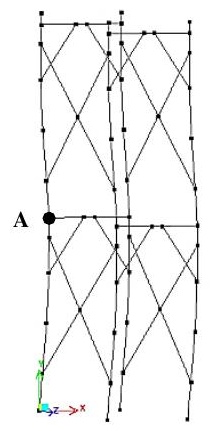

(A) Deformation after loading

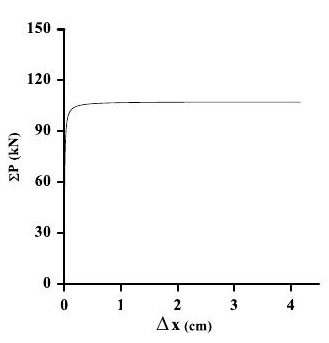

(B) Load vs. horizontal displacement diagram
Fig. 10 Results of the second-order elastic analysis with semi-rigid joints on the two-story scaffolding system with basic configuration

As shown in Table 1, the analysis value, $107.19 \mathrm{kN}$, is very close to the test value, $107.383 \mathrm{kN}$. The deviation of both values is around $0.2 \%$. The joint stiffnesses of the steel tubes, adjustable base jacks, and adjustable U-head jacks adopted in other scaffold configurations in this study are the same as those used in this scaffold configuration.

\subsubsection{Scaffolding system with extended adjustable U-head jacks}

Two sets of scaffolding systems were adopted in the experiment. The test results show that the mean critical load of these scaffolding systems is 109.903 $\mathrm{kN}$, which is also shown in Table 1. Fig. 11 shows that the deformation of the scaffolding system after loading occurs in the in-plane direction of the back-row 
scaffolds. After unloading, the scaffolding system was rearranged to prepare for the second load. The mean critical load of the second loading tests was 81.185 $\mathrm{kN}$. The deformation of the scaffolding system under the second load also occurred in the back row of the scaffolding system.

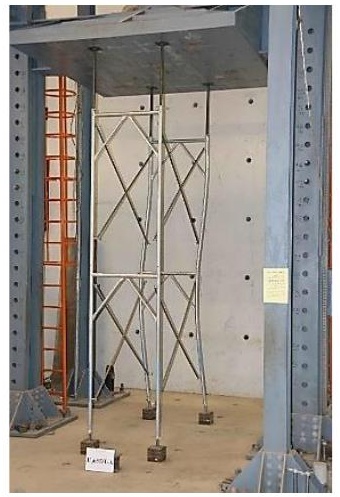

Fig. 11 Deformation of the scaffolding system with extended adjustable U-head jacks after loading

As shown in Fig. 11, although the adjustable U-head jacks are extended to $65 \mathrm{~cm}$, when the scaffolding structure fails, the deformation does not occur on the extended U-head jacks, but in the in-plane direction of the back-row scaffolds. As shown in Table 1, when the length of the U-head jacks is $10 \mathrm{~cm}$, the critical load of the scaffolding system is $107.383 \mathrm{kN}$; when the length of the U-head jacks is $65 \mathrm{~cm}$, the critical load of the scaffolding system is $109.903 \mathrm{kN}$. The failure of the scaffolding system is due to buckling in both cases, indicating that the effect of the extended $65 \mathrm{~cm} \mathrm{U}$-head jacks on the critical load is not obvious.

In the numerical analysis, the stiffnesses of the various joints of previous scaffolding systems were adopted. From the second-order elastic analysis, the critical load was obtained as $106.80 \mathrm{kN}$ (as shown in Table 1). Fig. 12(A) shows the deformation of the scaffolding system with extended adjustable U-head jacks after loading, which is similar to that of the two-story scaffolding system shown in Fig. 11. Fig. 12(B) shows the relationship between the total vertical load and the horizontal displacement at point A of the scaffolding system. The analysis value, $106.80 \mathrm{kN}$, is close to the test value, $109.903 \mathrm{kN}$. The deviation of both values is around $2.8 \%$. The deformation and the critical load of the scaffolding system are similar to the failure model of the scaffolding systems being tested.

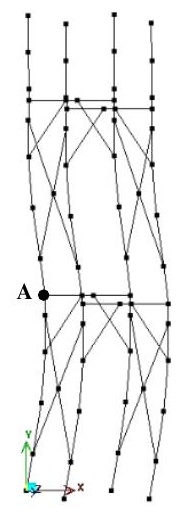

(A) Deformation after loading

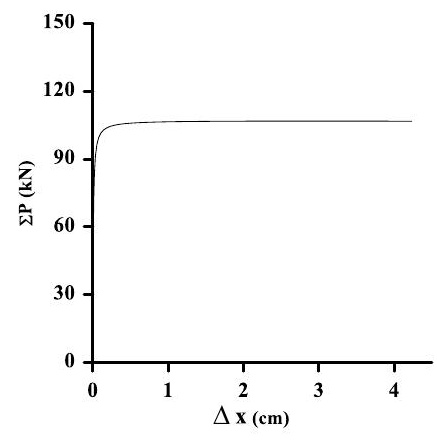

(B) Load vs. horizontal displacement diagram
Fig. 12 Results of the second-order elastic analysis with semi-rigid joints on the scaffolding system with extended adjustable U-head jacks

6.1.3. Scaffolding system with extended adjustable U-head jacks and base jacks Two tests were conducted, in which both the adjustable U-head jacks and base jacks were extended to $65 \mathrm{~cm}$. The test results in Table 1 show that the mean critical load of the scaffolding system is $78.179 \mathrm{kN}$. Fig. 13 shows the deformation of the scaffolding system, and Fig. 14 shows the details of the deformation of the adjustable U-head jacks after loading. The load-bearing capacity of the scaffolding system is lower than those of the previous two scaffold configurations. Additionally, the deformation of the scaffolding system after loading is different from those of the previous two scaffold configurations, mainly because the structural failure of the scaffolding system occurs on the extended adjustable U-head jacks and base jacks, instead of on the scaffolding system itself.

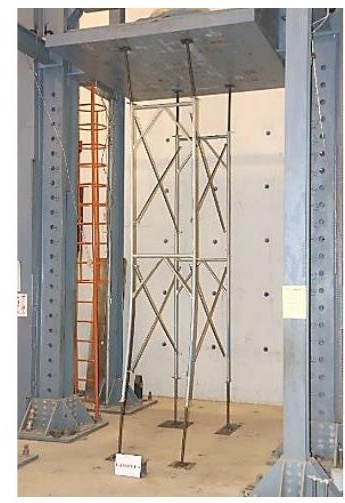

Fig. 13 Deformation of the scaffolding system with both extended adjustable U-head jacks and base jacks after loading

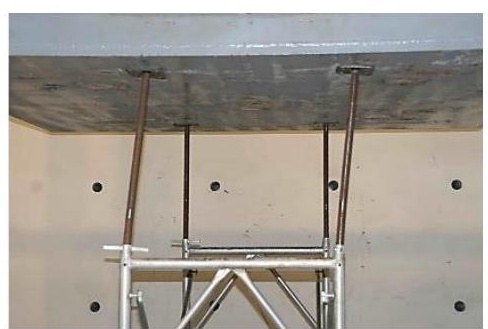

Fig. 14 Deformation of the adjustable U-head jacks of the scaffolding system with both extended adjustable U-head jacks and base jacks after loading

Similarly, after unloading, the scaffolding systems were rearranged to prepare for the second loading test. After testing, the mean critical load was found to be $59.791 \mathrm{kN}$, and the deformation of the scaffolding systems at failure was the same as that after the first load.

As shown in Fig. 15, the critical load, $78.179 \mathrm{kN}$, of the scaffolding system with both extended adjustable U-head jacks and base jacks is around 0.73 (= 78.179/107.383) times that of the scaffolding system with a basic configuration, $107.383 \mathrm{kN}$. This indicates that when the adjustable U-head jacks and base jacks are both extended to $65 \mathrm{~cm}$, the load-bearing capacity of the scaffolding system is not significantly affected. It retains around $70 \%$ of its original load-bearing capacity.

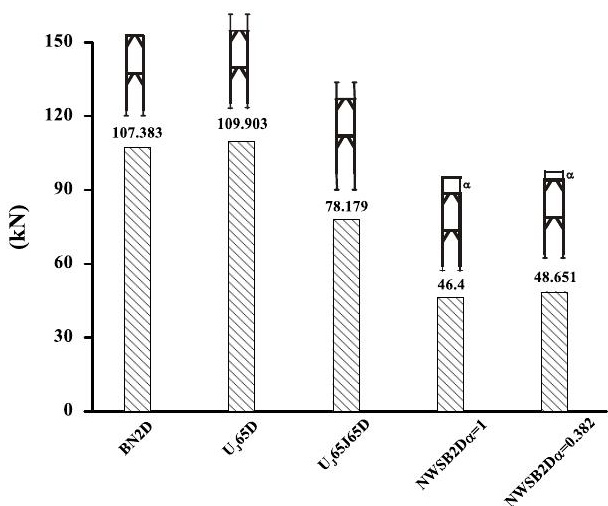

Fig. 15 Comparison of the critical loads of different scaffolding systems with extended adjustable U-head jacks and base jacks and top wooden shores 
Table 2

Test results of the combined system of scaffolds with wooden shores of different lengths

\begin{tabular}{|c|c|c|c|c|c|c|c|c|c|c|}
\hline \multirow{2}{*}{ Item } & \multirow{2}{*}{ Type } & \multirow{2}{*}{$\begin{array}{l}\text { Fig- } \\
\text { ure }\end{array}$} & \multirow{2}{*}{$\begin{array}{l}\text { Configu- } \\
\text { ration }\end{array}$} & \multirow{2}{*}{ Numbering } & \multirow{2}{*}{ Unit } & \multicolumn{3}{|c|}{ (a).Test value } & \multirow{2}{*}{$\begin{array}{l}\text { (b).Analy- } \\
\text { sis }(\mathrm{kN})\end{array}$} & \multirow{2}{*}{$\begin{array}{l}((a-b) / a) \\
\times 100 \%\end{array}$} \\
\hline & & & & & & Group A & Group B & Mean & & \\
\hline \multirow[b]{2}{*}{1} & \multirow{4}{*}{$\begin{array}{l}2 \text {-story com- } \\
\text { bined system } \\
\text { with wooden } \\
\text { shores }\end{array}$} & & \multirow[b]{2}{*}{$\alpha=1$} & $\begin{array}{c}\text { NWSB2D } \alpha=1 \\
(\text { NWSB2DT) }\end{array}$ & $\mathrm{kN}$ & $\begin{array}{c}47.758 \\
(36.324) \\
\end{array}$ & $\begin{array}{c}45.042 \\
(33.009) \\
\end{array}$ & $\begin{array}{c}46.400 \\
(34.667) \\
\end{array}$ & \multirow[b]{2}{*}{50.02} & \multirow[b]{2}{*}{$-7.8 \%$} \\
\hline & & & & Deformation & $\mathrm{mm}$ & $\begin{array}{l}10.062 \\
(7.431)\end{array}$ & $\begin{array}{c}8.810 \\
(7.150)\end{array}$ & $\begin{array}{c}9.436 \\
(7.291)\end{array}$ & & \\
\hline \multirow[t]{2}{*}{2} & & & \multirow[t]{2}{*}{$\alpha=0.382$} & $\begin{array}{c}\text { NWSB2D } \alpha= \\
0.382(38.5 \mathrm{~cm}) \\
(\mathrm{NWSB} 2 \mathrm{DT})\end{array}$ & $\mathrm{kN}$ & $\begin{array}{c}47.670 \\
(32.980)\end{array}$ & $\begin{array}{c}49.631 \\
(29.773)\end{array}$ & $\begin{array}{c}48.651 \\
(31.377)\end{array}$ & \multirow[t]{2}{*}{51.00} & \multirow[t]{2}{*}{$-4.8 \%$} \\
\hline & & & & Deformation & $\mathrm{mm}$ & $\begin{array}{c}9.246 \\
(7.387)\end{array}$ & $\begin{array}{l}11.347 \\
(7.912)\end{array}$ & $\begin{array}{l}10.297 \\
(7.650)\end{array}$ & & \\
\hline
\end{tabular}

Notes:

1. Data in parentheses denote test values of the second load after the scaffolding system is unloaded and then reloaded.

2. $\alpha$ denotes the ratio of the length of longer wooden shores to that of the scaffold unit.

3. In numerical analysis, the joint stiffness between the wooden shores and the steel scaffolds:

$\alpha=1.0, \mathrm{ks}=250 \mathrm{kN}-\mathrm{cm} / \mathrm{rad} ; \alpha=0.382, \mathrm{ks}=750 \mathrm{kN}-\mathrm{cm} / \mathrm{rad}$.

Based on the stiffnesses of various joints of previous scaffolding systems in the second-order elastic analysis, the critical load of this scaffolding system was obtained as $74.49 \mathrm{kN}$. As shown in Table 1, the analysis value, $74.49 \mathrm{kN}$, is close to the test value, $78.179 \mathrm{kN}$. The deviation of both values is around $4.7 \%$. Additionally, in the analysis, the deformation of the scaffolding system with extended adjustable U-head jacks and base jacks is similar to that of the scaffolding system being tested.

\subsection{Two-story combined system of scaffolds with wooden shores}

\subsubsection{Top wooden shores of the same length $(\alpha=1.0)$}

A two-story scaffolding system with four wooden shores of the same length $(170 \mathrm{~cm})$ on the top was adopted $(\alpha=1.0)$ in the experiment. Therefore, the total height of the structural system was the same as a three-story scaffolding system. As shown in Table 2, the mean critical load of these two scaffolding systems is $46.400 \mathrm{kN}$. Fig. 16 shows the deformation of the scaffolding system after loading. As shown in Fig. 16, the buckling failure of the combined system of scaffolds with wooden shores mainly occurs in the in-plane direction; the maximum horizontal deformation mainly occurs at the junction of the top scaffolds and the wooden shores, which is also in the in-plane direction. After unloading the first load, the mean critical load of the second load was taken as $34.667 \mathrm{kN}$, and the deformation of the scaffolding system also mainly occurred in the in-plane direction.

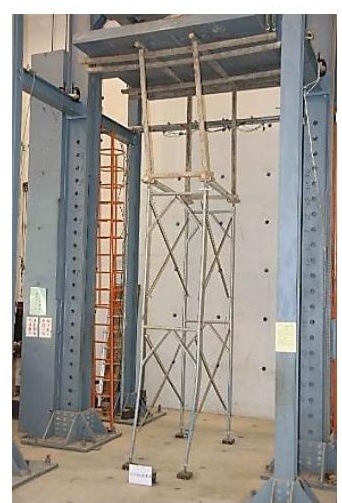

Fig. 16 Deformation of the combined system of scaffolds with wooden shores $(\alpha=1)$ after loading

As shown in Fig. 15, the critical load of the two-story combined system of scaffolds with wooden shores is $46.400 \mathrm{kN}$, which is around 0.43 (= 46.4/107.383) times the magnitude of the two-story scaffolding system with a basic configuration $(107.383 \mathrm{kN})$. This indicats that when $170 \mathrm{~cm}$ wooden shores are set up on top of the two-story scaffolding system, the load-bearing capacity of the scaffolding system reduces to around half. Therefore, regarding the use of scaffolding systems on construction sites, it is advisable to avoid adopting the combined system of scaffolds with wooden shores.

In the analysis of the combined system of scaffolds with wooden shores, the stiffnesses of various joints of previous scaffolding systems are adopted (as shown in Fig. 9(B)). With reference to the joint stiffness of scaffolding systems, the joint stiffness $\left(k_{S 3}\right)$ of the combined system of scaffolds with wooden shores is adopted as $250 \mathrm{kN}-\mathrm{cm} / \mathrm{rad}$. In the second-order elastic analysis, the critical load of the combined system of scaffolds with wooden shores is obtained as $50.02 \mathrm{kN}$ (as shown in Table 2). Fig. 17(A) shows the deformation of the combined system of scaffolds with wooden shores after loading, which is similar to that of the combined system of scaffolds with wooden shores shown in Fig. 16. Fig. 17(B) shows the relationship between the total vertical load and horizontal displacement at point A of the combined system of scaffolds with wooden shores. The analysis value, $50.02 \mathrm{kN}$, is close to the test value, 46.400 $\mathrm{kN}$. The deviation of both values is around $-7.8 \%$.

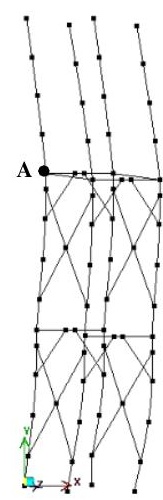

(A) Deformation after loading

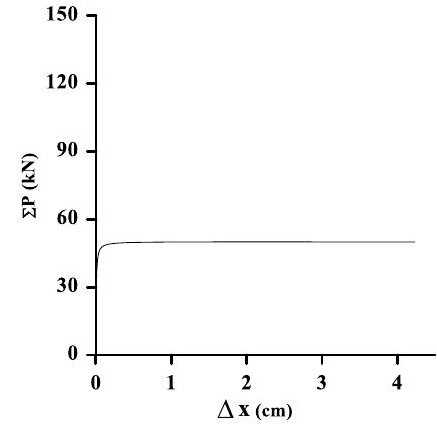

(B) Load vs. horizontal displacement diagram
Fig. 17 Results of the second-order elastic analysis with semi-rigid joints of the two-story combined system of scaffolds with wooden shores $(\alpha=1)$

6.2.2. Top wooden shores of the same length $(\alpha=0.382)$

A two-story scaffolding system with four wooden shores of the same but shorter lengths on the top was adopted $(\alpha=0.382)$ in the experiment. As shown in Table 2, the mean critical load of these two scaffolding systems is $48.651 \mathrm{kN}$. Fig. 18 shows that the deformation of the combined system of scaffolds with wooden shores mainly occurs in the in-plane direction of the back-row scaffolds, which is similar to that of the combined system of scaffolds with wooden shores of $170 \mathrm{~cm}$ in length. Similarly, the second loading tests were conducted on the scaffolding structures. The mean critical load is obtained as $31.377 \mathrm{kN}$, as shown in Table 2.

As shown in Fig. 15, the critical load, $48.651 \mathrm{kN}$, of the two-story combined system of scaffolds with shorter wooden shores $(\alpha=0.382)$ is close to that $(46.400 \mathrm{kN})$ of the two-story combined system of scaffolds with wooden shores of $170 \mathrm{~cm}$ in length $(\alpha=1.0)$

As shown in Fig. 15, under the same condition of height, the critical load, $48.651 \mathrm{kN}$, of the two-story combined system of scaffolds with shorter wooden shores $(\alpha=0.382)$ is $0.44(=48.651 / 109.903)$ of that of the scaffolding system with adjustable U-head jacks extended to $65 \mathrm{~cm}, 109.903 \mathrm{kN}$. Therefore, it is advisable to consider extending adjustable U-head jacks on the top of the scaffolding system instead of adopting the combined system of scaffolds with wooden shores. 


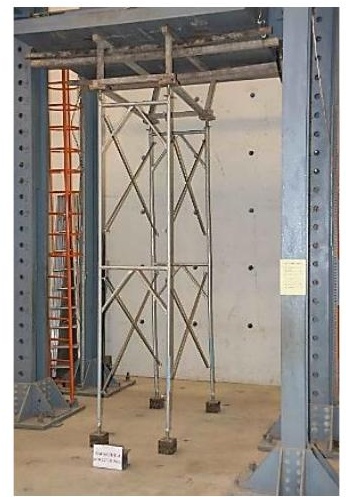

Fig. 18 Deformation of the combined system of scaffolds with wooden shores $(\alpha=0.382)$ after loading

The stiffnesses of various joints of previous scaffolding systems are adopted in the analysis. Based on the results of previous studies on scaffolding systems, it is observed that the shorter the wooden shores on the top of the combined system, the greater the joint stiffness at the junction of the scaffolds and the wooden shores. As shown in Fig. 9(B), the joint stiffness $\left(k_{S 3}\right)$ of the combined system of scaffolds with wooden shores is adopted as $750 \mathrm{kN}-\mathrm{cm} / \mathrm{rad}$. In the second-order elastic analysis, the critical load of the combined system of scaffolds with wooden shores is obtained as $51.00 \mathrm{kN}$ (as shown in Table 2). The deformation model obtained in the analysis is similar to that obtained in the testing described in Fig. 18. The analysis value, $51.00 \mathrm{kN}$, is close to the test value, $48.651 \mathrm{kN}$. The deviation of both values is around $-4.8 \%$.

Table 3

Test results of the combined system of scaffolds with wooden shores with different inclined planes

\begin{tabular}{|c|c|c|c|c|c|c|c|c|c|c|c|c|}
\hline \multirow[b]{2}{*}{ Item } & \multirow[b]{2}{*}{ Type } & \multirow{2}{*}{\multicolumn{2}{|c|}{ Fig-ure }} & \multirow{2}{*}{$\begin{array}{l}\text { Configu- } \\
\text { ration }\end{array}$} & \multirow[b]{2}{*}{ Numbering } & \multirow[b]{2}{*}{ Unit } & \multicolumn{4}{|c|}{ (a). Test value } & \multirow{2}{*}{$\begin{array}{l}\text { (b). Analy- } \\
\text { sis }(\mathrm{kN})\end{array}$} & \multirow{2}{*}{$\begin{array}{l}((a-b) / a) \\
\times 100 \%\end{array}$} \\
\hline & & & & & & & Group A & Group B & Group C & Mean & & \\
\hline \multirow{2}{*}{1} & \multirow{4}{*}{ Upper slope } & \multirow{4}{*}{$\frac{\stackrel{\Xi}{\Xi}}{\frac{a}{a}}$} & & \multirow{2}{*}{$\begin{array}{c}\text { In-plane } \\
\begin{array}{c}\theta=30^{\circ} \\
\alpha=1\end{array}\end{array}$} & $\begin{array}{c}\text { WSDUIY } \\
\theta=30^{\circ}, \alpha=1 \\
\text { (WSDUIYT) }\end{array}$ & $\mathrm{kN}$ & $\begin{array}{c}30.303 \\
(30.508)\end{array}$ & $\begin{array}{c}42.129 \\
(40.080)\end{array}$ & $\begin{array}{c}30.773 \\
(27.478)\end{array}$ & $\begin{array}{c}34.402 \\
(32.689)\end{array}$ & \multirow{2}{*}{32.56} & \multirow{2}{*}{$5.4 \%$} \\
\hline & & & & & Deformation & $\mathrm{mm}$ & $\begin{array}{c}14.894 \\
(15.012)\end{array}$ & $\begin{array}{c}13.406 \\
(14.950)\end{array}$ & $\begin{array}{c}13.225 \\
(15.612)\end{array}$ & $\begin{array}{c}13.842 \\
(15.191)\end{array}$ & & \\
\hline \multirow{2}{*}{2} & & & & \multirow{2}{*}{$\begin{array}{c}\text { In-plane } \\
\theta=30^{\circ} \\
\alpha=0.32\end{array}$} & 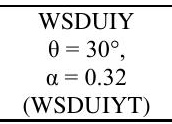 & $\mathrm{kN}$ & $\begin{array}{c}80.150 \\
(59.997)\end{array}$ & $\begin{array}{c}90.231 \\
(29.459)\end{array}$ & --- & $\begin{array}{c}85.191 \\
(44.728)\end{array}$ & \multirow{2}{*}{85.52} & \multirow{2}{*}{$-0.4 \%$} \\
\hline & & & & & Deformation & $\mathrm{mm}$ & $\begin{array}{c}24.232 \\
(16.517)\end{array}$ & $\begin{array}{c}24.819 \\
(15.731)\end{array}$ & --- & $\begin{array}{c}24.526 \\
(16.124)\end{array}$ & & \\
\hline \multirow{2}{*}{3} & \multirow{2}{*}{ Upper slope } & \multirow{2}{*}{$\begin{array}{l}\frac{0}{0} \\
\frac{\pi}{2} \\
\frac{1}{0} \\
0 \\
0 \\
0\end{array}$} & & \multirow{2}{*}{$\begin{array}{l}\text { Out-of -plane } \\
\qquad \begin{array}{c}\theta=30^{\circ} \\
\alpha=1\end{array}\end{array}$} & $\begin{array}{c}\text { WSDUIX } \\
\theta=30^{\circ}, \alpha=1 \\
(\text { WSDUIXT) }\end{array}$ & $\mathrm{kN}$ & $\begin{array}{c}45.130 \\
(36.000)\end{array}$ & $\begin{array}{c}41.463 \\
(36.491)\end{array}$ & --- & $\begin{array}{c}43.297 \\
(36.246)\end{array}$ & \multirow{2}{*}{47.27} & \multirow{2}{*}{$-9.2 \%$} \\
\hline & & & & & Deformation & $\mathrm{mm}$ & $\begin{array}{c}8.950 \\
(7.294)\end{array}$ & $\begin{array}{c}8.937 \\
(8.454)\end{array}$ & --- & $\begin{array}{c}8.944 \\
(7.874)\end{array}$ & & \\
\hline \multirow[t]{2}{*}{4} & \multirow{4}{*}{$\begin{array}{l}\text { Upper\& } \\
\text { Lower } \\
\text { slope }\end{array}$} & \multirow[t]{2}{*}{$\frac{\stackrel{0}{\Xi}}{\stackrel{\Xi}{a}}$} & & \multirow{2}{*}{$\begin{array}{c}\text { In-plane } \\
\theta=30^{\circ} \\
\alpha=0.5 \\
\beta=0.15\end{array}$} & $\begin{array}{c}\text { WSDUGIJY } \\
\theta=30^{\circ}, \alpha=0.5 \\
\beta=0.15 \\
\text { (WSDUGIJYT) }\end{array}$ & $\mathrm{kN}$ & $\begin{array}{c}41.865 \\
(23.654)\end{array}$ & $\begin{array}{c}37.373 \\
(25.233)\end{array}$ & $\begin{array}{l}32.980 \\
(21.124)\end{array}$ & $\begin{array}{c}37.406 \\
(23.337)\end{array}$ & \multirow[t]{2}{*}{38.64} & \multirow[t]{2}{*}{$-3.3 \%$} \\
\hline & & & & & Deformation & $\mathrm{mm}$ & $\begin{array}{c}18.988 \\
(13.931)\end{array}$ & $\begin{array}{c}22.169 \\
(19.113)\end{array}$ & $\begin{array}{c}13.444 \\
(10.169)\end{array}$ & $\begin{array}{c}18.200 \\
(14.404)\end{array}$ & & \\
\hline \multirow[t]{2}{*}{5} & & \multirow{2}{*}{$\begin{array}{l}\frac{0}{3} \\
\frac{\pi}{2} \\
\frac{1}{0} \\
\frac{1}{3} \\
0\end{array}$} & & \multirow[t]{2}{*}{$\begin{array}{c}\text { Out-of -plane } \\
\begin{array}{c}\theta=30^{\circ} \\
\alpha=0.7 \\
\beta=0.15\end{array}\end{array}$} & $\begin{array}{c}\text { WSDUGIJX } \\
\theta=30^{\circ}, \\
\alpha=0.7 \\
\beta=0.15 \\
\text { (WSDUGIJXT) }\end{array}$ & $\mathrm{kN}$ & $\begin{array}{c}50.249 \\
(34.637)\end{array}$ & $\begin{array}{c}45.101 \\
(31.970)\end{array}$ & $\begin{array}{c}47.778 \\
(33.558)\end{array}$ & $\begin{array}{c}47.709 \\
(33.388)\end{array}$ & \multirow[t]{2}{*}{43.05} & \multirow[t]{2}{*}{$9.8 \%$} \\
\hline & & & & & Deformation & $\mathrm{mm}$ & $\begin{array}{l}12.550 \\
(8.216)\end{array}$ & $\begin{array}{l}10.887 \\
(8.783)\end{array}$ & $\begin{array}{l}10.309 \\
(8.272)\end{array}$ & $\begin{array}{l}11.249 \\
(8.424) \\
\end{array}$ & & \\
\hline
\end{tabular}

Notes:

1. Data in parentheses denote test values of the second load after the scaffolding system is unloaded and then reloaded.

2. $\alpha$ denotes the ratio of the length of longer wooden shores to that of the scaffold unit; $\beta$ denotes the ratio of the length of the extended base jacks to that of the scaffold unit.

3. The angle of inclination of the ceiling slab $\theta=30^{\circ}$.

4. In numerical analysis, the joint stiffness of the steel scaffolds is $2500 \mathrm{kN}-\mathrm{cm} / \mathrm{rad}$; that of the adjustable base and U-head jacks is $450 \mathrm{kN}-\mathrm{cm} / \mathrm{rad}$

Joint stiffness between the wooden shores and steel scaffolds:

$\alpha=1.0, \mathrm{ks}=250 \mathrm{kN}-\mathrm{cm} / \mathrm{rad} ; \alpha=0.7, \mathrm{ks}=450 \mathrm{kN}-\mathrm{cm} / \mathrm{rad} ; \alpha=0.5, \mathrm{ks}=500 \mathrm{kN}-\mathrm{cm} / \mathrm{rad} ; \alpha=0.32, \mathrm{ks}=1500 \mathrm{kN}-\mathrm{cm} / \mathrm{rad}$

Setup of top linear springs (in-plane): inclination (weak direction), $\mathrm{kx}=0.1 \mathrm{kN} / \mathrm{cm}$; inclination (strong direction), $\mathrm{k}_{\mathrm{z}}=1 \mathrm{kN} / \mathrm{cm}$

Setup of top linear springs (out-of-plane): inclination (weak direction): $3 \mathrm{kN} / \mathrm{cm}$; inclination (strong direction): $30 \mathrm{kN} / \mathrm{cm}$ 


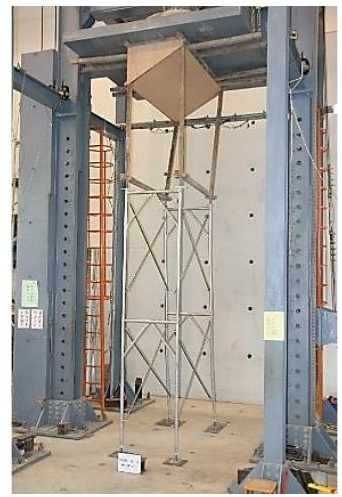

Fig. 19 Deformation of the combined system of scaffolds with wooden shores under inclined slab after loading $\left(\alpha=1.0 / \theta=30^{\circ}\right.$ in the in-plane direction $)$

The stiffnesses of various joints of previous scaffolding systems, as well as those of the adjustable base jacks and U-head jacks, are adopted in the analysis (as shown in Fig. 20(A)). The joint stiffness $\left(k_{S 3}\right)$ at the junction of the scaffolds and the wooden shores is adopted as $250 \mathrm{kN}-\mathrm{cm} / \mathrm{rad}$. Since the junction of the top of the wooden shores and the inclined ceiling slab cannot be perfectly fixed, some horizontal displacement might occur after loading. Therefore, linear springs are used to simulate the situation during analysis. The stiffness $\left(k_{X}\right)$ of the linear springs used in this study is $0.1 \mathrm{kN} / \mathrm{cm}$ in the inclination direction (xyplane) and $1 \mathrm{kN} / \mathrm{cm}$ in the yz-plane. The definition of these linear springs is shown in Fig. 20(A)

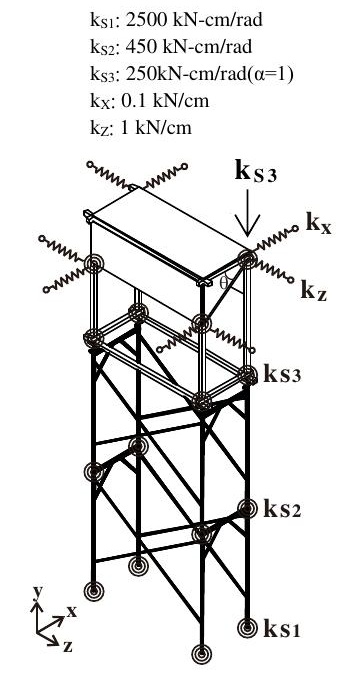

(A) Ceiling slab inclining in the in-plane direction $\mathrm{k}_{\mathrm{s} 1}: 2500 \mathrm{kN}-\mathrm{cm} / \mathrm{rad}$

$\mathrm{k}_{\mathrm{s} 2}: 450 \mathrm{kN}-\mathrm{cm} / \mathrm{rad}$

$\mathrm{k}_{\mathrm{S} 3}: 250 \mathrm{kN}-\mathrm{cm} / \mathrm{rad}(\alpha=1)$

$\mathrm{kx}_{\mathrm{x}}: 30 \mathrm{kN} / \mathrm{cm}$

$\mathrm{k}_{\mathrm{z}:} 3 \mathrm{kN} / \mathrm{cm}$

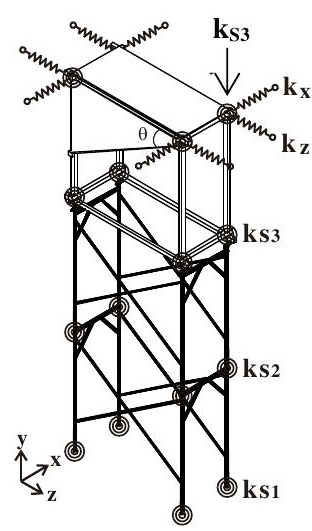

(B) Ceiling slab inclining in the out-ofplane direction
Fig. 20 Schematic diagram of the positions of different joint stiffnesses in the combined system of scaffolds with wooden shores in different inclined planes

In second-order elastic analysis with semi-rigid joints, the critical load of the scaffolding system is obtained as $32.56 \mathrm{kN}$ (as shown in Table 3). Fig. 21(A) shows the deformation of the combined system of scaffolds with wooden shores with the ceiling slab inclining in the in-plane direction (xy-plane) after loading, which is similar to that of the scaffolding system tested in Fig. 19. Fig. 21(B) shows the relationship between the total vertical load and horizontal displacement on point $\mathrm{A}$ of the scaffolding system. The analysis value, 32.56 $\mathrm{kN}$, is very close to the test value, $34.402 \mathrm{kN}$. The deviation of both values is around $5.4 \%$.

- Situation of long wooden shores with $\alpha=0.32$

The configuration of the scaffolding system with the "situation of long wooden shores with $\alpha=0.32$ " in the experiment is the same as that of the scaffolding system with the "situation of long wooden shores with $\alpha=1.0$ ", except that the wooden shores are of different lengths. The scaffold configuration is defined as the "situation of long wooden shores with $\alpha=0.32$ ", namely, the longest wooden shores are $54.4 \mathrm{~cm}$ and the ceiling slab is inclined with a downward angle $30^{\circ}$ (as shown in Fig. 5(A)). As shown in Table 3, the test results show that the mean critical load of the two scaffolding systems is $85.191 \mathrm{kN}$. The deformation of the combined system of scaffolds with wooden shores mainly occurs in the in-plane direction and the maximum horizontal deformation mainly occurs at the junction of the scaffolds and the wooden shores. Similarly, the second loading test is conducted on the scaffolding structures and the mean critical load is obtained as $44.728 \mathrm{kN}$. The buckling failure of the scaffolding structure in the second loading test is similar to that of the first loading test, which also occurs in the in-plane direction.

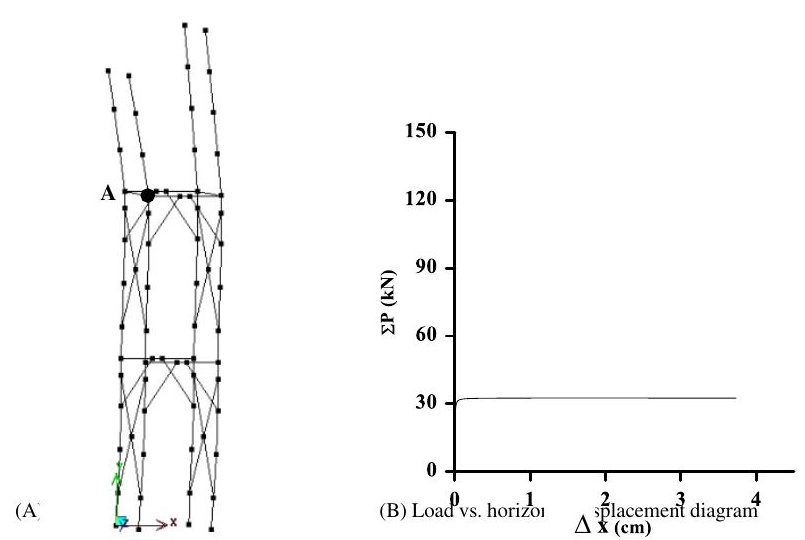

Fig. 21 Results of the second-order elastic analysis with semi-rigid joints of the scaffolding system with the ceiling slab inclining in the in-plane direction ( $x y$-plane) $\left(\alpha=1.0 / \theta=30^{\circ}\right.$ in the in-plane direction)

For the scaffolding systems underneath an inclined plane in the in-plane direction, the critical load of the scaffolding system with long wooden shores with $\alpha=0.32$ is $85.191 \mathrm{kN}$, which is $2.47(=85.191 / 34.402)$ times that of the scaffolding system with long wooden shores with $\alpha=1.0(34.402 \mathrm{kN})$, indicating that the combined system of scaffolds with shorter wooden shores has a greater load-bearing capacity.

The stiffnesses of various joints obtained from previous scaffolding systems were adopted in the analysis. The definitions of various joints are shown in Fig. 20(A). Since the wooden shores in the scaffolding system are shorter, the joint stiffness $\left(k_{S 3}\right)$ at the junction of the top of the scaffolds and the wooden shores is defined as $1500 \mathrm{kN}-\mathrm{cm} / \mathrm{rad}$. Linear springs are used to simulate the junction of the top of the wooden shores and the inclined ceiling slab. The stiffness $\left(k_{X}\right)$ of the linear springs is $0.1 \mathrm{kN} / \mathrm{cm}$ in the inclination direction ( $x y$-plane) and the stiffness $\left(k_{Z}\right)$ is $1 \mathrm{kN} / \mathrm{cm}$ in the $y z$-plane. The definitions of these linear springs are shown in Fig. 20(A). In the second-order elastic analysis, the critical load of the scaffolding system is obtained as $85.52 \mathrm{kN}$ (as shown in Table 3). The deformation model obtained in the analysis is similar to that obtained in the tests as described in Fig. 19. The analysis value, $85.52 \mathrm{kN}$, is close to the test value, $85.191 \mathrm{kN}$. The deviation of both values is around $-0.4 \%$.

\subsubsection{Ceiling slab inclined in the out-of-plane direction (yz-plane) $(\alpha=1.0)$}

The configuration of the scaffolding system with different lengths of wooden shores on the top of the scaffold is shown in Fig. 5(B), which is under a ceiling slab inclined in the out-of-plane direction of the scaffold. In the experiment, $\alpha=1.0$ is defined for the two longest wooden shores $(170 \mathrm{~cm})$ used to fit a ceiling slab inclined in the out-of-plane direction by $30^{\circ}$ downward (as shown in Fig. 5(B)). As shown in Table 3, the test yields a mean critical load of $43.297 \mathrm{kN}$.

Fig. 22 shows the deformation of the test configuration after loading, which mainly occurs in the back row of the shorter wooden shores in the in-plane direction. The maximum horizontal deformation occurs at the junction of the scaffolds and the wooden shores. The deformation of the test configuration after loading is unique, in that the deformation first occurs in the out-of-plane direction and then switches to the in-plane direction until the structure fails. After the second loading test, the mean critical load was obtained as $36.246 \mathrm{kN}$ The buckling failure occurred in the in-plane direction of the scaffolding system, which was similar to that of the first loading test. 


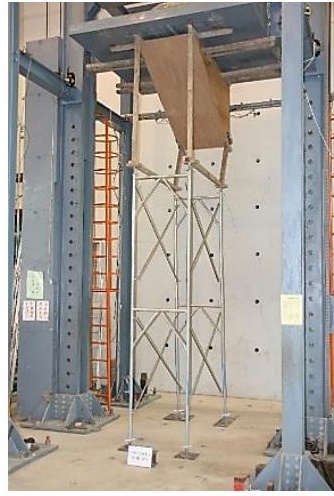

Fig. 22 Deformation of the combined system of scaffolds with wooden shores under inclined slab after loading $\left(\alpha=1.0 / \theta=30^{\circ}\right.$ in the out-of-plane direction

By dividing the critical load of the scaffolding system with the ceiling slab inclined in the out-of-plane direction $(43.297 \mathrm{kN})$ by that of the combined system of scaffolds with wooden shores with the ceiling slab inclined in the inplane direction $(34.402 \mathrm{kN})$, the ratio $1.26(=43.297 / 34.402)$ is obtained. Thus, in the case of a combined system of scaffolds with wooden shores to be set up under an inclined ceiling slab on a construction site, it is advisable to set it up in the out-of-plane direction (as shown in Fig. 5(B)).

Fig. 23 integrates the test results as described in Table 2 and Table 3, which makes a comparison of the test values of the combined systems underneath a flat ceiling slab and those underneath an inclined ceiling slab. As shown in Fig. 23 , by dividing the critical load of the combined system of the scaffolds with wooden shores with the ceiling slab inclining in the out-of-plane direction $(43.297 \mathrm{kN})$ by that of the combined system of scaffolds with wooden shores with a flat ceiling slab $(46.4 \mathrm{kN})$, the ratio $0.93(=43.297 / 46.4)$ is obtained. This indicates that the load-bearing capacities of these two scaffold configurations were quite close.

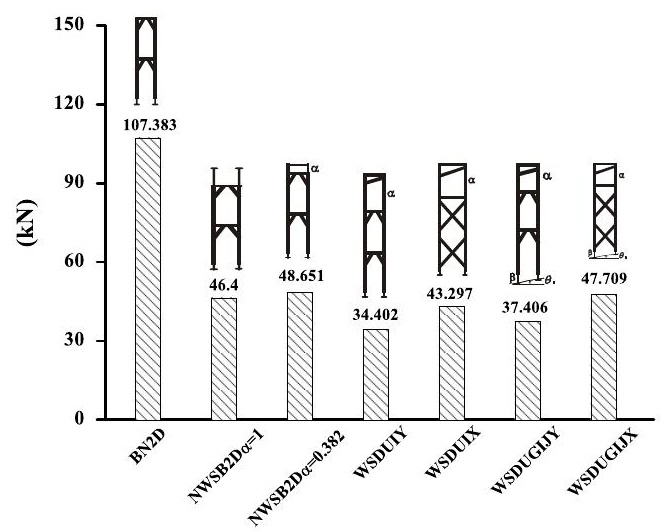

Fig. 23 Comparison of critical loads of the combined systems of scaffolds with wooden shores underneath an inclined plane of different angles and on different ground situation

The stiffnesses of various joints in the previous scaffolding systems were adopted in the analysis. The definition of the joint stiffness is shown in Fig. 20(B). The joint stiffness $\left(k_{S 3}\right)$ at the junction of the scaffolds and the wooden shores was set as $250 \mathrm{kN}-\mathrm{cm} / \mathrm{rad}$. The joint type between the wooden shore and the ceiling slab inclined in the out-of-plane direction is different from that inclined in the in-plane direction, as shown from previous inclined ceiling slab tests.

As shown in these inclined ceiling slab tests, the stiffness at the junction of the wooden shores and the ceiling slab inclined in the out-of-plane direction is greater than that of the junction of the wooden shores and the ceiling slab inclined in the in-plane direction. The stiffness $\left(k_{Z}\right)$ of the linear springs adopted in this analysis is $3 \mathrm{kN}$-cm in the $y z$-plane, and the stiffness $\left(k_{X}\right)$ in the $x y$-plane is $30 \mathrm{kN}-\mathrm{cm}$. The definitions of these linear springs are shown in Fig. 20(B)

From the second-order elastic analysis, the critical load of the scaffolding system was obtained as $42.27 \mathrm{kN}$ (as shown in Table 3). Fig. 24(A) shows the deformation of the combined system of scaffolds with wooden shores after loading with the ceiling slab inclining in the out-of-plane direction (yz-plane), which is similar to that of the scaffold configuration shown in Fig. 22. Fig. 24(B) shows the relationship between the total vertical load and horizontal displacement at point A of the scaffolding system. The analysis value, $42.27 \mathrm{kN}$, is close to the test value, $43.297 \mathrm{kN}$. The deviation of both values is around $-9.2 \%$

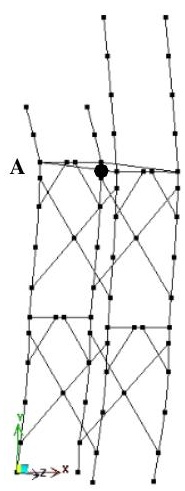

(A) Deformation after loading

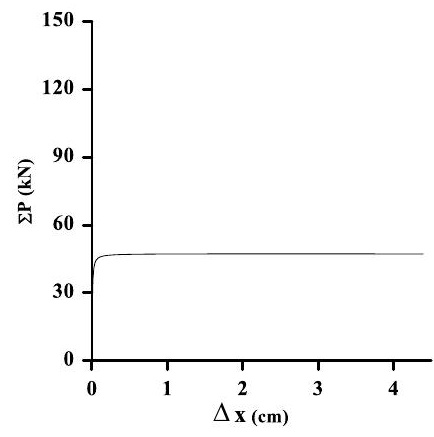

(B) Load vs. horizontal displacement diagram
Fig. 24 Results of the second-order elastic analysis with semi-rigid joints of the scaffolding system with the ceiling slab inclining in the out-of-plane direction ( $y z$-plane) $(\alpha=1.0)$

6.2.5. Ceiling slab inclined in the in-plane direction (xy-plane) $(\alpha=0.5)$ with elevation difference on the ground surface $(\beta=0.15)$

The test configuration consists of a ceiling slab inclined in the in-plane direction ( $x y$-plane) with an elevation difference on the ground surface, as shown in Fig. 6(A). In Fig. 6(A), the longer wooden shores of $85 \mathrm{~cm}(=0.5 \times 170$ $\mathrm{cm}$ ) are used with $\alpha=0.5$, and the ceiling slab is inclined downward with an angle $30^{\circ}$ in the in-plane direction. The definition of ' $\beta=0.15$ ' indicates that there is an elevation difference of $25.5 \mathrm{~cm}(=0.15 \times 170 \mathrm{~cm})$ on the ground due to the extension of the base jacks, as shown in Fig. 6(A). Since the deviations between the first two tests are quite large, the third test is conducted. Then, a mean critical load of $37.406 \mathrm{kN}$ is obtained, as shown in Table 3.

Fig. 25 shows the deformation of the scaffolding system after loading, which mainly occurs in the front row of the scaffolds and in the in-plane direction. Again, the maximum horizontal deformation occurred at the junction of the scaffolds and the wooden shores. The mean critical load of the second loading test was obtained as $23.337 \mathrm{kN}$. The buckling failure of the scaffolding system in the second loading test was similar to that in the first loading test, and the deformation also mainly occurred in the in-plane direction.

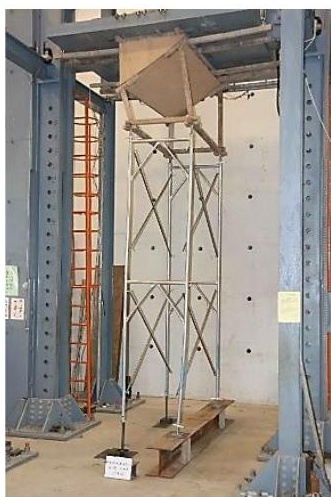

Fig. 25 Deformation of the combined system of scaffolds with wooden shores under inclined slab and uneven base after loading $\left(\alpha=0.5 / \beta=0.15 / \theta=30^{\circ}\right.$ in the in-plane direction)

In the analysis, the stiffnesses of the various joints of the previous scaffolding systems were adopted. The definitions of the joint stiffnesses are shown in Fig. 20(A). Additionally, the joint stiffness $\left(k_{S 3}\right)$ at the junction of the scaffolds and the wooden shores was adopted as $500 \mathrm{kN}-\mathrm{cm} / \mathrm{rad}$. In this test, since the ceiling slab was inclined in the in-plane direction, linear springs were used to simulate the junction of the wooden shores and the inclined ceiling slab. The stiffness of the linear springs was $0.1 \mathrm{kN} / \mathrm{cm}\left(k_{X}\right)$ in the inclination direction (xy-plane) and $1 \mathrm{kN} / \mathrm{cm}\left(k_{\mathrm{Z}}\right)$ in the $y z$-plane. The definition of these linear springs is shown in Fig. 20(A).

From the second-order elastic analysis, the critical load of the scaffolding system is obtained as $38.64 \mathrm{kN}$, as shown in Table 3. The deformation model obtained in the analysis is similar to that obtained in the tests as described in Fig. 25. The analysis value, $38.64 \mathrm{kN}$, is close to the test value, $37.406 \mathrm{kN}$. The deviation of both values is around $-3.3 \%$ 
6.2.6. Ceiling slab inclined in the out-of-plane direction (yz-plane) $(\alpha=0.7)$ with elevation difference on the ground surface $(\beta=0.15)$

In this test, the scaffolding system configuration consists of a ceiling slab inclined in the out-of-plane direction ( $y z$-plane) and an elevation difference on the ground, as shown in Fig. 6(B). In Fig. 6(B), the longer wooden shores of $119 \mathrm{~cm}(=0.7 \times 170 \mathrm{~cm})$ with $\alpha=0.7$ are adopted, and the ceiling slab is inclined downward with an angle $30^{\circ}$ in the out-of-plane direction. The definition of ' $\beta$ $=0.15^{\prime}$ indicats that there is an elevation difference of $25.5 \mathrm{~cm}(=0.15 \times 170 \mathrm{~cm})$ on the ground due to the extension of the base jacks, as shown in Fig. 6(B). Since the deviations of the first two tests are quite large, the third test is conducted. A mean critical load of $47.709 \mathrm{kN}$ is obtained, as shown in Table 3.

Fig. 26 shows the deformation of the test configuration after loading, which mainly occurs in the front row of scaffolds and in the in-plane direction. The maximum horizontal deformation occurs at the junction of the scaffolds and the wooden shores. Similarly, the mean critical load of the second loading test is obtained as $33.388 \mathrm{kN}$. The buckling failure of the scaffolding structure in the second loading test is similar to that in the first loading test, and the deformation mainly occurs in the in-plane direction.

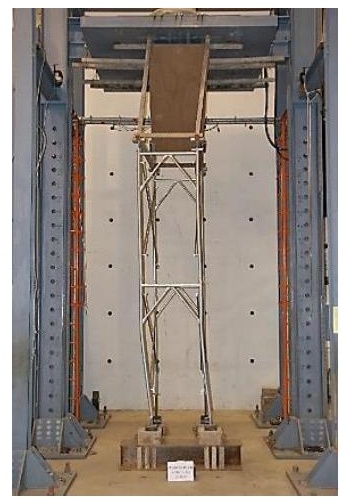

Fig. 26 Deformation of the combined system of scaffolds with wooden shores under inclined slab and uneven base after loading $\left(\alpha=0.7 / \beta=0.15 / \theta=30^{\circ}\right.$ in the out-of-plane direction)

As shown in Table 3 and Fig. 23, the case of the combined system with the ceiling slab inclined in the out-of-plane direction and an elevation difference on the ground produces a critical load of $47.709 \mathrm{kN}$, while the case with the ceiling slab inclined in the in-plane direction and an elevation difference on the ground produces a critical load of $37.406 \mathrm{kN}$. The ratio of the two values is $1.28(=$ 47.709/37.406). Additionally, the critical load of the former scaffolding configuration $(47.709 \mathrm{kN})$ is very close to that of the combined system of scaffolds with wooden shores with a flat ceiling slab $(46.4 \mathrm{kN})$.

In the analysis, the stiffnesses of various joints of the previous scaffolding systems were adopted. The definition of joint stiffness is shown in Fig. 20(B). The joint stiffness $\left(k_{s 3}\right)$ at the junction of the scaffolds and the wooden shores is adopted as $450 \mathrm{kN}-\mathrm{cm} / \mathrm{rad}$. In this test, since the ceiling slab is inclined in the out-of-plane direction, linear springs are used to simulate the junction of the wooden shores and the inclined ceiling slab. The stiffness of the linear springs is $3 \mathrm{kN}-\mathrm{cm}\left(k_{z}\right)$ in the inclination direction (yz-plane) and $30 \mathrm{kN}-\mathrm{cm}\left(k_{X}\right)$ in the $x y$-plane. The definition of these linear springs is shown in Fig. 20(B).

From the second-order elastic analysis, the critical load of the scaffolding system is obtained as $43.05 \mathrm{kN}$, as shown in Table 3. The deformation model obtained in the analysis is similar to that obtained in the tests described in Fig. 26. The analysis value, $43.05 \mathrm{kN}$, is close to the test value, $47.709 \mathrm{kN}$. The deviation of both values is around $9.8 \%$.

In conclusion, it is observed that the critical load of the combined system of scaffolds with wooden shores, the ceiling slab inclined in the out-of-plane direction, and an elevation difference on the ground is greater than that of the same scaffold configuration with a ceiling slab inclined in the in-plane direction. Therefore, in the case of an inclined ceiling slab and an elevation difference on the ground, it is advisable to set up the top inclined ceiling slab in the out-ofplane direction of the scaffolds on construction sites, as shown in Fig. 6(B).

\subsection{Lower bound of load-bearing capacity of the repeatedly used scaffolds}

\subsubsection{The scaffolding system}

In this study, two loading tests were conducted on various scaffolding systems. The critical load obtained in the second loading test is considered as the lower bound of the load-bearing capacity of the scaffolding systems installed by reused scaffolds. The strength reduction factor $(\phi)$ of the scaffolding systems installed by reused scaffolds is calculated by dividing the critical load of the second loading test by that of the first loading test. As shown in Table 4, the mean value $\left(\mu_{\phi}\right)$ of the strength reduction factor $(\phi)$ of the door-type reused steel scaffolds is around 0.79 and the standard deviation $(\sigma)$ is around 0.07 .
Table 4

Critical load of various scaffolding systems in the first and the second loading tests, and the ratio $\phi$

\begin{tabular}{|c|c|c|c|c|c|c|}
\hline \multirow[b]{2}{*}{ Item } & \multirow[b]{2}{*}{ Numbering } & \multicolumn{2}{|c|}{ Test value $(\mathrm{kN})$} & \multirow[b]{2}{*}{$\begin{array}{c}\phi= \\
(\mathrm{B}) /(\mathrm{A})\end{array}$} & \multirow{2}{*}{$\begin{array}{c}\mu_{\phi} \\
\text { Mean } \\
\text { value }\end{array}$} & \multirow{2}{*}{$\begin{array}{c}\sigma_{\phi} \\
\text { Standard } \\
\text { deviation }\end{array}$} \\
\hline & & $\begin{array}{l}\text { First load- } \\
\text { bearing } \\
\text { capacity (A) }\end{array}$ & $\begin{array}{l}\text { Second load- } \\
\text { bearing } \\
\text { capacity (B) }\end{array}$ & & & \\
\hline 1 & BN2D-A & 108.80 & 96.38 & 0.886 & \multirow{6}{*}{0.791} & \multirow{6}{*}{0.071} \\
\hline 2 & BN2D-B & 105.97 & 90.90 & 0.858 & & \\
\hline 3 & Uj65D-A & 111.79 & 79.34 & 0.710 & & \\
\hline 4 & Uj65D-B & 108.02 & 83.03 & 0.769 & & \\
\hline 5 & Uj65J65D-A & 81.35 & 65.38 & 0.804 & & \\
\hline 6 & Uj65J65D-B & 75.01 & 54.21 & 0.723 & & \\
\hline
\end{tabular}

Subtracting one standard deviation from the mean value of the strength reduction factor of the scaffolding system installed by reused scaffolds, $\phi$ gives $0.72\left(\phi=\mu_{\phi}-\sigma_{\phi}=0.79-0.07\right)$; similarly, subtracting two standard deviations from that, $\phi$ gives $0.65\left(\phi=\mu_{\phi}-2 \sigma_{\phi}=0.79-2 \times 0.07\right)$; subtracting three standard deviations from that, $\phi$ gives $0.58\left(\phi=\mu_{\phi}-3 \sigma_{\phi}=0.79-3 \times 0.07\right)$. Based on the on-site safety requirements, any of the above three strength reduction factors $(\phi)$ can be multiplied by the load-bearing capacity of the scaffolding system installed by new scaffolds to obtain the lower bound of the load-bearing capacity of the door-type reused steel scaffolds. This can serve as a reference for the strength design of the scaffolding system.

\subsubsection{The combined system of scaffolds with wooden shore}

Table 5 shows the critical loads of the combined system of scaffolds with wooden shores in the first and second loading tests, as well as the ratio $(\phi)$ of the critical load in the second loading test to that in the first loading test. This ratio $(\phi)$ can be considered as the strength reduction factor of the combined system of scaffolds with wooden shores installed by reused scaffolds. As shown in Table 5 , the mean value $\left(\mu_{\phi}\right)$ of the strength reduction factor of the combined system of scaffolds with wooden shores $(\phi)$ is around 0.73 and the standard deviation $\left(\sigma_{\phi}\right)$ is around 0.16 .

Subtracting one standard deviation from the mean value of the strength reduction factor of the combined system of scaffolds with wooden shores installed by reused scaffolds, $\phi$ gives $0.57\left(\phi=\mu_{\phi}-\sigma_{\phi}=0.73-0.16\right)$; subtracting two standard deviations from that, $\phi$ gives $0.41\left(\phi=\mu_{\phi}-2 \sigma_{\phi}=0.73\right.$ $-2 \times 0.16)$; subtracting three standard deviations from that, $\phi$ gives 0.25 ( $\phi=\mu_{\phi}$ $-3 \sigma_{\phi}=0.73-3 \times 0.16$ ). To satisfy the on-site safety requirements, any of the above three strength reduction factors $(\phi)$ can serve as a reference for the strength design of the combined system of scaffolds with wooden shores.

\section{Table 5}

Critical load of various combined systems of scaffolds with wooden shores in the first and the second loading tests, and the ratio $\phi$

\begin{tabular}{|c|c|c|c|c|c|c|c|}
\hline \multirow[b]{2}{*}{ Item } & \multirow[b]{2}{*}{ Type } & \multirow[b]{2}{*}{ Numbering } & \multicolumn{2}{|c|}{ Test value $(\mathrm{kN})$} & \multirow[b]{2}{*}{$\begin{array}{c}\phi= \\
(\mathrm{B}) /(\mathrm{A})\end{array}$} & \multirow[b]{2}{*}{$\begin{array}{c}\mu_{\phi} \\
\text { Mean } \\
\text { value }\end{array}$} & \multirow[b]{2}{*}{$\begin{array}{c}\sigma_{\phi} \\
\text { Standard } \\
\text { deviation }\end{array}$} \\
\hline & & & $\begin{array}{c}\text { First } \\
\text { load- } \\
\text { bearing } \\
\text { capacity } \\
\text { (A) }\end{array}$ & $\begin{array}{l}\text { Second } \\
\text { load- } \\
\text { bearing } \\
\text { capacity } \\
\text { (B) }\end{array}$ & & & \\
\hline 1 & \multirow{2}{*}{$\alpha=1$} & NWSB2D1-A & 47.76 & 36.32 & 0.760 & \multirow{17}{*}{0.727} & \multirow{17}{*}{0.159} \\
\hline 2 & & NWSB2D1-B & 45.04 & 33.01 & 0.733 & & \\
\hline 3 & \multirow{2}{*}{$\begin{array}{c}\alpha= \\
0.382\end{array}$} & NWSB2D0.38-A & 47.67 & 32.98 & 0.692 & & \\
\hline 4 & & NWSB2D0.38-B & 49.631 & 29.773 & 0.600 & & \\
\hline 5 & \multirow{3}{*}{$\alpha=1$} & WSDUIY1-A & 30.303 & 30.508 & 1.007 & & \\
\hline 6 & & WSDUIY1-B & 42.129 & 40.08 & 0.951 & & \\
\hline 7 & & WSDUIY1-C & 30.773 & 27.478 & 0.893 & & \\
\hline 8 & \multirow{2}{*}{$\alpha=0.32$} & WSDUIY0.32-A & 81.150 & 59.997 & 0.739 & & \\
\hline 9 & & WSDUIY0.32-B & 90.231 & 29.459 & 0.326 & & \\
\hline 10 & \multirow{2}{*}{$\alpha=1$} & WSDUIX1-A & 45.130 & 36.000 & 0.798 & & \\
\hline 11 & & WSDUIX1-B & 41.463 & 36.491 & 0.880 & & \\
\hline 12 & \multirow{3}{*}{$\begin{array}{l}\alpha=0.5 \\
\beta=0.15\end{array}$} & WSDUGIJY-A & 41.865 & 23.654 & 0.565 & & \\
\hline 13 & & WSDUGIJY-B & 37.373 & 25.233 & 0.675 & & \\
\hline 14 & & WSDUGIJY-C & 32.98 & 21.124 & 0.641 & & \\
\hline 15 & \multirow{3}{*}{$\begin{array}{l}\alpha=0.7 \\
\beta=0.15\end{array}$} & WSDUGIJX-A & 50.249 & 34.637 & 0.689 & & \\
\hline 16 & & WSDUGIJX-B & 45.101 & 31.97 & 0.709 & & \\
\hline 17 & & WSDUGIJX-C & 47.778 & 33.558 & 0.702 & & \\
\hline
\end{tabular}




\section{Conclusions}

This study investigates the stability behavior of various scaffolding systems, including an inclined ceiling slab, adjustable U-head jacks, base jacks of different lengths, and an elevation difference on the ground surface. The loading tests and the second-order elastic analyses with semi-rigid joints are conducted, and the major findings of this study are summarized as follows:

1. When the adjustable U-head jacks are extended to $65 \mathrm{~cm}$, the load-bearing capacity of the entire scaffolding system is not changed obviously. When both the adjustable U-head jacks and adjustable base jacks are extended to $65 \mathrm{~cm}$, the load-bearing capacity of the scaffolding system is around $70 \%$ of that of the scaffolding system with a basic configuration. The loadbearing capacity of the scaffolding system with wooden shores of the same length, as an extension of the above adjustable U-head jacks, is around $40 \%$ of that of the scaffolding system with the adjustable U-head jacks extended to $65 \mathrm{~cm}$. Therefore, if the height of the scaffolding system needs to be extended by less than $65 \mathrm{~cm}$ on construction sites, it is advisable to consider extending adjustable U-head jacks to meet the purpose. Nevertheless, it is required to confirm the limit of extended adjustable Uhead jacks and base jacks in the following studies.

2. If wooden shores are used to adjust the height of the combined system of scaffolds with wooden shores under an inclined ceiling slab, the load-bearing capacity of the combined system under the inclined ceiling slab in the out-of-plane direction is greater than that of the same combined system under the inclined ceiling slab in the in-plane direction. Therefore, in the case of a combined system of scaffolds with wooden shores to be set up under an inclined ceiling slab, it is suggested that the system is set up in the out-of-plane direction of the scaffold.

3. Based on the loading test results for different configurations of scaffolding systems, similar analysis results can be obtained, provided that the appropriate stiffness values of various joints are appropriately selected in the "second-order elastic analysis with semi-rigid joints".

4. Based on the results of the loading tests on various scaffolding systems, the lower bound of load-bearing capacity of various systems installed by reused scaffolds can be obtained. By calculating the mean value and standard deviation of these lower bound values, the strength reduction factor $(\phi)$ of various systems installed by reused scaffolds can be obtained as well. For the strength reduction factor of the scaffolding system installed by reused scaffolds, it is suggested that the strength reduction factor $\phi_{(\mu-\sigma)}$ is $0.72, \phi_{(\mu-2 \sigma)}$ is 0.65 , and $\phi_{(\mu-3 \sigma)}$ is 0.58 . For the strength reduction factor of the combined system of scaffolds with wooden shores installed by reused scaffolds, it is suggested that the strength reduction factor $\phi_{(\mu-\sigma)}$ is $0.57, \phi_{(\mu-2 \sigma)}$ is 0.41 , and $\phi_{(\mu-3 \sigma)}$ is 0.25 . Depending on the on-site safety requirements, constructors can adopt an appropriate strength reduction factor $(\phi)$ to calculate the lower bound of the load-bearing capacity of different systems installed by reused scaffolds, which may serve as a reference for the strength design of reused scaffolds.

\section{Acknowledgements}

The funds for this study are provided by the Ministry of Science and Technology (MOST 109-2221-E-224-011), the National Natural Science Foundation (Grant No. U1602232), the Fundamental Research Funds for the Central Universities (Grant No. N170108029), and the Liaoning Science and Technology Project (2019JH2/10100035). The tests were completed with the assistance of Mr. Wei-Liang Lai. We would like to thank all of them.

\section{References}

[1] Yu, W.K. and Chung K.F., "Prediction on Load Carrying Capacities of Multi-storey Doortype Modular Steel Scaffolds", Steel and Composite Structures, 4, 6, 471-487, 2004a.

[2] Yu, W.K., Chung, K.F. and Chan, S.L., "Structural Instability of Multi-storey Door-type Modular Steel Scaffolds," Engineering Structures, 26, 867-881, 2004b.

[3] Pieńko, M. and Błazik-Borowa, E., "Numerical Analysis of Load-bearing Capacity of Modular Scaffolding Nodes," Engineering Structures, 48, 1-9, 2013.

[4] Jia, L., Liu, H., Chen, Z., Liu, Q. and Wen, S., "Mechanical Properties of Right-Angle Couplers in Steel Tube-Coupler Scaffolds," Journal of Constructional Steel Research, 125, 43-60, 2016.

[5] Zhao, Z. and Chen, Z., "Analysis of Door-Type Modular Steel Scaffolds Based on A Novel Numerical Method," Advanced Steel Construction, 12, 316-327, 2016.

[6] Peng, J.L., Ho, C.M., Lin, C.C. and Chen, W.F., "Load-Carrying Capacity of Single-Row Steel Scaffolds with Various Setups," Advanced Steel Construction, 11, 185-210, 2015.

[7] Peng, J.L., Wang, C.S., Wu, C.W. and Chen, W.F., "Experiment and Stability Analysis on Heavy-Duty Scaffold Systems with Top Shores," Advanced Steel Construction, 13, 293-317, 2017.

[8] Liu, H., Chen, Z., Wang, X. and Zhou, T., "Theoretical Analysis and Experimental Research on Stability Behavior of Structural Steel Tube and Coupler Falsework with X-Bracing," Advanced Steel Construction, 6, 949-962, 2010.

[9] Sevim, B., Bekiroglu, S. and Arslan, G., "Experimental Evaluation of Tie Bar Effects on Structural Behavior of Suspended Scaffolding Systems," Advanced Steel Construction, 13,
$62-77,2017$

[10] Zhang, H., Chandrangsu, T. and Rasmussen, K.J.R., "Probabilistic study of the strength of steel scaffold systems," Structural Safety, 32, 393-401, 2010.

[11] Zhang, H., Rasmussen, K.J.R. and Ellingwood, B.R., "Reliability assessment of steel scaffold shoring structure for concrete formwork," Engineering Structures, 36, 81-89, 2012.

[12] Chan, S.L. and Cho, S.H., "Second-order P- $\Delta-\delta$ Analysis and Design of Angle Trusses Allowing for Imperfections and Semi-Rigid Connections," Advanced Steel Construction, 1, 157-172, 2005.

[13] Chan, S.L., Zhou, Z.H., Chen, W.F., Peng, J.L. and Pan, A.D., "Stability Analysis of Semirigid Steel Scaffolding," Engineering Structures, 17, 568-574, 1995.

[14] Liu, S.W., Chan, J.L.Y., Bai, R. and Chan, S.L., "Curved-quartic-function Elements with End-springs in Series for Direct Analysis of Steel Frames," Steel and Composite Structures, 29, 623-633, 2018a.

[15] Liu, S.W., Ziemianc, R.D., Chen, L., Chan, S.L., "Bifurcation and large-deflection analyses of thin-walled beam-columns with non-symmetric open-sections," Thin-Walled Struct. 132, 287-301, 2018b 


\title{
ENHANCING COLLAPSE-RESISTANCE OF STEEL FRAME JOINTS BASED ON FOLDED AXILLARY PLATES
}

\author{
Bao Meng ${ }^{1,2}$, Liang-De Li ${ }^{1}$, Wei-Hui Zhong ${ }^{1,}{ }^{*}$, Ji-Ping Hao ${ }^{1}$ and Zheng Tan ${ }^{1}$ \\ ${ }^{1}$ School of Civil Engineering, Xi'an University of Architecture \& Technology, Xi'an 710055, China \\ ${ }^{2}$ Key Lab of Structural Engineering and Earthquake Resistance, Ministry of Education (XAUAT), Xi' an 710055, China \\ *(Corresponding author: E-mail: zhongweihui1980@163.com)
}

\section{A B S T RA C T}

To address the limited anti-collapse ability of traditional rigid connections under progressive collapse, this study improves upon the traditional fully welded connection based on folded axillary plates. These folded axillary plates were arranged on the outer side of the beam-end flanges. The movement mechanisms of the tension and compression folded axillary plates under progressive collapse were revealed based on theoretical analysis. Using the validated numerical model, the performance against progressive collapse and key parameters of the improved connection were discussed in detail. No significant effects were observed on the stress of the structure, given the small deformation, and the ultimate deformation and resistance of the steel structure could be significantly improved in later stages. Subsequently, the catenary mechanism in the beam was fully developed, and the beam member was fully utilized. The failure sequence of the substructure with folded axillary plates first involved the folded axillary plate on the tension side gradually straightening, followed by the two plastic regions forming at the beam flange. Afterward, either the tension beam flange at the beam root and the folded axillary plate broke successively or the tension beam flange broke at the point where the plastic hinge moved outward. Additionally, the anti-progressive collapse design process for the folded axillary plate and the design parameters were suggested following theoretical and numerical analyses.

\section{ART I C LE H IS TORY}

\begin{tabular}{|c|c|}
\hline Received: & 9 June 2020 \\
\hline Revised: & 30 November 2020 \\
\hline Accepted: & 2 December 2020 \\
\hline
\end{tabular}

\section{K E Y W O R D S}

\section{Steel frame;}

Folded axillary plate;

Rigid connection;

Collapse-resistance

Numerical analysis;

\section{Introduction}

Progressive collapse of structures caused by accidents can often lead to a painful teaching for structural engineers and is thus widely studied. How to effectively improve the collapse resistance and ensure the overall stability of the structure under accidental load has become a research focus in the field of structural engineering. According to their different understanding of the progressive collapse of structures, Britain [1], Europe [2], the United States [3,4], Japan [5], and other countries, proposed their own unique design codes and standards for the anti-progressive collapse of structures. The structural design methods for preventing progressive collapse mainly include the conceptual design, tie force, local resistance, and alternative load path methods. Among them, the conceptual design method has been sufficiently studied in the national standards and design guidelines, mainly through a reasonable layout of the structure, strengthening the connection, and using ductile materials to enhance the anti-collapse ability of the structure.

At present, considerable progress has been made in research concerning the enhancement of the anti-collapse ability of frame structures based on the conceptual design method. There are generally three methods whereby this enhancement can be achieved. The first method is to enhance the ultimate resistance of the structure, without significantly changing the ultimate deformation of the structure. Yu and Tan [6] used special detailed techniques at little or no additional cost to improve the structural resistance to resist progressive collapse. Wang and Qin [7] made improvements to the diaphragm connection, which could enhance the structural resistance. Meng et al. [8] proposed adding triangular plates at the beam-column connections to increase the combined action between the upper and lower stories, thereby improving the structural resistance. The second method is to improve the ultimate deformation of the structure, without significantly changing the ultimate bearing capacity. Vasdravellis et al. [9] proposed a seismically designed steel selfcentering moment frame against progressive collapse, which could exhibit greater ductility upon incorporation and usage of energy dissipation devices. Wei et al. [10] developed a modified steel frame structure with a corrugated steel plate to increase its ductility. Qiang et al. [11] improved the ductility of reinforced concrete (RC) frame structures by adding kinked rebar configurations. The third method is to simultaneously enhance the ultimate deformation and bearing capacity of the structure. Qiu et al. [12] proposed a retrofit way to enhance the anti-collapse ability of RC frame by installing steel cables between columns. Gao et al. [13] proposed a type of reinforced composite semi-rigid joint that could increase the ultimate deformation and bearing capacity of the structure. Lu et al. [14] proposed a seismic and antiprogressive collapse, composite frame structural system, which had a larger collapse resistance compared to traditional composite frames. Meng et al. [15] proposed a novel RBS connection with "V" shape structural plates, which exhibited good anti-collapse capacity. When the cost of the structure is not significantly increased, simultaneously increasing the ultimate deformation and bearing capacity of the structure against progressive collapse is more economical and efficient to ensure a more robust structure.

According to an experimental study by Lew et al. [16], Li [17], and Meng et al. [18], it has been shown that the collapse resistance of full welded connections and welded unreinforced flange-bolted web connections is poor under the condition of progressive collapse. The brittle fracture of the joint is caused by the crack of the weld and beam-end flange, as shown in Fig. 1. The premature fracture of the beam-end flange restrains the development of the beam axial force and the catenary mechanism of the structure cannot be fully exerted, resulting in the beam not being fully utilized under large deformations. Therefore, to meet the large deformation demand of steel frame structures with traditional rigid connection, it is necessary to improve the traditional rigid joint under the accidental load.

Regarding the limited anti-collapse ability of traditional rigid connections under the condition of progressive collapse, this study improves traditional fullwelded connections by adding folded axillary plates at the beam end. The stress of the structure was not significantly affected for small deformations and the ultimate deformation and corresponding bearing capacity of the frame structure could be considerably improved during later stages. Finally, the catenary mechanism in the beam was fully developed and the beam member was fully utilized. Based on a theoretical analysis, the movement mechanisms of the folded axillary plate were revealed. The anti-collapse performance of the improved connection was analyzed following the verification of the nonlinear numerical model. Additionally, the anti-progressive collapse design process for the folded axillary plate and the design parameters were suggested following theoretical and numerical analyses. 


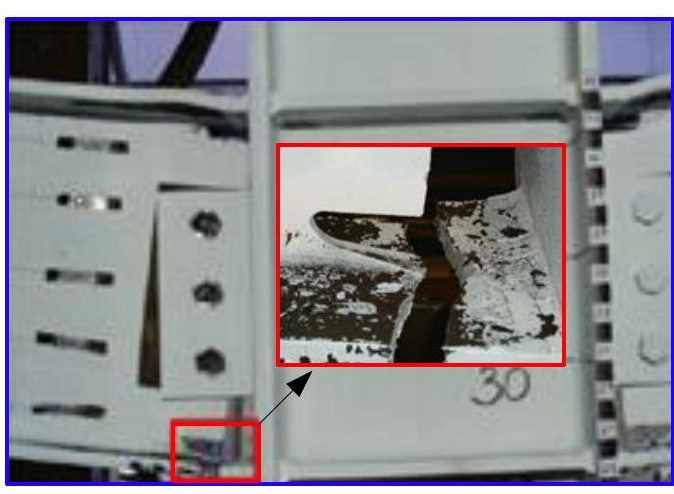

(a)Lew et al.'s test [16]

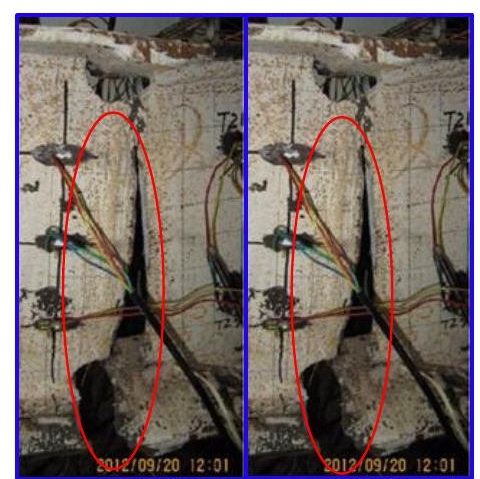

(b) Li 's test [17]

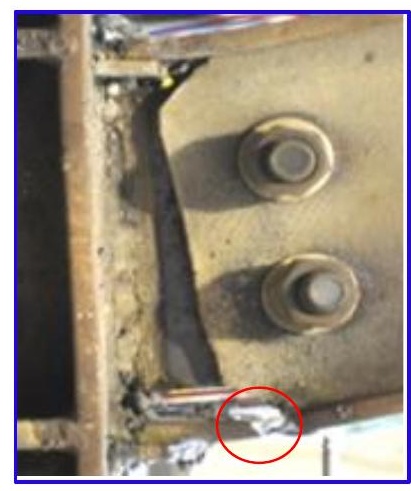

(c) Meng et al.'s test [18]

Fig. 1 Damage mode of traditional rigid joint

\section{Methodology}

\subsection{Improved rigid connection model}

According to the alternate load path method ( ALPM), the double-span beam-column substructure is often adopted to analyze the ability of the substructure against progressive collapse, after the failure of a column because of the relatively simple and clear stress [19-23], as shown in Fig. 2(a). Generally, the resistance development curve of a substructure includes the flexure stage, flexure-catenary mixed stage, and catenary stage. The deformation of the joint will move from elastic to plastic deformation, even for large deformations. The joint mainly bears the combined action of the axial force and bending moment, which develop disproportionately until the joint fails. Under an internal columnremoval scenario, the traditional rigid connection (such as full-welded connections, welded unreinforced flange-bolted web connections, etc.) loses its deformation and bearing capacity early because of the stress concentration at the beam root or the weld (as shown in Fig. 2 (b)), which leads to local failure of the structure. In seismic design, to prevent brittle damage of the full welded connection, the plastic hinge at the beam root is moved outward via the addition of an axillary plate at the beam-column connection, which can increase the ductility of the joint to a certain extent. However, under an internal columnremoval scenario, the rigid connection with axillary plates, subjected to the combined action of the axial force and bending moment, will cause premature cracking at the location where the plastic hinge moves out (as shown in Fig. 2 (c)). The catenary mechanism of the structure is not well developed, which limits the rotational capability of the joint. Hence, it is necessary to improve the anti-collapse ability of this kind of full-welded connection and a full-welded connection with axillary plates.

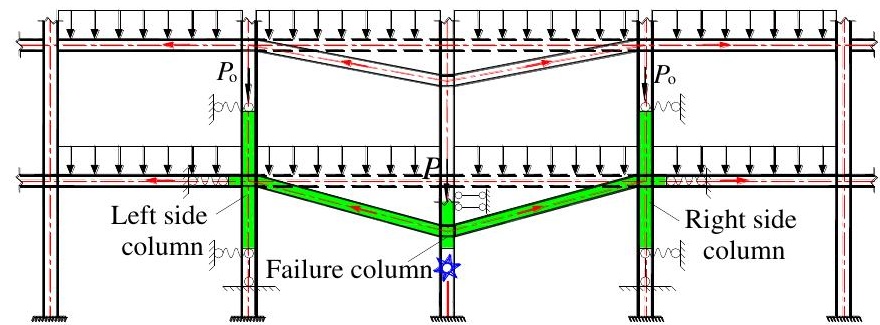

(a) Double-full-span subassembly

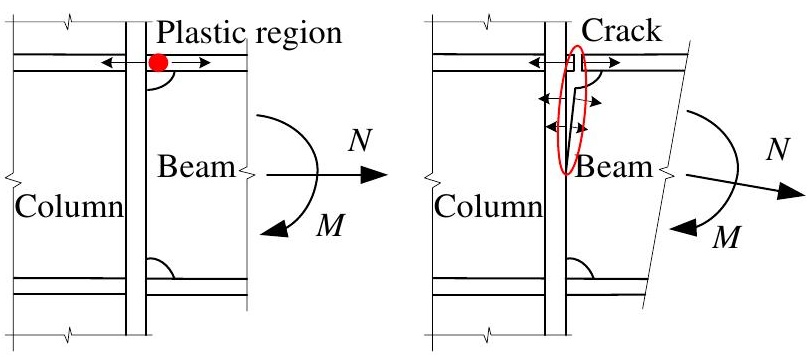

(b) Full welded connection
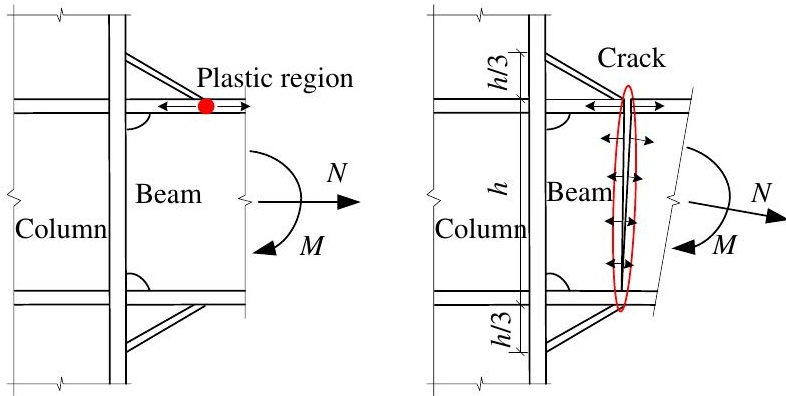

(c) Full-welded connection with axillary plates

Fig. 2 Failure modes of traditional joints

In this study, folded axillary plates are added the outer side of the beam-end flanges in an attempt to overcome the above shortcomings of traditional rigid connections, as shown in Fig. 3. The long and short legs of the folded axillary plate are connected to the beam and column flange, respectively, via slot welding to ensure a reliable connection. The aim of increasing the folded axillary plates is to enhance the ultimate deformation and bearing capacity of the structure against progressive collapse; thus avoiding premature brittle cracking at the beam end.

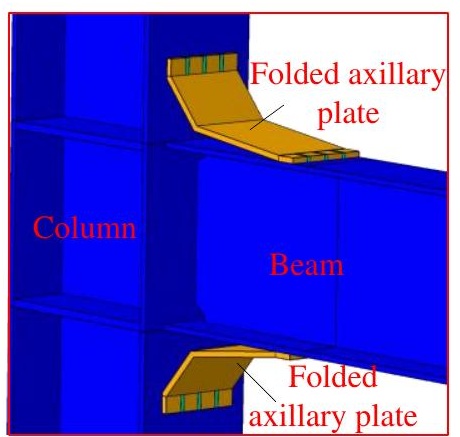

(a) 3D diagram

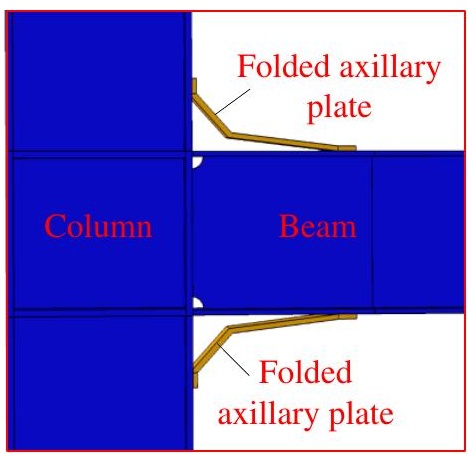

(b) Elevation 


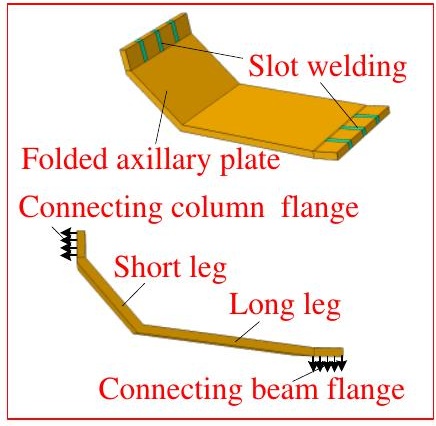

(c) Folded axillary plate

Fig. 3 Improved full-welded connection

\subsection{Working principle of substructure with folded axillary plates}

\subsubsection{Collapse-resistance target of substructure with folded axillary plates}

Generally, the resistance process of the beam-column substructure with full-welded connections, following the failure of the internal column, primarily involved the elastic stage $(\mathrm{OA})$ and the flexure-catenary mixed stage $(\mathrm{AB})$, as shown in the "TWC" curve in Fig. 4. At point B, the bearing capacity of the substructure was lost owing to the premature crack of the beam end weld or beam flange. In this study, folded axillary plates are added the outer side of the beam-end flanges in an attempt to make the deformation and resistance of the structure continue to develop on the basis of the original curve, ultimately resulting in the formation of the collapse resistance improved stage (BC), as shown in the "IWC" curve in Fig. 4. When the tension beam-end flange breaks, the substructure will not lose its bearing capacity immediately. At this time, the internal forces in the beam flange are transmitted by the folded axillary plates and the resistance of the substructure continues to grow until the folded axillary plate cracks. It should be noted that the formation of the "IWC" curve is closely related to the geometric parameters and mechanical properties of the folded axillary plate, which are analyzed and discussed in detail in Sections 4 and 5 of this paper.

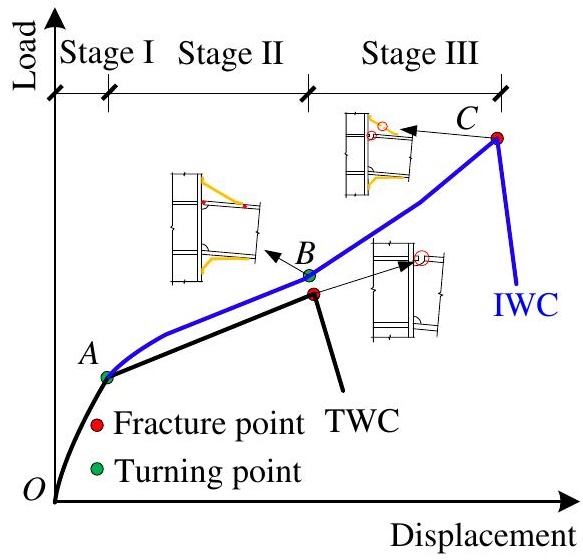

Fig. 4 Resistance curve

\subsubsection{Expected failure mode of substructure with folded axillary plates}

To achieve the collapse resistance improved target of the "IWC" curve in Fig. 4, the failure sequence of the substructure with folded axillary plates is expected to occur as follows. In the initial stage, the axial force of the joint is small and the folded axillary plate does not participate in the stress of the substructure. At the end of this stage (point A in Fig. 4), a plastic region appears in the flange at the beam root and the deformation of the joint is shown in Fig. 5 (a). Then, the substructure enters the flexure-catenary mixed stage and the axial force of the joint increases rapidly. At this time, the tension and compression folded axillary plates start to work, forming a certain bending moment to resist the external load. At the end of this stage (point B in Fig. 4), the folded axillary plate at the tension side is straightened and two plastic regions are developed at the beam-end flanges, as shown in Fig. 5 (b). With the increase in joint deformation, the substructure enters the collapse resistance improved stage. Two failure modes may occur owing to the different degrees of plastic development of the beam root and the location where the plastic hinge moves out, as shown in Fig. 5 (c). For failure mode I, the tension beam flange at the beam root cracks and then extends to the beam web. The folded axillary plate in tension gradually appears in the plastic zone and then begins to shrink or even break. For failure mode II, the tension beam flange breaks at the place where the plastic hinge moves out and then extends to the beam web. The folded axillary plate in compression is squeezed and its long leg gradually moves closer to the beam flange, as shown in Fig. 5 (c).

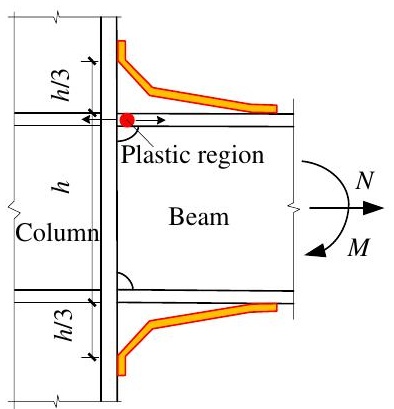

(a) Elastic stage

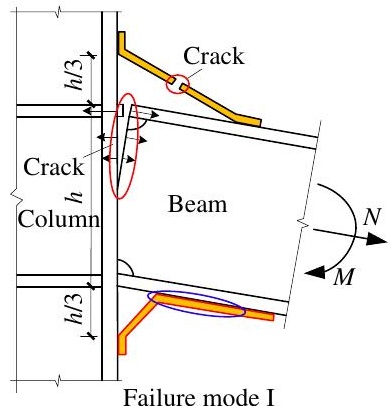

(c) Collapse-resistance improved stage

\subsubsection{Working mechanism of folded axillary plate}

The deformation of the folded axillary plate in the initial state is shown in Fig. 6 (a), and its shape is determined by parameters $a, b, l_{1}$, and $l_{2}$. For the fullwelded connection with axillary plates, to reduce the clearance requirements at the connection, FEMA-267 recommended parameter $a$ as $1 / 3 h$ and parameter $b$ as $0.5-0.6 h$ ( $h$ is the beam height) [24]. In this study, the parameter $a$ is assumed to be $1 / 3 h$ for the connection with the folded axillary plate. Parameter $b$ will affect the position of the plastic hinge moving out, and the elongation deformation of the folded axillary plate, as discussed in Section 5.4. If parameters $a$ and $b$ are selected and the lengths of $l_{1}$ and $l_{2}$ are determined, the shape of the folded axillary plate can be determined.

In the case of the beam-column substructure without the folded axillary plates, when the tension beam flange was broken, the beam-end rotation was defined as $\varphi_{0}$ in this study, which can be calculated according to Eq. (1). This could be determined according to existing tests and finite element analysis (FEA). In reference [17], it was suggested that when the tension beam flange of the substructure with full welded connections and welded unreinforced flangebolted web connections broke, the beam-end rotation $\varphi_{0}$ could be assumed to be $0.08-1.10 \mathrm{rad}$. For the substructure with the folded axillary plates, the beamend rotation is $\varphi$, as shown in Fig. 6 (b). To avoid the loss of resistance of the substructure with the folded axillary plates, owing to the crack of the tension beam-end flange, $\varphi=\varphi_{0}$ is assumed, the folded axillary plate is straightened and it starts to work in the stress of the developed substructure. The value of $\varphi_{0}$ is critical for determining the lengths of the short and long legs of the folded axillary plate. Therefore, the value of $\varphi_{0}$ should be determined before $l_{1}$ and $l_{2}$ are selected.

$\varphi_{0}=\arctan \frac{\delta}{L}$

where $\delta$ is the displacement of the middle column in the substructure without the axillary plates and $L$ is the beam length.

In the case of the folded axillary plate at the tension side, its short leg moves around the fixed point $M$ from point $A$ to $C$, and its long leg moves around the 
fixed point $O$ from point $B$ to $D$, as shown in Fig. 6 (b). According to the kinematic geometry relationship of the folded axillary plate at the tension side, the relationship equation between the design parameters $l_{1}$ and $l_{2}$ and the given parameters $a, b$, and $\varphi$ can be derived. The details are as follows:

The length of MD in triangle OMD can be determined based on the cosine theorem of triangles, as shown in Eq. (2).

$l_{\mathrm{MD}}^{2}=a^{2}+b^{2}-2 a b \cos \left(\varphi_{0}+90^{\circ}\right)=a^{2}+b^{2}+2 a b \sin \varphi_{0}$

Based on the cosine theorem of triangles, the length of BD in triangle OBD can be obtained, as shown in Eq. (3).

$l_{\mathrm{BD}}=\sqrt{2} b \sqrt{1-\cos \varphi_{0}}$

The angle MBD of triangle MBD can be obtained via the cosine theorem of triangles, following which Eqs. (2) and (3) are substituted into Eq. (4).

$$
\begin{aligned}
& \angle M B D=\arccos \frac{l_{\mathrm{MB}}^{2}+l_{\mathrm{BD}}^{2}-l_{\mathrm{MD}}^{2}}{2 l_{\mathrm{MB}} \cdot l_{\mathrm{BD}}} \\
& =\arccos \frac{b-b \cos \varphi_{0}-a \sin \varphi_{0}}{\sqrt{2} \sqrt{a^{2}+b^{2}} \sqrt{1-\cos \varphi_{0}}}
\end{aligned}
$$

In triangle $\mathrm{ABD}$, the length of $\mathrm{AD}$ can be obtained based on the cosine theorem of triangles, as shown in Eq. (5).

$l_{\mathrm{AD}}^{2}=l_{\mathrm{AB}}^{2}+l_{\mathrm{BD}}^{2}-2 l_{\mathrm{AB}} \cdot l_{\mathrm{BD}} \cos \angle A B D$

$=l_{\mathrm{AB}}^{2}+l_{\mathrm{BD}}^{2}-2 l_{\mathrm{AB}} \cdot l_{\mathrm{BD}} \cos \left(\angle M B D-\theta_{2}\right)$

Similarly, in triangle BMD, the angle BMD can be obtained via the cosine theorem of triangles, following which Eqs. (2) and (3) are substituted into Eq. (6). In triangle DMA, the length of $\mathrm{AD}$ can be obtained via the cosine theorem of triangles, as shown in Eq. (7).

$$
\begin{aligned}
& \angle B M D=\arccos \frac{l_{\mathrm{MB}}^{2}+l_{\mathrm{MD}}^{2}-l_{\mathrm{BD}}^{2}}{2 l_{\mathrm{MB}} \cdot l_{\mathrm{MD}}} \\
& =\arccos \frac{a^{2}+a b \sin \varphi_{0}+b^{2} \cos \varphi_{0}}{\sqrt{a^{2}+b^{2}} \sqrt{a^{2}+b^{2}+2 a b \sin \varphi_{0}}}
\end{aligned}
$$

$l_{\mathrm{AD}}^{2}=l_{\mathrm{MD}}^{2}+l_{\mathrm{MA}}^{2}-2 l_{\mathrm{MD}} \cdot l_{\mathrm{MA}} \cos D M A$

$=l_{\mathrm{MD}}^{2}+l_{\mathrm{MA}}^{2}-2 l_{\mathrm{MD}} \cdot l_{\mathrm{MA}} \cos \left(\theta_{1}-\angle B M D\right)$

By combining Eqs. (5) and (7), the functional equation of parameters $l_{1}$ and $l_{2}$ with respect to $a, b$, and $\varphi_{0}$ can be obtained; that is, the values of parameters $l_{1}$ and $l_{2}$ satisfy Eq. (8).

$F\left(l_{1}, l_{2}\right)=g\left(a, b, \varphi_{0}\right)$

$=l_{1}^{2}-l_{2}^{2}+a^{2}-b^{2}+2 a b \sin \varphi_{0}+2 b^{2} \cos \varphi_{0}$

$+2 \sqrt{2} l_{2} b \sqrt{1-\cos \varphi_{0}} \cos \angle A B D$

$-2 l_{1} \sqrt{a^{2}+b^{2}+2 a b \sin \varphi_{0}} \cos \angle D M A=0$

where,

$$
\angle A B D=\arccos \frac{b-b \cos \varphi_{0}-a \sin \varphi_{0}}{\sqrt{2} \sqrt{a^{2}+b^{2}} \sqrt{1-\cos \varphi_{0}}},
$$

$$
-\arccos \frac{l_{2}^{2}+a^{2}+b^{2}-l_{1}^{2}}{2 l_{2} \sqrt{a^{2}+b^{2}}}
$$

$\angle D M A=\arccos \frac{l_{1}^{2}+a^{2}+b^{2}-l_{2}^{2}}{2 l_{1} \sqrt{a^{2}+b^{2}}}$

$-\arccos \frac{a^{2}+a b \sin \varphi_{0}+b^{2} \cos \varphi_{0}}{\sqrt{a^{2}+b^{2}} \sqrt{a^{2}+b^{2}+2 a b \sin \varphi_{0}}}$
The short leg of the folded axillary plate on the compression side moves around the fixed point $N$ from point $E$ to $G$ and its long leg moves around the fixed point $O$ ' from point $F$ to $H$, as shown in Fig. 6(b). If the values of the initial design parameters $l_{1}$ and $l_{2}$ are unreasonable, point $G$ will cross O'F and $\mathrm{O}^{\prime} \mathrm{H}$, which is not in line with the actual situation. To avoid this situation, the distance from point $G$ to O'F in the initial stage should be greater than 0 , so that Eq. (9) is satisfied. At the same time, when the beam-end rotation is $\varphi_{0}$, the distance DG from point $G$ to O'H should be greater than 0 . If the angle O'NG $=\beta$, the coordinates of points $G$ and $H$ are $\left(l_{1} \sin \beta,-a+l_{1} \cos \beta\right)$ and $\left(b \cos \varphi_{0}\right.$, $\left.b \sin \varphi_{0}\right)$, respectively. The distance from point $G$ to O'H is DG, as shown in Eq (10). Then, Eq. (11) can be obtained by simplifying Eq. (10).

$$
\begin{aligned}
& l_{1}<\frac{a}{\cos \left(\arctan (a / b)-\theta_{1}\right)} \\
& d_{\mathrm{G}}=\frac{\left|l_{1} \tan \varphi_{0} \sin \beta-a+l_{1} \cos \beta\right|}{\sqrt{1+\tan ^{2} \varphi_{0}}}>0
\end{aligned}
$$

$$
l_{1}<\frac{a}{\tan \varphi_{0} \sin \beta+\cos \beta}
$$

$\beta$ needs to be solved in Eq. (11), which can be obtained from Eq. (15). The specific derivation is as follows:

The length of the $\mathrm{NH}$ in the triangle $\mathrm{FNH}$ is obtained via the cosine theorem of triangles, as shown in Eq. (12).

$l_{\mathrm{NH}}^{2}=a^{2}+b^{2}-2 a b \cos \left(90^{\circ}-\varphi_{0}\right)=a^{2}+b^{2}-2 a b \sin \varphi_{0}$

Based on the cosine theorem of triangles, the angle $\mathrm{O}^{\prime} \mathrm{NH}$ in triangle $\mathrm{O}$ ' $\mathrm{NH}$ can be obtained, as shown in Eq. (13).

$$
\begin{aligned}
& \angle O^{\prime} N H=\arccos \frac{l_{\mathrm{O}^{\prime} \mathrm{N}}^{2}+l_{\mathrm{NH}}^{2}-l_{\mathrm{O}^{\prime} \mathrm{H}}^{2}}{2 l_{\mathrm{O}^{\prime} \mathrm{N}} \cdot l_{\mathrm{NH}}} \\
& =\arccos \frac{a-b \sin \varphi_{0}}{\sqrt{a^{2}+b^{2}-2 a b \sin \varphi_{0}}}
\end{aligned}
$$

In the triangular $\mathrm{NGH}$, the length of $\mathrm{GH}$ can be obtained via the cosine theorem of triangles. When the folded axillary plate is compressed, the length $l_{2}$ of the long leg is equal to the length of GH, as shown in Eq. (14).

$l_{\mathrm{GH}}^{2}=l_{\mathrm{NG}}^{2}+l_{\mathrm{NH}}^{2}-2 l_{\mathrm{NG}} \cdot l_{\mathrm{NH}} \cos \angle G N H$

$=l_{\mathrm{NG}}^{2}+l_{\mathrm{NH}}^{2}-2 l_{\mathrm{NG}} \cdot l_{\mathrm{NH}} \cos \left(\angle O^{\prime} N H-\beta\right)=l_{2}^{2}$

If Eqs. (12) and (13) are introduced into Eq. (14), the calculation formula for angle $\beta$ can be obtained, as shown in Eq. (15).

$$
\begin{gathered}
\beta=\arccos \frac{a-b \sin \varphi_{0}}{\sqrt{a^{2}+b^{2}-2 a b \sin \varphi_{0}}} \\
-\arccos \frac{l_{1}^{2}-l_{2}^{2}+a^{2}+b^{2}-2 a b \sin \varphi_{0}}{2 l_{1} \sqrt{a^{2}+b^{2}-2 a b \sin \varphi_{0}}}
\end{gathered}
$$

When the beam-column substructure with the folded axillary plates enters the collapse resistance improved stage, two failure modes may occur because of the different degrees of plastic development of the beam root and the point where the plastic hinge moves out. The anti-collapse performance of the substructure in this stage is also related to the width and thickness of the folded axillary plate, as discussed in Section 5. When the tension beam flange was broken, the force in the tension beam flange was mainly transmitted by the folded axillary plate. In this case, according to the balance relationship between the folded axillary plate and the tension beam flange, when the thickness of the folded axillary plate was determined, its width could be calculated according to Eq. (16).

$w=\frac{b b_{\mathrm{f}} t_{\mathrm{f}} f_{\mathrm{bu}}}{f_{\mathrm{u}} t \sqrt{a^{2}+b^{2}}}$ 
where $t_{\mathrm{f}}$ is the thickness of the beam flange, $b_{\mathrm{f}}$ is the width of the beam flange, $f_{\mathrm{bu}}$ is the tensile strength of the beam flange, $f_{\mathrm{u}}$ is the tensile strength of the folded axillary plate and $t$ is the thickness of the folded axillary plate.

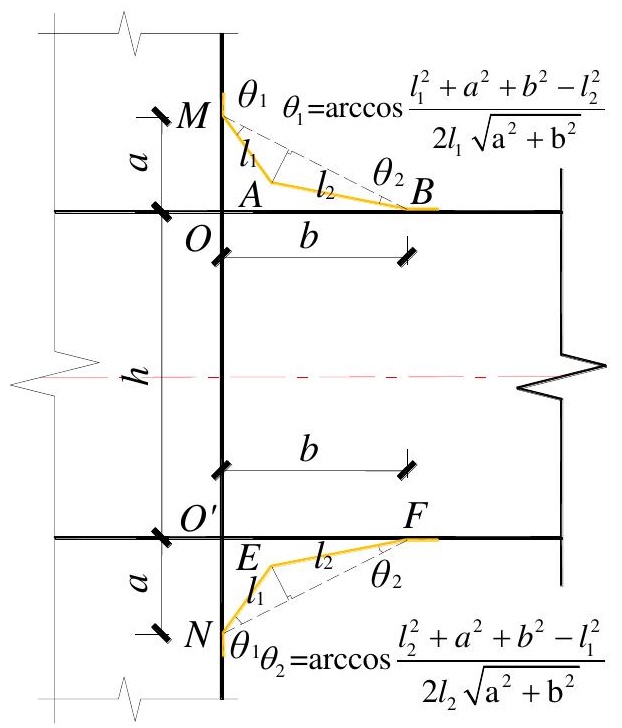

(a) Before deformation

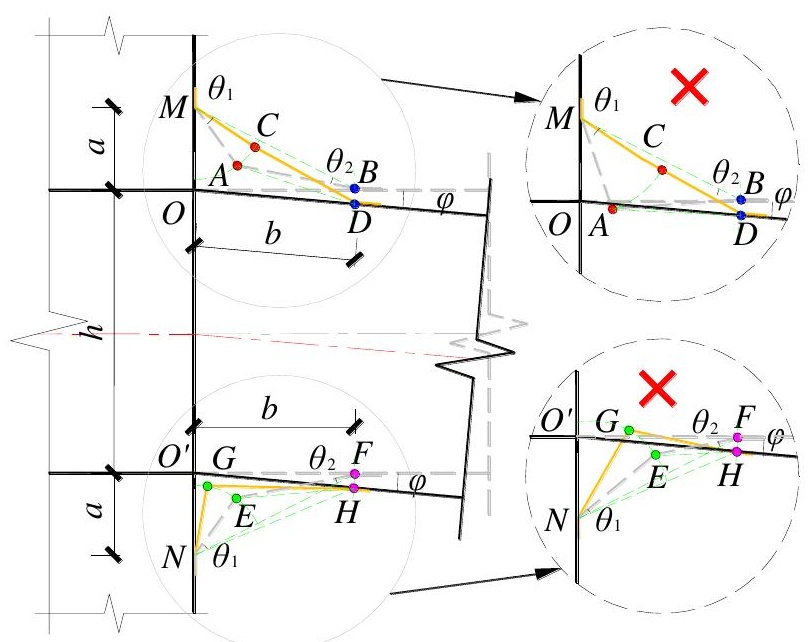

(b) After deformation

Fig. 6 Working mechanism of improved full welded connection

\subsubsection{Design process of folded axillary plate}

Reasonable design of the folded axillary plate is the key to enhance the ultimate deformation and bearing capacity of the structure with full welded connections with folded axillary plates, at the same time. The design of the folded axillary plate includes seven parameters: $\varphi_{0}, a, b, l_{1}, l_{2}, t$, and $w . \varphi_{0}$ is defined as the beam-end rotation of the substructure, without the folded axillary plate, when the tension beam flange breaks at the root of the beam. This can be determined by existing tests and FEA. In this study, parameter $a$ is recommended to be $1 / 3 h$ for the folded axillary plate. The parameter $b$ affects the position of the plastic hinge moving outward, and its value is discussed in Section 5.4. If $l_{2}$ is initially selected, $l_{1}$ can be calculated using Eq. (8) and should satisfy Eqs. (9) and (11): The thickness of the folded axillary plate is discussed in Section 5.1. Subsequently, the width of the folded axillary plate $w$ can be calculated using Eq. (16).

The design process of the folded axillary plate is as follows: (1) first, the beam-end rotation $\varphi_{0}$ of the substructure with full welded connection is determined; (2) parameters $a, b, t$, and $l_{2}$ are initially selected; (3) length $l_{1}$ of the short leg of the folded axillary plate is calculated according to Eq. (8); (4) the value of $l_{1}$ is checked to determine whether it satisfies the requirements of Eqs. (9) and (11); (5) the width of the folded axillary plate is calculated using Eq. (16) according to the thickness of the folded axillary plate selected in (2). The specific design process is shown in Fig. 7.

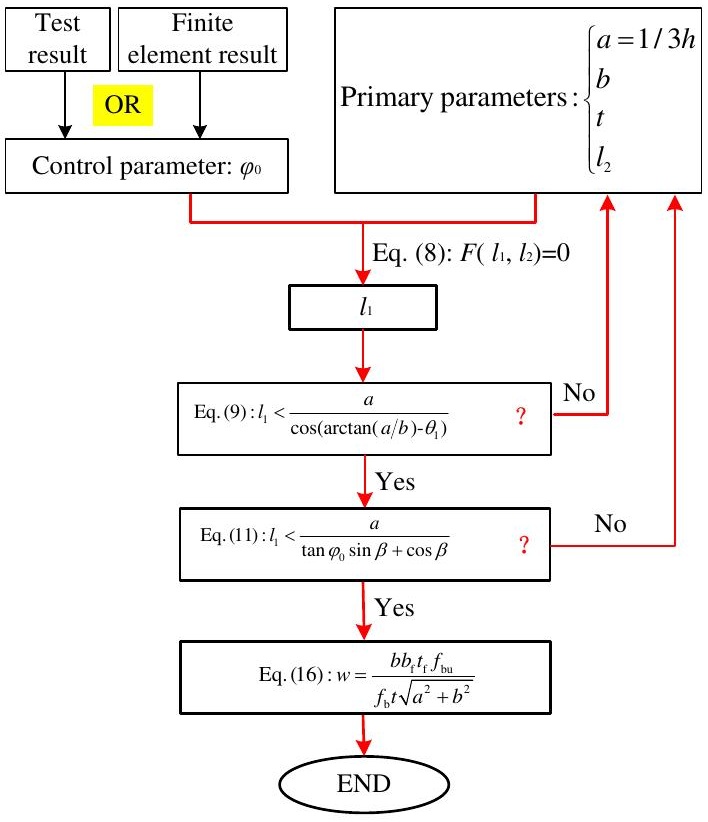

Fig. 7 Design process of folded axillary plate

\section{Verification of finite element model}

To verify the accuracy of the finite element model, the double-full-span beam-column substructure test conducted by Lew et al. [25] was selected, as shown in Fig. 8(a). The selected beam-column connection was the welded unreinforced flange-bolted web connection. According to the section and geometric dimensions of the beam and column components in the literature [25], a finite element model of the test specimen was built, as shown in Fig. 8(b). Based on the boundary conditions of the substructure in the test, the upper end of the side column was hinge-restrained, that is, $\mathrm{U} 1=\mathrm{U} 2=\mathrm{U} 3=0$ and the lower end of the side column was restrained, that is, $\mathrm{U} 1=\mathrm{U} 2=\mathrm{U} 3=\mathrm{UR} 1=\mathrm{UR} 2=\mathrm{UR} 3$ $=0$. To ensure vertical movement of the failure column, U1 and U2 at the upper and lower ends of the failure column were constrained. The beam, column, shear plate, and bolt adopted solid elements (C3D8R). The beam flanges and shear plate were connected to the column flange using the "tie" command in ABAQUS. The contact relationship between the bolt and the beam web and shear plate was set as the general contact. The Coulomb friction contact was utilized in the tangential direction and the friction coefficient was 0.3 . The normal direction was set as a hard contact. To decrease the effect of mesh sensitivity on steel fracture, a mesh of $5 \mathrm{~mm}$ in size was adopted at the shear plate, bolt, and beam end in the connection area. A $30 \mathrm{~mm}$ grid was adopted for the rest of the column and beam. The constitutive relation and fracture parameters of steel are detailed in reference [25]. The displacement-controlled loading method was adopted at the top of the failure column until the bearing capacity of the specimen was lost. The explicit dynamic quasi-static method was used to simulate the failure process of the substructure. During loading, no significant dynamic effect was introduced to maintain that the simulation process was static, i.e., the kinetic energy of the structural system during the simulation loading process was kept within $10 \%$ of its internal energy [26].

Fig. 9(a) shows a comparison between the numerical simulation data and the test results for the load-displacement curve of the model specimen designed by Sadek et al. [25]. The numerical simulation results were in good agreement with the experimental results. Owing to the limited loading range of the test, the test specimen had to be unloaded when the displacement of the middle column was approximately 475 $\mathrm{mm}$ and then loaded again. However, the numerical simulation did not unload but continued loading the specimen until failure. Fig. 9(b) shows the damage mode of the numerical simulation of the specimen, which is consistent with the test failure mode in Fig. 8(a). Both failures were due to the first fracture of the tension beam-end flange, which resulted in a sudden decrease in the resistance of the specimen. Above all, the numerical simulation method can accurately simulate the resistance of the specimen and its damage mode. 

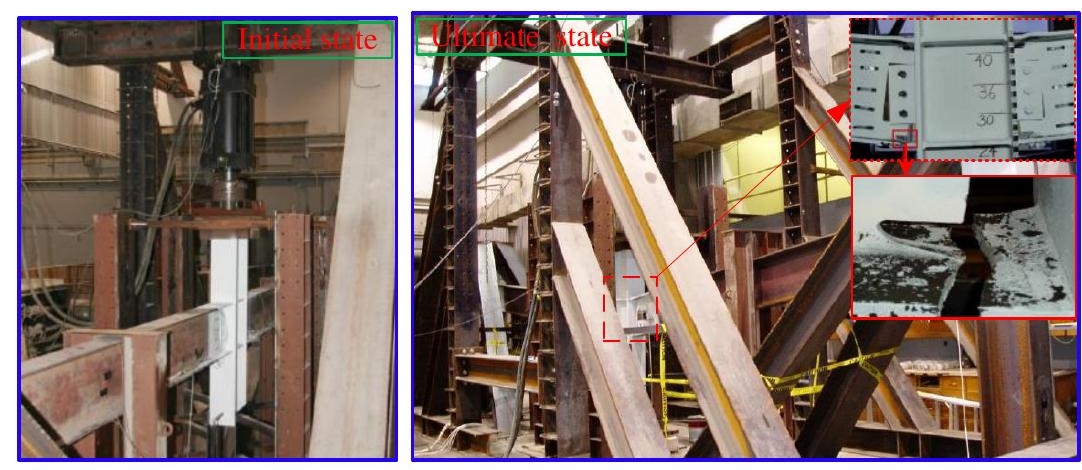

(a) Tested steel frame [25]

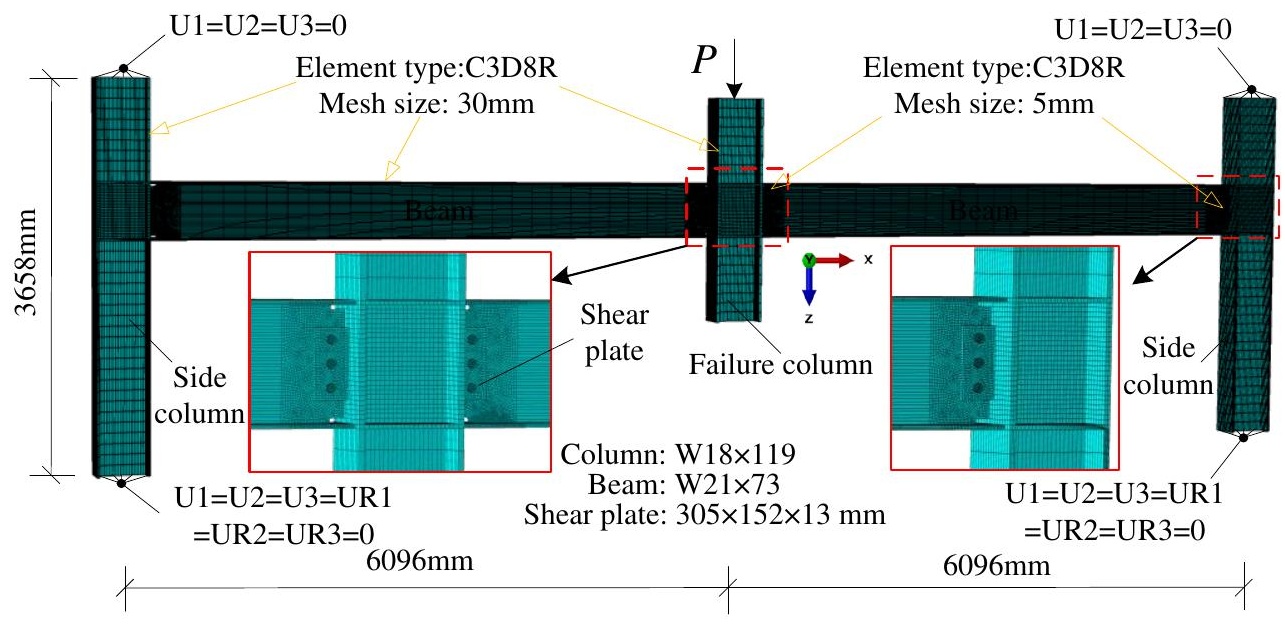

(b) 3-D numerical model

Fig. 8 Validated numerical model

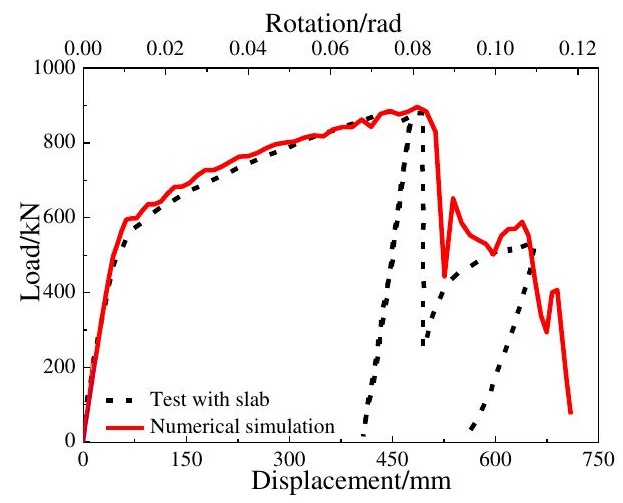

(a) Load-displacement curves

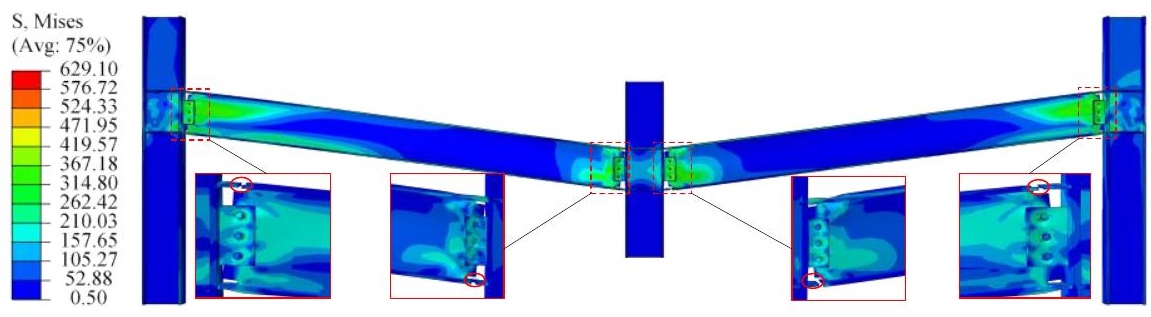

(b) Failure model

Fig. 9 Results of the numerical model

\section{Anti-collapse behavior of the improved connection}

\subsection{Specimen design}

Three model specimens with different connection forms were designed. The three types of connections were fully welded (FW), fully welded with axillary plates (FWA), and fully welded with folded axillary plates (FWFA); their details are shown in Fig. 10. According to the symmetry of the double-full-span beam-column substructure in Fig. 2, 1/4 of the model specimen was selected [27,28], as shown in Fig. 11(a). H $450 \mathrm{~mm} \times 200 \mathrm{~mm} \times 9 \mathrm{~mm} \times 14 \mathrm{~mm}$ and $\mathrm{H} 500 \mathrm{~mm} \times 300 \mathrm{~mm} \times$ $11 \mathrm{~mm} \times 18 \mathrm{~mm}$ were selected for the sections of the beam and column, respectively. According to the design process of the folded axillary plate in Fig. (7), the parameters of the folded axillary plate in the FWFA connection met the requirements of Eqs. (8), (9), (11), and (16) in Section 2, as shown in Fig. 10. All members contained Q235 steel and the constitutive relation of the steel was simplified, as shown in Fig. 11(b) [29]. The fracture parameters of Q235 steel as per reference [30] were adopted for the three model specimens. To consider the ax ial restraint of the peripheral members of the substructure on the beam end, a boundary axial spring was considered in the numerical model, as shown in Fig. 11(a), and its elastic stiffness was assumed to be the axial stiffness of the steel beam. The symmetry plane of the failure column was restrained, that is, U1 = $\mathrm{UR} 2=\mathrm{UR} 3=0$. The end of the beam was set as hinged, i.e., $\mathrm{U} 2=\mathrm{U} 3=0$. The grid size of the beam, column, and folded axillary steel plates was approximately $5 \mathrm{~mm}$. A pushdown load with displacement-controlled was applied slowly to the top of the middle column. The loading process was terminated until the model specimen was damaged.

\subsection{Performance analysis of subassemblies}

Fig. 12(a) presents the vertical load versus the displacement of the middle column of the three specimens. In the initial stage, the stiffnesses of the three specimens were essentially the same. As the displacement of the middle column increased, 
the specimens entered the flexure-catenary mixed phase. The load of the FWA, FWFA, and FW specimens successively decreased. Subsequently, the load of the specimen FW dropped suddenly owing to the fracture of the beam flange. This indicated that $\varphi_{0}$ was $0.083 \mathrm{rad}$. However, the loads of the FWA and FWFA specimens continued to develop owing to the load transfer of the axillary plate. When compared to the FW specimen, the FWA and FWFA specimens could attain improved collapse resistance; the maximum resistance and corresponding deformation of the FWA specimen could be increased by $75.7 \%$ and $53.2 \%$, respectively. The maximum resistance and corresponding deformation of the FWFA specimen could be increased by $169.7 \%$ and $129.6 \%$, respectively. However, compared to the FWA specimen, the FWFA specimen demonstrated a greater resistance and deformation via the folded axillary plates. Its maximum resistance and corresponding deformation could be increased by $53.5 \%$ and $49.9 \%$, respectively.

Figs. 12 (b) and 12(c) show the moments at Sections S0 and S1, respectively, versus the displacement of the middle column. For the FW specimen, the development trends of the bending moments at Sections S0 and S1 were similar; these were halted owing to the crack of the tension beam-end flange. With regard to FWA specimen, the development trends of the bending moments in Sections S0 and S1 were different. This was because the upper and lower axillary plates at Section S0 would also form a bending moment to resist the load; hence, the bending moment of the FWA specimen was smaller than that of the other two model specimens, as shown in Fig. 12(b). With regard to FWFA specimen, given that the folded axillary plate does not participate in the stress of the substructure in the initial phase, the bending moment of the beam end was the same as that of the FW specimen. With the increase of the middle column deformation, the folded axillary plate gradually participated in the stress of the substructure, which caused the bending moment at the beam end to continue to develop, compared with the FW specimen. Finally, the development of the bending moments was terminated owing to the fracture of the beam-end flange and folded axillary plate.

Figs. 12(d) and 12(e) show the curves of the axial force in the beam at Sections S0 and S1, respectively. Fig. 12(f) shows the curves of the axial force transmitted by the upper and lower axillary plates. With regard to FW specimen, the axial force of each section in the beam was equal. With regard to FWA substructure, the beam axial force at Section S0 was greater than that in Section S1 before the specimen obtained the maximum bearing capacity. This indicates that the axial compressive force was transmitted in the upper and lower axillary plates. Subsequently, the total axial force in the upper and lower axillary plates was transformed from compression to tension. Finally, the development of the beam axial force was stopped owing to the fracture of the beam-end flange in Section S1. With regard to the FWFA substructure, the beam axial force at Section S0 was less than that in Section S1, until the substructure lost its main load. This indicates that part of the axial tensile force was transmitted by the upper and lower folded axillary plates. Compared to that of the FW and FWA specimens, the axial force in the beam of the FWFA specimen could attain the yield value, which indicates that the catenary action can be fully played out under the large deformations.

Additionally, according to the design principle of the folded axillary plate shown in Section 2, the folded axillary plate does not significantly affect the stress of the structure at small deformations and will greatly improve the ultimate deformation and resistance of the structure with FWFA connections at later stages. The substructure realized the collapse resistance improved stage by the folded axillary plates. Then, the catenary mechanism is fully played out and the beam performance is fully utilized.

Fig. 13 shows final failure states of the three model specimens with different connections. For the FW specimen, the first mode involved the tension beam flange at the beam root being broken, followed by the beam web gradually fracturing, as shown in Fig. 13(a). With regard to the FWA specimen, the plastic hinge at the beam root first moved outward, following which the beam flange and web at Section S1 broke successively, as shown in Fig. 13(b). With regard to the FWFA specimen, the folded axillary plate on the tension side was first gradually straightened, following which the folded axillary plate on the compression side gradually moved closer to the beam flange. Then, the two plastic regions formed at Sections S0 and S1 of the tension beam flange. With an increase in the connection deformation, the tension beam flange at the beam root breaks, followed by the folded axillary plate, as shown in Fig. 13(c), which is consistent with the expected damage mode I in Fig. 5.

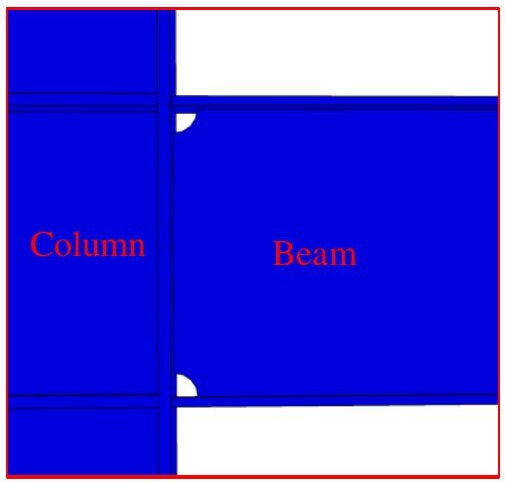

(a) FW connection

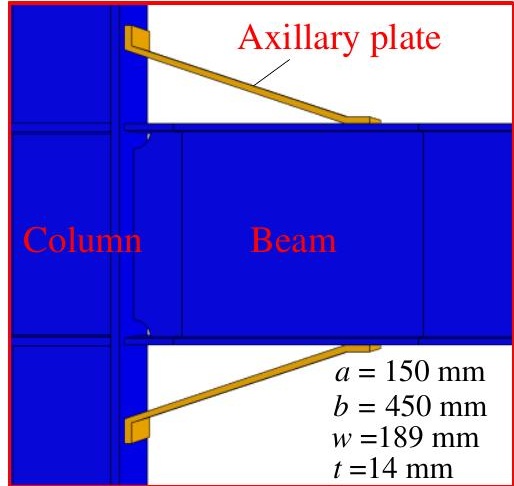

(b) FWA connection

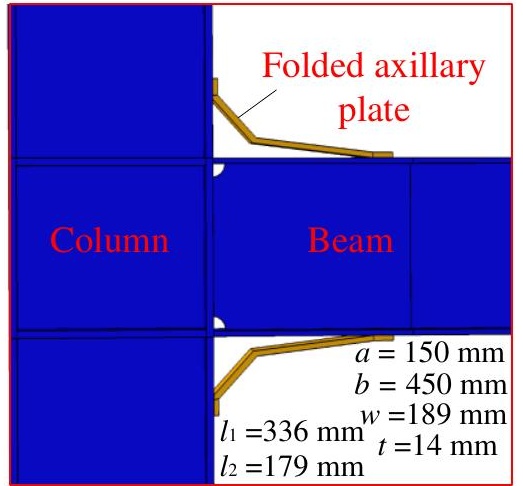

(c) FWFA connection

Fig. 10 Improved full welded connection
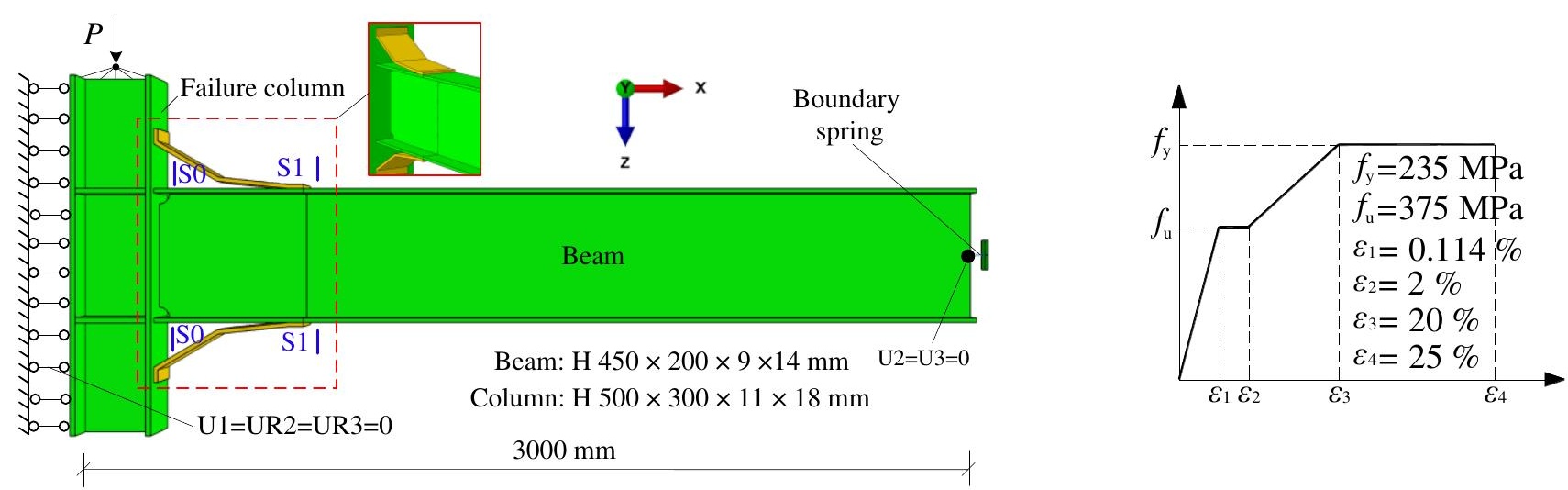

(a) $1 / 4$ substructure model

(b) Stress-strain relationship of steel [29]

Fig. 11 Numerical model for substructure with folded axillary plates 


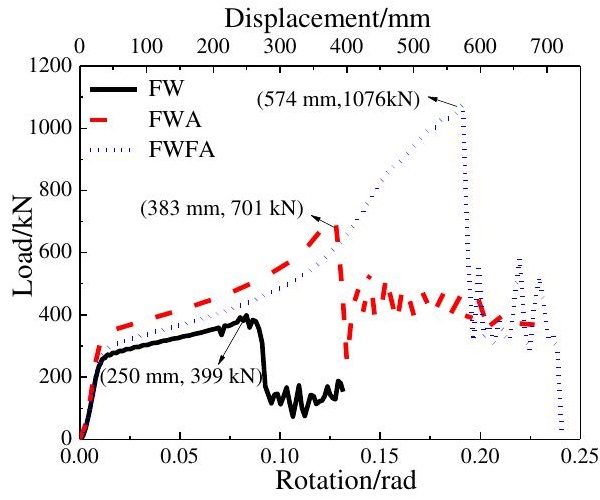

(a) Load vs. displacement

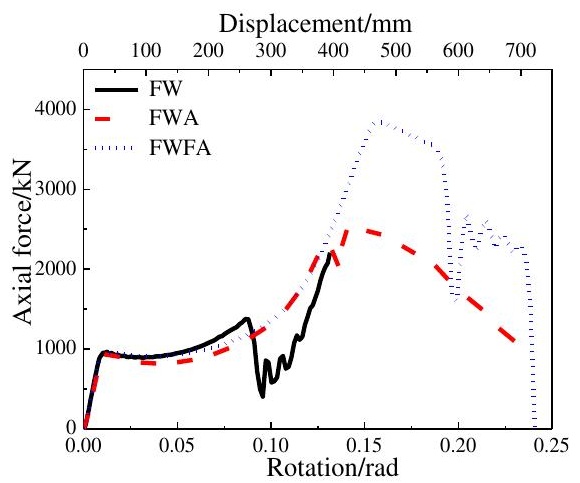

(d) Axial force in beam at Section S0

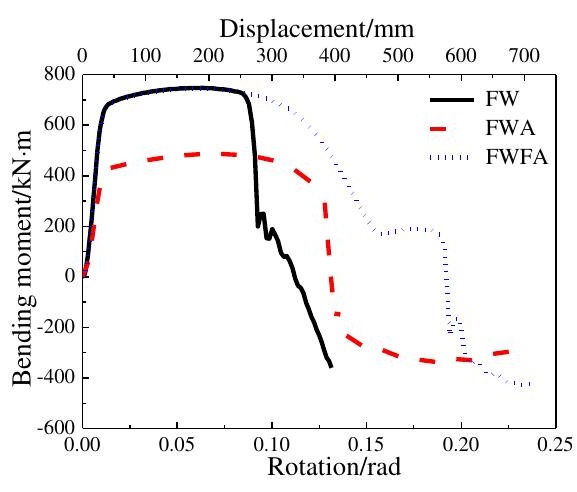

(b) Bending moments at Section S0

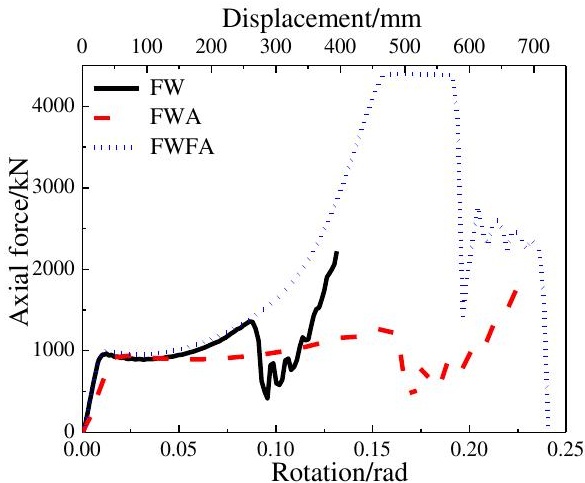

(C) Axial force in beam at Section S1

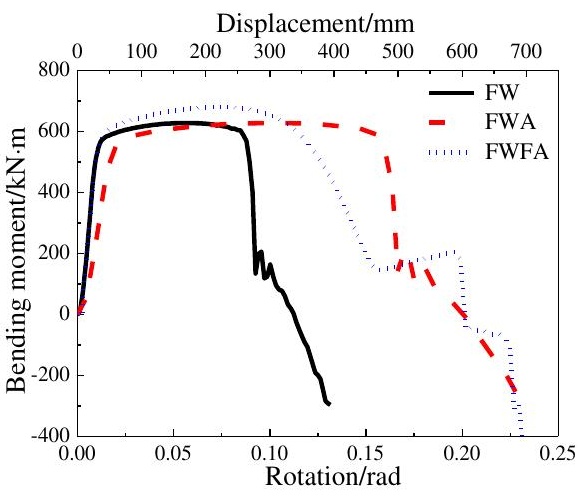

(c) Bending moments at Section S1

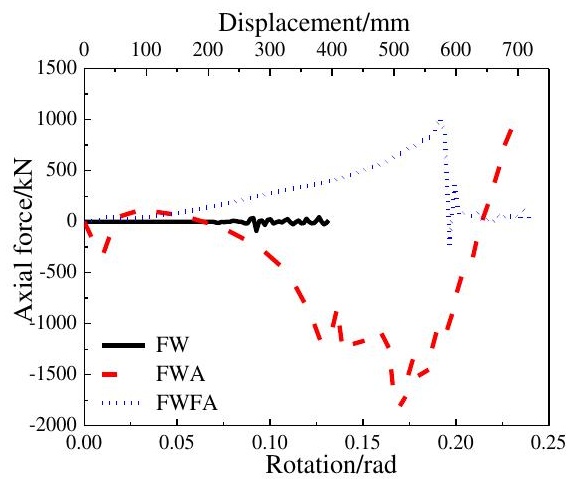

(f) Axial force in axillary plates

Fig. 12 Performance analysis results of subassemblies
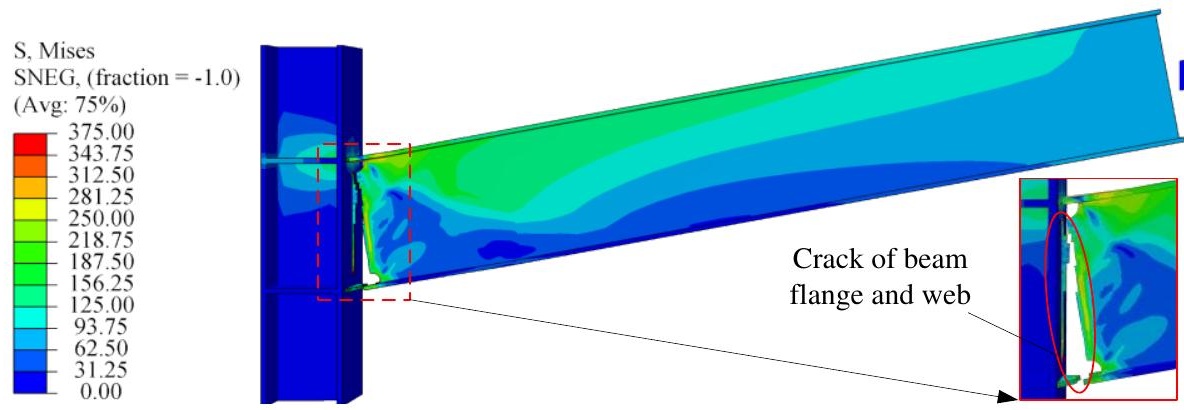

(a) Final failure state of FW connection

$\mathrm{S}$, Mises

SNEG, (fraction $=-1.0$ )

(Avg: 75\%)
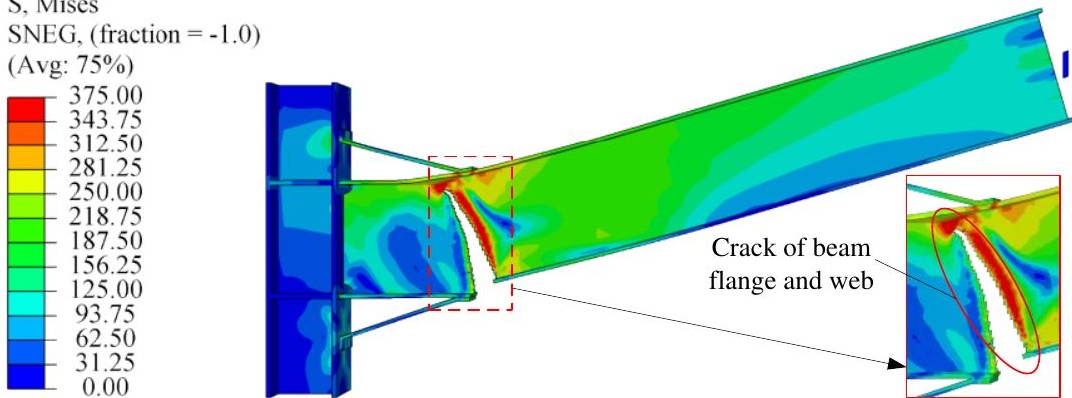

(b) Final failure state of FWA connection 


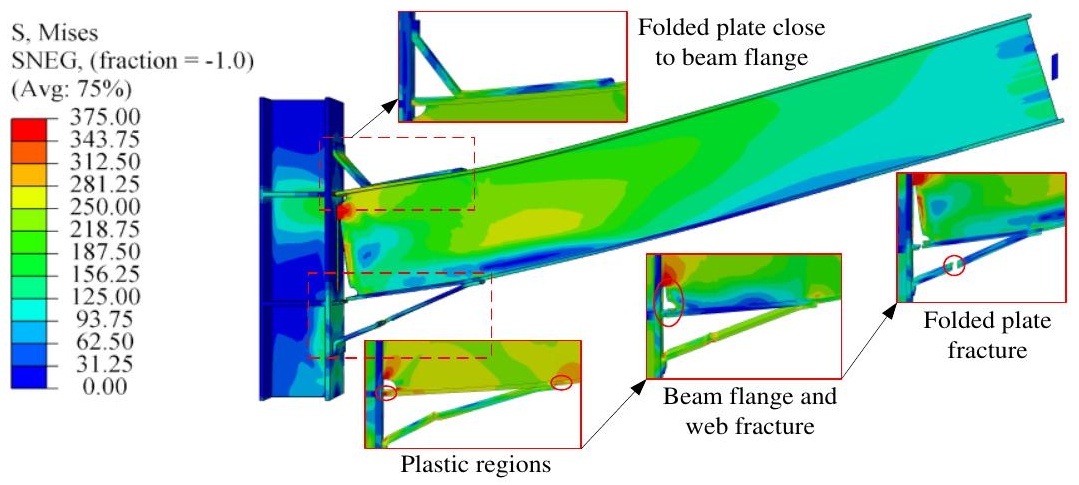

(c) Final failure state of FWFA connection

Fig. 13 Final failure states of connections

\section{Parameter study}

\subsection{Thickness of folded axillary plate}

To investigate the effect of the thickness of the folded axillary plate on anti-collapse behavior of the beam-column substructure with the FWFA connection, five model specimens were selected and analyzed. The thicknesses of the folded axillary plates were 6, 10, 14, 18, and $22 \mathrm{~mm}$. Fig. 14(a) depicts the load-displacement curves of the specimens. Except for the specimen with a $6 \mathrm{~mm}$ thick folded axillary plate, all other specimens achieved collapse resistance improvement by the folded axillary plate. The maximum resistance and corresponding deformation were close to 1070 and $574 \mathrm{~mm}$, respectively. For the specimen with a $6 \mathrm{~mm}$ thick folded axillary plate, when the tension flange at the beam root was broken, the folded axillary plate broke immediately due to the thin folded axillary plate, reducing the collapse resistance. Therefore, the thickness of the folded axillary plate should not be too small. When the folded axillary plate is too thick, the process appears uneconomical; however, relatively large initial imperfections may be generated in the process of manual bending. Therefore, it is suggested to assume $0.75-1.0 t_{\mathrm{f}}$ as the thickness of the folded axillary plate.

\subsection{Width of the folded axillary plate}

Five specimens were selected to study the effect of the width of the folded axillary plate on the anti-collapse behavior of the substructure with the FWFA connection. The widths of the folded axillary plate were 120, 140, 160, 180, and $200 \mathrm{~mm}$. Fig. 14(b) depicts the load-displacement curves of the five model specimens. With the increase in the width of the folded axillary plate, the displacement and load of the specimens gradually increased. The failure mode first involved the tension beam flange being damaged, followed by the broken folded axillary plate. The failure sequence of the substructure with folded axillary plates involved the folded axillary plate on the tension side first gradually straightening, followed by the two plastic regions forming at the beam flange. Subsequently, either the tension beam flange at the beam root and the folded axillary plate broke successively or the tension beam flange broke at the location where the plastic hinge moved outward. For all specimens, the folded axillary plates improved the collapse resistance. Therefore, when the thickness of the folded axillary plate is determined, its width should meet the requirement of Eq. (16).

\subsection{Ratio of $l_{1} / l_{2}$}

To investigate the influence of the ratio of long to short leg on the collapse resistance of the substructure with the FWFA connection, five specimens were designed according to the design process of the folded axillary plate in Fig. 7. The lengths of the short and long leg of the five model specimens were selected, as shown in Table 1, which met the requirements of Eqs. (8), (9), (11), and (16). The loaddisplacement curves of the five model specimens are shown in Fig. 14(c). The five specimens can realize the collapse resistance improvement and their final failure states are similar, as shown in Fig. 13(c). However, when the ratio of $l_{1} / l_{2}$ is larger, the specimen will obtain a larger bearing capacity and deformation.

Table 1

Model specimens on the ratio of $l_{1} / l_{2}$

\begin{tabular}{cccccc}
\hline Specimens & FWFA-R1 & FWFA-R2 & FWFA-R3 & FWFA-R4 & FWFA-R5 \\
\hline$l_{1}(\mathrm{~mm})$ & 179 & 170 & 160 & 150 & 140 \\
$l_{2}(\mathrm{~mm})$ & 336 & 345 & 355 & 365 & 375 \\
$l_{1} / l_{2}$ & 0.533 & 0.493 & 0.451 & 0.411 & 0.374 \\
\hline
\end{tabular}

\subsection{Parameter $b$}

To study the effect of parameter $b$ of the folded axillary plate on the anti-collapse behavior of the structure with the FWFA connection, five specimens were designed according to the content in Section 2.2.3, with parameters $b$ of 300, 350, 400, 450, and $500 \mathrm{~mm}$. When parameter $b$ changes, with $l_{1}$ unchanged, $l_{2}$ will change accordingly. Fig. 15(a) depicts the load-displacement curves of the five model specimens. Compared to the specimen with a FW connection, the five specimens can achieve a collapse resistance improvement. With the increase in parameter $b$, the maximum load and deformation will increase initially and then decrease. In particular, when parameter $b$ is greater than $1.0 h$, the maximum resistance of the model specimen will be significantly reduced. Therefore, it is suggested that parameter $b$ is assumed to be $0.7-1.0 h$. Additionally, when the value of parameter $b$ is greater than or equal to 1.0 $h$, damage mode I will occur, as shown in Fig. 15(b). however, when parameter $b$ is less than $1.0 h$, the substructure with the FWFA connection will experience damage mode II, as shown in Fig. 15(c). These two damage modes are consistent with the expected damage modes in Fig. 5.

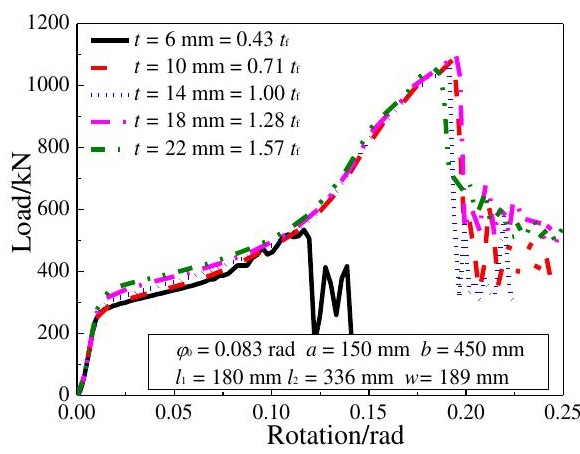

(a) Thickness

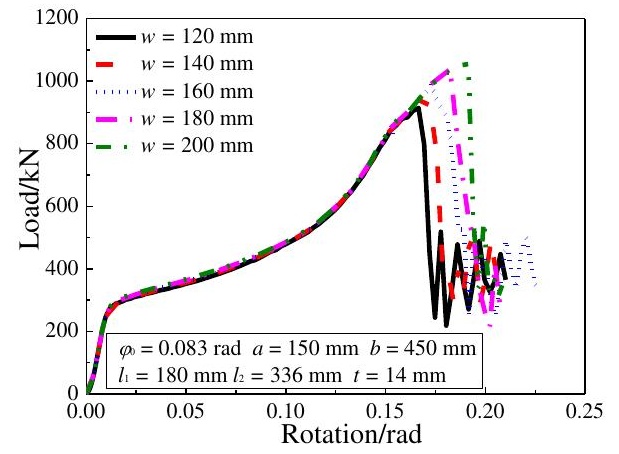

(b) Width

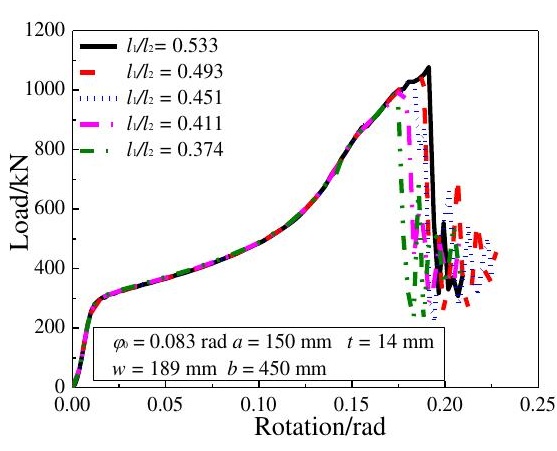

(c) Ratio of $/ l_{1} / l_{2}$

Fig. 14 Parameter analysis results of folded axillary plate 


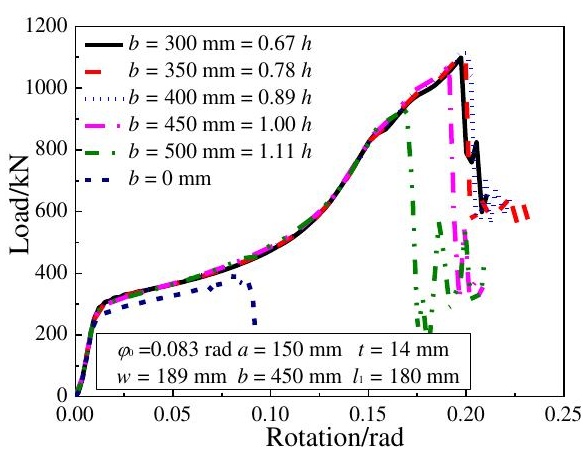

(a) Load vs. displacement

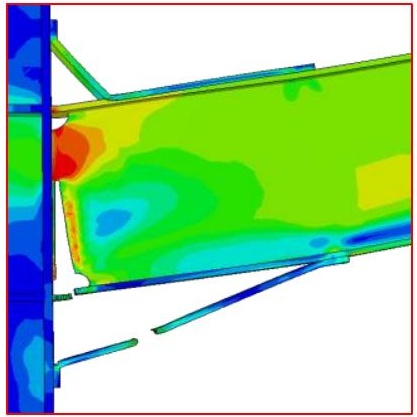

(b) Damage mode I

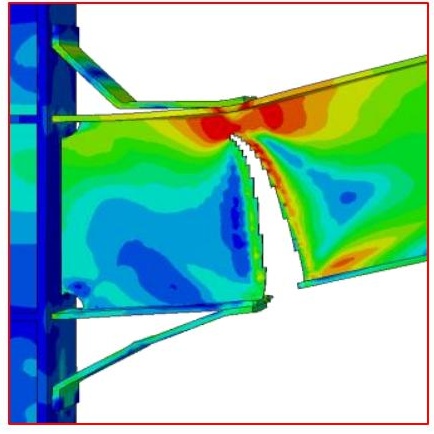

(c) Damage mode II

Fig. 15 Analysis results of parameter $b$

\subsection{Beam depth-to-span ratio}

In this section, the model specimen described in the previous section was used to discuss the influence of the beam depth-to-span ratio on the anti-collapse behavior of the structure with the FWFA connection. In the case of maintaining the height of the steel beam section $(h=450 \mathrm{~mm})$ and the other parameters $\left(\varphi_{0}\right.$ $=0.083 \mathrm{rad}, a=150 \mathrm{~mm}, b=450 \mathrm{~mm}, l_{1}=180 \mathrm{~mm}, l_{2}=150 \mathrm{~mm}, t=14 \mathrm{~mm}$, and $w=189 \mathrm{~mm}$ ) unchanged, only the length of the beam was changed. Six specimens were selected, and the lengths of the beams were 4500, 5400,6000, $7500,9000,10500$, and $11250 \mathrm{~mm}$. The depth-to-span ratios of these model specimens met the requirements of the standards for the design of steel structures in China [31].

Fig. 16 and Table 2 show the analysis results of the resistance and internal forces of the substructures with different beam depth-to-span ratios. In the initial stage, the load and internal forces of the substructures were different owing to the different flexural rigidities of the beams. With decreasing beam depth-tospan ratio, the resistance of the specimen decreased. Afterward, with the in- crease of the displacement of the middle column, all specimens entered the collapse resistance improved stage and obtained the maximum peak loads. At this time, with decreasing beam depth-to-span ratio, the maximum resistances and corresponding axial forces of the specimens first increased and then decreased. The bending moment at Section S1 decreased gradually; the axial force in the beams first increased and then remained at the yield value, except for the specimen with the beam depth-to-span ratio of 1/10, as shown in Fig. 16(c). For this specimen, the development of the beam axial force was insufficient and was interrupted before the yield value was reached, which led to the specimen to lose its bearing capacity too early. In addition, with decreasing beam depth-tospan ratio, the contribution of the flexural mechanism to the total resistance decreased gradually, whereas the contribution of the catenary mechanism to the total resistance increased gradually. This indicates that the continuous growth of the axial force in beam was key to realizing the collapse resistance improved stage of the substructure with the FWFA connections. Therefore, when the structure with the FWFA connections is designed to resist progressive collapse, it is suggested that the beam depth-to-span ratio of the steel frame structure is $1 / 12$ $1 / 20$.

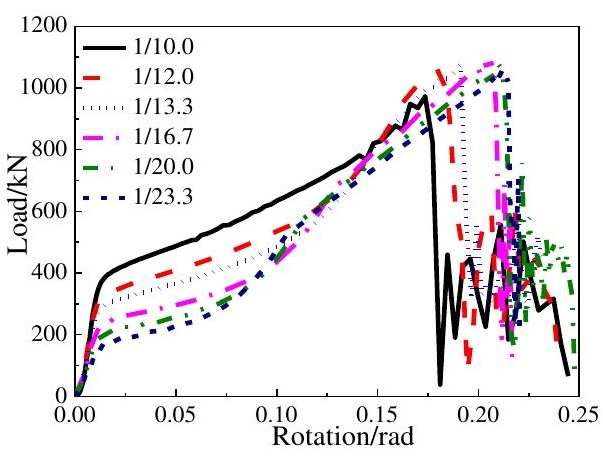

(a) Load vs. displacement

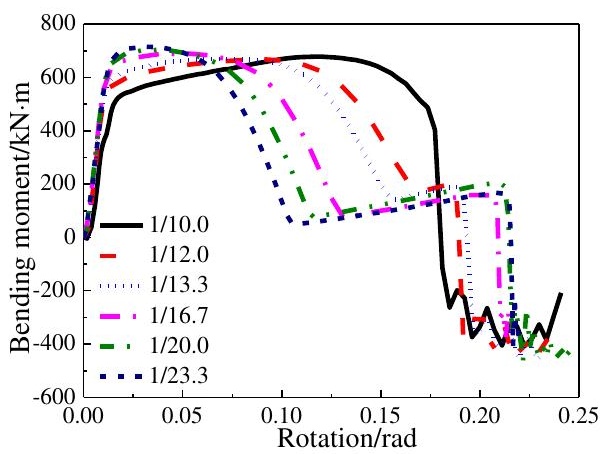

(b) Bending moments at Section S1

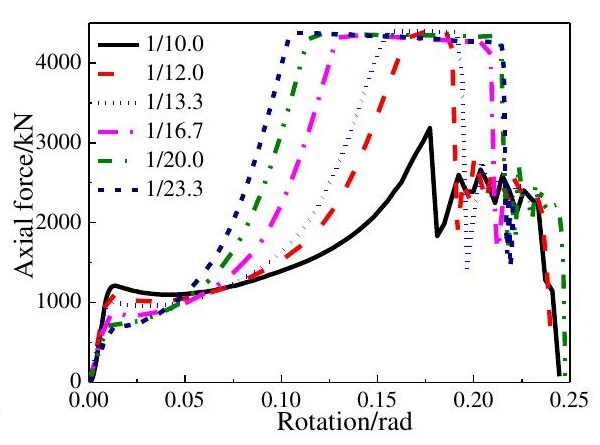

(c) Axial force in beam at Section S1

Fig. 16 Performance analysis results of subassemblies with FWFA connection

Table 2

Results of model specimens at the maximum peak point

\begin{tabular}{|c|c|c|c|c|c|c|c|}
\hline Specimens & $\begin{array}{l}\text { Length of } \\
\text { beam } / \mathrm{mm}\end{array}$ & Depth-to-span ratio & $\begin{array}{l}\text { Maximum re- } \\
\text { sistance/kN }\end{array}$ & Displacement/mm & Rotation/rad & $\begin{array}{l}\text { Bending mo- } \\
\text { ment } / \mathrm{kN} \cdot \mathrm{m}\end{array}$ & Axial force/kN \\
\hline FWFA-L1 & 4500 & $1 / 10.0$ & 972.9 & 390.6 & 0.173 & 487.4 & 3011.3 \\
\hline FWFA-L2 & 5400 & $1 / 12.0$ & 1060.2 & 493.6 & 0.179 & 191.7 & 4390.4 \\
\hline FWFA-L3 & 6000 & $1 / 13.3$ & 1076.8 & 573.8 & 0.191 & 189.1 & 4384.1 \\
\hline FWFA-L4 & 7500 & $1 / 16.7$ & 1097.7 & 772.4 & 0.206 & 165.9 & 4366.7 \\
\hline FWFA-L5 & 9000 & $1 / 20.0$ & 1076.5 & 946.1 & 0.210 & 164.7 & 4350.2 \\
\hline FWFA-L6 & 10500 & $1 / 23.3$ & 1057.1 & 1112.2 & 0.212 & 161.1 & 4252.3 \\
\hline
\end{tabular}

\section{Conclusions}

In this study, the traditional full-welded connection is improved based on the folded axillary plates, which are arranged at the outer side of the beam-end flanges. On the basic of the theoretical analysis, the movement mechanisms of the tension- and compression-folded axillary plates are revealed. Through the validated numerical model, the anti-collapse behavior and key parameters of the improved connection (FWFA connection) are discussed, following which the design process of the folded axillary plate is given. The specific conclusions are as follows:

(1) Based on the theoretical analysis, the motion equation of the short and long legs of the folded axillary plate under the condition of progressive collapse is given, as shown in Eq. (8).

(2) When the design of the folded axillary plate is reasonable, the ultimate 
bearing capacity and deformation of the beam-column substructure will be simultaneously increased. Compared to the specimen with the full welded connection with the axillary plates, the specimen with the FWFA connection could obtain greater bearing capacity and deformation by the folded axillary plates. Its maximum deformation and corresponding bearing capacity could be increased by $49.9 \%$ and $53.5 \%$, respectively.

(3) The failure sequence of the substructure with folded axillary plates involved the folded axillary plate on the tension side first gradually straightening, followed by the two plastic regions forming at the beam flange. Subsequently, either the tension beam flange at the beam root and the folded axillary plate broke successively or the tension beam flange broke at the location where the plastic hinge moved outward.

(4) To improve the collapse resistance of the folded axillary plate, it is suggested through numerical parameter analysis that $a$ is $1 / 3 h ; b$ can be taken as $0.7-1.0 h ; t$ can be taken as $0.75-1.0 t_{\mathrm{f}}$; and the width of the folded axillary plate $w$ is calculated according to Eq. (16). The design process for the folded axillary plate is suggested, as shown in Fig. 7.

(5) When the structure with the FWFA connection is designed to resist progressive collapse, it is suggested that the beam depth-to-span ratio of the steel frame structure should be assumed to be $1 / 12-1 / 20$. When the ratio of the short to long leg of the folded axillary plate of the substructure with the FWFA connection is larger, the specimen will obtain a larger bearing capacity and deformation.

\section{Acknowledgements}

The research presented in this paper is supported by National Science Foundation for Young Scientists of China through Grant No. 51908449, Young talents program of Shaanxi Natural Science Basic Research Program through Grant No. 2020JQ-660, Scientific research plan projects of Shaanxi Education Department Program through Grant No.20JK0713, China Postdoctoral Science Foundation Funded Project through Grant No. 2018M643593, Talent Science and Technology of Xi'an University of Architecture and Technology through Grant No. RC1827, the National Natural Science Foundation of China through Grant No. 51678476, and the Key Research and Development Project of Shaanxi Province through Grant No. 2018ZDXM-SF-097. All opinions, findings, conclusions, and recommendations expressed in this paper are those of the writers and the authors have declared that no conflict of interest exists.

\section{References}

[1] The building regulations 2000, Part A, Schedule 1: A3, Disproportionate collapse, Office of the Deputy Prime Minister, London, 2004.

[2] EN 1991-1-7., Eurocode 1: Actions on structures. Part 1-7: General Actions-Accidental actions (CEN 2006), European Committee for Standardization, Brussels, 2006.

[3] GSA 2013. Alternate path analysis and design guidelines for progressive collapse resistance, United States General Services Administration, Washington, D.C., USA, 2013.

[4] UFC 4-023-03. Design of structures to resist progressive collapse, Department of Defense, Washington, D.C., USA, 2013.

[5] Japanese Society of Steel Urban Construction Council on Tall Buildings and Urban Habitat. Guidelines for Collapse Control Design-Construction of Steel Buildings with High Redundancy, Tokyo, Japan, 2004

[6] Yu J. and Tan K.H, "Special detailing techniques to improve structural resistance against progressive collapse", Journal of Structural Engineering, 140 (3): 04013077, 2014

[7] Wang W. and Qin X., "Retrofitted connection details of through diaphragm joint for structural robustness enhancement", Journal of Tongji University (Natural Science), 43(5): 685692,2015

[8] Meng B., Zhong W.H., Hao J.P., et al., "Improved steel frame performance against progressive collapse with infill panels", Journal of Constructional Steel Research, 158: 201-212, 2019

[9] Vasdravellis G., Baiguera M., Al-Sammaraie D., "Robustness assessment of a steel self-centering moment-resisting frame under column loss", Journal of Constructional Steel Research, 141: 36-49, 2018

[10] Wei J.P., Tian L.M., Hao J.P., et al., "Novel principle for improving performance of steel frame structures in column-loss scenario", Journal of Constructional Steel Research, 163: $105768,2019$.

[11] Qiang H.L., Yang J.X., Feng P., et al., "Kinked rebar configurations for improving the progressive collapse behaviours of RC frames under middle column removal scenarios", Engineering Structures, 211: 110425, 2020.

[12] Qiu L., Lin F., Wu K.C., "Improving progressive collapse resistance of RC beam-column subassemblages using external steel cables", Journal of Performance of Constructed Facilities, 34(1): 04019079, 2020.

[13] Gao S., Guo L.H., Zhang S.M., "Study on anti-collapse performance of semi-rigid composite joint strengthened by steel plate considering material damage", Journal of Building Structures, 40(3): 240-246, 2019.

[14] Lu X.Z., Zhang L., Lin K.Q., et al., "Improvement to composite frame systems for seismic and progressive collapse resistance", Engineering Structures, 170: 106119, 2020.

[15] Meng B., Zhong W.H., Hao J.P., et al., "Improving anti-collapse performance of steel frame with RBS connection", Journal of Constructional Steel Research, 158: 201-212, 2019

[16] Lew H.S., Main J.A., Robert S.D., et al., "Performance of steel moment connections under a column removal scenario. I: Experiments", Journal of Structural Engineering, 139(1): 98-107, 2013.

[17] Li L. Behavior of steel beam-to-column connections in structural progressive collapse, D.E., Tongji University, Shanghai, China, 2014.
[18] Meng B., Zhong W.H., Hao J.P., “Anti-collapse performances of steel beam-to-column assemblies with different span ratios", Journal of Constructional Steel Research, 140(1): 125 $138,2018$.

[19] Dinu F., Marginean I., Dubina D., "Experimental testing and numerical modelling of steel moment-frame connections under column loss", Engineering Structures, 151: 861-878, 2017.

[20] Stylianidis P.M., Nethercot D.A., "Modeling of connection behaviour for progressive collapse analysis", Journal of Constructional Steel Research, 113(6): 169-184, 2015.

[21] Yang B., Tan K.H., Xiong G., et al., "Experimental tests of different types of bolted steel beam-column joints under a central-column-removal scenario", Journal of Constructional Steel Research, 121: 341-351, 2016.

[22] Yang B., Tan K.H., "Experimental study about composite frames under an internal columnremoval scenario", Engineering Structures, 54: 112-30, 2013

[23] Meng B., Zhong W.H., Hao J.P., et al., "Calculation of the resistance of an unequal span steel substructure against progressive collapse based on the component method", Engineering Structures, 182: 13-28, 2019

[24] FEMA-267. Interim guidelines: evaluation, repair, modification and design of welded steel moment frames, Federal Emergency Management Agency, Washington, D.C.,1995.

[25] Sadek F., Main J.A., Lew H.S., et al., "An experimental and computational study of steel moment connections under a column removal scenario, NIST 1669", National Institute of Standards and Technology, 2010.

[26] ABAQUS Analysis User's Manual, 6.17, ABAQUS, Inc., Dassault Systemes. USA, 2017.

[27] Yang B. and Tan K.H., "Numerical analyses of steel beam-column joints subjected to catenary action", Journal of Constructional Steel Research, 70 (3): 1-11, 2012.

[28] Yang B., Tan K.H., Xiong G., "Behaviour of composite beam-column joints under a middlecolumn-removal scenario: Component-based modelling", Journal of Constructional Steel Research, 104:137-154, 2015.

[29] Jiang L., Wang X.L., Yang W.W. "Stress analysis of beam-column joint with different web corner cutting forms", Journal of Lanzhou University of Technology, 39(2): 106-109, 2013.

[30] Zhou T.H., Li W.C., Guan Y., et al., "Damage analysis of steel frames under cyclic load based on stress triaxiality", Engineering Mechanics, 31(7): 146-155, 2014.

[31] GB 50017-2017. Standard for design of steel structures, China Architecture \& Building Press, Beijing, China, 2017. 